\title{
Revision of the Leucosphyrus group of Anopheles (Cellia) (Diptera, Culicidae) ${ }^{1}$
}

\author{
Maria Anice Mureb Sallum²,3, E L Peyton², Bruce Arthur Harrison ${ }^{4} \&$ Richard Charles Wilkerson ${ }^{2}$
}

\begin{abstract}
${ }^{1}$ This research was performed under a Memorandum of Understanding between the Walter Reed Army Institute of Research and the Smithsonian Institution, with institutional support provided by both organizations. The material to be published reflects the views of the authors and should be not construed to represent those of the Department of the Army or the Department of Defense. This publication is partially supported by FAPESP (05/00372-9), São Paulo, Brazil. / and U. S. NRC DAM D 17-00-2-0002 to MAMS.

${ }^{2}$ Department of Entomology, Walter Reed Biosystematics Unit, Museum Support Center, Smithsonian Institution, 4210 Silver Hill Road, Suitland, MD, 20746, U.S.A.

${ }^{3}$ Núcleo de Pesquisa Taxonômica e Sistemática em Entomologia Médica, Faculdade de Saúde Pública, Universidade de São Paulo, Brazil. Avenida Dr. Arnaldo 715, São Paulo, São Paulo, Brazil, 01246-904.

${ }^{4} \mathrm{NC}$ DENR Public Health Pest Managment 585 Waughtown Street Winston-Salem, NC 27107, U.S.A.

ABSTRACT. Revision of the Leucosphyrus Group of Anopheles (Cellia) (Diptera, Culicidae). This is a comprehensive revision of 20 species of the Leucosphyrus Group of the Neomyzomyia Series of Anopheles (Cellia). Morphological description of the adults, male and female, male genitalia, pupa and fourth-instar larva are provided for each taxon in addition to bionomics, distribution data and systematic discussion for each species, including diagnostic characters. Identification keys for females and fourth-instar larvae are provided. When possible medical importance of each species is included. Illustrations of of the adults, fourth-instar larvae and pupae are provided. Distribution maps for each species are mainly based on the material examined; however, when possible published data were also used. Tables on adult character variations, fourth-instar larval and pupal setal branching are included as appendices. A neotype for An. takasagoensis Morishita and An. sulawesi Koesoemawinangoen, and a lectotype for An. balabacensis Baisas, are designated. The authorship of An. sulawesi previously cited as Waktoedi is corrected to Koesoemawinangoen.
\end{abstract}

KEYWORDS. Anophelinae; Cellia; Distribution; Morphology; Revision; Taxonomy.

RESUMO. Revisão do Grupo Leucosphyrus de Anopheles (Cellia) (Diptera, Culicidae). Apresenta-se a revisão taxonômica de 20 espécies do Grupo Leucosphyrus da Série Neomyzomyia de Anopheles (Cellia). Apresentam-se as descrições morfológicas dos adultos, machos e fêmeas, genitália masculina, pupa e larva de quarto estádio, bem como dados de bionomia, distribuição e discussão sistemática para cada espécie, incluindo caracteres diagnósticos. Foram acrescentadas chaves dicotômicas de identificação para as espécies, utilizando caracteres dos adultos fêmeas e larvas de quarto estádio. Quando possível, foram incluídos dados sobre a importância médica de cada espécie. Foram também apresentadas ilustrações dos adultos, das larvas de quarto estádio e das pupas. Os mapas de distribuição das espécies foram elaborados com base no material examinado, no entanto, quando possível utilizou-se dados adicionais publicados na literatura. Fornecem-se tabelas com as variações dos caracteres dos adultos, das cerdas das larvas de quarto estádio das pupas. São designados os neótipos de An. takasagoensis Morishita e An. sulawesi Koesoemawinangoen, e o lectótipo de An. balabacensis Baisas. O nome do autor de An. sulawesi previamente citado como sendo Waktoedi foi corrigido para Koesoemawinangoen.

PALAVRAS CHAVE. Anophelinae; Cellia; Distribuição; Morfologia; Revisão; Taxonomia.

Species belonging to the genus Anopheles Meigen are vectors of parasites of the genus Plasmodium that cause human malaria, a primarily tropical disease that threatens 42 percent of the world population in 100 countries and territories. The World Health Organization estimates the annual global incidence of acute malaria cases at 300-500 million, resulting in an estimated 1.5 to 2.7 million deaths per year, of which approximately one million occur among children less than five years of age. In addition to their role as primary vectors of malaria, mosquitoes of the genus Anopheles additionally impact human health by transmitting lymphatic filariasis (Service 1993) and various mosquito-borne viruses (Gillies \& Coetzee 1987).

The subgenus Cellia includes 224 of the 465 Anopheles species and is divided into 6 informal series: Cellia, Myzomyia, Neocellia, Neomyzomyia, Paramyzomyia and Pyretophorus.
The internal classification within the subgenus Cellia was first proposed by Edwards (1932) and later modified by several authors as seen in Harbach (2004). The subgenus Cellia was demonstrated to be monophyletic based on cladistic analyses of both morphological characters (Sallum et al. 2000) and DNA sequence data of several mitochondrial and nuclear genes (Krzywinski et al. 2001a,b; Sallum et al. 2002).

The Leucosphyrus Group belongs in the Neomyzomyia Series of the subgenus Cellia (King \& Baisas 1936; Colless 1956b; Reid \& Knight 1961; Reid 1968) and currently includes 14 named species, two geographical forms (Peyton 1989), and six recently described species (Sallum et al. 2005). The geographical distribution of the Leucosphyrus Group ranges from southwestern India eastwards to southern China, Taiwan, mainland Southeast Asia, Indonesia and the Philippines (Fig. 1) (Reid 1968; Reid 1970). The internal classification of the 
Leucosphyrus Group, its species, and geographical distribution are listed in Table 1.

This study of the Leucosphyrus Group is a product of over 25 years of planned collaborative efforts by many individuals. It started in 1977 when EL Peyton (deceased) of the U. S. Army's Medical Entomology Project at the Smithsonian Institution, initiated a morphological study of the species in the Leucosphyrus Group. At that time the group was defined by the works of Colless (1956b, 1957) and Reid (1968), who recognized six species, two subspecies, and five geographical forms that contained several important malaria vectors in Southeast Asia. After six months of examining specimens available for study in the Smithsonian Institution, it became apparent that more species were probably involved, but additional specimens were needed to continue the study. In early 1978, Peyton and Harrison started a cooperative study with Harrison conducting field studies that targeted populations of the group, making larval and adult collections for rearing adults with associated larval and pupal exuviae, establishing colonies, conducting crossing studies, and shipping study specimens back to the Smithsonian Institution. The initial product of this joint arrangement was the discovery and description (Peyton \& Harrison 1979) of a new species, An. dirus Peyton and Harrison, masquerading as $A n$. balabacensis Baisas, which until that time had been recognized as a primary vector of human malaria in an area stretching from east India to the Philippines. Shortly thereafter eggs were obtained and specimens reared of an uncommon species from Taiwan previously considered a synonym of An. balabacensis. Those specimens plus the few available pinned feral specimens revealed the Taiwan specimens to be a valid species, $A n$. takasagoensis Morishita, which was distinct from $A n$. balabacensis. These discoveries meant that An. balabacensis, considered at that time as a primary vector of malaria throughout Southeast Asia, was not a single species, but a complex of three or more species. These morphological findings were met with considerable opposition and not initially accepted by the WHO malaria staff and many malaria scientists and workers in the Southeast Asian Region. This reaction by malaria control professionals led to a reconsideration of approaches for conducting this study. It was decided that beside morphological studies other disciplines and approaches were needed to provide direction for morphological studies and to confirm or refute the current species based on morphological studies. Initially, these new approaches were conducted in Thailand and included genetic and cross-mating studies of the various members in the group, with specimens of suspected distinct species then shipped to the Smithsonian Institution and studied for morphological characters to differentiate the species.

By late 1979, Professor Visut Baimai, a geneticist at Mahidol University, Bangkok, had agreed to join the cooperative study. Initial studies on the members of the group (Baimai et al. 1980, 1981) included differentiation of the species by karyotypes, polytene chromosomes, and crossing studies. These findings and confirmation of the above morphological findings instigated a number of additional multidisciplinary studies (Baimai et al. 1984a,b; Baimai \& Green 1985; Baimai et al. 1987).

The studies of Baimai and collaborators, as well as other independent workers, continued and eventually helped to distinguish additional members of the group.

Peyton (1989) corroborated the classification of Colless (1956b) and Reid (1968) for the Leucosphyrus Group and confirmed the Hackeri (as Elegans), Leucosphyrus, and Riparis Subgroups (Table 1). These three subgroups are distinguished based on the ratio of the length of the proboscis to the length of the forefemur (Fig. 2). The Leucosphyrus Group was demonstrated to be monophyletic and the earliest-diverged lineage within the subgenus Cellia (Sallum et al. 2000). However, phylogenetic relationships within the Leucosphyrus Group, such as the monophyly of the Hackeri, Leucosphyrus, and the Riparis Subgroups, and relationships among species have not been tested using phylogenetic methods. Furthermore, the systematics of the Leucosphyrus Group is problematic because it is a morphologically homogeneous group and identification of its species from a single life stage using morphological features is difficult and sometimes impossible. Consequently, in order to distinguish the species correctly it is necessary to use all life stages (adult, pupa, and fourth-instar larva), ultrastructure of eggs (Damrongphol \& Baimai 1989), and also alternative methods for identification such as those developed by Baimai et al. (1987), Baimai et al. (1988c,d), Sawadipanich et al. (1990), Walton et al. (1999), Huong et al. (2001), and Manguin et al. (2002).

The Leucosphyrus Subgroup includes the Dirus Complex, the Leucosphyrus Complex, An. baisasi Colless, and the geographical form named Con Son. The Dirus Complex comprises seven species (Table 1). Whereas Peyton \& Harrison (1979) relied heavily on morphological characters of the adult, pupal, and larval stages to describe $A n$. dirus, their elevation of An. takasagoensis to species status (Peyton \& Harrison, 1980) and separation of this taxon from both $A n$. dirus and An. balabacensis relied heavily on cross-mating and cytogenetic, as well as morphological evidence. Thereafter, the discovery of most members of the Dirus Complex was achieved primarily with crossing studies, cytogenetic studies, polytene chromosome banding patterns (Baimai et al. 1987; Baimai et al. 1988a,c,d; Sawadipanich et al. 1990; Poopittayasataporn \& Baimai 1995), and allozyme data (Green et al. 1992). More recently, polymerase chain reaction (PCR) based methods were developed in Thailand using speciesspecific primers to differentiate An. dirus, An. cracens Sallum and Peyton, An. scanloni Sallum and Peyton, and An. baimaii Sallum and Peyton, of the Dirus Complex (Huong et al. 2001). Similarly, a species diagnostic polymerase chain reaction assay based on differences in the ITS2 sequences of the rDNA was developed to separate populations of An. dirus A and An. dirus D from China (XU et al. 1998). Walton et al. (1999) showed that ITS2 sequence of Chinese 'species D' of Xu \& Qu (1997b) is distinct from Thailand specimens and thus it may represent an unrecognized species of the complex. Also, the allelespecific polymerase chain reaction using ITS2 sequence was 
Table 1. Internal classification, list of species and geographical distribution of the Leucophyrus Group

\begin{tabular}{|c|c|c|c|}
\hline Subgroup & Complex & Species & Distribution \\
\hline \multirow[t]{12}{*}{ Leucosphyrus } & Leucosphyrus & An. leucosphyrus Dönitz & Indonesia, Sumatra \\
\hline & & An. latens Sallum \& Peyton & Indonesia, East Malaysia, West Malaysia, Thailand \\
\hline & & An. introlatus Colless & Indonesia, West Malaysia, Thailand \\
\hline & & An. balabacensis Baisas & Brunei, Indonesia, East Malaysia, Philippines \\
\hline & - & An. baisasi Colless & Philippines \\
\hline & Dirus & An. dirus Peyton \& Harrison & Cambodia, China, Vietnam, Laos, Thailand \\
\hline & & An. cracens Sallum \& Peyton & Indonesia, West Malaysia, Thailand \\
\hline & & An. scanloni Sallum \& Peyton & Thailand \\
\hline & & An. baimaii Sallum \& Peyton & Bangladesh, India, Thailand, Myanmar, China \\
\hline & & An. elegans (James) & Southwestern India \\
\hline & & An. takasagoensis Morishita & China: Taiwan \\
\hline & & An. nemophilous Peyton \& Ramalingam & West Malaysia, Thailand \\
\hline \multirow[t]{5}{*}{ Hackeri } & - & An. mirans Sallum \& Peyton & India, Sri Lanka \\
\hline & - & An. hackeri Edwards & East and West Malaysia, Philippines, Thailand \\
\hline & - & An. pujutensis Colless & Indonesia, East and West Malaysia, Thailand \\
\hline & - & An. recens Sallum \& Peyton & Indonesia \\
\hline & - & An. sulawesi Koesoemawinangoen & Indonesia \\
\hline \multirow[t]{3}{*}{ Riparis } & - & An. riparis King \& Baisas & Philippines \\
\hline & - & An. cristatus King \& Baisas & Philippines \\
\hline & - & An. macarthuri Colless & East and West Malaysia, Thailand \\
\hline
\end{tabular}

demonstrated to be an unambiguous and reliable identification method to distinguish five species of the Dirus Complex in Thailand (Walton et al. 1999). Recently, a multiplex PCR method using paired-primers was developed to distinguish An. dirus, An. cracens, An. scanloni, and An. baimaii in Southeast Asia (Manguin et al. 2002). The Leucosphyrus Complex comprises four species (Table 1). Two species in the complex, An. latens Sallum and Peyton and An. leucosphyrus Dönitz, were distinguished on the basis of mitotic chromosome karyotype and crossing experiments (Baimai et al. 1988c).

Several studies using cytogenetic and molecular tools were carried out to investigate species recognition, gene flow, and genetic population structure of the Leucosphyrus Subgroup (Baimai et al. 1987, 1988a,c,d; Sawadipanich et al. 1990; XU et al. 1998; Walton et al. 1999, 2000, 2001; Huong et al. 2001; Manguin et al. 2002). Few studies have addressed phylogenetic relationships among members of the Leucosphyrus Subgroup, except for the Dirus Complex. Baimai et al. (1987), using polytene and mitotic chromosomes, found that An. dirus is closely related to An. scanloni. In contrast, Walton et al. $(2000,2001)$ found genetic evidence to support a sister group relationship between An. dirus and An. cracens, rather than between An. dirus and An. scanloni. More recently, Manguin et al. (2002) observed that An. scanloni shares SCAR fragment with $A n$. dirus. In conclusion, evolutionary history and phylogenetic relationships among members of the Dirus Complex are not fully understood and remain unresolved.

Several species of the Leucosphyrus Group are of epidemiological importance as highly competent vectors of human malaria parasites in Southeast Asia: An. balabacensis (White 1983; Schultz 1992; Barcus et al. 2002), An. latens (Zulueta 1956; White 1983), An. leucosphyrus (Warren et al. 1963), An. baimaii (Rahman et al. 1977; Rosenberg \&
Maheswary 1982b; Dutta et al. 1991; Prakash et al. 2001), An. dirus (Eyles et al. 1964; Scanlon \& Sandhinand 1965; Sloof \& Verdrager 1972; Ismail et al. 1974,1975; Wilkinson et al. 1978; Deng et al. 1982; Trung et al. 2004), and An. sulawesi Koesoemawinangoen (Warren \& Wharton 1963). Other species of the group are suspected to transmit simian malaria parasites (Warren \& Wharton 1963; Coatney et al. 1971; Tsukamoto et al. 1978; Fooden 1994). Additional information regarding the role of each member of the Leucosphyrus Group in the transmission of either human or simian malaria parasites (or both) is provided below under each species.

The primary objectives of this study are: (1) to review the systematics of 20 species of the Leucosphyrus Group; (2) to provide morphological characters to identify the Leucosphyrus Group; (3) to provide morphological characters to differentiate species of the Leucosphyrus Group; (4) to provide indentification keys for both the fourth-instar larvae and adult females; and (5) to provide distribution data for each species included in the Leucosphyrus Group. The two geographical forms, Anopheles leucosphyrus Con Son form, and Anopheles leucosphyrus Negros form were not included in this revision because few specimens are available and they are in poor condition.

\section{MATERIAL AND METHODS}

The terminology adopted is that proposed by Harbach \& Knight $(1980,1982)$ except for the wing veins and wing spots for which we used Belkin (1962) and Wilkerson \& Peyton (1990), respectively (Fig. 3). The toothed margin index of the pupal paddle was defined by Colless (1956b) to express the ratio of the lengths, (a) from the tip of the inner basal tubercle of the paddle to the base of the most distant marginal tooth and (b) 
from the same point to the base of seta 1-Pa (Fig. 31). The basal extension of the PSD spot on vein $\mathrm{R}$ as compared to the HD, PSP and PSD spots on the Costa defines the level of extension of the PSD (Peyton \& RamalingaM 1988). Level 1 is defined as the PSD on vein R not extending basally beyond the PSD on the Costa, level 2 the PSD extends basally but not beyond 0.5 of the PSP, level 3 the PSD extends basally beyond 0.5 of the PSP but not to the level of the HD, level 4 the PSD extends basally to the level of the HD but not beyond 0.5 of the HD, level 5 the PSD extends basally beyond 0.5 of the HD but not beyond the HD, and level 6 the PSD extends basally beyond the HD (Fig. 3). As it was defined in Peyton \& Ramalingam (1988) "the level of basal extension is determined by any dark scales occurring beyond the PSD spot of the vein C. It does not have to be a continuous uninterrupted extension of dark scales as it is often interrupted by one or more pale spots and these can occur beyond the PSP spot or, the most basal dark scales can be a small isolated spot of a few scales or rarely a few scattered dark scales." The number of pale interruptions on PSD-PD spots is defined as the sum of pale interruptions along the area that includes the PSD and PD spots of vein R (Fig. 3).

Abbreviations and format used. Wing spots (Fig. 3): AD, apical dark spot; ASP, accessory sector pale spot; HD, humeral dark spot spot; HP, humeral pale spot; PD, posterior dark spot; PHP, prehumeral pale spot; PP, preapical pale spot; PSD, presector dark spot; PSP, presector pale spot; SCP, subcostal pale spot; SD, sector dark spot; SP, sector pale spot; ASA, allele-specific amplification; PCR, polymerase chain reaction; SCAR, sequence characterized amplified regions; RFLP, restriction fragment length polymorphism; mtDNA, mitochondrial DNA; ITS2, internal transcribed spacer 2 of the ribosomal DNA; H-banding, heterochromatin bands of the chromosome; L, larva; Le, larval exuviae; P, pupa; Pe, pupal exuviae; M, male; F, female; acc. no., colletion accession number; NHM, Natural History Museum, London, U.K.; NMNH, National Museum of Natural History, U.S.A.; AFRIMS, Armed Forces Research Institute of Medical Sciences, Bangkok. An asterisk (*) after the life stage means that at least part of the organism has been illustrated. Distribution records are listed in the following order and format: COUNTRY, Administrative division and locality name (latitude longitude). Species distribution maps are mainly based on the material examined, except for An. dirus, An. scanloni, An. baimaii and An. nemophilous from which we also included published data by Walton et al. (1999), Huong et al. (2001), and Manguin et al. (2002).

\section{LEUCOSPHYRUS GROUP}

Other references: Strickland 1913, 1925; Roper 1914; Christophers 1916, 1924; Swellengrebel 1919, 1921; Swellengrebel \& Swellengrebel de Graaf 1920a, 1920b; SeniorWhite 1925; Christophers et al. 1927; Covell 1927; Strickland \& Choudhury 1927; Borel 1930; Brug \& Edwards 1931: 251; Doorenbos 1931a,b; Swellengrebel \& Rodenwaldt 1932;
Christophers 1933; Russell \& Baisas 1934a, 1934b, 1936; Stoker 1934; King \& Baisas 1936; Covell \& Harbhagwan 1939; Covell 1944; McArthur 1946, 1947, 1948, 1949, 1950a, 1950b; 1954; Brug \& Bonne-Wepster 1947; Reid 1949; Colless 1950, 1956b, 1957; Bonne-Wepster \& Swellengrebel 1953; Stojanovich \& Scott 1966; Reid 1968; Chow 1970; Reid 1970; Wilkinson et al. 1970; O’Corner \& Sopa 1981; Harinasuta et al. 1982; Sandosham \& Thomas 1982; Ramachandra Rao 1984; O’Conner \& Arwati 1985; Prasittisuk 1985; Kondrashin 1986; Salazar et al. 1988; Jayaprakash 1990; Kondrashin et al. 1991; Marwoto \& Arbani 1991; Sharma et al. 1991; Mya et al. 2002; Sithiprasasna et al. 2003.

The Leucosphyrus Group can be distinguished from the remaining members of Cellia by the presence of a broad, whitescaled apical band covering the tibio-tarsal joint of the hindleg (King \& Baisas 1936; Colless 1956b; Reid 1968), and both the $\mathrm{Cu}_{1}$ and the $\mathrm{M}$ veins noticeably wavy, vein $\mathrm{M}$ slightly less wavy than $\mathrm{Cu}_{1}$ (Fig. 3). The Leucosphyrus Group contains 20 named species (Peyton 1989; Sallum et al. 2004) and two geographical forms (Peyton 1989) divided between the Leucosphyrus, Riparis and Hackeri Subgroups (Table 1; Fig. 1). Reid (1949) suggested that the Leucosphyrus Group consisted of six or seven distinct taxa. Previously, Colless (1950) listed six subspecies, An. l. leucosphyrus, An. l. balabacensis, An. l. elegans, An. l. riparis, An. l. pujutensis and An. l. hackeri, and An. cristatus, and the "hackeri-like form of Celebes" whose taxonomic status was unknown at that time. The "hackeri-like form of Celebes" is currently known as An. sulawesi. Colless (1956a) considered An. pujutensis, $A n$. riparis and An. hackeri valid species because they were sympatric and morphologically distinct from each other as well as from other members of the Leucosphyrus Group. The first comprehensive revision of the group was published by Colless (1956b), who included 13 taxa (four species, four subspecies and five geographical forms, An. l. leucosphyrus, An. l. balabacensis, An. leucosphyrus Luzon Form (=An. baisasi), An. leucosphyrus Negros Form, An. leucosphyrus Fraser's Hill form (=An. nemophilous), An. leucosphyrus Kepong Form (=An. introlatus), An. riparis riparis, An. riparis macarthuri, An. cristatus, An. pujutensis, An. elegans, An. hackeri and An. leucosphyrus Celebes Form (=An. sulawesi). Colless (1957) suggested that the Kepong Form was genetically distinct but morphologically similar to $A n$. $l$. balabacensis in the adult, larval, and pupal stages. Consequently, Colless elevated An. balabacensis to species and considered the Kepong Form a subspecies (An. b. introlatus). Additionally, he described the Luzon Form as a subspecies of An. balabacensis, An. b. baisasi. Reid (1968) included eight species of the Leucosphyrus Group in his study on mosquitoes of Malaya and Borneo, An. leucosphyrus, An. b. balabacensis, An. sulawesi, An. hackeri, An. elegans (=An. mirans), An. pujutensis, An. riparis, and An. cristatus. He also discussed morphological variation observed among populations without giving a formal description or name to those forms. Studies on members of the Leucosphyrus Complex intensified after the publication of An. dirus by 
Peyton \& Harrison (1979). Following this study, Peyton \& Harrison (1980) noted that a multidisciplinary approach, including morphology, biology, cross-mating experiments, and cytogenetics had shown that An. balabacensis represents a species complex consisting of several morphologically similar species. They recognized, An. b. balabacensis, An. b. baisasi, An. b. introlatus, An. dirus, and An. takasagoensis as members of the complex. Furthermore, using laboratory hybridization and cytogenetic data, they resurrected An. takasagoensis from synonymy of An. balabacensis. Baimai et al. (1981) using mitotic and meiotic karyotypes and polytene salivary chromosome banding pattern showed significant differences between An. dirus, An. takasagoensis, and An. balabacensis (Perlis Form).Those differences were useful to both differentiate those taxa and to support their species status. Consequently, several other multidisciplinary studies were carried out to define and separate species within the $A n$. balabacensis species complex, i.e. morphological studies (Sucharit \& Choochote 1983; Hii 1986; Peyton \& Ramalingam 1988; Damrongphol \& Baimai 1989), cytogenetic and crossmating experiments (Kanda et al. 1981, 1983; HII 1984b; Wibowo et al. 1984; Baimai et al. 1987, 1988a, 1988c, 1988d; Baimai 1988b; Sawadipanich et al. 1990; Poopittayasataporn \& Baimai 1995), enzyme electromorphs (Takai 1986; Green et al. 1992), DNA hybridization (Audtho et al. 1995), and molecular makers (Xu \& Qu 1997b; Xu et al. 1998; Walton et al. 1999; Huong et al. 2001; Manguin et al. 2002).

Members of the Leucosphyrus Group are primarily jungle breeders and have been incriminated as vectors of human Plasmodium in widely separated areas throughout their geographical distribution in Malaysia, Thailand, Vietnam, Cambodia, Laos, Myanmar, Indonesia, the Philippines, China, Bangladesh, and India (Coatney et al. 1971; Rahman et al. 1977; Chang et al. 1995; Chareonviriyaphap et al. 2000; Mya et al. 2002; Oo et al. 2003; Sithiprasasna et al. 2003; Kobayashi et al. 2004; Trung et al. 2004). They are mostly primate feeders but also possibly bite small canopy mammals (Eyles et al. 1964), and at least seven species are involved in the transmission of non-human malarias in tropical broad-leaf evergreen forests and mangrove forests in Southeast Asia, as well as in areas of southern India and Sri Lanka (Coatney et al. 1971). Anopheles mirans (as An. elegans) is a vector of macaque malaria in southwestern India and Sri Lanka, $A n$. cracens (as An. dirus), An. hackeri, An. latens (as An. leucosphyrus), and An. introlatus are vectors in west Malaysia, An. balabacensis in Palawan, and An. takasagoensis is a possible vector in Taiwan. Furthermore, An. balabacensis plays a major role in the epidemiology of filariasis (Cheong et al. 1984; Hii et al. 1985; Pokrovskii et al. 1986; Atmosoedjono et al. 1993). Geographic distribution of non-human primate malarias, especially macaque malaria, is determined by the distribution of the Leucosphyrus Group, which is disjunct and coincident with that of tropical broad-leaf evergreen rain forest. The disjunct geographical distribution of the Leucosphyrus Group may be the result of either wind dispersal between Southeast Asia and southwestern India and Sri Lanka or disappearance of a former rain forest connection. Interestingly, some rain forest mammals show the same distribution pattern (Fooden 1994).

\section{LEUCOSPHYRUS SUBGROUP}

The Leucosphyrus Subgroup is comprised of the Leucosphyrus and the Dirus Complexes. The Leucosphyrus Complex includes An. leucosphyrus, An. latens, An. balabacensis, and An. introlatus. The Dirus Complex includes An. dirus, An. cracens, An. scanloni, An. baimaii, An. elegans, An. nemophilous, and An. takasagoensis. Anopheles baisasi and the Con Son form were placed outside both complexes (Table 1) (Peyton 1989). Members of the Leucosphyrus Subgroup can be distinguished from those of the Riparis and Hackeri Subgroups in having a proboscis as long as or longer than the forefemur, and the ratio of the length of proboscis to length of forefemur is 1.00-1.17 (Fig. 1; Table 2.1). Distinction among species of the Leucosphyrus Subgroup is not always possible using morphological characters. Members of the Leucosphyrus and the Dirus Complexes are morphologically similar in all life stages and no characters were found in the larval and pupal stages to separate the two complexes. Definitions of the Leucosphyrus and the Dirus Complexes are

Table 2.1. Proboscis, forefemur, maxillary palpus lengths and rations for subgroups of the Leucosphyrus Group.

\begin{tabular}{|c|c|c|c|c|c|c|c|}
\hline Subgroup / Character & & P length $\mathrm{mm}$ & Fe-I mm & Plp length mm & Ratio P/Fe-I & Ratio Plp/P & Ratio Plp/Fe-I \\
\hline \multirow[t]{3}{*}{ Leucosphyrus } & $\mathrm{R}$ & $1.62-2.60$ & $1.44-2.35$ & $1.49-2.40$ & $1.00-1.17$ & $0.81-1.00$ & $0.90-1.12$ \\
\hline & MR & $1.81-2.38$ & $1.61-2.20$ & $1.65-2.27$ & $1.06-1.13$ & $0.87-0.95$ & $0.97-1.06$ \\
\hline & $\mathrm{MG}$ & 2,07 & 1,89 & 1,9 & 1,09 & 0,93 & 1,01 \\
\hline \multirow[t]{3}{*}{ Elegans } & $\mathrm{R}$ & $2.17-3.04$ & $1.69-2.43$ & $1.62-2.45$ & $1.16-1.45$ & $0.71-0.93$ & $0.88-1.18$ \\
\hline & MR & $2.50-2.59$ & $1.87-2.08$ & $1.90-2.22$ & $1.21-1.35$ & $0.75-0.87$ & $0.97-1.11$ \\
\hline & MG & 2,54 & 1,98 & 2,05 & 1,27 & 0,81 & 1,03 \\
\hline \multirow[t]{3}{*}{ Cristatus } & $\mathrm{R}$ & $1.34-2.00$ & $1.37-2.12$ & $1.21-1.85$ & $0.88-0.99$ & $0.86-1.00$ & $0.81-0.97$ \\
\hline & MR & $1.48-1.80$ & $1.59-1.89$ & $1.38-1.69$ & $0.92-0.95$ & $0.93-0.94$ & $0.85-0.90$ \\
\hline & MG & 1,63 & 1,73 & 1,52 & 0,93 & 0,93 & 0,87 \\
\hline
\end{tabular}

$\mathrm{P}=$ proboscis $-\mathrm{Fe}-\mathrm{I}=$ forefemur $-\mathrm{Plp}=$ maxillary palpus $-\mathrm{R}=$ range $-\mathrm{MR}=$ mean range $-\mathrm{MG}=$ mean subgroup 
primarily based on characters of the adult stages. The Leucosphyrus Complex has the following combination of charaters that distinguish it from the Dirus Complex: 1) ASP spot extending onto vein $\mathrm{C}$ at least on one wing; 2) hindtarsomere 4 without pale scales at base; 3 ) hindtarsomere 5 without basal pale scales. Although An. balabacensis is placed in the Leucosphyrus Complex with the ASP spot usually present on vein $\mathrm{C}$, infrequently it is absent on both veins $\mathrm{C}$ and subcosta. Also, hindtarsomere 4 always has a small patch of pale scales at the base on the dorsal surface, however this patch is usually less developed than in members of the Dirus Complex. Similarly, in An. introlatus the ASP spot is either present or absent on vein $\mathrm{C}$, but the hindtarsomere 4 is always dark-scaled at base. The placement of An. baisasi within the Leucosphyrus Subgroup was based on the ratio of the length of the maxillary palpus and the length of the forefemur of the female. However, the assignment of this species to either of the two species complexes is not possible using morphological characters because An. baisasi exhibits characters that can place it in both. In common with species of the Dirus Complex, An. baisasi has the ASP spot often absent on vein C (except for two individuals in which a short ASP spot (2,3 pale scales) is present on one wing); however, similar to members of the Leucosphyrus Complex, the hindtarsomere 4 is always darkscaled at the base.

\section{LEUCOSPHYRUSCOMPLEX}

The Leucosphyrus Complex can be distinguished from the Dirus Complex in having the ASP wing spot on the veins C, subcosta and R, and by the absence of pale scales at the base of hindtarsomere 4. In the Dirus Complex, the ASP spot usually does not extend onto vein $\mathrm{C}$ and hindtarsomere 4 is palescaled at base. Although generally useful to identify members of the Leucosphyrus Complex, An. balabacensis and An. introlatus are polymorphic for these characters and thus overlap with members of the Dirus Complex. Anopheles latens and An. leucosphyrus are morphologically identical. Differentiation of these two species is only possible using cytogenetic evidence and cross-mating experiments. Anopheles latens has telocentric and subtelocentric sex chromosomes with a distinctive band of intercalary heterochromatin in the $\mathrm{X}$ chromosome, whereas $A n$. leucosphyrus has submetacentric $\mathrm{X}$ and $\mathrm{Y}$ chromosomes (Baimai et al., 1988c). Members of the Leucosphyrus Complex occur in several countries throughout Southeast Asia, however no species has been found in India, China or Taiwan (Table 1). Members of the Leucosphyrus Complex are predominantly forest mosquitoes and also important vectors of human malaria parasites, An. leucosphyrus (Warren et al. 1963), An. latens (Chang et al. 1995), An. balabacensis (Hii et al. 1985, 1988c; Schultz 1992; Barcus et al. 2002), non-human primate Plasmodium, An. introlatus (Eyles et al. 1963; Warren \& Wharton 1963) and An. balabacensis (Tsukamoto et al. 1978), and filariases, An. balabacensis (Cheong et al. 1984; Hii et al. 1984, 1985; Pokrovskii et al. 1986; Atmosoedjono et al. 1993).

\section{Anopheles (Cellia) leucosphyrus Dönitz}

(Figs. 4, 7-10, 52-54)

Anopheles leucosphyrus Dönitz (1901:37) (F). Syntypes two females, 1 female deposited in the Zoology Museum Berlin, Germany, and 1 female in the NHM.

Anopheles leucosphyrus of Dönitz (1902:56) (F*); Stanton (1915a:254) (distribution); Bais (1920:1-137) (Plasmodium isolation); Carter (1921:354) (identification key); Edwards (1921:70) (taxonomic notes); Swellengrebel \& Rodenwaldt (1932:193) (F*, M*, L*); Russell et al. (1943:116) (identification key); Reid (1949:48) (A*); Koesoemawinangoen (1954:63, 93) (A, identification key); Colless (1956b:55) (F*, $\left.\mathrm{P}^{*}, \mathrm{~L}^{*}\right),(1957: 133)\left(\mathrm{F}, \mathrm{L}^{*}\right.$, in part, Sumatra); Chow (1961) (distribution, $\mathrm{F}^{*}$, identification key, in part, Sumatra); Reid (1968:386) $\left(\mathrm{M}^{*}, \mathrm{~F}^{*}, \mathrm{P}^{*}, \mathrm{~L}^{*}\right.$, in part, Sumatra); Townsend (1990:94) (type information).

Anopheles leucosphyrus B of Baimai et al. (1988c:44) (karyotype, cross-mating experiments); Peyton (1989:197) (taxonomy).

Anopheles leucosphyrus leucosphyrus of Taylor (1944:44) (A*, L*, distribution, bionomics, A, L, identification keys); Puri (1949:488) (in part, Sumatra).

Anopheles leucophyrus of Theobald (1901:307) (F); Giles (1902:312) $\left(\mathrm{F}^{*}\right)$; Theobald $(1903: 3)\left(\mathrm{F}^{*}\right)$.

Neomyzomyia leucosphyra of Swellengrebel (1919:1) (A, identification key); Swellengrebel et al. (1919:1-64) (vector competence); Doorenbos (1927:21) (Plasmodium isolation); Soesilo (1929a:1) (Plasmodium isolation); Soesilo (1929b:350) (Plasmodium isolation); Doorenbos (1931a:1228) (Plasmodium isolation); Doorenbos (1931b:1459) (Plasmodium isolation).

Nyssorhynchus leucosphyrus of Blanchard (1905:213) (F, in part, Sumatra).

Pyretophorus leucosphyrus Theobald (1910:44) (in part, Sumatra).

Female (Figs. 4, 7, 8). Head: proboscis uniformly darkscaled, length $1.90-2.38 \mathrm{~mm}($ mean $=2.17 \mathrm{~mm})$, ratio of length to forefemur 1.06-1.14 (mean $=1.09)$, maxillary palpus (Fig. 7) length $1.67-2.15 \mathrm{~mm}($ mean $=1.97 \mathrm{~mm})$, ratio of length to proboscis $0.88-0.94$ (mean $=0.91)$, ratio of length to forefemur $0.98-1.01($ mean $=0.99)($ Table 2.2$)$, ratio of length of palpomeres $3 / 41.56-1.86($ mean $=1.72), 3 / 51.92-3.00($ mean $=2.52), 4 / 51.15$ $1.62($ mean $=1.47), 4-5 / 30.87-1.12($ mean $=0.98)$, palpomeres 2,3 with narrow apical band of silvery white scales, palpomeres 4,5 with apical pale cream-colored band, band of palpomere 4 larger than those on palpomeres 2 and 3 (Fig. 7), length of apical pale band of palpomere $51.00-2.00($ mean $=1.51)$ length of basal dark band of palpomere 5, ratio of length of apical pale band of palpomere 4 to length of basal dark band of palpomere $50.43-1.33($ mean $=0.78)($ Table 3$)$. Thorax: pleural setae as follows: 2-5 upper proepisternal, 1-3 prespiracular, 6-9 prealar, 4-6 upper mesokatepisternal, 2,3 lower mesokatepisternal, 4-9 upper mesepimeral. Wing (Fig. 4): length 3.29-3.95 mm (mean = $3.53 \mathrm{~mm}$ ); pale scales on all veins light cream-colored, spots on veins $\mathrm{C}$ and subcosta more obviously cream-colored, those on vein $\mathrm{R}$ and posterior veins lighter, bordering on whitish, not strongly contrasting with others; PHP spot of vein $\mathrm{C}$ usually small, occasionally prominent or absent, HP spot always present and prominent, PSP spot usually present and prominent, rarely absent, SP spot usually prominent, occasionally reduced, never absent, ASP spot usually present, prominent, rarely reduced or absent on vein $C$, always present on vein R, PP spot 0.67-1.55 (mean =1.03) length of SCP spot, AD 1.35-2.80 $($ mean $=1.99)$ length of preapical pale spot, PSD 
Table 2.2. Proboscis, forefemur, maxillary palpus lengths and rations for species of the Leucosphyrus Group.

\begin{tabular}{|c|c|c|c|c|c|c|c|}
\hline Species / Character & & P length mm & Fe-I mm & Plp length mm & Ratio P/Fe-I & Ratio Plp/P & Ratio Plp/Fe-I \\
\hline \multicolumn{8}{|c|}{ LEUCOSPHYRUS SUBGROUP } \\
\hline An. baisasi & $\mathrm{R}$ & $1.64-2.03$ & $1.49-1.95$ & $1.49-1.83$ & $1.03-1.12$ & $0.88-0.94$ & $0.93-1.00$ \\
\hline$(n=8)$ & M & 1.81 & 1.72 & 1.65 & 1.06 & 0.91 & 0.97 \\
\hline \multicolumn{8}{|c|}{ LEUCOSPHYRUS COMPLEX } \\
\hline An. leucosphyrus & $\mathrm{R}$ & $1.90-2.38$ & $1.67-2.15$ & $1.67-2.15$ & $1.06-1.14$ & $0.88-0.94$ & $0.98-1.01$ \\
\hline$(n=14)$ & M & 2.17 & 1.99 & 1.97 & 1.09 & 0.91 & 0.99 \\
\hline An. latens & $\mathrm{R}$ & $1.92-2.25$ & $1.70-2.05$ & $1.62-2.15$ & $1.06-1.16$ & $0.81-0.95$ & $0.91-1.07$ \\
\hline$(n=24)$ & M & 2.11 & 1.88 & 1.89 & 1.12 & 0.89 & 1.00 \\
\hline An. introlatus & $\mathrm{R}$ & $1.85-2.28$ & $1.67-2.18$ & $1.64-2.10$ & $1.02-1.11$ & $0.89-0.94$ & $0.93-0.98$ \\
\hline$(n=20)$ & M & 2.09 & 1.97 & 1.91 & 1.06 & 0.92 & 0.97 \\
\hline An. balabacensis & $\mathrm{R}$ & $1.92-2.28$ & $1.72-2.17$ & $1.62-2.15$ & $1.01-1.11$ & $0.86-0.95$ & $0.90-1.00$ \\
\hline$(n=22)$ & M & 2.08 & 1.96 & 1.91 & 1.06 & 0.92 & 0.97 \\
\hline \multicolumn{8}{|l|}{ DIRUS COMPLEX } \\
\hline An. dirus & $\mathrm{R}$ & $1.12-2.28$ & $1.52-2.10$ & $1.49-2.13$ & $1.03-1.15$ & $0.91-0.96$ & $0.99-1.10$ \\
\hline$(n=25)$ & M & 2.05 & 1.88 & 1.93 & 1.09 & 0.94 & 1.03 \\
\hline An. cracens & $\mathrm{R}$ & $1.97-2.25$ & $1.75-2.07$ & $1.82-2.10$ & $1.09-1.17$ & $0.89-0.97$ & $1.01-1.12$ \\
\hline$(n=14)$ & $\mathrm{M}$ & 2.11 & 1.87 & 1.96 & 1.13 & 0.93 & 1.05 \\
\hline An. scanloni & $\mathrm{R}$ & $1.64-2.27$ & $1.47-2.09$ & $1.52-2.15$ & $1.07-1.14$ & $0.90-0.98$ & $1.00-1.10$ \\
\hline$(\mathrm{n}=10)$ & M & 1.95 & 1.77 & 1.82 & 1.1 & 0.93 & 1.03 \\
\hline An. baimaii & $\mathrm{R}$ & $1.97-2.38$ & $1.77-2.18$ & $1.77-2.18$ & $1.01-1.14$ & $0.88-1.00$ & $0.96-1.05$ \\
\hline$(n=32)$ & M & 2.09 & 1.94 & 1.96 & 1.08 & 0.94 & 1.00 \\
\hline An. elegans & $\mathrm{R}$ & $2.03-2.30$ & $1.93-2.15$ & $1.93-2.20$ & $1.03-1.11$ & $0.90-0.99$ & $0.98-1.02$ \\
\hline$(n=14)$ & M & 2.2 & 2.04 & 2.06 & 1.08 & 0.94 & 1.01 \\
\hline An. nemophilous & $\mathrm{R}$ & $1.85-2.36$ & $1.65-2.26$ & $1.55-2.29$ & $1.00-1.15$ & $0.84-0.99$ & $0.93-1.01$ \\
\hline$(n=34)$ & M & 2.17 & 2.0 & 1.96 & 1.09 & 0.9 & 0.98 \\
\hline An. takasagoensis & $\mathrm{R}$ & $2.17-2.60$ & $1.92-2.35$ & $1.97-2.40$ & $1.04-1.14$ & $0.89-1.00$ & $0.99-1.08$ \\
\hline$(n=16)$ & M & 2.38 & 2.2 & 2.27 & 1.08 & 0.95 & 1.03 \\
\hline \multicolumn{8}{|c|}{ HACKERI SUBGROUP } \\
\hline An. mirans & $\mathrm{R}$ & $2.17-2.86$ & $1.77-2.25$ & $1.85-2.45$ & $1.19-1.31$ & $0.84-0.93$ & $1.02-1.15$ \\
\hline$(\mathrm{n}=18)$ & M & 2.59 & 2.02 & 2.22 & 1.25 & 0.87 & 1.1 \\
\hline An. hackeri & $\mathrm{R}$ & $2.25-2.83$ & $1.77-2.15$ & $1.69-2.02$ & $1.22-1.38$ & $0.72-0.81$ & $0.93-1.04$ \\
\hline$(n=19)$ & M & 2.53 & 1.94 & 1.9 & 1.31 & 0.75 & 0.98 \\
\hline An. pujutensis & $\mathrm{R}$ & $2.33-2.93$ & $1.69-2.28$ & $1.92-2.58$ & $1.29-1.45$ & $0.76-0.88$ & $1.06-1.18$ \\
\hline$(n=18)$ & M & 2.06 & 1.91 & 2.11 & 1.35 & 0.82 & 1.11 \\
\hline An. recens & $\mathrm{R}$ & $2.28-2.68$ & $1.75-2.30$ & $1.80-2.33$ & $1.16-1.30$ & $0.79-0.86$ & $0.97-1.05$ \\
\hline$(\mathrm{n}=10)$ & M & 2.5 & 2.07 & 2.1 & 1.21 & 0.83 & 1.01 \\
\hline An. sulawesi & $\mathrm{R}$ & $2.28-3.04$ & $1.72-2.43$ & $1.62-2.38$ & $1.23-1.30$ & $0.71-0.84$ & $0.88-1.06$ \\
\hline$(n=14)$ & M & 2.53 & 2.03 & 1.97 & 1.25 & 0.78 & 0.97 \\
\hline \multicolumn{8}{|c|}{ RIPARIS SUBGROUP } \\
\hline An. riparis & $\mathrm{R}$ & $1.42-1.69$ & $1.47-1.90$ & $1.21-1.64$ & $0.88-0.96$ & $0.86-0.97$ & $0.81-0.89$ \\
\hline$(n=10)$ & $\mathrm{M}$ & 1.6 & 1.72 & 1.49 & 0.92 & 0.93 & 0.85 \\
\hline An. cristatus & $\mathrm{R}$ & $1.34-1.67$ & $1.37-1.82$ & $1.26-1.64$ & $0.89-0.98$ & $0.88-1.00$ & $0.81-0.93$ \\
\hline$(\mathrm{n}=9)$ & M & 1.48 & 1.59 & 1.38 & 0.93 & 0.93 & 0.87 \\
\hline An. macarthuri & $\mathrm{R}$ & $1.42-2.00$ & $1.57-2.12$ & $1.34-1.85$ & $0.90-0.99$ & $0.88-0.98$ & $0.82-0.97$ \\
\hline$(n=29)$ & $\mathrm{M}$ & 1.8 & 1.89 & 1.69 & 0.95 & 0.94 & 0.9 \\
\hline
\end{tabular}

$\mathrm{P}=$ proboscis $-\mathrm{Fe}-\mathrm{I}=$ forefemur $-\mathrm{Plp}=$ maxillary palpus $-\mathrm{R}=$ range $-\mathrm{M}=$ mean

spot of vein R extending basally from level 4 to level 6 (Fig. 4) on one or both wings (Table 4), PSD spot of vein R entirely dark or with 1-5 small pale interruptions (Table 5), SD spot of vein $R$ with 1-4 pale interruptions (Table 6), sum of pale interruptions on PSD-PD spots of vein R varying from 5 to 12 for each wing, ratio of length of cell $\mathrm{R}_{2}$ to vein $\mathrm{R}_{2+3} 1.49-2.10$ (mean $=1.70)$, ratio of length of cell $\mathrm{R}_{2}$ to cell $\mathrm{M}_{1+2} 1.22-1.42$ $($ mean $=1.33)$. Legs (Fig. 8): femora, tibiae, and tarsomeres 1 dark-scaled, speckled with pale spots; foretarsomeres 2 and 3 with conspicuous basal and apical pale bands and 1,2 middle pale spots, foretarsomere 4 with apical and basal pale bands, foretarsomere 5 with basal and apical pale bands, sometimes basal pale band absent or indistinct, apical pale band sometimes poorly distinct, pale bands on foretarsomeres 3-5 less distinct or absent on ventral surface; midtarsomeres 2,3 with apical and basal pale spots and 1,2 middle pale spots on dorsal surface, midtarsomere 4 with apical and basal pale spots on dorsal surface, basal pale spots absent or poorly distinct, midtarsomere 5 with indistinct apical pale band on dorsal surface; hindtarsomeres 2,3 with apical pale band, indistinct 
Table 3. Length, ratio, pale and dark scaled bands of female palpomeres 1-5 for species of the Leucosphyrus Group.

\begin{tabular}{|c|c|c|c|c|c|c|c|c|c|c|c|c|c|c|c|}
\hline Species/character & & Plp 1-2 mm & $\mathrm{p} 3 \mathrm{~mm}$ & Plp $4 \mathrm{~mm}$ & Plp 5 mm & $\begin{array}{r}\text { Plp } 5 \\
\text { APBmm }\end{array}$ & $\begin{array}{r}\text { Plp } 5 \\
\text { BDBmm }\end{array}$ & $\begin{array}{r}\text { Plp } 4 \\
\text { APBmm }\end{array}$ & $\begin{array}{r}\text { Ratio } \\
\text { Plp 1-2/3 }\end{array}$ & $\begin{array}{r}\text { Ratio } \\
\text { Plp 3/4 }\end{array}$ & $\begin{array}{r}\text { Ratio } \\
\text { Plp 3/5 }\end{array}$ & $\begin{array}{r}\text { Ratio } \\
\text { Plp } 4 / 5\end{array}$ & $\begin{array}{r}\text { Ratio } \\
\text { Plp 4-5/3 }\end{array}$ & $\begin{array}{r}\text { Ratio Plp } \\
5 \mathrm{APB} / \mathrm{BDB}\end{array}$ & $\begin{array}{r}\text { Ratio } \\
\text { Plp 4APB/ } \\
\text { Plp5BDB }\end{array}$ \\
\hline \multicolumn{16}{|l|}{ LEUCOSPHYRUS } \\
\hline \multicolumn{16}{|l|}{ SUBGROUP } \\
\hline An. baisasi & $\mathrm{R}$ & $8-0.68$ & $8-0.61$ & $5-0.33$ & $8-0.25$ & $5-0.15$ & $05-0.15$ & $02-0.13$ & $08-1.21$ & $1.82-2.00$ & $2.40-2.75$ & $1.22-1.57$ & $82-1.00$ & $33-3.00$ & $.14-1.67$ \\
\hline $\mathrm{n}=7$ ) & M & 0.62 & 0.55 & 0.29 & 0.21 & 0.09 & 0.1 & 0.04 & 1.12 & 1.88 & 2.7 & 1.4 & 0.92 & 1.12 & 0.57 \\
\hline \multicolumn{16}{|l|}{ LEUCOSPHYRUS } \\
\hline \multicolumn{16}{|l|}{ COMPLEX } \\
\hline n. leucosphyrus & $\mathrm{R}$ & $1-0.76$ & $6-0.71$ & $30-0.43$ & $0.20-0.33$ & $9-0.17$ & $77-0.11$ & $4-0.10$ & 00-1.09 & $1.56-1.86$ & $1.92-3.00$ & $1.15-1.62$ & $87-1.12$ & $00-2.00$ & $.43-1.33$ \\
\hline =14) & M & 0.68 & 0.65 & & 0.26 & 0.13 & 0.09 & 0.06 & 1.06 & 1.72 & 2.52 & 1.47 & 0.98 & 1.51 & 0.78 \\
\hline te & $\mathrm{R}$ & $61-0.76$ & $3-0.68$ & $28-0.40$ & $20-0.30$ & $2-0.20$ & $07-0.18$ & $0.00-013$ & $00-1.14$ & $1.62-2.08$ & $7-2.87$ & $1.22-1.62$ & $4-1.08$ & $17-4.00$ & $0.00-1.67$ \\
\hline 24) & M & 0.67 & & & 25 & 0.1 & 0.12 & 0.05 & 1.09 & 1.77 & 2.44 & 1.3 & 0.98 & 1.18 & 0.51 \\
\hline I. intr & $\mathrm{R}$ & $8-0.73$ & $3-0.68$ & $3-0.40$ & $0-0.30$ & 7-0.16 & $9-0.14$ & $4-0.06$ & $0-1.09$ & $0-1.92$ & $7-2.78$ & $5-1.67$ & $1-1.12$ & $3-2.00$ & $7-0.57$ \\
\hline . & $\mathrm{M}$ & 0.65 & 0.62 & 0.37 & 0.27 & 0.12 & 0.12 & 0.05 & 1.05 & 1.66 & 2.38 & 1.43 & 1.02 & 1.08 & 0.44 \\
\hline ensis & $\mathrm{R}$ & $56-0.73$ & $33-0.71$ & $28-0.40$ & $20-0.30$ & $7-0.16$ & $66-0.14$ & 84-0.11 & $00-1.12$ & $57-2.15$ & $2.17-2.67$ & $1.08-1.62$ & $91-1.08$ & $67-2.00$ & $33-1.28$ \\
\hline$(n=22)$ & M & 0.67 & 0.63 & 0.35 & 0.26 & 0.13 & 0.1 & 0.06 & 1.06 & 1.77 & 2.41 & 1.36 & 0.99 & 1.2 & 0.59 \\
\hline \multicolumn{16}{|l|}{ DIRUS COMPLEX } \\
\hline & $\mathrm{R}$ & -0.77 & -0. & 5 & $\pi 1$ & $5-0.18$ & $4-0.14$ & .07 & -1.17 & $4-1.85$ & 2.70 & 1 & 1.09 & & $36-1.33$ \\
\hline & $\mathrm{M}$ & 0.68 & & & & 0.14 & 0.08 & 0.05 & 1.09 & 1.68 & 2.41 & & 1.01 & 1.6 & 0.64 \\
\hline cens & $\mathrm{R}$ & $68-0.78$ & $8-0.68$ & $33-0.40$ & $23-0.28$ & $2-0.22$ & 84-0.09 & $4-0.09$ & $08-1.18$ & $67-1.92$ & $18-2.78$ & $1.20-1.56$ & $8-1.05$ & $3-3.67$ & -1.25 \\
\hline$=14)$ & M & 0.71 & 0.63 & 36 & 0.26 & 0.15 & 0.06 & 0.06 & 1.12 & 1.78 & 2.45 & 1.37 & 0.97 & 2.12 & 0.88 \\
\hline ni & $\mathrm{R}$ & $6-0.73$ & $8-0.68$ & $28-0.43$ & $20-0.30$ & $9-0.19$ & 4-0.09 & $3-0.05$ & $03-1.19$ & $1.53-2.00$ & $2.18-2.71$ & $1.22-1.50$ & $1-1.08$ & $0-3.50$ & $28-2.00$ \\
\hline & M & & & & & 0.14 & 88 & 0.05 & 1.1 & 1.75 & & & & 1.87 & 0.79 \\
\hline ( & $\mathrm{R}$ & $1-0.68$ & $6-0.68$ & $3-0.45$ & $0.023-0.30$ & $2-0.20$ & $7-0.13$ & $5-0.10$ & 4-1.14 & $0-1.67$ & $8-2.78$ & $5-1.6$ & $6-1.20$ & 2.33 & $7-1.00$ \\
\hline $\mathrm{n}=30)$ & M & 0.65 & & & 0.27 & 0.15 & 0.11 & 0.06 & 1.07 & 1.63 & 2.27 & 1.39 & 1.06 & 1.39 & 0.64 \\
\hline An. eleg & $\mathrm{R}$ & $66-0.73$ & $3-0.71$ & $8-0.43$ & $25-0.33$ & $2-0.18$ & $8-0.15$ & $8-0.10$ & $4-1.16$ & $3-1.69$ & $8-2.55$ & $1.31-1.60$ & $0-1.16$ & $1-1.83$ & $27-0.78$ \\
\hline-90 & M & 0.7 & & & 0.28 & 0.14 & 0.12 & 0.06 & 1.08 & 1.59 & 2.28 & 14 & 1.07 & 1.21 & 0.56 \\
\hline ilous & $\mathrm{R}$ & $3-0.76$ & $0-0.76$ & $8-0.48$ & $0-0.33$ & $8-0.20$ & 7-0.14 & $3-0.08$ & $0-1.19$ & $0-1.85$ & $8-2.88$ & $1.22-1$ & $1-1.16$ & 2.00 & $22-0.83$ \\
\hline$n=2$ & $\mathrm{M}$ & 0.66 & 0.63 & & 0.26 & 0.14 & 0.1 & 0.05 & 1.06 & 1.61 & 2.4 & 1. & 1.04 & 1.46 & 0.52 \\
\hline goensis & $\mathrm{R}$ & $3-0.83$ & $6-0.78$ & $5-0.48$ & $0-0.33$ & $3-0.23$ & 6-0.11 & $4-0.13$ & $3-1.15$ & $3-1.86$ & $7-3.25$ & $1-1.73$ & 5-1.11 & 3.60 & $3-1.67$ \\
\hline$(n=16)$ & M & 0.79 & 0.73 & 0.44 & 0.29 & 0.18 & 0.08 & 0.06 & 1.08 & 1.63 & 2.51 & 1.53 & 1.05 & 2.36 & 0.82 \\
\hline \multicolumn{16}{|l|}{ HACKE } \\
\hline 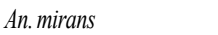 & $\mathrm{R}$ & .83 & -078 & $3-0.51$ & $5-0.38$ & $3-0.23$ & 0.18 & 13 & 17 & 1.77 & $3-2.54$ & 1 & o & 2.67 & $33-1.00$ \\
\hline & $M$ & & & & & 0.16 & 3 & 0.07 & 09 & 1.55 & 2.21 & 1. & 1.1 & 1.4 & $e^{2}>$ \\
\hline$r i$ & $\mathrm{R}$ & $3-0.76$ & $6-0.66$ & $0-0.40$ & $8-0.25$ & $0-0.07$ & $5-0.20$ & $2-0.05$ & $04-1.22$ & $1.62-2.08$ & $2.60-3.37$ & $1.33-2.00$ & 1-0.96 & $0-0.50$ & $12-0.40$ \\
\hline (III) & M & 0.7 & & & & 0.03 & 0.17 & 0.03 & 1.11 & 1.71 & 2.87 & 1.63 & 0.92 & 0.16 & 0.23 \\
\hline An. pujutensis & $\mathrm{R}$ & $8-0.86$ & $3-0.83$ & $15-0.53$ & $0.25-0.35$ & $0-0.20$ & $5-0.15$ & $2-0.07$ & $0-1.12$ & 7-1.86 & $7-2.73$ & $1.25-1.64$ & -1.12 & -4.00 & $0-1.00$ \\
\hline & M & & & & & & & 0.05 & & 1.67 & 24 & & & 1.5 & 0.51 \\
\hline & $\mathrm{R}$ & $8-0.81$ & $1-0.78$ & $28-0.45$ & $0.20-0.30$ & $0-0.13$ & $3-0.18$ & 5-0.10 & $00-1.12$ & $1.67-2.54$ & $2.50-3.62$ & $1.22-2.1$ & $0-1.00$ & -1.00 & $.00-0.67$ \\
\hline & M & & & & & 0.08 & & 0.07 & 1.06 & 1.94 & 3.05 & 1. & 0.85 & 0.5 & 0.21 \\
\hline An. sulawesi & $\mathrm{R}$ & $0.61-0.86$ & $53-0.81$ & $0.25-0.48$ & $20-0.28$ & $0-0.04$ & $18-0.25$ & $4-0.05$ & $1.04-1.14$ & $1.58-2.18$ & $2.33-3.25$ & $1.10-1.75$ & $3-1.00$ & $0.00-0.20$ & $0.15-0.27$ \\
\hline$(\mathrm{n}=16)$ & M & 0.7 & 0.66 & 0.36 & 0.24 & 0.01 & 0.21 & 0.04 & 1.06 & 1.86 & 2.67 & 1.45 & 0.91 & 0.09 & 0.19 \\
\hline \multicolumn{16}{|l|}{ RIPARI } \\
\hline An rinuric & $\mathrm{R}$ & $8-0.61$ & . & 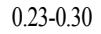 & $12-0.20$ & 5-0.10 & 15-0.1 & 0. & 4-1.19 & $1.75-2.10$ & $2.50-3.33$ & $1.37-1$. & 0. & $5-1.00$ & $0-0.50$ \\
\hline & M & & & & & 0.06 & 0 & 05 & 1.07 & 1.92 & 2.83 & 1.4 & 0.88 & 0.69 & 0.5 \\
\hline$A n$. & $\mathrm{R}$ & $0.51-0.61$ & $4-0.58$ & $0.20-0.30$ & $0.13-0.18$ & $0.02-0.07$ & $0.07-0.15$ & $0.00-0.15$ & $1.04-1.25$ & $1.67-2.37$ & $2.67-3.80$ & $1.28-2.00$ & $68-0.90$ & $0.17-1.00$ & $0.00-2.00$ \\
\hline$(\mathrm{n}=9)$ & M & 0.54 & 0.47 & 0.23 & 0.15 & 0.05 & 0.09 & 0.7 & 1.15 & 2.07 & 3.27 & 1.59 & 0.79 & 0.59 & 0.92 \\
\hline An. $n$ & $\mathrm{R}$ & $0.51-0.66$ & $5-0.63$ & $0.20-0.33$ & $0.18-0.25$ & $0.05-0.13$ & $55-0.13$ & $5-0.18$ & $1.00-1.13$ & $1.82-2.50$ & $2.22-3.57$ & $1.07-1.86$ & $2-1.00$ & $0.40-2.50$ & $0.40-2.33$ \\
\hline$(\mathrm{n}=29$ & M & 0.62 & 0.58 & 0.28 & 0.21 & 0.1 & 0.08 & 0.08 & 1.07 & 2.1 & 2.84 & 1.36 & 0.87 & 1.36 & \\
\hline
\end{tabular}

$\mathrm{Plp}=$ palpomere $-\mathrm{APB}=$ apical pale band $-\mathrm{BDB}=$ basal dark band $-\mathrm{R}=$ range $-\mathrm{M}=$ mean

basal pale band and 2,3 middle pale spots, middle spots sometimes reduced to 1,2 pale scales, hindtarsomeres 4 and 5 with apical pale bands (Fig. 8). Abdomen: tergum VI with few inconspicuous narrow, nearly transparent scales on posterolateral margin, occasionally without scales, tergum VII with few, sparse, nearly transparent narrow scales on posterior margin, tergum VIII covered with golden scales; sternum VI usually without scales, rarely with few dark scales on posteromedial margin, sternum VII with patch of dark scales posteromedially, sternum VIII with small, sparse lateral patches of whitish scales.

Male. Essentially as in female except for sexual characters. Wing generally paler with reduced scaling, pale spots usually longer than in female. Palpomere 2 with dorsal patch of pale scales at middle, extending laterally, and few pale scales at base on dorsal surface, apex of palpomere 2 bare; palpomere 3 with long dorsal patch of pale scales at middle, extending laterally, apex of palpomere 3 with broad band of pale scales covering dorsal, lateral, and ventral surfaces except for narrow, ventrolateral spot of dark scales at apex; palpomeres 4 and 5 mainly pale-scaled with narrow basal band of dark scales. Abdomen: sternum VIII covered with pale cream-colored scales. Genitalia: gonocoxite covered with pale golden to yellowish scales ventrally, black scales dorsolaterally; 4,5 parabasal setae; ventral and dorsal clapette poorly separated, ventral claspette moundlike, more sclerotized laterally, membranous medially, with ventromedial spicules, 1 long, strong, apicolateral seta, approximately equal to length of club, 
Table 4. Frequency distribution (f) and percentage (\%) of levels of basal extension of PSD spot on vein R in females of species of the Leucosphyrus group.

\begin{tabular}{|c|c|c|c|c|c|c|c|c|c|c|c|c|c|c|c|c|c|}
\hline Species / Levels & & $1: 1$ & $1: 2$ & $2: 2$ & $3: 1$ & $3: 2$ & $3: 3$ & $4: 1$ & $4: 2$ & $4: 3$ & $4: 4$ & $5: 3$ & $5: 4$ & $5: 5$ & $5: 6$ & $6: 4$ & $6: 6$ \\
\hline \multicolumn{18}{|l|}{ LEUCOSPHYRUS } \\
\hline \multicolumn{18}{|l|}{ SUBGROUP } \\
\hline An. baisasi & $\mathrm{f}$ & 0 & 0 & 0 & 0 & 0 & $2 / n$ & 0 & $1 / \mathrm{n}$ & $2 / \mathrm{n}$ & $4 / n$ & 0 & $1 / \mathrm{n}$ & 0 & 0 & 0 & 0 \\
\hline$(\mathrm{n}=10)$ & $\%$ & - & - & - & - & - & 20 & - & 10 & 20 & 40 & - & 10 & - & - & - & - \\
\hline \multicolumn{18}{|l|}{ LEUCOSPHYRUS } \\
\hline \multicolumn{18}{|l|}{ COMPLEX } \\
\hline An. latens & $\mathrm{f}$ & 0 & 0 & 0 & 0 & 0 & 0 & 0 & 0 & 0 & $1 / \mathrm{n}$ & 0 & $8 / \mathrm{n}$ & $44 / \mathrm{n}$ & $14 / \mathrm{n}$ & 0 & $7 / \mathrm{n}$ \\
\hline$(n=74)$ & $\%$ & - & - & - & - & - & - & - & - & - & 1.3 & - & 10.8 & 59.4 & 18.9 & - & 9.4 \\
\hline An. leucosphyrus & $\mathrm{f}$ & 0 & 0 & 0 & 0 & 0 & 0 & 0 & 0 & 0 & $2 / n$ & 0 & $12 / \mathrm{n}$ & $26 / n$ & $1 / \mathrm{n}$ & $1 / \mathrm{n}$ & 0 \\
\hline$(\mathrm{n}=42)$ & $\%$ & - & - & - & - & - & - & - & - & - & 4.8 & - & 28.6 & 61.9 & 2.4 & 2.4 & - \\
\hline An. introlatus & $\mathrm{f}$ & $27 / \mathrm{n}$ & $9 / \mathrm{n}$ & 0 & $3 / \mathrm{n}$ & $2 / \mathrm{n}$ & $1 / \mathrm{n}$ & 0 & 0 & 0 & 0 & 0 & 0 & 0 & 0 & 0 & 0 \\
\hline$(n=42)$ & $\%$ & 64.3 & 21.4 & - & 7.1 & 4.8 & 2.4 & - & - & - & - & - & - & - & - & - & - \\
\hline An. balabacensis & $\mathrm{f}$ & $47 / \mathrm{n}$ & $29 / \mathrm{n}$ & $11 / \mathrm{n}$ & $18 / \mathrm{n}$ & $19 / \mathrm{n}$ & $21 / \mathrm{n}$ & $1 / \mathrm{n}$ & $3 / \mathrm{n}$ & $6 / n$ & $4 / n$ & 0 & 0 & 0 & 0 & 0 & 0 \\
\hline$(n=159)$ & $\%$ & 29.5 & 18.2 & 6.9 & 11.3 & 11.9 & 13.2 & 0.6 & 1.9 & 3.8 & 2.5 & - & - & - & - & - & - \\
\hline \multicolumn{18}{|l|}{ DIRUS COMPLEX } \\
\hline An. dirus & $\mathrm{f}$ & 0 & $1 / \mathrm{n}$ & 0 & $3 / \mathrm{n}$ & $5 / \mathrm{n}$ & $10 / \mathrm{n}$ & $2 / n$ & $10 / \mathrm{n}$ & $34 / \mathrm{n}$ & $104 / \mathrm{n}$ & $3 / \mathrm{n}$ & $25 / \mathrm{n}$ & $35 / \mathrm{n}$ & $3 / \mathrm{n}$ & 0 & $1 / \mathrm{n}$ \\
\hline$(n=236)$ & $\%$ & - & 0.4 & - & 1.3 & 2.1 & 4.2 & 0.8 & 4.2 & 14.4 & 44.1 & 1.3 & 10.6 & 14.8 & 1.3 & - & 0.4 \\
\hline An. cracens & $\mathrm{f}$ & 0 & 0 & $4 / n$ & $1 / \mathrm{n}$ & $1 / \mathrm{n}$ & $9 / \mathrm{n}$ & $1 / \mathrm{n}$ & $1 / \mathrm{n}$ & $10 / \mathrm{n}$ & $25 / \mathrm{n}$ & $1 / \mathrm{n}$ & $1 / \mathrm{n}$ & $4 / n$ & 0 & 0 & 0 \\
\hline$(\mathrm{n}=58)$ & $\%$ & - & - & 6.9 & 1.7 & 1.7 & 15.5 & 1.7 & 1.7 & 17.2 & 43.1 & 1.7 & 1.7 & 6.9 & - & - & - \\
\hline An. scanloni & $\mathrm{f}$ & $7 / \mathrm{n}$ & $1 / \mathrm{n}$ & $2 / n$ & $6 / \mathrm{n}$ & $3 / \mathrm{n}$ & $12 / \mathrm{n}$ & 0 & $1 / \mathrm{n}$ & $6 / \mathrm{n}$ & $8 / \mathrm{n}$ & 0 & $4 / n$ & $4 / n$ & 0 & 0 & 0 \\
\hline$(n=54)$ & $\%$ & 13 & 1.8 & 3.7 & 11.1 & 5.5 & 22.2 & - & 1.8 & 11.1 & 14.8 & - & 7.4 & 7.4 & - & - & - \\
\hline An. baimaii & $\mathrm{f}$ & $18 / \mathrm{n}$ & $18 / \mathrm{n}$ & $6 / n$ & $17 / \mathrm{n}$ & $9 / \mathrm{n}$ & $28 / \mathrm{n}$ & $10 / \mathrm{n}$ & $3 / \mathrm{n}$ & $24 / \mathrm{n}$ & $41 / n$ & 0 & $3 / \mathrm{n}$ & $3 / \mathrm{n}$ & 0 & 0 & 0 \\
\hline$(\mathrm{n}=180)$ & $\%$ & 10 & 10 & 3.3 & 9.4 & 5 & 15.5 & 5.5 & 1.7 & 13.3 & 22.8 & - & 1.7 & 1.7 & - & - & - \\
\hline An. elegans & $\mathrm{f}$ & 0 & 0 & 0 & 0 & 0 & 0 & 0 & $1 / \mathrm{n}$ & $2 / \mathrm{n}$ & $9 / \mathrm{n}$ & $1 / \mathrm{n}$ & $6 / \mathrm{n}$ & $23 / \mathrm{n}$ & 0 & 0 & 0 \\
\hline$(n=42)$ & $\%$ & - & - & - & - & - & - & - & 2.4 & 4.8 & 21.4 & 2.4 & 14.3 & 54.8 & - & - & - \\
\hline An. nemophilous & $\mathrm{f}$ & $96 / \mathrm{n}$ & $13 / \mathrm{n}$ & $6 / n$ & $3 / \mathrm{n}$ & $8 / \mathrm{n}$ & $6 / n$ & 0 & 0 & 0 & 0 & 0 & 0 & 0 & 0 & 0 & 0 \\
\hline$(n=132)$ & $\%$ & 72.7 & 9.8 & 4.5 & 2.3 & 6.1 & 4.5 & - & - & - & - & - & - & - & - & - & - \\
\hline An. takasagoensis & $\mathrm{f}$ & $40 / n$ & $4 / n$ & $8 / \mathrm{n}$ & $2 / \mathrm{n}$ & $5 / \mathrm{n}$ & $7 / \mathrm{n}$ & 0 & 0 & 0 & $1 / \mathrm{n}$ & 0 & 0 & 0 & 0 & 0 & 0 \\
\hline$(n=67)$ & $\%$ & 59.7 & 6 & 11.9 & 3 & 7.5 & 10.4 & - & - & - & 1.5 & - & - & - & - & - & - \\
\hline \multicolumn{18}{|l|}{ HACKERI SUBGROUP } \\
\hline An. mirans & $\mathrm{f}$ & $33 / \mathrm{n}$ & $16 / \mathrm{n}$ & $5 / \mathrm{n}$ & $2 / \mathrm{n}$ & $3 / \mathrm{n}$ & $5 / n$ & 0 & $2 / \mathrm{n}$ & $3 / \mathrm{n}$ & $1 / \mathrm{n}$ & - & - & - & - & - & - \\
\hline$(\mathrm{n}=70)$ & $\%$ & 47.1 & 22.8 & 7.1 & 2.8 & 4.3 & 7.1 & - & 2.8 & 4.3 & 1.4 & - & - & - & - & - & - \\
\hline An. hackeri & $\mathrm{f}$ & $23 / \mathrm{n}$ & $11 / \mathrm{n}$ & $7 / \mathrm{n}$ & $2 / n$ & 0 & $1 / \mathrm{n}$ & $1 / \mathrm{n}$ & $1 / \mathrm{n}$ & $3 / \mathrm{n}$ & $2 / \mathrm{n}$ & 0 & 0 & 0 & 0 & 0 & 0 \\
\hline$(n=51)$ & $\%$ & 45.1 & 21.6 & 14 & 3.9 & - & 2 & 2 & 2 & 5.9 & 3.9 & - & - & - & - & - & - \\
\hline An. pujutensis & $\mathrm{f}$ & $24 / n$ & $9 / \mathrm{n}$ & $2 / n$ & 0 & $1 / \mathrm{n}$ & 0 & 0 & 0 & 0 & 0 & 0 & 0 & 0 & 0 & 0 & 0 \\
\hline$(\mathrm{n}=36)$ & $\%$ & 66.7 & 25 & 5.5 & - & 2.8 & - & - & - & - & - & - & - & - & - & - & - \\
\hline An. recens & $\mathrm{f}$ & 0 & 0 & 0 & 0 & $1 / \mathrm{n}$ & 0 & 0 & 0 & $1 / \mathrm{n}$ & $8 / \mathrm{n}$ & 0 & 0 & 0 & 0 & 0 & 0 \\
\hline$(n=10)$ & $\%$ & - & - & - & - & 10 & - & - & - & 10 & 80 & - & - & - & - & - & - \\
\hline An. sulawesi & $\mathrm{f}$ & 0 & 0 & 0 & 0 & $1 / \mathrm{n}$ & 0 & 0 & 0 & $4 / n$ & $16 / \mathrm{n}$ & 0 & $2 / \mathrm{n}$ & $3 / \mathrm{n}$ & 0 & 0 & 0 \\
\hline$(n=26)$ & $\%$ & - & - & - & - & 3.8 & - & - & - & 15.4 & 61.5 & - & 7.7 & 11.5 & - & - & - \\
\hline \multicolumn{18}{|l|}{ RIPARIS SUBGROUP } \\
\hline An. cristatus & $\mathrm{f}$ & $14 / \mathrm{n}$ & 0 & 0 & 0 & 0 & 0 & 0 & 0 & 0 & 0 & 0 & 0 & 0 & 0 & 0 & 0 \\
\hline$(n=14)$ & $\%$ & 100 & - & - & - & - & - & - & - & - & - & - & - & - & - & - & - \\
\hline An. macarthuri & $\mathrm{f}$ & $111 / \mathrm{n}$ & 0 & 0 & 0 & 0 & 0 & 0 & 0 & 0 & 0 & 0 & 0 & 0 & 0 & 0 & 0 \\
\hline$(n=111)$ & $\%$ & 100 & - & - & - & - & - & - & - & - & - & - & - & - & - & - & - \\
\hline An. riparis & $\mathrm{f}$ & $27 / \mathrm{n}$ & $4 / \mathrm{n}$ & $1 / \mathrm{n}$ & $1 / \mathrm{n}$ & 0 & 0 & 0 & 0 & 0 & 0 & 0 & 0 & 0 & 0 & 0 & 0 \\
\hline$(n=33)$ & $\%$ & 81.9 & 12.1 & 3 & 3 & - & - & - & - & - & - & - & - & - & - & - & - \\
\hline
\end{tabular}

smaller short setae arising medially with transition to long lateral seta, all 3 setae inserted in sclerotized, lateral area; dorsal claspette sclerotized, with stout lateral club formed by 4,5 long, apically fused setae, setae from club separate at base; aedeagus narrow, elongate, dorsally curved, 7-9 leaflets arising on each side of tip, leaflets serrated on one or both edges; tergum IX with weakly sclerotized angulate lateral lobes, membranous, with minute spicules on median portion; proctiger coneshaped, membranous, with minute spicules.

Pupa (Fig. 9). Position and development of setae as figured; range and modal number of branches in Table 7. All measurements from 10-16 specimens. Integument without distinctive color pattern, mostly light brown to yellowish; sterna II-V with narrow dark band near anterior margin. Cephalothorax: setae 1-3-CT about equal in length, 4-CT usually triple, 5-CT with 5-7 branches, 6-CT double or triple, 7CT usually triple, 8-CT single or double, 9-CT with 3-5 branches, 10-CT double or triple, 11-12-CT with 2-4 branches. Seta 9-II, III lightly pigmented, 9-IV-VIII pigmented light brown, slightly darker at base. Abdomen: seta 6-I usually double, 7-I with 4-6 branches; 1-II dendritic with 10-20 fine branches arising from 1-3 strong stem branches, 6-II usually double, 7-II with 2-6 
Table 5. Frequency distribution (f) and percentage (\%) of pale spots on PSD of vein R in females of species of the Leucosphyrus group.

\begin{tabular}{|c|c|c|c|c|c|c|c|c|c|c|c|c|c|c|c|c|c|}
\hline \multirow{2}{*}{\multicolumn{18}{|c|}{$\frac{\text { Species / spots }}{\text { LECOSPHYRUS }}$}} \\
\hline & & & & & & & & & & & & & & & & & \\
\hline \multicolumn{18}{|l|}{ SUBGROUP } \\
\hline An. baisasi & $\mathrm{f}$ & 0 & 0 & 0 & 0 & $1 / \mathrm{n}$ & $2 / \mathrm{n}$ & $1 / \mathrm{n}$ & $5 / \mathrm{n}$ & 0 & 0 & 0 & 0 & $1 / \mathrm{n}$ & 0 & 0 & 1.95 \\
\hline$(n=10)$ & $\%$ & - & - & - & - & 10 & 20 & 10 & 50 & - & - & - & - & 10 & - & - & - \\
\hline \multicolumn{18}{|l|}{ LEUCOSPHYRUS } \\
\hline \multicolumn{18}{|l|}{ COMPLEX } \\
\hline An. leucosphyrus & $\mathrm{f}$ & 0 & 0 & 0 & 0 & 0 & $1 / \mathrm{n}$ & 0 & $5 / \mathrm{n}$ & $14 / \mathrm{n}$ & $2 / \mathrm{n}$ & $1 / \mathrm{n}$ & $12 / \mathrm{n}$ & $7 / \mathrm{n}$ & 0 & 0 & 2.77 \\
\hline$(\mathrm{n}=42)$ & $\%$ & - & - & - & - & - & 2.4 & - & 11.9 & 33.3 & 4.8 & 2.4 & 28.6 & 16.7 & - & - & - \\
\hline An. latens & $\mathrm{f}$ & 0 & 0 & 0 & 0 & 0 & $2 / \mathrm{n}$ & $2 / n$ & $2 / \mathrm{n}$ & $21 / \mathrm{n}$ & $5 / \mathrm{n}$ & 0 & $22 / \mathrm{n}$ & $16 / \mathrm{n}$ & $2 / \mathrm{n}$ & $2 / \mathrm{n}$ & 2.94 \\
\hline$(n=74)$ & $\%$ & - & - & - & - & - & 2.7 & 2.7 & 2.7 & 28.4 & 6.7 & - & 29.7 & 1.6 & 2.7 & 2.7 & - \\
\hline An. introlatus & $\mathrm{f}$ & 0 & $6 / n$ & $2 / \mathrm{n}$ & 0 & $18 / \mathrm{n}$ & $15 / \mathrm{n}$ & 0 & $1 / \mathrm{n}$ & 0 & 0 & 0 & 0 & 0 & 0 & 0 & 1.13 \\
\hline$(n=42)$ & $\%$ & - & 14.3 & 4.8 & - & 42.8 & 35.7 & - & 2.4 & - & - & - & - & - & - & - & - \\
\hline An. balabacensis & $\mathrm{f}$ & $1 / \mathrm{n}$ & $19 / \mathrm{n}$ & $4 / n$ & 0 & $66 / \mathrm{n}$ & $40 / \mathrm{n}$ & $1 / \mathrm{n}$ & $27 / \mathrm{n}$ & 0 & 0 & 0 & 0 & 0 & 0 & 0 & 1.24 \\
\hline$(n=158)$ & $\%$ & 0.6 & 12 & 2.5 & - & 41.8 & 25.3 & 0.6 & 17.1 & - & - & - & - & - & - & - & - \\
\hline \multicolumn{18}{|l|}{ DIRUS COMPLEX } \\
\hline An. dirus & $\mathrm{f}$ & 0 & 0 & 0 & 0 & $8 / \mathrm{n}$ & $32 / \mathrm{n}$ & $4 / \mathrm{n}$ & $93 / \mathrm{n}$ & $70 / \mathrm{n}$ & $4 / \mathrm{n}$ & 0 & $20 / n$ & $5 / \mathrm{n}$ & 0 & 0 & 2.18 \\
\hline$(n=236)$ & $\%$ & - & - & - & - & 3.4 & 13.5 & 1.7 & 39.4 & 29.7 & 1.7 & - & 8.5 & 2.1 & - & - & - \\
\hline An. cracens & $\mathrm{f}$ & 0 & 0 & 0 & 0 & $14 / \mathrm{n}$ & $18 / \mathrm{n}$ & $2 / \mathrm{n}$ & $21 / \mathrm{n}$ & $3 / \mathrm{n}$ & 0 & 0 & 0 & 0 & 0 & 0 & 1.63 \\
\hline$(\mathrm{n}=58)$ & $\%$ & - & - & - & - & 24.1 & 31 & 3.4 & 36.2 & 5.2 & - & - & - & - & - & - & - \\
\hline An. scanloni & $\mathrm{f}$ & 0 & $2 / n$ & 0 & 0 & $24 / \mathrm{n}$ & $24 / \mathrm{n}$ & 0 & $4 / n$ & 0 & 0 & 0 & 0 & 0 & 0 & 0 & 0 \\
\hline$(n=54)$ & $\%$ & - & 3.7 & - & - & 44.4 & 44.4 & - & 7.4 & - & - & - & & - & - & - & - \\
\hline An. baimaii & $\mathrm{f}$ & 0 & $2 / n$ & $4 / \mathrm{n}$ & $3 / \mathrm{n}$ & $34 / \mathrm{n}$ & $63 / \mathrm{n}$ & $2 / n$ & $52 / \mathrm{n}$ & $17 / \mathrm{n}$ & $1 / \mathrm{n}$ & 0 & $1 / \mathrm{n}$ & $1 / \mathrm{n}$ & 0 & 0 & 1.65 \\
\hline$(n=180)$ & $\%$ & - & 1.1 & 2.2 & 1.7 & 18.9 & 35 & 1.1 & 28.9 & 9.4 & 0.5 & - & 0.5 & 0.5 & - & - & - \\
\hline An. elegans & $\mathrm{f}$ & 0 & 0 & 0 & 0 & 0 & $2 / \mathrm{n}$ & 0 & $14 / \mathrm{n}$ & $11 / \mathrm{n}$ & $1 / \mathrm{n}$ & 0 & $12 / \mathrm{n}$ & $1 / \mathrm{n}$ & $1 / \mathrm{n}$ & 0 & 2.5 \\
\hline$(n=42)$ & $\%$ & - & - & - & - & - & 4.8 & - & 33.3 & 26.2 & 2.4 & - & 28.6 & 2.4 & 2.4 & - & - \\
\hline An. nemophilous & $\mathrm{f}$ & $15 / \mathrm{n}$ & $31 / \mathrm{n}$ & $4 / \mathrm{n}$ & 0 & $46 / \mathrm{n}$ & $29 / \mathrm{n}$ & 0 & $6 / n$ & $1 / \mathrm{n}$ & 0 & 0 & 0 & 0 & 0 & 0 & 0.93 \\
\hline$(\mathrm{n}=132)$ & $\%$ & 11.4 & 23.5 & 3 & - & 34.8 & 22 & - & 4.5 & 0.8 & - & - & - & - & - & - & - \\
\hline An. takasagoensis & $\mathrm{f}$ & - & - & $3 / \mathrm{n}$ & 0 & $23 / \mathrm{n}$ & $24 / \mathrm{n}$ & 0 & $14 / \mathrm{n}$ & $3 / \mathrm{n}$ & 0 & 0 & 0 & 0 & 0 & 0 & 1.45 \\
\hline$(n=67)$ & $\%$ & - & - & 4.5 & - & 34.3 & 35.8 & - & 20.9 & 4.5 & - & - & - & - & - & - & - \\
\hline \multicolumn{18}{|c|}{ HACKERI SUBGROUP } \\
\hline An. mirans & $\mathrm{f}$ & $234 / \mathrm{n}$ & 0 & 0 & 0 & 0 & 0 & 0 & 0 & 0 & 0 & 0 & 0 & 0 & 0 & 0 & 0 \\
\hline$(n=234)$ & $\%$ & 100 & - & - & - & - & - & - & - & - & - & - & - & - & - & - & - \\
\hline An. hackeri & $\mathrm{f}$ & $75 / \mathrm{n}$ & 0 & 0 & 0 & 0 & 0 & 0 & 0 & 0 & 0 & 0 & 0 & 0 & 0 & 0 & 0 \\
\hline$(n=75)$ & $\%$ & 100 & - & - & - & - & - & - & - & - & - & - & - & - & - & - & - \\
\hline An. pujutensis & $\mathrm{f}$ & $36 / \mathrm{n}$ & 0 & 0 & 0 & 0 & 0 & 0 & 0 & 0 & 0 & 0 & 0 & 0 & 0 & 0 & 0 \\
\hline$(n=36)$ & $\%$ & 100 & - & - & - & - & - & - & - & - & - & - & - & - & - & - & - \\
\hline An. recens & $\mathrm{f}$ & 0 & 0 & 0 & 0 & $1 / \mathrm{n}$ & $2 / \mathrm{n}$ & 0 & $3 / \mathrm{n}$ & $2 / \mathrm{n}$ & $1 / \mathrm{n}$ & 0 & $1 / \mathrm{n}$ & 0 & 0 & 0 & 2.1 \\
\hline$(n=10)$ & $\%$ & - & - & - & - & 10 & 20 & - & 30 & 20 & 10 & - & - & - & - & - & - \\
\hline An. sulawesi & $\mathrm{f}$ & 0 & 0 & 0 & 0 & 0 & $3 / \mathrm{n}$ & 0 & $7 / \mathrm{n}$ & $13 / \mathrm{n}$ & 0 & 0 & $2 / \mathrm{n}$ & $1 / \mathrm{n}$ & 0 & 0 & 2.33 \\
\hline$(n=26)$ & $\%$ & - & - & - & - & - & 11.5 & - & 26.9 & 50 & - & - & 7.7 & 3.8 & - & - & - \\
\hline \multicolumn{18}{|l|}{ RIPARIS SUBGROUP } \\
\hline An. riparis & $\mathrm{f}$ & $34 / \mathrm{n}$ & 0 & 0 & 0 & 0 & 0 & 0 & 0 & 0 & 0 & 0 & 0 & 0 & 0 & 0 & 0 \\
\hline$(n=34)$ & $\%$ & 100 & - & - & - & - & - & - & - & - & - & - & - & - & - & - & - \\
\hline An. cristatus & $\mathrm{f}$ & $14 / \mathrm{n}$ & 0 & 0 & 0 & 0 & 0 & 0 & 0 & 0 & 0 & 0 & 0 & 0 & 0 & 0 & 0 \\
\hline$(n=14)$ & $\%$ & 100 & - & - & - & - & - & - & - & - & - & - & - & - & - & - & - \\
\hline An. macarthuri & $\mathrm{f}$ & $111 / \mathrm{n}$ & 0 & 0 & 0 & 0 & 0 & 0 & 0 & 0 & 0 & 0 & 0 & 0 & 0 & 0 & 0 \\
\hline$(n=111)$ & $\%$ & 100 & - & - & - & - & - & - & - & - & - & - & - & - & - & - & - \\
\hline
\end{tabular}

branches, 8 -II rarely present with 3,4 branches, 9-II very short, stout, arising distad from posterior margin of segment, length 0.010-0.013 mm (mean $=0.012 \mathrm{~mm}), 10,11$-II absent; 1-III with 47 branches, 5-III with 5-7 branches, 6-III usually double, 9-III short, stout, length 0.01-0.02 $\mathrm{mm}$ (mean $=0.02 \mathrm{~mm}) ; 1-\mathrm{IV}$ with 3,4 branches, 5-IV with 4,5 branches, 6-IV single or double, 9IV short, length $0.02-0.04 \mathrm{~mm}$ (mean $=0.03 \mathrm{~mm})$, ratios of length of 9-IV/III 1.28-2.67 $($ mean $=1.90)$ and 9-IV/V 0.21-0.40 $($ mean $=$ $0.30)$; 1,6-V usually single, 5-V with 4-6 branches, 9-V long, length $0.09-0.11 \mathrm{~mm}($ mean $=0.10 \mathrm{~mm}) ; 1$-VI normally double, 5-VI with 4,5 branches, 6-VI single or double, 9-VI long, length $0.10-0.12 \mathrm{~mm}$ (mean $=0.10 \mathrm{~mm})$ frequently simple, sometimes with small spicules; 1-VII single or double, 5-VII with 2-5 branches, 6-VII usually double, 9-VII long, frequently simple, sometimes with small spicules, length $0.10-0.11 \mathrm{~mm}$ (mean = $0.10 \mathrm{~mm}$ ); 9-VIII with 10-15 branches. Paddle: lightly tanned, buttress slightly darker, midrib faint, outer basolateral serration prominent, filamentous spicules on outer apical margin and most of inner margin prominent; seta 1-Pa strong, dark pigmented, 2-Pa with 1-3 branches, toothed margin index (= ratio of length a/b, see Fig. 31) 0.89-0.95 (mean=0.91).

Larva (Figs. 9, 10, 52, 53). Position and development of setae as figured; range and modal number of branches in Table 8. All measurements from 11-22 specimens. Head: integument 
Table 6. Frequency distribution (f) and percentage (\%) of pale spots on SD spot of vein R in females of species of the Leucosphyrus Group.

\begin{tabular}{|c|c|c|c|c|c|c|c|c|c|c|c|c|c|}
\hline Species / spots & & $1: 1$ & $1: 2$ & $1: 3$ & $2: 2$ & $2: 3$ & $2: 4$ & $3: 3$ & $3: 4$ & $4: 4$ & $4: 5$ & $5: 2$ & Mean \\
\hline \multicolumn{14}{|c|}{ LECOSPHYRUS SUBGROUP } \\
\hline An. baisasi & $\mathrm{f}$ & 0 & 0 & $1 / \mathrm{n}$ & $2 / \mathrm{n}$ & $4 / \mathrm{n}$ & 0 & $2 / \mathrm{n}$ & 0 & 0 & 0 & 0 & 2.44 \\
\hline$(\mathrm{n}=10)$ & $\%$ & - & - & 11.1 & 22.2 & 44.4 & - & 22.2 & - & - & - & - & - \\
\hline \multicolumn{14}{|c|}{ LEUCOSPHYRUS COMPLEX } \\
\hline An. leucosphyrus & $\mathrm{f}$ & 0 & $3 / n$ & 0 & $12 / \mathrm{n}$ & $10 / \mathrm{n}$ & $1 / \mathrm{n}$ & $13 / \mathrm{n}$ & $1 / \mathrm{n}$ & $1 / \mathrm{n}$ & 0 & 0 & 2.51 \\
\hline$(n=42)$ & $\%$ & - & 7.3 & - & 28.2 & 25.6 & 2.6 & 30.8 & 2.6 & 2.6 & - & - & - \\
\hline An. latens & $\mathrm{f}$ & $1 / \mathrm{n}$ & $5 / n$ & 0 & $28 / \mathrm{n}$ & $23 / \mathrm{n}$ & $3 / \mathrm{n}$ & $14 / \mathrm{n}$ & 0 & 0 & 0 & 0 & 2.34 \\
\hline$(n=74)$ & $\%$ & 1.3 & 6.7 & - & 7.8 & 1.1 & 4.0 & 8.9 & - & - & - & - & - \\
\hline An. introlatus & $\mathrm{f}$ & $1 / \mathrm{n}$ & $5 / \mathrm{n}$ & 0 & $20 / \mathrm{n}$ & $8 / \mathrm{n}$ & 0 & $3 / \mathrm{n}$ & 0 & 0 & 0 & 0 & 2.09 \\
\hline$(n=42)$ & $\%$ & 2.7 & 13.5 & - & 54.0 & 21.6 & - & 8.1 & - & - & - & - & - \\
\hline An. balabacensis & $\mathrm{f}$ & 0 & $6 / n$ & $4 / \mathrm{n}$ & $53 / \mathrm{n}$ & $62 / \mathrm{n}$ & $5 / \mathrm{n}$ & $24 / \mathrm{n}$ & $3 / n$ & $1 / \mathrm{n}$ & 0 & 0 & 2.4 \\
\hline$(n=158)$ & $\%$ & - & 3.8 & 2.5 & 33.5 & 39.2 & 3.2 & 15.2 & 1.9 & 0.6 & - & - & - \\
\hline \multicolumn{14}{|l|}{ DIRUS COMPLEX } \\
\hline An. dirus & $\mathrm{f}$ & 0 & $1 / \mathrm{n}$ & $1 / \mathrm{n}$ & $24 / \mathrm{n}$ & $64 / \mathrm{n}$ & $12 / \mathrm{n}$ & $80 / \mathrm{n}$ & $43 / \mathrm{n}$ & $11 / \mathrm{n}$ & 0 & 0 & 2.89 \\
\hline$(n=236)$ & $\%$ & - & 0.4 & 0.4 & 10.2 & 27.1 & 5.1 & 33.9 & 18.2 & 4.7 & - & - & - \\
\hline An. cracens & $\mathrm{f}$ & 0 & $1 / \mathrm{n}$ & 0 & $12 / \mathrm{n}$ & $18 / \mathrm{n}$ & $2 / \mathrm{n}$ & $20 / \mathrm{n}$ & $3 / \mathrm{n}$ & $1 / \mathrm{n}$ & 0 & $1 / \mathrm{n}$ & 2.66 \\
\hline$(\mathrm{n}=58)$ & $\%$ & - & 1.7 & - & 20.7 & 31.0 & 3.4 & 34.5 & 5.2 & 1.7 & - & - & \\
\hline An. scanloni & $\mathrm{f}$ & $14 / \mathrm{n}$ & $21 / \mathrm{n}$ & 0 & $14 / \mathrm{n}$ & $5 / n$ & $\begin{array}{c}0 \\
0\end{array}$ & 0 & 0 & 0 & 0 & 0 & 1.59 \\
\hline$(n=54)$ & $\%$ & 25.9 & 38.9 & - & 25.9 & 9.2 & - & - & - & - & - & - & - \\
\hline An. baimaii & $\mathrm{f}$ & $7 / \mathrm{n}$ & $20 / n$ & $2 / n$ & $62 / \mathrm{n}$ & $50 / \mathrm{n}$ & $2 / \mathrm{n}$ & $29 / \mathrm{n}$ & $8 / \mathrm{n}$ & 0 & 0 & 0 & 2.28 \\
\hline$(\mathrm{n}=180)$ & $\%$ & 3.9 & 11.1 & 1.1 & 34.4 & 27.8 & 1.1 & 16.1 & 4.4 & - & - & - & - \\
\hline An. elegans & $\mathrm{f}$ & $2 / \mathrm{n}$ & $9 / \mathrm{n}$ & $2 / n$ & $20 / \mathrm{n}$ & $7 / \mathrm{n}$ & 0 & $2 / \mathrm{n}$ & 0 & 0 & 0 & 0 & 1.98 \\
\hline$(n=42)$ & $\%$ & 4.8 & 21.4 & 4.8 & 47.6 & 16.7 & - & 4.8 & - & - & - & - & - \\
\hline An. nemophilous & $\mathrm{f}$ & $57 / \mathrm{n}$ & $35 / \mathrm{n}$ & $2 / n$ & $31 / \mathrm{n}$ & $7 / \mathrm{n}$ & 0 & 0 & 0 & 0 & 0 & 0 & 1.46 \\
\hline$(n=132)$ & $\%$ & 43.2 & 26.5 & 1.5 & 23.5 & 5.3 & - & - & - & - & - & - & - \\
\hline An. takasagoensis & $\mathrm{f}$ & 0 & $2 / \mathrm{n}$ & $1 / \mathrm{n}$ & $9 / \mathrm{n}$ & $21 / \mathrm{n}$ & $3 / \mathrm{n}$ & $21 / \mathrm{n}$ & $6 / n$ & $2 / \mathrm{n}$ & $2 / \mathrm{n}$ & 0 & 2.75 \\
\hline$(\mathrm{n}=67)$ & $\%$ & - & 3.0 & 1.5 & 13.4 & 31.3 & 4.5 & 31.3 & 9.0 & 3.0 & 3.0 & - & - \\
\hline \multicolumn{14}{|c|}{ HACKERI SUBGROUP } \\
\hline An. mirans & $\mathrm{f}$ & $232 / \mathrm{n}$ & 0 & 0 & 0 & 0 & 0 & 0 & 0 & 0 & 0 & 0 & 1.0 \\
\hline$(n=234)$ & $\%$ & 100 & - & - & - & - & - & - & - & - & - & - & - \\
\hline An. hackeri & $\mathrm{f}$ & $74 / \mathrm{n}$ & 0 & 0 & 0 & 0 & 0 & 0 & 0 & 0 & 0 & 0 & 0 \\
\hline$(n=75)$ & $\%$ & 100 & & & & & & & & & & & \\
\hline An. pujutensis & $\mathrm{f}$ & $6 / \mathrm{n}$ & $8 / \mathrm{n}$ & $2 / n$ & $14 / \mathrm{n}$ & $6 / \mathrm{n}$ & 0 & 0 & 0 & 0 & 0 & 0 & 1.80 \\
\hline$(\mathrm{n}=36)$ & $\%$ & 16.7 & 22.2 & 5.5 & 38.9 & 16.7 & - & - & - & - & - & - & - \\
\hline An. recens & $\mathrm{f}$ & 0 & $3 / \mathrm{n}$ & 0 & $6 / n$ & 0 & 0 & $1 / \mathrm{n}$ & 0 & 0 & 0 & 0 & 1.95 \\
\hline$(\mathrm{n}=10)$ & $\%$ & - & 30.0 & - & 60.0 & - & - & 10.0 & - & - & - & - & - \\
\hline An. sulawesi & $\mathrm{f}$ & 0 & 0 & 0 & 0 & $3 / \mathrm{n}$ & 0 & $16 / \mathrm{n}$ & $5 / \mathrm{n}$ & $1 / \mathrm{n}$ & $1 / \mathrm{n}$ & 0 & 3.10 \\
\hline$(n=26)$ & $\%$ & - & - & - & - & 11.5 & - & 61.5 & 19.2 & 3.8 & 3.8 & - & - \\
\hline \multicolumn{14}{|c|}{ RIPARIS SUBGROUP } \\
\hline An. riparis & $\mathrm{f}$ & $32 / n$ & 0 & 0 & $1 / \mathrm{n}$ & 0 & 0 & 0 & 0 & 0 & 0 & 0 & 1.03 \\
\hline$(n=34)$ & $\%$ & 97.0 & - & - & 3.0 & - & - & - & - & - & - & - & - \\
\hline An. cristatus & $\mathrm{f}$ & $14 / \mathrm{n}$ & 0 & 0 & 0 & 0 & 0 & 0 & 0 & 0 & 0 & 0 & 0 \\
\hline$(n=14)$ & $\%$ & 100 & - & - & - & - & - & - & - & - & - & - & - \\
\hline An. macarthuri & $\mathrm{f}$ & $111 / \mathrm{n}$ & 0 & 0 & 0 & 0 & 0 & 0 & 0 & 0 & 0 & 0 & 0 \\
\hline$(n=111)$ & $\%$ & 100 & - & - & - & - & - & - & - & - & - & - & - \\
\hline
\end{tabular}

light brown to yellowish without pattern of dark spots; length and width not measured; antenna length $0.27-0.29 \mathrm{~mm}$ (mean $=$ $0.28 \mathrm{~mm})$, ratio of distance base to 1 A to antenna length 0.26 0.41 (mean $=0.33)$; seta $2-\mathrm{C}$ long, single with sparse minute spicules on apical $0.5 ; 3-\mathrm{C}$ single, length $0.07-0.09 \mathrm{~mm}$ (mean = $0.08 \mathrm{~mm}$ ); distance between base of 2-C and 3-C 0.03-0.04 mm $($ mean $=0.04 \mathrm{~mm}) ; 4-\mathrm{C}$ posterolaterad of 2-C, single to triple, length $0.06-0.09 \mathrm{~mm}$ (mean $=0.07 \mathrm{~mm})$, usually not reaching base of 2-C, distance between basal insertions of 2-C and 4-C $0.07-0.10 \mathrm{~mm}($ mean $=0.08 \mathrm{~mm})$, ratio of length of $4-\mathrm{C}$ to distance between the insertions of 2-C and 4-C 0.63-1.04 ( mean $=0.80)$, distance between bases of 3-C and 4-C 0.05-0.09 $\mathrm{mm}$ (mean = $0.07 \mathrm{~mm}$ ), 5-C longer than antennal shaft, reaching anterior margin of head, 7-11 branches, 6-C with 10-17 branches, 7-C with 9-15 branches. Thorax: tubercles of all large setae light brown to yellowish; seta 1-P with 11-18 branches, stem stout, not noticeably expanded, flattened basally, arising from large tubercle, usually separate from tubercle of 2,3-P (Fig. 53), rarely narrowly joined to tubercle of 2,3-P, each tubercle either without or with small, inconspicuous apical lip arising from posterodorsal side and projecting forward over bases of 1,2-P, 14-P 5,6-branched; 4-M with 2-4 branches, 6-M usually triple, 14-M with 4-9 branches; 3-T (Fig. 52) poorly developed, palmate, with 5-8 narrow, nearly transparent lanceolate leaflets. Abdomen: seta 1-I small, somewhat palmate, with 4-7 narrow, nearly transparent, lanceolate leaflets, 2-I single or double, 3- 
Table 7. Number of branches for seta of pupae of An. leucosphyrus: range (mode).

\begin{tabular}{|c|c|c|c|c|c|c|c|c|c|c|c|}
\hline \multicolumn{2}{|c|}{ Seta Cephalothorax } & \multicolumn{9}{|c|}{ Abdominal segments } & \multirow{2}{*}{$\begin{array}{c}\text { Paddle } \\
\mathrm{Pa}\end{array}$} \\
\hline No. & $\mathrm{CT}$ & I & II & III & IV & $\mathrm{V}$ & VI & VII & VIII & IX & \\
\hline$\overline{0}$ & - & - & 1 & 1 & 1 & 1 & 1 & 1 & 1 & - & - \\
\hline 1 & 3 & n.c. & $10-20(10)$ & $4-7(5)$ & $3,4(3)$ & $1-3(1)$ & $1-3(2)$ & $1,2(2)$ & - & 1 & $1,2(1)$ \\
\hline 2 & $2,3(2)$ & $5-8(6)$ & $5-7(5)$ & $5-7(5)$ & $3,4(3)$ & 3 & $1-4(3)$ & $2,3(3)$ & - & - & $1-3(1)$ \\
\hline 3 & $2,3(3)$ & $1,2(1)$ & $2,3(3)$ & $3-5(3)$ & $5-8(7)$ & $2-4(3)$ & $1-3(2)$ & $2-4(3)$ & - & - & - \\
\hline 4 & $2-4(3)$ & $4-7(5)$ & $5-8(6)$ & $4-6(5)$ & $1-4(3)$ & $5-6(5)$ & $1-3(2)$ & $1-3(2)$ & $1-3(3)$ & - & - \\
\hline 5 & $5-7(6)$ & $3,4(3)$ & $3-5(4)$ & $5-10(7)$ & $4-5(5)$ & $4-6(5)$ & $4-5(5)$ & $2-5(5)$ & - & - & - \\
\hline 6 & $2,3(3)$ & $2,3(2)$ & $2,3(2)$ & $2,3(2)$ & $1,2(1)$ & $1,2(1)$ & $1,2(1)$ & $1,2(2)$ & - & - & - \\
\hline 7 & $3,4(3)$ & $4-6(5)$ & $2-6(4)$ & $2-4(3)$ & $2-4(3)$ & $1-4(3)$ & $1-5(1)$ & $1,2(1)$ & - & - & - \\
\hline 8 & $1,2(1)$ & - & $3,4(3)$ & $2-4(3)$ & $2,3(3)$ & $2,3(2)$ & $2-3(3)$ & $2,3(2)$ & - & - & - \\
\hline 9 & $3-5(3)$ & 1 & 1 & 1 & 1 & 1 & 1 & 1 & $10-15(10)$ & - & - \\
\hline 10 & $2,3(2)$ & - & - & $3,4(3)$ & 2 & $2,3(2)$ & $1-3(2)$ & $2,3(3)$ & - & - & - \\
\hline 11 & $2-4(3)$ & - & - & 1 & 1 & 1 & 1 & $1-3(2)$ & - & - & - \\
\hline 12 & $2-4(3)$ & - & - & - & - & - & - & - & - & - & - \\
\hline 13 & - & - & - & - & - & - & - & - & - & - & - \\
\hline 14 & - & - & - & - & 1 & 1 & 1 & 1 & 1 & - & - \\
\hline
\end{tabular}

n.c. $=$ not counted

I usually single, 9-I with 4-6 branches; 1-II small, less pigmented than 1-I, somewhat palmate, with 5-11 narrow, nearly transparent, lanceolate leaflets, basal stem narrow, poorly pigmented; 2-IV with 3,4 branches, 3-IV with 3,4 branches, 13IV long with 3-5 branches, ratio of length to 10-IV 0.42-0.54 (mean $=0.47)$; 2-V with 3,4 branches; 1-VII smaller and less pigmented than 1-VI, with 11-17 moderately broad lanceolate leaflets with minute apicolateral serration and apical filaments; 1-X long, single, inserted on saddle; 12-14 pecten spines (Fig. 9), 4-6 long spines alternating with 7-9 short.

Type data. Syntypes, two females. Zoology Museum Berlin, Germany, and NHM, London, U.K. Type locality: INDONESIA, Sumatra Island, Tapanuli, Kajutanan (Kajoe Janam), north of Padang.

Material examined. One hundred twenty-eight specimens as follows: $48 \mathrm{~F}, 20 \mathrm{M}, 28 \mathrm{Le}, 30 \mathrm{Pe}, 2 \mathrm{~L}$, derived from 20 separate collections from natural habitats (20 adult) and 7 progeny broods. INDONESIA. Sumatra: K. T. [Tapanuli, Kajutanan] (2 $51^{\circ} 0$ "N $98^{\circ} 16^{\prime} 0$ "E), 1F. Labuhandeli $\left(3^{\circ} 45^{\prime} 0^{\prime \prime N} 98^{\circ} 41^{\prime} 60^{\prime} \mathrm{E}\right)$, [Bonne-Wepster coll. nos., 12-80, -81, -82, $84,-86,-89,-90,-91,-92,-93,-96,-98]$, no dates, pre-1940, 14F; [17-12], no locality or date, 1F. Propinsi Sumatera Utara, Medan $\left(3^{\circ} 35^{\prime} \mathrm{N} 98^{\circ} 40^{\prime} \mathrm{E}\right), 1 \mathrm{~F}$. Martapura (419'S 10422'E), 26 Oct. 1977, 1F. Selatan, Baturaja (4'8'S 104'10'E), 19 Sept. 1975, 1F. Selatan, Lebisbadak, 21 Dec. 1977, 1F. Propinsi Jambi: Bukit Baru (near Muarabungo) (1 $\left.{ }^{\circ} 28^{\prime} \mathrm{S} 102^{\circ} 7^{\prime} \mathrm{E}\right)$, [ID1-B], 7 Apr. 1986, 18F; [ID1-002, -003, -005, -007, -011, -018, -019], 7 Apr. 1986, progeny, (002), 1F, 4M, 5LePe; (003), 1F, 4M, 4LePe; (005), 1M, 3LePe, $1 \mathrm{~L}$; (007), 2F, 2M, 3LePe, $1 \mathrm{Pe}, 2 \mathrm{~L}$; (011), 3M, 1LePe, 1Pe, 1L; (018), 3F, 6M, 6LePe, 2Pe; (019), 3F, 1M, 4LePe (V. Baimai and R.E. Harbach).

Distribution (Table 1; Fig. 54). Anopheles leucosphyrus seems to be an endemic species from Sumatra, Indonesia. Most of the published literature on An. leucosphyrus refers to An. latens, which has a more widespread distribution (Sallum et al. 2004).

Bionomics and medical importance. Little is known about the bionomics of An. leucosphyrus s.s. because this species has been largely misidentified as An. latens and most published records refer to $A n$. latens except for those from Sumatra, Indonesia. Adults of An. leucosphyrus were attracted to human bait in Bukit Baru, near Muarabungo, in Bungo Tebo Regency, Jambi Province, Sumatra. The collections were carried out inside and outside houses situated at the edge of secondary tropical rain forest in hilly areas (Baimai et al. 1988c). This species may be involved in the transmission of human malaria parasites in Sumatra (Warren et al. 1963). Adults were dissected and found infected with Plasmodium sp. in localities in Siantar Estate (Bais 1920), Kisiran (Doorenbos 1927, 1931a,b), Mandahiling (Swellengrebel et al. 1919) and Nies Island, Gawo River (Soesilo 1929a,b; Soesilo et al. 1935).

Systematics. Three allopatric populations of $A n$. leucosphyrus l.s. from south Kalimantan, Sumatra and Thailand were investigated using karyotypes and cross-mating experiments. As a result, it was found that An. leucosphyrus l.s. included two distinct species, An. leucosphyrus A (=An. latens), which occurs in Thailand and south Kalimantan, and An. leucosphyrus s.s. which is confined to Sumatra. Genetic isolation between An. latens and An. leucosphyrus probably occurred either as a consequence of genetic shift or as by a product of genetic divergence within isolated populations on Sumatra. Based on the degree of synapsis in the polytene chromosomes of F1 hybrids, An. latens seems to be more closely related to An. balabacensis and members of the Dirus Complex than is An. leucosphyrus (Baimai et al. 1988c).

Anopheles leucosphyrus cannot be distinguished from An. latens based on morphological characters of the adult, pupa, and fourth-instar larva. Because these two species are allopatric, their geographical distribution should be considered when making an identification. Anopheles leucosphyrus can be distinguished from the remaining species by the following combination of characters. Adult: 1) proboscis slightly longer than forefemur, ratio of proboscis length to forefemur varying from $1.06-1.14 ; 2$ ) apical pale band of palpomere 5 distinctly pale cream-colored, contrasting with silvery-white bands of 
Table 8. Number of branches for setae of fourth-instar larvae of An. leucosphyrus: range (mode).

\begin{tabular}{|c|c|c|c|c|c|c|c|c|c|c|c|c|c|}
\hline \multirow{2}{*}{$\begin{array}{l}\text { Seta } \\
\text { No. }\end{array}$} & \multirow{2}{*}{$\begin{array}{c}\text { Head } \\
\mathrm{C}\end{array}$} & \multicolumn{3}{|c|}{ Thorax } & \multicolumn{9}{|c|}{ Abdominal segments } \\
\hline & & $\mathrm{P}$ & $\mathrm{M}$ & $\mathrm{T}$ & $\mathrm{I}$ & II & III & $\mathrm{IV}$ & $\mathrm{V}$ & $\mathrm{VI}$ & VII & VIII & $\mathrm{X}$ \\
\hline$\overline{0}$ & 1 & 1 & - & - & - & 1 & 1 & 1 & 1 & 1 & 1 & 1 & - \\
\hline 1 & 1 & $11-18(15)$ & $23-36(25)$ & $1-2(1)$ & $4-7(5)$ & $5-11(5)$ & $18-24(20)$ & $19-23(20)$ & $18-22(20)$ & $17-22(18)$ & $11-17(13)$ & 1 & 1 \\
\hline 2 & 1 & $9-13(12)$ & $1-3(1)$ & 1 & $1-2(2)$ & $6-9(7)$ & $5-9(6)$ & $3-4(3)$ & $3-4(4)$ & $3-5(5)$ & $4-7(6)$ & $5-9(6)$ & $16-23(20)$ \\
\hline 3 & 1 & 1 & 1 & $5-8(6)$ & $1-3(1)$ & $1-2(1)$ & 1 & $1-3(2)$ & 1 & 1 & $2-3(3)$ & $5-9(7)$ & $8-11(9)$ \\
\hline 4 & $1-3(1)$ & $14-18(15)$ & $2-4(3)$ & $3-5(4)$ & $3-5(5)$ & $4-6(5)$ & $3-4(3)$ & $1-3(3)$ & $2-4(3)$ & 1 & 1 & 1 & 9 \\
\hline 5 & $7-11(9)$ & n.c. & 1 & $26-35(30)$ & $3-4(4)$ & $4-6(5)$ & $3-5(3)$ & $2-4(3)$ & $3-4(3)$ & $3-5(4)$ & $3-5(5)$ & $3-6(4)$ & - \\
\hline 6 & $10-17(11)$ & 1 & $3-5(3)$ & $2-4(3)$ & $16-22(19)$ & $23-29(26)$ & $13-19(15)$ & $1-3(2)$ & $1-2(2)$ & $3-4(3)$ & $3-6(4)$ & $1-S$ & $4-7(6)$ \\
\hline 7 & $9-15(13)$ & $16-24(22)$ & $2-3(3)$ & $26-31(30)$ & $12-17(16)$ & $16-24(21)$ & $4-6(5)$ & $4-6(5)$ & $3-6(4)$ & $2-5(3)$ & $2-4(3)$ & $2-S$ & $4-7(5)$ \\
\hline 8 & $1-3(2)$ & $24-32(29)$ & $18-29(21)$ & $23-34(31)$ & - & $1-3(2)$ & $1-3(2)$ & $2-3(2)$ & $2-4(2)$ & $2-3(2)$ & $4-5(4)$ & $6-\mathrm{S}$ & 2 \\
\hline 9 & $2-4(3)$ & 1 & 1 & 1 & $4-6(5)$ & $6-10(7)$ & $6-9(8)$ & $6-10(7)$ & $5-9(6)$ & $5-8(5)$ & $4-6(5)$ & $7-S$ & $1-2(2)$ \\
\hline 10 & $1-2(1)$ & 1 & 1 & 1 & 1 & $2-3(2)$ & 1 & $1-2(1)$ & 1 & $2-3(2)$ & $3-7(5)$ & 8-S & $2-4(3)$ \\
\hline 11 & $25-32(30)$ & 1 & 1 & 1 & 3 & 1 & $2-3(3)$ & $2-3(2)$ & $2-3(2)$ & $2-3(2)$ & $2-3(2)$ & 9-S & $2-4(3)$ \\
\hline 12 & $1-3(2)$ & 1 & 1 & $2-3(2)$ & $2-4(3)$ & 1 & $2-4(2)$ & $2-3(2)$ & $2-3(2)$ & $1-2(1)$ & 1 & - & - \\
\hline 13 & $3-5(5)$ & $3-6(4)$ & $5-6(5)$ & $1-4(3)$ & $4-6(5)$ & $4-7(5)$ & $4-7(5)$ & $3-5(4)$ & $3-5(3)$ & $5-8(6)$ & 3 & - & - \\
\hline 14 & n.c. & $5-6(5)$ & $4-9(6)$ & - & - & - & - & 1 & 1 & 1 & 1 & 1 & - \\
\hline 15 & n.c. & - & - & - & - & - & - & - & - & - & - & - & - \\
\hline
\end{tabular}

n.c. $=$ not counted

palpomeres 2 and 3; 3) ASP spot usually extending onto the vein $\mathrm{C}$ on one or both wings, rarely absent on vein $\mathrm{C}$ on both wings; 4) hindtarsomere 4 without basal pale band; 5) hindtarsomere 5 without basal pale band; 6) hindtarsomere 5 with apical pale band; 7) PSD spot of vein R extending basally from level 4 to level 6;8) PSD spot of vein R entirely dark or with 1-5 pale interruptions; 7) wing fringe with pale spot between veins $1 \mathrm{~A}$ and $\mathrm{Cu}_{2} ; 10$ ) fork of cell $\mathrm{R}_{2}$ in line or basal to fork of cell $\mathrm{M}_{1+2}$. Fourth-instar larva: 1) seta 3-C single; 2) seta 5-C conspicuously longer than antenna; 3) basal sclerotized tubercle of seta 1-P without prominent tooth or spine arising from posterolateral margin; 4) basal sclerotized tubercle of seta 1-P usually well separated from tubercle of 2-P, rarely both tubercles narrowly joined, tubercle of seta 1-P smaller than that of seta 2-P, distance between bases wide, equal or greater than basal width of tubercle of 1-P; 5) seta 1-II not fully developed, noticeably smaller than seta 1-III-VI. Pupa: 1) ratio of length of 9-IV to length of 9-V 0.21-0.40 (mean =0.30); 2) seta 4-II with 5-8 branches; 3) seta 7-II with 2-4 branches; 4) seta 10-IV always double; 5) 9-V length 0.09-0.11 mm (mean = $0.10 \mathrm{~mm})$; 6) 9-VI length $0.10-0.12 \mathrm{~mm}($ mean $=0.10 \mathrm{~mm}) ; 7)$ toothed margin index $0.89-0.95($ mean $=0.91)$.

\section{Anopheles (Cellia) latens Sallum \& Peyton}

(Figs. 4, 7, 11, 12, 49, 52, 54)

Anopheles latens Sallum \& Peyton, 2005, in Sallum et al. (2005) (F, $\left.\mathrm{M}, \mathrm{P}^{*}, \mathrm{~L}^{*}\right)$. Holotype male with associated slide mounted larval and pupal exuviae, deposited in the NMNH.

Anopheles leucophyrus of Leicester (1903:291) (bionomics).

Anopheles leucosphyrus of Stanton (1912:6) (L); Bonne-Wepster \& Swellengrebel (1953:259) ( $\mathrm{F}^{*}, \mathrm{M}^{*}, \mathrm{~L}^{*}$, identification keys); Zulueta (1956:651) (vector human Plasmodium); Colless (1957:131) (F, L, P, in part, Sarawak, Borneo); Zulueta (1957:699) (vector $W$. bancrofti); Macdonald \& Traub (1960:79) (bionomics notes); Chow (1961) (F* identification key, distribution, Malaya, Sarawak); Wharton et al. (1962:758) (vector $P$. inui); Ramalingam (1974:147) (distribution note); Kanda et al. (1981:321) (hybridization, systematics); Kanda et al. (1983:193) (chromosomal polymorphism, phylogeny); Takai et al. (1984:145) (genetics); Takai (1986:45) (in part, electrophoresis, Sarawak); Harbach et al. (1987b:241) (bionomics); Chang et al. (1995:192) (bionomics); Seng et al. (1999:454) (bionomics).

Anopheles leucosphyrus species A of Baimai (1988b:667) (cytogenetics, distribution); Baimai et al. (1988c:44) (cytogenetics, crossing); Peyton (1989:197) (taxonomy); Harrison et al. (1990:202) (taxonomy, distribution notes).

Anopheles leucosphyrus leucosphyrus of Mendoza (1954) (A*, L*, identification keys); Colless (1956a:115) (bionomics); BonneWepster (1963:705) (F, identification key, in part).

Myzomyia leucophyrus of Daniels (1908:1) (An. hackeri and An. leucosphyrus mixed, bionomics); Leicester (1908a:7) (bionomics); Leicester (1908b:18) (F, M, bionomics, probably mixed with $A n$. hackeri); Leicester (1908c:267) (feeding behavior, probably mixed with An. hackeri).

Neomyzomyia elegans of James \& Stanton (1912:59).

Neomyzomyia eurysphyrus of de Meijere (1913:338) (in part).

Neomyzomyia leucosphyra of Swellengrebel \& Swellengrebel de Graff (1920b:83) (L*).

Nyssorhynchus leucosphyrus of Blanchard (1905:213) (F, Borneo).

Female (Figs. 4, 7). Head: proboscis uniformly dark-scaled, length $1.92-2.25 \mathrm{~mm}$ (mean $=2.11 \mathrm{~mm})$, ratio of length to forefemur 1.06-1.16 (mean=1.12), maxillary palpus (Fig. 7) length $1.62-2.15 \mathrm{~mm}($ mean $=1.89 \mathrm{~mm})$, ratio of length to proboscis 0.81-0.95 (mean $=0.89)$, ratio of length to forefemur 0.91-1.07 $($ mean $=1.00)($ Table 2.2$)$, ratio of length of palpomeres $3 / 4$ $1.62-2.08($ mean $=1.77), 3 / 52.17-2.87($ mean $=2.44), 4 / 51.22$ $1.62($ mean $=1.37), 4-5 / 30.84-1.08($ mean $=0.98)$, palpomeres 2 and 3 with narrow apical band of silvery-white scales, apical pale band of palpomere 4 variable, absent to larger than those of palpomeres 2 and 3, scales pale cream-colored to golden, slightly contrasting with those on palpomeres 2 and 3 , palpomere 5 dark-scaled at base, with apical band of pale creamcolored to golden scales, length of apical pale band 0.17-4.00 $($ mean $=1.18)$ length of basal dark band of palpomere 5, ratio of length of apical pale band of palpomere 4 to length of basal dark band of palpomere 5 0.0-1.67 $($ mean $=0.51)($ Table 3$)$. 
Thorax: pleural setae as follow: 1-4 upper proepisternal, 0-2 prespiracular, 5-8 prealar, 4-6 upper mesokatepisternal, 2,3 lower mesokatepisternal, 4-7 upper mesepimeral. Wing (Fig. 4): length $3.16-3.62 \mathrm{~mm}($ mean $=3.46 \mathrm{~mm})$, pale scales on vein $\mathrm{C}$ and subcosta light pale yellow, those on remaining veins white, not strongly contrasting with others, PHP spot of vein C small, always present, HP spot always present, usually prominent, rarely very small, PSP spot always present and prominent, rarely reduced, SP spot usually small, sometimes prominent, ASP spot usually present, occasionally reduced or absent, PP spot 0.55-1.54 (mean = 1.03) length of SCP spot, AD spot 1.173.00 (mean $=1.84)$ length of PP spot, PSD spot of vein R extending basally from level 4 to level 6 (Fig. 4) on both wings (Table 4), PSD spot of vein R with 1-5 small pale interruptions (Table 5), SD spot of vein R with 1-4 pale interruptions (Table 6), sum of pale interruptions on PSD-PD spots of vein $R$ varying from 4-12 for each wing, ratio of length of cell $R_{2}$ to vein $R_{2+3}$ 1.46-2.00 $($ mean $=1.69)$, ratio of length of cell $R_{2}$ to cell $M_{1+2}^{2+3}$ 1.19-1.34 $($ mean $=1.28)$. Legs: femora, tibiae, and tarsomeres 1 dark-scaled, speckled with pale spots; foretarsomere 2 with apical and basal pale bands, middle region dark-scaled, sometimes with 1-4 pale spots on dorsal surface, foretarsomeres 3 and 4 mostly dark-scaled, with basal and apical pale bands, foretarsomere 4 sometimes mostly palescaled with inconspicuous middle band of light brown scales, foretarsomere 5 variable, mostly pale-scaled with inconspicuous patch of tan scales on dorsal surface, or with basal dark band, pale-scaled at apex, dark scales on ventral surface of foretarsomeres 2-5 light brown to tan; midtarsomeres 2-5 mostly dark-scaled with narrow apical bands of pale scales; hindtarsomeres 2-5 dark-scaled with narrow apical bands of pale scales, hindtarsomeres 2,3 sometimes with few pale spots in middle dark area. Abdomen: tergum VI frequently without scales, sometimes with 2,3 golden scales on posterolateral margin, tergum VII with few cream-colored to golden scales on posterior margin or rarely without scales, tergum VIII covered with yellowish to golden scales; sternum VI without scales, sternum VII with posteromedial patch of dark scales, sternum VIII with small lateral patch of whitish scales.

Male. Essentially as in female except for sexual characters. Wing generally paler with reduced scaling, pale spots usually longer than in female. Palpomere 2 with patch of pale scales at middle of dorsal surface, extending to lateral surface, apex of palpomere 2 bare; palpomere 3 dark-scaled, with long dorsal patch of pale scales at middle, extending to lateral surface, apex of palpomere 3 with broad band of pale scales interrupted by short patch of dark scales at apex of ventrolateral surface; palpomeres 4 and 5 mostly pale-scaled with narrow basal band of dark scales. Abdomen: sternum VIII covered with pale creamcolored scales. Genitalia: 3,4 parabasal setae; ventral claspette with 2 apical large setae, medial seta slightly shorter than lateral seta, 1 smaller subapical seta; dorsal claspette with 4 long setae fused apically into club, setae separate at base; aedeagus with 5-7 serrated leaflets at each side of tip.

Pupa (Fig. 11). Position and development of setae as figured; range and modal number of branches in Table 9. All measurements from 20-22 specimens. In general as described for An. leucosphyrus, except for the following characters. Cephalothorax: seta 5-CT with 3-8 branches, 7-CT usually with 4 branches, 8-CT single to triple, 9-CT with 2-5 branches, 10CT with 2-4 branches. Abdomen: seta 6-I usually triple; 1-II dendritic, with $>30$ fine branches arising from strong basal stem; 7-II with 4-11 branches, 8-II always absent, 9-II very short, stout, length 0.010-0.014 mm $($ mean $=0.011), 10,11-\mathrm{II}$ rarely present; 1 -III with 5 -10 branches, 5-III with 6-11 branches, 9-III short, stout, length 0.01-0.03 mm (mean =0.02 mm); 1-IV with 3-7 branches, 5-IV with 4-8 branches, 9-IV short, length $0.02-0.05 \mathrm{~mm}($ mean $=0.04 \mathrm{~mm})$, ratio of length of 9-IV/III 1.25$4.0($ mean $=2.36)$ and 9-IV/V 0.19-0.52 $($ mean $=0.36) ; 1-\mathrm{V}$ usually triple, 5-V with 3-5 branches, 9-V long, length 0.08-0.12 mm $($ mean $=0.10 \mathrm{~mm})$; 1-VI usually triple, 5-VI with 3-7 branches, 6-VI single to triple, 9-VI long, length 0.09-0.13 $\mathrm{mm}$ (mean = $0.11 \mathrm{~mm}$ ); 5-VII with 4-7 branches, 9-VII long, length 0.09-0.12 $\mathrm{mm}($ mean $=0.11 \mathrm{~mm})$; 9-VIII with 12-20 branches. Paddle: toothed margin index 0.86-0.94 (mean $=0.91)$.

Larva (Figs. 11, 12, 49, 52). Position and development of setae as figured; range and modal number of branches in Table 10. All measurements from 10-24 specimens. In general as described for An. leucosphyrus, except for the following characters. Head: integument light brown to yellowish, either with or without pattern of darkened spots, if dark spots present, as follow: 1 dark spot placed posteriorly on dorsal apoteme; 2 lateral spots on dorsal apoteme posterior to seta 8-C, posteriorly on frontal ecdysial line; 1 dark spot ventral on lateralia encircling seta $12-\mathrm{C} ; 2$ dark spots on labiogula posterior to hypostomal suture; head length $0.60-0.70 \mathrm{~mm}$ ( mean $=0.67$ $\mathrm{mm})$, head width $0.63-0.74 \mathrm{~mm}($ mean $=0.68 \mathrm{~mm})$, antenna length $0.25-0.30 \mathrm{~mm}($ mean $=0.28 \mathrm{~mm})$; ratio of distance base to $1-\mathrm{A}$ to antenna length $0.31-0.42 \mathrm{~mm}($ mean $=0.38 \mathrm{~mm}), 3-\mathrm{C}$ length 0.07-0.09 $\mathrm{mm}($ mean $=0.08 \mathrm{~mm})$, distance between base of $2-\mathrm{C}$ and 3-C 0.03-0.04 $\mathrm{mm}($ mean $=0.04 \mathrm{~mm}), 4-\mathrm{C}$ always single, length $0.04-0.07 \mathrm{~mm}$ (mean $=0.06 \mathrm{~mm})$, distance between basal insertions of 2-C and 4-C 0.06- $0.10 \mathrm{~mm}($ mean $=0.08 \mathrm{~mm})$, ratio of length of 4-C to distance between the insertions of 2-C and 4-C 0.51-0.88 (mean =0.74), distance between base of 3-C and 4-C 0.06-0.09 $\mathrm{mm}($ mean $=0.07 \mathrm{~mm}), 5-\mathrm{C}$ extending beyond anterior margin of head, 6-C with 8-14 branches. Thorax: tubercles of all large setae light brown; tubercle of seta 1-P widely separated from that of 2,3-P or occasionally both tubercles joined at base, 14-P with 5-8 branches; 14-M with 511 branches; 3-T (Fig. 52) with 8-11 narrow, lanceolate nearly transparent leaflets. Abdomen: seta 1-I small, with 3-7 rigid branches, 2-I double or triple, 9-I with 3-5 branches; 1-II with 8-14 narrow, lanceolate branches; 3-IV single to triple, 13-IV long, ratio of length to 10-IV 0.46-0.64 $($ mean $=0.55) ; 11-15$ pecten spines (Fig. 49), 4-6 long elements alternating with 6-10 short.

Type data. Holotype male with associated slide mounted larval and pupal exuviae deposited in the NMNH [Acc. no. 08161-10], collected by AFRIMS staff, 25 May 1980, deposited in the NMNH. Type locality: THAILAND, Phangnga, Ban Bang Kaeo (8³5’N 98³2’E). 
Table 9. Number of branches for seta of pupae of An. latens: range (mode).

\begin{tabular}{|c|c|c|c|c|c|c|c|c|c|c|c|}
\hline \multirow{2}{*}{$\begin{array}{l}\text { Seta } \\
\text { No. }\end{array}$} & \multirow{2}{*}{$\begin{array}{c}\text { Cephalothorax } \\
\text { CT }\end{array}$} & \multicolumn{9}{|c|}{ Abdominal segments } & \multirow{2}{*}{$\begin{array}{c}\text { Paddle } \\
\mathrm{Pa}\end{array}$} \\
\hline & & $\mathrm{I}$ & II & III & IV & $\mathrm{V}$ & VI & VII & VIII & IX & \\
\hline 0 & - & - & 1 & 1 & 1 & 1 & 1 & 1 & 1 & - & - \\
\hline 1 & $2-5(3)$ & n.c. & $13-26$ & $5-10(6)$ & $3-7(5)$ & $2-4(3)$ & $2,3(3)$ & $2,3(2)$ & - & 1 & 1 \\
\hline 2 & $2,3(2)$ & 4-9 (6) & $4-8(6)$ & 4-7 (6) & $2-6(4)$ & $2-5(4)$ & $2-5(4)$ & $3-6(4)$ & - & - & $1-3(2)$ \\
\hline 3 & $3-6(4)$ & $1,2(1)$ & $2-4(3)$ & $2-5(3)$ & $5-11(6)$ & $1-5(4)$ & $1-3(3)$ & $2-5(4)$ & - & - & - \\
\hline 4 & $2,3(3)$ & $4-8(6)$ & $4-8(7)$ & $3-7(6)$ & $2-5(4)$ & $3-8(5)$ & $2-4(3)$ & $1-3(3)$ & $1-3(2)$ & - & - \\
\hline 5 & $3-8(6)$ & $3,4(3)$ & $3-6(4)$ & $6-11(8)$ & $4-8(5)$ & $3-5(5)$ & $3-7(5)$ & 4-7 (6) & - & - & - \\
\hline 6 & $2-4(3)$ & $2-4(3)$ & $2,3(2)$ & $2-4(2)$ & $1-3(2)$ & 1,2 (1) & $1-3(2)$ & $1,2(2)$ & - & - & - \\
\hline 7 & $3-6(4)$ & $3-9(5)$ & $4-11(5)$ & $2-6(3)$ & $2-5(4)$ & $2-6(4)$ & $1,2(1)$ & 1,2 (1) & - & - & - \\
\hline 8 & $1-3(1)$ & - & - & $2-4(3)$ & $2,3(2)$ & $2-4(2)$ & $2,3(3)$ & $2-4(3)$ & - & - & - \\
\hline 9 & $2-5(3)$ & 1 & 1 & 1 & 1 & 1 & 1 & 1 & $12-20(14)$ & - & - \\
\hline 10 & $2-4(2)$ & - & $0-3$ & $2-5(3)$ & $1,2(2)$ & $2,3(2)$ & $1-3(2)$ & $2-4(3)$ & - & - & - \\
\hline 11 & $2-4(2)$ & - & $0-2$ & 1 & 1 & 1,2 (1) & 1,2 (1) & $1-4(2)$ & - & - & - \\
\hline 12 & $2-5(3)$ & - & - & - & - & - & - & - & - & - & - \\
\hline 13 & - & - & - & - & - & - & - & - & - & - & - \\
\hline 14 & - & - & - & - & 1 & 1 & 1 & 1 & 1 & - & - \\
\hline
\end{tabular}

n.c. $=$ not counted

Material examined. Two hundred sixty three specimens as follows: $73 \mathrm{~F}, 43 \mathrm{M}, 55 \mathrm{Le}, 69 \mathrm{Pe}, 23 \mathrm{~L}$ derived from 52 separate collections from natural habitats (28 adults, 24 immature) and 10 progeny broods. INDONESIA. Kalimantan: Tana Laut, Salaman (349'S 115'5'E), [IDK43], 18-23 Sept. 1986, 1F, 3M, 4LePe (R. Harbach and V. Baimai). MALAYSIA (EAST). State of Sabah: Beaufort $\left(5^{\circ} 20^{\prime} \mathrm{N} 115^{\circ} 45^{\prime} \mathrm{E}\right)$, [S368], 4 Apr. 1970, 1M, 1LePe. Sandakan (Sugut-Labuk) (550’ N 188 ${ }^{\circ}$ 'E), [S-848], 12 May 1970, 1F, 1LePe, 1L. (U. Malaya). State of Sarawak: Tebangan (3'24'N 114'52'E), [LT/12/16], 8/53, 1M, 1LePe; [LT/18/2], 8/53, 1F, 1LePe; 8/53, 2F; 7 Aug. 1953, 2F (D.H. Colless). Long Tebangan (3'22'N 114'52'E) [19], 6 July 1953, 1F (J.A. Reid). Kuap $\left(1^{\circ} 25^{\prime} \mathrm{N} 110^{\circ} 22^{\prime} \mathrm{E}\right), 10$ Oct. 1906, 1F (J.C. Moulton). Bidi (1'23’N $\left.110^{\circ} 8^{\prime} \mathrm{E}\right)$, Jan. 1906, 2F (J.C. Moulton). Belaga (242'N $\left.113^{\circ} 47^{\prime} \mathrm{E}\right)$, Dec. 1954, 1F. Locality unknown, [Saw-85], 1985, progeny, 2F (V. Baimai). MALAYSIA (WEST). Malay States (Central, $4^{\circ} 00^{\prime} \mathrm{N}$ 10200’E), [483.E.8], 1920, 1M (H.P. Hacker). Negeri Kelantan: Ayer Lanas (5'20'N 102 00'E), 16 Apr. 1971, 2F (R.G. Andre). Negeri Sembilan: Kampong Pilah Tengah (2 $\left.{ }^{\circ} 44^{\prime} \mathrm{N} 102^{\circ} 15^{\prime} \mathrm{E}\right)$, [393/3], 5/49, 1F. Negeri Pahang: Chegar Perah (4'25'N 101'56'E), [595], 15 Apr. 1967, 1F. Negeri Perak: Chior Forest Reserve (459’N 101''E), [878], 26 Oct. 1967, 1F. (U. Malaya). Negeri Perlis: Bukit Bintang Forest Reserve (6 $\left.33^{\circ} \mathrm{N} 101^{\circ} 11^{\prime} \mathrm{E}\right),[1055], 4$ Dec. 1967, 1F, 1M, 1Pe, $1 \mathrm{~L}$ (U. Malaya). Negeri Selangor: Ulu Gombak, 16 th mile $\left(3^{\circ} 18^{\prime} \mathrm{N}\right.$ $\left.101^{\circ} 45^{\prime} \mathrm{E}\right),[0130], 01 / 57,3 \mathrm{~F}$ (J.A. Reid); 17 th mile $\left(3^{\circ} 18^{\prime} \mathrm{N} 101^{\circ} 46^{\prime} \mathrm{E}\right)$, [0139], 21 Jan. 1957, 1F, 1M. Ulu Gombak, 15 th mile $\left(3^{\circ} 17^{\prime} \mathrm{N}\right.$ 101 $\left.45^{\prime} \mathrm{E}\right)$, [983], Feb. 1956, 1F, 1M; [984], Feb. 56, 1F, 1M (J.A. Reid); 13 miles from Kuala Lumpur ( $\left.3^{\circ} 17^{\prime} \mathrm{N} 101^{\circ} 44^{\prime} \mathrm{E}\right)$, [BM-350], 18 Apr. 1903, 1M (G.W. Daniels, G.F. Leicester). Kampong Kubu Bhuru

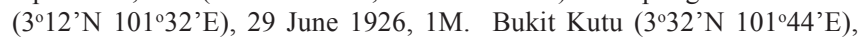
[1329], 10 June 1968, 1M, 1Pe. (U. Malaya). Bukit Lanjan (3¹1'N 101³6'E), 16 Apr. 1971, 2F (R.G. Andre). THAILAND. Chumphon: Pathiu, Ban Chong Rakam, Ban Chong Mut, Mu 3 (1044'N 99¹8'E), [08003], 13 Sept. 1978, 2F; [08007], 18 Sept. 1978, 5F; [08007 (3)], 18 Sept. 1978, progeny, 1F, 1M, 3LePe (AFRIMS). Nakhon Si Thammarat: Tung Song, Nam Tok ( $\left.8^{\circ} 10^{\prime} \mathrm{N} 99^{\circ} 30^{\prime} \mathrm{E}\right)$, [TS39 (F-2)], 1985, progeny, 1F, 3M, 5LePe, 3 L; [TS104], 23-26 June 1985, progeny, 3M, 3LePe; [TS301], 10 Nov. 1986, progeny, 4F, 1M, 5LePe. Tung Yai, Ban Tham Phae Dan (8'22'N 99²0'E), [TY001], 3-8 Dec. 1985, progeny, 2F, 2M, 4LePe, 1Pe; [TY14], Dec. 1985, progeny, 1F; [TY23], Dec. 1985, 1LePe; [TY26], Dec. 1985, 1F (V. Baimai). Narathiwat: Waeng (556'N 101'54'E), [NV-80], 12 Feb. 1965, 2M, 1LePe; [NV-97], 2 Mar. 1965, 2F, 2LePe. Waeng, Kao Lau (556’ N 10148'E), [445], 7 Sept. 1965, 1F; [0446], 7 Sept. 1965, 2F, 2M, 2LePe, 2Pe; [0447], 7 Sept. 1965, 3F, 1Pe; [0451], 8 Sept. 1965, 1 L; [0465], 8 Sept. 1965, 1M, 1Pe; [0473], 9 Sept. 1965, 3M, 1LePe,
1Pe, 12 L. Phangnga: Ban Bang Kaeo ( ${ }^{\circ} 35^{\prime}$ N 98 $32^{\circ}$ 'E), [08161], 25 May 1980, 6F, 9M, 12LePe, 4Pe; [08162], 25 May 1980, 3F, 2M, 5LePe, 1Pe, 1L; [08163], 25 May 1980, 1F; [08167], 26 May 1980, 1L; [08190], 29 May 1980, 1F; [08197], 30 May 1980, 2F; [08204], 31 May 1980, 3F; [08212], 2 June 1980, 2F; [08223], 4 June 1980, 2F. Satun: Khlong Baraket (6 $\left.{ }^{\circ} 52^{\prime} \mathrm{N} 100^{\circ} 4^{\prime} \mathrm{E}\right)$, [0527], 20 Sept. 1965, 1 L (AFRIMS). Songkhala: Sadao, Padang Besa, Khao Rup Chang (60'N 100¹9’E), [PB53], 12 Dec. 1986, progeny, 4F, 1M, 4LePe, 1Pe, 2 L (V. Baimai).

Distribution (Fig. 54). Anopheles latens is known from Indonesia (Kalimantan), east Malaysia (Sabah, Sarawak), west Malaysia (Malay States, Kelantan, Sembilan, Pahang, Perak, Perlis, and Selangor), southern Thailand (Chumphon, Nakhon Si Thammarat, Narathiwat, Phangnga, Satun, and Songkla).

Bionomics and medical importance. Anopheles latens was incriminated as a vector of both human malaria and Brancroftian filarial parasites in forested areas and villages situated $0.5 \mathrm{~km}$ from the forests. Female activity peaked around midnight in forested areas and soon after dusk in village settlements (Chang et al. 1995). This species was also considered a primary vector of human Plasmodium in montainous areas in Sarawak where An. latens was more abundant between 2400 and $0200 \mathrm{~h}$ (Zulueta 1956), and in the region of the Akah River where the species showed preference for humans, biting throughout the night but peaking from $2200-0400 \mathrm{~h}$ in the dry season and from $2200 \mathrm{~h}-2400 \mathrm{~h}$ in the wet season (Colless 1956a). Anopheles latens also seems to be involved in the transmission of filariasis since females were found infected with $W$. bancrofti in Sarawak, Leppu Leju, upper Tingar (Zulueta 1957). Macdonald \& Traub (1960) noted that An. latens was collected more frequently in the canopy than at ground level in lowland secondary dipterocarp forest of Selangor, Malaya. However, it also occurs in environments that have been impacted by human activities. In Sarawak, east Malaysia, An. latens was found to be more abundant in farm huts than in village settlements in a mountainous area in tropical rain forest. In both ecoregions females were attracted more to human bait than to CDC light 
Table 10. Number of branches for setae of fourth-instar larvae of An. latens: range (mode).

\begin{tabular}{|c|c|c|c|c|c|c|c|c|c|c|c|c|c|}
\hline \multirow{2}{*}{$\begin{array}{l}\text { Seta } \\
\text { No. }\end{array}$} & \multirow{2}{*}{$\begin{array}{c}\text { Head } \\
\mathrm{C}\end{array}$} & \multicolumn{3}{|c|}{ Thorax } & \multicolumn{9}{|c|}{ Abdominal segments } \\
\hline & & $\mathrm{P}$ & M & $\mathrm{T}$ & $\mathrm{I}$ & II & III & $\mathrm{IV}$ & $\mathrm{V}$ & $\mathrm{VI}$ & VII & VIII & $\mathrm{X}$ \\
\hline 0 & 1 & 1 & - & - & - & 1 & 1 & 1 & 1 & 1 & 1 & 1 & - \\
\hline 1 & 1 & $10-17(13)$ & $22-32(28)$ & $2-3(3)$ & $3-7(6)$ & $8-14(10)$ & $11-20(18)$ & $13-21(18)$ & $15-21(19)$ & $14-19(16)$ & $11-17(12)$ & 1 & 1 \\
\hline 2 & $1-2(1)$ & $9-13(12)$ & $2-5(3)$ & 1 & $2-3(2)$ & $5-9(7)$ & $5-9(6)$ & $3-5(3)$ & $3-5(4)$ & $4-7(5)$ & $4-8(6)$ & $6-10(7)$ & $17-21(17)$ \\
\hline 3 & 1 & 1 & 1 & $8-11(9)$ & $1-2(1)$ & 1 & 1 & $1-3(2)$ & 1 & 1 & $3-4(3)$ & $6-10(8)$ & $7-11(8)$ \\
\hline 4 & 1 & $13-20(16)$ & $2-4(3)$ & $2-4(3)$ & $3-6(5)$ & $3-9(6)$ & $3-5(3)$ & $3-5(3)$ & $3-4(3)$ & 1 & $1-2(1)$ & 1 & 9 \\
\hline 5 & $7-11(9)$ & $25-44(31)$ & 1 & $21-38(34)$ & $3-4(3)$ & $3-6(5)$ & $1-5(3)$ & $3-4(3)$ & $3-4(3)$ & $3-5(4)$ & $4-6(5)$ & $3-7(3)$ & - \\
\hline 6 & $8-14(12)$ & 1 & $3-4(3)$ & $2-4(3)$ & $14-21(17)$ & $18-29(21)$ & $10-19(14)$ & $1-3(2)$ & $1-3(2)$ & $2-4(3)$ & $3-5(3)$ & $1-S$ & $3-5(5)$ \\
\hline 7 & $9-16(12)$ & $15-26(21)$ & $1-4(2)$ & $20-32(30)$ & $11-19(13)$ & $17-24(20)$ & $3-6(4)$ & $4-6(5)$ & $2-5(4)$ & $2-5(3)$ & $1-6(4)$ & $2-S$ & $4-7(6)$ \\
\hline 8 & $1-3(2)$ & $19-29(27)$ & $12-21(16)$ & $16-26(21)$ & - & $1-3(2)$ & $1-3(2)$ & $2-3(3)$ & $2-3(2)$ & $2-3(3)$ & $3-5(4)$ & $6-\mathrm{S}$ & $1-3(2)$ \\
\hline 9 & $2-4(4)$ & $1-2(2)$ & $1-2(1)$ & $1-2(1)$ & $3-5(4)$ & $6-8(7)$ & $6-11(9)$ & $5-12(8)$ & $5-8(6)$ & $5-7(6)$ & $4-6(5)$ & $7-S$ & 1 \\
\hline 10 & $1-2(2)$ & 1 & 1 & 1 & 1 & $2-4(3)$ & 1 & 1 & 1 & $2-4(3)$ & $4-7(6)$ & 8-S & $2-4(3)$ \\
\hline 11 & $18-30(21)$ & 1 & 1 & 1 & $3-4(3)$ & 1 & $2-4(3)$ & $2-4(3)$ & $2-4(3)$ & $1-3(3)$ & $1-3(2)$ & 9-S & $3-5(4)$ \\
\hline 12 & $1-2(2)$ & 1 & 1 & $2-3(2)$ & $2-4(3)$ & 1 & $2-4(3)$ & $2-5(3)$ & $1-4(3)$ & 1 & $1-2(1)$ & - & - \\
\hline 13 & $3-6(6)$ & $3-6(5)$ & $3-7(5)$ & $2-4(3)$ & $2-6(4)$ & $3-5(3)$ & $4-7(5)$ & $3-5(3)$ & $3-5(4)$ & $5-8(7)$ & $2-4(3)$ & - & - \\
\hline 14 & $3-5(5)$ & $5-8(6)$ & $5-11(8)$ & - & - & - & - & 1 & 1 & 1 & 1 & 1 & - \\
\hline 15 & $3-5(5)$ & - & - & - & - & - & - & - & - & - & - & - & - \\
\hline
\end{tabular}

n.c. $=$ not counted

traps. Additionally, it was observed that malaria transmission was more intense in farm huts than in the village settlements where An. latens and An. donaldi Reid were predominant. The inoculation rate of An. latens in farm huts was 0.023 (Seng et al. 1999). Human bait collections carried out in a remote village located in a heavily forested area in South Kalimantan, Indonesia, showed that An. latens and An. balabacensis were predominant outside houses in villages, whereas the number was lower in nearby forest. The sporozoite infection rate was $1.0 \%$ for An. latens and less than 1.3\% for An. balabacensis (Harbach et al. 1987b).

Anopheles latens is mainly a forest breeding mosquito. In west Malaysia, immatures were found in a muddy pool in a cart track running through dense jungle and in the longitudinal half of a split bamboo stem on the ground (Leicester 1903). Additionally, larvae were taken from jungle streams in Selangor, Jugra (Leicester 1908a). Collections carried out in Thailand with the purpose of obtaining samples for the present study included immatures of An. latens from ground pools along stream margins, flood pools, seepage pools, sandy pools in stream banks, small shallow running streams and elephant footprints. The water was always fresh, stagnant or standing, turbid or clear, sometimes with some degree of pollution and decaying leaves. The habitats were partially or heavily shaded in primary and secondary rain forests either in mountains or valleys at elevations ranging from $76 \mathrm{~m}$ to $520 \mathrm{~m}$ above sea level. Immatures were found in association with Aedes orbitae Edwards, Ae. vexans (Meigen), Verrallina atria (Barraud), An. introlatus Colless, An. macarthuri Colless, An. pujutensis Colless, An. baimaii Sallum and Peyton, An. nemophilous Peyton and Ramalingam, An. maculatus Theobald, An. bengalensis Puri, Cx. fraudatrix (Theobald), $C x$. nigropunctatus Edwards, Cx. mimulus Edwards, $C x$. minor (Leicester), Culex spp., Ur. bicolor Leicester, Ur. trilineata Leicester, and Uranotaenia spp. Adults were collected on human bait in secondary evergreen forest and secondary rain forest, secondary rain forest with fruit and/or rubber plantations and/or orchards near villages and/or mixed fruit plantations. Collections were made at the edge of forest or near human habitations in villages, valleys, or mountainous or hilly areas.

Immatures were found in swamps in East Malaysia. The water was fresh, stagnant, and clear. Larval habitats were in partial shade in secondary rain forest in hilly areas. Immatures were found in association with Ve. gibbosa (Delfinado), Ae. caecus (Theobald), Ae. scutellaris (Walker), Anopheles hodgkini Reid, An. scanloni Sallum and Peyton, Culex mammilifer (Leicester), Cx. foliatus Brug., Cx. mimulus, and Ur. bicolor. Adults were collected on human bait at ground level and in forest canopy.

Systematics. Based on hybridization and cytogenetic evidence, Kanda et al. (1981) suggested that specimens from populations of Sabah and Kuching (SWK) and Niabet (SWN) in Sarawak, Malaysia, belonged to a separate species they designated as “An. leucosphyrus sensu stricto". Later, Kanda et al. (1983) using chromosomal polymorphisms confirmed that both SWK and SWN populations belonged to "An. leucosphyrus s.s." Using seven protein loci, Takai (1986) was able to distinguish five taxa within the Leucosphyrus Group and confirmed the hypothesis of Kanda et al. $(1981,1983)$ that specimens of An. leucosphyrus from SWK belonged to a distinct species. Finally, Baimai et al. (1988c) found cytogenetic evidence that An. leucosphyrus included two allopatric species, one inhabiting Borneo, west Malaysia and southern Thailand (designated as An. leucosphyrus A) and one confined to Sumatra (An. leucosphyrus s.s.). Based on the results of Baimai et al., we concluded that the specimens identified as An. leucosphyrus s. s. by Kanda et al. $(1981,1983)$ and Takai (1986) were An. latens.

Anopheles latens is morphologically more similar to $A n$. 
leucosphyrus than to any other species of the Leucosphyrus Complex. The male, female, pupal, and larval stages of $A n$. latens are indistinguishable from those of An. leucosphyrus. The same characters listed for An. leucosphyrus can be used to distinguished An. latens from other members of the Leucosphyrus Group. Since An. latens and An. leucosphyrus are allopatric, distribution should be considered when making identifications.

\section{Anopheles (Cellia) introlatus Colless} (Figs. 4, 7, 13, 14, 49, 50-53, 54)

Anopheles balabacensis introlatus Colless (1957:137) (F, P, L). Holotype female with associated larval and pupal exuviae on microscope slide, deposited in the NHM.

Anopheles balabacensis introlatus of Macdonald \& Traub (1960:79) (bionomics notes); Chow (1961) (distribution, $\mathrm{F}^{*}$, identification key); Bonne-Wepster (1963:705) (F, identification key); Eyles et al. (1963:134) (Plasmodium cynomolgi vector); Russell et al. (1963:705) (F, identification key); Scanlon \& Sandhinand (1965:61) (distribution, bionomics); Peyton \& Scanlon (1966:7,41) (F*, identification key); Scanlon et al. (1967:79) (taxonomy, bionomics notes); Scanlon et al. (1968a:20) (checklist); Tsukamoto et al. (1987:291) (checklist).

Anopheles introlatus of Hii et al. (1988a:41) (elevated to full species status); Peyton (1989:197) (taxonomy).

Anopheles leucosphyrus Kepong Form of Colless (1956b:63) (F, P, L, taxonomy, distribution notes).

Female (Figs. 4, 7). Head: proboscis dark-scaled, occasionally with ventral patch of pale scales, length 1.85 $2.28 \mathrm{~mm}$ (mean $=2.09 \mathrm{~mm}$ ), ratio of length to forefemur 1.02$1.11($ mean $=1.06)$, maxillary palpus (Fig. 7) length 1.64-2.10 $\mathrm{mm}($ mean $=1.91 \mathrm{~mm})$, ratio of length to proboscis $0.89-0.94$ (mean $=0.92)$, ratio of length to forefemur 0.93-0.98 (mean = 0.97 ) (Table 2), ratio of length of palpomeres 3/4 1.50-1.92 (mean $=1.66), 3 / 52.17-2.78($ mean $=2.38), 4 / 51.25-1.67($ mean $=1.43)$, 4-5/3 0.91-1.12 $($ mean $=1.02)($ Table 3$)$, palpomeres $2-4$ with narrow apical silvery-white bands similar in size, pale scales on palpomere 5 light cream-colored, bordering on white, length of apical pale band of palpomere 5 0.73-2.00 $($ mean $=1.08)$ length of basal dark band of palpomere 5 , ratio of length of apical pale band of palpomere 4 to length of basal dark band of palpomere $50.27-0.57($ mean $=0.44)($ Table 3$)$. Thorax: pleural setae as follow: 2-5 upper proepisternal, 1,2 prespiracular, 4,5 prealar, 2-6 upper mesokatepisternal, 1-4 lower mesokatepisternal, 3-6 upper mesepimeral. Wing (Fig. 4): length $3.09-3.77 \mathrm{~mm}($ mean $=3.50 \mathrm{~mm})$, pale scales on veins $\mathrm{C}$ and subcosta pale cream-colored, those on the remaining veins bordering to white, not strongly contrasting with those on veins $\mathrm{C}$ and subcosta, PHP spot of vein $\mathrm{C}$ usually small, occasionally absent, HP spot always present, prominent, PSP spot always present, small or prominent, SP spot usually prominent, occasionally reduced, ASP spot present or absent, sometimes prominent or reduced, PP spot 0.63-2.00 (mean = 0.94 ) length of SCP spot, $\mathrm{AD}$ spot 1.33-2.70 (mean = 1.97) length of PP, PSD spot of vein R extending from level 1 to level 3 on one or both wings (Table 4), PSD spot of vein $\mathrm{R}$ with 1,2 small pale interruptions (Table 5), SD spot of vein $\mathrm{R}$ with 1-3 pale interruptions (Table 6), sum of pale interruptions on PSD-PD spots of vein $R$ varying from 3-8 spots for each wing, ratio of length of cell $\mathrm{R}_{2}$ to $\mathrm{R}_{2+3} 1.36-1.86$ (mean $=1.62$ ), ratio of length of cell $\mathrm{R}_{2}$ to cell $\mathrm{M}_{1+2} 1.17-1.33$ (mean =1.26). Legs: femora, tibiae and tarsomeres 1 dark-scaled, speckled with pale spots; foretarsomere 2 variable, mostly dark-scaled with conspicuous basal and apical pale bands, sometimes with 1,2 pale spots on middle dark area, less frequently mostly pale-scaled along ventral surface with 2,3 dark spots, foretarsomeres 3 and 4 dark-scaled with conspicuous basal and apical pale bands, foretarsomere 5 with apical band of pale scales, occasionally foretarsomeres 4 and 5 mostly pale-scaled; midtarsomeres 2 and 3 dark-scaled with apical bands of pale scales, sometimes with 1-4 spots of pale scales, midtarsomeres 4 and 5 darkscaled with apical band of pale scales; hindtarsomeres 2-5 mostly dark-scaled with apical band of pale scales, hindtarsomere 2 with 1-4 pale spots on middle dark area, hindtarsomere 4 only rarely with small, inconspicuous basal pale band on dorsal surface, most frequently dark-scaled at base. Abdomen: tergum VI usually without scales, rarely with 2,3 narrow scales laterally, tergum VII with few, sparse, pale cream-colored scales on posterior margin, tergum VIII covered with golden scales; sternum VI usually without scales, sometimes with 2,3 dark scales on posterior margin, sternum VII with patch of dark scales posteromedially, rarely scales cream-colored, sternum VIII with small patch of whitish scales laterally.

Male. Essentially as in female except for sexual characters. Wing generally paler with reduced scaling, pale spots usually longer than in female. Palpomere 2 dark-scaled with extensive dorsal pale spot at middle extending to lateral surface, apex of palpomere 2 bare; palpomere 3 dark-scaled with large pale spot at middle extending to lateral surface, pale-scaled at apex, with patch of dark scales at apex of ventrolateral surface, palpomeres 4 and 5 mostly pale-scaled with basal dark bands. Abdomen: sternum VIII covered with pale cream-colored scales. Genitalia: 4 parabasal setae; ventral claspette with 1 long apicolateral seta, slightly longer than club, mesal setae slightly shorter than apicolateral seta, 1 smaller subapical seta; dorsal claspette with 4 long setae fused apically into club; aedeagus with 5-7 serrated leaflets.

Pupa (Fig. 13). Position and development of setae as figured; range and modal number of branches in Table 11. All measurements from 12-26 specimens. In general as described for An. leucosphyrus except for the following characters. Cephalothorax: seta 10-CT single to 4-branched; seta 9-III moderately pigmented, 9-IV-VIII pigmented medium brown, slightly darker at base. Abdomen: seta 6-I usually triple, 7-I with 4-8 branches; 8-II always absent, 9-II length 0.007-0.015 $\mathrm{mm}($ mean $=0.012 \mathrm{~mm})$; 1-III with 6-11 branches, 5-III with 8-13 branches, 6-III usually triple, 9-III short, length $0.02-0.04 \mathrm{~mm}$ $($ mean $=0.02 \mathrm{~mm}) ; 1-\mathrm{IV}$ with $6-10$ branches, 5-IV with 7-10 branches, 9-IV long, length $0.07-0.11 \mathrm{~mm}$ (mean $=0.10 \mathrm{~mm}$ ), ratios of length of 9-IV/III 2.96-6.53 (mean $=4.44)$ and 9-IV/V $0.67-1.03$ (mean $=0.88) ; 1-\mathrm{V}$ with 3-7 branches, $5-\mathrm{V}$ with 6-9 branches, 9-V long, frequently without spicules on medial 
edges, rarely with few spicules, length $0.09-0.12 \mathrm{~mm}$ (mean = $0.11 \mathrm{~mm}$ ); 1-VI with 3-7 branches, 5-VI with 6-11 branches, 9-VI long, rarely with spicules, length $0.08-0.12 \mathrm{~mm}$ (mean $=0.11$ $\mathrm{mm}$ ); 1-VII double to 4-branched, 5-VII with 6-8 branches, 9VII long, rarely with spicules, length $0.08-0.12 \mathrm{~mm}$ (mean $=0.10$ $\mathrm{mm})$; 9-VIII with 12-18 branches. Paddle: toothed margin index $0.81-0.99$ (mean $=0.87)$.

Larva (Figs. 13, 14, 49-53). Position and development of setae as figured; range and modal number of branches in Table 12. In general as described for An. leucosphyrus except for the following characters. All measurements from 10-20 specimens unless otherwise indicated. Head: length $0.65-0.68 \mathrm{~mm}$ (mean $=0.66 \mathrm{~mm})(\mathrm{n}=6)$, width $0.67-0.72 \mathrm{~mm}($ mean $=0.69 \mathrm{~mm})(\mathrm{n}=6)$; antenna length $0.27-0.34 \mathrm{~mm}$ (mean $=0.29 \mathrm{~mm})$, ratio of distance base to 1-A to antenna length $0.35-0.49($ mean $=0.38)$; seta 2$\mathrm{C}$ long, single and simple; $3-\mathrm{C}$ length $0.09-0.12 \mathrm{~mm}$ (mean = $0.10 \mathrm{~mm}$ ), distance between base of 2-C and 3-C 0.03-0.04 mm (mean $=0.04 \mathrm{~mm}$ ), 4-C always single, length $0.09-0.13 \mathrm{~mm}$ (mean $=0.10 \mathrm{~mm}$ ), extending beyond base of $2-\mathrm{C}$, distance between basal insertions of 2-C and 4-C 0.06-0.09 $\mathrm{mm}$ ( mean $=0.08 \mathrm{~mm}$ ), ratio of length of 4-C to distance between insertions of 2-C and 4-C 1.13-1.71 (mean =1.40), distance between base of 3-C and 4-C 0.05-0.08 mm (mean $=0.07 \mathrm{~mm}$ ), 5-C long, extending beyond anterior margin of head, 10-16 branched, $6-\mathrm{C}$ with 1215 branches, 7-C with 11-17 branches. Thorax: tubercles of all large setae light to medium brown; tubercles of seta 1-P broadly joined basally to tubercle of 2,3-P by posterior bridge (Fig. 53), 14-P with 5-9 branches. Abdomen: seta 1-I with 4-10 branches, 3-I usually triple, 1-II (Fig. 51) more developed and more pigmented than that of An. leucosphyrus, with 7-15 branches; ratio of length of 13-IV to length of 10-IV 0.43-0.80 (mean = 0.55); 1-VII (Fig. 50) apicolateral serrations and apical filament more developed and more evident than that of $A n$. leucosphyrus (Fig. 50); 11-16 pecten spines (Fig. 49), 5-8 long elements alternating with 6-12 short.

Type data. Holotype female with associated larval and pupal exuviae mounted on microscope slide, deposited in the NHM, London, U.K. Type locality: MALAYSIA, Malaya, Selangor, 15th mile from Ulu Gombak.

Material examined. One hundred twenty-two specimens as follows: $45 \mathrm{~F}, 35 \mathrm{M}, 10 \mathrm{Le}, 15 \mathrm{Pe}, 17 \mathrm{~L}$ derived from 30 separate collections from natural habitats (10 adults, 20 immature). INDONESIA. Sumatra: Selatan, Baturaja-Simpang Road (4'20'S 104'20'E), [IN686], 30 Mar.

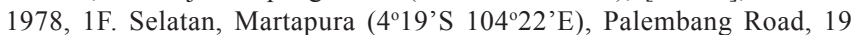
Km from Baturaja, [IN698], 1 Apr. 1978, 3F. (U. Malaya). Moearatebo [Muaratebo], (1'30'S 102²6'E), [3311], 22 Dec., 1F (de Rook, det. Brug as An. (Myzomyia) leucosphyrus). MALAYSIA (WEST). Malaya

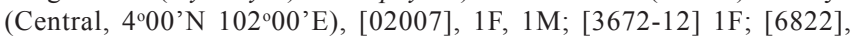
2L (C. Strickland as An. leucosphyrus). Kelantan: Ayer Lanas $\left(5^{\circ} 20^{\prime} \mathrm{N}\right.$ $102^{\circ} 00^{\prime} \mathrm{E}$ ), 4 June 1971, 2F (USAMRU). Negeri Sembilan: Gemas ( $\left.2^{\circ} 35^{\prime} \mathrm{N} 102^{\circ} 37^{\prime} \mathrm{E}\right)$, [L453/6], 10 Mar. 1951, 1M, (J.A. Reid as $A n$. pujutensis). Pahang: Gunong Benom ( $\left.3^{\circ} 50^{\prime} \mathrm{N} 102^{\circ} 6^{\prime} \mathrm{E}\right)$, [505], 21 Mar. 1967, 1F; [510], 23 Mar. 1967, 3F, 1M, 4LePe, 1Le. (U. Malaya). Kampong Janda Baik ( $\left.3^{\circ} 19^{\prime} \mathrm{N} 101^{\circ} 52^{\prime} \mathrm{E}\right), 16$ Feb. 1972, 8F, 4M; 8 May 1972, 4F, 7M; 22 May 1972, 1M; 29 May 1972, 1F (USAMRU). Selangor: Ulu Gombak ( $\left.3^{\circ} 18^{\prime} \mathrm{N} 101^{\circ} 47^{\prime} \mathrm{E}\right)$, Mar. 1956, 2F (J.A. Reid as An. leucosphyrus balabacensis). $15^{\text {th }}$ mile, Ulu Gombak $\left(3^{\circ} 17^{\prime} \mathrm{N}\right.$ $\left.101^{\circ} 46^{\prime} \mathrm{E}\right)$, [971], Jan. 1956, 2F, 2M (paratypes); [967], Jan. 1956, $3 \mathrm{~F}, 2 \mathrm{M}$ (includes holotype and paratype, Colless). $17^{\text {th }}$ mile, Ulu Gombak (318’N 10146’E), [956], Jan. 1956, 2F, 1LePe (J.A. Reid); [958], Jan. 1956, 1F, 1M. THAILAND. Narathiwat: Kilometer 11 between Soi Teo and Waeng (556'N 101'54'E), [NV24], 15 Jan. 1964, 2L; [NV80], 12 Feb. 1965, 1L; [NV97], 2 Mar. 1965, 1M, 1LePe. Waeng,

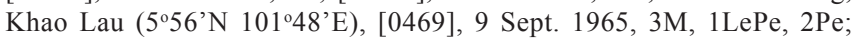
[0470], 1M, 1Pe, 3L; [0473], 3M, 2Pe, 2L; [0475], 7F, 6M, 1LePe, 2L; [0480], 1Pe. Songkhla: Hat Yai, Ton Nga Chang Waterfall (6 ${ }^{\circ} 56^{\prime} \mathrm{N}$ $\left.101^{\circ} 19^{\prime} \mathrm{E}\right)$, [SL75], 25 Mar. 1965, 1M, 1LePe. Yala: Kampong Yalabong (6 $\left.{ }^{\circ} 16^{\prime} \mathrm{N} 101^{\circ} 22^{\prime} \mathrm{E}\right),[0507], 15$ Sept. 1965, 1F, 2L; [0513], 1F, 3L (All, J.E. Scanlon, AFRIMS).

Distribution (Fig. 54). Anopheles introlatus is known from Indonesia (Sumatra); West Malaysia (Malaya, Kelantan, Negeri Sembilan, Pahang, Selangor) and Thailand (Narathiwat, Songkla, Yala).

Bionomics and medical importance. Anopheles introlatus is a jungle-breeding mosquito distributed throughout hilly forest regions of central Malaysia. This species is not very

Table 11. Number of branches for seta of pupa of An. introlatus: range (mode).

\begin{tabular}{|c|c|c|c|c|c|c|c|c|c|c|c|}
\hline \multicolumn{2}{|c|}{ Seta Cephalothorax } & \multicolumn{9}{|c|}{ Abdominal segments } & \multirow{2}{*}{$\begin{array}{c}\text { Paddle } \\
\mathrm{Pa}\end{array}$} \\
\hline No. & $\mathrm{CT}$ & I & II & III & IV & $\mathrm{V}$ & VI & VII & VIII & IX & \\
\hline 0 & - & - & 1 & 1 & 1 & 1 & 1 & 1 & 1 & - & - \\
\hline 1 & $2-4(2)$ & n.c. & $20-30$ & $6-11(9)$ & $6-10(8)$ & $3-7(5)$ & $3-7(4)$ & $2-4(3)$ & - & 1 & 1 \\
\hline 2 & $2-3(2)$ & $5-10(7)$ & $5-8(5)$ & $5-10(7)$ & $4-8(5)$ & $4-7(5)$ & 4-6 (4) & $3-4(4)$ & - & - & $2-4(2)$ \\
\hline 3 & $3-5(3)$ & 1 & $3-4(3)$ & $3-594)$ & $5-9(7)$ & $3-5(3)$ & $2,3(3)$ & $2-6(5)$ & - & - & - \\
\hline 4 & $2-5(3)$ & $4-8(7)$ & $3-7(6)$ & $5-8(6)$ & 4-7 (6) & $4-7(5)$ & $2-4(3)$ & $1-5(3)$ & $2,3(3)$ & - & - \\
\hline 5 & 4-7 (5) & $3-6(4)$ & $3-7(4)$ & $8-13(9)$ & $7-10(8)$ & $6-9(7)$ & $6-11(7)$ & $6-8(6)$ & - & - & - \\
\hline 6 & $2,3(3)$ & $2-4(3)$ & $2-3(3)$ & $2-4(3)$ & $2-3(2)$ & $2,3(2)$ & $2,3(2)$ & $1-3(2)$ & - & - & - \\
\hline 7 & $2-4(2)$ & $4-8(6)$ & $4-7(6)$ & $3-5$ (4) & $2-5(3)$ & $2-5(3)$ & $1,2(2)$ & $1-3(2)$ & - & - & - \\
\hline 8 & $1-3(1)$ & - & - & $2-4(3)$ & $2-4(3)$ & $2,3(3)$ & $2,3(3)$ & $2-5(3)$ & - & - & - \\
\hline 9 & $2-4(3)$ & 1 & 1 & 1 & 1 & 1 & 1 & 1 & $12-18(13)$ & - & - \\
\hline 10 & $1-4(3)$ & - & - & $2-5(3)$ & $2-3(2)$ & $1-3(2)$ & $1-3(2)$ & $2-4(3)$ & - & - & - \\
\hline 11 & $2-6(3)$ & - & - & 1 & 1 & 1 & 1 & $2,3(3)$ & - & - & - \\
\hline 12 & $2-5(3)$ & - & - & - & - & - & - & - & - & - & - \\
\hline 13 & - & - & - & - & - & - & - & - & - & - & - \\
\hline 14 & - & - & - & - & 1 & 1 & 1 & 1 & 1 & - & - \\
\hline
\end{tabular}

n.c. $=$ not counted 
Table 12. Number of branches for setae of fourth-instar larvae of An. introlatus: range (mode).

\begin{tabular}{|c|c|c|c|c|c|c|c|c|c|c|c|c|c|}
\hline \multirow{2}{*}{$\begin{array}{l}\text { Seta } \\
\text { No. }\end{array}$} & \multirow{2}{*}{$\begin{array}{c}\text { Head } \\
\text { C }\end{array}$} & \multicolumn{3}{|c|}{ Thorax } & \multicolumn{9}{|c|}{ Abdominal segments } \\
\hline & & $\mathrm{P}$ & $\mathrm{M}$ & $\mathrm{T}$ & $\mathrm{I}$ & II & III & $\mathrm{IV}$ & $\mathrm{V}$ & $\mathrm{VI}$ & VII & VIII & $\mathrm{X}$ \\
\hline$\overline{0}$ & 1 & 1 & - & - & - & 1 & 1 & 1 & 1 & 1 & 1 & 1 & - \\
\hline 1 & 1 & $11-19(16)$ & $22-33(26)$ & 1 & $4-10(7)$ & $7-15(9)$ & $17-23(20)$ & $16-24(18)$ & $17-21(17)$ & $14-21(17)$ & $11-15(12)$ & 1 & 1 \\
\hline 2 & 1 & $8-13(11)$ & $1-3(1)$ & 1 & $1-3(2)$ & $5-9(8)$ & $5-10(7)$ & $3-5(5)$ & $3-6(4)$ & $4-7(5)$ & $5-7(6)$ & $5-8(6)$ & $18-31(18)$ \\
\hline 3 & 1 & 1 & 1 & $4-7(5)$ & $1-4(3)$ & 1 & 1 & $2-4(3)$ & 1 & 1 & $2-5(3)$ & $4-8(6)$ & $7-11(11)$ \\
\hline 4 & 1 & $11-19(14)$ & $2-3(2)$ & $2-5(3)$ & $4-6(5)$ & $3-6(5)$ & $3-5(4)$ & $3-5(4)$ & $3-43(3)$ & 1 & 1 & 1 & 9 \\
\hline 5 & $10-16(12)$ & $27-43$ & 1 & $26-39(27)$ & $3-4(3)$ & $4-5(4)$ & $3-5(3)$ & $3-4(3)$ & $3-4(3)$ & $3-6(3)$ & $3-5(3)$ & $3-5(3)$ & - \\
\hline 6 & $12-15(12)$ & 1 & $3-5(4)$ & $2-4(3)$ & $16-29(22)$ & $17-28(22)$ & $15-21(15)$ & $1-3(2)$ & $1-3(2)$ & $2-3(3)$ & $3-5(4)$ & $1-S$ & $3-5(4)$ \\
\hline 7 & $11-17(14)$ & $20-26(24)$ & $3-4(3)$ & $25-36(28)$ & $13-20(20)$ & $22-24(22)$ & $4-6(5)$ & $3-6(4)$ & $3-5(4)$ & $2-3(3)$ & $3-4(3)$ & $2-S$ & $4-7(6)$ \\
\hline 8 & $1-2(1)$ & $21-33(28)$ & $22-30(23)$ & $24-34(29)$ & - & $2-3(2)$ & $1-3(2)$ & $2-3(2)$ & $2-3(2)$ & $2-3(2)$ & $4-6(5)$ & $6-S$ & $2-3(3)$ \\
\hline 9 & $2-4(3)$ & 1 & 1 & 1 & $3-5(5)$ & $5-9(8)$ & $7-10(7)$ & $7-9(9)$ & $6-10(8)$ & $5-8(7)$ & $3-5(4)$ & $7-S$ & $1-2(2)$ \\
\hline 10 & $1-2(1)$ & 1 & 1 & 1 & 1 & $2-4(3)$ & 1 & 1 & 1 & $1-4(3)$ & $5-7(6)$ & 8-S & $2-4(3)$ \\
\hline 11 & $21-29(24)$ & 1 & 1 & 1 & $3-4(3)$ & 1 & $2-4(3)$ & $2-4(3)$ & $2-3(3)$ & $2-3(2)$ & 2 & 9-S & $2-5(3)$ \\
\hline 12 & 2 & 1 & $1-2(1)$ & $2-3(2)$ & $2-5(3)$ & 1 & $2-4(2)$ & $2-4(3)$ & $2-4(3)$ & $1-2(1)$ & 1 & - & - \\
\hline 13 & $4-7(4)$ & $3-6(4)$ & $4-7(5)$ & $2-4(3)$ & $2-5(3)$ & $3-5(4)$ & $2-6(4)$ & $2-4(3)$ & $3-4(3)$ & $4-8(6)$ & $2-4(3)$ & - & - \\
\hline 14 & n.c. & $5-9(7)$ & $5-10(7)$ & - & - & - & - & 1 & 1 & 1 & 1 & 1 & - \\
\hline 15 & $6-10(6)$ & - & - & - & - & - & - & - & - & - & - & - & - \\
\hline
\end{tabular}

n.c. $=$ not counted

abundant in peninsular Malaysia and southern Thailand. Extensive collections carried out in Thailand captured a single male in Ranong Province, above $10^{\circ} \mathrm{N}$ latitude (Scanlon et al. 1967). It was more extensively collected in regions of Thailand south of approximately $8^{\circ} \mathrm{N}$ latitude.

Little is known about the medical and veterinary importance of An. introlatus. Apparently, this species is not involved in the transmission of human Plasmodium (Warren et al. 1963). However, it is vector of simian Plasmodium. Eyles et al. (1963) showed that An. introlatus was a vector of P. cynomolgi in Ulu Gombak area near Kuala Lumpur, Malaysia since when parasites isolated from the salivary glands of naturally infected females were injected into uninfected rhesus monkey R302, they developed malaria. Anopheles introlatus is also involved in the transmission of P. fieldi on the Malayan peninsula. The involvement of An. introlatus in the transmission of simian Plasmodium to humans is not high because this mosquito occurs in low densities, consequently it is more difficult for the mosquito to have contact with both infected monkeys and humans (Warren \& Wharton 1963), and apparently it does not occur in the human environment (Warren et al. 1970). Anopheles introlatus was collected on human biting collections carried out at ground level and in a monkey trap in the forest canopy (Warren \& Wharton 1963; Warren et al. 1970). In Sumatra, Indonesia, females were also collected biting humans in secondary tropical rain forest in an area situated 50 $\mathrm{m}$ above sea level, around $1 \mathrm{~km}$ distant from houses and 1 to 2 $\mathrm{m}$ above ground.

Apparently, An. introlatus prefers shaded seeps and pools, particularly animal wallows as breeding habitats (Warren et al. 1963), but they were also found in rocky stream pools (Scanlon et al. 1967) and aqueducts (Macdonald \& Traub 1960). Immatures were taken from ground pools and wheel ruts in primary tropical rain forest in a mountainous area. The water was fresh, stagnant, in partial shade, at elevations varying from 244 to $610 \mathrm{~m}$ above sea level. Immatures were found in association with Aedes orbitae, An. hackeri Edwards, $C x$. papuensis (Taylor), Cx. halifaxii Theobald and Cx. traubi Colless. In Thailand, immatures were collected in pools along stream margins, in animal hoofprints, rock pools, ground pools, elephant footprints, flood pools, and stream pools with banana leaves in primary tropical rain forest in mountainous areas. The water was fresh, clear or turbid. The breeding places were partially, heavily, lightly shaded, or in full sun, at elevations from 150 to $260 \mathrm{~m}$ above sea level. Immatures of Ae. caecus, Ae. orbitae, An. macarthuri, An. latens, An. pujutensis Colless, An. kochi Dönitz, An. hackeri, Cx. mimulus, Cx. papuensis, $C x$. halifaxii, Cx. scanloni Bram and Ur. bicolor were found associated with An. introlatus.

Systematics. Colless (1957) described and named the Kepong Form of An. leucosphyrus (Colless 1956b) An. balabacensis introlatus, and Peyton (1989) elevated An. introlatus to species status. This species can be recognized by the following combination of characters. Adult: 1) proboscis usually dark-scaled, occasionally with subapical ventral patch of pale scales; 2) proboscis as long as or slightly longer than forefemur, ratio of proboscis length to forefemur length 1.021.11 ; 3 apical pale band of palpomere 5 light cream-colored, bordering to white, not strongly contrasting with pale bands on palpomeres $2-4 ; 4$ ) ASP spot usually extending onto vein C at least on one wing, always present on subcosta vein; 5) hindtarsomere 4 dark-scaled at base; 8) PSD spot of vein R with 1,2 pale interruptions; 6 ) hindtarsomere 5 without basal pale band; 7) hindtarsomere 5 with apical pale band; 8) PSD spot of vein $\mathrm{R}$ usually extending to level 1 , less frequently to level 2 and level 3 at least on one wing, rarely on both wings; 9) wing fringe with pale spot between veins $\mathrm{Cu}_{2}$ and $1 \mathrm{~A} ; 10$ ) fork of cell $\mathrm{R}_{2}$ proximal to fork of cell $\mathrm{M}_{1+2}$;11) 16 cibarial elements. Fourth-instar larva: 1) seta 3-C single; 2) seta 5-C conspicuously longer than antenna; 3) basal sclerotized 
tubercle of seta 1-P with prominent tooth or spine arising from posterodorsal margin; 4) seta 4-C long, always extending noticeably beyond base of 2-C; 5) seta 1 -II moderately developed with distinct moderately broad leaflets, basal stem stout and distinctly inflated; 6) individual leaflets of seta 1-VII with clearly differentiated apicolateral serrations and apical filament. The pupa of An. introlatus is very similar to that of An. balabacensis, however it can be distinguished from $A n$. balabacensis in having the paddle teeth less developed and weaker. Additionally, An. introlatus differs from the remaining species of the Leucosphyrus Complex by possessing seta 9IV long, ratio of length of 9-IV to length of $9-\mathrm{V}$ varying from 0.67-1.03.

\section{Anopheles (Cellia) balabacensis Baisas}

(Figs. 4, 6a,b, 7, 15, 16, 49, 51, 52, 54)

Anopheles leucosphyrus balabacensis Baisas (1936a:65) (F*, M, P*, L*). Lectotype female with associated larval exuviae, LOT R804, deposited in the NMNH. LECTOTYPE DESIGNATION.

Anopheles Balabac species or variety of Russell \& Baisas (1934b:328) (L*, Figs. 27, 31, 33, identification key);

Anopheles balabacensis of Bonne-Wepster \& Swellengrebel (1953:259) (F*, M*, L*, identification key, bionomics, distribution); Senevet \& Andarelli (1955:327, 335) (L notes); Do-Van-Quy (1962b:28, 33) (F, L, identification key); Wattal $(1963: 682,688)(\mathrm{F}, \mathrm{L}$, identification keys); Baisas \& Dowell $(1965: 9,46)\left(\mathrm{F}^{*}, \mathrm{~L}^{*}\right.$, identification keys); Cheng (1967:620) (behavior to DDT spraying); Tsukamoto et al. (1978:39) (vector simian Plasmodium); Kanda et al. (1981:321) (hybridization); Yong et al. (1983:611) (genetic relationship); Ye et al. (1983:48) (vector competence, malaria); Chiang et al. (1984:179) (bionomics); Cheong et al. (1984:19) (natural infection); Hii (1984a:104) (insecticide susceptibility), (1985b:173) (genetic variability, behavior), (1986:125) (morphometry immature stages); Hii et al. (1984:281) (vector W. bancrofti), (1985:93) (bancroftian filariasis, malaria vector), (1988b:689) (protein variability), (1988c:91) (vectorial capacity malaria), (1990:135) (survival rate, oviposition cycle), (1991:675) (genetic population, bionomics); Hii \& Vun (1985:121) (dispersal, survival rate), (1987:67) (host feeding, behavior); Tsukamoto et al. (1985:149) (checklist); Kirnowardoyo (1985:129) (vector human Plasmodium); Pokrovskii et al. (1986:47) (lymphatic filariasis vector); Verdrager (1986:111) (vector human Plasmodium); Harbach et al. (1987b:241) (bionomics); Kirnowardoyo (1988:713) (bionomics notes); Oberst et al. (1988:41) (vector human Plasmodium); Harrison et al. (1990:196) (restricted distribution record); Iwangaga \& Kanda (1990:231) (blood feeding, mating, flight activity); Peyton (1989:197) (taxonomy); Schultz (1992:464) (bionomics), (1993:376) (checklist); Atmosoedjono et al. (1993:390) (vector W. kalimantani); Baird et al. (1996:98) (vector human Plasmodium); Rohani et al. (1999:31) (bionomics); Barcus et al. (2002:287) (malaria vector).

Anopheles balabacensis balabacensis of Colless (1957:131) (F, L, P, distribution); Chow (1961) (F, pictorial identification key); Baisas (1963:697, 700) (F, L, identification keys); Bonne-Wepster (1963:705, 711) (F, L, identification keys); Russell et al. (1963:705) (F, identification key); Reid (1968:291) (F*, M*, cibarial armature*, P*, L*, E*); Miyagi (1973:163) (bionomics); Catangui (1985:190) (bionomics notes); Cagampang-Ramos \& Darsie (1970) (A, L, identification keys); Cagampang-Ramos et al. (1985:1) (distribution, Philippines).

Anopheles leucosphyrus var. balabacensis of Baisas (1936b:214) (P*, identification key), (1938:223) (L, P, A); Simmons \& Aitken (1942:141) (distribution, bionomics notes); Russell et al. (1943:131) (distribution, bionomics notes); Bohart (1945:18) (distribution, identification notes); Colless (1948:100) ( $\mathrm{F}^{*}, \mathrm{M}^{*}, \mathrm{~L}^{*}$, bionomics),
(1950:378) (resurrected from synonymy with An. leucosphyrus), (1956b:43) ( $\mathrm{F}^{*}, \mathrm{~L}^{*}, \mathrm{M}, \mathrm{P}^{*}, \mathrm{E}$, in part); Puri (1949:489, 498) (distribution, bionomics notes, F, identification key); Reid (1949:44) (taxonomy, synonymy An. leucosphyrus); Mendoza (1954) (L, F, pictorial identification key); Koesoemawinangoen $(1954: 63$, 93) (A, identification key); Baisas \& Pagayon (1956:215) (taxonomy, 1st-instar L*, E*).

Anopheles leucosphyrus species group of Miyagi et al. (1994:19) (distribution).

Female (Figs. 4, 6a,b, 7). Head: proboscis dark-scaled, length $1.92-2.28 \mathrm{~mm}$ (mean $=2.08 \mathrm{~mm})$, ratio of length to forefemur 1.01-1.11 (mean=1.06), maxillary palpus (Fig. 7) length $1.62-2.15 \mathrm{~mm}$ (mean $=1.91 \mathrm{~mm})$, ratio of length to proboscis 0.86-0.95 (mean $=0.92)$, ratio of length to forefemur 0.90-1.00 $($ mean $=0.97)($ Table 2.2$)$, ratio of length of palpomeres $3 / 4$ $1.57-2.15($ mean $=1.77), 3 / 52.17-2.67($ mean $=2.41), 4 / 51.08$ $1.62($ mean $=1.36), 4-5 / 30.91-1.08($ mean $=0.99)$, palpomeres 2 4 with narrow apical silvery white bands, all bands similar in size and development, pale scales on palpomere 5 white to whitish, length of apical pale band of palpomere 5 0.67-2.00 $($ mean $=1.20)$ length of basal dark band of palpomere 5, ratio of length of apical pale band of palpomere 4 to length of basal dark band of palpomere 5 0.33-1.28 $($ mean $=0.59)($ Table 3$)$. Thorax: pleural setae as follows: 1-3 upper proepisternal, 0-2 prespiracular, 3-5 prealar, 3-5 upper mesokatepisternal, 1-3 lower mesokatepisternal, 2-4 upper mesepimeral. Wing (Figs. 4, 6a,b): length 3.01-3.67 mm (mean $=3.29)$, pale scales on vein $C$, subcosta and $\mathrm{R}$ light cream-colored to yellowish, those on remaining veins slightly lighter, not strongly contrasting with others; PHP spot of vein C usually small, sometimes absent, HP spot always present, small or prominent, PSP spot always present, small or prominent, SP spot always present, usually prominent, occasionally reduced, ASP spot usually present and prominent, sometimes reduced or absent, PP spot 0.601.50 (mean $=1.05$ ) length of SCP spot, AD spot 1.50-3.33 (mean $=2.09$ ) length of PP spot, PSD spot of vein R extending basally from level 1 to level 4 on one or both wings (Table 4), PSD spot of vein $\mathrm{R}$ with 1,2 pale spots, rarely with 3 pale interruptions on one wing or entirely dark-scaled (Table 5), SD spot of vein $\mathrm{R}$ with 1-4 pale interruptions (Table 6 ), sum of pale interruptions on PSD-PD spots of vein R 2-9 on each wing, ratio of length of cell $R_{2}$ to vein $R_{2+3} 1.60-2.03$ (mean $=1.74$ ), ratio of length of cell $\mathrm{R}_{2}$ to cell $\mathrm{M}_{2+3} 1.26-1.44$ (mean = 1.33). Legs: femora, tibiae and tarsomeres 1 dark-scaled, speckled with spots of pale scales; foretarsomeres 2 and 3 with basal and apical bands of pale scales, foretarsomere 2 with 1,2 pale spots in dark middle area or mostly pale-scaled on dorsal surface, with 1,2 dark spots in middle area, foretarsomere 4 with basal and apical pale bands, sometimes mostly pale-scaled, dark area reduced, foretarsomere 5 dark-scaled with apical pale band, occasionally mostly pale-scaled; midtarsomeres 2,4 mostly dark-scaled with apical pale band sometimes with indistinct basal pale band, midtarsomere 2 sometimes with 1,2 pale spots in dark area, midtarsomere 5 dark-scaled with prominent apical band of pale scales, sometimes indistinct; hindtarsomeres 2 dark-scaled with apical pale band, hindtarsomere 2 sometimes with 1-3 pale spots or entirely dark-scaled at middle dark area, hindtarsomere 
3 dark-scaled with apical pale band, sometimes apical pale band absent, hindtarsomere 4 dark-scaled with apical pale band and short patch of white scales at base of dorsal surface, hindtarsomere 5 dark-scaled with apical pale band. Abdomen: tergum VI usually without scales, rarely with 2,3 narrow, pale scales posterolaterally, tergum VII normally without scales, sometimes with few narrow pale scales posteriorly, tergum VIII covered with elongate, narrow, golden scales; sternum VI usually without scales or with 2-4 pale scales posteromedially, sternum VII with posteromedial patch of dark scales, sternum VIII with anterolateral patches of whitish scales.

Male. Essentially as in female except for sexual characters. Wing generally paler with reduced scaling, pale spots usually longer than in female. Proboscis dark-scaled with narrow palescaled band at apex basal to labella, more distinct on ventral surface; palpomere 2 with dorsal patch of white scales at middle extending to lateral surface, apex of palpomere 2 bare; palpomere 3 with long patch of white scales at middle, extending to ventral surface, apex of palpomere 3 with broad pale-scaled band and small patch of dark scales at apex of ventrolateral surface; palpomeres 4 and 5 mainly pale-scaled with narrow basal band of dark scales, basal dark band of palpomere 5 extending along ventral surface, not reaching apex of segment. Abdomen: sternum VIII covered with pale cream to yellowish scales. Genitalia: 4 large parabasal setae; ventral clapette with 1 long, well-developed apicolateral seta, slightly longer than club of dorsal claspette, 1,2 short, poorly developed apicomedial setae and 1 short, poorly developed subapical seta; dorsal claspette with 3-5 setae fused apically into stout club; aedeagus with 6,7 leaflets, leaflets serrated at least on one edge, sometimes on both.

Pupa (Fig. 15). Position and development of setae as figured; range and modal number of branches in Table 13. All measurements from 35-39 specimens. In general as described for An. leucosphyrus except for the following characters. Cephalothorax: seta 10-CT single to 5-branched. Seta 9-IV-
VIII pigmented light to medium brown. Abdomen: seta 1-II distinct from that of An. leucosphyrus, dendritic, with 13-33 fine branches arising from strong basal stem; 9-II length 0.008$0.016 \mathrm{~mm}($ mean $=0.012 \mathrm{~mm}) ; 1$-III with $7-14$ branches, 5 -III with 7-12 branches, 9-III length 0.01-0.03 mm (mean $=0.02$ $\mathrm{mm}$ ); 1-IV with 5-10 branches, 5-IV with 5-11 branches, 9-IV long, usually without spicules, rarely with spicules, length 0.05-0.09 $\mathrm{mm}($ mean $=0.07 \mathrm{~mm})$, ratios of length of 9-IV/9-III 2.78-6.36 $($ mean $=4.16)$ and 9-IV/9-V 0.46-1.13 (mean =0.80); 1V usually 4-branched, 5-V with 5-9 branches, 9-V long, normally without spicules, rarely with spicules, length $0.07-0.11 \mathrm{~mm}$ $($ mean $=0.09 \mathrm{~mm})$; 1-VI usually triple, 5-VI with 5-9 branches, 9-VI long, length $0.07-0.13 \mathrm{~mm}$ (mean $=0.10 \mathrm{~mm}$ ); 5-VII with 48 branches, 9-VII long, length 0.08-0.12 $\mathrm{mm}$ (mean $=0.10 \mathrm{~mm})$; 9-VIII with 11-17 branches. Paddle: lightly tanned; seta 1-Pa single or double, toothed margin index 0.75-0.98 (mean $=0.84)$.

Larva (Figs. 15, 16, 49, 51, 52). Position and development of branches as figured; range and modal number of branches in Table 14. All measurements from 14-28 specimens unless otherwise indicated. In general as described for $A n$. leucosphyrus except for the following characters. Head: integument light brown to yellowish with 1 darkened spot posteriorly at dorsal apoteme, surrounded by 2 small darkened spots laterally and 2 darkened spots posteriorly; 1 darkened spot between seta 7,8-C along ecdysial line; 1 median darkened spot posterior to insertions of 5-C; 2 poorly defined dark spots on ventral lateralia: 1 spot in area of insertion of $12-\mathrm{C}$ and 1 smaller darkened spot posteriorly; 2 spots on labiogula at level of posterior tentorial pit; length $0.59-0.69 \mathrm{~mm}($ mean $=0.64 \mathrm{~mm})$ $(\mathrm{n}=6)$, width 0.61-0.78 mm $($ mean $=0.69 \mathrm{~mm})(\mathrm{n}=6)$; antenna length $0.25-0.33 \mathrm{~mm}$ (mean $=0.28 \mathrm{~mm})$, ratio of distance base to 1 -A to antenna length $0.28-0.42($ mean $=0.36)$; seta $2-\mathrm{C}$ long and single with spicules on apical 0.5 , these spicules more developed than those of An. leucosphyrus ; 3-C length 0.06$0.09 \mathrm{~mm}($ mean $=0.08 \mathrm{~mm})$, distance between base of $2-\mathrm{C}$ and 3-C 0.02-0.05 $\mathrm{mm}($ mean $=0.04 \mathrm{~mm})$; 4-C always single, length

Table 13. Number of branches for setae of the pupa of An. balabacensis: range (mode).

\begin{tabular}{|c|c|c|c|c|c|c|c|c|c|c|c|}
\hline \multicolumn{2}{|c|}{ Seta Cephalothorax } & \multicolumn{9}{|c|}{ Abdominal segments } & \multirow{2}{*}{$\begin{array}{c}\text { Paddle } \\
\mathrm{Pa}\end{array}$} \\
\hline No. & $\mathrm{CT}$ & I & II & III & IV & $\mathrm{V}$ & VI & VII & VIII & IX & \\
\hline 0 & - & - & 1 & 1 & 1 & 1 & 1 & 1 & 1 & - & - \\
\hline 1 & $2-3(2)$ & n.c. & $13-33(20)$ & $7-14(9)$ & $5-10(7)$ & $2-5(4)$ & $2-4(3)$ & $1-2(1)$ & - & 1 & $1-2(1)$ \\
\hline 2 & $2-3(2)$ & $4-10(7)$ & $5-8(5)$ & $4-7(5)$ & $3-6(3)$ & $3-5(3)$ & $3-5(3)$ & $2-5(3)$ & - & - & $1-3(1)$ \\
\hline 3 & $2-4(3)$ & 1 & $2-5(3)$ & $1-5(3)$ & $6-10(7)$ & $2-4(3)$ & $1-3(2)$ & $2-5(3)$ & - & - & - \\
\hline 4 & $2-4(3)$ & $4-8(5)$ & $3-7(4)$ & $3-5(4)$ & $2-4(3)$ & $3-6(4)$ & $1-4(2)$ & $1-3(2)$ & $1-2(2)$ & - & - \\
\hline 5 & $3-7(5)$ & $2-5(3)$ & $3-5(4)$ & $7-12(8)$ & $5-11(7)$ & $5-9(7)$ & $5-9(6)$ & $4-8(6)$ & - & - & - \\
\hline 6 & $1-3(2)$ & $2-3(2)$ & $1-3(2)$ & $1-3(2)$ & $1-2(1)$ & $1-2(1)$ & $1-2(1)$ & $1-3(1)$ & - & - & - \\
\hline 7 & $3-5(4)$ & $3-6(5)$ & $2-5(4)$ & $2-5(3)$ & $2-6(3)$ & $2-6(3)$ & $1-2(1)$ & $1-2(2)$ & - & - & - \\
\hline 8 & $1-3(1)$ & - & - & $2-4(3)$ & $2-4(3)$ & $1-3(2)$ & $1-3(2)$ & $1-4(3)$ & - & - & - \\
\hline 9 & $2-4(3)$ & 1 & 1 & 1 & 1 & 1 & 1 & 1 & $11-17(13)$ & - & - \\
\hline 10 & $1-5(3)$ & - & - & $1-4(2)$ & $1-2(1)$ & $1-3(1)$ & $1-3(2)$ & $1-4(3)$ & - & - & - \\
\hline 11 & $1-4(2)$ & - & - & 1 & $1-2(1)$ & 1 & 1 & $1-3(2)$ & - & - & - \\
\hline 12 & $1-4(3)$ & - & - & - & - & - & - & - & - & - & - \\
\hline 13 & $1-2(1)$ & - & - & - & - & - & - & - & - & - & - \\
\hline 14 & - & - & - & - & 1 & 1 & 1 & 1 & 1 & - & - \\
\hline
\end{tabular}

n.c. $=$ not counted 
0.06-0.09 $\mathrm{mm}$ (mean $=0.08 \mathrm{~mm})$, extending to base of 2-C, distance between basal insertions of 2-C and 4-C 0.06-0.08 mm (mean $=0.08 \mathrm{~mm}$ ), ratio of length of $4-\mathrm{C}$ to distance between insertions of 2-C and 4-C 0.83-1.32 (mean $=1.05)$, distance between base of 3-C and 4-C 0.05-0.08 $\mathrm{mm}$ (mean $=0.07 \mathrm{~mm}$ ), 5$\mathrm{C}$ extending beyond anterior margin of head, with 9-15 branches, 7-C with 12-17 branches. Thorax: tubercles of all large setae medium brown to yellowish; seta 1-P arising from large tubercle, tubercle of 1-P broadly joined to tubercle of 2,3$\mathrm{C}$ basally, tubercles of 1-P and 2-P with strong apical blunt spine arising from posterodorsal margin, projecting over base of each seta, 14-P with 4-8 branches; 3-T (Fig. 52) more developed than that of An. leucosphyrus. Abdomen: seta 1-I more developed than that of An. leucosphyrus, palmate, with 4-11 leaflets; 1-II (Fig. 51) moderately developed, equally pigmented as seta 1-I, palmate, with 9-18 leaflets, basal stem moderately developed, slightly more pigmented than leaflets; 13-IV with 2,3 branches, ratio of length to 10-IV 0.50-0.86 (mean $=0.67$ ); seta 1 -VII with long and narrow leaflets, leaflet tapered to apex, ending in long slender apical filament, without apicolateral serrations; pecten spines (Fig. 49) 11-14 with 3-5 long spines alternating with 6-10 short spines.

Type data. Baisas (1936a) restricted the use of the name An. leucosphyrus for specimens from Luzon, Phillipines and proposed An. leucosphyrus var. balabacensis for specimens found in Palawan and Balabac, Philippines. He selected a composite type series consisting of 1 male (LOT R80-34), 1 female (LOT R80-12), both with associated larval exuviae and an unspecified number of cotypes. All specimens were deposited in the Bureau of Health, Manila, Philippines. Four specimens of the type series were transferred to the NMNH, 1 male R80-22 with associated larval exuviae, 1 female R80-4 with associated larval exuviae, 1 male LOT80-13 (ACC\#686) and 1 female LOT80-9 (ACC\#686), all collected in Balabac
Island, June 1934. Since Baisas (1936a) selected more than one type specimen "The type specimens of .." and cotypes (page 65), the specimens are syntypes. The specimens LOTR8034 and LOTR80-12, Baisas (1936a) designated as "the types" have been considered to be in an unknown locality by Knight \& Stone (1977) and were not found in the NMNH. Knight \& Stone (1977) considered the four specimens deposited in the NMNH to be paratypes of An. balabacensis, however all the evidence shows that Baisas (1936a) did not select the holotype, thus the designation of paratypes is incorrect. Since there is no holotype and four syntypes are deposited in the NMNH, we are designating the female R80-4 as the lectotype of $A n$. balabacensis, and consequently the specimens LOT80-9, LOT80-13 and R80-22 are paralectotypes. Designation of the lectotype is essential for maintaining stability of the name $A n$. balabacensis, which has been widely confused with other species of the Leucosphyrus Group.

Material examined. Five hundred fifty-eight specimens as follow: $212 \mathrm{~F}, 90 \mathrm{M}, 104 \mathrm{Le}, 123 \mathrm{Pe}, 29 \mathrm{~L}$, derived from 80 separate collections from natural habitats (26 adults, 54 immatures). BRUNEI. Central (4³0'N 114³0'E), 1951, 2F (D.H.Colless).INDONESIA.BonneWepster specimens, no localities, no dates, [collection numbers: 13 00, 13-01, 13-08, 13-09], probably Kalimantan, 2F, 2M. Java: Purwakarta $\left(6^{\circ} 34^{\prime}\right.$ 'S $107^{\circ} 26^{\prime}$ E), 8 Mar. 1978, 2F. Jogjakarta, Sudimoro (7055'S 110²6'E), [30/12], 1 Le (Det. D.H. Colless). Kalimantan: (Borneo) (Bonne-Wepster), no other data, 2 F. Balikpapan $\left(1^{\circ} 17^{\prime}\right.$ 'S 116 $\left.{ }^{\circ} 50^{\prime} \mathrm{E}\right)$, [13-10], 1M (Bonne-Wepster). Salaman, Kintap, kilometer 18, (35'ㅇ $\left.115^{\circ} 13^{\prime} \mathrm{E}\right),[1-55], 1989,37 \mathrm{~F}, 7 \mathrm{M}, 39 \mathrm{LePe}, 5 \mathrm{Pe}$ (M. Bongs). Kalimantan Timur, Kilometer 28, Samarinda-Balikpapan Road $\left(0^{\circ} 43^{\prime} \mathrm{S} 117^{\circ} 1^{\prime} \mathrm{E}\right), 23-27$ Mar. 1978, 4F. Lombok: Senaru (8²1'S $116^{\circ} 21^{\prime} \mathrm{E}$, approximate), [911225-3], Oct. 1991, 1F (I. Miyagi and T. Toma). Suranadi ( $\left.8^{\circ} 45^{\prime} \mathrm{S} 116^{\circ} 30^{\prime} \mathrm{E}\right)$, [L\#6], 1 Mar. 1975, 1F (Y. Wada) Malaysia (East). Wilayah Persekutuan Labuan: (5¹9’ $\left.115^{\circ} 13^{\prime} \mathrm{E}\right)$, Feb. 1949, 1M; June, 1950, 1LePe (D.H. Colless). Pulau Banggi [Island] $\left(7^{\circ} 17^{\prime} \mathrm{N} 117^{\circ} 12^{\prime} \mathrm{E}\right)$, [S-708], 2 May 1970, 1F, 1Pe (S. Ramalingam). Pulau Gaya [Island]: (4'37’N 118 45'E), [S-38A], 15 Mar. 1970, 3LePe, 2L; [S-38C], 15 Mar. 1970, 8F; [S-43], 15 Mar. 1970, 1F, 3M, 1LePe,

Table 14. Number of branches for setae of the fourth-instar larva of An. balabacensis: range (mode).

\begin{tabular}{|c|c|c|c|c|c|c|c|c|c|c|c|c|c|}
\hline \multirow{2}{*}{$\begin{array}{l}\text { Seta } \\
\text { No. }\end{array}$} & \multirow{2}{*}{$\begin{array}{c}\text { Head } \\
\text { C }\end{array}$} & \multicolumn{3}{|c|}{ Thorax } & \multicolumn{9}{|c|}{ Abdominal segments } \\
\hline & & $\mathrm{P}$ & $\mathrm{M}$ & $\mathrm{T}$ & I & II & III & IV & $\mathrm{V}$ & VI & VII & VIII & $\mathrm{X}$ \\
\hline 0 & 1 & 1 & - & - & - & 1 & 1 & 1 & 1 & 1 & 1 & 1 & - \\
\hline 1 & 1 & $11-19(13)$ & $25-29(25)$ & $1-2(1)$ & $4-11(6)$ & $9-18(10)$ & $17-20(19)$ & $16-21(18)$ & $16-19(18)$ & $15-19(17)$ & $9-16(14)$ & 1 & 1 \\
\hline 2 & 1 & $9-13(10)$ & $2-5(3)$ & 1 & $1-2(2)$ & $1-8(6)$ & $4-7(5)$ & $3-4(3)$ & $3-4(3)$ & $3-4(4)$ & $3-7(6)$ & $4-7(5)$ & $16-20(18)$ \\
\hline 3 & 1 & 1 & 1 & $3-7(6)$ & $1-3(1)$ & 1 & 1 & $2-3(2)$ & 1 & 1 & $2-3(3)$ & $5-8(6)$ & $10-12(12)$ \\
\hline 4 & 1 & $12-16(13)$ & $2-3(2)$ & $3-4(3)$ & $4-5(5)$ & $3-7(5)$ & $2-3(3)$ & $2-3(3)$ & $2-3(3)$ & 1 & 1 & 1 & $8-9(9)$ \\
\hline 5 & $9-15(10)$ & n.c. & 1 & $29-34$ & $2-3(3)$ & $4-6(5)$ & 3 & 3 & $3-5(3)$ & $4-5(4)$ & $3-5(4)$ & $3-4(3)$ & - \\
\hline 6 & $12-17(13)$ & 1 & $2-5(4)$ & $1-4(3)$ & 19 & $21-23$ & 11,12 & $2-3(2)$ & $2-3(2)$ & $2-3(3)$ & $2-5(4)$ & $1-S$ & $3-6(4)$ \\
\hline 7 & $12-17(13)$ & $19-23(19)$ & $2-4(3)$ & 24 & 13 & 19,20 & $3-5(4)$ & $3-5(4)$ & $3-5(4)$ & $2-3(2)$ & 3 & $2-S$ & $3-6(4)$ \\
\hline 8 & 1 & $18-21(18)$ & $18-30(18)$ & 25,26 & - & $1-2(1)$ & $1-2(1)$ & $1-2(2)$ & $2-3(2)$ & $1-2(2)$ & $2-5(4)$ & $6-\mathrm{S}$ & $2-3(2)$ \\
\hline 9 & $1-3(2)$ & 1 & 1 & 1 & $3-5(3)$ & $5-10(6)$ & $5-8(6)$ & $5-8(6)$ & $5-6(5)$ & $4-7(5)$ & $3-4(4)$ & $7-S$ & $1-2(2)$ \\
\hline 10 & $1-2(2)$ & 1 & 1 & 1 & 1 & $2-3(2)$ & 1 & 1 & 1 & $2-4(3)$ & $4-6(4)$ & 8-S & $2-3(2)$ \\
\hline 11 & $16-29$ & 1 & 1 & 1 & $2-3(3)$ & 1 & $2-3(2)$ & $2-3(3)$ & 2 & 2 & $1-2(2)$ & 9-S & $2-4(3)$ \\
\hline 12 & $1-3(2)$ & 1 & 1 & $2-3(2)$ & $3-4(3)$ & 1 & 2 & 2 & $1-2(2)$ & $1-2(1)$ & 1 & - & - \\
\hline 13 & $1-6(3)$ & $4-6(5)$ & $3-5(3)$ & $2-3(3)$ & $2-5(3)$ & $3-4(4)$ & $3-5(4)$ & $2-3(3)$ & 3 & $4-7(5)$ & $2-3(2)$ & - & - \\
\hline 14 & n.c. & $4-8(6)$ & $4-6(5)$ & - & - & - & - & 1 & 1 & 1 & 1 & 1 & - \\
\hline 15 & $3-5(4)$ & - & - & - & - & - & - & - & - & - & - & - & - \\
\hline
\end{tabular}

n.c. $=$ not counted 
1Pe, 3L; [S-45], 15 Mar. 1970, 2F, 2M, 2LePe, 3Pe (S. Ramalingam). Sabah: Mt. Kinabalu (6 $\left.{ }^{\circ} 5^{\prime} \mathrm{N} 116^{\circ} 33^{\prime} \mathrm{E}\right)$, [S-211], 2 Apr. 1970, 1L; [S216], 2 Apr. 1970, 1LePe; [S-217], 2 Apr. 1970, 1L (S. Ramalingam). Keningau ( $\left.5^{\circ} 20^{\prime} \mathrm{N} 116^{\circ} 10^{\prime} \mathrm{E}\right), 14$ July 1950, 2F (J.A. Reid); 20 Sept. 1960, 1F (F.Y. Cheng). Keningau, Kampong Liawan (5'23'N 116 ${ }^{\circ}$ 'E), [S-580], 18 Apr.1970, 1F; [S-576], 18 Apr. 1970, 1F, 1Pe (S. Ramalingam). Kudat (6 $\left.6^{\circ} 53^{\prime} \mathrm{N} 116^{\circ} 50^{\prime} \mathrm{E}\right)$, [334], 16 May 1966, 1F.

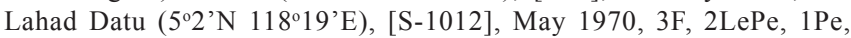

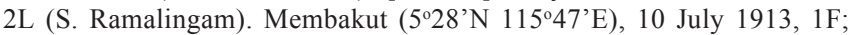
16 July 1913, 1F (R. Roper); Nawao (vicinity of Membakut?), 27 July 1913, 3F; 14 Aug. 1913, 1F; 1914, 1M (R. Roper). Papar, Lingan (53'ㅅ $\left.115^{\circ} 59^{\prime} \mathrm{E}\right)$, [LP-8, 83], 2 July 1979, 21F, 9M, 30LePe (J. Hii).

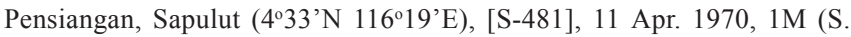

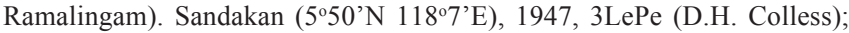
[S-806], 10 May 1970, 3F, 2LePe; 34 mile Tepulid Road, [S-818], 10 May 1970, 2F, 1LePe, 1Pe, 3L; Kampong Sim Sim, [S-908], 16 May 1970, 1F, 2L (S. Ramalingam). Tambunan (540'N $\left.116^{\circ} 22^{\prime} \mathrm{E}\right), 1949$, 49F, 48M, 5L; June 1950, 2F, 1M (D.H. Colless); Tawau $\left(4^{\circ} 15^{\prime} \mathrm{N}\right.$ $\left.117^{\circ} 54^{\prime} \mathrm{E}\right), 23$ June 1960, 1F (F.Y. Cheng); Tawau, Mt. Tiger $\left(4^{\circ} 25^{\prime} \mathrm{N}\right.$ 117 $\left.{ }^{\circ} 44^{\prime} \mathrm{E}\right)$, [S-1063], 28 May 1970, 2F, 1LePe, 2L; [S-1117], 30 May 1970, 7F (S. Ramalingam). Timbua, Ranau (6 $\left.{ }^{\circ} 29^{\prime} \mathrm{N} 116^{\circ} 44^{\prime} \mathrm{E}\right)$, [343],

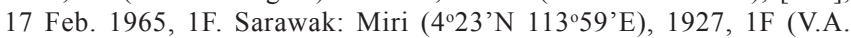
Stookes). PHILIPPINES ISLANDS. Balabac: (Central, $\left.7^{\circ} 57^{\prime} \mathrm{N} 117^{\circ} 1^{\prime} \mathrm{E}\right)$, 23 Nov. 1970, 4F (I. Miyagi); [Lot 80], June 1934, 2F, 2M, 2Le (F.E. Baisas); [LotR-77], 15-24 June 1934, 1F, 4Pe (F.E. Baisas and P.F.

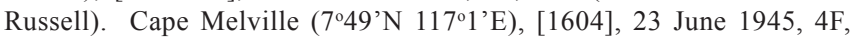
1LePe, 1L; [1610], 23 June 1945, 1F, 1LeP. Culion: Pilapil (11 ${ }^{\circ} 50^{\prime} \mathrm{N}$ $\left.119^{\circ} 55^{\prime} \mathrm{E}\right)$, [1506], 20 June 1945, 1M, 1LeP. Palawan: 2 Nov. 1981, 1F; 3 Dec. 1981, 1F; 16-26 Oct. 1982, 1F (I. Miyagi and T. Toma). Balahahan River (9 $\left.9^{\circ} 5^{\prime} \mathrm{N} 118^{\circ} 41^{\prime} \mathrm{E}\right)$, [889], 13 June 1945, 3F, 3LePe; [890A], 13 June 1945, 1L. Irahan River ( $\left.9^{\circ} 47^{\prime} \mathrm{N} 118^{\circ} 42^{\prime} \mathrm{E}\right)$, [840], 2 June 1945, 1F, 3M, 2LePe, 1Pe; [841], 2 June 1945, 2F, 1LePe, 1Pe; [842], 2 June 1945, 1F, 1M; [845], 2 June 1945, 3F, 1M, 3LePe, 1Le; [861], 4 June 1945, 1LePe; [882], 11 June 1945, 1L. Iwahig ( $8^{\circ} 36^{\prime} \mathrm{N}$ $\left.117^{\circ} 32^{\prime} \mathrm{E}\right),[\mathrm{R}-66], 19$ June 1934, 2F. Panitian, Quezon $\left(9^{\circ} 5^{\prime} \mathrm{N}\right.$ $\left.118^{\circ} 5^{\prime} \mathrm{E}\right),[1-22,-38,-51,-52,-56,-60,-69,-100]$, May $1967,5 \mathrm{~F}$, 3M, 1LePe, 4Pe; May 1967, 5F. Puerto Princesa (944'N 118 $44^{\prime} \mathrm{E}$ ), 14 Mar. 1972, 5F; [P283], 14 Sept. 1945, 1F; [P288], 14 Sept. 1945, 1L; [P305], 18 Sept. 1945, 1L; [P341], 27 Sept. 1945, 2L; [P378], 11 Oct. 1941, 1M; [P520], 15 Sept. 1945, 1L. Mt. Molinao $\left(9^{\circ} 30^{\prime} \mathrm{N}\right.$ 11803ㅌ), [2/49-58], May 1967, 1M; [2/64-65], May 1967, 1M; [3/ 1-4], May 1967, 1F.

Distribution (Fig. 54). Anopheles balabacensis is known from Brunei, Indonesia (Java, Kalimantan (Borneo), Lambok), east Malaysia (Labuan, Pulau Banggi, Pulau Gaya, Sabah, Sarawak), Philippine Islands (Balabac, Culion, Palawan).

Bionomics and medical importance. Anopheles balabacensis is considered the main vector of human Plasmodium in northern Borneo, Indonesia (Peters et al. 1976; White 1983; Hii et al. 1985; Hoedojo 1989), in Sabah and Sarawak, East Malaysia (Hii 1980; Hii \& Vun 1985; Hii et al. 1988c), Banggi (Hii et al. 1985), in hillside forest in central Java (Baird et al. 1996), in Menoreh Hills and forested foothills of Dieng Plateau of central Java, Indonesia (Barcus et al. 2002). Additionally, it is a secondary vector of human Plasmodium in Palawan, Philippine Islands (Shultz 1992). Harbach et al.(1987b) found one specimen of An. balabacensis positive for sporozoites of P. falciparum using ELISA and the infection rate was $1.3 \%$ in South Kalimantan, Indonesia. In two small isolated forest communities and coastal villages on Banggi Island and Sabah, East Malaysia, where malaria is holoendemic, An. balabacensis is the most important vector of human malaria parasites. Females are highly anthropophilic and survive long enough to reach infectivity for $P$. falciparum, and the estimated vectorial capacity varied from 1.44 to 19.7 in Kapitangan and from 7.44 to 9.97 in P. Darat (Hii et al. 1988c). In addition, evidence shows that An.balabacensis is the most important vector of simian Plasmodium in Palawan, Philippine Islands (Tsukamoto et al. 1978). This species was demonstrated to be highly susceptible to $P$. inui with a gut infection rate of $98.02-100 \%$ and all salivary glands were intensively infected (Ye et al. 1983). Also, in eastern Sabah, An. balabacensis was demonstrated to be competent to transmit $P$. pitheci and $P$. silvaticum among orangutan, Pongo pygmaeus (Linnaeus) in the dipterocarp forest. Females were attracted to both orangutan and humans (Peters et al. 1976). Anopheles balabacensis is also involved in the transmission of Brugia malayi, Wuchereria bancrofti and Brugia timori (Pokrovskii et al. 1986), Wuchereria kalimantani in East Kalimantan, Indonesia (Atmosoedjono et al.1993), W. bancrofti in Sabah, East Malaysia (Hii et al.1984) and in upper Kanibatangan, Banggi, East Malaysia (Hii et al.1985). Females were also found naturally infected with Brugia (probably B. malayi) (Cheong et al. 1984).

In Palawan, Philippine Islands, An. balabacensis was demonstrated to be endophagic (bites indoors) and anthropophilic, and primarily active between 2000-00300 h (Schultz 1992). In Sabah, it was mainly exophagic (bites outdoors) but could also feed indoors and rest outdoors (exophilic). Also, there were two distinct subpopulations, one more zoophilic and the other more anthropophilic and females could feed on both humans and water buffalo. Also, the activity peaked from 2200 to 0200 h (Hii 1985b; Hii \& Vun 1987; Hii et al. 1990; Hii et al.1991). Genetic variation was found between endophilic and exophilic subpopulations using isozyme loci. Genetic heterozygosity for the isozyme loci examined was greater in exophilic than in endophilic subpopulations (Hii et al. 1991). Miyagi (1973) found that females were attracted to humans, monkey and carabao (water bufallo) but they were more frequently caught in monkey traps. Also, $29 \%$ of females attracted to monkeys were positive for oocysts and $12.5 \%$ for sporozoites. In a capture-release-recapture study carried out in a fringe area of mixed secondary tropical forest with rubber, rice and nipah palm patches in Lingan, Papar District, Sabah, East Malaysia, the daily survival rate of An. balabacensis varied from 0.719 to 0.787 , and the recovery rates of marked mosquitoes were $16.1 \%$. The dispersion was nearly random and about $112 \mathrm{~m}$ within the forest fringe. The estimated survival rate was 13 days after emergence during the inter-mansoon season (Hii \& Vun 1985). In South Kalimantan, Indonesia, An. balabacensis comprised $97.7 \%$ of total number of mosquitoes collected outside houses and it was more frequent in human biting collections carried out in villages than inside the forest (Harbach et al. 1987b). Chiang et al. (1984) noted that the peak activity of An. balabacensis in Pantai and two neighbouring villages in Sabah was shortly after midnight. Similarly, Hii (1985b) found that the peak biting was from 2200-0200 h. Additionally, An. balabacensis was collected with CDC light traps 2-10 m above ground level, both with and without $\mathrm{CO}_{2}$, 
in forested areas about $300 \mathrm{~m}$ above sea level. Laboratory studies showed that mated females of An. balabacensis were more easily attracted to a blood source than unmated females and therefore insemination may induce biting behavior (Iwangaga \& Kanda 1990). Since An. balabacensis is predominantly exophilic, using DDT and fenitrothion to control this species may be not very effective, especially because only part of the population will be affected (Hii 1984a).

Immatures breeds at the edges of swamps, rarely in slowmoving stretches of streams, mostly in rock pools along stream margins and in temporary roadside ground pools during the rainy months. The habitats were under heavy shade inside the forest or under roadside shrubs (Kirnowardoyo 1988). Larvae were also taken from temporary open ground pools, carabao footprints, roadside excavations and ditches (Miyagi 1973). Additionally, immatures were taken from rock pools along stream in mountainous, forested areas $600 \mathrm{~m}$ above sea level. In East Malaysia, immatures were taken from ground pools, ground pools beside river margins, rock pools, wheel tracks, buffalo hoofprints, and puddles, in villages and the forest. The breeding places were in either hilly areas or in valleys. The water was fresh, stagnant, clear, or colored, in partial shade or full sun, at elevations up to $518 \mathrm{~m}$ above sea level. The immatures were found in association with Ve. andamanensis (Edwards), Ve. johnsoni (Laffoon), An. macarthuri, An. saungi Colless, Cx. quadripalpis (Edwards), Cx. halifaxii, Cx. bengalensis Barraud, Cx. foliatus Brug., Cx. malayi (Leicester), Cx. mimulus, Cx. pseudovishnui Colless, Ur. lateralis Ludlow, Ur. bicolor, and Ur. campestris Leicester. In the Philippine Islands, the breeding places were situated in both well preserved forest areas and in human environments. In dense forested areas, immatures were found in large ground pools near streams, half barrel, rock holes, and road ruts, whereas in areas impacted by human activities the breeding places were sunny grassy fields with some algae, ruts and puddles in roads, coconut shells in the shade, top of oil drums in the shade, and in large packing containers. Additionally, immatures were taken from a large metal-lined box, a sunlit truck rut, muddy sunlit pools, rain-filled rock depressions, wooden buckets, densely shaded seepages, sunlit stream pools, and ground pools.

Systematics. Anopheles balabacensis was described by Baisas (1936a) based on specimens collected in Balabac, Balabac Island, Philippine Islands. It was considered a subspecies of either An. leucosphyrus or An. balabacensis by several authors. Phylogenetic relationships and morphological comparisons of seven populations of members of the Leucosphyrus Group showed that An. balabacensis was not distinct from An. dirus at the species level (Kanda et al. 1983). Similarly, Yong et al. (1983) used a 15 gene-enzyme system to examine genetic diversity in three taxa of the Leucosphyrus Group, one from Thailand, one from Perlis, and $A n$. balabacensis from Sabah, East Malaysia. They observed that An.balabacensis was monomorphic for all 15 loci tested and that there was no unique gene-enzyme marker to separate it from the other two taxa. They concluded that the genetic distances indicated that the three groups were subspecies of the same species. In contrast, HII (1985a) using polytene chromosome banding pattern and cross-mating experiments found that An. balabacensis from Sabah was distinct from both An. dirus (Thailand population of YONG et al. 1983) and An. cracens (Perlis population of YONG et al. 1983) with genetic differences in the autosomes and X chromosomes. HII (1986) using a discriminant analysis tested morphological characters of the larva and pupa of the same three populations above to show that An. dirus, An. cracens, and An. balabacensis were distinct biological species.

Anopheles balabacensis can be recognized by the following combination of characters. Adult: 1) proboscis nearly as long as forefemur, ratio of proboscis length to forefemur length 1.01-1.11 (mean=1.06); 2) PSD spot of vein R never extending beyond level 4, most frequently to level 1-3; 3 ) PSD spot of vein R usually with 1 or 2 , rarely 3 pale interruptions; 4) PD usually with 1-3, rarely 4 pale interruptions; 5) ASP spot usually present on vein $C$, always present on subcosta and R; 6) dark spot of vein $R$ basal to split of vein $R_{s}$ reduced when compared to ASP and SP of vein R, often absent because SP and ASP are fused; 7) wing fringe between apex of veins $1 \mathrm{~A}$ and $\mathrm{Cu}_{2}$ mostly dark, except for pale scales at apex of $\left.\mathrm{Cu}_{2} ; 8\right)$ pale scales of wing cream-colored to yellow to golden, without white scales, including scales on PSP and SP spots; 9) apical pale band on palpomere 5 whitish to white; 10) hindtarsomere 4 with patch of white scales at base of dorsal surface. Fourth-instar larva: 1) seta 3-C single; 2) seta 4-C single, ratio of length of 4-C to distance between the insertions of 2-C and 4-C 0.83-1.32; 4) seta 5-C conspicuously longer than antenna; 5) basal sclerotized tubercle of seta 1-P with prominent tooth arising from posterodorsal margin; 6) tubercle of seta 1-P broadly joined to tubercle of setae $2,3-\mathrm{C}$; 7) seta 1II moderately developed, less developed than seta 1-III-VI, with distinct splayed, narrow, lanceolate leaflets arising from expanded basal stem; 8) seta 2-IV,V with 3,4 branches. The pupal stage of An.balabacensis can be distinguished from those of An.leucosphyrus, An. latens, and An.baisasi, but not An. introlatus, by the following characters: 1) seta 9-IV long, length $0.05-0.09 \mathrm{~mm}$ (mean $=0.07 \mathrm{~mm}$ ), ratio of length of 9-IV to length of 9-V 0.46-1.13 (mean =0.80). Based on the specimens examined, the pupa of An. balabacensis can be separated from that of An. introlatus in having the paddle marginal teeth more developed and stronger.

\section{Without Complex Assignment To Complex}

Anopheles (Cellia) baisasi Colless

(Figs. 4, 7, 17, 18, 49, 52, 54)

Anopheles balabacensis baisasi colless (1957:137) (F, P, L). Holotype female with associated larval and pupal exuviae on separate microscope slides, deposited in the NHM.

Anopheles balabacensis baisasi of Chow (1961) (distribution, pictorial identification key); Baisas (1963) in Russell et al. (1963:697) (F, identification key); Baisas \& Dowell $(1965: 10,41,44)\left(\mathrm{F}^{*}, \mathrm{~L}^{*}\right.$, identification keys); Cagampang-Ramos \& Darsie (1970:4) (F*, $\mathrm{L}^{*}$, identification keys); Cagampang-Ramos et al. (1985:1) 
(distribution); Tsukamoto et al. (1985:149) (checklist).

Anopheles baisasi of Peyton (1989:197) (taxonomy).

Anopheles leucosphyrus of Baisas (1932:254, 256) (L, A), (1936a:84) (cibarial armature, Fig. 15.1, bionomics, in part, Luzon),(1936b:214) (P*),(1938:223) (L, P, A),(1946:27) (distribution); Russell \& Baisas (1934a:300) (bionomics, in part, Luzon), (1934b:328) (L*, Figs. 14, 29F, 32(10), larval key, in part, Luzon), (1936:38) (F*, $\mathrm{M}^{*}$, in part, Luzon, Plate 12, Plate 31-12);

Anopheles leucosphyrus leucosphyrus of Bohart (1945:18) (Philippine Island, Luzon); Cook (1954:79) (L, A, F, pictorial identification key).

Anopheles leucosphyrus Luzon form of Reid (1949:48) (taxonomic notes); Baisas \& Pagayon (1956:216) (E); Colless (1956b:60) (F, $\left.\mathrm{P}, \mathrm{L}^{*}\right)$.

Female (Figs. 4, 7). Head: proboscis uniformly dark-scaled, length $1.64-2.03 \mathrm{~mm}$ (mean $=1.81 \mathrm{~mm})$, ratio of length to forefemur 1.03-1.12 (mean=1.06), maxillary palpus (Fig.7) length $1.49-1.83 \mathrm{~mm}($ mean $=1.65 \mathrm{~mm})$, ratio of length to proboscis length 0.88-0.94 (mean $=0.91)$, ratio of length to forefemur length 0.93-1.00 $($ mean $=0.97)($ Table 2.2$)$, ratio of length of palpomeres $3 / 41.82-2.00($ mean $=1.88), 3 / 52.40-2.75($ mean $=$ $2.70), 4 / 51.22-1.57($ mean $=1.40), 4-5 / 30.82-1.00($ mean $=0.92)$, palpomeres 2-4 with narrow apical silvery-white bands, all bands similar in development, pale scales on palpomere 5 pale golden to cream-colored, length of apical pale band of palpomere 5 varying from $0.33-3.00($ mean $=1.12)$ length of basal dark band of palpomere 5 , ratio of length of apical pale band of palpomere 4 to length of basal dark band of palpomere 5 varying from $0.14-1.67($ mean $=0.57)($ Table 3$)$. Thorax: pleural setae as follow: 1-3 upper proepisternal, 1,2 prespiracular, 4-6 prealar,3-5 upper mesokatepisternal, 1,2 lower mesokatepisternal, $2-5$ upper mesepimeral. Wing (Fig. 4): length 2.81-3.67 $\mathrm{mm}$ (mean $=3.29 \mathrm{~mm})$, pale scales on all veins light cream-colored, bordering to whitish, pale spots not strongly contrasting with others; $\mathrm{PH}, \mathrm{HP}$ and PSP spots of vein C always present, usually prominent, occasionally reduced, SP spot prominent, ASP spot usually absent except for few pale scales present on one wing of 2 specimens, always present and prominent on subcosta and $\mathrm{R}$ veins, $\mathrm{PP}$ spot $0.92-2.00$ (mean $=$ 1.17) length of SCP spot, AD spot 1.35-2.73 (mean=2.12) length of preapical pale spot, PSD spot of vein R extending basally from level 2 to level 5 at least in one wing (Table 4), PSD spot of vein $\mathrm{R}$ with 1-4 small pale interruptions (Table 5), SD of vein $R$ with 1-3 pale interruptions (Table 6 ), sum of pale interruptions on PSD-PD spots of vein R varying from 6-8 for each wing; ratio of length of cell $\mathrm{R}_{2}$ to vein $\mathrm{R}_{2+3} 1.15-1.76($ mean $=1.36$ ), ratio of length of cell $\mathrm{R}_{2}$ to cell $\mathrm{M}_{1+2} 1.05-1.63$ (mean = 1.13). Legs: femora, tibiae and tarsomeres 1 dark-scaled, speckled with spots of pale scales; foretarsomeres 2,3 with small basal and apical incomplete pale bands, foretarsomere 2 with 1,2 middle pale spots on dorsal and anterior surfaces, occasionally with long basal pale spot, extending to basal 0.5 , foretarsomere 4 with small dorsobasal incomplete band of pale scales, rarely with small dorsoapical patch of pale scales, foretarsomeres 24 dark-scaled on most of ventral and posterior surfaces, foretarsomere 5 entirely dark-scaled; midtarsomeres 2-4 mostly dark-scaled with small patch of pale scales at apex of posterior surface, midtarsomere 5 dark-scaled; hindtarsomeres 2-4 darkscaled with narrow apical pale band, hindtarsomere 5 darkscaled. Abdomen: tergum VI without scales, tergum VII with few apical pale scales, tergum VIII with sparse posteromedial patch of narrow elongate, pale cream-colored scales; sternum VI without scales, sternum VII with a small, posteromedial patch of narrow dark scales, sternum VIII with small, sparse, anterolateral patches of narrow elongate whitish scales.

Male. Essentially as in female except for sexual characters. Wing generally paler with reduced scaling, pale spots usually longer than in female. Palpomere 2 with dorsal patch of pale scales at middle, extending laterally, apex of palpomere 2 bare; palpomere 3 with long dorsal patch of pale scales at middle, extending laterally, apex of palpomere 3 with broad apical band of pale scales covering dorsal, lateral and ventral surfaces except for small patch of dark scales at apex of ventral surface; palpomeres 4 and 5 mainly pale-scaled with narrow basal band of dark scales, basal dark band of palpomere 5 projecting into ventral surface, not reaching apex of segment. Abdomen: sternum VIII covered with pale cream-colored to yellowish scales. Genitalia: 4 large parabasal setae; ventral clapette with 1 long apicolateral seta, 1 short, poorly developed apical seta arising medially, and 1 short, poorly developed subapical seta; dorsal claspette with 3,4 setae fused apically into club with distinct basal stems; aedeagus with 7,8 leaflets on each side of tip, leaflets serrated in one, or occasionally, both edges.

Pupa (Fig. 17). Range and modal number of branches in Table 15. All measurements from 7,8 specimens. In general as described for An. leucosphyrus except for the following characters. Cephalothorax: seta 5-CT with 3-6 branches, 7-CT with 2-5 branches, 9-CT single or double, 11-CT single to triple, 12-CT usually single. Abdomen: seta 7-I with 2-4 branches; 1 II dendritic, with 14-27 fine branches, 8-II absent, 9-II length $0.010-0.015 \mathrm{~mm}$ (mean $=0.012 \mathrm{~mm}$ ), 10,11-II absent; 9-III length $0.01-0.02 \mathrm{~mm}$ ( mean $=0.02 \mathrm{~mm}$ ); 6-IV always single, 9-IV length $0.02-0.04 \mathrm{~mm}$ (mean $=0.03 \mathrm{~mm}$ ), ratios of length of 9-IV/9-III 1.39-2.11 (mean =1.64) and 9-IV/9-V 0.22-0.50 (mean=0.32); 1$\mathrm{V}$ usually double, 6-V single, 9-V long, length $0.07-0.08 \mathrm{~mm}$ (mean $=0.08 \mathrm{~mm}$ ); 5-VI with 3-7 branches, 6-VI always single, 9-VI long, length 0.08-0.09 $\mathrm{mm}$ (mean $=0.08 \mathrm{~mm})$, margins smooth; 9-VII long, with small spicules on medial margin, length 0.076-0.103 mm (mean $=0.09 \mathrm{~mm})$; 9-VIII with 8-14 branches. Paddle: toothed margin index 0.75-0.80 (mean $=0.79)$.

Larva (Figs. 17, 18, 49, 52). Position and development of setae as figured. Range and modal number of branches in Table 16. Only 1 or 2 measurements were made because the specimens available are in very poor condition. In general as described for An.leucosphyrus, except for the following characters. Head: seta 2-C single and simple; 3 -C length 0.08 $\mathrm{mm}$, distance between base of 2-C and 3-C 0.026-0.032 mm (mean $=0.029 \mathrm{~mm}$ ), 4-C single, length $0.10 \mathrm{~mm}$, distance between basal insertion of 2-C and 4-C 0.08-0.09 $\mathrm{mm}$ (mean $=0.09 \mathrm{~mm}$ ), ratio of length of 4-C to distance between insertions of 2-C and 4-C 1.07, distance between base of 3-C and 4-C 0.07-0.08 $\mathrm{mm}($ mean $=0.08 \mathrm{~mm}), 5-\mathrm{C}$ longer than antennal shaft, extending beyond anterior margin of head, with 12,13 branches, $6-\mathrm{C}$ with 
13-15 branches, $7-\mathrm{C}$ with 14,15 branches. Thorax: seta 1-P with 13-17 branches, tubercle of seta 1-P broadly joined to tubercle of seta 2,3-P, tubercle of seta 1-P with strong blunt apical tooth, tubercle of 2-P with less prominent apical tooth tapering to apex, ending in blunt tip, 14-P with 4-7 branches; 4-M 2,3 branches, 6 -M with 3,4 branches, $14-\mathrm{M}$ with 7,8 branches; $3-\mathrm{T}$ (Fig. 52) with 5-8 leaflets. Abdomen: seta 1-I with 8-10 leaflets, 2-I single to triple, 3-I single, 9-I with 4,5 branches; 1 -II with 15 leaflets; 2-IV with 3-5 branches, 3-IV triple, 13-IV triple, ratio of length to 10 -IV $0.53 ; 2-\mathrm{V}$ with 3,4 branches; 1 -VII with 13,14 leaflets, apicolateral serration not seen; 13-16 pecten spines (Fig. 49), 4,5 long spines alternating with 7-12 short.

Type data. Holotype female with associated larval and pupal exuviae on microscope slide, head and mouth parts dissected and mounted on a separate microscope slide, deposited in the NHM. Type locality: Luzon, the Philippines, coll.9 Jan.1935, F.E.Baisas.

Material examined. Twenty-two specimens as follows: 10F, 4M, 4Le, 4Pe, derived from 9 separate collections from natural habitats (1 adult, 8 immature). PHILIPPINE ISLANDS. Luzon: Laguna, Los Baños (14'13'N 121 $\left.{ }^{\circ} 11^{\prime} \mathrm{E}\right)$, [Lot 123], 25 Jan. 1931, 4F, 1Le (W.V. King); [R53], Mar. 1930, 1F (P.F. Russell); [6,7], 21 Feb. 1969, 1F, 1M; [Lot

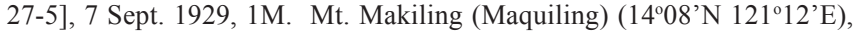

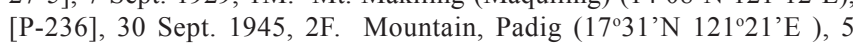

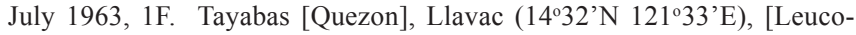
1,-2,-3], 3 July 1940, 1Pe; 4 July 1940, 2LePe (F.E. Baisas). Luzon, [probably Los Baños], [A-D], 1929, 2F, 2M (F.E. Baisas); [Lot 9-4], 6 Mar. 1939, 1LePe.

Distribution (Fig. 54). Anopheles baisasi is known from the Philippine Islands (Luzon). Bionomics and medical importance.

Little is know about the bionomics and medical importance of An. baisasi. It is a rare species in Luzon, Philippine Islands (Russell \& Baisas 1934a; Baisas \& Pagayon 1956). Immatures were found in rock holes and stagnant pools in the beds of mountain creeks in a heavily shaded areas (Russell \& Baisas 1934a). They were found in quiet corners of forest creeks and also in large stagnated portions of forest streams and rivers with debris always well shaded by trees. The breeding habitats were markedly seasonal (Baisas 1936a). In Llavac jungle, the breeding habitats were found some distance away from the road, and in Molawin Creek in Laguna Province, larvae were found in rock holes and quiet places along the edges of creeks and in a temporary, drying stream. Immatures of An. baisasi were also found in muddy ground pools. Always, only few immatures were found in all the habitats. The larval habitats in the Mount Makiling were located $819 \mathrm{~m}$ above sea level, in partial shade. Apparently, An. baisasi does not feed on either humans or domestic animals (Baisas \& Pagayon 1956).

Systematics. Anopheles baisasi was first recognized as An. leucosphyrus Luzon Form by Russell \& Baisas (1934b) and Baisas (1936b). Later, Colless (1956b) considered the Luzon Form a distinct geographic form of An. leucosphyrus, intermediate between An. leucosphyrus and An. balabacensis. Additionally, Colless hypothesized that the distribution of the Luzon Form was suggestive of derivation from $A n$. balabacensis through colonization across the PalawanMindoro zoogeographic boundary. Colless (1957) considered An. baisasi as a subspecies of An. balabacensis with distribution restricted to the type locality, Los Baños, Luzon. Anopheles baisasi was elevated to species status and included in the Leucosphyrus Subgroup outside the Leucosphyrus and Dirus Complexes (Peyton 1989).

Anopheles baisasi can be recognized by the following combination of characters. Adult: 1) proboscis nearly as long as forefemur, ratio of proboscis length to forefemur 1.03-1.12 $(\mathrm{men}=1.06) ; 2)$ apical pale band of palpomere 5 pale creamcolored to yellowish, contrasting with silvery-white bands of palpomeres 2-4; 3) ASP spot of vein R not extending to vein C, rarely 2,3 pale scales present on vein $\mathrm{C}$ on one wing; 4) hindtarsomere 4 without pale scales at base; 5) hindtarsomere 5 entirely dark-scaled; 6) PSD spot of vein R extending basally

Table 15. Number of branches for seta of the pupa of An. baisasi: range (mode).

\begin{tabular}{|c|c|c|c|c|c|c|c|c|c|c|c|}
\hline \multicolumn{2}{|c|}{ Seta Cephalothorax } & \multicolumn{9}{|c|}{ Abdominal segments } & \multirow{2}{*}{$\begin{array}{c}\text { Paddle } \\
\mathrm{Pa}\end{array}$} \\
\hline No. & $\mathrm{CT}$ & I & II & III & IV & $\mathrm{V}$ & VI & VII & VIII & IX & \\
\hline 0 & - & - & 1 & 1 & 1 & 1 & 1 & 1 & 1 & - & - \\
\hline 1 & 1 & n.c. & $14-27(18)$ & $4-8(5)$ & $2-4(3)$ & $1-3(2)$ & $1-2(1)$ & $1-2(1)$ & - & 1 & $1-2(1)$ \\
\hline 2 & $1-2(2)$ & 4-7 (7) & $3-6(3)$ & 4-6 (4) & $1-4(3)$ & $1-4(2)$ & $1-3(2)$ & $2-4(2)$ & - & - & $1-3(2)$ \\
\hline 3 & $2-3(3)$ & $1-2(1)$ & $2-4(3)$ & $2-5(4)$ & $2-8(6)$ & $2-4(3)$ & $1-3(2)$ & $1-3(3)$ & - & - & - \\
\hline 4 & $2-3(2)$ & $1-6(4)$ & $2-3(4)$ & $2-5(3)$ & $2-5(3)$ & $1-5(3)$ & $1-2(2)$ & $1-2(2)$ & $1-2(2)$ & - & - \\
\hline 5 & $3-6(4)$ & $1-4(3)$ & $2-3(2)$ & $4-8(7)$ & $3-6(4)$ & $3-6(4)$ & $3-7(5)$ & $3-6(4)$ & - & - & - \\
\hline 6 & 2 & $1-2(2)$ & $1-2(2)$ & $1-2(1)$ & 1 & 1 & 1 & $1-2(1)$ & - & - & - \\
\hline 7 & $2-5(4)$ & $2-4(3)$ & $2-4(3)$ & $1-4(3)$ & $1-4(2)$ & $2-3(3)$ & $1-2(1)$ & $1-2(2)$ & - & - & - \\
\hline 8 & $1-3(3)$ & - & - & $1-3(2)$ & $2-3(2)$ & $1-2(2)$ & $1-2(2)$ & $1-2(2)$ & - & - & - \\
\hline 9 & $1-2(2)$ & 1 & 1 & 1 & 1 & 1 & 1 & 1 & $8-14(11)$ & - & - \\
\hline 10 & $1-4(2)$ & - & - & $1-3(2)$ & 1 & $1-3(2)$ & $1-2(1)$ & $1-3(3)$ & - & - & - \\
\hline 11 & $1-3(2)$ & - & - & 1 & 1 & 1 & 1 & $1-3(2)$ & - & - & - \\
\hline 12 & $1-2(1)$ & - & - & - & - & - & - & - & - & - & - \\
\hline 13 & - & - & - & - & - & - & - & - & - & - & - \\
\hline 14 & - & - & - & - & 1 & 1 & 1 & 1 & 1 & - & - \\
\hline
\end{tabular}

n.c. $=$ not counted 
Table 16. Number of branches for setae of the larva of An. baisasi: range (mode).

\begin{tabular}{|c|c|c|c|c|c|c|c|c|c|c|c|c|c|}
\hline \multirow{2}{*}{$\begin{array}{l}\text { Seta } \\
\text { No. }\end{array}$} & \multirow{2}{*}{$\begin{array}{c}\text { Head } \\
\mathrm{C}\end{array}$} & \multicolumn{3}{|c|}{ Thorax } & \multicolumn{9}{|c|}{ Abdominal segments } \\
\hline & & $\mathrm{P}$ & $\mathrm{M}$ & $\mathrm{T}$ & $\mathrm{I}$ & II & III & IV & $\mathrm{V}$ & $\mathrm{VI}$ & VII & VIIII & $\mathrm{X}$ \\
\hline 0 & 1 & 1 & - & - & - & 1 & 1 & 1 & 1 & 1 & 1 & 1 & - \\
\hline 1 & 1 & $13-17(17)$ & $27-36$ & $2-3(3)$ & $8-10(10)$ & 15 & $15-20$ & $17-20(17)$ & $16-21(19)$ & $14-20$ & $13-14(14)$ & 1 & 1 \\
\hline 2 & 1 & $12-15$ & $2-3(3)$ & 1 & $1-3(1)$ & $6-7(6)$ & $5-7(7)$ & $3-5(3)$ & $3-4(4)$ & $3-5(5)$ & 5 & $6-8(6)$ & n.c. \\
\hline 3 & 1 & 1 & 1 & $5-8(5)$ & 1 & 1 & 1 & 3 & 1 & 1 & 3 & $6-8(6)$ & 8 \\
\hline 4 & $1-2(2)$ & 15 & $2-3(2)$ & $3-4(3)$ & $5-7$ & 5 & $3-4(3)$ & 3 & 3 & 1 & 1 & 1 & $8-8.5$ \\
\hline 5 & $12-14(14)$ & 40 & 1 & $22-29$ & $3-4(3)$ & $4-6(5)$ & $3-5(4)$ & $3-4(3)$ & $3-5(3)$ & $4-5(4)$ & $4-5$ & 3 & - \\
\hline 6 & $12-15$ & $1-2(1)$ & $3-4(3)$ & $2-3(3)$ & $16-20(17)$ & $17-19(18)$ & $13-14(14)$ & 2 & $2-3(2)$ & $2-3(3)$ & $3-5$ & $1-S$ & $4-5(4)$ \\
\hline 7 & $14-16$ & $19-25$ & $2-3(3)$ & $21-25$ & $13-16(15)$ & $12-21$ & $4-8$ & 6 & $3-5$ & $4-5$ & 3 & $2-S$ & $4-6(6)$ \\
\hline 8 & 2 & 26 & $23-28(23)$ & $23-28$ & - & 2 & $1-2(2)$ & $2-3(3)$ & 3 & $4-5$ & 5 & $6-\mathrm{S}$ & $3-4$ \\
\hline 9 & $4-5(4)$ & 1 & 1 & 1 & $4-5(4)$ & $7-10(7)$ & $7-10(7)$ & $6-8(6)$ & $5-6(6)$ & $3-8$ & 6 & $7-S$ & 2 \\
\hline 10 & $2-3(2)$ & 1 & 1 & 1 & 1 & $3-4(3)$ & 1 & 1 & 1 & $2-3(3)$ & 6 & $8-\mathrm{S}$ & 3 \\
\hline 11 & $24-31$ & $1-2(1)$ & 1 & 1 & 3 & 1 & 3 & $2-3(3)$ & $2-3(3)$ & 2 & 2 & 9-S & $2-4(4)$ \\
\hline 12 & $2-3(2)$ & 1 & 1 & $2-3(3)$ & 3 & 1 & $2-3(3)$ & $2-4(4)$ & $2-3(3)$ & 1 & 1 & - & - \\
\hline 13 & $4-5(5)$ & $4-7(4)$ & 6 & 3 & $3-4(4)$ & $4-6(5)$ & $4-6(4)$ & 3 & $3-4(3)$ & $7-8$ & $3-4(3)$ & - & - \\
\hline 14 & - & 6 & $7-8(7)$ & - & - & - & - & 1 & 1 & 1 & 1 & 1 & - \\
\hline 15 & 5 & - & - & - & - & - & - & - & - & - & - & - & - \\
\hline
\end{tabular}

n.c. $=$ not counted

from level 2 to level 5; 7) PSD spot of vein R with 1-4 pale interruptions; 8) wing fringe without pale spot between veins $1 \mathrm{~A}$ and $\mathrm{Cu}_{2} ; 9$ ) fork of cell $\mathrm{R}_{2}$ distinctly distal to fork of cell $\mathrm{M}_{1+2} ; 10$ ) foretarsomeres with very short incomplete bands over joints of 1-2, 2-3, 3-4; 11) foretarsomere 4 with indistinct basal spot of pale scales on dorsal surface, apex entirely dark or with very small dorsoapical pale spot; 12) foretarsomere 5 entirely dark-scaled; 13) ventral surface of foretarsomeres 1-5 all dark, not even faint pale bands at joints; 14) midtarsomere pale bands very short; 15) hindtarsal pale bands very short, barely as long as width of tarsomeres; 16) about 10 cibarial elements. Fourth-instar larva of An. basasi cannot be distinguished from those of An. cracens and An. baimaii, however it can be distinguished from other members of the Leucosphyrus Group by the following characters: 1) seta 3-C single; 2) seta 4-C not strongly developed, extending to base of seta 2-C, ratio of length of 4-C to distance between insertions of 2-C and 4-C 1.07; 3) seta 1-II less developed than seta 1-III$\mathrm{VI}$; 4) seta 5-C noticeably longer than antenna; 5) basal sclerotized tubercle of seta 1-P with prominent spine arising from posterodorsal margin; 6) seta 1-II poorly developed, with narrow lanceolate or filiform branches; 7) seta 2-IV with 3-5 branches and $2-\mathrm{V}$ with 3,4 branches; 8 ) seta $1-\mathrm{X}$ inserted in marginal notch or at edge of saddle; 9) seta 14-P with 4-8 branches; 10) tubercles of seta 1-P broadly joined to tubercle of setae 2,3-P. Pupa: 1) seta 9-IV short, ratio of length of 9-IV to length of 9-V 0.22-0.50 (mean $=0.32) ; 2$ ) seta 7-II with 2-4 branches; 3) seta 4-II double or triple; 4) seta 10-IV always single; 5) seta 9-V length $0.07-0.08 \mathrm{~mm}$ (mean $=0.08 \mathrm{~mm})$; 6) 9VI length $0.08-0.09 \mathrm{~mm}($ mean $=0.08 \mathrm{~mm})$.

\section{TAXONOMIC DISCUSSION}

Morphological distinction among species of the Leucosphyrus Complex as well as An. baisasi and members of the Dirus Complex is problematic, especially because they exhibit polymorphym for some characters used for identification. Based on the specimens examined, An. baisasi can be separated from An. latens and An. leucosphyrus by the absence of pale fringe spots between veins $1 \mathrm{~A}$ and $\mathrm{Cu}_{2}$, in having the fork of cell $\mathrm{R}_{2}$ noticeably distal to the fork of cell $\mathrm{M}_{1+2}$, hindtarsomere 5 entirely dark-scaled, and PSD spot of vein R extending basally from level 2 to level 5, whereas $A n$. latens and $A n$. leucosphyrus possess one pale fringe spot between veins $1 \mathrm{~A}$ and $\mathrm{Cu}_{2}$, fork of cell $\mathrm{R}_{2}$ in line or basal to fork of cell $\mathrm{M}_{1+2}$, hindtarsomere 5 with apical band of pale scales, and PSD spot of vein R extending basally from level 4 to level 6. Adults of An. balabacensis with the ASP spot present on the vein $\mathrm{C}$ are similar to An. introlatus in having the PSD spot of vein $\mathrm{R}$ often not extending basally beyond the level of the PSP spot on the vein C (level 3), and rarely extending into the apical 0.5 of the HD spot on vein $\mathrm{C}$, never reaching to or extending beyond level 4 , and the apical pale band on palpomere 5 distinctly white or whitish, not strongly contrasting with light bands on palpomeres 2 and 3 . Anopheles introlatus can be separated from An. balabacensis in having hindtarsomere 4 entirely dark-scaled at base, or rarely with small, inconspicuous basal pale patch, whereas in $A n$. balabacensis hindtarsomere 4 has a more distinct patch of pale scales at the base on dorsal surface. Anopheles latens and An. leucosphyrus can be distinguished from An. introlatus and An. balabacensis with ASP spot present on the vein C by possessing the PSD spot of vein R extending basally well into the level of the humeral dark (HD) spot of the vein $\mathrm{C}$ or beyond (level 4 to level 6), and the apical pale band on palpomere 5 distinctly cream-colored or yellowish, strongly contrasting with silvery-white band on palpomeres 2 and 3. Anopheles latens and An. leucosphyrus are indistinguishable in the adult stage. However, because these species are allopatric, their distributions should be considered when making 
identifications. Anopheles baisasi is restricted to Luzon, Philippine Islands, whereas An. leucosphyrus is known from Sumatra, Indonesia and An. latens is more widespread and has been found in Indonesia (Kalimantan), East and West Malaysia and southern Thailand. Individuals of $A n$. balabacensis and An. introlatus, in which the ASP spot is absent on the vein $\mathrm{C}$, are similar to species of the Dirus Complex. Anopheles balabacensis can be recognized by possessing a patch of pale scales on the dorsal surface of the hindtarsomere 4, which is less developed than in members of the Dirus Complex. Individuals of An. introlatus can usually be distinguished from species of the Dirus Complex by the absence of pale scales at the base of hindtarsomere 4. However, in a few individuals examined for the study, there is a small inconspicuous pale patch at the base on the dorsal surface. Females of An. introlatus can also be misidentified as An. nemophilous of the Dirus Complex because a small number of individuals of the latter species do not have pale scales at the base of the hindtarsomere 4. However, the ASP spot never extends into the vein $\mathrm{C}$ in An. nemophilous, and is usually present in An. introlatus.

The fourth-instar larvae of An. introlatus, An. balabacensis, and An. baisasi are similar in having the tubercles of setae 1,2-P broadly joined basally, each tubercle possessing a strong pointed or blunt tooth arising from the posterodorsal side, projecting over the base of each seta. In contrast, An. leucosphyrus and An. latens are similar in having tubercles of seta 1,2-P without a tooth or at most with a weak and inconspicuous lip, both tubercles usually well separated. However, both species rarely exhibit tubercles partially joined basally. The fourth-instar larva of An. introlatus can be separated from those of An. balabacensis and An. baisasi in having the ratio of the length of 4-C to distance between insertions of 4-C and 2-C 1.13-1.71, seta 3,4-C long, 4-C extending noticeably beyond the base of $2-\mathrm{C}$, and $3-\mathrm{C}$ extending well beyond the anterior margin of the head, whereas the ratio of the length of 4-C to the distance between the insertions of 4-C and 2-C is 0.83-1.32 in An. balabacensis and about 1.07 in An. baisasi, setae 3,4-C are shorter, 4-C usually do not reach the base of 2-C, and 3-C extends to or only slightly beyond the anterior margin of the head. The fourth-instar larva of An. balabacensis can be distinguished from that of $A n$. baisasi in having seta 1-II moderately developed with distinct, splayed, narrow lanceolate leaflets, and seta 3-T is palmate, with narrow, lanceolate leaflets, whereas in An. baisasi seta 1II is poorly developed with filiform branches and seta 3-T is similar to 1-II with filiform branches. Fourth-instar larva of $A n$. latens and An. leucosphyrus are indistinguishable.

Pupae of An. introlatus can be separated from those of An. leucosphyrus, An. latens and An. baisasi, but not from An. balabacensis, in having seta 9-IV long, length 0.07-0.11 $\mathrm{mm}$, and ratio of the length of 9-IV to the length of $9-\mathrm{V}$ varys from $0.67-1.03$, whereas in the remaining three species, the maximum length observed for 9 -IV was $0.05 \mathrm{~mm}$, and the ratio of the length of seta 9-IV/9-V is 0.52 . In the specimens examined, the pupa of An. balabacensis can be separated from that of
An. introlatus in having the paddle teeth more developed and stronger. The pupal stage of An. latens can be distinguished from those of An. leucosphyrus and An. baisasi by possessing seta 7-II with 4-11 branches, whereas in An. baisasi and An. leucosphyrus seta 7-II has 2-4 branches. Apparently the only character to separate An. latens from An. leucosphyrus and An. baisasi is the number of branches of seta 7-II. However, there is an overlap and some individuals can be misidentified. Anopheles leucosphyrus can be separated from An. baisasi in having seta 4-II with 5-8 branches, 10-IV always double, 9-V length $0.09-0.11 \mathrm{~mm}$ (mean $=0.10 \mathrm{~mm}$ ), 9-VI length $0.10-0.12$ $\mathrm{mm}(\mathrm{mean}=0.10 \mathrm{~mm})$, and a toothed margin index of 0.89-0.95 (mean $=0.91$ ), whereas in An. baisasi seta 4-II is double or triple, $10-\mathrm{IV}$ is always single, $9-\mathrm{V}$ length is $0.07-0.08 \mathrm{~mm}$ (mean $=0.08 \mathrm{~mm}$ ), $9-\mathrm{VI}$ length is $0.08-0.09 \mathrm{~mm}($ mean $=0.08 \mathrm{~mm})$, and the toothed margin index is $0.75-0.80($ mean $=0.79)$.

\section{DIRUS COMPLEX}

Some members of the Dirus Complex are important vectors of human malaria parasites in forested and hilly forested areas of Southeast Asia (Baimai 1988b; 1989; Gringrich et al.1990; Rosenberg et al. 1990a, 1990b; Meek 1995; Rajavel \& Das 1998; Chareonviriyaphap et al. 2000; Mya et al. 2002; Erhart et al. 2004; Sithiprasasna et al. 2003; Kobayashi et al. 2004; Trung et al. 2004). In West Malaysia, An. dirus l. s. does not seem to be strongly involved in the dynamics of malaria transmission as it is in other countries (Rahman et al. 1997). This may be related to the fact that only An. cracens and An. nemophilous occur in West Malaysia and their epidemiological importance is not fully understood. The Dirus Complex is widely distributed throughout the Oriental Region from southwestern India eastwards through all countries of Southeast Asia, Taiwan and southern China (Fig. 2) (Baimai et al. 1988e). Peyton (1989) included seven species in the Dirus Complex, An. dirus, $A n$. nemophilous, An. takasagoensis, An. dirus B, An. dirus C, An. dirus D, and An. dirus E. Sallum et al. (2004) showed that An. dirus $\mathrm{E}$ is An. elegans and not a new species as it had been proposed by Tewari et al. (1987), Peyton \& Ramalingan (1988), Peyton (1989), and Sawadipanich et al. (1990). Anopheles dirus $\mathrm{B}$ (=An. cracens), An. dirus $\mathrm{C}$ (=An. scanloni), and An. dirus $\mathrm{D}$ (=An. baimaii) were recently described by Sallum and Peyton (in Sallum et al. 2005). Anopheles dirus s. s. is widespread on the mainland from central to northern Thailand, extending to Cambodia, Vietnam, Laos, and southern China. Anopheles cracens is found in southern Thailand, northern peninsular Malaysia, and Sumatra, Indonesia. Anopheles scanloni has been found only in southern Thailand. Anopheles baimaii has a more western distribution, occuring in the eastern and central parts of Thailand and extending to Bangladesh, Burma, and northeastern India, including Andaman Islands and western Bengal. Anopheles nemophilous is known from the Thailand-Malayian border, including West Malaysia and Thailand. Anopheles elegans occurs only in southwestern India; and An. takasagoensis only in Taiwan. Evidence for the existence of a species complex 
originated initially from morphological studies, specially those of Colless (1956b, 1957), Reid (1968, 1970), Slooff \& Verdrager (1972), Peyton \& Harrison $(1979,1980)$, and others. Later, cytological evidence from mitotic and meiotic chromosomes, banding patterns of polytene salivary gland chromosomes, and cross-mating experiments (Hii 1984b; Wibowo et al. 1984; Hii 1985a; Baimai \& Traipakvasin 1987; Baimai et al. 1987, 1988a, 1988c, 1988d; Tewari et al. 1987; Peyton \& Ramalingan 1988; Poopittayasatapan \& Baimai 1995), as well as morphometric and morphological data of the male genitalia, immature stages, including the egg (Sucharit \& Choochote 1983; Hii 1986; Damrongphol \& Baimai 1989), corroborated the species status of An. dirus, An. cracens, An. scanloni and An. baimaii. More recently, recombinant DNA techniques, enzymatic tests, DNA probes, and DNA markers were developed to distinguish members of the Dirus Complex and confirm their species status (Panyim et al. 1985, 1988a, 1988b; Green et al. 1992; Audtho et al. 1995; Xu \& Qu 1997b; Xu et al. 1998; Walton et al. 1999; Huong et al. 2001; Manguin et al. 2002). Species of the Dirus Complex can be separated based on distinct patterns of major blocks of constitutive heterochromatin in the sex chromosomes and also banding patterns and densities of bands of the salivary gland polytene chromosomes (Baimai et al. 1981; Baimai et al. 1987; Baimai et al. 1988b; Baimai et al. 1988c; Wibowo et al. 1984).

The metaphase karyotype of all members of the Dirus Complex except for An. cracens exhibits typical telocentric sex chromosomes of various sizes due to different amounts of heterochromatin in the vicinity of the centromere and qualitative differences of intercalary heterochromatin (Baimai 1988b). Anopheles baimaii shows fixed inversions in the X chromosome (Baimai et al. 1987), whereas An. dirus, An. cracens, and An. balabacensis exhibit differences mainly in the free ends of X chromosomes (Baimai 1988b). The salivary gland polytene chromosomes and mitotic karyotypes of $A n$. dirus and An. scanloni are similar, showing identical banding patterns and nearly complete synapsis in the F1 hybrid polytene chromosome complement (Baimai et al. 1987). However, these two species can be unambiguously differentiated based on the polytene chromosome of F1 hybrids at the tip of the $\mathrm{X}$ chromosome and arms $2 \mathrm{~L}$ and $2 \mathrm{R}$, and in the amount of heterochromatin (Wibowo et al. 1984). Anopheles cracens is distinct from An. dirus and An. scanloni by the salivary gland polytene chromosome and mitotic karyotype (Baimai et al. 1981). Xu \& Qu (1991) distinguished An. dirus from An. baimaii in China using the heterochromatin pattern of the mitotic chromosome karyotype. Additionally, in China, rDNA ITS2 sequence was used to corroborate species distinctions. Whereas no intraspecife variation was observed in An. dirus, variation at one position was found in An. baimaii and interspecific differences were located in the subrepeat structure (Xu \& Qu 1997a; Xu \& Qu 1997b). The presence of An. dirus in Hainan Province, and An. baimaii in Yunnan Province, China, was corroborated in studies employing heterochromatin of mitotic chromosomes, SEM of the eggs, and rDNA ITS2 sequences (Qu et al. 1998). In contrast, Walton et al. (1999) found that ITS2 sequence generated from specimens of An. baimaii collected in Yunnan Province is substantiatly distinct from those of specimens from Thailand, thus it could represent a different species.

Certain species of the Dirus Complex are sympatric, whereas others are allopatric (Baimai et al. 1988d; Baimai et al. 1988e; Peyton \& Ramalingan 1988; Tewari et al. 1987), and they also can differ in bionomical aspects such as seasonal abundance in sympatric populations, blood feeding activity, and their roles as vector of Plasmodium (Baimai et al. 1988d). Apparently, An. baimaii is genetically distant from the other species of the Dirus Complex (Baimai et al. 1987), i.e. based on differences in the position of the centromere and amount of constitutive heterochromatin in the sex chromosomes. Baimai et al. (1981) found that An. dirus and An. takasagoensis are more closely related to each other than either is to An. cracens. Walton et al. (2000) using COI mitochondrial gene base pair sequence data of 14 populations of An. dirus, An. scanloni, and An. baimaii observed that there is no gene flow between the northern and the southern populations of An. scanloni and that An. dirus and An. baimaii are parapatric. Additionally, the excess of low frequency mutations indicates that there is a population expansion in An. dirus and An. baimaii. Later, Walton et al. (2001) compared data for 11 microsatellite loci with that of the COI mitochondrial gene using the same 14 populations. All three species were well differentiated from each other at the microsatellite loci. Also, the northern and southern populations of An. scanloni showed a high degree of differentiation and similarly to the results of the COI, suggesting that they are incipient species.

\section{Anopheles (Cellia) dirus Peyton \& Harrison}

(Figs. 4, 6i, 7, 8, 19, 20, 49-52, 55)

Anopheles dirus Peyton \& Harrison (1979:40) (F*, M, P*, L*). Holotype female with associated larval and pupal exuviae, deposited in the NMNH.

Anopheles balabacensis of Colless (1957:137) (in part, taxonomy); Do-Van-Quy (1962a:23) (distribution, vector status), (1962b:26) (A, L, identification keys); Scanlon \& Esah (1965:138); Scanlon \& Sandhinand (1965:61); Gould et al. (1966:363) (malaria vector); Peyton \& Scanlon (1966:1) (F*, identification key); Stone et al. (1966) (F, L, identification keys, larval habitats); Scanlon et al. (1967:79) (bionomics), (1968a:19) (checklist, bionomics notes), (1968b:45) (in part, vector ecology); Chin et al. (1968:355) (vector competence $P$. knowlesi); Reid (1968:297) (in part, taxonomy); Chin (1969:1-12) (bionomics notes), (1970:1-14) (bionomics notes); Rutledge et al. (1969:615) (vector competence $P$. vivax, $P$. falciparum); Rattanarithikul \& Harrison (1973:2) (L*, identification key); Ismail et al. (1974:129) (bionomics data), (1975:206-231) (bionomics data); Harrison \& Klein (1975:9) (checklist); Klein (1977:107) (bionomics notes); Wilkinson et al. (1976:306) (vector of chloroquine-resistant $P$. falciparum), (1978:666) (bionomics data); Miyagi et al. (1986:181) (distribution, bionomics notes).

Anopheles balabacensis balabacensis of Büttiker \& Beales (1964:190) (A, L, identification keys, Cambodia); Collins et al. (1967a:841) (susceptibility to P. knowlesi, H strain), (1967b:1130) (susceptibility to $P$. coatneyi), (1968:376) (susceptibility to $P$. fieldi), (1971:961) (susceptibility to P. knowlesi, H strain); Teng et al. (1974:463) (morphological description).

Anopheles dirus A of Klein et al. (1982:265) (longevity, infection $P$. 
cynomolgi); Baimai et al. (1984a:536) (cytogenetics, species identification), (1984b:633) (heterochromatin variation); Hii (1984b:192) (X chromosome, male sterility), (1985a:185) (polytene chromosomes, cross-mating, species identification), (1986:125) (morphometry, male genitalia);Wibowo et al. (1984:425) (metaphase chromosomes, heterochromatin, species identification); Klein et al. (1986:901) (survival rate, infection $P$. cynomolgi); Takai (1986:45) (protein loci, systematics); Baimai \& Green (1987:481) (mating behavior); Tsukamoto et al. (1987:291) (checklist); Damrongphol \& Baimai (1989:563) (SEM eggs, species identification); Green et al.(1992:29) (enzyme electromorphs, species identification); Audtho et al. (1995:107) (DNA hybridization); Poopittayasataporn \& Baimai (1995:426) (polytene chromosome, phylogeny); Rattanarithikul et al. (1995:428) (bionomics), (1996a:52) (biting activity, blood source), (1996b:75) (bionomics, parity rate), (1996c:114) (bionomics, vector competence for $P$. vivax, P. falciparum); Xu \& Qu (1997b:134) (ITS2, species identification); Xu et al. (1998:385) (ITS2, species identification); Walton et al.(1999:24) (ASA PCR species identification), (2000:962) (population genetics, COI), (2001:569) (genetic population); Huong et al. (2001:615) (PCR species identification); Manguin et al. (2002:46) (SCAR multiplex PCR); Trung et al. (2004:230) (bionomics, human Plasmodium, vector competence).

Anopheles dirus of Baimai et al.(1980:319) (salivary chromosome map), (1981:81) (karyotype, species identification); Deng et al.(1982:332) (first use for An. balabacensis balabacensis from Hainan); Sucharit \& Choochote (1983:90) (morphometry, male genitalia, mating behavior); Sucharit et al. (1983:127) (esterase isozyme pattern, species identification); Rosenberg \& Andre (1985:188) (vector human Plasmodium); Choochote et al. (1987:511) (SEM pupal seta 9-III-V); Harbach et al. (1987a:296) (bionomics); Peyton (1989:197) (taxonomy); Gingrich et al. (1990:1016) (vectorial capacity, human malaria); Kitthawee et al.(1990:328) (bionomics), (1992a:128) (bionomics), (1992b:921) (bionomics), (1993:143) (bionomics),(1995:573) (bionomics); Xu \& Qu (1991:286) (heterochromatin mitotic chromosome, species identification); Rattanarithikul \& Panthusiri (1994:20) (bionomics data, A, L, identification keys); Suwonkerd et al. (1990:1) (DDT, FNT resistance); Cui et al.(1992:283) (gas chromatography cuticular hydrocarbons); Kitthawee \& Edman (1995:582) (biting activity); Frances et al. (1996:990) (vector competence $P$. falciparum); Kobayashi et al.(1997:615) (bionomics), (2004:299) (bionomics, malaria control); Xu \& Qu (1997a:272) (ITS2, species identification); Xu et al. (1998:385) (ITS2 species identification); Singhasivanon et al. (1999:399) (bionomics); Toma et al. (2002:532) (vector competence human Plasmodium); Van Bortel et al. (2001:729) (vector competence human Plasmodium); Vythilingam et al. (2001:83) (bionomics).

Anopheles leucosphyrus of Barnes (1923b:121); Barraud \& Christophers (1931:274); Causey (1937:403); Wilson \& Reid (1949:266); Baba (1950:1) (malaria, Hainan, China); Sandhinand (1951:37); Martin \& Stage (1954:4) (F, identification keys); Tansathit et al. (1962:138); Ayurakitkosol \& Griffith (1962:125); Stojanovich \& Scott (1965) (L, F, identification keys).

Anopheles leucosphyrus balabacensis of Colless (1956b:55) (in part, taxonomy); Thurman (1959:5).

Female (Figs. 4, 6i, 7, 8). Head: proboscis uniformly darkscaled, length $1.12-2.28 \mathrm{~mm}$ (mean $=2.05 \mathrm{~mm}$ ), ratio of length to forefemur 1.03-1.15 (mean=1.09), maxillary palpus (Fig. 7) length $1.49-2.13 \mathrm{~mm}$ (mean $=1.93 \mathrm{~mm})$, ratio of length to proboscis $0.91-0.96$ (mean $=0.94)$, ratio of length to forefemur $0.99-1.10$ (mean $=1.03)$ (Table 2.2), ratio of length of palpomeres $3 / 41.44-1.85($ mean $=1.68), 3 / 52.11-2.70($ mean $=2.41), 4 / 51.22$ $1.78($ mean $=1.43), 4-5 / 30.96-1.09($ mean $=1.01)$; palpomeres 2 4 with narrow apical silvery-white bands, pale band of palpomere 4 larger than those on palpomeres 2,3, pale scales of palpomere 5 white, length of apical pale band of palpomere 5 varying from $1.00-3.00($ mean $=1.60)$ length of basal dark band of palpomere 5, ratio of length of apical pale band of palpomere 4 to length of basal dark band of palpomere 50.36 $1.33($ mean $=0.64)($ Table 3$)$. Thorax: pleural setae as follows: 1 3 upper proepisternal, 0-3 prespiracular, 4-6 prealar, 3-7 upper mesokatepisternal, 1-4 lower mesokatepisternal, 3-7 upper mesepimeral. Wing (Figs. 4, 6i): length 2.78-3.67 mm (mean= $3.33 \mathrm{~mm}$ ), pale scales on most veins light cream, scales of PSP and SP spots shiny white, PSP strongly contrasting with other pale spots, PHP spot of vein C small to prominent, rarely absent, HP spot usually present and prominent, rarely absent, PSP spot always present and prominent, SP spot frequently present and prominent, rarely reduced or absent, ASP spot always absent, PP spot 0.75-3.00 (mean = 1.21) length of SCP spot, AD spot 1.18-3.50 $($ mean $=2.14)$ length of PP spot, PSD spot of vein R extending basally to level 6 on both veins (Table 4), PSD spot of veins $R$ with 1-4 small pale interruptions (Table 5), SD spot of veins R with 1-4 pale interruptions (Table 6), sum of pale interruptions on PSD-PD spots of veins R 4-11 for each wing, ratio of length of cell $R_{2}$ to vein $R_{2+3} 1.46-2.05$ (mean = 1.74), ratio of length of cell $\mathrm{R}_{2}$ to cell $\mathrm{M}_{1+2} 1.13-1.35$ (mean = 1.22). Legs (Fig. 8): femora, tibiae, and tarsomeres dark-scaled speckled with pale spots; foretarsomeres 2,3 with conspicuous basal and apical pale bands and few pale spots in middle dark area, foretarsomere 4 with basal and apical pale spots, foretarsomere 5 variable, usually dark-scaled at base, rarely with complete or incomplete pale band, always with apical pale scales; midtarsomeres 2,3 with small apical patch of pale scales and 1-3 middle pale spots, midtarsomere 4 mainly darkscaled with small apical pale patch, midtarsomere 5 variable, entirely dark-scaled or with faint apical pale band or with prominent apical pale band, rarely with basal pale scales; hindtarsomere 2 usually with basal pale spot, rarely without pale scales, always with apical pale spot, hindtarsomeres 3 always with apical pale band, dark-scaled at base, hindtasomere 4 with distinct basal pale band or patch, band usually complete, sometimes incomplete on ventral surface, apical pale band always present and evident, hindtarsomere 5 with apical pale band, basal pale band either present or absent. Abdomen: tergum VI usually with few, narrow, elongate dark scales on posterior margin, sometimes without scales, tergum VII always with few scales on apical margin, tergum VIII covered with narrow, elongate golden to pale cream-colored scales on apical 0.5 ; sternum VI normally without scales, rarely with 1,2 dark scales posteromedially, sternum VII with dense or sparse posteromedial patch of dark scales, sternum VIII with basolateral patches of whitish scales.

Male. Essentially as in female except for sexual characters. Wing generally paler with reduced scaling, pale spot usually longer than in female. Palpomere 2 with dorsal patch of pale scales at middle, extending laterally, apex of palpomere 2 bare; palpomere 3 with long dorsal patch of pale scales at middle extending to lateral surface, apex of palpomere 3 with broad band of pale scales, covering dorsal, lateral, and ventral 
surfaces except for small, ventrolateral patch of dark scales at apex; palpomere 4 mainly pale-scaled with basal dark band, palpomere 5 pale-scaled with basal dark band, extending along ventral surface, not reaching apex of segment. Abdomen: tergum VIII with sparse dark scales posteromedially; sternum VIII covered with pale cream-colored scales. Genitalia: 4,5 parabasal setae; ventral claspette with 1 long apicolateral seta shorter than club of dorsal clapette; dorsal clapette with 5,6 setae fused apically into club, 1 narrow, short, pointed, isolated seta arising lateral to club; aedeagus with 6-8 leaflets arising from tip, leaflets serrated on one or both edges.

Pupa (Fig. 19). Position and development of setae as figured; range and modal number of branches in Table 17. All measurements from 25-42 specimens. In general as described for An.leucosphyrus except for the following characters. Integument mostly light brown with darkened areas without distinctive color pattern, darkened spots as follow: 1 dark spot on central area of dorsal apoteme; sterna II-VII with narrow dark band near anterior margin. Cephalothorax: seta 4-CT usually double, 5-CT with 2-6 branches, 9-CT single to triple. Seta 9-II-VIII pigmented light to medium brown, slightly darker at base. Abdomen: seta 1-II with 23-35 branches, 9-II length $0.008-0.018 \mathrm{~mm}($ mean $=0.012 \mathrm{~mm})$; 1 -III with 5-11 branches, 5 III with 6-11 branches, 9-III length 0.01-0.03 mm (mean $=0.02$ $\mathrm{mm}$ ); 1-IV with 3-8 branches, 5-IV with 5-11 branches, 6-IV single, 9-IV length $0.03-0.07 \mathrm{~mm}$ (mean $=0.05 \mathrm{~mm})$, ratios of length of 9-IV/9-III 1.48-3.25 (mean = 2.23) and 9-IV/9-V 0.28$0.68($ mean $=0.43) ; 1-\mathrm{V}$ double to 4-branched, 6-V single, $9-\mathrm{V}$ with spicules, length $0.09-0.12 \mathrm{~mm}($ mean $=0.11 \mathrm{~mm}) ; 5$-VI with 5-8 branches, 6-VI single, 9-VI with spicules, length 0.10-0.12 $\mathrm{mm}($ mean $=0.11 \mathrm{~mm}) ; 9-$ VII with spicules, length $0.09-0.13 \mathrm{~mm}$ (mean $=0.11 \mathrm{~mm})$; 9-VIII with $10-18$ branches. Paddle: toothed margin index $0.83-1.25($ mean $=0.94)$, teeth strong, tapering to apex ending in sharply acute apex.

Larva (Figs. 19, 20, 49, 50, 51, 52). Position and development of setae as figured; range and modal number of branches in
Table 18. All measurements from 25-30 specimens unless otherwise indicated. In general as described for $A n$. leucosphyrus except for the following characters. Head: integument entirely light brown to yellowish, sometimes with darkened spots. When dark spots present, as follow: 2 small dark spots placed posteriorly on dorsal apoteme; 1 dark spot placed slightly anterior to those 2 posterior spots of dorsal apoteme; 1 dark spot placed central on dorsal apoteme, posterior to seta 5-C; 2 lateral dark spots in dorsal apoteme between insertions of seta 7-C and 8-C along dorsal ecdysial line; 2 dark spots on ventral lateralia, 1 placed on area of 12-C insertion and 1 slightly posterior; 2 dark spots on labiogula at level of hypostomal suture; length $0.61-0.75 \mathrm{~mm}$ (mean $=0.65$ $\mathrm{mm}$ ), width $0.62-0.78 \mathrm{~mm}$ (mean $=0.71 \mathrm{~mm})$; antenna length $0.28-0.32 \mathrm{~mm}($ mean $=0.30 \mathrm{~mm})$, ratio of distance base to $1-\mathrm{A}$ to antenna length 0.19-0.46 $($ mean $=0.35)$; seta $3-\mathrm{C}$ length 0.07 $0.09 \mathrm{~mm}($ mean $=0.08 \mathrm{~mm})$, distance between base of $2-\mathrm{C}$ and 3-C 0.03-0.05 mm (mean $=0.04 \mathrm{~mm}), 4-\mathrm{C}$ single or double, usually extending forward to near or beyond base of 2-C, length $0.07-0.09 \mathrm{~mm}$ (mean $=0.08 \mathrm{~mm})$, distance between basal insertions of 2-C and 4-C 0.07-0.09 $\mathrm{mm}$ ( mean $=0.08 \mathrm{~mm})$, ratio of length of 4-C to distance between insertions of 2-C and 4-C $0.81-1.20($ mean $=0.99)$, distance between base of 3-C and 4-C $0.05-0.10$ (mean $=0.08), 5-C$ extending beyond anterior margin of head. Thorax: tubercles of all large setae light to medium brown; seta 1-P inserted in tubercle, either entirely joined or partially connected by posterior bridge or sometimes entirely separate from tubercle of 2,3-P, each tubercle with strong apical tooth projecting forward over base of each seta, 14-P with 3-8 branches; 3-T (Fig. 52) with 3-8 slender branches, occasionally with weak, nearly transparent, narrow, lanceolate leaflets. Abdomen: seta 1-I small, somewhat palmate, with 3-9 narrow nearly transparent lanceolate leaflets, 2-I single to triple; 1-II small, more developed than 1-I, palmate with 5-18 leaflets (Fig. 51); 2-IV with 3-6 branches, 3-IV double or triple, ratio of length of 13-IV to 10-IV 0.51-1.00 $($ mean $=0.66) ; 2-V$ with 4-6 branches;

Table 17. Number of branches for setae of the pupa of An. dirus: range (mode).

\begin{tabular}{|c|c|c|c|c|c|c|c|c|c|c|c|}
\hline \multicolumn{2}{|c|}{ Seta Cephalothorax } & \multicolumn{9}{|c|}{ Abdominal segments } & \multirow{2}{*}{$\begin{array}{c}\text { Paddle } \\
\mathrm{Pa}\end{array}$} \\
\hline No. & $\mathrm{CT}$ & I & II & III & IV & $\mathrm{V}$ & VI & VII & VIII & IX & \\
\hline 0 & - & - & 1 & 1 & 1 & 1 & 1 & 1 & 1 & - & - \\
\hline 1 & $1-3(2)$ & n.c. & $23-35(30)$ & $5-11(9)$ & $3-8(5)$ & $2-4(2)$ & $1-2(2)$ & $1-3(1)$ & - & 1 & $1-2(1)$ \\
\hline 2 & $1-2(2)$ & $4-9(6)$ & $4-7(6)$ & $4-7(6)$ & $3-6(3)$ & $2-5(3)$ & $2-5(3)$ & $2-4(3)$ & - & - & $1-2(1)$ \\
\hline 3 & $1-3(3)$ & $1-2(1)$ & $1-3(2)$ & $2-4(3)$ & $5-8(7)$ & $1-4(2)$ & $1-2(1)$ & $1-4(3)$ & - & - & - \\
\hline 4 & $1-4(2)$ & $2-7(5)$ & $2-5(4)$ & $2-7(4)$ & $2-5(4)$ & $1-7(4)$ & $1-3(2)$ & $1-2(2)$ & $1-3(2)$ & - & - \\
\hline 5 & $2-6(4)$ & $2-4(3)$ & $2-4(3)$ & $6-11(9)$ & $5-11(6)$ & $4-7(6)$ & $5-8(5)$ & $4-6(5)$ & - & - & - \\
\hline 6 & $1-3(2)$ & $1-3(2)$ & $1-2(2)$ & $1-3(2)$ & 1 & 1 & 1 & $1-2(2)$ & - & - & - \\
\hline 7 & $1-4(3)$ & $2-5(4)$ & $2-4(3)$ & $1-5(3)$ & $1-4(3)$ & $1-5(3)$ & 1 & $1-2(1)$ & - & - & - \\
\hline 8 & $1-3(2)$ & - & - & $2-4(3)$ & $1-3(3)$ & $1-3(2)$ & $1-3(2)$ & $1-4(3)$ & - & - & - \\
\hline 9 & $1-3(3)$ & 1 & 1 & 1 & 1 & 1 & 1 & 1 & $10-18(12)$ & - & - \\
\hline 10 & $2-5(2)$ & - & - & $1-4(2)$ & $1-2(1)$ & $1-2(2)$ & $1-3(1)$ & $1-3(2)$ & - & - & - \\
\hline 11 & $1-4(3)$ & - & - & 1 & $1-2(1)$ & 1 & $1-3(1)$ & $1-4(2)$ & - & - & - \\
\hline 12 & $1-3(2)$ & - & - & - & - & - & - & - & - & - & - \\
\hline 13 & - & - & - & - & - & - & - & - & - & - & - \\
\hline 14 & - & - & - & - & 1 & 1 & 1 & 1 & 1 & - & - \\
\hline
\end{tabular}

n.c. $=$ not counted 
1-VII (Fig. 50) with 10-18 moderately broad, lanceolate leaflets, usually with smooth margins, rarely with minute apicolateral serration; pecten spines (Fig. 49) 12-16, with 3-5 long spines alternating with 7-12 short spines.

Type data. Holotype female with associated larval and pupal exuviae on microscope slide, deposited in NMNH. Type locality: Thailand, Prachin Buri, Ban Bu Phram.

Material examined. Seven thousand six hundred eighty-three specimens, as follows: 1432F, 1205M, 2117Le, 2298Pe, 631L, derived from 193 separate collections from natural habitats (66 adults, 128 immature) and 253 progeny broods from feral females. CAMBODIA. Batambang: Pang, Rolim, Pailin (12 $\left.{ }^{\circ} 51^{\prime} \mathrm{N} 102^{\circ} 36^{\prime} \mathrm{E}\right), 1962,11 \mathrm{~F}$ (Australian Nat. Inst. Coll.). Kampong Spoe: Kirirom $\left(11^{\circ} 21^{\prime} \mathrm{N}\right.$ $\left.104^{\circ} 31^{\prime} \mathrm{E}\right), 27$ Jan. 1969, 1F. Kampot: Bok Kou [Bokor] $\left(10^{\circ} 37^{\prime} \mathrm{N}\right.$ 104³’E), 23 Dec. 1969, 2F; 2 June 1969, 2M. Kaoh Kong: Pich Nil

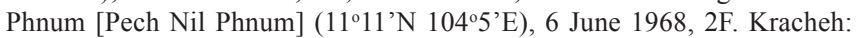
Snoul (12²'N 106 $26^{\circ}$ 'E), 8 Oct. 1961, 8F; 5 Nov. 1961, 3F; 1962, 7F.

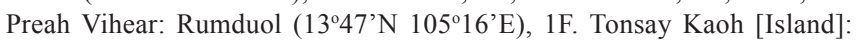
(10²6’N 104²0’E), 12 Jan. 1962, 1F (all above, J.M. Klein).

SOCIALIST REPUBLIC OF VIETNAM. Unknown locality, 1934, 1F. Buon Blech $\left(13^{\circ} 12^{\prime} \mathrm{N} 108^{\circ} 13^{\prime} \mathrm{E}\right), 4$ Nov. 1968, 3F. D'Linh, 1F. Con Son Island: (Central, 8 ${ }^{\circ} 43^{\prime} \mathrm{N} 106^{\circ} 36^{\prime} \mathrm{E}$ ), [2215], 5 Nov. 1966, 7F; [2217], 5 Nov. 1966, 5F; [2218], 5 Nov. 1966, 9F; [2473], 2 Nov. 1966, 1F, 1M; [2520], 20 Nov. 1966, 2M; Acc. \#418, 1F; [CS6493], 1966, 1F. LAO PEOPLE'S DEMOCRATIC REPUBLIC. Unknown locality, (Central, $\left.18^{\circ} 00^{\prime} \mathrm{N} 105^{\circ} 00^{\prime} \mathrm{E}\right), 24$ Jan. 1932, $1 \mathrm{~F}$ (C. Toumanoff). THAILAND. Chanthaburi: Thai Mai, Ban Bo Phu

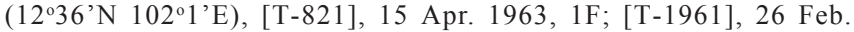
1963, 4F, 1M, 8LePe; [0565], 28 Oct. 1965, 1F, 7L; [0587], 1 Nov. 1965, 1F, 1Pe, 3L; [0588], 1 Nov. 1965, 1M, 1LePe. Ban Tha Mai $\left(12^{\circ} 37^{\prime} \mathrm{N} 102^{\circ} 02^{\prime} \mathrm{E}\right),[0540], 6$ Oct.1965, 1F; [0541], 6 Oct. 1965 , 1M, 1Pe, 2L; [0543], 6 Oct. 1965, 1L; [0544], 6 Oct. 1965, 1F, 1Pe, 2L; [0545], 6 Oct. 1965, 4L; [0546], 5 Oct. 1965, 4F; [0547], 6 Oct. 1965, 5F. Ban Chak Yai (12³1'N 102'1'E), [0567], 29 Oct. 1965, 2F, 2LePe; [0568], 29 Oct. 1965, 2F, 1M, 3LePe; [0569], 29 Oct. 1965, $1 \mathrm{~F}, 1 \mathrm{LePe}, 4 \mathrm{~L} ;[0570], 29$ Oct. 1965, 6L; [0571], 29 Oct. 1965, 1L; [0572], 29 Oct. 1965, 2F, 2M, 2LePe, 2Pe, 1L; [0579], 31 Oct. 1965, 8L; [0580], 31 Oct.1965, 1L; [0584], 31 Oct.1965, 2F, 1M, 3LePe; [0585], 31 Oct.1965, 1F, 3M, 3Pe, 3L. Khao Phra Bat $\left(12^{\circ} 50^{\prime} \mathrm{N}\right.$ $\left.102^{\circ} 10^{\prime} \mathrm{E}\right),[0605], 3$ Nov. 1965, 1F, 1Pe; [0608], 3 Nov. 1965, 2L. Khao Hin Phoeng (12³1'N 102²'E), [0618], 5 Nov. 1965, 2M, 2LePe, 2L; [0620], 5 Nov. 1965, 2L; [0626], 5 Nov. 1965, 1Pe, 2L; [0629], 5 Nov. 1965, 2F, 2M, 3Pe, 3L; [0631], 5 Nov. 1965, 4F, 4M, 4LePe, 4Pe, 2L. Khao Soi Dao Tai $\left(12^{\circ} 57^{\prime} \mathrm{N} 102^{\circ} 11^{\prime} \mathrm{E}\right)$, [0964], 26 Mar. 1966, 1M, 1L; [0975], 29 Mar. 1966, 1F, 1M, 1LePe, 1Pe. Ban Si Phraya (12³6'N 102'3'E), [06423], 8 Aug. 1973, 3F, 9M, 3LePe, 6Pe; [06424], 8 Aug. 1973, 3F, 2LePe, 2L; [06426], 8 Aug. 1973, 2F, 2M, 3LePe, 1Pe; [06427], 8 Aug. 1973, 1F, 4M, 5LePe, 6L; [06430], 8 Aug. 1973, 1M, 1LePe, 3L; [06431], 8 Aug. 1973, 2F, 1LePe, 1Pe; [06432], 8 Aug. 1973, 4F, 2M, 6LePe, 3L. Ban Klong Ka Thing (15 $\left.{ }^{\circ} 52^{\prime} \mathrm{N} 102^{\circ} 8^{\prime} \mathrm{E}\right)$, [06441], 9 Aug. 1973, 1F, 1Pe. Klong Pra Tong

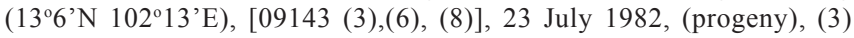
$1 \mathrm{~F}, 8 \mathrm{M}, 8 \mathrm{LePe}, 1 \mathrm{~L}$; (6) 5F, 6M, 11LePe, 1L; (8) 4F, 1M, 5LePe, 1L. Khlong Ta Riu (12 $\left.59^{\prime} \mathrm{N} 102^{\circ} 5^{\prime} \mathrm{E}\right)$, [09144 (40)], 24 July 1982, (progeny), 3F, 1M, 3LePe. Ban Makham, or Wat Phluang $\left(12^{\circ} 48^{\prime} \mathrm{N}\right.$ 102 $\left.09^{\prime} \mathrm{E}\right),[09196$ (31), (33, 34), (43), (71), (93)], 24 June 1983, (progeny), (31) 6F, 4M, 9LePe; (33) 4F, 4M, 7LePe; (34) 6F, 4M, 10LePe; (43) 4F, 4M, 8LePe, 2L; (71) 7F, 1M; (93) 6F, 1M, 6LePe, 1L; [09198 (8)], 24 June 1983, (progeny), 2F, 4M, 4LePe, 2L; [09231 (2), (6), (8), (10), (12)], 31 June 1983, (progeny), (2) 2F, 5M, 5LePe, 5Pe, 9L; (6) 1F, 4M, 5LePe, 2L; (8) 2F, 8M, 5LePe, 5Pe, 9L; (10) 1F, 4M, 5LePe, 1L; (12) 1F, 4M, 5LePe, 3L; [09276 (6-10), (12-26)], 30 Aug. 1983, (progeny), (6) 2F, 2LePe, 1L; (7) 3F, 2M, 5LePe, 1L; (8) $1 \mathrm{~F}, 2 \mathrm{M}, 2 \mathrm{LePe}, 1 \mathrm{~L}$; (7) 3F, 2M, 5LePe, 1L; (8) 1F, 2M, 2LePe, 1L; (9) 4F, 2M, 5LePe, 1L; (10) 2F, 5M, 6LePe, 1L; (12) 3F, 3M, 5LePe, 1L; (13) $2 \mathrm{M}, 2 \mathrm{LePe}$; (14) 6F, 1M, 6LePe, 2L; (15) 4F, 3M, 6LePe, 2L; (16) $7 \mathrm{~F}, 1 \mathrm{M}, 7 \mathrm{LePe}, 1 \mathrm{~L}$; (17) $2 \mathrm{~F}, 7 \mathrm{M}, 8 \mathrm{LePe}, 1 \mathrm{~L}$; (18) $1 \mathrm{~F}, 2 \mathrm{M}, 2 \mathrm{LePe}$,
1L; (19) 3F, 3M, 5LePe; (20) 1F, 1LePe, 2L; (21) 5F, 4M, 5LePe, 1Pe, $1 \mathrm{~L}$; (22) 8F, 4M, 8LePe, 3Pe, 1L; (23) 2F, 3M, 4LePe, 1L; (24) 7F, 6LePe, 1L; (25) 7F, 5M, 11LePe, 2L; (26) 6F, 1M, 6LePe; [09277 (68), (10), (19), (21-24), (26-27), (30-31), (33-38)], 30 Aug. 1983, (progeny), (6) 2F, 2M, 4LePe, 1L; (7) $1 \mathrm{~F}, 1 \mathrm{M}, 1 \mathrm{LePe}$; (8) $1 \mathrm{~F}, 5 \mathrm{M}$ $5 \mathrm{LePe}, 2 \mathrm{~L}$; (10) 6F, 5M, 10LePe, 2L; (19) 3F, 2M, 4LePe, 2L; (21) 4F, 2M, 5LePe; (22) 4F, 1M, 4LePe, 2L; (23) 2F, 4M, 5LePe, 1L; (24) $3 \mathrm{~F}, 1 \mathrm{M}, 3 \mathrm{LePe}, 1 \mathrm{~L}$; (26) 2F, 1M, 2LePe, 2L; (27) 3F, 3M, 4LePe, 2L; (30) $8 \mathrm{~F}, 1 \mathrm{M}, 6 \mathrm{LePe}, 2 \mathrm{Pe}, 2 \mathrm{~L}$; (31) 4F, 1M, 4LePe, 1L; (33) 2F, 4M, $5 \mathrm{LePe}$; (34) 4F, 3LePe; (35) 4F, 1M, 3LePe, 1Pe, 2L; (36) 4F, 3M, $5 \mathrm{LePe}, 1 \mathrm{Pe}, 1 \mathrm{~L}$; (37) 4F, 2M, 5LePe, 1L; (38) 2F, 1M, 2LePe, 1L; [09424], 6 Nov. 1984, 5F, 3M, 7LePe, 1Pe, 2L; [09425], 2F, 2LePe, 1L; [09426], 6 Nov. 1984, 4F, 6M, 10LePe; [09427], 6 Nov. 1984, 2F, 4M, 7LePe, 4L, 3L; [TH-1], 24 Sept. 1985, 1M, 1LePe; [TH-3], 24 Sept. 1985, (progeny), 2F, 4M, 4LePe, 1Pe; [TH-8 (1-4)], 23 Sept. 1985, (progeny), (1) 2F, 5M, 7LePe, 4L; (2) 7F, $1 \mathrm{M}, 8 \mathrm{LePe}, 5 \mathrm{~L}$; (3) 4F, 4M, 8LePe, 5L; (4) 3F, 4M, 7LePe; [TH-9 (1-5)], 25 Sept. 1985, (progeny), (1) 5F, 1M, 6LePe, 5L; (2) 2F, 5M, 7LePe, 4L; (3) 7F, 2M, 9LePe, 22L; (4) 6F, 3M, 9LePe, 8L; (5) 4F, 1M, 4LePe, 6L; [TH-10], 25 Sept. 1985, (progeny), 6F, 3M, 9LePe , 6L; [ TH-12 (1-8)], 27 Sept. 1985, (progeny), (1) 7F, 1M, 8LePe, 5L; (2) 3F, 4M, 7LePe, 5L; (4) $1 \mathrm{M}, 1 \mathrm{LePe}, 3 \mathrm{~L}$; (5) 4F, 3M, 7LePe, 5L; (6) 1F, 2M, 1LePe, 6L; (7) 2F, 4M, 2LePe, 5L; (8) 5F, 2M, 5LePe, 3L; [TH-13 (1, 2)], 26 Sept. 1985, (progeny), (1) 4F, 4M, 8LePe, 10L; (2) 2F, 4M, 6LePe, 10L; [TH 511 (1)], 16 July 87, (progeny), 19F, 7M, 25LePe; [85239 WRG1], 29 Aug. 1985, (progeny), 6F, 2M, 7LePe, 1Pe, 1L; [85241 WRG4], 29 Aug. 1985, 8F, 11M, 19LePe; [QD5241 DRX3], 29 Aug.1985, (progeny), 6F, 10M, 16LePe, 10L; [QD5241 DRX4], 29 Aug. 1985, (progeny), 5F, 4M, 9LePe, 5L; [QD5241 DRX5], 29 Aug. 1985, (progeny), 7F, 6M, 13LePe, 4L; [QD5297 DRX 2-6], Aug. 1985, 6F; [QD5298 DRX-9], Aug. 1985, 1F (all above, AFRIMS). Chiang Mai: Hang Dong, Doi Sutep (1848’N 98 54'E), [T-1171], 1 May 1962, 1F, (E.I. Coher and P.F. Beales). Doi Sutep, [M591a], 12 Mar. 1953, 1M (D.L. and E.B. Thurman). Doi Sutep Road, 6 Dec. 1959, 1F, 1LePe (E.I. Coher and P.F. Beales). Doi Sutep, Suan Kwinnin [T-1208], 9 Aug. 1962, 1F. Doi Sutep, Tham Khun Kan [T-1683], 8 Oct. 1962, 1F. (AFRIMS). Doi Sutep, Ban Pong (18 $45^{\prime}$ N 98 $54^{\circ}$ 'E), [84], 18 Sept. 1959, 7F, 1L; [88], 3 Sept. 1959, 2L; 14 Oct. 1959, 2F (E.I.Coher and P.F.Beales). Hang Dong, Ban Huai Kaeo (18 $\left.{ }^{\circ} 40^{\prime} \mathrm{N} 98^{\circ} 49^{\prime} \mathrm{E}\right)$, [M 445], 4 Feb. 1953, 2F (D.L. and E.B. Thurman). Hot, Ban Mea Sanam (18 ${ }^{\circ}{ }^{\prime} \mathrm{N}$ 98¹9'E), [T-1753], 2 Nov. 1962, 1F; [T-1754], 2 Nov. 1962, 3F; [T1758], 2 Nov. 1962, 1F (AFRIMS). Chon Buri: Bang La Mung, Khao Mai Kaeo (12 $\left.{ }^{\circ} 57^{\prime} \mathrm{N} 101^{\circ} 2^{\prime} \mathrm{E}\right)$, [U-11], 18 May 1963, 1F; [U-133], 1963, 1F; [U-695], 8 Oct. 1963, 3F; [U-681], 6 Oct. 1963, 3F; [U709], 9 Oct. 1963, 1F (J.E. Scanlon and U. Sandhinand); [CL-14], 8 Oct. 1963, 1Pe; [CL-68], 11 Oct. 1963, 3L; [CL-83], 22 Oct. 1963, 2F, 1Pe; [CL-84], 22 Oct. 1963, 1F, 1L; [CL-89], 23 Oct. 1963, 2M, 1Pe; [CL-90], 23 Oct. 1963, 1M, 1LePe; [CL-91], 23 Oct.1963, 2F, 2Pe; 1963, 8F, 5M; 1964 (Original SEATO, Bangkok (Chon Buri) colony F-1, F-2), 20F (J.E.Scanlon). Kanchanaburi: Huai Mae Nam

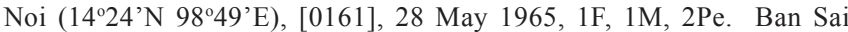

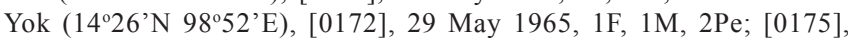
29 May 1965, 1M, 1Pe. Huai Bong Ti $\left(14^{\circ} 5^{\prime} \mathrm{N}\right.$ 990'E), [202], 3 June 1965, 1M, 1LePe; [203], 3 June 1965, 1F, 1LePe. (AFRIMS). Lampang: Ngao $\left(18^{\circ} 45^{\prime} \mathrm{N} 99^{\circ} 55^{\prime} \mathrm{E}\right)$, [LG 2], 1963, 1F, 1L. Ban Pha Daeng (1859'N 99 48’E), [01948], 11 Apr. 1967, 1F; [01950], 11 Apr. 1967, 1F, 1Pe; [01960], 11 Apr. 1967, 2F, 1M, 1LePe, 1Pe. Ban Pha Khoi (1855’N 9956'E), [01972], 21 Apr. 1967, 4F, 5M; [01973], 21 Apr. 1967, 2F, 5M, 5Pe. Ngao, Ban Rai Na Dieo (18 59’ N $99^{\circ}$ 55'E), [02832], 24 May 1968, 28F. (All, AFRIMS). Loei: Ban Si Than (16 $\left.58^{\prime} \mathrm{N} 101^{\circ} 52^{\prime} \mathrm{E}\right)$, [08349], 23 Oct. 1980, 2F, 2M, 1L; [08351], 23 Oct. 1980, 1LePe; [08352], 23 Oct. 1980, 7F, 3M, 8LePe, 1Pe, 10L; [08353], 23 Oct. 1980, 1Pe, 6L (all, AFRIMS). Nakhon Nayok: Khao Yai, Sariga Waterfall (14 $\left.25^{\prime} \mathrm{N} 101^{\circ} 25^{\prime} \mathrm{E}\right),[\mathrm{NY} 220$, 16 June 1964, 1F, 1Pe; [NY 233], 16 June 1964, 1LePe, 1Pe; [NY 227], 16 June 1964, 3F, 4M, 7Pe. Huai Sai Noi (14² $\left.23^{\prime} \mathrm{N} 101^{\circ} 29^{\prime} \mathrm{E}\right)$, [0034], 1 May 1965, 1M, 1LePe; [0035], 1 May 1965. 2F, 1M, 1LePe; [0038], 1 May 1965, 1M, 1LePe, 1L; [0039], 1 May 1965, 1M; [0040], 1 May 1965, 2F, 2M, 4LePe, 3L; [0043], 1 May 1965, 1F; [0044], 1 May 1965, 5F, 1M, 3LePe, 4Pe; [0047], 1 May 1965, 2F, 
Table 18. Number of branches for setae of the larva of An. dirus: range (mode).

\begin{tabular}{|c|c|c|c|c|c|c|c|c|c|c|c|c|c|}
\hline \multirow{2}{*}{$\begin{array}{l}\text { Seta } \\
\text { No. }\end{array}$} & \multirow{2}{*}{$\begin{array}{c}\text { Head } \\
\text { C }\end{array}$} & \multicolumn{3}{|c|}{ Thorax } & \multicolumn{9}{|c|}{ Abdominal segments } \\
\hline & & $P$ & M & $\mathrm{T}$ & $\mathrm{I}$ & II & III & IV & $\mathrm{V}$ & $\mathrm{VI}$ & VII & VIII & $X$ \\
\hline$\overline{0}$ & 1 & 1 & - & - & - & 1 & 1 & 1 & 1 & 1 & 1 & 1 & - \\
\hline 1 & 1 & $11-18(13)$ & $22-36(30)$ & $1-2(1)$ & $3-9(4)$ & $5-18(7)$ & $15-22(18)$ & $16-21(19)$ & $15-22(18)$ & $15-21(16)$ & $10-18(13)$ & 1 & 1 \\
\hline 2 & 1 & $8-17(10)$ & $1-4(2)$ & $1-2(1)$ & $1-3(2)$ & $5-10(7)$ & $5-8(7)$ & $3-6(4)$ & $4-6(4)$ & $4-6(5)$ & $4-7(5)$ & $4-8(5) 1$ & $15-20(18)$ \\
\hline 3 & 1 & $1-2(1)$ & 1 & $3-8(4)$ & $1-4(3)$ & $1-3(1)$ & 1 & $2-3(2)$ & 1 & 1 & $2-4(3)$ & $5-9(7) 7$ & $7-11(10)$ \\
\hline 4 & $1-2(1)$ & $12-16(13)$ & $1-3(2)$ & $2-4(3)$ & $4-6(5)$ & $2-6(4)$ & $2-4(3)$ & $3-4(3)$ & $2-3(3)$ & 1 & 1 & 1 & 9 \\
\hline 5 & $9-13(11)$ & $23-49(41)$ & 1 & $28-36(36)$ & $2-4(3)$ & $3-7(5)$ & $3-5(4)$ & $3-4(3)$ & $3-5(3)$ & $4-6(5)$ & $3-6(4)$ & $3-4(3)$ & - \\
\hline 6 & $9-15(13)$ & 1 & $3-6(3)$ & $1-3(2)$ & $12-27(19)$ & $13-27(23)$ & $11-19(14)$ & $1-3(2)$ & $2-3(2)$ & $2-4(3)$ & $3-6(4)$ & $1-\mathrm{S}$ & $4-7(5)$ \\
\hline 7 & $10-16(13)$ & $19-27(23)$ & $2-4(2)$ & $21-35(34)$ & $11-19(17)$ & $13-23(17)$ & $4-6(5)$ & $3-6(4)$ & $3-6(4)$ & $2-3(3)$ & $3-4(3)$ & $2-S$ & $4-7(7)$ \\
\hline 8 & $1-3(1)$ & $21-35(28)$ & $14-24(14)$ & $21-34(28)$ & - & $1-2(2)$ & $1-2(2)$ & $2-3(2)$ & $2-4(2)$ & $1-3(2)$ & $3-8(4)$ & $6-S$ & $2-3(2)$ \\
\hline 9 & $1-6(2)$ & $1-2(1)$ & 1 & 1 & $3-5(4)$ & $6-10(7)$ & $6-11(8)$ & $5-11(7)$ & $5-9(6)$ & $6-9(7)$ & $4-7(5)$ & $7-S$ & $1-3(2)$ \\
\hline 10 & $1-2(1)$ & 1 & 1 & 1 & 1 & $2-3(2)$ & 1 & 1 & 1 & $2-3(3)$ & $4-7(5)$ & 8-S & $2-4(2)$ \\
\hline 11 & $15-29(21)$ & 1 & 1 & 1 & $2-5(3)$ & 1 & $2-3(3)$ & $2-3(3)$ & $2-3(2)$ & $1-3(2)$ & $1-2(2)$ & 9-S & $2-4(3)$ \\
\hline 12 & $1-3(2)$ & 1 & 1 & $2-3(2)$ & $2-4(3)$ & 1 & $1-3(2)$ & $2-4(2)$ & $2-3(2)$ & 1 & 1 & - & - \\
\hline 13 & $3-7(6)$ & $3-7(4)$ & $3-6(5)$ & $2-4(3)$ & $2-4(4)$ & $4-6(4)$ & $4-7(5)$ & $2-4(3)$ & $2-4(3)$ & $4-10(6)$ & $2-3(2)$ & - & - \\
\hline 14 & $3-5(4)$ & $3-8(5)$ & $6-10(7)$ & - & - & - & - & 1 & 1 & 1 & 1 & 1 & - \\
\hline 15 & $2-6(3)$ & - & - & - & - & - & - & - & - & - & - & - & - \\
\hline
\end{tabular}

n.c. $=$ not counted

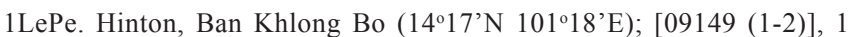
Sept. 1982, (progeny), (1) 10F, 1M, 5LePe, 6Pe, 1L; (2) 2F, 10M, 10LePe, 2L (all, AFRIMS). Nakhon Ratchasima: Pak Chong (14 $42^{\circ} \mathrm{N}$ 101² 25'E), [NR 23], Apr. 1963, 1F; [NR 371], 1 Apr. 1964, 1LePe 1L; [NR 375], 1 Apr. 1964, 1F, 1M, 1LePe; [NR398], 3 Apr. 1964, 1L. Khlong Phai (14 22’N 101 50’E), [02001], 21 May 1967, 1M, 1LePe; [02003], 21 May 1967, 1F, 1M, 1LePe, 1Pe; [02008], 21 May 1967, 1F, 1Pe. Kilometer 83 between Kabinburi and Pak Tong Chai [02021], 24 May 1967, 2F, 2M, 3Pe, 4L; [02022], 24 May 1967, 1M. Khai

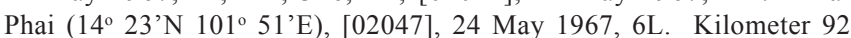
between Kabinburi and Pak Tong Chai [02053], 27 May 1967, 2L. Khao I Phrom (14을 $21^{\prime} \mathrm{N} 101^{\circ} 50$ 'E), [06573], 23 Oct. 1973, 1M, 1Pe; [06574], 23 Oct. 1973, 1M, 1Pe (all, AFRIMS). Nhakon Sawan:

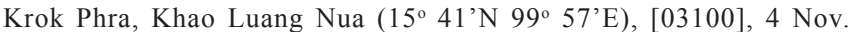
1968, 2L. Krok Phra, Huai Krachang Ngam ( $15^{\circ} 34^{\prime} \mathrm{N}$ 99 $\left.58^{\circ} \mathrm{E}\right)$, [03119], 8 Nov. 1968, 1F, 2M, 1LePe, 2Pe, 4L; [03123], 8 Nov. 1968, 1L. Nan: Ban Fang Min (18 31'N 100 34'E), [01463], 14 Aug. 1966, 2F, 1M, 1Pe (all, AFRIMS). Ban Pang Chom Phu (18 31'N $\left.100^{\circ} 36^{\prime} \mathrm{E}\right),[01473$ ], 15 Aug. 1966, 1M, 1Pe. Phitsanulok: Wang Thong, Wang Nok ( $\left.16^{\circ} 50^{\prime} \mathrm{N} 100^{\circ} 26^{\prime} \mathrm{E}\right), 20$ Sept. 1985, (progeny), [PN102], 2F, 2LePe, 1Pe, 1L; [PN114], 2F, 1Pe, 1L; [PN162], 3F, $1 \mathrm{LePe}, 1 \mathrm{Pe}, 1 \mathrm{~L}$; [PN209], 3F, 2LePe, 1Pe, 1L; [PN441], 4F, 1M, 6LePe, 1L; [PN446], 2F, 1M, 5LePe, 2L; [PN459], 3F, 2M, 6LePe, 1L; [PN530], 2F, 1M, 3LePe, 1L; [PN599], 7F, 6LePe, 1Pe, 1L; [PN630], 1F, 2M, 5LePe, 1L. (All, V. Baimai). Phrae: Rong Kwang, Ban Phai Thon (18²1'N 100'19'E), [T-77], 19 Nov. 1961, 6L (J.E. Scanlon). Prachinburi: Khao Suan Hom (14'21'N 101 $\left.1^{\circ} 53^{\prime} \mathrm{E}\right)$, [02013], 23 May 1967, 1F, 3M, 1LePe, 1L. Ban Wang Mut (14'16'N 101 $\left.{ }^{\circ} 55^{\prime} \mathrm{E}\right)$, [02072], 30 May 1967, 1F, 1LePe, 2L; [02073], 30 May 1967, 1F, 1LePe; [02074], 30 May 1967, 3F, 3M, 4LePe,1Pe. Ban Thap Lan (14²15'N 101'55'E), [06000], Aug. 1971, 1M; [06033], 20 July 1971, 1M, 1Le; [06037], 27 July 71, 1F, 1LePe; [06053], 29 July 1971, 3F, 1M, 1LePe, 2Pe; [06064], 17 Aug. 1971, 4F, 1LePe, 1Pe; [06068], 20 Aug. 1971, 1L; [06089], 7 Sept. 1971, 2F, 2M, 1LePe, 1Pe; [06101], 25 Oct. 1971, 1M; [P-3], 20 July 1971, 2F, 2M, 1LePe. Ban Bu Phram (14 $\left.{ }^{\circ} 16^{\prime} \mathrm{N} 101^{\circ} 54^{\prime} \mathrm{E}\right)$, [06022], 12 July 1971, 1F, 1LePe; [06042], 21 July 1971, 6F, 3M, 3LePe, 3Pe, 1L; [06047], 28 July 1971, 2F; [06097], 21 Sept. 1971, 1F, 1M; [P-12], 28 July 1971, 1M; [09146 (1, 2), (4), (7-9), (11-18), (20), (22-30)], 3 Aug. 1982, (progeny); (1) 3F, 2M, $5 \mathrm{LePe}, 1 \mathrm{~L}$; (2) 2F, 3M, 5LePe, 2L; (4) $5 \mathrm{~F}, 1 \mathrm{M}, 6 \mathrm{LePe}, 2 \mathrm{~L}$; (7) $1 \mathrm{~F}, 1 \mathrm{M}$, $1 \mathrm{LePe}, 1 \mathrm{Pe}, 1 \mathrm{~L} ;(8) 1 \mathrm{~F}, 6 \mathrm{M}, 6 \mathrm{LePe}$ (9) $1 \mathrm{~F}, 5 \mathrm{M}, 5 \mathrm{LePe}, 2 \mathrm{~L}$; (11) $1 \mathrm{~F}$, 2M, 3LePe, 2L; (12) 1F, 5M, 6LePe, 2L; (13) 1F, 4M, 5LePe, 4L; (14) 5F, 4M, 8LePe, 3L; (15) 2F, 4M, 6LePe, 3L; (16) 4F, 5M, 9LePe; (17) 3F, 4M, 7LePe, 2L; (18) 3F, 3M, 6LePe, 3L; (21) 3F, 4M, 7LePe; (22)
4F, 4M, 6LePe, 2Pe, 2L; (23) 4F, 5M, 8LePe; (24) 3F, 4M, 6LePe; (25) $1 \mathrm{~F}, 4 \mathrm{M}, 5 \mathrm{LePe}, 2 \mathrm{~L}$; (26) 2F, 4M, 6LePe, 1L; (27) 5F, 1M, 5LePe; (28) 6F, 3M, 5LePe, 3Pe, 1L; (29) 3F, 2M, 5LePe; (30) 3F, 4M, 7LePe, 2L; [09147 (1-11), (13, 14), (16-23), (25-29)], 4 Aug. 1982, (progeny), (1) $2 \mathrm{~F}, 3 \mathrm{M}, 5 \mathrm{LePe}, 2 \mathrm{~L}$; (2) $5 \mathrm{M}, 5 \mathrm{LePe}, 2 \mathrm{~L}$; (3) $1 \mathrm{~F}, 5 \mathrm{M}$, 6LePe; (4) $7 \mathrm{~m}, 7 \mathrm{LePe}$; (5) 2F, 3M, 5LePe, 5L; (6) 4F, 2M, 6LePe; (7) $1 \mathrm{~F}, 4 \mathrm{M}, 5 \mathrm{LePe}, 2 \mathrm{~L}$; (8) 3F, 2M, 5LePe, 2L; (9) $1 \mathrm{~F}, 4 \mathrm{M}, 5 \mathrm{LePe}, 5 \mathrm{~L}$; (10) 1F, 4 m, 5LePe; (11) 3F, 3M, 6LePe, 4L; (13) 2F, 3M, 5LePe, 2L; (14) $3 \mathrm{~F}, 2 \mathrm{M}, 2 \mathrm{LePe}, 3 \mathrm{Pe}$; (16) 2F, 3M, 5LePe, 5L; (17) 3F, $2 \mathrm{M}$, 5LePe, 2L; (18) 6F, 4M, 6LePe, 4Pe; (19) 5F, 2M, 7LePe; (20) 6F, $3 \mathrm{M}, 8 \mathrm{LePe}, 1 \mathrm{Pe}$; (21) 3F, 2M, 5LePe, 1L; (22) 3F, 3M, 5LePe, 1Pe, 3L; (23) 3F, 4M, 7LePe, 2L; (25) 2F, 4M, 5LePe; (26) 4F, 3M, 7LePe, $3 \mathrm{~L}$; (27) 3F, 3M, 6LePe; (28) 3F, 2M, 5LePe, 1L; (29) $2 \mathrm{~F}, 3 \mathrm{M}$, 4LePe,1 Pe, 3L (all above, AFRIMS). Prachuap Kiri Khan: Hua Hin $\left(12^{\circ} 34^{\prime} \mathrm{N} 99^{\circ} 58^{\prime} \mathrm{E}\right)$, [M-860], 28 Sept. 1957, 11L (Thurman). Sakon Nakhon: Phu Pong Daeng (176'N 104³'E), [08361], 31 Oct. 1980,

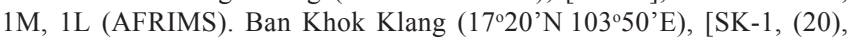
(43), (47), (50)], 26-30 Aug. 1985, (progeny), [SK-1], 2F, 3M, 5LePe, $1 \mathrm{~L}$; [SK-20], 4M, 3LePe; [SK- 43], 2F, 5M, 6LePe, 1Pe, 1L; [SK-47], 3F, 3M, 6LePe, 1L; [SK-50], 6F, 6M, 12LePe, 1L (V. Baimai). Tak:

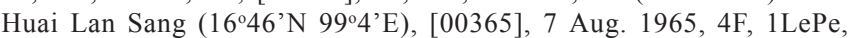
$3 \mathrm{Pe}$ (AFRIMS). Tha Song Yong, Mae Tan, Komali Ko $\left(17^{\circ} 21^{\prime} \mathrm{N}\right.$ 98¹4'E), [TH549(1)], 13-16 Nov. 1987 (progeny), 14F, 8M, 13LePe, 9Pe. Mae Sot, Thum Rua (16²0’N 9840’E), [TH 1690 (1-8), (13)], 7 Aug. 1989, (progeny), (1) 20F, 20M, 40LePe, 2L; (2) 10F, 11M, 20LePe, 1L; (3) 15F, 26M, 40LePe, 4L; (4) 12F, 8M, 20LePe, 2L; (5) $3 \mathrm{~F}, 2 \mathrm{M}, 4 \mathrm{LePe}, 2 \mathrm{~L}$; (6) 6F, 15M, 20LePe, 2L; (7) 30F, 31M, 30LePe, $2 \mathrm{~L}$; (8) 1F, 2M, 3LePe, 1L; (13) 6F, 9M, 15LePe, 2L; [TH1746, (410)], 4 Oct. 1989, (progeny); (4) 4F, 6M, 10LePe, 3L; (5) 7F, 7M, 14LePe, 2L; (6) 12F, 18M, 30LePe, 3L; (7) 5F, 1M, 6LePe, 1L; (8) 9F, 2M, 10LePe; (9) 7F, 5M, 8LePe, 3Pe, 4L; (10) 7F, 13M, 20LePe, 2L. Mae Sot, Ban Kariang, Thum Rua (16 $40^{\prime}$ N 98 $48^{\circ}$ 'E), [MS 010 (26), (10-15), (18-25)], 3-9 July 1989, (progeny), (2) 6F, 14M, 20LePe, $2 \mathrm{~L}$; (3) $10 \mathrm{~F}, 10 \mathrm{M}, 20 \mathrm{LePe}, 2 \mathrm{~L}$; (4) $12 \mathrm{~F}, 12 \mathrm{M}, 24 \mathrm{LePe}, 1 \mathrm{~L}$; (5) $10 \mathrm{~F}$, $10 \mathrm{M}, 18 \mathrm{LePe}, 1 \mathrm{~L}$; (6) 7F, 13M, 20LePe, 2L; (8) 3F, 4M, 7LePe, 2L; (10) $12 \mathrm{~F}, 14 \mathrm{M}, 24 \mathrm{LePe}, 2 \mathrm{~L}$; (11) 7F, 12M, 18LePe, 1L; (12) 15F, 4M, $17 \mathrm{LePe}, 4 \mathrm{~L}$; (13) 10F, 3M, 12LePe, 2L; (14) 8F, 15M, 22LePe, 2L; (15) $17 \mathrm{~F}, 17 \mathrm{M}, 33 \mathrm{LePe}, 3 \mathrm{~L}$; (18) 10F, 9M, 19LePe, 3L; (19) 4F, 2M, 6LePe, 2L; (20) 1F, 1LePe; (21) 2M, 2LePe, 2L; (22) 1F, 2M, 3LePe, $3 \mathrm{~L}$; (23) 12F, 13M, 20LePe, 3L; (24) 10F, 5M, 19LePe, 1L; (25) 1F, $1 \mathrm{M}, 2 \mathrm{LePe}, 1 \mathrm{~L}$. Mae Sot [E1 (1), (3), (5) (6)], $(8,9),(11,12)], 8$ Nov. 1989, (progeny), (1) 1F, 1M, 2LePe, 2L; (3) 9F, 22M, 31LePe, 2L; (5) 10F, 4M, 14LePe, 2L; (6) 10F, 1M; (8) 9F, 6M, 6LePe, 1L; (9) 2F, 7M, 9LePe, 1Pe, 2L; (11) 10F, 2M, 12LePe, 8Pe, 2L; (12) 3F, 1M, 3LePe, 
1Pe, 2L; [E2 (1)], 8 Nov. 1989, (progeny), 5F, 5M, 10LePe, 2L; [E3 $(1,2)$ ], 8 Nov. 1989, (1) 10F, 9M, 19LePe; (2) 7F, 2M, 9LePe, 2L; [E5 (2)], 1F, 1M, 2LePe, 1L. Mae Sot, Ban Tham Sua, Ban Pha Te $\left(16^{\circ} 40^{\prime} \mathrm{N}\right.$ 983을), [DCR (3), (7), (14), (16-18), (27), (30-37), (43), (48), (49), (56), (59), (63), (65), (67), (69), (76)], Oct. 1989, (progeny), (3) 6F, $1 \mathrm{M}, 7 \mathrm{LePe}, 1 \mathrm{~L}$; (7) 3F, 3LePe, 1L; (14) $2 \mathrm{~F}, 5 \mathrm{M}, 8 \mathrm{LePe}, 1 \mathrm{~L}$; (16) $1 \mathrm{~F}$, $1 \mathrm{M}, 2 \mathrm{LePe}, 2 \mathrm{~L}$; (17) $2 \mathrm{~F}, 8 \mathrm{M}, 10 \mathrm{LePe}, 2 \mathrm{~L}$; (18) 7F, 3M, 19LePe, 1L; (22) 5F, 4M, 4LePe, 5Pe, 1L; (23) 4F, 4M, 8LePe; (24) 7M, 7LePe, $1 \mathrm{~L}$; (26) 1F, 1M, 2LePe, 1L; (27) 4F, 6M, 8LePe, 1Pe, 1L; (30) $1 \mathrm{M}$, $1 \mathrm{LePe}, 2 \mathrm{~L}$; (31) 5F, 5M, 2L; (32) 2F, 2M, 2L; (33) 2F, 2LePe, 1L; (34) 2F, 2M, 3LePe, 1Pe, 1L; (35) 2F, 2M, 2LePe, 1L; (36) 5M, 4LePe, $1 \mathrm{Pe}, 1 \mathrm{~L}$; (37) 5M, 4LePe, 1Pe, 1L; (43) 2F, 4M, 6LePe, 1L; (48) 3F, $3 \mathrm{M}, 6 \mathrm{LePe}, 1 \mathrm{~L}$; (49) 1F, 2M, 3LePe, 1Pe, 2L; (56) 2F, 3M, 5LePe, $1 \mathrm{Pe}, 1 \mathrm{~L}$; (59) $1 \mathrm{M}, 1 \mathrm{LePe}, 1 \mathrm{~L}$; (63) $2 \mathrm{~F}, 1 \mathrm{M}, 3 \mathrm{LePe}, 1 \mathrm{~L}$; (75) $1 \mathrm{~F}$, 1LePe, 1L; (76) 1F, 1M, 1LePe, 1L (all above, V. Baimai). Trat: Ko [Island] Chang, Khao Chang Yai $\left(12^{\circ} 1^{\prime} \mathrm{N} 102^{\circ} 1^{\prime} \mathrm{E}\right)$, [02456], 12 Dec. 1967, 2F, 2LePe, 2L; [02457], 12 Dec. 1967, 1M, 1LePe, 1L; [02464], 12 Dec. 1967, 1M, 1Pe; [02465], 12 Dec. 1967, 1M, 1Pe; [02470], 13 Dec. 1967, 1F, 1Pe, 3L. Ban Khong Thian [02490], 19 Dec. 1967, 1L (AFRIMS). Ubon Ratchathani: Na Chaluai, Phu Phalan Sung (Wat), Ban Chaluai $\left(14^{\circ} 31^{\prime} \mathrm{N} 105^{\circ} 12^{\prime} \mathrm{E}\right)$, [TH23(1,2)], 25 Aug. 1987, (progeny), (1) 14F, 15M, 29LePe, 4L; (2) 23F, 13M, 36LePe, 5L; [TH 535 (3-5)], 27 Sept. 1987, (progeny), (3) 13F, 5M, 18LePe, 5L; (4) $15 \mathrm{~F}, 5 \mathrm{M}, 20 \mathrm{LePe}, 7 \mathrm{~L}$; (5) 4F, 8M, 12LePe, 2L (AFRIMS).

Distribution (Fig. 55). Anopheles dirus is known from Cambodia (Batambang, Kampong Soe, Kampot, Kaoh Kong, Kracheh, Preah Vihear, Tonsay Kaoh Island), Socialist Republic of Vietnam (Buon Blech, Con Son Island), Lao People's Democratic Republic, Thailand (Chanthaburi, Chiang Mai, Chon Buri, Kanchanaburi, Lampang, Loei, Nakhon Nayok, Nakhon Ratchasima, Nhkon Sawan, Nan, Phitsanulok, Prachinburi, Prachuap Kiri Kan, Sakon Nakhon, Tak, Trat, Ubon Ratchathani), and China (Hainan Province).

Bionomics and medical importance. Anopheles dirus is widely distributed in central, northern, and eastern Thailand and also Laos, Cambodia, Vietnam, and Hainan Province of China. It is an extremely important vector of human Plasmodium in forested and hilly forested areas throughout its distribution range. However, it seems to be also adapted to human changes in the environment and it is suspected to be as efficient at transmitting human malarial parasites in areas of commercial tree crop plantations and gem mining areas as it is in forest and foothills in Thailand (Gomes et al.1998; Singhasivanon et al.1999), and in Chanthaburi, Thailand, where it occurs in both forest and rubber plantations (Ketrangsee et al. 1991). Furthermore, An. dirus can maintain malaria transmission in areas where the species is not dense (Rosenberg et al. 1990a; Trung et al. 2004). Although being a primary vector, the rule of $\mathrm{An}$. dirus in the transmission of human malaria parasites is variable and depends on the area. In southern Thailand, An. dirus is considered to be secondary vector, whereas in southeastern areas it is the primary vector (Rattanarithikul et al. 1996c). In a Karen village, Mae Tha Waw, in the northwestern mountains of Tak Province, An. dirus was not abundant and was considered to be a secondary vector of malaria (Harbach et al. 1987a). In a hyperendemic village for malaria in Thailand, Gingrich et al. (1990) found $0.9 \%$ of $A n$. dirus positive for $P$. falciparum and $0.4 \%$, positive for $P$. vivax, suggesting that $A n$. dirus was the primary vector as its vectorial capacity was higher than that of An. minimus. In two provinces in eastern Thailand, $P$. falciparum CS protein was detected in $0.3 \%$ of An. dirus examined (Frances et al. 1996). Rosenberg \& Andre (1985) considered An. dirus the only malaria vector in Chantaburi Province, Thailand where in dry season $24 \%$ of the individual specimens were infective for human Plasmodium. The sporozoite infection rate was higher in An. dirus than in An. minimus and specimens were found infected in the salivary gland with either $P$. falciparum or $P$. vivax or mixed (Ketrangsee et al. 1991). Anopheles dirus is also a primary vector of human Plasmodium in Lao PDR (Vythilingam et al. 2001; Toma et al. 2002; Kobayashi et al. 2004; Trung et al. 2004). Vythilingam et al. (2001) found specimens of An. dirus infected with oocysts on both indoor and outdoor human bait collections. In Khammouane Province, southeastern Laos, An. dirus was involved in the transmission of $P$. falciparum and $P$. vivax. The vectorial capacity was 0.009 0.428 and the inoculation rate was 0.052-0.137 (Toma et al. 2002). In 360 villages in three provinces (Vientiane, Burikhamxay, and Khammouane) in central and southern Laos, where An. dirus is the main vector of human Plasmodium, the density and the parity rate decreased as a result of a program for malaria control using impregnated bed nets, specially because of the biting behavior of An. dirus (Kobayashi et al. 2004). Anopheles dirus is also considered to be a primary vector of human Plasmodium in Vietnam (Van Bortel et al.2001; Trung et al. 2004). Additionally, An. dirus appears to be the primary vector of chloroquine-resistant $P$. falciparum (Wilkinson et al.1972; 1976).

Anopheles dirus was shown to be susceptible to infection and can transmit $P$. coatneyi originally isolated from $A n$. hackeri (Collins et al. 1967b), P. fieldi (Collins et al. 1968) and P. knowlesi $\mathrm{H}$ strain isolated from human infection (Collins et al. 1967a; Collins et al. 1971). However, it does not seem to be a good vector of $P$. cynomolgi because infection decreases the longevity and increases the mortality rate of An. dirus when compared to uninfected mosquitoes. The survival rate of An. dirus infected with more than 10 oocysts of P. cynomolgi is significantly shorter than that of non-infected mosquitoes. Decrease in longevity and survival rate seems to be related to the fact that infected mosquitoes carry an excessive number of bacteria and show deterioration of both the gut and salivary glands (Klein et al. 1982, 1986).

Large body size of adults is positively correlated with survivorship and consequently tends to increase the vectorial capacity of An. dirus. Adult size is correlated to larval density and protein accumulation during the larval stage. Increased adult density is correlated with decreased adult size. Additionally, larval populations fluctuated seasonally with rainfall, and thus adult size was negatively related to rainfall (Kitthawee et al. 1990; Kitthawee et al. 1992b; Kitthawee \& Edman 1995; Kitthawee et al. 1995). Females with a smaller body size are more abundant in the rainy season but are larger in cool and early dry seasons. Consequently, the potential to transmit malaria is higher during the cool and early dry season and first half of the rainy season (Kithawee et al. 1992a). In five villages situated in southern Thailand, females of An. dirus 
collected using human bait, bovid bait and light traps were positive for circumsporozoite antigen of $P$. vivax and $P$. falciparum. The combined entomologic inoculation rate for both P. vivax and P. falciparum in the wet season was 0.05 , and 0.0 in the dry season (Rattanarithikul et al. 1996c). In southern Thailand, An. dirus was collected on human bait from 1900-0400 h, however the peak collections were between 2000-2300 h. Among the specimens examined for blood feeding, most were positive for bovine blood, whereas a few specimens had more than one host blood (Rattanarithikul et al. 1996a). Anopheles dirus was also attracted to $\mathrm{CO}_{2}$-CDC light trap on the Myanmar border in southern Thailand (Rattanarithikul et al.1996b). Adults were collected on human bait (Rattanarathikul et al. 1996b), and were more abundant immediately after the end of the wet season and early in the wet season (Rosenberg et al. 1990a,b), and lowest during the dry season (Ismail et al. 1974). Peyton \& Harrison (1979) observed that $A n$. dirus was abundant during the rainy season when the immature stages were found in several small, shallow, shaded, temporary ground pools.

The habitats sometimes were rich in organic matter and the water was turbid but always freshened by rain. In Thailand, larval habitats are elephant footprints, human and domestic animal footprints, puddles on foot paths, pools in dry stream beds, pools at edges of streams and springs, streams, ground pools, seepages, tank leakages, wheel ruts, pits dug for mining gems, rock pools, bamboo stumps, bases of large fallen tree trunks, and depressions in hollow logs. The breeding habitats had sandy, rocky or muddy bottoms (Peyton \& Harrison 1979). In a malaria endemic village near Mae Sot, Thailand, An. dirus occurs in habitats similar to those of An. scanloni and seems to prefer to lay eggs in temporary habitats. Habitats include domestic elephant footprints, wheel tracks, and cart tracks along paths and roads, flooded pools, pools in drying stream beds, margins of streams with shallow water, the water was stagnant or very slow running, under partial or heavy shade with a few habitats exposed to the sun. A few larvae were taken from a $1 \mathrm{~m}$ long, $50 \mathrm{~cm}$ deep cut in a tree stump (Rattanarithikul et al.1995). In Tha Mai District, Chanthaburi, Thailand, immatures of An. dirus were found in human-made gem pits. The water was clear, under full sun or partial shade (Kitthawee et al. 1993). Anopheles dirus showed resistance to DDT and FNT (fenitrothion) in Phetchabun Province, Thailand (Suwonkerd et al. 1990).

Systematics. Following the description of An. dirus by Peyton \& Harrison (1979) several studies confirmed its species status and also found new members of the Dirus Complex. Baimai et al. (1981) used cytological evidence from mitotic and meiotic karyotypes and polytene salivary chromosome banding patterns of An. dirus, An. cracens, and An. takasagoensis to show differences in the sex chromosomes relative to the position of the centromere, and the amount of constitutive heterochromatin and euchromatin support of the species status of those three genetic species. Additional, comparisons of the metaphase chromosomes of An. dirus, An. cracens, An. scanloni, and An. takasagoensis showed differences in the amount and distribution of the constitutive heterochromatin of the sex chromosomes that corroborated the results of cross-breeding experiments and morphological studies indicating that there were at least three species in the Dirus Complex (Wibowo et al. 1984). Hii et al. (1985), using characters of the polytene chromosomes and cross-breeding data, confirmed the species status of An. dirus and that it is was a complex of at least two species (An. dirus and $A n$. cracens). Additionally, they proposed that genetic changes had occurred in both autosomes and $\mathrm{X}$ chromosomes. The $\mathrm{X}$ chromosome seems to play an important role in male sterility (Hii 1984b). Discriminat analysis of morphometric data of the fourth-instar larva and pupa (Hii 1986), as well as morphometric studies on the male genitalia and the frequency of clasper movement, showed differences between An. dirus and An. cracens. Anopheles dirus was observed to be eurigamous species in the laboratory (Sucharit \& Choochote 1983). Ultrastructure of the eggs of An. dirus, An. cracens, An. scanloni, and An. baimaii showed that there are differences in the outer chorionic cells between the frill and the floats that are species specific (Damrongphol \& Baimai 1989). Additionally, species status of An. dirus was corroborated by enzyme electromorphs (Green et al. 1992), gas chromatography of cuticular hydrocarbons (Cui et al. 1992), a nonradioactive DNA hybridization method (Audtho et al 1995), chromosome banding pattern (Poopittayasataporn \& Baimai 1995), ITS2 base sequences (Xu \& Qu 1997b; Xu et al. 1998), ASA method using ITS2 (Walton et al. 1999), a PCR based method (Huong et al. 2001), and a SCAR single multiplex PCR-based method (Manguin et al. 2002). Anopheles dirus is not a genetically homogeneous species in Thailand. It shows heterochromatin variation in the sex chromosomes, and probably evolution of these chromosomes results from changes in constitutive heterochromatin (Baimai et al. 1984b).

Anopheles dirus can be recognized by the following combination of characters: Adult: 1) proboscis slightly longer than forefemur, ratio of proboscis length to forefemur length varying from 1.03-1.15 (mean =1.09); 2) PSD spot of vein $\mathrm{R}$ with 1-4 pale interruptions, most frequently with 2 pale interruptions on one or both wings; 3) ASP spot always absent on vein $\mathrm{C}$; 4) hindtarsomere 4 always with conspicuous basal pale patch on dorsal surface; 5) apical pale band on hindtibia without dark interruption; 6) vein $1 \mathrm{~A}$ without noticeable long pale spot at level of PSD; 7) PSD of vein R extending basally from level 1 to level 6, most frequently to level 4 on one or both wings. Anopheles dirus can be also distinguished from An. cracens by the absence of a posteromedian patch of dark scales on sternum VI, rarely with 1,2 scales, whereas $A n$. cracens has at least a small posteromedial patch of dark scales, always present on adults of both sexes. Additionally, this species has the brightest shiny white scales on wing spots PSP and SP. The SP is always bright and closely approximates the bright pure-white scales on the halteres, strongly contrasting with the yellowish scales of the SCP and PP, 
whereas the other spots are white and cream-colored to yellowish. The fourth-instar larva of An. dirus is morphologically more similar to An. cracens, An. baimaii, and An. baisasi than to any other member of the Dirus Complex. It can be distinguished in having the following characters: 1) seta 3-C single; 2) seta 5-C noticeably longer than antenna; 3 ) basal sclerotized tubercle of seta 1-P with prominent tooth arising from posterodorsal margin; 4) seta 4-C usually not reaching base of 2-C, sometimes extending slightly beyond base of 2-C, ratio of length of 4-C to distance between 4-C and 2-C 0.80-1.09 (mean $=0.93)$; 5) seta 1-II weakly developed, noticeably less developed than seta 1-III-VI with narrow lanceolate or filiform branches; 6) seta 2-IV,V usually with 4 branches; 7) seta $1-\mathrm{X}$ inserted inside or at edge of saddle, never in marginal notch; 8 ) seta 14-P with 3-8 branches.

\section{Anopheles (Cellia) cracens Sallum \& Peyton} (Figs. 4, 7, 21, 22, 49, 51, 52, 56)

Anopheles cracens Sallum \& Peyton (2005) (F, M, P*, L*). Holotype adult female with associated larval and pupal exuviae on microscope slide, deposited in the NMNH.

Anopheles balabacensis balabacensis of Sandosham et al. (1963:46) (vector human Plasmodium); CHEONG et al. (1965:1314) (vector competence P. cynomolgi, P. inui), (1968:243) (biting activity).

Anopheles balabacensis Perlis/Thai Form of Reid (1968:297) (taxonomy).

Anopheles balabacensis Perlis Form of Baimai et al. (1981:81) (cytogenetics, chromosome differentiation, evolution); Sucharit \& Choochote (1983:90) (morphometry male genitalia, frequency gonostylus movement); Sucharit et al. (1983:127) (esterase isozyme pattern, species identification); Choochote et al. (1987:511) (SEM pupal setae 9-III-V).

Anopheles balabacensis perlisiensis of Yong et al. (1983:611) (electromorphs, species diferentiation); Ward (1984:34) (nomen nudum).

Anopheles dirus of Kanda et al. (1980:585) (salivary gland polytene chromosome).

Anopheles dirus B of Baimai et al. (1984a:536) (metaphase chromosomes); Wibowo et al. (1984:425) (H-banding pattern of sex chromosomes); Peyton (1989:197) (taxonomy); Klein et al. (1991:481) (susceptibility P. cynomolgi B strain); Prapanthadara et al. (2000:395) (glutathione S-transferase).

Anopheles dirus species B of Hii (1984a:104) (DDT/fenitrothion tolerance), (crossbreeding), (1985a:185) (polytene chromosomes, crossbreeding), (1986:125) (morphometry L, P); Baimai \& Traipakvasin (1987:401) (heterochromatin sex chromosome); Baimai (1988a:13) (heterochromatin sex chromosomes, distribution, evolution), (1988b:667) (cytogenetics, distribution, bionomics); Baimai et al. (1988a:372) (polytene chromosomes), (1988d:333) (crossbreeding, heterochromatin), (1988e:151) (bionomics, distribution); Yasothornsrikul et al. (1988:703) (RFLPs); Damrongphol \& Baimai (1989:563) (egg morphology); Green et al. (1992:29) (enzyme electromorphs); Audtho et al. (1995:107) (DNA hybridization); Poopittayasataporn \& Baimai (1995:426) (polytene chromosome, phylogeny); Sithiprasasna et al. (1996:483) (methoprene resistance); Walton et al. (1999:24) (ASA PCR species identification); Huong et al. (2001:615) (PCR species identification); Manguin et al. (2002:46) (SCAR multiplex PCR).

Anopheles leucosphyrus Perlis (IMR) of Crawford (1938:75) (P*); Kanda et al. (1981:321) (hybridization, phylogeny).
Female (Figs. 4, 7). Head: proboscis dark-scaled, length $1.97-2.25 \mathrm{~mm}($ mean $=2.11 \mathrm{~mm})$, ratio of length to forefemur 1.09-1.17 (mean =1.13), maxillary palpus (Fig. 7) length 1.82$2.10 \mathrm{~mm}$ (mean $=1.96 \mathrm{~mm}$ ), ratio of length to proboscis 0.89 0.97 (mean $=0.93$ ), ratio of length to forefemur 1.01-1.12 (mean $=1.05)$ (Table 2.2), ratio of length of palpomeres 3/4 1.67-1.92 $($ mean $=1.78), 3 / 52.18-2.78($ mean $=2.45), 4 / 51.20-1.56($ mean $=$ 1.37), 4-5/3 0.88-1.05 (mean $=0.97)$; palpomeres $2-4$ with narrow apical silvery white band, pale scales of palpomere 5 white to pale cream-colored, length of apical pale band of palpomere 5 1.43-3.67 $($ mean $=2.12)$ length of basal dark band of palpomere 5 , ratio of length of apical pale band of palpomere 4 to length of basal dark band of palpomere $50.50-1.25($ mean $=0.88)($ Table 3). Thorax: pleural setae as follow: 1-3 upper proepisternal, 13 prespiracular, 3-5 prealar, 3-6 upper mesokatepisternal, 2,3 lower mesokatepisternal, 3-5 upper mesepimeral. Wing (Fig. 4): length $3.21-3.74 \mathrm{~mm}$ (mean $=3.45 \mathrm{~mm})$, pale scales on all veins light cream-colored, spots on vein $\mathrm{C}$ and subcosta slightly more obviously cream-colored, not strongly contrasting with others, $\mathrm{PH}$ spot of vein $\mathrm{C}$ always present, prominent or reduced, HP spot always present, small, PSP and SP spots always present and prominent, ASP spot always absent, PP spot 0.75-1.44 (mean = 1.14) length of SCP spot, AD spot 1.56-3.00 $($ mean $=2.13)$ length of preapical pale spot, PSD spot of vein R extending basally from level 1 to level 5 in one or both wings (Table 4), PSD spot of vein R with 1-3 small pale interruptions (Table 5), SD spot of vein $\mathrm{R}$ with 1-5 pale interruptions, sum of pale interruptions on PSD-PD spots of vein $R$ 4-9 for each wing, ratio of length of cell $R_{2}$ to vein $R_{2+3}$ 1.33-1.95 (mean =1.66), ratio of length of cell $\mathrm{R}_{2}$ to cell $\mathrm{M}_{1+2}$ 1.23-1.38 (mean =1.30). Legs: femora, tibiae and tarsomeres 1 dark-scaled speckled with pale spots; foretarsomeres 2 and 3 with prominent basal and apical pale spots, middle dark-scaled part of foretarsomere 2 entirely dark-scaled or with 1-3 pale spots on dorsal surface, usually foretarsomere 2 mostly palescaled on dorsal surface with small dark middle band and mainly dark-scaled on ventral surface, apical and basal palescaled areas of foretarsomere 3 usually prominent, sometimes less developed, foretarsomere 4 noticeably pale-scaled at base, apical pale band usually prominent, rarely small, foretarsomere 5 mostly dark-scaled with pale scales at apex, foretarsomeres 1-5 mostly dark-scaled on ventral surface, basal and apical pale bands of ventral surface present but less evident than those of dorsal surface; midtarsomere 2 usually without basal pale band, rarely with inconspicuous basal pale band, middle dark region usually with 1-3 pale spots, rarely entirely darkscaled, basal and apical pale bands complete or incomplete, midtarsomere 3 with apical pale band more distinct on dorsal surface, midtarsomeres 4,5 with complete or incomplete apical pale bands, sometimes mostly pale-scaled on ventral surface; hindtarsomere 2 with apical pale spot, basal pale spot absent or inconspicuous, middle dark part entirely dark-scaled or with 1-7 small pale spots, hindtarsomere 3 with apical pale band, hindtarsomere 4 with apical and complete or incomplete basal pale bands, hindtarsomere 5 usually without basal pale scales, sometimes with inconspicuous basal pale band, apical pale 
band always present. Abdomen: tergum VI usually with 2-5 lateral, pale cream-colored to tan scales, tergum VII variable, with few or several apicolateral scales, scales varying from pale cream-colored to tan to dark, tergum VIII with apicomedial pale cream-colored to golden scales; sternum VI with small patch of dark scales posteromedially, sternum VII with posteromedial patch of dark scales, rarely with 2,3 lateral pale scales, sternum VIII with small anterolateral patches of whitish scales.

Male. Essentially as in female except for sexual characters. Wing: generally paler with reduced scaling, pale spots usually longer than in female. Palpomere 2 with dorsal patch of pale scales at middle, extending to lateral surface, apex of palpomere 2 bare; palpomere 3 with long dorsal patch of pale scales at middle, extending to lateral surface, apex of palpomere 3 with a broad band of pale scales covering dorsal, lateral and ventral surfaces except for a narrow, ventral line of dark scales; palpomeres 4 and 5 mainly pale-scaled with a narrow basal band of dark scales, basal dark band of palpomere 5 with a short extension on ventral surface not reaching apex of segment. Genitalia: 4 large parabasal setae; ventral clapette with 1 long apicolateral seta, shorter than club, 1,2 short, poorly developed apical setae arising medially and 1 short, poorly developed subapical seta; dorsal claspette with 3-5 setae fused apically into club with distinct basal stems; aedeagus with 58 leaflets on each side of tip, leaflets serrated on one or both edges.

Pupa (Fig. 21). Position and development of setae as figured; range and modal number of branches in Table 19. All measurements from 20-75 specimens. In general similar to $A n$. leucosphyrus except for the following characters. Sterna IIVII with narrow dark band near anterior margin; seta 9-II-VII lightly pigmented, 9-VIII pigmented light brown, slightly darker at base. Abdomen: setae 8,10,11-II absent; 9-II length 0.01$0.02 \mathrm{~mm}$ (mean $=0.01 \mathrm{~mm}$ ); 1 -III with 8 - 17 branches, 5 -III with 7-15 branches, 9-III length 0.01-0.03 $\mathrm{mm}$ (mean $=0.02 \mathrm{~mm}$ ); 1IV with 4-13 branches, 5-IV with 6-14 branches, 6-IV always single, 9-IV long, usually spiculate, length $0.04-0.11 \mathrm{~mm}$ (mean $=0.08 \mathrm{~mm})$, ratios of length of 9-IV/9-III 2.00-6.86 $($ mean $=4.35)$ and 9-IV/9-V 0.41-0.96 (mean $=0.78)$; $1-\mathrm{V}$ with 2-6 branches, 9$\mathrm{V}$ usually spiculate, length $0.09-0.12 \mathrm{~mm}$ (mean $=0.11 \mathrm{~mm}) ; 5$ VI with 4-8 branches, 9-VI usually spiculate, length $0.10-0.13$ $\mathrm{mm}$ (mean $=0.11 \mathrm{~mm}) ; 9$-VII usually spiculate, length 0.09-0.13 $\mathrm{mm}($ mean $=0.11 \mathrm{~mm})$; 9-VIII with $12-18$ branches. Paddle: toothed margin index 0.80-0.92 $($ mean $=0.87)$, teeth well developed, strong, widely separated from each other.

Larva (Figs. 21, 22, 49, 51, 52). Position and development of setae as figured; range and modal number of branches in Table 20. All measurements from 8-29 specimens. In general similar to An. leucosphyrus except for the following characters. Pigmentation of sclerotized structures very light, inapparent, light tan to pale straw-yellow, margins of sclerotized tubercles of larger setae, anterior and posterior tergal plate and saddle are not discernable, head capsule (except for very dark collar), including antennal shaft uniformly very pale tan to straw, larger setae light brown, seta 1-III-VI slightly darker; small scattered inconspicuous colorless spicules on inner ventral aspect of antennal shaft and on posterolateral surface on saddle of segment X. Head: length $0.59-0.77 \mathrm{~mm}$ (mean $=0.70 \mathrm{~mm}$ ), width $0.66-0.82 \mathrm{~mm}$ (mean $=0.751 \mathrm{~mm})$; antenna length $0.26-0.32 \mathrm{~mm}$ $($ mean $=0.29 \mathrm{~mm})$, ratio of distance base to $1-\mathrm{A}$ to antenna length $0.30-0.53$ (mean $=0.40$ ), seta $3-C$ length $0.07-0.10 \mathrm{~mm}$ (mean $=0.08 \mathrm{~mm}$ ); distance between base of 2-C and 3-C 0.03$0.05 \mathrm{~mm}$ (mean $=0.04 \mathrm{~mm})$, 4-C length $0.05-0.10 \mathrm{~mm}$ (mean = $0.07 \mathrm{~mm}$ ), either extending to or not reaching base of 2-C, distance between basal insertions of 2-C and 4-C 0.06-0.10 mm (mean $=0.08 \mathrm{~mm}$ ), ratio of length of $4-\mathrm{C}$ to distance between the insertions of 2-C and 4-C 0.73-1.09 (mean $=0.92$ ), distance between base of 3-C and 4-C 0.06-0.09 $\mathrm{mm}$ (mean $=0.07 \mathrm{~mm}$ ), 5$\mathrm{C}$ longer than antennal shaft, not reaching anterior margin of head. Thorax: tubercle of seta 1-P entirely joined to tubercle of 2,3-P, each tubercle with a strong apical tooth arising from posterodorsal side and projecting over bases of 1,2-P; 3-T (Fig. 52) moderately developed, palmate, with 3-6 narrow, nearly transparent, lanceolate leaflets. Abdomen: seta 1-II (Fig. 51) more developed than 1-I, palmate, with 5-17 narrow, lanceolate, nearly transparent leaflets; ratio of length of 13 -IV to 10-IV $0.54-0.79$ (mean $=0.65)$; pecten spines (Fig. 49) 11-16, with 3-5 long spines alternating with 7-12 short spines.

Type data. Holotype female with associated larval and pupal exuviae on microscope slide [MH0023 (1)-4], collected in (West) Malaysia, Terengganu, Kampong Tapah $\left(5^{\circ} 6^{\prime} \mathrm{N}\right.$ $102^{\circ} 55^{\prime} \mathrm{E}$ ) by V. Baimai and R.G. Andre, 28 Apr. 1982, deposited in the NMNH.

Material examined. Three hundred thirty specimens, as follows: $82 \mathrm{~F}, 39 \mathrm{M}, 93 \mathrm{Le}, 95 \mathrm{Pe}, 21 \mathrm{~L}$, derived from 15 separate collections from natural habitats (12 adult, 3 immature) and 12 progeny broods. INDONESIA. Sumatra: Aceh, Sabang Island [Pulau Weh] (5 $51^{\prime} \mathrm{N}$ 95'18’E), 12 Jan. 1977, 1F (Mustari); 24 July 1985, 1F (J. Hudson). Anak Laut [Aneuklaot] (5⒌' $\left.{ }^{\circ} \mathrm{N} 95^{\circ} 19^{\prime} \mathrm{E}\right), 30$ Jan. 1976, $1 \mathrm{~F}$ (C.T. Oconner). MALAYSIA (WEST). Perlis: Kaki Bukit $\left(6^{\circ} 39^{\prime} \mathrm{N} 100^{\circ} 12^{\prime}\right.$ E), no date, 16F; Padang Besar (6 $\left.6^{\circ} 40^{\prime} \mathrm{N} 100^{\circ} 19^{\prime} \mathrm{E}\right), 1970$, 1F; 17 Nov. 1941, 1F (J.A. Reid). Terengganu: Kampong Dura (54'N 102 $56^{\circ}$ 'E), [MH0001 (3), (7)], 25 Apr. 1982, (progeny), (3), 1F, 1M, 2Le, 2Pe; (7), 1M, 1Le, 1Pe; [MH0008 (1)], 26 Apr. 1982, (progeny), 3F, 5M, 8LePe, 5 L; [MH0016 (1), (6)], 28 Apr. 1982, (progeny), (1), 6F, 4M,

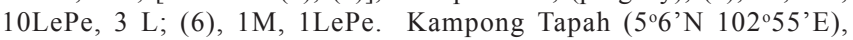
[0023 (1), (2)], 29 Apr. 1982, (progeny), (1), 5F, 3M, 8LePe, 4 L; [0023(2), F8, colony, 23F, 11M, 33LePe, 7 L (all, V. Baimai and R.G. Andre). Kuala Berang ( $\left.5^{\circ} 4^{\prime} \mathrm{N} 103^{\circ} 1^{\prime} \mathrm{E}\right), 1970,2 \mathrm{~F}$ (USAMRU).

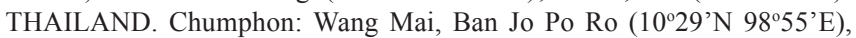
[08009], 20 Sept. 1978, 1F, 2M, 2LePe, 1 Pe. Phangnga: Khao Pak Chaung ( $\left.8^{\circ} 17^{\prime} \mathrm{N} 98^{\circ} 23^{\prime} \mathrm{E}\right),[1650], 13$ Oct. 66, 2M, 2LePe (all above, AFRIMS). Phattalung: Tanod, Ban Lo Chang Kra ( $\left.7^{\circ} 10^{\prime} \mathrm{N} 99^{\circ} 30^{\prime} \mathrm{E}\right)$, [PT-18, -23, -51, -58, -59], Feb. 1985, (progeny), (18), 3F, 1LePe, 1 L; (23), 4F, 4LePe; (51), 3F, 3LePe; (58), 2F, 2LePe; (59), 8F, 9M, $16 \mathrm{LePe}, 1 \mathrm{Pe}, 1 \mathrm{~L}$ (V. Baimai).

Distribution (Fig. 56). Anopheles cracens is known from Indonesia (Sumatra), West Malaysia (Perlis, Terengganu), and Thailand (Chumphon, Phangnga, Phattalung).

Bionomics and medical importance. Anopheles cracens is an anthropophilic species, showing peak feeding activity from 1900-2100 $\mathrm{h}$ and a low level of activity throughout the night in outdoor biting collections carried out in Phatthalung, Thailand (Baimai et al. 1988e). In Indonesia, Aceh, Sabang (Pulau Weh), 
Table 19. Number of branches for seta of pupa of An. cracens: range (mode).

\begin{tabular}{|c|c|c|c|c|c|c|c|c|c|c|c|}
\hline \multirow{2}{*}{$\begin{array}{l}\text { Seta } \\
\text { No. }\end{array}$} & \multirow{2}{*}{$\begin{array}{c}\text { Cephalothorax } \\
\text { CT }\end{array}$} & \multicolumn{9}{|c|}{ Abdominal segments } & \multirow{2}{*}{$\begin{array}{c}\text { Paddle } \\
\mathrm{Pa}\end{array}$} \\
\hline & & $\mathrm{I}$ & II & III & IV & $\mathrm{V}$ & $\mathrm{VI}$ & VII & VIII & IX & \\
\hline$\overline{0}$ & - & - & 1 & 1 & 1 & 1 & 1 & 1 & 1 & - & - \\
\hline 1 & $2-4(2)$ & n.c. & $>30$ & $8-17(11)$ & $4-13(7)$ & $2-6(3)$ & $2-4(2)$ & $1-3(2)$ & - & 1 & 1 \\
\hline 2 & $2-3(2)$ & $3-9(6)$ & $4-8(5)$ & $4-8(6)$ & $3-4(3)$ & $2-4(3)$ & $3-4(3)$ & $3-4(3)$ & - & - & $1-2(1)$ \\
\hline 3 & $3-4(3)$ & 1 & $2-4(3)$ & $3-5(3)$ & $5-9(7)$ & $3-6(3)$ & $2-3(2)$ & $3-4(3)$ & - & - & - \\
\hline 4 & $3-4(4)$ & $4-8(6)$ & $5-9(5)$ & $3-5(5)$ & $3-5(4)$ & $3-7(5)$ & $1-3(3)$ & $1-2(2)$ & $2-3(2)$ & - & - \\
\hline 5 & $5-7(5)$ & $3-5(3)$ & $3-6(5)$ & $7-15(10)$ & $6-14(8)$ & $5-9(7)$ & $4-8(6)$ & $4-8(5)$ & - & - & - \\
\hline 6 & $2-4(3)$ & $1-3(2)$ & $1-3(2)$ & $1-3(2)$ & 1 & $1-2(1)$ & 1 & $1-2(2)$ & - & - & - \\
\hline 7 & $3-5(4)$ & $3-7(5)$ & $3-7(4)$ & $2-5(3)$ & $2-6(3)$ & $2-5(3)$ & $1-2(1)$ & $1-2(2)$ & - & - & - \\
\hline 8 & $1-3(2)$ & - & - & $2-3(2)$ & $1-4(3)$ & $2-3(3)$ & $1-3(2)$ & $2-4(3)$ & - & - & - \\
\hline 9 & $2-4(3)$ & 1 & 1 & 1 & 1 & 1 & 1 & 1 & $12-18(16)$ & - & - \\
\hline 10 & $1-3(2)$ & - & - & $2-5(3)$ & $1-3(2)$ & $1-3(2)$ & $1-4(2)$ & $2-4(2)$ & - & - & - \\
\hline 11 & $2-5(3)$ & - & - & $1-2(1)$ & 1 & 1 & 1 & $1-2(2)$ & - & - & - \\
\hline 12 & $2-5(3)$ & - & - & - & - & - & - & - & - & - & - \\
\hline 13 & - & - & - & - & - & - & - & - & - & - & - \\
\hline 14 & - & - & - & - & 1 & 1 & 1 & 1 & 1 & - & - \\
\hline
\end{tabular}

n.c. $=$ not counted

Sumatra, An. cracens was captured biting humans at night. In West Malaysia, adult females were captured on human-bait collections at night in secondary tropical rain forest and in villages in localities situated either in mountainous or hilly areas. Additionally, An. cracens was caught biting humans during daytime under shade. Because it is an outdoor biter, it can transmit human Plasmodium outdoors in the daytime (Cheong et al. 1968). Also, An. cracens was assumed to be involved in the human Plasmodium transmission in areas where houses were close to the jungle because females were found infected with oocysts and sporozoites and $88 \%$ were parous (Sandosham et al. 1963). However, it is possible that the importance of An. cracens in the epidemiology of malaria transmission is secondary since it also occurs in areas of low transmission (Meek 1995). Additionally, An. cracens is competent to transmit simian Plasmodium in monsoon rain forest in the state of Perlis, Malaysia. Some individuals were found infected with $P$. cynomolgi and $P$. inui and the sporozoites isolated from the salivary glands caused malaria in rhesus monkey (Cheong et al. 1965, 1966). Studies on the susceptibility to the simian malaria parasite Plasmodium cynomolgi B strain in comparison to other Southeast Asian Anopheles showed that $77 \%$ of An. cracens were infected (Klein et al. 1991). Anopheles cracens is also involved in the transmission of Brugia pahangi microfilariae since females were orally infected (Zahedi \& White 1994). Studies on the susceptibility of a colony of An. cracens to DDT, fenitrothion, propuxur, and malathion showed a considerable degree of tolerance to the first two chemicals (Hii 1984a). Anopheles cracens was found to be a stenogamic species in the laboratory (Sucharit \& Choochote 1983).

In Thailand, immatures were taken from elephant and other animal footprints. The water was fresh, stagnant, temporary, clear or colored, in full sun or partial shade. The larval habitats were in secondary rain forest situated in both plains and mountainous areas. Immatures of Ae. caecus, Ae. orbitae, An. kochi Dönitz, An. baimaii Sallum and Peyton and An. barbirostris Van der Wulp were found in association with $A n$. cracens.

Systematics. Cytological evidence from mitotic and meiotic karyotypes, and polytene salivary gland chromosome banding patterns of individuals from a population designated as $A n$. balabacensis Perlis Form showed support for species status (Baimai et al. 1981). Morphometric studies of the male genitalia and the frequency of clasper movement also showed that $A n$. dirus (Bangkok colony) and An. cracens (as An. balabacensis Perlis Form) belonged to two distinct species (Sucharit \& Choochote 1983). Examination of the polytene chromosomes and crossbreeding of laboratory colonies not only confirmed the species status of $A n$. dirus, but also showed that it consisted of at least one more species designated as An. dirus species B (= An. cracens) (Baimai et al. 1984a; Hii 1985a). Additionally, several cross-breeding and cytogenetic studies (Baimai et al. 1988a, 1988d; Hii 1984b, 1985a; Wibowo et al. 1984; Baimai \& Traipakvasin 1987; Poopittayasatapan \& Baimai 1995), as well as morphometric and morphological data for the immature stages, including eggs, confirmed that An. cracens was a distinct species within the Dirus Complex (Hii 1986; Damrongphol \& Baimai 1989). Enzymatic probes, DNA probes, and DNA markers also were developed to separate members of the Dirus Complex and to confirm their species status, including An. cracens (Sucharit et al. 1983; Yasothornsrikul et al. 1988; Green et al. 1992; Audtho et al. 1995; Walton et al. 1999; Huong et al. 2001; Manguin et al. 2002). Backcrosses between An. dirus and An. cracens showed that both the autosomes and the $\mathrm{X}$ chromosome might contribute to sterility (Hii 1984b; Hii 1985a).

Anopheles cracens can be recognized by the following combination of characters. Adults: 1) proboscis uniformly darkscaled, slightly longer than forefemur, ratio of proboscis length to forefemur length 1.09-1.17 (mean =1.13); 2) PSD spot of vein R with 1-3 small pale interruptions; 3) ASP spot always 
Table 20. Number of branches for setae of the larva of An. cracens: range (mode).

\begin{tabular}{|c|c|c|c|c|c|c|c|c|c|c|c|c|c|}
\hline \multirow{2}{*}{$\begin{array}{l}\text { Seta } \\
\text { No. }\end{array}$} & \multirow{2}{*}{$\begin{array}{c}\text { Head } \\
\text { C }\end{array}$} & \multicolumn{3}{|c|}{ Thorax } & \multicolumn{9}{|c|}{ Abdominal segments } \\
\hline & & $\mathrm{P}$ & $\mathrm{M}$ & $\mathrm{T}$ & $\mathrm{I}$ & II & III & $\mathrm{IV}$ & $\mathrm{V}$ & $\mathrm{VI}$ & VII & VIII & $\mathrm{X}$ \\
\hline$\overline{0}$ & 1 & 1 & - & - & - & 1 & 1 & 1 & 1 & 1 & 1 & 1 & - \\
\hline 1 & 1 & $7-20(15)$ & $25-29(27)$ & 1 & $4-10(9)$ & $5-17(5)$ & $15-21(21)$ & $13-20(19)$ & $11-21(20)$ & $14-18(17)$ & $7-13(11)$ & 1 & 1 \\
\hline 2 & 1 & $9-12(11)$ & $1-3(1)$ & 1 & $1-3(2)$ & $6-8(8)$ & $6-8(6)$ & $3-5(4)$ & $3-5(4)$ & $4-5(5)$ & $4-7(6)$ & $4-7(5)$ & $15-23(22)$ \\
\hline 3 & 1 & 1 & 1 & $3-6(4)$ & $1-3(2)$ & 1 & 1 & $2-3(2)$ & 1 & 1 & $2-3(3)$ & $5-7(6)$ & $9-14(9)$ \\
\hline 4 & 1 & $13-19(15)$ & $2-3(3)$ & $2-5(4)$ & $3-7(4)$ & $4-7(5)$ & $3-4(4)$ & $2-4(3)$ & $3-5(3)$ & 1 & 1 & 1 & 9 \\
\hline 5 & $7-12(11)$ & $32-38(38)$ & $1-2(1)$ & $24-40(29)$ & $3-6(3)$ & $3-7(5)$ & $3-5(4)$ & $3-5(3)$ & $3-5(3)$ & $4-5(5)$ & $3-5(3)$ & $3-4(3)$ & - \\
\hline 6 & $9-16(13)$ & 1 & $2-5(4)$ & $2-3(3)$ & $15-23(20)$ & $15-29(23)$ & $12-22(14)$ & $1-3(2)$ & $1-3(2)$ & $2-3(3)$ & $2-4(3)$ & $1-\mathrm{S}$ & $4-6(5)$ \\
\hline 7 & $11-16(11)$ & $17-27(24)$ & $2-3(3)$ & $24-35(29)$ & $15-23(16)$ & $20-26(20)$ & $3-5(4)$ & $4-6(5)$ & $4-6(4)$ & $2-5(3)$ & 3 & $2-S$ & $4-7(4)$ \\
\hline 8 & $1-2(1)$ & $21-32(30)$ & $18-29(25)$ & $23-35(27)$ & - & $1-2(1)$ & $1-2(1)$ & $2-3(2)$ & $2-3(2)$ & $2-3(2)$ & $3-8(3)$ & $6-S$ & $2-3(2)$ \\
\hline 9 & $1-5(2)$ & 1 & 1 & 1 & $3-5(4)$ & $5-9(8)$ & $6-9(9)$ & $7-12(9)$ & $7-9(8)$ & $6-8(7)$ & $4-5(4)$ & $7-S$ & $1-2(2)$ \\
\hline 10 & $1-2(1)$ & 1 & 1 & 1 & 1 & $1-3(3)$ & 1 & 1 & 1 & $1-4(3)$ & $4-7(5)$ & 8-S & 2 \\
\hline 11 & $24-40(31)$ & 1 & 1 & 1 & $3-4(3)$ & 1 & $2-4(3)$ & $2-3(3)$ & $2-3(2)$ & $2-3(2)$ & 2 & 9-S & $2-4(3)$ \\
\hline 12 & $1-2(2)$ & 1 & 1 & $1-3(2)$ & $2-5(3)$ & $1-3(1)$ & $2-3(2)$ & $2-3(2)$ & $2-3(3)$ & 1 & 1 & - & - \\
\hline 13 & $4-7(6)$ & $4-6(4)$ & $2-5(5)$ & $2-3(3)$ & $2-5(4)$ & $3-6(4)$ & $3-7(5)$ & $3-4(3)$ & $3-4(3)$ & $3-8(6)$ & $2-3(2)$ & - & - \\
\hline 14 & 4 & $4-8(6)$ & $4-8(7)$ & - & - & - & - & 1 & 1 & 1 & 1 & 1 & - \\
\hline 15 & $4-7(7)$ & - & - & - & - & - & - & - & - & - & - & - & - \\
\hline
\end{tabular}

n.c. $=$ not counted

absent on vein $\mathrm{C}$; 4) hindtarsomere 4 either complete or incomplete basal pale band; 5) hindtarsomere 5 usually darkscaled at base, rarely with an inconspicuous pale band; 6) apical white band of hindtibia without a dark extension into the basal portion; 7) vein $1 \mathrm{~A}$ without a noticeably longer pale spot at the level of the PSD spot of the vein C; 8) PSD spot of vein $\mathrm{R}$ frequently extending basally to level 3 and level 4, less frequently to level 5, and rarely to level 1 and level 2;9) sternum VI with a small posteromedial patch of dark scales present in both sexes. Fourth-instar larvae of An. cracens can be recognized by the following combination of characters: 1) pigmentation of sclerotized structures very light, inapparent, light tan to pale straw-yellow, the margins of sclerotized tubercles of the larger setae, the anterior and posterior tergal plates, and the saddle not discernable, the head capsule (except for very dark collar), including antenna, uniformly very pale tan to straw, larger setae light brown, seta 1-III-VI slightly darker, small scattered nearly colorless spicules on inner ventral aspect of antenna and on posterolateral surface of saddle; 2) seta 3-C single; 3) seta 5-C longer than antenna; 4) basal sclerotized tubercle of seta 1-P with a prominent tooth or spine arising from posterodorsal margin; 4) tubercles of setae 1,2-P broadly joined basally; 5) seta 1-P small and weak, not noticeably expanded basally, with 7-20 branches; 6) seta 4-C short, either not reaching base of $2-\mathrm{C}$ or extending slightly beyond it, ratio of length of 4-C to distance between the insertions of 2-C and 4-C 0.73-1.09; 7) seta 3-C short, extending to or only slightly beyond anterior margin of head; 8) seta 1-II palmate, weakly developed, with 5-17 narrow, lanceolate leaflets; 9) seta 2-IV,V with 3-5 branches; 10) seta 1-X inserted in a marginal notch or at the edge of the saddle; 11) seta 14-P with 4-8 branches. Identification of An. cracens based on pupal characters is more difficult, but the overall pigmentation of the pupa is distinctive in comparison to other members of the Dirus Complex. Especially evident is the lack of pigmentation of seta 9-III-VII, which is very light yellow, only slightly darker than the integument. Additionally, the male genital lobe of $A n$. cracens is noticeably constricted at mid-length.

\section{Anopheles (Cellia) scanloni Sallum \& Peyton}

(Figs. 5, 6c,d, 7, 23, 24, 51, 52, 57)

Anopheles scanloni of Sallum \& Peyton (2005) (F, M, L*, P*). Holotype female with associated larval and pupal exuviae on microscope slide, deposited in the NMNH.

Anopheles dirus species C of Baimai et al. (1984a:536) (cytogenetics), (1987:157) (crossing, chromosomes), (1988a:372) (polytene chromosomes); Wibowo et al. (1984:425) (H-banding pattern sex chromosomes); May (1987:886) (neuroblast chromosomes); Baimai (1988a:13) (heterochromatin, evolution, distribution), (1988b:667) (population cytogenetics); Yasothornsrikul et al. (1988:703) (RFLPs); Damrongphol \& Baimai (1989:563) (egg morphology); Peyton (1989:197) (taxonomy); Sawadipanich et al. (1990:477) (cytogenetics, crossing, evolution); Green et al. (1992:29) (enzyme electromorphs); Audtho et al. (1995:107) (DNA hybridization); Poopittayasataporn \& Baimai (1995:426) (polytene chromosomes, phylogeny); Walton et al. (1999:24) (ASA PCR species identification), (2000:962) (mtDNA genetic structure), (2001:569) (population genetics, microsatellites); Huong et al. (2001:615) (PCR species identification); Manguin et al. (2002:46) (SCAR markers, multiplex PCR).

Female (Figs. 5, 6c,d, 7). Head: proboscis uniformly darkscaled, length $1.64-2.27 \mathrm{~mm}$ (mean $=1.95 \mathrm{~mm})$, ratio of length to forefemur 1.07-1.14 $($ mean $=1.10)$, palpus $($ Fig. 7) length 1.52$2.15 \mathrm{~mm}($ mean $=1.82 \mathrm{~mm})$, ratio of length to proboscis 0.90 $0.98($ mean $=0.93)$, ratio of length to forefemur 1.00-1.10 (mean $=1.03$ ) (Table 2$)$, ratio of length of palpomeres 3/4 1.53-2.00 $($ mean $=1.75), 3 / 52.18-2.71($ mean $=2.43), 4 / 51.22-1.50($ mean $=$ $1.42), 4-5 / 30.91-1.08($ mean $=0.99)$, palpomeres $2-4$ with narrow apical white bands, length of apical pale band of palpomere 5 1.00-3.50 $($ mean $=1.87)$ length of basal dark band of palpomere 5 , ratio of length of apical pale band of palpomere 4 to length of basal dark band of palpomere $50.28-2.00($ mean $=0.79)$ (Table 
3). Thorax: pleural setae as follows: 1,2 upper proepisternal, 0 2 prespiracular, 3-5 prealar, 3-5 upper mesokatepisternal, 2-4 lower mesokatepisternal, 2-4 upper mesepimeral. Wing (Figs. $5,6 \mathrm{c}, \mathrm{d})$ : length 2.63-3.72 $\mathrm{mm}$ ( mean $=3.08 \mathrm{~mm}$ ), pale scales on all veins light cream, spots on veins $C$ and subcosta slightly more obviously cream, not strongly contrasting with others, PHP spot of vein $\mathrm{C}$ absent, reduced or prominent, HP spot usually present, reduced or small, rarely absent, PSP spot always present, reduced or prominent, SP spot always present, prominent, ASP spot always absent, PP spot 0.13-1.60 (mean = $0.84)$ length of SCP spot, AD spot 1.10-4.75 (mean =2.10) length of PP spot, PSD spot of vein R extending basally from level 1 to level 5 on both wings (Table 4), PSD spot of vein R entirely dark-scaled or with 1,2 pale interruptions (Table 5), SD of vein $\mathrm{R}$ with 1-3 pale interruptions (Table 6 ), sum of pale interruptions on PSD-PD spots of vein R 2-7 for each wing, ratio of length of cell $R_{2}$ to $R_{2+3} 1.25-1.70$ (mean $=1.39$ ), ratio of length of cell $R_{2}$ to cell $\mathrm{M}_{1+2}$ 1.14-1.41 (mean =1.27). Legs: femora, tibiae and tarsomeres 1 dark-scaled, speckled with spots of pale scales; foretarsomeres 2,3 with complete or incomplete basal and apical pale bands, middle dark region of foretarsomere 2 entirely dark-scaled or with 1,3 pale spots, foretarsomere 4 with basal pale band, apical pale band reduced or absent, foretarsomere 5 mostly dark-scaled, apical pale scales reduced or absent, foretarsomeres 2-5 mostly pale-scaled along ventral surface, pale-scaled spots less noticeable than on dorsal surface; midtarsomeres 2-4 usually dark-scaled with small apical patch of pale scales on dorsal surface, occasionally apical pale patch inconspicuous, midtarsomere 5 dark-scaled with faint pale apical band; hindtarsomere 2,3 mostly dark-scaled with small apical pale band, hindtarsomere 4 with apical and basal pale bands, hindtarsomere 5 with basal and apical pale bands, basal pale band sometimes absent or reduced to dorsal pale patch, apical pale band always present. Abdomen: tergum VI without scales, tergum VII with few, sparse, dark scales on posterior margin, tergum VIII with large posteromedial patch of yellowish to golden scales; sternum VI without scales, sternum VII with posteromedial patch of dark scales, sternum VIII variable, without scales or with few lateral pale scales or with anterolateral patches of pale scales.

Male. Essentially as in female except for sexual characters. Wing generally paler with reduced scaling, pale spots usually longer than in female. Palpomere 2 with patch of pale scales at middle extending laterally, apex of palpomere 2 bare; palpomere 3 with long dorsal patch of pale scales at middle, extending laterally, apex of palpomere 3 with broad basal band of pale scales covering dorsal, lateral, and ventral surfaces except for narrow, ventrolateral spot of dark scales, palpomeres 4 and 5 mainly pale-scaled with narrow basal band of dark scales. Abdomen: sternum VIII covered with yellowish to golden scales. Genitalia: 4,5 parabasal setae; ventral clapette with 1 long apicolateral seta, shorter than club, 1,2 short, poorly developed apical setae arising medially and 1 short, poorly developed subapical seta; dorsal claspette with 3-7 setae fused apically into club, with distinct basal stems; aedeagus with 58 leaflets on each side of tip, leaflets serrated on one or both edges.
Pupa (Fig. 23). Position and development of setae as figured; range and modal number of branches in Table 21. All measurements from 20-30 specimens. In general as described for An. leucosphyrus except for the following characters. Sterna II-VII with narrow, dark band near anterior margin. Cephalothorax: seta 5-CT with 2-5 branches, 6-CT single or double, 9-CT single, double or triple, 10-CT single to 4branched. Seta 9-IV-VII pigmented light to medium brown. Abdomen: seta 1-II with more than 20 branches, 8,10,11-II absent, 9-II length $0.008-0.016 \mathrm{~mm}$ (mean $=0.012 \mathrm{~mm}) ; 1$-III with 5-10 branches, 5-III with 6-10 branches, 9 -III length 0.02 $0.03 \mathrm{~mm}$ ( mean $=0.02 \mathrm{~mm}$ ); 1-IV with 4-7 branches, 6-IV single, 9-IV length $0.03-0.10 \mathrm{~mm}$ (mean $=0.05 \mathrm{~mm}$ ), rates of length of 9IV/9-III 1.09-4.75 $($ mean = 2.31) and 9-IV/9-V 0.28-0.88 (mean = 0.46 ); 1 -V usually double, 6-V always single, 9-V length 0.08 $0.13 \mathrm{~mm}$ (mean $=0.11 \mathrm{~mm}$ ), rarely with 1,2 minute spicules; $9-\mathrm{VI}$ length $0.10-0.13 \mathrm{~mm}$ (mean $=0.12 \mathrm{~mm}$ ), rarely with 1,2 minute spicules; 9-VII length $0.11-0.14 \mathrm{~mm}$ ( mean $=0.12 \mathrm{~mm}$ ), rarely with 1,2 minute spicules; 9-VIII with 9-17 branches. Paddle: filamentous spicules on outer apical margin either absent or few, sparse spicules present, spicules always absent on inner margin; paddle tooth narrow, tapering to apex, ending in acute, sharply pointed apex; toothed margin index $0.82-0.90$ (mean = 0.86 ).

Larva (Figs. 23, 24, 51, 52). Position and development of setae as figured; range and modal number of branches in Table 22. All measurements from 18-40 specimens. In general as described for An.leucosphyrus except for the following characters. Head: integument light brown to yellowish either with or without a pattern of darkened spots, as follows: 1 small spot posteriorly at dorsal apoteme and 2 more developed darkened spots slightly anterior; 1 well developed dark spot posteriorly to the area between seta 8 -C and 2 small dark spots laterally; 2 lateral dark spots at dorsal apoteme, posteriorly to seta 7-C; 1 dark, faint area on lateralia along frontal ecdysial line; 1 dark spot in ventral lateralia in the area of insertion of 12-C; 2 lateral dark spots at the level of posterior tentorial pit in labiogula; length $0.60-0.73 \mathrm{~mm}$ ( mean $=0.67 \mathrm{~mm}$ ), width 0.68 $0.78 \mathrm{~mm}$ (mean $=0.74 \mathrm{~mm}$ ); antenna length $0.29-0.32 \mathrm{~mm}$ (mean $=0.30 \mathrm{~mm})$, ratio of distance base to $1-\mathrm{A}$ to antenna length $0.26-0.48$ (mean $=0.34)$; seta $2-\mathrm{C}$ without spicules, $3-\mathrm{C}$ length $0.07-0.10 \mathrm{~mm}$ (mean $0.09 \mathrm{~mm}$ ), distance between base of 2-C and 3-C 0.03-0.04 $\mathrm{mm}$ (mean $=0.04 \mathrm{~mm}$ ), 4-C length 0.10-0.22 $\mathrm{mm}($ mean $=0.13 \mathrm{~mm})$, extending well beyond base of 2-C, distance between basal insertions of 2-C and 4-C 0.06-0.10 mm (mean $=0.08 \mathrm{~mm}$ ), ratio of length of 4-C to distance between insertions of 2-C and 4-C 1.20-3.26 (mean $=1.70)$, distance between base of 3-C and 4-C 0.05-0.08 $\mathrm{mm}$ (mean $=0.07 \mathrm{~mm}$ ), 5 $\mathrm{C}$ shorter than antenna, not reaching anterior margin of head. Thorax: tubercles of all large setae light to medium brown; seta 1-P with 10-13 branches, tubercle of 1-P frequently separate from tubercle of 2,3-P, rarely joined to tubercles of 2,3-P on one side, each tubercle with well developed apical tooth arising from posterodorsal side and projecting forward over bases of setae 1,2-P; 3-T (Fig. 52) moderately developed, palmate, with 3,4 weak, nearly transparent, lanceolate leaflets 
Table 21. Number of branches for seta of pupae of An. scanloni: range (mode).

\begin{tabular}{|c|c|c|c|c|c|c|c|c|c|c|c|}
\hline \multirow{2}{*}{$\begin{array}{l}\text { Seta } \\
\text { No. }\end{array}$} & \multirow{2}{*}{$\begin{array}{c}\text { Cephalothorax } \\
\text { CT }\end{array}$} & \multicolumn{9}{|c|}{ Abdominal segments } & \multirow{2}{*}{$\begin{array}{c}\text { Paddle } \\
\mathrm{Pa}\end{array}$} \\
\hline & & $\mathrm{I}$ & II & III & IV & $\mathrm{V}$ & VI & VII & VIII & IX & \\
\hline 0 & - & - & 1 & 1 & 1 & 1 & 1 & 1 & 1 & - & - \\
\hline 1 & $2,3(2)$ & n.c. & $>20$ & $5-10(6)$ & $4-7(5)$ & $1-3(2)$ & $1-3(2)$ & $1,2(1)$ & - & 1 & 1 \\
\hline 2 & 2 & $3-6(5)$ & 4-7 (5) & $3-6(5)$ & $2,3(3)$ & $2-4(3)$ & $2-4(3)$ & $2,3(2)$ & - & - & 1 \\
\hline 3 & $2,3(2)$ & 1 & $1-3(2)$ & $1-3(2)$ & $5-8(6)$ & $2,3(2)$ & $1-3(2)$ & $1-3(2)$ & - & - & - \\
\hline 4 & $1-4(2)$ & $2-6(4)$ & $3-7(4)$ & $1-5(4)$ & $2-5(3)$ & $3-5(4)$ & $1,2(2)$ & $1,2(2)$ & $1,2(1)$ & - & - \\
\hline 5 & $2-5(3)$ & $1-3(2)$ & $2-7(3)$ & $6-10(7)$ & $4-7(5)$ & $3-6(5)$ & $3-6(4)$ & $3-6(4)$ & - & - & - \\
\hline 6 & $1,2(2)$ & $1-3(2)$ & $1,2(2)$ & $1,2(2)$ & 1 & 1 & $1,2(1)$ & $1,2(1)$ & - & - & - \\
\hline 7 & $2-4(2)$ & $3-5(3)$ & $2-5(3)$ & $1-4(2)$ & $1-4(2)$ & $1-3(2)$ & 1 & 1 & - & - & - \\
\hline 8 & $1-3(2)$ & - & - & $1-3(2)$ & $1-3(2)$ & $1,2(1)$ & $1,2(1)$ & $1,2(1)$ & - & - & - \\
\hline 9 & $1-3(2)$ & 1 & 1 & 1 & 1 & 1 & 1 & 1 & $9-17(10)$ & - & - \\
\hline 10 & $1-4(2)$ & - & $1,2(1)$ & $1-4(2)$ & $1-3(1)$ & $1,2(1)$ & $1,2(2)$ & $1,2(2)$ & - & - & - \\
\hline 11 & $1-4(3)$ & - & - & 1 & 1 & 1 & 1 & 1 & - & - & - \\
\hline 12 & $1-3(2)$ & - & - & - & - & - & - & - & - & - & - \\
\hline 13 & - & - & - & - & - & - & - & - & - & - & - \\
\hline 14 & - & - & - & - & 1 & 1 & 1 & 1 & 1 & - & - \\
\hline
\end{tabular}

n.c. $=$ not counted

arising from long, narrow basal stem. Abdomen: seta 9-I with 3,4 branches; 1-II (Fig. 51) more developed than 1-I, palmate, with 10-16 leaflets, basal stem more pigmented than leaflets; 3 IV single or double, 13-IV triple, ratio of length to 10-IV 0.700.88 (mean $=0.80) ; 1$-VII leaflets normally without apicolateral serration, rarely a few leaflets with minute apicolateral serration; 12-17 pecten spines (Fig. 23), 4-6 long spines alternating with 7-11 short spines.

Type data. Holotype female with associated larval and pupal exuviae on microscope slide [Acc. no. 08126-15], collected in Thailand, Kanchanaburi, Sai Yok (Office of Livestock) (14 $21^{\circ}$ 'N 98 59'E) by AFRIMS staff, 18 November 1979, deposited in the NMNH.

Material examined. One thousand three hundred fifty-eigth specimens, as follow: $221 \mathrm{~F}, 228 \mathrm{M}, 431 \mathrm{Le}, 437 \mathrm{Pe}, 41 \mathrm{~L}$, derived from 18 separate collections from natural habitats (10 adult, 8 immature) and 28 progeny broods. THAILAND. Kanchanaburi: Huai Bong Ti (14²19’ $\left.98^{\circ} 58^{\prime} \mathrm{E}\right)$, [0181], 2 June 1965, 1 M, 1 Pe; [0185], 2 June 1965, 2M, 2LePe. Nam Tok, Khao Na Chang (14 $\left.13^{\prime} \mathrm{N} 99^{\circ} 5^{\prime} \mathrm{E}\right)$, [0225], 6 June 1965, 1F, 1M, 1LePe. Phao Phu Thong (135'N 99²4'E), [06537], 21 Sept. 1973, 2F, 1LePe. Nam Tok, Sai Yok Yai $\left(14^{\circ} 25 \mathrm{~N} 98^{\circ} 51^{\prime} \mathrm{E}\right),[08121], 17$ Nov. 1979, 1M, 1LePe. Sai Yok (Office of Livestock) (14²1'N 98 $\left.59^{\circ} \mathrm{E}\right)$, [08125], 18 Nov. 1979, 6F, 6LePe; [08126], 18 Nov. 1979, 12F, 10M, 25LePe, 3 L. Huai Mae, Khamin (14³8' N 9900’E), [08153], 24 Nov. 1979, 5F, 6M, 10LePe. Ban Plai Huai, Kaeng Riang (14²4’N 99 $\left.5^{\circ} \mathrm{E}\right)$, [09137 (1)], 7 June 1982, (progeny), 16F, 12M, 28LePe. Ban Tab Tao, Mu 2 (14 $\left.24^{\circ}{ }^{\prime} \mathrm{N} 99^{\circ} 9^{\prime} \mathrm{E}\right)$, [09139 (14, 15)], 8 June 1982, (progeny), (14), 5F, 4M, 8LePe; (15), 17F, 17M, 29LePe. Ban Huai Duan (14²4'N 99 $5^{\prime}$ E), [09142 (2)], 10 June 1982, (progeny), 19F, 24M, 42LePe, 1 Pe. Tha Kradan, Ban Phu Taka, Mu 3 (14²7’ N 995'E), [09120 (1-6)], 1 July 1981, (progeny), (1), 12F, 11M, 22LePe, $4 \mathrm{~L}$; (2), 9F, 5M, 13LePe, $6 \mathrm{~L}$; (3), $15 \mathrm{~F}, 19 \mathrm{M}, 33 \mathrm{LePe}, 5 \mathrm{~L}$; (4) 18F, 19M, 36LePe, $3 \mathrm{~L}$; (5), 12F, 16M, $27 \mathrm{LePe}, 3 \mathrm{~L}$; (6), 18F, 19M, 32LePe, 4 Pe, 4 L. Sai Yok $\left(14^{\circ} 26^{\prime} \mathrm{N}\right.$ 9852’ E), [KA 70], 1985-86, (progeny), 9M, 9LePe, 1 L (all above,

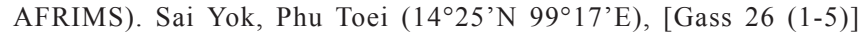
1987, (progeny), (1), 4F, 2M, 6LePe, 2L; (2), 4F, 5M, 8LePe, $2 \mathrm{~L}$; (3), $1 \mathrm{~F}, 1 \mathrm{M}, 2 \mathrm{LePe}$ (4), 12F, 10M, 30LePe, $2 \mathrm{~L}$; (5), 5F, 13M, 18LePe, 4L. Nakhon Si Thammarat: Si Chon, Sikeed ( $\left.8^{\circ} 55^{\prime} \mathrm{N} 99^{\circ} 35^{\prime} \mathrm{E}\right)$, [SC003], Dec. 1984, (progeny), 2F, 1LePe; [SC009], 2F, 1LePe; [SC028], 7F, 13M, 20LePe; [SC90], 1F, 1LePe; [SC142], 1F; [SC144], 2F, 1 Pe (V.
Baimai). Thung Yai, Ban Tham Phae Dan ( $8^{\circ} 10^{\prime} \mathrm{N}$ 99²0’E), [TY109], Dec. 1985, (progeny), 1F, 1M, 2LePe; [TY181], 3F, 1M, 4LePe; [TY214], 3F, 2M, 5LePe (V. Baimai). Thung Song, Tambon Nam Tok (754'N 9943’E), [TS372], June 1985, 2F, 2M, 4LePe (V. Baimai). Phattalung: Tanod, Ban Lo Chang Kra ( $\left.7^{\circ} 10^{\prime} \mathrm{N} 99^{\circ} 30^{\prime} \mathrm{E}\right)$, [PT15], Feb. 1985, (progeny), 3F, 2LePe, 1 L; [PT57], 1F, 2M, 1LePe, 1 L (V. Baimai).

Distribution (Fig. 57). Anopheles scanloni is known only from Thailand (Kanchanaburi, Nakhon Si Thammarat, and Phatthalung).

Bionomics and medical importance. Anopheles scanloni may be competent to transmit malaria parasites in Southeast Asia (Manguin et al. 2002). However, the precise involvement of the species in the dynamics of the malaria transmission is not fully understood because morphological identification is problematical and An. scanloni has been confused with other members of the Dirus Complex. However, it is possible that the importance of An. scanloni in the epidemiology of malaria transmission is secondary since it also occurs in areas of low transmission (Meek 1995).

Adults were collected in human bait collections in evergreen forest, deciduous forest, secondary deciduous forest, cultivated field, corn field plantation surrounded by forest, villages, and $10 \mathrm{~m}$ from human habitation. Immatures of $A n$. scanloni were taken from rock pools, ground pools, and seepage springs. The water was fresh, stagnant, colored or clear, sometimes with some degree of pollution, and in partial shade. Larval habitats were in primary bamboo groves, tropical rain forest, deciduous forest, and scrub environments situated in mountains and also in valleys at elevations from 75 to $480 \mathrm{~m}$ above sea level. Immatures were found in association with $O c$. assamensis (Theobald), An. barbirostris, An. kochi, An. nigerrimus Giles, An. vagus Dönitz, An. maculatus, Cx. infantulus Edwards, Cx. minor (Leicester), and $C x$. fuscocephalus Theobald.

Systematics. Wibowo et al.(1984) proposed Anopheles scanloni (as An. dirus C) as a new genetically distinct taxon 
Table 22. Number of branches for setae of larvae of An. scanloni: range (mode).

\begin{tabular}{|c|c|c|c|c|c|c|c|c|c|c|c|c|c|}
\hline \multirow{2}{*}{$\begin{array}{l}\text { Seta } \\
\text { No. }\end{array}$} & \multirow{2}{*}{$\begin{array}{c}\text { Head } \\
\text { C }\end{array}$} & \multicolumn{3}{|c|}{ Thorax } & \multicolumn{9}{|c|}{ Abdominal segments } \\
\hline & & $P$ & $\mathrm{M}$ & $\mathrm{T}$ & I & II & III & IV & $\mathrm{V}$ & VI & VII & VIII & $\mathrm{X}$ \\
\hline 0 & 1 & 1 & - & - & - & 1 & 1 & 1 & 1 & 1 & 1 & 1 & - \\
\hline 1 & 1 & $10-13(13)$ & $25-30(26)$ & 1 & $3-7(5)$ & $10-16(10)$ & $18-21(19)$ & $18-21(19)$ & $17-20(17)$ & $15-18(17)$ & $9-13(12)$ & 1 & 1 \\
\hline 2 & 1 & $7-12(11)$ & $2-3(3)$ & 1 & $1-3(2)$ & $5-7(5)$ & $5-6(6)$ & $3-5(4)$ & $3-5(4)$ & $4-5(5)$ & $4-6(6)$ & $5-6(6)$ & $13-14(13)$ \\
\hline 3 & 1 & 1 & 1 & $3-4(4)$ & $1-2(1)$ & 1 & 1 & $1-2(2)$ & 1 & 1 & 3 & $4-5(5)$ & 7 \\
\hline 4 & $1-4(1)$ & $13-18$ & $2-3(2)$ & $3-4(3)$ & $4-6(6)$ & $4-6(5)$ & $2-3(3)$ & $2-3(3)$ & $2-3(2)$ & 1 & 1 & 1 & 9 \\
\hline 5 & $8-11(9)$ & n.c. & 1 & $28-37(28)$ & 3 & $4-7(5)$ & $3-4(3)$ & $3-5(3)$ & $3-5(5)$ & $4-5(5)$ & $4-5(5)$ & 3 & - \\
\hline 6 & $10-14(11)$ & 1 & 3 & 2 & $18-22(20)$ & $22-27(22)$ & $12-18(12)$ & $1-2(2)$ & $1-2(2)$ & $2-3(3)$ & $4-5(4)$ & $1-\mathrm{S}$ & $4-5(4)$ \\
\hline 7 & $8-16(10)$ & $14-25(22)$ & $2-4(3)$ & $27-33$ & $14-17(15)$ & $19-22(20)$ & $4-5(5)$ & $4-6(5)$ & $4-6(6)$ & $3-5(3)$ & 3 & $2-S$ & $5-6(6)$ \\
\hline 8 & $1-2(2)$ & $23-29(27)$ & $17-29(23)$ & $29-33$ & - & 2 & 2 & $2-3(2)$ & $2-3(3)$ & $2-3(3)$ & $4-5(5)$ & $6-S$ & 2 \\
\hline 9 & $3-5(3)$ & 1 & 1 & 1 & $3-4(3)$ & $6-8(8)$ & $7-8(8)$ & $6-7(7)$ & 6 & $5-8(5)$ & 4 & 7-S & 1 \\
\hline 10 & $1-2(2)$ & 1 & 1 & 1 & 1 & 2 & 1 & 1 & 1 & $3-4(3)$ & $5-6(5)$ & $8-S$ & $1-3(2)$ \\
\hline 11 & $26-29(29)$ & 1 & 1 & 1 & $2-3(3)$ & 1 & $2-3(2)$ & $2-3(2)$ & $2-3(3)$ & 2 & 2 & 9-S & $1-3(3)$ \\
\hline 12 & 2 & $1-3(1)$ & 1 & $2-3(2)$ & $3-4(3)$ & 1 & $2-3(2)$ & 2 & 2 & 1 & 1 & - & - \\
\hline 13 & $5-8(6)$ & $4-5(5)$ & $4-5(5)$ & $2-3(3)$ & $4-5(4)$ & $3-6(5)$ & $4-7(6)$ & 3 & $2-3(3)$ & $5-9(6)$ & $2-3(3)$ & - & - \\
\hline 14 & n.c. & $5-8(6)$ & $7-8(8)$ & - & - & - & 1 & 1 & 1 & 1 & 1 & 1 & - \\
\hline 15 & n.c. & - & - & - & - & - & - & - & - & - & - & - & - \\
\hline
\end{tabular}

n.c. $=$ not counted

based on analysis of the H-banding pattern of metaphase sex chromosomes. Several crossing, chromosomal, and RFLP studies confirmed the species status of An. scanloni (Baimai et al. 1984a; 1987; 1988a; May 1987; Baimai 1988a, 1988b; Yasothornsrikul et al. 1988; Sawadipanich et al. 1990; Audtho et al. 1995; Poopittayasataporn \& Baimai 1995). Scanning electron micrographs of the eggs of An. scanloni and An. dirus showed that the eggs of both species are similar in size and shape, and that the pattern of the outer chorionic cells between the frill and the floats may be useful for species identification (Damrongphol \& Baimai 1989). The banding pattern of the larval salivary gland polytene chromosomes showed speciesspecific differences, particularly at the free ends of the X, 2R, and 2L arms, which distinguish An. scanloni, An. dirus, and An. cracens (Baimai et al. 1988a). The species status of $A n$. scanloni was also based on isozyme electromorphs (Green et al. 1992), a non-radioactive DNA hybridization method (Audtho et al. 1995), an allele-specific polymerase chain reaction of the ITS2 region of rDNA (Walton et al. 1999), and nucleotide sequence data of the COI mitochondrial gene (Walton et al. 2000). More recently, a PCR test employing species-specific primers was developed to separate four species of the Dirus Complex, including An. scanloni (Huong et al. 2001), and a multiplex PCR-based method using speciesspecific primers (Manguin et al. 2002). Studies on the population genetics of An. scanloni employing 11 microsatellite loci showed that there is a high degree of differentiation between the northern and the southern populations, suggesting the presence of two incipient species (Walton et al. 2001).

Anopheles scanloni can be recognized by the following combination of characters. Adult: 1) proboscis dark-scaled, slightly longer than forefemur, ratio of proboscis length to forefemur length 1.07-1.14 (mean =1.10);2) PSD spot on vein R normally with 1,2 pale interruptions; 3 ) ASP spot absent on vein $C$; 4) hindtarsomere 4 with basal pale band; 5) apical white band on hindtibia with dark linear extension into basal portion of ventral surface (occurs only in specimens from Kanchanaburi) or without dark extension; 6) vein 1A with noticeably long pale spot at the level of the PSD spot of vein C; 7) PSD spot of vein R extending from level 1 to level 5 on one or both wings, most frequently to level 3 or $4 ; 8$ ) pale spots and bands along dorsolateral surface of foretarsomeres 1 and 2 usually small, discrete, occupying less surface than the dark portions along this surface; 9) pale spots on foretarsomere 1 usually not fused, not forming long lines or splashes of pale scales along entire length, often restricted to 2-4 spots; 10) middle dark area of foretarsomere 2 usually without pale spot on dorsal surface, occasionally with 1-3 small pale spots. The fourth-instar larva: 1) 3-C single; 2) seta 1-II not fully developed; 3) 5-C shorter than antenna, not reaching anterior margin of head; 4) seta 1-X inserted on the saddle; 5) tubercle of seta 1-P usually separate, occasionally narrowly joined to tubercle of 2,3-P on one side; 6) 2-C single and simple; 7) 4-C long, extending well beyond base of 2-C, ratio of length of 4-C to distance between the insertions of 2 $\mathrm{C}$ and $4-\mathrm{C} 1.20-3.26$; 8) length of seta $4-\mathrm{C}$ varying from 0.10 $0.22 \mathrm{~mm}($ mean $=0.13 \mathrm{~mm})$. The pupa of An. scanloni can be recognized by the absence of a fringe of filamentous spicules on the inner margin of the paddle. However, An. mirans of the Hackeri Subgroup exhibits polymorphism for this character and some individuals may be misidentified as An. scanloni when using only pupal characters. It is important to consider that An. scanloni and An. mirans are allopatric, thus their geographical distribution should be considered when separating An. scanloni from An. mirans.

\section{Anopheles (Cellia) baimaii Sallum \& Peyton}

(Figs. 4, 6k-m, 7, 8, 25, 26, 52, 55)

Anopheles (Cellia) baimaii Sallum \& Peyton (2005) (F, M, P*, L*). 
Holotype female with associated larval and pupal exuviae on microscope slide, deposited in the NMNH.

Anopheles balabacensis of Tandon \& Hati (1978:187) (vector human Plasmodium); Nagpal \& Sharma (1983:7) (checklist); Malhotra et al. (1984:125) (distribution), (1987a:225) (vector human Plasmodium), (1987b:151) (distribution); Thu et al. (1985:394) (hybridization, cytogenetics, morphology, isozyme, species identification); Nagpal \& Sharma (1987:143) (distribution), (1995:84) (distribution, bionomics, type information).

Anopheles balabacensis balabacensis of Krishnan \& Halernkar (1967:35) (distribution, bionomics notes); Khin-Maung-Kyi (1970:217) (bionomics, distribution notes), (1971:297) (bionomics, distribution notes), (1974:1) (bionomics, distribution notes); Sen et al. (1973:98) (bionomics); Khin-Maung-Kyi \& Winn (1976:11) (bionomics, distribution notes); Rahman et al. (1977:1) (bionomics, malaria vector); Rajagopal (1979:71) (vector human Plasmodium); Pattanayak et al. (1980:211) (DDT, pirimiphos-methyl susceptibility).

Anopheles dirus D of Baimai et al.(1984a:536) (cytogenetics), (1987:157) (crossing, chromosomes), (1988a:372) (cytological differences, chromosome rearrangment), (1988b:661) (chromosomal polymorphism, distribution); Wibowo et al. (1984:425) (H-banding pattern sex chromosomes); Baimai (1988a:13) (heterochromatin, evolution, distribution), (1988b:667) (population cytogenetics); Panyim et al. (1988b:47) (DNA probe); Yasothornsrikul et al. (1988:703) (RFLPs); Damrongphol \& Baimai (1989:563) (egg morphology); Peyton (1989:197) (taxonomy); Green et al. (1992:29) (enzyme electromorphs); Audtho et al. (1995:107) (DNA hybridization); Poopittayasataporn \& Baimai (1995:426) (polytene chromosomes, phylogeny); Rattanarithikul et al. (1995:428) (bionomics); Xu \& Qu (1997b:134) (ITS2 marker); Xu et al. (1998:385) (ITS2 species identification); Walton et al. (1999:24) (ASA PCR species identification), (2000:962) (mtDNA genetic structure), (2001:569) (genetics, microsatellites); Huong et al. (2001:615) (PCR species identification); Manguin et al. (2002:46) (SCAR multiplex PCR).

Anopheles dirus of Harinasuta et al. (1982:1) (vector human Plasmodium); Rosenberg (1982:192) (breeding habitats); Rosenberg \& Maheswary (1982b:183) (bionomics); Thu et al. (1986a:245) (hybridization test, species identification); Dutta et al. (1989a:149) (sporozoite detection), (1989b:95) (bionomics, sporozoite detection), (1991:121) (vector incrimination), (1992:245) (sporozoite detection), (1993:135) (bionomics), (1996:378) (feeding behavior), (1997:204) (bionomics); Myo-Paing et al. (1989a:122) (distribution, bionomics), (1989b:52) (distribution), (1990:88) (bionomics); Das et al. (1990a:131) (A, identification key), (1990b:127) (vector human Plasmodium), (1991:129) (bionomics notes); Haq \& Maheswary (1991:67) (vector human Plasmodium); Tin \& Tun (1991:133) (vector human Plasmodium); $\mathrm{Xu} \& \mathrm{Qu}$ (1991:286) (mitotic chromosome karyotype heterochromatin, species identification), (1997b:134) (ITS2, species identification); Misra et al. (1993:62) (bionomics); Nandi et al.(1993:18) (vector competence), (1996:279) (bionomics), (2000:95) (feeding habits); Tun-Lin et al. (1987:291) (bionomics), (1988: 68) (allozyme polymorphism, esterase), (1995:401) (bionomics, infectivity, human Plasmodium); Prakash et al. (1997a:31) (biting behavior, parity rate), (1997b:117) (bionomics), (1997c:610) (bionomics, feeding behavior), (1998a:291) (insecticide susceptibility), (1998b:191) (bionomics), (2000a:97) (bionomics), (2000b:121) (bionomics), (2001:231) (vectorial capacity), (2002:95) (breeding habitats); Khan et al. (1998:131) (bionomics); Qu et al. (1998:246) (heterochromatin mitotic chromosomes, SEM egg, ITS2, species identification); Moore et al. (2001:282) (bionomics);

Anopheles leucosphyrus of Covell (1927:47) (in part, distribution), (1931b:241) (in part, distribution); Roy (1942:318) (malaria vector); Sweet et al. (1942:25) (checklist); Macan (1948:237) (bionomics data); Thu et al.(1986b:249) (chromosomal polymorphism).
Female (Figs. 4, 6k-m, 7, 8). Head: proboscis dark-scaled, length $1.97-2.38 \mathrm{~mm}$ (mean $=2.09 \mathrm{~mm}$ ), ratio of length to forefemur 1.01-1.14 (mean=1.08), maxillary palpus (Fig. 7) length $1.77-2.18 \mathrm{~mm}($ mean $=1.96 \mathrm{~mm})$, ratio of length to proboscis $0.88-1.00($ mean $=0.94)$, ratio of length to forefemur 0.96-1.05 $($ mean $=1.00)($ Table 2$)$, ratio of length of palpomeres $3 / 41.50$ $1.67($ mean $=1.63), 3 / 52.08-2.78($ mean $=2.27), 4 / 51.25-1.67$ $($ mean $=1.39), 4-5 / 3$ 0.96-1.20 $($ mean $=1.06)$; palpomeres $2-4$ with narrow apical pale band, length of apical pale band of palpomere $51.00-2.33($ mean $=1.39)$ length of basal dark band of palpomere 5 , ratio of length of apical pale band of palpomere 4 to length of basal dark band of palpomere 5 varying from $0.37-1.00($ mean $=0.64)($ Table 3$)$. Thorax: pleural setae as follows: 1-3 upper proepisternal, 0-4 prespiracular, 2-6 prealar, 3-5 upper mesokatepisternal, 1-3 lower mesokatepisternal, 3,4 upper mesepimeral. Wing (Figs. 4, 6k-m): length 3.09-3.54 mm $($ mean $=3.39 \mathrm{~mm})$, pale scales of all veins light cream-colored, spots on veins $\mathrm{C}$ and subcosta more obviously cream-colored, sometimes bordering to pale golden, pale spots on the remaining wing veins lighter, not strongly contrasting with others; PHP spot of vein C always present, small or prominent, HP spot always present, small or prominent, PSP spot usually prominent, occasionally small, never absent, ASP spot always absent, PP spot 0.38-2.00 (mean = 1.01) length of SCP spot, AD spot 1.15-4.17 (mean = 2.11) length of PP, PSD spot of vein $R$ extending basally from level 1 to level 5 on both wings (Table 4), PSD spot of vein R entirely dark or with 1-4 small pale spots (Table 5), SD spot of vein R with 1-4 pale spots (Table 6), sum of pale spots on PSD-PD spots of vein R varying from 3-10 for each wing, ratio of length of cell $\mathrm{R}_{2}$ to vein $\mathrm{R}_{2+3} 1.17-1.77$ (mean $=1.48$ ), ratio of length of cell $\mathrm{R}_{2}$ to cell $\mathrm{M}_{1+2} 1.12-1.26$ (mean = 1.19). Legs (Fig. 8): femora, tibiae, and tarsomeres 1 darkscaled speckled with spots of pale scales; foretarsomere 2 variable, sometimes entirely pale-scaled along dorsal and lateral surfaces or dark-scaled with basal and apical pale bands, middle dark area variable, usually mostly pale along dorsal and lateral surfaces, dark scales restricted to 1,2 middle dark bands, less frequently mostly dark-scaled with or without 1,2 pale spots, foretarsomeres 3 dark-scaled with basal and apical pale bands, foretarsomere 4 usually dark-scaled with basal and apical pale patches, occasionally dark part less distinct, pale scales varying from light brown to tan, foretarsomere 5 entirely palescaled or with poorly distinct, tan to light brown basal band, pale at apex, foretarsomeres 2-5 tan-scaled along ventral surface, basal and apical pale bands less noticeable on ventral surface; midtarsomeres 2-4 with apical patches of pale scales more evident on dorsal surface, sometimes pale patches poorly evident, midtarsomere 2 with or without 1,2 spots of pale scales on dorsal surface, midtarsomere 5 variable from tan to light brown or dark at base and pale at apex; hindtarsomeres 2 and 3 with apical pale bands, hindtarsomere 2 with 1-3 pale spots on middle dark region, occasionally reduced to 1,2 pale scales, hindtarsomeres 4 and 5 with basal and apical pale bands, sometimes reduced to few basal and apical pale scales on hindtarsomere 5. Abdomen: tergum VI usually without scales, sometimes with 2-4 thin, pale cream scales, tergum VII with 
few brownish scales on posterior margin, tergum VIII covered with cream-colored to yellowish to golden scales, sometimes scales reduced to small patch; sternum VI usually without scales, occasionally with 1-4 dark, posterolateral scales, sternum VII with dense, posteromedial patch of dark scales, sternum VIII with small, anterolateral, sparse patch of pale scales.

Male (Fig. 7). Essentially as in female except for sexual characters. Wing generally paler with reduced scaling, pale spots usually longer than in female. Palpomere 2 (Fig. 7) with a dorsal patch of pale scales at middle, apex of palpomere 2 bare, palpomere 3 with long, dorsal patch of pale scales at middle extending laterally, apex of palpomere 3 with broad band of pale scales covering dorsal, lateral and ventral surfaces except for narrow, ventrolateral line of dark scales at apex, palpomeres 4 and 5 pale-scaled with basal band of dark scales, sometimes reduced to a very narrow dark band on palpomere 5 , more visible at dorsal and ventral surfaces, scales on lateral surface entirely pale or tan at base, dark band of palpomeres 4 and 5 with ventral dark extension, nearly reaching apex of palpomere. Abdomen: sternum VIII covered with narrow, elongate scales, scales white to pale cream-colored centrally, yellowish laterally. Genitalia: with 4 parabasal setae; ventral clapette with 1 long apicolateral seta, blunt at apex, slightly shorther than club, 1,2 short, poorly developed apical setae arising medially and 1 short, poorly developed subapical seta; dorsal claspette with 4 setae fused apically into club, with distinct basal stems; aedeagus with 7 leaflets on each side of tip, leaflets serrated on one or both edges.

Pupa (Fig. 25). Position and development of setae as figured; range and modal number of branches in Table 23. All measurements from 20-38 specimens. In general as described for An. leucosphyrus except for the following characters. Integument without distinctive color pattern, mostly light brown to yellowish; sterna II-VII with narrow, dark band near anterior margin, usually darker on segments II-V. Cephalothorax: seta 4-CT usually double, 9-CT with 2,3 branches, 10-CT with 2-5 branches, 11,12-CT usually triple. Seta 9-II-III lightly pigmented brown, darker than in $A n$. leucosphyrus, 9-IV-VIII pigmented light to medium brown. Abdomen: seta 1-II with more than 30 branches, 9-II length $0.010-0.019 \mathrm{~mm}($ mean $=0.014 \mathrm{~mm})$; 1 -III with $5-10$ branches, 5 III with 6-14 branches, 9-III length 0.01-0.02 $\mathrm{mm}$ (mean $=0.02$ $\mathrm{mm}$ ); 1-IV with 3-7 branches, 5-IV with 4-10 branches, 9-IV length $0.02-0.09 \mathrm{~mm}$ (mean $=0.04 \mathrm{~mm})$, ratios of length of seta 9-IV/9-III 1.15-4.4 (mean = 2.15) and seta 9-IV/9-V 0.20-0.84 (mean $=0.42) ; 1-\mathrm{V}$ with 2-4 branches, 6-V always single, 9-V length $0.04-0.12 \mathrm{~mm}$ (mean $=0.10 \mathrm{~mm}) ; 5-\mathrm{VI}$ with $3-7$ branches, 6-VI single, 9-VI length $0.07-0.13 \mathrm{~mm}$ (mean $=0.10 \mathrm{~mm})$; 9-VII length $0.09-0.14 \mathrm{~mm}$ (mean $=0.11 \mathrm{~mm})$; 9-VIII with 9-16 branches. Paddle: toothed margin index $0.76-0.88$ (mean $=0.84)$, paddle teeth well developed, tapering to apex, ending in an acute apex, teeth well spaced.

Larva (Figs. 25, 26). Position and development of setae as figured; range and modal number of branches in Table 24. All measurements from 15-40 specimens. In general as described for An. leucosphyrus except for the following characters. Head: integument rarely with the common dark pigmentation as in An. dirus; length $0.62-0.75 \mathrm{~mm}$ (mean $=0.67 \mathrm{~mm})$, width 0.66 $0.81 \mathrm{~mm}($ mean $=0.76 \mathrm{~mm})$; antenna length $0.28-0.34 \mathrm{~mm}$ (mean $=0.31 \mathrm{~mm})$, ratio of distance base to $1-\mathrm{A}$ to antenna length $0.25-0.40($ mean $=0.32)$; seta $2-C$ single and simple, rarely with 1,2 spicules at apical $0.5,3-\mathrm{C}$ length $0.06-0.10 \mathrm{~mm}(\mathrm{mean}=0.08$ $\mathrm{mm}$ ), distance between base of 2-C and 3-C 0.03-0.04 mm (mean $=0.04 \mathrm{~mm}), 4-\mathrm{C}$ length $0.07-0.12 \mathrm{~mm}($ mean $=0.09 \mathrm{~mm})$, extending to or beyond base of 2-C, distance between basal insertions of 2-C and 4-C 0.08-0.13 $\mathrm{mm}$ (mean $=0.10 \mathrm{~mm}$ ), ratio of length of 4-C to distance between the insertions of 2-C and 4-C $0.67-$ $1.31($ mean $=0.94)$, distance between base of 3-C and 4-C 0.08$0.13 \mathrm{~mm}$ (mean $=0.09 \mathrm{~mm}), 5-\mathrm{C}$ longer than antennal shaft, not reaching anterior margin of head, with $8-12$ branches. Thorax: seta 1-P with 13-22 branches, tubercle of 1-P joined to tubercle of 2,3-C, each tubercle with prominent, apical tooth arising from posterodorsal side and projecting forward over bases of each setae; 3-T moderately developed, somewhat palmate, with 3-8 narrow, nearly transparent, lanceolate leaflets arising from a long, narrow basal stem (Fig. 52). Abdomen: seta 1-I small, somewhat palmate, with 4-8 narrow, nearly transparent, lanceolate leaflets; 1-II similar to 1-I with 4-13 branches; 3-IV double or triple, ratio of length of seta 13-IV to 10-IV 0.46-0.88 $($ mean $=0.71)$; 1-VII with 10-16 leaflets, leaflets frequently smooth, sometimes with minute apicolateral serration, apical filament poorly defined; 1-X long, single, inserted either inside or at the edge of saddle; pecten spines (Fig. 25) 11-16, with 3 5 long spines alternating with 8-11 short spines.

Type data. Holotype adult female with associated larval and pupal exuviae on microscope slide, collection acc. no. [TH1690(11)-15], collected in Thailand, Mae Sot, Ban Kariang, Thum Rua (1640’N 9840’E) by V. Baimai, 7 August 1989, progeny, deposited in the NMNH.

Material examined. Five thousand six hundred and thirteen specimens, as follows: 1355F, 898M, 1403Le, 1653Pe, 304L, derived from 295 separate collections from natural habitats (74 adult, 225 immature) and 84 progeny broods. BANGLADESH. Chittagong: Sylhet, Chaklapungee Tea Estate $\left(24^{\circ} 00^{\prime} \mathrm{N} 91^{\circ} 25^{\prime} \mathrm{E}\right)$, [025], 24 Apr. 1975, 1F; [029], 26 Apr. 1975, 1F; [031], 25 Apr. 1975, 1F; [038], 27 Apr. 1975, 1F; [045], 28 Apr. 1975, 2F, 1M; [047], 28 Apr. 1975, 1F; [060], 26 May 1975, 10L; [063], 27 May 1975, 2F, 2M, 19L; [064], 26 May 1975, 1F; [066], 28 May 1975, 1F; [072], 27 June 1975, 11F, 13M 17LePe, 2Pe; [160], 4 May 1975, 2F, 1M; [188], 29 July 1975, 1LePe, 1L; [202], 31 July 1975, 5L; [203], 1 Aug. 1975, 1L; [204], 2 Aug. 1975, 2M; [212], 27 Aug. 1975, 2M; [217], 27 Aug. 1975, 3M; [240], 1 Sept. 1975, 3F; [255], 3 Sept. 1975, 1M; [258], 24 Sept. 1975, 1F; [259], 24 Sept. 1975, 2M, [266], 26 Sept. 1975, 1F; [272], 28 Sept. 1975, 2F; [273], 28 Sept. 1975, 2F, 1L; [284], 22 Oct. 1975, 1F; [286], 22 Oct. 1975, 1F; [287], 22 Oct. 1975, 3F, 3M; [293], 24 Oct. 1975, 2F, 1M; [295], 24 Oct. 1975, 3F, 1M; [296], 24 Oct. 1975, 7F, 3M; [299], 25 Oct. 1975, 2M; [302], 26 Oct. 1975, 1LePe; [310], 31 Oct. 1975, 1LePe, 2L; [312], 31 Oct. 1975, 1F, 1LePe; [366], 22 Nov. 1975, 8L; [369], 22 Nov. 1975, 1F, 1LePe, 2L; [372], 21 Nov. 1975, 1F, 1M, 3LePe, 4L; [411], 28 Dec. 1975, 1M, 2L; [412], 28 Dec. 1975, 1F, 2LePe, 2L; [418], 30 Dec. 1975, 1L; [427], 24 Jan. 1976, 4F, 2M, 6LePe; [435], 25 Jan. 1976, 6L; [447], 29 Jan. 1976, 1M, 1LePe; [451], Feb. 1976, 13F, 5M , 7LePe, 2L; [454], 26 Feb. 1976, 1M, 3L; [457], 27 Feb. 1976, 1M; [463], 29 Feb. 1976, 2L; [465], 29 Feb. 1976, 4L; [466], 29 Feb. 1976, 1L; [468], 29 Feb. 1976, 2L; 
Table 23. Number of branches for setae of pupae of An. baimaii: range (mode).

\begin{tabular}{|c|c|c|c|c|c|c|c|c|c|c|c|}
\hline \multicolumn{2}{|c|}{ Seta Cephalothorax } & \multicolumn{9}{|c|}{ Abdominal segments } & \multirow{2}{*}{$\begin{array}{c}\text { Paddle } \\
\mathrm{Pa}\end{array}$} \\
\hline No. & $\mathrm{CT}$ & $\mathrm{I}$ & II & III & IV & $\mathrm{V}$ & VI & VII & VIII & IX & \\
\hline 0 & - & - & 1 & 1 & 1 & 1 & 1 & 1 & 1 & - & - \\
\hline 1 & $2-3(3)$ & n.c. & $>30$ & $5-10(7)$ & $3-7(5)$ & $2-4(3)$ & $1-3(2)$ & $1-2(1)$ & - & 1 & 1 \\
\hline 2 & $2-4(2)$ & $4-9(5)$ & $4-8(5)$ & $4-7(6)$ & $3-5(3)$ & $2-5(3)$ & $2-4(3)$ & $2-4(2)$ & - & - & $1-2(2)$ \\
\hline 3 & $2-4(2)$ & 1 & $2-4(3)$ & $2-4(3)$ & $5-8(7)$ & $2-4(2)$ & $1-2(2)$ & $2-6(3)$ & - & - & - \\
\hline 4 & $2-3(2)$ & $4-9(6)$ & $4-7(5)$ & $4-8(4)$ & $2-7(5)$ & $3-7(5)$ & $1-3(2)$ & $1-3(2)$ & $1-3(2)$ & - & - \\
\hline 5 & $3-7(4)$ & $2-4(3)$ & $2-5(3)$ & $6-14(8)$ & $4-10(5)$ & $4-7(7)$ & $3-7(5)$ & $3-7(6)$ & - & - & - \\
\hline 6 & $1-3(2)$ & $2-3(2)$ & $1-5(2)$ & $2-3(2)$ & $1-2(1)$ & 1 & 1 & $1-3(2)$ & - & - & - \\
\hline 7 & $2-3(2)$ & $3-5(3)$ & $2-5(3)$ & $2-5(3)$ & $2-5(3)$ & $2-4(3)$ & $1-2(1)$ & $1-2(1)$ & - & - & - \\
\hline 8 & $1-3(2)$ & - & - & $2-5(3)$ & $2-4(2)$ & $2-3(3)$ & $1-3(2)$ & $2-4(3)$ & - & - & - \\
\hline 9 & $2-3(3)$ & 1 & 1 & 1 & 1 & 1 & 1 & 1 & $9-16(13)$ & - & - \\
\hline 10 & $2-5(3)$ & - & - & $2-4(3)$ & $1-2(1)$ & $1-2(2)$ & $1-3(2)$ & $2-4(2)$ & - & - & - \\
\hline 11 & $3-5(3)$ & - & - & 1 & 1 & 1 & 1 & $1-3(2)$ & - & - & - \\
\hline 12 & $2-4(3)$ & - & - & - & - & - & - & - & - & - & - \\
\hline 13 & - & - & - & - & - & - & - & - & - & - & - \\
\hline 14 & - & - & - & - & 1 & 1 & 1 & 1 & 1 & - & - \\
\hline
\end{tabular}

n.c. $=$ not counted

[470], 24 Mar. 1976, 2F, 1LePe; [472], 24 Mar. 1976, 1M, 1L; [473], 27 Mar. 1976, 2M; [474], 27 Mar. 1976, 1F, 2M, 1LePe, 6L; [476], 27 Mar. 1976, 1F, 1L; [477], 27 Mar. 1976, 22F, 31M, 33LePe, 1L; [478], 27 Mar. 1976, 1F, 1LePe; [479], 27 Mar. 1976, 1Pe; [490], 1 Apr. 1976, 1Le 1Pe; [493], 1 Apr. 1976, 6F, 1M, 5LePe, 2L; [494], 17 Apr. 1976, 1F, 1M; [497], 17 Apr. 1976, 24F, 11M, 17LePe, 5Pe, 2L; [499], 18 Apr. 1976, 1L; [506], 22 Apr. 1976, 1M, 1LePe; [508], 22 Apr. 1976, 1LePe, 1L; [524], 1 May 1976, 1L; [527], 14 May 1976, 11F, 4M; [530], 15 May 1975, 1F, 1M; [531], 17 May 1976, 1L; [540], 20 May 1976, 2L; [541], 20 May 1976, 1L; [542], 21 May 1976, 2L; [543], 21 May 1976, 3L; [546], 22 May 1976, 8F, 12M; [548], 1F, 1M, 2LePe, 7L; [549], 22 May 1976, 1M, 1LePe; [550], 22 May 1976, 1F, 1LePe; [552], 22 May 1976, 1F, 3M, 4LePe; [554], 22 May 1976, 5F, 2M; [555], 23 May 1976, 1M, 1LePe, 4L; [557], 25 May 1976, 2F, 2M, 4LePe, 1L; [560], 17 June 1976, 1F, 2M, 3LePe; [561], 17 June 1976, 1M, 1LePe; [563], 17 June 1976, 1F, 1Le; [568], 18 June 1976, 1F, 2M, 1LePe, 1Pe, 1Le, 4L; [572], 19 June 1976, 1LePe; [573], 19 June 1976, 1L; [575], 20 June 1976, 3F, 3M, 5LePe, 2Pe, 1Le; [577], 20 June 1976, 1M; [578], 21 June 1976, 2F, 1M, 3LePe, 2L; [580], 22 June 1976, 1L; [581], 22 June 1976, 1M, 1LePe; [582], 22 June 1976, 1F, 1Pe, 1L; [583], 22 May 1976, 6F, 3M, 8LePe, 1Pe, 1L; [584], 22 June 1976, 2M, 2LePe, 1L; [585], 22 June 1976, 1M, 1LePe; [586], 22 June 1976, 4F, 5M; [588], 24 June 1976, 1LePe; [594], 30 June 1976, 1L; [608], 7 July 1976, 1M, 1LePe; [609], 8 July 1976, 1M, 1LePe; [616], 10 July 1976, 1M; [621], 12 July 1976, 6L; [624], 14 July 1976, 2L; [628], 15 July 1976, 2F, 2M, 1LePe, 2Pe, 10L; [629], 15 July 1976, 1M, 4L; [638], 16 July 1976, 1F, 1M; [639], 16 July 1976, 1F, 1M; [640], 16 July 1976, 1F, 1M, 3LePe; [641], 16 July 1976, 3F, 3M, 6LePe; [642], 16 July 1976, 1F, 2Pe, 1L; [645], 18 July 1976, 1F; [646], 18 July 1976, 3F, 2M, 2LePe; [647], 18 July 1976, 1F, 1M, 1LePe; [649], 18 July 1976, 4F, 4M, 3LePe, 1Pe, 1L; [651], 18 July 1976, 1M; [652], 18 July 1976, 1M; [656], 18 July 1976, 1F; [662], 21 July 1976, 2F; [663], 21 July 1976, 1F, 1M; [664], 21 July 1976, 1M; [666], 21 July 1976, 1F, 2M. Chaklapungee, Forest Beat $\left(24^{\circ} 1^{\prime} \mathrm{N} 91^{\circ} 24^{\prime} \mathrm{E}\right),[321], 2$ Nov. 1975, 4F, 4M, 9LePe, 1Le; [381], 25 Dec. 1975, 3F, 1LePe, 2Pe; [630], 15 July 1976, 1M, 1LePe; [631], 15 July 1976, 1F, 5L; [633], 15 July 1976, 1LePe, 9L; [634], 15 July 1976, 2F, 2LePe, 4L; [635], 15 July 1976, 3F, 2M, 2LePe, 1L; [636], 15 July 1976, 1F, 3M, 3LePe, 1Pe; [637], 15 July 1976, 4F, 3LePe, 1Pe. Chaklapungee, S. of Shatchuri [102], 24 June 1975, 1L. Chaklapungee, Shatchuri [373], 23 Nov. 1975, 6L; [407], 25 Dec. 1975, 1LePe, 1L; [486], 29 Mar. 1976, 1LePe. Hill Track, Kaptai $\left(22^{\circ} 21^{\prime} \mathrm{N} 92^{\circ} 17^{\prime} \mathrm{E}\right)$, [361], 20 Nov. 1975, 1L (all above, R. Rosenberg). Sylhet, Juri (2436'N 92 $\left.{ }^{\circ} 7^{\prime} E\right)$, 1937, 4F (Hamilton). INDIA. No locality, 1930, 1F (Christophers). Andaman Islands: General
(Central, $\left.12^{\circ} 30^{\prime} \mathrm{N} 92^{\circ} 45^{\circ} \mathrm{E}\right), 1908,1 \mathrm{~F}, 1 \mathrm{M}, 1 \mathrm{~F}$ wing and head on 2 separate slides (R. White); 1920, 1M. Assam: State of $\left(26^{\circ} 00^{\prime} \mathrm{N} 93^{\circ} 0^{\prime} \mathrm{E}\right)$, 1F. Ledo $\left(27^{\circ} 18^{\prime} \mathrm{N} 95^{\circ} 44^{\prime} \mathrm{E}\right), 2$ Apr. 1945, 1F; 1944, 7F, 4M (V.L. Miles). Cachar, Lebac $\left(25^{\circ} 5^{\prime} \mathrm{N} 92^{\circ} 55^{\circ} \mathrm{E}\right), 1934,2 \mathrm{~F}$ (G. Fraser). Rupsi $\left(26^{\circ} 8^{\prime} \mathrm{N} 89^{\circ} 56^{\prime} \mathrm{E}\right), 5$ Nov. 1943, 1F (D.E. Hardy). Tin Sukia, $\left(27^{\circ} 30^{\prime} \mathrm{N}\right.$ 95²2'E), Apr. 1945, 1F, 1M; May 1945, 11 F, 2M (H.M. Gelfand). Meghalaya: Tura $\left(25^{\circ} 31^{\prime} \mathrm{N} 90^{\circ} 13^{\prime} \mathrm{E}\right), 1934,4 \mathrm{~F}, 1 \mathrm{M}$. West Bengal: Jalpaiguri $\left(26^{\circ} 31^{\prime} \mathrm{N} 88^{\circ} 44^{\prime} \mathrm{E}\right)$, 8 July 1907, 1F (C. Wallich); 1933, 1F (B.M. Khan).

THAILAND. Chumphon: Province of: $\left(10^{\circ} 30^{\prime} \mathrm{N} 99^{\circ} 10^{\prime} \mathrm{E}\right)$, Sept. 1964, 1F; Ban Khao Thalu (10²'N 98 $56^{\circ}$ E), [07945], 4 Sept. 1978, 1F. Pathiu, Ban Chong Mut (10 44'N 99 $\left.18^{\circ} \mathrm{E}\right)$, [07964], 8 Sept. 1978, 1F, 1M, 2LePe; [07967], 8 Sept. 1978, 1M, 1Pe; [07998], 13 Sept. 1978, 3M, 3LePe; [07999], 13 Sept. 1978, 4F, 3M, 7LePe; [08003], 13 Sept. 1978, 3F; [08003(3)], 13 Sept. 1978, (progeny), 3F, 2LePe; [08007], 18 Sept. 1978, 1F; [08007(5)], 18 Sept. 1978, (progeny), 4F, 2M, 5LePe. Wang Mai, Ban Jo Po Ro $\left(10^{\circ} 29^{\prime} \mathrm{N} 98^{\circ} 55^{\circ}\right.$ E), [07970], 9 Sept. 1978, 33F; [07970 45-53], 10F; [07970, (4, 5, 8, 9, 22, 39)], 9 Sept. 1978, (progeny), (4) 7F, 3M, 9LePe, 1Pe; (5) 34F, 29M, 57LePe, 4Pe; (8) 3M, 3LePe; (9) 38F, 37M, 59LePe, 2Pe; (22) 9F, 18M, 25LePe; (39) 27F, 25M, 35LePe, 2Pe; [08005 (1, 2, 5, 7, 9, 10, 12)], 15 Sept. 1978, (progeny), (1) 22F, 23M, 41LePe, 2Pe; (2) 14F, 9M, 23LePe; (5) 2F, 2M, 4LePe; (7) 3F, 5M, 8LePe; (9) 6F, 8M, 14LePe; (10) 2F, 1M, 2LePe; (12) 3F, 4M, 6LePe; [08005], 15 Sept. 1978, 10F; [08008], 19 Sept. 1979, 24F; [08008(9)], 19 Sept. 1978, (progeny), 5F, 15M, 20LePe; [08009], 20 Sept. 1979, 46F, 32M, 57LePe, 21Pe; [08010], 20 Sept. 1978, 71F, 43M , 77LePe, 32Pe; [08011], 20 Sept. 1978, 21F, 28M, 38LePe, 12Pe, 1L; [08012], 20 Sept. 1978, 6F, 1M, 6LePe; [0813], 20 Sept. 1978, 11F, 8M, 14LePe, 4Pe; [08014], 20 Sept. 1978, 21F, 19M, 35LePe, 2L. Ban Ngao $\left(9^{\circ}\right.$ $\left.55^{\prime} \mathrm{N} 99^{\circ} 2^{\prime} \mathrm{E}\right),[07976], 11$ Sept. 1978, 1F, 1M, 1LePe, $1 \mathrm{Pe}$.

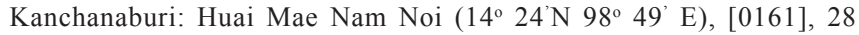
May 1965 , 7F, 5M, 5LePe, 4Pe, 2L. Ban Sai Yok (14 $\left.{ }^{\circ} 26^{\prime} \mathrm{N} 98^{\circ} 52^{\prime} \mathrm{E}\right)$, [0171], 29 May 1965, 1F, 1Pe; [0172], 29 May 1965, 3F, 6M, 4Pe; [0175], 29 May 1965, 1F, 1Pe. Sai Yok, Huai Bong Ti $\left(14^{\circ} 23^{\prime} \mathrm{N}\right.$ 99²'E), [202], 3 June 1965, 1F, 1LePe; [203], 3 June 1965, 2F, 1LePe.

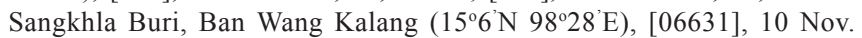
1973, 1F, 1L; [06632], 10 Nov. 1973, 1L; [06865], 4 July 1974, 3F,

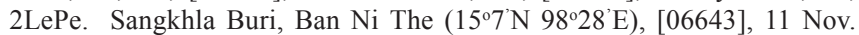
1973, 1F, 1LePe, 1L; [06645], 14 Oct. 1979, 1L; [07255], 1F, 1M, 2Pe. Ban Lawa $\left(15^{\circ} 5^{\circ} \mathrm{N} 98^{\circ} 28^{\prime} \mathrm{E}\right)$, [06657], 15 Nov. 1975, 1L; [06894], 10 July 1974, 1F, 1LePe, 3L; [06896], 10 July 1974, 2F, 6M, 7LePe, 4L; [06899], 10 July 1974, 2L; [06900], 10 July 1974, 2F, 1M, 2LePe, 1Pe; [07568], 1 Mar. 1975, 1F, 1Pe. Sangkhla Buri, Ban Ku Phadu

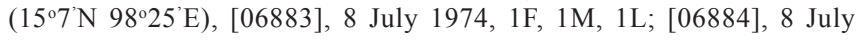


Table 24. Number of branches for setae of larvae of An. baimaii: range (mode).

\begin{tabular}{|c|c|c|c|c|c|c|c|c|c|c|c|c|c|}
\hline \multirow{2}{*}{$\begin{array}{l}\text { Seta } \\
\text { No. }\end{array}$} & \multirow{2}{*}{$\begin{array}{c}\text { Head } \\
\text { C }\end{array}$} & \multicolumn{3}{|c|}{ Thorax } & \multicolumn{9}{|c|}{ Abdominal segments } \\
\hline & & $\mathrm{P}$ & $\mathrm{M}$ & $\mathrm{T}$ & $\mathrm{I}$ & II & III & $\mathrm{IV}$ & $\mathrm{V}$ & $\mathrm{VI}$ & VII & VIII & $\mathrm{X}$ \\
\hline$\overline{0}$ & 1 & 1 & - & - & - & 1 & 1 & 1 & 1 & 1 & 1 & 1 & - \\
\hline 1 & 1 & $13-22(16)$ & $25-38(28)$ & 1 & $4-8(6)$ & $4-13(8)$ & $16-24(19)$ & $15-22(16)$ & $16-21(17)$ & $12-20(17)$ & $10-16(13)$ & 1 & 1 \\
\hline 2 & 1 & $9-15(10)$ & $1-5(2)$ & 1 & $1-3(2)$ & $5-8(7)$ & $5-7(6)$ & $3-5(4)$ & $3-5(4)$ & $4-5(4)$ & $4-7(6)$ & $4-8(6)$ & $13-23(16)$ \\
\hline 3 & 1 & 1 & 1 & $3-8(5)$ & $1-3(1)$ & $1-2(1)$ & 1 & $2-3(3)$ & 1 & 1 & $2-4(2)$ & $4-8(6)$ & $8-11(10)$ \\
\hline 4 & $1-2(1)$ & $12-20(13)$ & $2-3(3)$ & $3-5(3)$ & $4-7(5)$ & $4-9(5)$ & $2-4(3)$ & $3-4(3)$ & $3-4(3)$ & 1 & 1 & 1 & 9 \\
\hline 5 & $8-12(9)$ & n.c. & 1 & $23-40(33)$ & $3-4(3)$ & $4-6(5)$ & $3-4(3)$ & $3-4(3)$ & $3-5(3)$ & $3-5(4)$ & $3-6(5)$ & $3-5(3)$ & - \\
\hline 6 & $10-16(14)$ & 1 & $3-6(3)$ & $1-3(3)$ & $18-21(20)$ & $17-26(20)$ & $13-18(15)$ & $2-3(2)$ & $2-3(2)$ & $2-3(3)$ & $2-5(4)$ & $1-S$ & $3-6(5)$ \\
\hline 7 & $9-14(12)$ & $18-25(20)$ & $2-3(3)$ & $21-29$ & $15-19(15)$ & $15-26(19)$ & $3-6(5)$ & $4-7(4)$ & $3-6(5)$ & $3-4(3)$ & $2-4(3)$ & $2-S$ & $4-7(6)$ \\
\hline 8 & $1-2(1)$ & $22-31(27)$ & $17-28(26)$ & $24-28(24)$ & - & $1-2(2)$ & 2 & $2-3(2)$ & $2-3(2)$ & $2-3(2)$ & $3-5(4)$ & $6-S$ & $1-3(2)$ \\
\hline 9 & $1-4(2)$ & 1 & 1 & 1 & $3-5(4)$ & $5-12(6)$ & $7-9(8)$ & $6-9(8)$ & $4-7(6)$ & $4-8(6)$ & $3-6(4)$ & $7-S$ & 1 \\
\hline 10 & $1-2(1)$ & 1 & 1 & 1 & 1 & $2-4(2)$ & 1 & 1 & 1 & $2-3(3)$ & $3-7(5)$ & $8-S$ & $2-3(3)$ \\
\hline 11 & $24-30(30)$ & 1 & 1 & 1 & $3-4(3)$ & 1 & $2-4(3)$ & $2-4(3)$ & $2-4(3)$ & $2-4(2)$ & $1-4(2)$ & 9-S & $2-4(3)$ \\
\hline 12 & $1-2(1)$ & 1 & 1 & $2-3(2)$ & $3-4(3)$ & 1 & $2-3(2)$ & $2-3(3)$ & $2-3(3)$ & 1 & 1 & - & - \\
\hline 13 & $4-7(5)$ & $1-7(5)$ & $4-6(5)$ & $2-3(3)$ & $3-5(4)$ & $4-6(5)$ & $3-7(5)$ & $3-4(3)$ & $3-4(3)$ & $3-8(6)$ & $2-4(2)$ & - & - \\
\hline 14 & n.c. & $4-7(5)$ & $4-8(6)$ & - & - & - & - & 1 & 1 & 1 & 1 & 1 & - \\
\hline 15 & $3-5(5)$ & - & - & - & - & - & - & - & - & - & - & - & - \\
\hline
\end{tabular}

n.c. $=$ not counted

1974, 1L. Sangkhla Buri, Ban Nong Plang Khong (157'N 98²9’E), [06902], 12 July 1974, 4L; [06904], 12 July 1974, 3F, 2M, 5LePe, 2L; [06906], 12 July 1974, 1F, 1M, 2LePe, 2L. Sangkhla Buri (15ํN N 98 27'E), [07071], 22 Aug. 1974, 1F, 1LePe. Huai Nong Bon, (vicinity of $\left.14^{\circ} 25^{\prime} \mathrm{N} 99^{\circ} 25^{\prime} \mathrm{E}\right)$, [08131], 19 Nov. 1979, 1F, 1Pe. Ban Phu Rat [08137], 22 Nov. 1979, 1F, 1LePe; [08139], 22 Nov. 1979, 1M; [08140], 22 Nov. 1979, 1F, 1LePe. Huai Kop [08144], 23 Nov. 1979, 1F, 1LePe. Khao Nuam (1426’ ${ }^{\circ}$ 99²'E), [09034], 25 Sept. 1979, 8F, 4M, 12LePe (all above, AFRIMS). Krabi: Plai Phraya, Ban Bang Haeng ( $\left.8^{\circ} 34^{\prime} \mathrm{N} 98^{\circ} 44^{\prime} \mathrm{E}\right)$, [KB17, 50, 87, 106, 108], Nov. 1986, (progeny), (17), 3F, 3LePe; (50), 3F, 3M, 5LePe, 1Pe; (87), 2M, 2LePe; (106), 1F, 1M, 2LePe; (108), 1F, 1LePe, (V. Baimai); [KB] 1518 Nov. 1986, 3F, 3LePe, 1L (V. Baimai). Mae Hong Son: Mae Sariang,

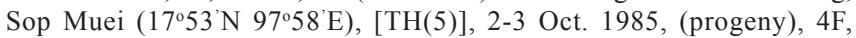
10M, 8LePe, 3Pe, 4L; [TH(34)], 2-3 Oct. 1985, (progeny), 4F, 5M, 9LePe. Ban Mae Ho Nua $\left(18^{\circ} 8^{\prime} \mathrm{N} 98^{\circ} 3^{\prime} \mathrm{E}\right)$, [01523], 15 Sept. 1966, 1F, 1Pe; [01527], 15 Sept. 1966, 1M, 1Pe; [01528], 15 Sept. 1966, 3M, $1 \mathrm{LePe}, 1 \mathrm{Pe}$; [01609], 15 Sept. 1966, 1M, 1Pe; [01610], 15 Sept. 1966, 1M, 1Pe; [01611], 15 Sept. 1966, 1F, 1Pe, 2L; [01615], 15 Sept. 1966, 6F, 2M, 2LePe, 6Pe, 4L. Ban Pa Chi $\left(18^{\circ} 8^{\prime} \mathrm{N} 98^{\circ} 2^{\prime} \mathrm{E}\right)$, [01533], 10 Sept. 1966, 1F, 1L; [01534], 10 Sept. 1966, 2F, 1M, 1LePe, 2Pe; [01536], 10 Sept. 1966, 1M, 1Pe; [01549], 10 Sept. 1966, 2F, 2M, 1LePe, 3Pe. Ban Mae Tia (18¹8'N 97 $\left.57^{\circ} \mathrm{E}\right)$, [01557], 11 Sept. 1966, 1M, 1Pe; [01558], 11 Sept. 1966, 1F, 1Pe, 1L. Doi Chang (18 $8^{\circ} 33^{\prime} N$ 97058'E), [01559], 11 Sept. 1966, 1L; [01562], 11 Sept. 1966, 1F, 1M, 1Pe; [01565], 11 Sept. 1966, 1F, 2M, 1LePe, 1Pe; [01574], 12 Sept. 1966, 2L; [01581], 12 Sept. 1966, 1M; [01586], 12 Sept. 1966, 1F, 1Pe; [01588], 12 Sept. 1966, 3F, 2LePe, 1Pe; [01590], 12 Sept. 1966, 1F, 3M, 1LePe, 3Pe, 3L; [01592], 12 Sept. 1966, 1L; [01593], 12 Sept. 1966, 1F, 1LePe, 1L; [01595], 12 Sept. 1966, 1L; [01599], 12 Sept. 1966, 1F, 1LePe; [01601], 12 Sept. 1966, 1F, 1Pe; [01602], 12 Sept. 1966, 1M, 1Pe, 2L; [01635], 21 Sept. 1966, 2L. Ban Mae Ho Kae, Mo Chae (18 $\left.{ }^{\circ}{ }^{\prime} \mathrm{N} 98^{\circ} 6^{\prime} \mathrm{E}\right)$, [01605], 13 Sept. 1966, $1 \mathrm{M}, 1 \mathrm{Pe}$. Ban Hua Yung $\left(1^{\circ} 16^{\prime} \mathrm{N} 97^{\circ} 57^{\prime} \mathrm{E}\right)$, [01620], 17 Sept. 1966, 2F, 1LePe, 1Pe, 1L. Nakhon Si Thammarat: Ban Rim Thanon $\left(8^{\circ} 21^{\prime} \mathrm{N}\right.$ $\left.100^{\circ} 12^{\prime} \mathrm{E}\right),[01055$ ], 5 June 1966, $1 \mathrm{M}$ (all above, AFRIMS). Tung Yai, Ban Tham Phae Dan ( $\left.8^{\circ} 10^{\prime}{ }^{\prime} 9^{\circ} 9^{\circ} 20^{\prime} E\right)$, [TY 58], 3-8 Dec. 1985, (progeny), 6F, 4M, 10LePe (V. Baimai). Phangnga: Khao Pak Chaung (Chong) ( $\left.8^{\circ} 17^{\prime} \mathrm{N} 98^{\circ} 23^{\prime} \mathrm{E}\right)$, [01650], 13 Oct. 1966, 4F, 1M, 1LePe, 3Pe. Ban Bang Kaeo ( $\left.8^{\circ} 35^{\prime} \mathrm{N} 98^{\circ} 32^{\prime} \mathrm{E}\right)$, [PG-30(F-3)], 23 Feb. 1986, (colony), 8F, 1M, 8LePe (V. Baimai); [08026], 9 May 1979, 12F; [08027], 10 May 1979, 11F, 7M, 18LePe, 1Pe, 2L; [08029], 10 May 1979, 1F, 1LePe, 4L; [08093], 19 May 1979, 9F; [08161], 22 May 1980, 2F, 10M, 9LePe, 3Pe; [08162], 25 May 1980, 12F, 6M, 16LePe,
2Pe; [08163], 25 May 1980, 4F; [08189], 29 May 1980, 6F; [08191], 30 May 1980, 1F, 1LePe; [08197], 30 May 1980, 67F; [08204], 31 May 1980, 1F; [08212], 2 June 1980, 7F; [08223], 4 June 1980, 29F; [08600 (3, 5)], 21 June 1982, (progeny), (3) 5F, 3M, 7LePe, 1L; (5) 1F, 1Pe; [08612], 25 June 1982, 1Pe; [08623 (1, 2)], 26 June 1982, (progeny), (1, F-2) 6F, 2M, 7LePe, 1L; (2, F-1) 12F, 24M, 6LePe, 29Pe; (2, F-2) 11F, 10Pe; [08624(1, 2, 4-8)], 27 June 1982, (progeny), (2) $2 \mathrm{~F}, 4 \mathrm{M}, 4 \mathrm{LePe}$; (2) $8 \mathrm{~F}, 10 \mathrm{M}, 7 \mathrm{LePe}, 9 \mathrm{Pe}, 1 \mathrm{~L}$; (4) $1 \mathrm{~F}, 2 \mathrm{M}, 1 \mathrm{LePe}$, 2Pe; (5) 4F, 3M, 5LePe, 2Pe, 3L; (6) 4F, 3M, 2LePe, 5Pe; (7) 2F, 4M, 6LePe; (8) 2F, 2M, 4LePe; [08628], 29 June 1982, 3F, 2M, 4LePe; [08636 (4),(5)], 30 June 1982, (progeny), (4) 3F, 3Pe; (5) 1F; [08639], 2 July 1982, 1M; [08639 $(1,2,5)], 2$ July 1982, 3F; [TH493], 26 May 1987, 3F, 3LePe; [TH498], 28 May 1987, 1F, 1M, 2LePe, 1L; [TH499], 28 May 1987, 3F, 1M, 3LePe, 1Pe; [TH500], 28 May 1987, 5F, 7M, 4LePe, 8Pe; [TH504(1-5,7-15)], 26 May 1987, (progeny), (1) 9F, 6M, 15LePe; (2) 7F, 6M, 13LePe; (3) $12 \mathrm{~F}, 6 \mathrm{M}$, $18 \mathrm{LePe}$; (4) $8 \mathrm{~F}, 5 \mathrm{M}, 13 \mathrm{LePe}$; (5) $1 \mathrm{~F}, 4 \mathrm{M}, 5 \mathrm{LePe}$; (7) $11 \mathrm{~F}, 7 \mathrm{M}, 18 \mathrm{LePe}$; (8) 8F, 5M, 13LePe; (9) 7F, 4M, 11LePe; (10) 9F, 5M, 14LePe; (11) $3 \mathrm{~F}, 6 \mathrm{M}, 9 \mathrm{LePe}$; (12) $8 \mathrm{~F}, 4 \mathrm{M}, 12 \mathrm{LePe}$; (13) 7F, 4M, $11 \mathrm{LePe}$; (14) $3 \mathrm{~F}$, $8 \mathrm{M}, 11 \mathrm{LePe}$; (15) 9F, 2M, 11LePe. Ban Bang Ra Ko ( $\left.8^{\circ} 38^{\prime} \mathrm{N} 98^{\circ} 32^{\prime} \mathrm{E}\right)$, [08053], 14 May 1979, 2L; [08058], 14 May 1979, 1L; [08068], 14 May 1979, 1F; [08109], 23 May 1979, 3L; [08113], 25 May 1979, 4F, 2M, 4LePe, 2Pe, 1L; [08114], 25 May 1979, 26F, 8M, 23LePe, 10Pe, 5L; [08171], 26 May 1979, 2F. Khlong [Ban] Chon $\left(8^{\circ} 33^{\prime} \mathrm{N}\right.$ 98 31'E), [08084], 16 May 1979, 1F. Ban Pling ( $\left.8^{\circ} 30^{\prime} \mathrm{N} 98^{\circ} 32^{\prime} \mathrm{E}\right)$, [08115], 25 May 1979, 3F. Ban Pa Ko ( $\left.8^{\circ} 30^{\prime} \mathrm{N} 98^{\circ} 30^{\prime} \mathrm{E}\right)$, [08213], 3 June 1980, 2F, 2LePe; [08217], 3 June 1980, 2L. Ban Nop Pling ( $\left.8^{\circ} 33^{\prime} \mathrm{N} 98^{\circ} 33^{\prime} \mathrm{E}\right)$, [08621], 25 June 1980, 2LePe. Ranong: Ban Hin

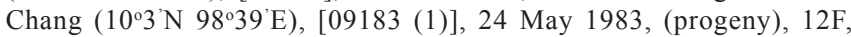
8M, 20LePe, 5L (all above, AFRIMS). Ranong: Province of: (9 $58^{\circ} \mathrm{N}$ 98 $\left.8^{\circ} 38^{\prime} \mathrm{E}\right)$, locality, date, unknown, [RN001, 005, 014, 016, 020, 074] 1985-86 (progeny), 12F, 9LePe, 2Pe (V. Baimai); [CP25] (progeny, possibly from first Mahidol U. colony) 1984?, 6F, 3M, 5LePe, 1L (V. Baimai). Khao Huay Rakung (?), [RN2-11], 18 Mar. 1964, 1F. Khao Chatri (9³1'N 98³4'E), [02151], 17 July 1967, 1M (V. Baimai). Tak: Tha Song Yang, Mae Tan, Komali Ko $\left(17^{\circ} 12^{\prime} \mathrm{N} 98^{\circ} 14^{\prime} \mathrm{E}\right)$, [TH509 (12)], 5-8 July 1987, (progeny), (1) 3F, 8M, 11LePe, 5L; (2) 19F, 8M, 27LePe, 3L; [TH516(1), 6-16 Aug. 1987, (progeny), 15F, 7M, 22LePe, 2L; [TH537(1,2)], 3-8 Oct. 1987, (progeny), (1) 6F, 6M, 12LePe, 5L; (2) 11F, 9M, 20LePe, 4L; [TH549 (1-3)], 13-16 Nov. 1987, (progeny), (1) $14 \mathrm{~F}, 8 \mathrm{M}, 13 \mathrm{LePe}, 9 \mathrm{Pe}$; (2) $5 \mathrm{~F}, 8 \mathrm{M}, 8 \mathrm{LePe}, 7 \mathrm{Pe}$; (3) $13 \mathrm{~F}, 3 \mathrm{M}$, $16 \mathrm{LePe}, 1 \mathrm{~L}$ (all above, AFRIMS). Mae Sot, Ban Kariang, Thum Rua $\left(16^{\circ} 40^{\prime} \mathrm{N} 98^{\circ} 40^{\prime} \mathrm{E}\right)$, [TH1690(10-12)], 7 Aug. 1989 (progeny), (10) $11 \mathrm{~F}, 3 \mathrm{M}, 12 \mathrm{LePe}, 2 \mathrm{~L}$; (11) 4F, 6M, 9LePe, 2L; (12) 3F, 5M, 7LePe, 
2L (V. Baimai). Mae Sot, Ban Tham Sua, Ban Pha Te $\left(16^{\circ} 40^{\prime} \mathrm{N} 98^{\circ} 38^{\prime} \mathrm{E}\right)$, [DCR $(20,28,29,38,40,44,46,51,53,75)]$, Oct. 1989, (progeny) (20) $2 \mathrm{~F}, 1 \mathrm{M}, 3 \mathrm{LePe}, 1 \mathrm{~L}$; (28) 2M, 2LePe, 1L; (29) 2M, 2LePe, 1L; (38) 1F, 2M, 3LePe, 1L; (40) 4M, 4LePe, 1L; (44) 2M, 2LePe, 1L; (46) $2 \mathrm{~F}, 1 \mathrm{M}, 3 \mathrm{LePe}, 1 \mathrm{~L}$; (51) 3M, 3LePe, 1L; (53) 2F, 1M, 3LePe, 1L; (75) 1F, 1LePe, 1L (V Baimai). Mae Sot [E 10], 8 Nov. 1989, (progeny), 10F, 6M, 16LePe, 2L (V. Baimai). UNION OF MYANMAR. Tenasserim Division: Mudon $\left(16^{\circ} 15^{\prime} \mathrm{N} 97^{\circ} 44^{\prime} \mathrm{E}\right)$, [Acc. 1297], 1987, 5F, 5M (MyoPaing); Mudon, Kwang-Ka-Thaung ( $\left.16^{\circ} 15^{\prime} \mathrm{N} 97^{\circ} 44^{\prime} \mathrm{E}\right)$, [KKT], 1987 (?), 3F, 2M. Pegu Division: Taikkyi, 50 miles, north of Yangon $\left(17^{\circ} 23^{\prime} \mathrm{N}\right.$ 96'3'E), [TKK], 1987 [?] (colony vouchers) 9F, 6M (M.M. Thu and Myo-Paing). Sagaing Division: Kebaw Valley (2420'N 9425'E), Oct. 1944, 1M (T.T. Macan).

Distribution (Fig. 55). Anopheles baimaii is known from Bangladesh (Chittagong), India (Andamans Island, Assam, Meghalaya and western Bengal), Thailand (Chumphon, Kanchanaburi, Krabi, Mae Hong Son, Nakhon Si Thammarat, Phangnga, Ranong, Tak), the Union of Myanmar (Tenasserim Division, Pegu Division, Sagaing Division).

Bionomics and medical importance. Anopheles baimaii seems to be an important vector of human malarial parasites in forested, forest fringes, and foothills areas and responsible for maintaining malaria transmission along its distribution range in Thailand, Myanmar, Bangladesh, and notheasthern India (Sen et al. 1973; Rajagopal 1979; Rosenberg 1982; Rosenberg \& Maheswary 1982b; Dutta et al. 1989a, 1989b, 1991; Myo-Paing et al. 1990; Haq \& Maheswary 1991; Tin \& Tun 1991; Green et al. 1992; Prakash et al. 1997b; 2001; Xu et al. 1998; Htay-Aung et al. 2001). Epidemiology studies on malaria in a forest community in Bangladesh, where malaria is holoendemic, showed that females of An. baimaii generally live long enough to reach infectivity to $P$. falciparum. The malaria transmission occurred only during the seven-month monsoon when more than $3.8 \%$ of the females of An. baimaii were infected with human Plasmodium (Rosenberg \& Maheswary 1982b). Anopheles baimaii is also involved in the transmission of $P$. vivax. In an isolated village in a tropical rain forest-fringe area in Assam, India, the vectorial capacity of An. baimaii for $P$. vivax was higher than for $P$. falciparum during the monsoon season, decreasing in post monsoon and reaching zero in the cold and dry season (Prakash et al. 2001). In Naga Hills, India, the prevalence of malaria is related to the vector density thus it was higher in localities closer to the forest where An. minimus and An. baimaii are collected more frequently (Prakash et al. 2000b). Human-bait collections carried out in upper Assam, India, showed that An. baimaii can bite indoors throughout the night, the feeding activity started around $1900 \mathrm{~h}$, peaked between 2100 and $0300 \mathrm{~h}$, and stopped at $0500 \mathrm{~h}$. During the postmonsoon season, peak biting activity was from 0300 to $0500 \mathrm{~h}$, whereas in the premonsoon and monsoon season it was from $2100 \mathrm{~h}$ to midnight. The anthropophilic index was 92.3\% (Prakash et al. 1997a). Similarly in northeastern areas in India, studies on the feeding behavior of An. baimaii showed that it is highly anthropophilic, biting throughout the night with peak activity between 2000-2100 h, $1100 \mathrm{~h}$ to midnight and 0200-0300 h (Dutta et al. 1996). In Dimapur PHC, Nagaland, India, An. baimaii was captured in low number on human bait collections carried out indoors throughout the night (Misra et al., 1993). Light trap collections in dwellings in a forest-fringe village in Dibrugarh District, Assam, India, showed that An. baimaii was seasonal and one of the most common mosquito collected indoors (Prakash et al. 1998b). In an isolated forest-fringe village in Assam, India, malaria prevalence was demonstrated to be seasonal showing a positive correlation with the density of An. baimaii since this species was the only anopheline collected. In addition, density of An. baimaii was correlated with the rainfall that occurred two weeks prior to the collections (Prakash et al. 1997b). In Tengakhat PHC, Dibrugarh Districy, India, An. baimaii was incriminated as vector of Plasmodium since it was one of the most abundant of 12 Anopheles species collected in July and September and the salivary gland of one individual was found infected (Dutta et al. 1989a). Anopheles baimaii was also incriminated as a vector of Plasmodium in Tirap District, Arunachal Pradesh, India because the salivary glands of one individual was found positive for sporozoites (Dutta et al. 1992). More evidence for the vector status of $A n$. baimaii came from a study carried out in Chanlang District, Arunachal Pradesh, India, where sporozoites were detected in the salivary glands of several specimens (Dutta et al. 1989b). Additionally, in Tlabong, State of Mizoram, India, An. baimaii was incriminated as a vector of human Plasmodium and the parity rate $33.69 \%$ suggests that the vectorial capacity of that population is high (Das et al. 1990). Indoors spraying DDT does not seems to be effective in eliminating malaria transimission in areas where An. baimaii is a vector, especially because of the exophilic behavior of the species. In the presence of DDT fewer females fed earlier indoors, whereas in the absence of DDT, females fed both indoors and outdoors (Rosenberg \& Maheswary 1982b). During a longitudinal study on malaria transmission carried out in three villages in Boko PHC, Assam, at the same time that indoor DDT spraying was being used for malaria control, An. baimaii was found in low number, but a few specimens were positive for sporozoites (Nandi et al. 1993). In western Bengal, An. baimaii was observed to be anthropophilic (Nandi et al. 2000), seasonal since it was more common during rainy months, and in close association with human environment (Nandi et al. 1996). Adults were collected in cattle sheds at night (Krishnan \& Halernkar 1967), and in the state of Tripura, northeast India, An. baimaii was collected in cowshed and piggery (Das et al. 1991). Females were collected in cowsheds and hospitals in Assam, Cachar District, India (Ramsay 1930) and at a settlement of brick-makers in a series of constructions made of bamboo, called "bashas", at Chunati near Chringa, Bangladesh (Macan 1950). In Myanmar, females were attracted by cattle and humans, but $2 \%$ of females collected on human bait were found positive for $P$. vivax during rainy and cool dry months (HtayAung et al. 1999). Although anthrophilic, An. baimaii can also feed on blood of other mammals. For example, females were found positive for human, ox or buffalo, chicken, dog, and pig blood. The human blood index was $38.2 \%$ among the specimens collected indoors at night time and $48 \%$ during the 
daytime, outdoors (Khin-Maung-Kyi 1971, 1974). In addition, An. baimaii was found to be a later biter, the biting activity peak was between 2000-2400 h both outdoors and indoors. Interestingly, more than $50 \%$ of the population live long enough for the development of sporozoites. Consequently, the longevity and the anthrophophilism make An. baimaii an efficient vector for the transmission of stable malaria in central Myanmar (Khin-Maung-Kyi \& Win 1976). In Minbyin Forest, central Myanmar, where malaria transmission is perennial, $A n$. baimaii is more abundant during the rainy season when the transmission is higher than in the dry season. In Bargo mountain range, south central Myanmar, An. baimaii is a primary vector of human Plasmodium in the postmonson season and infective samples were collected on human bait indoors (Tun-Lin et al. 1995). Although being considered a forest mosquito, An. baimaii appears to be also adapted to the peridomestic environment. In Myanmar, human changes in the natural environment are enhancing An. baimaii dispersal to human communities and can change the dynamics of malaria in that region (Htay-Aung et al. 1999). Furthermore, individuals from a peridomestic population differ from those of a forested population in esterase loci (Tun-Lin et al. 1988). In Thailand, adults of An. baimaii were collected biting humans in primary and secondary evergreen forest, primary and secondary deciduous forest, primary and secondary rain forest, secondary rain forest mixed with fruit plantations, orchards and rubber plantations, banana and pineapple plantations, villages, villages with fruit plantations, inside houses, and also in the canopy of rain forests $16.5 \mathrm{~m}$ above ground level.

The larval habitats of An. baimaii are similar to those of An. dirus. Although An. baimaii can share the same habitats with $A n$. dirus, the former is more common in temporary breeding places than the latter (Rattanarithikul et al. 1995). In Myanmar, immatures were found breeding in small rocky pools under dense shade and in bamboo stumps in deep forest (MyoPaing et al. 1990), in less frequently used domestic wells under shade (Htay-Aung et al. 1999), and in Mudon, immatures were taken from wells lined by laterite rock (Tun-Lin et al. 1987). Additionally, immatures were taken from rain filled slit trenches, roadside puddles, long marshy areas "luwins" through forest, rocky bed, stagnant ditches, swamps, cattle hoofprints, stream pockets, and paddy-fields. All breeding places were in shade (Khin-Maung-Kyi 1970). The breeding habitats also include great variety of stagnant waters in jungles, as well as domestic wells, earthern pots, ceramic jars, and cement tanks (Tin \& Tun 1991). Additionally, immatures were taken from domestic elephant and animal footprints, wheels and cart tracks along paths and roads, animal wallows, seepage pools, flood pools, pools in drying and dried streambeds and stream margins, ground pools, flood pools, large flood pools, seepage pools, limestone pools, sandy pools in banks of streams, shallow streams, ditches, flooded ditches, charcoal pits, small and large rock pools, swamps, and rice paddies. The water was always fresh, stagnant, clear, turbid, or sometimes with some degree of pollution. The pools were generally less than $2 \mathrm{~m}$ wide and $30 \mathrm{~cm}$ deep, under partial or heavy shade, or sometimes in sunlit areas. The larval habitats were inside primary bamboo grove forest, rimary and secondary rain forest, primary and secondary deciduous forest, primary and secondary evergreen forest, secondary scrub in villages, secondary forest mixed with fruit plantations, evergreen rain forest, rubber tree plantations, village with fruit plantations, and orchards and villages located in valleys, hilly, and mountainous areas. In India, immatures of An. baimaii were collected in wells, $100 \mathrm{~m}$ above sea level. In Upper Brahmaputra Valley, Assam, immatures were found exclusively in forested areas (Khan et al. 1998), whereas in a forest-fringe village in Assam, immatures were taken from small, shallow, rain filled, temporary, shady and partly shaded puddles and ground pools during rainy months. In dry months, immatures were taken from permanent streams in the forest adjoining a village (Prakash et al. 1997c). In Changland District, Arunachal Pradesh, An. baimaii is also a forest species found in small stagnant ground pools, completely or partially shaded by plants in open jungle (Dutta et al. 1989b). In Bangladesh, during the annual six-month monsoon season, immatures of An. baimaii was found in puddles on footpaths, and in turbulent pits at the heads of drainage gullies that held water for at least five days. In the dry season, the breeding places were streams about $3 \mathrm{~km}$ distant from the malaria focus. Immatures seem to be well adapted to small temporary pools. Eggs were laid above the water line and remained viable for about two weeks. Interestingly, larvae of An. baimaii were observed to leave a draining pool and crawl as far as $53 \mathrm{~cm}$, sometimes to another pool. Also, larvae remained alive up to $94 \mathrm{~h}$ at the bottom of drained pools (Rosenberg 1982).

During field collections carried out for the present study, immatures were collected from turbulence pit ground pools, turbulence pits, a narrow sand gully head, large pools, large turbulent pools in the middle of a stream bed, small ground pools, ground pools in a foot path, ground pools under a large steel bridge, stream pools, stream bed pools, head waters of streams, stream margins, cave pools, pools along roads, culvert pools, riverside pools, ditches on roads, ditches in streams, puddles in villages, sluggish streams, a stream bed below factory tank seepage, tank runoff, and a pothole. The water was always fresh, stagnant, clear, turbid, sometimes dark or brownish, usually in heavy or partial shade or in full sun. The larval habitats were situated in tropical rain forest, in mountainous, hilly areas, or in valleys. In Yunnan Province, southern China, larvae of An. baimaii were found in habitats situated near villages; however, no adults were captured in CDC light traps with UV or incandescent bulbs during 57 night collections (Moore et al. 2001).

Baimai et al. (1988b) showed that An. baimaii is highly polymorphic for chromosome inversions and that the distribution of the polymorphisms may be associated with the geography and dynamics of the malaria transmission. Anopheles baimaii showed resistance to DDT and $\mathrm{HCH}$ in Myanmar (Harinasuta et al. 1982).

Systematics. Using evidence from the heterochromatin of the metaphase sex chromosomes, Baimai et al. (1984a) found 
support for a fourth species within the Dirus Complex, which was designated as An. dirus D. The species status of $A n$. baimaii was confirmed by crossing experiments and chromosomal differences (Thu et al. 1985, 1986a; Baimai et al. 1987; 1988b), a DNA probe based on 7,000 recombinant clones derived from wild females (Panyim et al. 1988b), a nonradioactive DNA probe method (Audtho et al. 1995), nucleotide sequence of the ITS2 of rDNA (Xu \& Qu 1997b; Xu et al. 1998), allele-specific amplification in the nucleotide sequence of ITS2 (Walton et al. 1999), a PCR based method (Huong et al. 2001), and a SCAR marker and multiplex PCR-based method (Manguin et al. 2002). Additionally, Green et al. (1992) found support for the hypothesis that the four chromosomal / electrophoretic forms of the Dirus Complex represented four distinct biological species, and Damrongphol \& Baimai (1989) pointed out diagnostic morphological characters of the eggs, useful for distinguishing An. baimaii from the other members of the complex. Thu et al. (1985) showed that a population identified as An. balabacensis from Myanmar was distinct from An. dirus from Kanchanaburi, Thailand, in behavior, ecology, morphology, cytogenetics, and isozyme pattern. The phylogenetic relationships among five species of the complex, including An. baimaii, were investigated employing data on the fixed inversion of $3 \mathrm{Rb}$ and inversion polymorphism of the X chromosome (Poopittayasataporn \& Biamai 1995). Using 11 microsatellite loci, Walton et al. (2001) showed that An. dirus, An. baimaii, and An. scanloni are very distinctive, however, no differentiation was observed either within or between $A n$. dirus and An. baimaii based on COI gene sequences. The genetic diversity was higher in An. baimaii than in An. dirus suggesting that expansion occurred first in An. baimaii and then in An. dirus (Walton et al. 2000).

Anopheles baimaii can be recognized by the following combination of characters. Adults: 1) proboscis dark-scaled, slightly longer than forefemur, ratio of proboscis length to forefemur length 1.01-1.14 (mean=1.08); 2) PSD spot of vein $\mathrm{R}$ rarely entirely dark-scaled, frequently with 1 or 2 pale interruptions in one or both wings; 3) ASP spot absent on vein $\mathrm{C}$ and usually on subcosta; 4 ) hindtarsomere 4 with noticeably basal patch of pale scales on dorsal surface; 5) apical pale band on hindtibia entirely white, without dark extension into the basal portion; 6) vein 1A occasionally with long pale spot at level of the PSD spot at least on one wing, when present this spot is always the longest pale spot of vein $1 \mathrm{~A} ; 7)$ combined pale spots and bands along the dorsolateral line of foretarsomeres 1 and 2 dominate the dark portions along this line, often two or more of these pale spots on tarsomere 1 are fused, forming long lines or splashes of pale scales; 8) foretarsomere 2 with pale bands and spots fused, or completely pale dorsally, or the pale spots and bands are longer, reducing the dark areas in the middle to narrow bands; 9) PSD spot on vein $\mathrm{R}$ usually extends basally from level 1 to level 5, most often to level 1, level 3 and level 4. The fourth-instar larva of An. baimaii is indistinguishable from An. cracens, however it can be separated from other species by the following combination of characters: 1) seta 1-II noticeably less developed than seta 1-III-VI; 2) 5-C noticeably longer than antenna; 3) basal sclerotized tubercle of seta 1-P with prominent tooth or spine arising from posterodorsal margin; 4) seta 4-C short, usually not reaching or extending beyond base of 2-C, infrequently extending 0.3 beyond base of 2-C, ratio of 4-C length to distance between insertions of 2-C and 4-C 0.67-1.31 (mean $=0.94) ; 5)$ seta 3-C extends to or slightly beyond anterior margin of head; 6) seta $1-X$ inserted in a marginal notch or at the edge of the saddle; 7) seta 14-P with 4-8 branches. Except for An. scanloni and the male pupa of An. cracens, the pupal stage of An. baimaii is indistinguishable from those of the other members of the Dirus Complex. As mentioned above, the pupal paddle of An. scanloni does not have a fringe of spicules on its inner margin, whereas it is always present in An. baimaii. Additionally, the genital lobe of the male pupa of An. cracens is noticeably constricted at midlength, but not constricted in An. baimaii.

\section{Anopheles (Cellia) elegans (James)}

(Figs. 4, 6j, 7, 27, 28, 50-53, 56)

Myzomyia (?) elegans James (1903) in Theobald (1903:51) (F* wing, scales) (new species of James, possibly a variety of $A n$. leucosphyrus). Type specimen: Holotype female, deposited in the NHM.

Anopheles balabacensis of Reid (1970:56) (in part, systematics).

Anopheles dirus species E of Tewari et al. (1987:25) (bionomics, distribution); Peyton \& Ramalingam (1988:274); Bhat (1988:103) (distribution); Peyton (1989:197) (taxonomy); Sawadipanich et al. (1990:477) (cytogenetics, crossing).

Anopheles elegans of Townsend (1990:36) (type information).

Anopheles leucosphyrus of Covell (1927:47) (in part, distribution); Covell (1931b:241) (in part, distribution); Christophers (1933:177) (type information).

Anopheles leucosphyrus balabacensis of Colless (1956b:76) (taxonomic notes, type information).

Anopheles leucosphyrus var. elegans of Cogill (1903:330) (larval bionomics, in part); James \& Liston (1904:82) (wing, page 83); Reid (1949:46) (taxonomic notes, in part, type information).

Neomyzomyia elegans of Theobald $(1910: 29)$ (transferred to genus Neomyzomyia; in part, F*, Fig. 11); James \& Liston (1911:106) ( $\mathrm{F}^{*}$ wing).

Female (Figs. 4, 6j, 7). Head: proboscis uniformly darkscaled, length $2.03-2.30 \mathrm{~mm}($ mean $=2.20 \mathrm{~mm})$, ratio of length to forefemur 1.03-1.11 (mean =1.08), maxillary palpus (Fig. 7) length $1.93-2.20 \mathrm{~mm}($ mean $=2.06 \mathrm{~mm})$, ratio of length to proboscis $0.90-0.99$ (mean $=0.94)$, ratio of length to forefemur 0.98-1.02 $($ mean $=1.01)($ Table 2$)$, ratio of length of palpomeres $3 / 41.53-1.69($ mean $=1.59), 3 / 52.08-2.55($ mean $=2.28), 4 / 51.31$ $1.60($ mean $=1.44), 4-5 / 31.00-1.16($ mean $=1.07)$; palpomeres $2-$ 4 with conspicuous apical band of white scales, length of apical pale band of palpomere $50.91-1.83($ mean $=1.21)$ length of basal dark band of palpomere 5, ratio of length of apical pale band of palpomere 4 to length of basal dark band of palpomere 5 0.27-0.78 (mean $=0.56)($ Table 3$)$. Thorax: pleural setae as follows: 2-4 upper proespisternal, 0-4 prespiracular, 3-6 prealar, 3,4 upper mesokatepisternal, 2-4 lower mesokatepisternal, 3-6 upper mesepimeral. Wing (Fig. 4, 6j): length 2.78-3.67 mm (mean $=3.33 \mathrm{~mm}$ ), pale scales on all veins light cream-colored, spots 
on veins $C$, subcosta and $R_{1}$ veins more obvious cream-colored, those on vein $\mathrm{R}$ and posterior veins lighter, not strongly contrasting with others, PHP, HP, and PSP spots of vein C usually present, prominent or reduced, rarely absent, SP spot always present and prominent, ASP spot always absent, PP spot 0.63-1.36 (mean = 1.00) length of SCP spot, AD spot 2.003.20 (mean $=2.43$ ) length of preapical pale spot, PSD spot of vein R extending basally from level 2 to level 5 on one or both wings (Table 4), PSD spot of vein $R$ with 1-4 pale interruptions (Table 5), SD spot of vein $\mathrm{R}$ with 1-3 pale interruptions (Table 6), sum of pale interruptions on PSD-PD spots of vein R 4 to 9 for each wing, ratio of length of cell $R_{2}$ to vein $R_{2+3}$ 1.53-1.98 (mean = 1.85), ratio of length of cell $\mathrm{R}_{2}$ to cell $\mathrm{M}_{1+2}^{2+3} 1.18-1.28$ $(\mathrm{mean}=1.22)$. Legs: femora, tibiae, and tarsomeres 1 darkscaled, speckled with spots of pale scales; foretarsomeres 2,3 and 4 with broad, basal and apical bands of white scales on dorsal, lateral and anterior surfaces, tan to light brown-scaled along ventral surface, apical, and basal pale bands poorly evident or absent on ventral surface, foretarsomere 2 sometimes mostly pale-scaled on dorsal, lateral, and anterior surfaces, with 2 narrow, dark middle bands, foretarsomere 5 mostly darkscaled with pale scales at apex, occasionally entirely palescaled, dark scales on foretarsomeres 4,5 sometimes tan to light brown; midtarsomeres 2-4 with apical pale band patch on dorsal, lateral, and anterior surfaces, ventral surface entirely dark-scaled, midtarsomere 5 dark; hindtarsomeres 2,3 with short apical pale band, hindtarsomere 2 with 1-3 pale patches on middle dark region, hindtarsomere 4 with basal and apical pale bands, hindtarsomere 5 dark with pale scales at apex. Abdomen: tergum VI without scales, tergum VII with few, narrow, creamcolored to brownish scales at apex, tergum VIII with narrow, long, cream-colored to golden scales covering apical 0.5-0.8; sternum VI usually without scales, sometimes with 1-3 dark apicolateral scales, sternum VII with posteromedial patch of dark scales, sternum VIII with small basolateral patch of pale scales.

Male. Essentially as in female except for sexual characters. Wing generally paler, with reduced scaling, pale spots usually longer than in female. Palpomere 2 with dorsal patch of pale scales at middle extending laterally, apex of palpomere 2 bare, palpomere 3 with a long dorsal patch of pale scales at middle, extending laterally, apex of palpomere 3 with a broad band of pale scales covering dorsal, lateral, and ventral surfaces, with dark scales at apex of ventrolateral surface, palpomeres 4 and 5 mostly pale-scaled with narrow basal band of dark scales, both palpomeres with longitudinal line of dark scales on ventral surface, not reaching apex of palpomere 5. Abdomen: sterna VI,VII with posteromedial patches of dark scales, sternum VIII covered with pale cream-colored to yellowish scales. Genitalia: 4,5 large parabasal setae; ventral clapette with 1 long apicolateral seta, slightly longer than club of dorsal claspette, 1 short, slender apicomedial seta, and 3 short, slender subapical seta; dorsal claspette with 4-6 setae arising from apex, setae fused apically into stout club with distinct basal stems; aedeagus elongate, columnar, dorsally curved with about 7,8 leaflets on each side of tip, leaflets serrated on one or both edges.
Pupa (Fig. 27). Position and development of setae as figured; range and modal number of branches as in Table 25. All measurements from 18-20 specimens. In general similar to An. leucosphyrus except for the following characters. Sterna II-VII with narrow dark band near anterior margin. Cephalothorax: seta 6-CT single or double, 7-CT usually double, 9-CT single or double. Seta 9-II-VIII pigmented light to medium brown, slightly darker at base. Abdomen: seta 7-I with 2-4 branches; 1 -III with more than 30 branches, 8,10,11-II absent, 9-II length $0.010-0.014 \mathrm{~mm}($ mean $=0.011 \mathrm{~mm}) ; 5$-III with 6-11 branches, 9-III length $0.016-0.02 \mathrm{~mm}($ mean $=0.02$ $\mathrm{mm}$ ); 6-IV single, 9-IV length $0.02-0.05 \mathrm{~mm}$ (mean $=0.03 \mathrm{~mm}$ ), ratios of length of seta 9-IV/9-III 1.33-2.44 (mean =1.82) and 9IV/9-V 0.23-0.46 (mean =0.33); 1-V usually double, 6-V single, $9-\mathrm{V}$ either with or without spicules, length $0.07-0.13 \mathrm{~mm}$ (mean $=0.11 \mathrm{~mm})$; 9 -VI length $0.10-0.13 \mathrm{~mm}($ mean $=0.11 \mathrm{~mm})$, either with or without spicules; 9-VII length 0.11-0.14 mm (mean = $0.12 \mathrm{~mm}$ ), either with or without spicules; 9-VIII 10-20 branches. Paddle: filamentous spicules on outer apical margin and inner margin either prominent or absent; toothed margin index 0.78$0.90($ mean $=0.85)$.

Larva (Figs. 27, 28, 50-53). Position and development of branches as figured; range and modal number of branches as in Table 26. All measurements from 20-32 specimens unless otherwise indicated. In general similar to An. leucosphyrus except for the following characters. Head: length $0.68-0.72 \mathrm{~mm}$ $($ mean $=0.70 \mathrm{~mm})(\mathrm{n}=9)$, width $0.70-0.77 \mathrm{~mm}($ mean $=0.74 \mathrm{~mm})$ $(\mathrm{n}=9)$; antenna length $0.28-0.32 \mathrm{~mm}$ (mean $=0.30 \mathrm{~mm}$ ), ratio of distance base to 1-A to antenna length 0.31-0.44 (mean $=0.38)$; seta 2-C single, simple, 3-C length 0.07-0.10 mm (mean $=0.09)$, distance between base of 2-C and 3-C 0.03-0.04 mm (mean = $0.04 \mathrm{~mm}$ ), 4-C length $0.07-0.10 \mathrm{~mm}$ ( mean $=0.08 \mathrm{~mm}$ ), extending nearly or beyond base of 2-C, distance between basal insertions of 2-C and 4-C 0.08-0.11 $\mathrm{mm}$ (mean $=0.09 \mathrm{~mm}$ ), ratio of length of 4-C to distance between insertions of 2-C and 4-C 0.80-1.09 $($ mean $=0.93)(\mathrm{n}=19)$, distance between bases of 3$\mathrm{C}$ and 4-C 0.07-0.10 mm (mean $=0.08), 5-\mathrm{C}$ shorter, as long as or slightly longer than antennal shaft, not reaching anterior margin of head, with 5-10 branches. Thorax: tubercle of seta 1P partially joined to tubercle of 2,3-P (Fig. 53) by anterior, basal bridge, each tubercle with a strong, pointed apical tooth arising from posterodorsal margin, projecting over bases of 1,2-P; 3-T (Fig. 52) moderately developed, palmate, with 3-6 narrow, nearly transparent, lanceolate leaflets arising from a long, narrow basal stem. Abdomen: seta 1-I moderately developed; 1-II (Fig. 51) moderately developed; ratio of length of 13 -IV to 10 -IV 0.53 0.87 (mean $=0.67) ; 2-\mathrm{V}$ with 4,5 branches; leaflets of 1-VII (Fig. $50)$ without apicolateral serration; pecten spines $12-15$ elements, with 4-7 long spines alternating with 7-10 short spines (Fig. 27).

Type data. Holotype adult pinned female collected in India, Karnataka, Kårwår (144 48' N 74ㅇ' ' E), 26 Apr. 1902 by Cogill, deposited in the NHM.

Material examined. One thousand one hundred fifty-five specimens as follows: $176 \mathrm{~F}, 203 \mathrm{M}, 362 \mathrm{Le}, 369 \mathrm{Pe}, 45 \mathrm{~L}$, derived from only 3 separate collections from natural habitats (2 adult, 1 immature) and 
series from colony. INDIA. Karnataka: Kårwår, North Canara [Kanara]

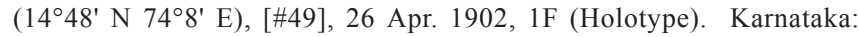
Shimoga, Kondagalale (14 $\left.19^{\prime} \mathrm{N} 75^{\circ} 7^{\prime} \mathrm{E}\right), 11-13 \mathrm{Aug} .1981$ and Shimoga, Keladi (14 $13^{\prime}$ N $\left.75^{\circ} 1^{\prime} \mathrm{E}\right), 12-14$ Aug. 1981, [eggs of females from both sites pooled for colony] (H. Bhat). Progeny from F3 and F13 of resulting colony (Bangkok colony): F3(1), 47F, 36M, 82LePe, 7L; F3(2), 25F, 34M, 57LePe, 1Pe, 5L; F3(3), 3F, 8M, 10LePe, 3L; F3(4), 31F, 25M, 49LePe, 6Pe, 5L; F13(5), 13F, 19M, 31LePe, 8L; F13(6), 15F, 25M, 39LePe, 5L; F13(7), 12F, 18M, 29LePe, 5L; F13(8), 17F, 17M, 33LePe, 4L; F13(9), 10F, 19M, 28LePe, 3L. Tamil Nadu: Nilgiris, Gudalur $\left(11^{\circ} 30^{\prime} \mathrm{N} 76^{\circ} 30^{\prime} \mathrm{E}\right),[158,166,172,174], 8$ May 1986, 2F, 2M, 4LePe (Tewari et al. as An. dirus, species E).

Distribution (Fig. 56). Anopheles elegans is known as the Western Ghat form of An. dirus in India (BHAT 1988). It is known only from India (Karnataka and Tamil Nadu).

Bionomics and medical importance. Immatures of $A n$. elegans were found in a jungle spring in association with $A n$. culiciformis Cogill and An. fluviatilis James in Apr. (Cogill1903), and in elephant footprints in association with An. mirans. They were also found in streams, muddy pools, spring pools and tree holes in the Nilgiris District, India (Tewari et al. 1987). Larval habitats were inside the forest and also in betel nut gardens (Bhat 1988). Adults were collected in humanbait collections, resting on vegetation, and in cattle sheds in the Kyasanur area of Shimoga District, Karnataka (Tewari et al. 1987).

Systematics. Systematics and nomenclature regarding to An. elegans has been discussed by Sallum et al. (2005). Adults of An. elegans can be recognized, except from An. scanloni and An. baimaii, by the following combination of characters: 1) proboscis dark-scaled, slightly longer than forefemur, ratio of proboscis length to forefemur length $1.03-1.11$;2) PSD spot of vein R rarely extending to level 1, 2 or 3 on at least one wing, more frequently extending to level 4 and 5 on one or both wings; 3) PSD spot of vein R usually with 2-4 pale interruptions on at least one wing, rarely with one pale interruption on one wing; 4) ASP spot absent on vein C and usually absent on subcosta; 5) hindtarsomere 4 with basal and apical pale bands; 6) hindtarsomere 5 dark-scaled at base; 7) apical pale band on hindtibia entirely white, without dark extension; 8) vein $1 \mathrm{~A}$ with long pale spot at level of PSD spot of vein R on at least one wing, this pale spot sometimes reduced but always the longest pale spot of $1 \mathrm{~A}$; 9) sternum VI usually without scales, occasionally with 1-3 posteromedial dark scales. The fourthinstar larva: 1) seta 3-C single; 2) seta 1-II noticeably less developed than seta 2-III-VI; 3) seta 5-C as long as or slightly longer than the antenna, not reaching the anterior margin of the head; 4) seta 1-X inserted on the saddle; 3) seta 2-C single, simple; 5) tubercle of seta 1-P narrowly joined to the tubercle of 2,3-P by an anterior basal bridge; 6) tubercle of setae 1,2-P with strong, pointed apical tooth arising from posterodorsal side and projecting over base of 1,2-P; 7) seta 4-C not reaching base or extending slightly beyond base of 2-C, ratio of length of 4-C to distance between 2-C and 4-C 0.80-1.0. Recognition of An. elegans based on pupal characters is not reliable. A few individuals examined did not have a fringe of filamentous spicules on the inner margin of the paddle, and thus they could have been misidentified as An. scanloni. Because An. elegans is the only species of the Leucosphyrus Subgroup that occurs in southwestern India, its geographical distribution should be used when making identifications.

\section{Anopheles (Cellia) takasagoensis Morishita}

(Figs. 5, 6e-h, 7, 29, 30, 52, 56)

Anopheles leucosphyrus var. takasagoensis Morishita (1946:21, 65) (F, M, L). NEOTYPE here designated: female, deposited in the NMNH.

Anopheles leucosphyrus var. takasagoensis Morishita (1946:21, 65) (F, M, L); Stone (1963:119) (Colless in litt. synonymy of $A n$. balabacensis); Reid (1968:297) (as synonym of An. balabacensis in footnote).

Anopheles leucosphyrus of Koidzumi (1925:318); Matumoto \& Motoura (1939:1642) (F*, M*); Chow (1949:1) (identification key, distribution); Chang et al. (1950:289); Chang \& Huang

Table 25. Number of branches for seta of pupae of An. elegans: range (mode).

\begin{tabular}{|c|c|c|c|c|c|c|c|c|c|c|c|}
\hline \multicolumn{2}{|c|}{ Seta Cephalothorax } & \multicolumn{9}{|c|}{ Abdominal segments } & \multirow{2}{*}{$\begin{array}{c}\text { Paddle } \\
\mathrm{Pa}\end{array}$} \\
\hline No. & $\mathrm{CT}$ & $\mathrm{I}$ & II & III & IV & $\mathrm{V}$ & VI & VII & VIII & IX & \\
\hline 0 & - & - & 1 & 1 & 1 & 1 & 1 & 1 & 1 & - & - \\
\hline 1 & $1-3(2)$ & n.c. & $>30$ & $4-6(5)$ & $2-6(3)$ & $1-3(2)$ & $1-3(1)$ & $1,2(1)$ & - & 1 & 1 \\
\hline 2 & $1-3(2)$ & $6-8(7)$ & $4-6(5)$ & $4-7(6)$ & $2-4(3)$ & $2-4(3)$ & $2,3(3)$ & $2,3(3)$ & - & - & $1,2(1)$ \\
\hline 3 & $2-3(3)$ & 1 & $1,2(2)$ & $2-4(2)$ & $5-7(6)$ & $1-3(2)$ & $1,2(2)$ & $2,3(3)$ & - & - & - \\
\hline 4 & $1-3(2)$ & 4-6 (4) & $4-6(5)$ & $2-6(4)$ & $3-5(4)$ & $2-5(4)$ & $1,2(2)$ & $1,2(2)$ & $1-3(2)$ & - & - \\
\hline 5 & $3-6(5)$ & $2,3(2)$ & $2-6(3)$ & $6-11(6)$ & $4-6(5)$ & $4-7(5)$ & $3-7(4)$ & $3-8(5)$ & - & - & - \\
\hline 6 & $1,2(2)$ & $1,2(2)$ & $1,2(2)$ & $1,2(2)$ & 1 & 1 & $1,2(1)$ & $1,2(2)$ & - & - & - \\
\hline 7 & $2-4(2)$ & $2-4(3)$ & $3-5(3)$ & $1-4(3)$ & $2-4(3)$ & $2-4(2)$ & 1 & 1 & - & - & - \\
\hline 8 & $1-3(2)$ & - & - & $1-4(3)$ & $1-3(3)$ & $1-3(2)$ & $1-3(2)$ & $1-3(2)$ & - & - & - \\
\hline 9 & $1,2(1)$ & 1 & 1 & 1 & 1 & 1 & 1 & 1 & $10-20(11)$ & - & - \\
\hline 10 & $2-4(3)$ & - & - & $1-3(2)$ & 1,2 (1) & $1,2(2)$ & $1,2(2)$ & $1-4(2)$ & - & - & - \\
\hline 11 & $2-4(3)$ & - & - & 1 & 1 & 1 & 1 & $1,2(2)$ & - & - & - \\
\hline 12 & $1-3(2)$ & - & - & - & - & - & - & - & - & - & - \\
\hline 13 & - & - & - & - & - & - & - & - & - & - & - \\
\hline 14 & - & - & - & - & 1 & 1 & 1 & 1 & 1 & - & - \\
\hline
\end{tabular}

n.c. $=$ not counted 
Table 26. Number of branches for setae of larvae of An. elegans: range (mode).

\begin{tabular}{|c|c|c|c|c|c|c|c|c|c|c|c|c|c|}
\hline \multirow{2}{*}{$\begin{array}{l}\text { Seta } \\
\text { No. }\end{array}$} & \multirow{2}{*}{$\begin{array}{c}\text { Head } \\
\text { C }\end{array}$} & \multicolumn{3}{|c|}{ Thorax } & \multicolumn{9}{|c|}{ Abdominal segments } \\
\hline & & $\mathrm{P}$ & M & $\mathrm{T}$ & $\mathrm{I}$ & II & III & IV & $\mathrm{V}$ & $\mathrm{VI}$ & VII & VIII & $\mathrm{X}$ \\
\hline 0 & 1 & 1 & - & - & - & 1 & 1 & 1 & 1 & 1 & 1 & 1 & - \\
\hline 1 & 1 & $11-17(13)$ & $23-33(24)$ & 1 & $3-6(5)$ & $6-10(7)$ & $17-22(20)$ & $17-22(20)$ & $18-21(19)$ & $16-20(18)$ & $9-13(13)$ & 1 & 1 \\
\hline 2 & 1 & $9-15(11)$ & $1-4(2)$ & 1 & $1-3(2)$ & $5-9(7)$ & $5-8(6)$ & $3-4(4)$ & $4-5(4)$ & $4-6(4)$ & $5-8(7)$ & $4-8(6)$ & 20 \\
\hline 3 & 1 & 1 & 1 & $3-6(5)$ & $1-2(1)$ & 1 & 1 & $2-3(3)$ & 1 & 1 & $1-3(2)$ & $3-5(4)$ & 8 \\
\hline 4 & 1 & $13-22(15)$ & $1-3(2)$ & $2-4(3)$ & $3-7(4)$ & $4-9(4)$ & $2-4(3)$ & $3-4(3)$ & $1-3(3)$ & 1 & 1 & 1 & 9 \\
\hline 5 & $5-10(8)$ & n.c. & 1 & $24-30(28)$ & $2-3(3)$ & $3-5(4)$ & $3-5(4)$ & $3-4(3)$ & $3-5(4)$ & $4-6(4)$ & $3-5(4)$ & $2-4(3)$ & - \\
\hline 6 & $7-13(10)$ & 1 & 3 & $2-3(2)$ & $15-20(15)$ & $17-23$ & $13-16(15)$ & $2-3(2)$ & $2-3(2)$ & 3 & $3-5(4)$ & $1-\mathrm{S}$ & $3-7(4)$ \\
\hline 7 & $7-11(9)$ & $14-25(18)$ & $2-3(2)$ & $22-28$ & 18 & n.c. & $3-5(4)$ & $2-5(5)$ & $3-4(4)$ & 2 & $1-3(2)$ & $2-S$ & $4-7(5)$ \\
\hline 8 & 1 & $20-26(26)$ & n.c. & n.c. & - & $1-2(1)$ & $1-3(2)$ & $1-3(2)$ & $2-5(2)$ & $2-3(2)$ & $3-8(4)$ & $6-S$ & $2-3(2)$ \\
\hline 9 & $1-3(2)$ & 1 & 1 & 1 & $3-4(3)$ & $5-8(6)$ & $6-10(8)$ & 7-9(8) & $6-8(7)$ & $6-7(7)$ & $2-5(3)$ & $7-S$ & 1 \\
\hline 10 & $1-2(1)$ & 1 & 1 & 1 & 1 & $2-4(2)$ & 1 & 1 & 1 & $2-4(3)$ & $3-5(4)$ & $8-\mathrm{S}$ & $2-3(2)$ \\
\hline 11 & n.c. & 1 & 1 & 1 & 3 & 1 & $2-4(2)$ & $2-3(2)$ & $2-3(2)$ & 2 & 2 & 9-S & $2-4(3)$ \\
\hline 12 & $1-2(1)$ & $1-3(1)$ & 1 & 2 & $2-3(3)$ & 1 & $2-3(2)$ & $2-3(2)$ & $1-3(2)$ & 1 & $1-2(1)$ & - & - \\
\hline 13 & $4-5(4)$ & $3-5(4)$ & $3-6(5)$ & $2-3(3)$ & $3-5(3)$ & $3-6(4)$ & $4-7(4)$ & $3-4(3)$ & $2-3(3)$ & $4-7(5)$ & 2 & - & - \\
\hline 14 & n.c. & $4-7(4)$ & $5-9(5)$ & - & - & - & - & 1 & 1 & 1 & 1 & 1 & - \\
\hline 15 & $5-6(6)$ & - & - & - & - & - & - & - & - & - & - & - & - \\
\hline
\end{tabular}

n.c. $=$ not counted

(1954:341) (F*, L*, key), (1955:60) (taxonomy, bionomics notes); Pletsch et al. (1956:614) (bionomics).

Anopheles leucosphyrus balabacensis of Colless (1956b:55) (in part, taxonomy).

Anopheles balabacensis balabacensis of Colless (1957:133) (in part, taxonomy); Chuang et al. (1967:3); Reid (1968:297) (in part, taxonomy); Knight \& Stone (1977:35) (catalog).

Anopheles balabacensis takasagoensis of Chuang et al. (1965:3); Reid (1968:297) (footnote, taxonomy).

Anopheles takasagoensis of Peyton \& Harrison (1980:335) (from synonymy of An. balabacensis); Baimai et al. (1981:81); Kanda et al. (1983:193), (1985:381); Wibowo et al. (1984:425); Takai (1986:45); Peyton (1989:197) (taxonomy); Lien (1991:208) (distribution, suspected vector $P$. inui).

Female (Figs. 5, 6e-h, 7). Head: proboscis dark-scaled, length $2.17-2.60 \mathrm{~mm}$ (mean $=2.38 \mathrm{~mm}$ ), ratio of length to forefemur 1.04-1.14 (mean =1.08), palpus (Fig. 7) length 1.97$2.40 \mathrm{~mm}($ mean $=2.27 \mathrm{~mm})$, ratio of length to proboscis 0.89 1.00 (mean $=0.95$ ), ratio of length to forefemur 0.99-1.08 (mean $=1.03$ ) (Table 2), ratio of length of papomeres 3/4 1.53-1.86 $($ mean $=1.63), 3 / 52.17-3.25($ mean $=2.51), 4 / 51.31-1.73($ mean $=$ $1.53), 4-5 / 3$ 0.85-1.11 (mean=1.05); palpomeres $2-4$ with narrow apical white bands, palpomere 5 with broad apical white band, length of apical pale band of palpomere 51.43-3.60 mm (mean $=2.36 \mathrm{~mm}$ ) length of basal dark band of palpomere 5 , ratio of length of apical pale band of palpomere 4 to length of basal dark band of palpomere 5 0.33-1.67 $($ mean $=0.82)($ Table 3$)$. Thorax: pleural setae as follow: 1-3 upper proepisternal, 0-3 prespiracular, 4-7 prealar, 4-6 upper mesokatepisternal, 2-4 lower mesokatepisternal, 4-7 upper mesepimeral. Wing (Fig. 5, 6eh): length 3.69-4.43 mm (mean $=4.12 \mathrm{~mm})$, color of costal pale spots usually pale yellowish to pale cream-colored, PSP and SP spots paler, bordering to white, pale scales on remaining veins light cream-colored to whitish, none strongly contrasting with others, PHP, HP, and PSP spots of vein C usually prominent, occasionally PHP and HP reduced, rarely absent, SP spot always present, prominent, ASP spot always absent,
PP spot 0.50-1.25 (mean $=0.82)$ length of SCP spot, AD spot 1.94-3.80 (mean $=2.76)$ length of PP spot, PSD spot of vein R extending basally from level 1 to level 3 on one or both wings, rarely to level 4 (Table 4), PSD spot of vein R rarely entirely dark or with 3 pale interruptions on one wing, usually 1 or 2 pale interruptions on one or both wings (Table 5), SD spot of vein $R$ with 1-5 pale interruptions (Table 6), sum of pale interruptions on PSD-PD spots of vein $\mathrm{R}$ varying from 4-11 for each wing, ratio of length of cell $R_{2}$ to vein $R_{2+3} 1.68-2.02$ (mean =1.86), ratio of length of cell $\mathrm{R}_{2}$ to cell $\mathrm{M}_{1+2} 1.14-1.29$ (mean = 1.19). Legs: femora, tibiae, and tarsomeres 1 speckled with pale spots; foretarsomeres 2-4 with broad apical pale bands, foretarsomeres 2-4 with basal pale bands, bands more or less complete but always less distinct on ventral surface, basal bands subequal to or slightly longer than apical bands, foretarsomeres 4,5 occasionally predominantly pale on dorsal surface; midtarsomeres 2-5 mostly dark-scaled with patches of pale scales along dorsal surface only, midtarsomeres 2-4 with small apical patch of pale scales, midtarsomere 2,3 usually dark-scaled at base, occasionally with inconspicuous basal patch of pale scales, midtarsomere 2 with 1-3 middle pale spots, midtarsomere 5 pale-scaled at apex; hindtarsomeres 2-4 with apical pale spots more evident on dorsal surface, middle dark area of hindtarsomeres 2,3 usually without pale spots, occasionally with 1-5 pale spots, hindtarsomere 4 with conspicuous basal pale band, hindtarsomere 5 occasionally with small basal pale band, apex usually pale-scaled. Abdomen: tergum VI usually without scales, occasionally with few inconspicuous, narrow dark scales posteriorly, tergum VII with few dark scales on posterior margin, tergum VIII covered with golden scales laterally, whitish scales posteromedially and occasionally with few dark scales laterally; sternum VI rarely with few scattered narrow dark scales posteriorly, sternum VII with dense posteromedial patch of dark scales, sternum VIII with small lateral patches of pale scales. 
Male (Fig. 7). Essentially as in female except for sexual characters. Wing generally paler with reduced scaling, pale spots usually longer than in female. Palpomere 2 (Fig. 7) with dorsal patch of pale scales, apex of palpomere 2 bare, palpomere 3 with long dorsal patch of pale scales at middle, apex with broad pale band and few dark scales on ventrolateral surface, palpomere 4 mainly pale scaled with basal dark band and ventrolateral line of dark scales usually extending from base to apex of segment, palpomere 5 mainly pale-scaled with basal dark band and ventromedial line of dark scales usually extending from base to apex of palpomere 5. Abdomen: sternum VIII covered with white scales. Genitalia: 5-7 large parabasal setae; ventral clapette with 1 long apicolateral seta, slightly shorther than club of dorsal claspette, 2 short, slender apicomedial seta, 3 short, slender subapical setae and 1 short, subapical seta displaced basally on membranous area; dorsal claspette with 4-6 setae arising from apex, setae fused apically into stout club with distinct basal stems, 1 seta separate from club; aedeagus with about 7,8 leaflets on each side of tip, leaflets serrated on one or both edges.

Pupa (Fig. 29). Position and development of setae as figured; range and modal number of branches in Table 27. All measurements from 20-44 specimens. In general similar to $A n$. leucosphyrus except for the following characters. Integument mostly yellowish to median brown, with dark faint areas without distinctive pattern of dark spots; sterna II-VII with narrow dark band area near anterior margin, intersegmental membrane between segments II-III, III-IV, IV-V and V-VI with dark dorsolateral areas, sometimes indistinct or absent. Cephalothorax: seta 4-CT usually double, 5-CT with 2-4 branches, 7-CT usually double. Abdomen: seta 1-II with more than 40 fine branches, 6-II usually single, 8,10,11-II absent, 9II length $0.011-0.016 \mathrm{~mm}$ (mean $=0.013 \mathrm{~mm}) ; 1-\mathrm{III}$ with $5-11$ branches, 5-III with 8-14 branches, 9-III length 0.01-0.20 mm $($ mean $=0.03 \mathrm{~mm})$; 1-IV with 3-6 branches, 5-IV with 5-9 branches, 6-IV always single, 9-IV length 0.03-0.06 $\mathrm{mm}$ (mean $=0.05 \mathrm{~mm})$, ratios of length of seta 9-IV/9-III 1.52-2.71 (mean = $2.20)$ and seta $9-\mathrm{IV} / 9-\mathrm{V} 0.33-0.55($ mean $=0.47) ; 9-\mathrm{V}$ length $0.08-0.11 \mathrm{~mm}$ (mean $=0.10 \mathrm{~mm}$ ), with or without spicules; $1-\mathrm{VI}$ single, 9-VI length $0.09-0.12 \mathrm{~mm}$ (mean $=0.11 \mathrm{~mm}$ ); 1-VII single, 5-VII with 4-6 branches, 9-VII length 0.10-0.12 $\mathrm{mm}$ (mean $=0.11$ $\mathrm{mm})$; 9-VIII with 13-16 branches. Paddle: toothed margin index $0.70-0.88$ (mean $=0.82$ ), paddle teeth small, slender, tapering to apex, ending in sharply acute apex.

Larva (Figs. 29, 30, 52). Position and development of setae as figured; range and modal number of branches in Table 28. All measurements from 24-50 specimens unless otherwise indicated. In general as described for An. leucosphyrus except for the following characters. Head: length 0.64-0.78 $\mathrm{mm}$ (mean $=0.74 \mathrm{~mm})(\mathrm{n}=10)$, width $0.62-0.78 \mathrm{~mm}($ mean $=0.73 \mathrm{~mm})(\mathrm{n}=$ $10)$; antenna length $0.28-0.34 \mathrm{~mm}$ (mean $=0.30 \mathrm{~mm})$, ratio of distance base to $1-A$ to antenna length $0.30-0.43($ mean $=0.34$ ); 3 -C length 0.07-0.09 $\mathrm{mm}$ (mean $=0.08 \mathrm{~mm})$, distance between base of 2-C and 3-C 0.03-0.04 mm (mean $=0.04 \mathrm{~mm}$ ), 4-C length 0.04-0.07 mm (mean $=0.06 \mathrm{~mm})$, not reaching base of 2-C, distance between basal insertions of 2-C and 4-C 0.08-0.11 mm (mean $=0.10 \mathrm{~mm})$, ratio of length of $4-\mathrm{C}$ to distance between insertions of 2-C and 4-C 0.46-0.76 (mean $=0.63)$, distance between base of 3-C and 4-C 0.08-0.10 $\mathrm{mm}$ (mean $=0.09 \mathrm{~mm}$ ), 5$\mathrm{C}$ shorter than antenna, not reaching anterior margin of head. Thorax: stem of seta 1-P strong, neither flattened nor expanded, similar in developemant to stem of 2-P, basal tubercles of setae 1,2-P basally joined, both with strong, apical, rounded, or pointed tooth projecting over base of each seta, 14-P with 710 branches; 14-M with 6-11 branches; 3-T (Fig. 52) moderately developed, with 3-8 narrow leaflets. Abdomen: seta 1-I small, somewhat palmate, with 4-8 leaflets; 1-II with 9-15 leaflets; ratio of length of seta 13-IV to 10-IV 0.48-0.93 (mean $=0.70)$; 2V with 3-6 branches; 1-VII with 10-14 leaflets without apicolateral serration and apical filament; 1 -X inserted at edge of saddle, 12-15 pecten spines, 4-6 long spines alternating with 6-11 short spines (Fig. 29).

Type data. Koidzumi (1925) was apparently the first to report An. takasagoensis, as a species "that resembled leucosphyrus" in Taiwan. Later, Matumoto \& Motoura (1939) described the adult and larva of this species as $A n$. leucosphyrus. Finally, Morishita (1946) recognized this species as An. leucosphyrus takasagoensis. Neither a type specimen nor a type series was designated by Morishita. The distribution listed by the author included Dairi, Tamazato District, Karenko Prefecture and Kanshirei, Kagi District, Tainan Prefecture. Stone (1963) listed An. takasagoensis as a junior synonym of An. balabacensis. Peyton \& Harrison (1980), based on laboratory hybridization tests and cytogenetic studies, resurrected An. takasagoensis from synonymy of An. balabacensis, described morphological structures of the male, female, fourth-instar larva, and pupa, but did not designate a neotype. Because there is no reference to a type designation in Morishita (1946), we are designating the neotype of $A n$. takasagoensis. The neotype is a female collected in Taiwan, Taichung $\left(24^{\circ} 15^{\prime} \mathrm{N} 120^{\circ} 55^{\prime} \mathrm{E}\right)$, Pei Tung, Takeng, Taiwan Valley, 7 Oct. 1954, P.T.Tseng et al. [Acc. no. 10040.8], deposited in the NMNH. Stability for the name An. takasagoensis is served with this designation since this taxon belongs to a group of cryptic species, which includes vectors of simian and human Plasmodium in Southeast Asia and India.

Material examined. Nine hundred sixty-three specimens, as follows: 164F, 167M, 255Le, 258Pe, 119 L, derived from 15 separate collections from natural habitats ( 7 adult, 8 immature) and series from colony. REPUBLIC OF CHINA. Taiwan [Formosa]: (Central, $23^{\circ} 30^{\prime} \mathrm{N}$ $\left.120^{\circ} 55^{\prime} \mathrm{E}\right), 1947$, 4F, 1M, 5 L; 1950, 1M, 1LePe (C.Y. Chow); no date

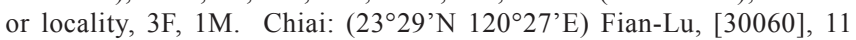
Dec. 1954, 2F, 2 L. Hsien Valley, Hsin-Chi Village, Wan Wan, Tai PinTung, 10 Feb. 1954, 1F (C.C.Lin). Pingtung (22 $\left.40^{\prime} \mathrm{N} 120^{\circ} 28^{\prime} \mathrm{E}\right)$ : Shimen, Mutan, [1539], 14 Feb. 1960, 6F, 6M (J.C. Lein). Taichung

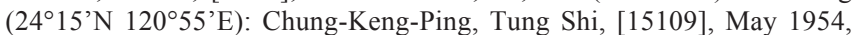
1F. Pei Tung, Takeng, Taiwan valley, [10040], 7 Oct. 1954, 1F, 1M, 2L. Tou-Pen-Ken, Taiping, Taiwan Valley, [10060], 3F, 3M. (P.T.Tseng and C.C.Lin). Taipei $\left(25^{\circ} 03^{\prime} \mathrm{N} 121^{\circ} 32^{\prime} \mathrm{E}\right)$ : Chung Ho, Hsin She, 16 Mar. 1959, 1F (J.F.Chin and W.L.Chen). Taitung $\left(23^{\circ} 00^{\prime} \mathrm{N} 120^{\circ} 00^{\prime} \mathrm{E}\right)$ : Chi-Fen-Keng, Hsin-She, [00494], 6-13 Dec. 1958, 4 L (J.F.Chin and W.L.Chen); Ta-Wu, 29 Oct. 1951, 1 L (H.C.Barnett). Peiyuan, Tungho, 9-10 Nov. 1966, 3F, 4M; [CU1504], 14 Dec. 1972, 3L; (colony, Taiwan, established in 1969), 1976, 40L (J.C. Lein); [TW (1), (2), F85, F118], 
Table 27. Number of branches for seta of the pupa of An. takasagoensis: range (mode).

\begin{tabular}{|c|c|c|c|c|c|c|c|c|c|c|c|}
\hline \multicolumn{2}{|c|}{ Seta Cephalothorax } & \multicolumn{9}{|c|}{ Abdominal segments } & \multirow{2}{*}{$\begin{array}{c}\text { Paddle } \\
\mathrm{Pa}\end{array}$} \\
\hline No. & $\mathrm{CT}$ & I & II & III & IV & $\mathrm{V}$ & VI & VII & VIII & IX & \\
\hline$\overline{0}$ & - & - & 1 & 1 & 1 & 1 & 1 & 1 & 1 & - & - \\
\hline 1 & $2,3(2)$ & n.c. & $>40$ & $5-11(7)$ & $3-6(4)$ & 1 & 1 & 1 & - & 1 & $1,2(2)$ \\
\hline 2 & 2 & $6-9(7)$ & 4-6 (4) & 4-6 (4) & $2,3(3)$ & $2,3(2)$ & $2,3(2)$ & $2,3(2)$ & - & - & $1,2(2)$ \\
\hline 3 & $2-4(3)$ & 1 & $2,3(2)$ & $2,3(3)$ & $6-10(7)$ & $1-3(2)$ & $1-3(2)$ & $1-4(2)$ & - & - & - \\
\hline 4 & $2,3(2)$ & $4-8(5)$ & $2-6(4)$ & $3-6(4)$ & $2-5(3)$ & $2-4(4)$ & $1,2(2)$ & $1,2(2)$ & $1,2(1)$ & - & - \\
\hline 5 & $2-4(3)$ & $2-4(2)$ & $3-6(3)$ & $8-14(11)$ & $5-9(7)$ & 4-7 (6) & $4-6(5)$ & 4-6 (4) & - & - & - \\
\hline 6 & $1-3(2)$ & $1-3(2)$ & 1,2 (1) & $1-4(2)$ & 1 & 1 & 1,2 (1) & $1,2(2)$ & - & - & - \\
\hline 7 & $2,3(2)$ & $4-6(5)$ & $2-5$ (4) & $1-5(3)$ & $2-4(3)$ & $1-4(3)$ & 1 & 1,2 (1) & - & - & - \\
\hline 8 & $2,3(2)$ & - & - & $2-4(3)$ & $2,3(2)$ & 1,2 (1) & $1,2(1)$ & $2-4(3)$ & - & - & - \\
\hline 9 & $2-4(2)$ & 1 & 1 & 1 & 1 & 1 & 1 & 1 & $13-16(14)$ & - & - \\
\hline 10 & $2-4(3)$ & - & & $2,3(2)$ & 1 & 1 & $2,3(2)$ & $2,3(2)$ & - & - & - \\
\hline 11 & $2-4(4)$ & - & - & 1 & 1 & 1 & 1,2 (1) & $1-3(2)$ & - & - & - \\
\hline 12 & $2,3(3)$ & - & - & - & - & 1 & - & - & - & - & - \\
\hline 13 & - & - & - & - & - & - & - & - & - & - & - \\
\hline 14 & - & - & - & - & 1 & 1 & 1 & 1 & 1 & - & - \\
\hline
\end{tabular}

n.c. $=$ not counted

28 Apr. 1980, (subcolony, Bangkok), 138F, 151M, 254Le, 257Pe, 62L (AFRIMS).

Distribution (Fig. 56). Anopheles takasagoensis is known from the Republic of China (Taiwan [Formosa], Chiai, Taitung, Taichung, Taipei, Taitung and Pingtung).

Bionomics and medical importance. Anopheles takasagoensis is closely associated with foothill and mountainous regions of central and southern Taiwan. Adults were collected in small numbers inside houses and stables during the daytime (Pletsch et al. 1956). It is also known from Taipei. Immatures were taken from "dirty" ponds (Matumoto \& Motoura 1939), grassy buffalo hoof prints marks and pools in a Chomphor tree forest on a hill, $189 \mathrm{~m}$ above sea level, at the inland side of a coastal mountain range. The larval habitats were approximately $10 \mathrm{~cm}$ deep, the water stagnant and dirty (Morishita 1946). Additionally, immatures were found in shaded rock pools, stream pools, and pools in drying stream beds. The breeding habitats were in heavily shaded rockpools and in beds of mountain streams under jungle cover, and also in highly shaded pools or in full sun (Chang \& Huang 1954). This species has never been incriminated as vector of malarial parasites. However, Chuang et al. $(1965,1967)$ found a high incidence of Plasmodium inui Halberstaed and von Prowazek, infections in $71.9 \%$ of the monkeys in Tungho township, Taitung county, southeastern Taiwan where this anopheline is attracted to monkey bait traps. Additionally, the authors found close association between the occurrence of P. inui and An. takasagoensis and thus they proposed that this mosquito could be involved in the transmission of the parasite in that area. Similarly, Lien (1991) suggested that An. takasagoensis may be involved in the transmission of $P$. inui in Taiwan. Comparing the susceptibility of Anopheles species of Southeast Asia to the malaria parasite P. cynomolgi in laboratory conditions, Klein et al. (1991) observed that 78\% of individuals of An. takasagoensis were infected with sporozoites and the mean number of oocysts in paired replicates of An. dirus and An. takasagoensis were not significantly different.

Systematics. Cytological studies and comparisons of the polytene chromosomes of the fourth-instar larva of $A n$. takasagoensis, An. dirus, and An. cracens showed differences in the sex chromosomes relative to the position of the centromere and amount of constitutive heterochromatin and euchromatin that corroborated the species status of these taxa (Baimai et al. 1981). Wibowo et al. (1984) confirmed the species status of An. takasagoensis and suggested that it belongs to a complex of sibling species. In contrast, Kanda et al. (1985) found no evidence to support separate specific status for $A n$. takasagoensis, and Takai (1986) using electrophoresis profiles of seven protein loci distinguished five taxa within the $A n$. leucosphyrus Group, but An. takasagoensis, as well as three other populations of the Leucosphyrus Group, lumped them into the Balabacensis Complex.

Anopheles takasagoensis is similar to the other members of the Dirus Complex and there are no distinguishing characters in the adult female. However, An. takasagoensis is the only species of the Leucosphyrus Group found in Taiwan. Consequently, geographical distribution may facilitate identification of this species. Additionally, the male genitalia of An. takasagoensis have 5-7 large parabasal spines and the dorsal claspette has 4-6 seta fused into a club and 1 seta isolated from the club. Fourth-instar larvae of $A n$. takasagoensis can be recognized by the following combination of characters: 1) seta 3-C single; 2) seta 4-C not strongly developed, never reaching base of 2-C; 3 ) seta 1-II not fully developed, less developed than 1-III-VI; 4) seta 5-C shorter, as long as, or slightly longer than the antenna; 5) seta $1-\mathrm{X}$ inserted at the edge of the saddle; 6) seta 2-C sparsely aciculate; 7) tubercle of 1-P joined to the tubercle of setae 2,3P. The pupal stage of An. takasagoensis cannot be distinguished from other members of the Dirus Complex, except 
Table 28. Number of branches for setae of the larva of An. takasagoensis: range (mode).

\begin{tabular}{|c|c|c|c|c|c|c|c|c|c|c|c|c|c|}
\hline \multirow{2}{*}{$\begin{array}{l}\text { Seta } \\
\text { No. }\end{array}$} & \multirow{2}{*}{$\begin{array}{c}\text { Head } \\
\text { C }\end{array}$} & \multicolumn{3}{|c|}{ Thorax } & \multicolumn{9}{|c|}{ Abdominal segments } \\
\hline & & $\mathrm{P}$ & $\mathrm{M}$ & $\mathrm{T}$ & $\mathrm{I}$ & II & III & $\mathrm{IV}$ & $\mathrm{V}$ & $\mathrm{VI}$ & VII & VIII & $X$ \\
\hline$\overline{0}$ & 1 & 1 & - & - & - & 1 & 1 & 1 & 1 & 1 & 1 & 1 & - \\
\hline 1 & 1 & $12-17(17)$ & $20-32(26)$ & 1 & $4-8(6)$ & $9-15(9)$ & $15-26(19)$ & $16-23(17)$ & $15-22(17)$ & $15-19(15)$ & $10-14(11)$ & 1 & 1 \\
\hline 2 & $1-2(1)$ & $8-15(11)$ & $2-4(3)$ & 1 & $1-2(2)$ & $5-9(7)$ & $5-8(6)$ & $3-5(4)$ & $3-6(4)$ & $3-6(5)$ & $5-7(5)$ & $5-9(6)$ & $16-29(17)$ \\
\hline 3 & 1 & 1 & 1 & $3-8(4)$ & $1-2(1)$ & 1 & 1 & $2-4(3)$ & $1-2(1)$ & $1-2(1)$ & $2-4(2)$ & $5-9(7)$ & $6-12(8)$ \\
\hline 4 & $1-2(2)$ & $11-17(14)$ & $2-3(2)$ & $2-4(3)$ & $2-7(6)$ & $4-7(5)$ & $2-4(4)$ & $2-3(3)$ & $2-3(3)$ & 1 & 1 & 1 & 9 \\
\hline 5 & $7-13(9)$ & n.c. & 1 & $30-42(35)$ & $2-3(3)$ & $3-5(4)$ & $3-4(3)$ & $3-4(3)$ & $3-5(3)$ & $3-5(4)$ & $3-6(4)$ & $3-6(4)$ & - \\
\hline 6 & $8-14(10)$ & 1 & $3-4(3)$ & $2-3(2)$ & $15-23(17)$ & $18-24(23)$ & $13-19(13)$ & $2-3(2)$ & $2-3(2)$ & $3-5(3)$ & $3-6(5)$ & $1-S$ & $3-5(4)$ \\
\hline 7 & $10-15(12)$ & $21-26$ & $2-4(2)$ & 28 & $11-18(13)$ & $14-21$ & $3-6(5)$ & $4-6(4)$ & $3-6(4)$ & $2-4(3)$ & $3-4(3)$ & $2-S$ & $4-6(4)$ \\
\hline 8 & $1-2(1)$ & $25-32(28)$ & $23-28(25)$ & $27-28(27)$ & - & $1-2(1)$ & 1 & $1-2(2)$ & $1-3(2)$ & $2-3(2)$ & $4-6(5)$ & 6-S & $2-3(2)$ \\
\hline 9 & $2-4(3)$ & 1 & 1 & 1 & $3-5(3)$ & $5-9(8)$ & $5-10(8)$ & $6-8(7)$ & $5-9(6)$ & $4-6(5)$ & $3-6(4)$ & $7-S$ & $1-2(2)$ \\
\hline 10 & $1-2(2)$ & 1 & 1 & $1-2(1)$ & 1 & $1-3(3)$ & 1 & $1-2(1)$ & 1 & $2-3(3)$ & $3-6(4)$ & 8-S & $2-4(2)$ \\
\hline 11 & $24-31(26)$ & 1 & 1 & 1 & $3-4(3)$ & 1 & $2-3(2)$ & $2-3(2)$ & $2-3(2)$ & $2-3(2)$ & $1-2(2)$ & 9-S & $1-5(3)$ \\
\hline 12 & $1-2(2)$ & $1-3(1)$ & 1 & $2-3(2)$ & $3-5(3)$ & 1 & $2-3(2)$ & $1-3(2)$ & $2-3(2)$ & 1 & 1 & - & - \\
\hline 13 & $3-5(5)$ & $4-7(5)$ & $5-8(5)$ & $2-3(3)$ & $3-6(4)$ & $4-8(5)$ & $3-9(6)$ & $3-4(3)$ & $3-4(3)$ & $5-10(8)$ & $2-3(2)$ & - & - \\
\hline 14 & $7-10(8)$ & $4-6(5)$ & $6-11(7)$ & - & - & - & - & 1 & 1 & 1 & 1 & 1 & - \\
\hline 15 & 5 & - & - & - & - & - & - & - & - & - & - & - & - \\
\hline
\end{tabular}

n.c. $=$ not counted

for An. scanloni, and the male pupa of An. cracens. Characters that are useful to distinguish these three species were listed before.

\section{Anopheles (Cellia) nemophilous Peyton \& Ramalingam} (Figs. 4, 6n, 7, 31, 32, 49, 52, 57)

Anopheles nemophilous Peyton \& Ramalingam (1988:272) (F*, M*, $\left.\mathrm{P}^{*}, \mathrm{~L}^{*}\right)$. Holotype female with associated pupal and larval exuviae deposited in the NMNH.

Anopheles leucosphyrus Fraser's Hill form of Colless (1956b:62) (F*, $\mathrm{P}^{*}, \mathrm{~L}^{*}$, taxonomy).

Anopheles balabacensis balabacensis Fraser's Hill form of Colless (1957:131) (A, P, L, taxonomy); Reid (1968:298) (F*, $\mathrm{P}^{*}, \mathrm{~L}^{*}$, taxonomy).

Anopheles balabacensis introlatus of Scanlon et al. (1967:78) (in part, misidentification of specimen reported from Ranong Province, Thailand).

Anopheles dirus F of Baimai et al.(1988b:333) (cytogenetics, bionomics data).

Anopheles nemophilous Peyton (1989:197) (taxonomy); Poopittayasataporn \& Baimai (1995:426) (polytene chromosomes, phylogeny); Walton et al. (1999:24) (ASA PCR, species identification).

Female (Figs. 4, 6n, 7). Head: dark-scaled, often with few inconspicuous pale scales ventrally basal to labella, length $1.85-2.36 \mathrm{~mm}($ mean $=2.17 \mathrm{~mm})$, ratio of length to forefemur $1.00-1.15($ mean $=1.09)$, maxillary palpus (Fig. 7) length 1.55 $2.29 \mathrm{~mm}$ (mean $=1.96 \mathrm{~mm})$, ratio of length to proboscis 0.84 0.99 (mean $=0.90$ ), ratio of length to forefemur 0.93-1.01 (mean $=0.98)($ Table 2.2), ratio of length of palpomeres 3/4 1.50-1.85 $($ mean $=1.61), 3 / 52.08-2.88($ mean $=2.40), 4 / 51.22-1.75($ mean $=$ 1.49), 4-5/3 0.91-1. 16 (mean=1.04), palpomeres $2-4$ with narrow silvery-white apical bands, apical pale band of palpomere 5 $0.86-2.00($ mean $=1.46)$ length of basal dark band of palpomere 5 , ratio of length of apical pale band of palpomere 4 to length of basal dark band of palpomere $50.22-0.83($ mean $=0.52)$ (Table
3). Thorax: pleural setae as follow: 1-4 upper proepisternal, 04 prespiracular, 3-6 prealar, 3-7 upper mesokatepisternal, 2-6 lower mesokatepisternal, 3-8 upper mesepimeral. Wing (Figs. $4,6 \mathrm{n})$ : length 3.11-4.05 $\mathrm{mm}($ mean $=3.63 \mathrm{~mm})$, color of costal pale spots usually pale yellowish or pale cream-colored, PHP, HP and PSP spots sometimes darker yellowish or golden, pale scales on other veins light cream-colored to whitish, PHP, HP, and PSP spots of vein C usually prominent, occasionally reduced to very small spots or rarely absent, SP spot always present, usually prominent, ASP spot always absent, PP spot $0.58-1.86($ mean $=1.17)$ length of SCP spot, AD spot 1.29-4.00 $($ mean $=2.14)$ length of preapical pale spot, PSD spot of vein R extending basally from level 1 to level 3 on one or both wings (Table 4), PSD spot of vein R usually entirely dark or with 1 pale interruption, occasionally with 2 pale interruptions on one or both wings, rarely with 3 pale interruptions on one wing (Table 5), SD spot of vein R usually with 1 pale spot on one or both wings, occasionally with 2,3 pale spots (Table 6), sum of pale interruptions on PSD-PD spots of vein $R$ varying from 1-8 for each wing, ratio of length of cell $R_{2}$ to vein $R_{2+3}$ $1.30-2.29($ mean $=1.77)$, ratio of length of cell $R_{2}$ to cell $\mathrm{M}_{1+2}$ 1.17-1.37 (mean $=1.27)$. Legs: femora, tibiae and tarsomeres dark-scaled with pale spots; foretarsomeres 1-4 with apical pale bands, basal pale bands on foretarsomere $2-4$, bands less noticeably on ventral, foretarsomere 2 with $0-2$ pale spots, occasionally fused to cover most of length of tarsomere, foretarsomere 5 dark-scaled at base with apical pale scales, rarely entirely dark-scaled or cream-scaled; midtarsomeres 1-5 with small apical bands of pale scales, occasionally very faint or absent, midtarsomere 2 with 0-3 pale spots; hindtarsomere 2 with $0-4$ pale spots, hindtarsomere 4 with prominent basal white band, occasionally without pale band on one or both legs. Abdomen: tergum VI without scales or with 1-5 dark scales posteriorly, tergum VII with few or several dark and/or pale scales posteriorly, tergum VIII covered with creamy-yellow 
scales on apical 0.3-0.8; sternum VI usually without scales, rarely with 2-4 dark scales posteromedially, sternum VII with dense posteromedial patch of dark scales, sternum VIII with few pale scales laterally, or sometimes also with scattered scales (2-8 scales) medially.

Male (Fig. 7). Essentially as in female except for sexual characters. Wing generally paler with reduced scaling, pale spot usually longer than in female. Palpomere 2 (Fig. 7) with dorsal patch of pale scales at middle, extending laterally, apex of palpomere 2 bare, palpomere 3 with long dorsal patch of pale scales at middle extending to lateral surface, apex of palpomere 3 with broad band of pale scales covering dorsal, lateral, and ventral surfaces except for small ventrolateral patch of dark scales at apex, palpomeres 4 and 5 mainly pale-scaled with basal dark band. Legs: foretarsomeres 1-4 without basal pale bands, tarsomere 4 occasionally without apical pale band. Abdomen: dark scales on sternum VII, occasionally with few pale scales intermixed, sternum VIII densely covered with cream-yellow scales. Genitalia: 4 large parabasal setae; ventral clapette with 1 long apicolateral seta, slightly shorter or nearly as long as club of dorsal claspette, 1 short, slender apicomedial seta, and 1 short, slender subapical seta; dorsal claspette with 4 setae arising from apex, 3,4 setae fused apically into stout club with distinct basal stems, sometimes 1 seta isolated from club; aedeagus elongate, columnar, dorsally curved with about 7-10 leaflets on each side of tip, leaflets serrated in one edge.

Pupa (Fig. 31). Position and development of setae as figured; number and modal number of branches in Table 29. All measurements from 18-40 specimens. In general similar to An. leucosphyrus except for the following characters. Cephalothorax: seta 11-CT single to 6-branched. Seta 9-IV-VII yellowish to light brown, 9-VIII light brown. Abdomen: seta 1II with 18-42 fine branches, setae 8,10,11-II always absent, 9-II length $0.010-0.018 \mathrm{~mm}($ mean $=0.012 \mathrm{~mm}) ; 1$-III with $5-9$ branches, 9-III length $0.02-0.03 \mathrm{~mm}$ (mean $=0.02 \mathrm{~mm}$ ); 1-IV with 4-7 branches, 5-IV with 4-8 branches, 6-IV single, 9-IV length $0.03-0.06 \mathrm{~mm}$ (mean $=0.05 \mathrm{~mm}$ ), ratios of length of seta 9-IV/9-III 1.67-3.00 (mean = 2.40) and 9-IV/9-V 0.29-0.58 (mean $=0.43$ ); $1-\mathrm{V}$ with $2-4$ branches, $9-\mathrm{V}$ length $0.10-0.14 \mathrm{~mm}$ (mean $=0.12 \mathrm{~mm}$ ), with or without spicules; 5-VI with 5-8 branches, 6VI single, 9-VI length $0.10-0.15 \mathrm{~mm}$ (mean $=0.12 \mathrm{~mm}$ ), with or without spicules; 5-VII with 4-8 branches, 9-VII length 0.10$0.16 \mathrm{~mm}$ (mean $=0.12 \mathrm{~mm})$, with or without spicules; 9-VIII with 11-17 branches. Paddle: toothed margin index 0.81-0.87 (mean $=0.84$ ), paddle tooth prominent, well developed, tapering to apex, ending in acute or blunt apex.

Larva (Figs. 32, 49, 52). Position and development of setae as figured; range and modal number of branches in Table 30. All measurements from 29-64 specimens unless otherwise indicated. In general similar to An. leucosphyrus except for the following characters. Head: integument pigmentation variable from light yellowish-brown to dark brown without distinct pattern of darkened spots; length $0.67-0.76 \mathrm{~mm}$ (mean $=0.72$ $\mathrm{mm})$, width $0.66-0.74 \mathrm{~mm}$ (mean $=0.71 \mathrm{~mm})$; antenna length $0.31-0.35 \mathrm{~mm}$ (mean $=0.33 \mathrm{~mm}$ ), ratio of distance base to 1-A to antenna length 0.31-0.44 (mean $=0.36)$, seta $3-\mathrm{C}$ length 0.10 -
$0.15 \mathrm{~mm}$ (mean $=0.12 \mathrm{~mm})$, distance between base of 2-C and 3-C 0.03-0.05 mm (mean $=0.04 \mathrm{~mm}$ ), 4-C length $0.10-0.20 \mathrm{~mm}$ $($ mean $=0.12 \mathrm{~mm})$, extending beyond base of 2-C, distance between basal insertions of 2-C and 4-C 0.06-0.09 $\mathrm{mm}$ (mean = $0.07 \mathrm{~mm}$ ), ratio of length of 4-C to distance between insertions of 2-C and 4-C 1.20-2.74 (mean = 1.56), distance between base of 3-C and 4-C 0.05-0.07 mm (mean $=0.06 \mathrm{~mm}$ ), 5-C reaching or extending beyond anterior margin of head, with 10-18 branches, 6-C with 11-19 branches, 7-C with 14-18 branches. Thorax: tubercles of all large setae light brown to yellowish; basal tubercle of seta 1-P entirely joined basally to tubercle of 2,3-P, each tubercle with strong apical tooth arising from posterodorsal margin, projecting over bases of 1,2-P, 14-P with 6-11 branches; 6-M with 3-5 branches; 3-T (Fig. 52) moderately developed with 3-10 leaflets arising from short basal stem. Abdomen: seta 1-I small, palmate, with 5-10 lanceolate leaflets; 1-II moderately developed, more pigmented than 1-I, palmate, with 9-19 distinct, lanceolate leaflets arising from short basal stem; 13-IV with 3,4 branches, ratio of length to 10-IV 0.63-1.05 $($ mean $=0.88) ; 1-$ VII with 11-15 leaflets without apicolateral serration and apical filament; 12-16 pecten spines, 3-6 long spines alternating with 6-10 short spines (Fig. 49).

Type data. Holotype female with associated larval and pupal skins on microscope slide, collected in Thailand, Phangnga, Ban Bang Ra Ko (8³6’N 98³2’E), 23 May 1979 (NMNH).

Material examined. One thousand one hundred twenty-six specimens: $157 \mathrm{~F}, 172 \mathrm{M}, 222 \mathrm{Le}, 294 \mathrm{Pe}, 6 \mathrm{P}, 275 \mathrm{~L}$; derived from 80 separate collections from natural habitats (5 adult, 75 immature) and progeny brood. MALAYSIA (WEST). Pahang: Fraser's Hill ( $3^{\circ} 43^{\prime} \mathrm{N}$ 1014' E), [395-13], 1F, 1LePe (J.A. Reid); [777-10], 27 Aug. 1967,

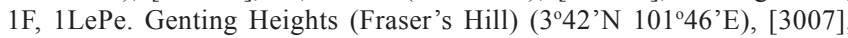
3 Sept. 1969, 1F, 1M, 2L; [3008], 3 Sept. 1969, 3F, 3M, 2L; [3394], 17 Dec. 1969, 13F, 9M, 9LePe, 2L (U. Malaya). THAILAND. Chanthaburi: Khao Hin Phoeng (Nr. Ban Chak Yai) (12 $31^{\prime} \mathrm{N} 102^{\circ} 13^{\prime} \mathrm{E}$ ), [0620], 5 Nov. 1965, 1F, 1LePe, 1L; [0629], 5 Nov. 1965, 1L; [0631], 5 Nov. 1965, 2F, 1M, 1LePe, 2Pe, 1L. Ban Chak Yai (12³1'N $\left.102^{\circ} 13^{\prime} \mathrm{E}\right),[0571], 29$ Oct. 1965, 3L. Khao Soi Dao Tai (1256’N $\left.102^{\circ} 12^{\prime} \mathrm{E}\right)$, [0854], 14 Mar. 1966, 1L, [0886], 16 Mar. 1966, 1F, 1M, 2LePe; [0887], 16 Mar. 1966, 9F, 9M, 18Pe, 7L; [0888], 16 Mar. 1966, 1L; [0889], 16 Mar. 1966, 1L; [890], 16 Mar. 1966, 1M, 1L; [0928], 22 Mar. 1966, 1M, 1Pe; [0929], 22 Mar. 1966, 1F, 1LePe; [0964], 26 Mar. 1966, 2L; [0967], 26 Mar. 1966, 1F, 1Pe, 2L; [0975], 29 Mar. 1966, 1F, 2M, 3Pe. Chon Buri: Ban Huai Kum (13¹4’N $101^{\circ} 0$ 'E), [02211], 17 Aug. 1966, 2F, 2LePe. Kanchanaburi: Huey Sai Yok (14'25'N 98 53'E), [08117], 16 Nov. 1979, (progeny), 8F, 6M, 12LePe, 2Pe, 6L. Nakhon Nayok: Khao Yai Sarika Waterfalls $\left(14^{\circ} 25^{\prime} \mathrm{N}\right.$ $\left.101^{\circ} 23^{\prime} \mathrm{E}\right)$, [NY 220], 16 June 1964, 1L; [NY 227], 16 June 1964, 4L. Huey Sai Noi (14²3'N 101 ${ }^{\circ} 29^{\prime}$ E), [047], 1 May 1965, 1F, 1 LePe. Nakhon Si Thammarat: Thung Song ( $\left.8^{\circ} 11^{\prime} \mathrm{N} 99^{\circ} 42^{\prime} \mathrm{E}\right),[01061], 6$ June 1966, 1M, 1LePe, 2L. Chong Khao (8¹2'N 9944'E), [01074], 8 June 1966, 2F, 3M, 3LePe, 2Pe; [01176], 17 June 1966, 1L; [01187], 17 June 1966, 1L. Ban Thuan Lek (8²6’N 9947'E), [01075], 10 June 1966, 3F, 7M, 4LePe, 5Pe, 1L; [01076], 10 June 1966, 6L; [01077], 10 June 1966, 1M, 1Pe; [01146], 15 June 1966; (8²6’N 9946’E), [1080], 10 June 1966, 2L. Khao Luang (8²8'N 9945'E), [01133], 14 June 1966, 7L; [01138], 14 June 1966, 1M, 1LePe. Narathiwat: Khao Lau (556'N 1014ㅇ'E), [0449], 8 Sept. 1965, 1F. Phangnga: Nam Tai (8³4'N 98³5'E), [01723], 18 Oct. 1966, 2F, 2M, 2LePe, 2Pe. Ban Bang Kaeo (8³5'N 98³2'E), [08029], 10 May 1979, 2L; [08093], 19 May 1979, 2F; [08191], 30 May 1980, 2F, 2M, 3LePe, 1Pe, 5L; [08197], 4 June 1980, 2F; [08223], 4 June 1980, 1F; [TH 498], 28 May 1987, 1F, 5M, 3LePe, 3Pe, 4L; [TH 499], 28 May 1987, 1M, 1LePe; [TH 500], 28 May 1987, 2F, 7M, 9LePe. Ban Bang 
Table 29. Number of branches for setae of the pupa of An. nemophilous: range (mode).

\begin{tabular}{|c|c|c|c|c|c|c|c|c|c|c|c|}
\hline \multirow{2}{*}{$\begin{array}{l}\text { Seta } \\
\text { No. }\end{array}$} & \multirow{2}{*}{$\begin{array}{l}\text { Cephalothorax } \\
\text { CT }\end{array}$} & \multicolumn{9}{|c|}{ Abdominal segments } & \multirow{2}{*}{$\begin{array}{c}\text { Paddle } \\
\mathrm{Pa}\end{array}$} \\
\hline & & I & II & III & IV & $\mathrm{V}$ & VI & VII & VIII & IX & \\
\hline 0 & - & - & 1 & 1 & 1 & 1 & 1 & 1 & 1 & - & - \\
\hline 1 & $2-3(2)$ & n.c. & $18-42(20)$ & $5-9(7)$ & $4-7(6)$ & $2-4(3)$ & $1-3(2)$ & $1-2(1)$ & - & 1 & 1 \\
\hline 2 & $2-3(2)$ & $5-11(7)$ & $3-7(6)$ & $5-8(6)$ & $2-4(3)$ & $2-3(3)$ & $2-4(3)$ & $2-3(3)$ & - & - & $1-2(1)$ \\
\hline 3 & $2-5(3)$ & $1-2(1)$ & $2-5(4)$ & $2-5(3)$ & $4-8(5)$ & $2-4(3)$ & $1-3(2)$ & $1-5(4)$ & - & - & - \\
\hline 4 & $1-3(2)$ & $2-7(6)$ & $1-7(5)$ & $3-6(4)$ & $3-6(4)$ & $2-6(5)$ & $1-3(2)$ & $1-2(2)$ & $1-2(2)$ & - & - \\
\hline 5 & $3-6(4)$ & $2-4(3)$ & $3-4(3)$ & $6-9(6)$ & $4-8(8)$ & $5-8(6)$ & $5-8(6)$ & $4-8(5)$ & - & - & - \\
\hline 6 & $1-3(2)$ & $1-4(2)$ & $1-2(2)$ & $1-3(2)$ & 1 & 1 & 1 & $1-2(1)$ & - & - & - \\
\hline 7 & $2-4(3)$ & $2-6(4)$ & $2-7(4)$ & $2-4(3)$ & $2-5(3)$ & $1-4(3)$ & $1-2(1)$ & $1-2(1)$ & - & - & - \\
\hline 8 & $1-4(2)$ & - & - & $2-4(3)$ & $2-4(3)$ & $2-4(3)$ & $1-4(2)$ & $1-3(2)$ & - & - & - \\
\hline 9 & $1-4(3)$ & 1 & 1 & 1 & 1 & 1 & 1 & 1 & $11-17(13)$ & - & - \\
\hline 10 & $2-5(3)$ & - & - & $2-3(3)$ & $1-2(1)$ & $1-2(2)$ & $1-3(2)$ & $1-3(2)$ & - & - & - \\
\hline 11 & $1-6(4)$ & - & - & 1 & 1 & $1-2(1)$ & 1 & $1-2(2)$ & - & - & - \\
\hline 12 & $1-3(3)$ & - & - & - & - & - & - & - & - & - & - \\
\hline 13 & - & - & - & - & - & - & - & - & - & - & - \\
\hline 14 & - & - & - & - & 1 & 1 & 1 & 1 & 1 & - & - \\
\hline
\end{tabular}

n.c. $=$ not counted

Ra Ko (8³6’N 98³2’E), [08051], 14 May 1979, 1LeP 4L; [08052], 14 May 1979, 1F, 1LePe, 3LeP, 1L; [08103], 23 June 1966, 10F, 13M, 22LePe, 1Pe; [08104], 23 May 1979, 2F, 3M, 3LePe, 2Pe, 8L; [08105], 23 May 1979, 5F, 7M, 12LePe, 8L; [08106], 23 May 1979, 13F, 11M, 17LePe, 9Pe, 3L; [08107], 23 May 1979, 4F, 6M, 7LePe, 6L; [08108], 23 May 1979, 7F, 4M, 10LePe, 1Pe, 12L; [08110], 25 May 1979, 7F, 8M, 8LePe, 7Pe, 4L; [08111], 25 May 1979, 5F, 3M, 6LePe, 2Le, 2Pe, 2L; [08113], 25 May 1979, 2L; [08114], 25 May 1979, 2F, 2LePe, 5L; [08166], 26 May 1980, 2F, 8M, 8LePe, 2Pe, 2L; [08167], 26 May 1980, 6F, 5M, 9LePe, 2Pe, 8L; [08168], 26 May 1980, 8F, 14M, 19LePe, 2Pe, 11L; [08169], 26 May 1980, 3F, 3LePe, 3L; [08185], 29 May 1980, 2M, 2LePe; [08186], 29 May 1980, 1F, 2LePe, 3L; [08187], 29 May 1980, 1F, 2M, 1LePe, 2Pe, 16L; [08188], 29 May 1980, 4F, 1M, 5LePe, 1L; [08220], 4 June 1980, 1F, 4M, 5Pe, 44L; [08221], 4 June 1980, 2F, 2Pe, 19L. Ranong: Kraburi, Petkasam

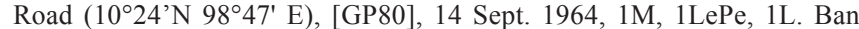
Chatri $\left(9^{\circ} 32^{\prime} \mathrm{N} 98^{\circ} 32^{\prime} \mathrm{E}\right)$, [02085], 10 July 1966, 5F, 3M, 5LePe, 2Pe; [02086], 10 July 1966, 2F, 1LePe. Songkhla: Rattaphum, Boriphat Waterfalls $\left(7^{\circ} 05^{\prime} \mathrm{N} 100^{\circ} 14^{\prime} \mathrm{E}\right)$, [SL15], 16 Mar. 1965, 1F; [SL33], 20 Mar. 1965, 1M, 1L. Had Yai (Satun Road), Ton Nga Chang Waterfalls (6 $\left.{ }^{\circ} 56^{\prime} \mathrm{N} 100^{\circ} 19^{\prime} \mathrm{E}\right)$, [SL49], 22 Mar. 1965, 2M, 1LePe; [SL88], 27 Mar. 1965, 1L (all above, AFRIMS). Sadao, Padang Besa (640’ N $\left.100^{\circ} 19^{\prime} \mathrm{E}\right),[\mathrm{PB}], 12$ Dec. 1986, (progeny), 1M, 1LePe, 1L (V. Baimai).

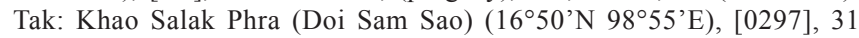
July 1965, 1L; [0298], 31 July 1965, 3F, 8M, 9LePe, 38L (AFRIMS). MALAYSIA. Perak: Maxwell's Hill [Maxwell Bukit], Larut Hills (450’N 10052'E) (Reid 1968). Negeri Sembilan: Kampong Inas $\left(2^{\circ} 37^{\prime} \mathrm{N} 102^{\circ} 15^{\prime} \mathrm{E}\right)$ (COLLESS 1956b).

Distribution (Fig. 57). Anopheles nemophilous is known from Malaysia (Pahang, Perak, Negeri Sembilan) and Thailand (Chanthaburi, Chon Buri, Kanchanaburi, Nakhon Nayok, Nakhon Si Thammarat, Narathiwat, Phangnga, Ranong, Songkhla, Tak).

Bionomics and medical importance. In Thailand, An. nemophilous was found in forested mountains and foothills, occurring at elevations from $100 \mathrm{~m}$ to $1,500 \mathrm{~m}$ above sea level. The larval habitats were situated as high as $1,220 \mathrm{~m}$ in central peninsular Malaysia and 1,500 $\mathrm{m}$ in southeastern Thailand. The habitats of the immature stages were small to moderate in size, shallow (rarely deeper than $30 \mathrm{~cm}$ ), temporary pools, usually in clay soil or rock pools, in stream beds, and usually with organic matter such as fallen leaves and sticks and/or animal waste. The water was colored or turbid, always fresh due to frequent freshening or flooding by rains, under partial or heavy shade, without grassy edges. Immatures were also found in elephant footprints, elephant wallows in bogs, flood pools in drying streambed, stream pools or near stream margins, rock pools, flood pools, seepage ponds, wheel ruts, puddles, and ground pools. Forty mosquito species have been collected in association with An. nemophilous (Peyton \& Ramalingam 1988). Adults were collected outdoor using human bait from $1830-2200 \mathrm{~h}$, in collections carried out in a village about $10 \mathrm{~m}$ from houses, and also in the forest canopy (Peyton \& Ramalingam 1988). Anopheles nemophilous apparently feeds primarily above ground level on monkeys and other small mammals in the forest canopy (Baimai et al. 1988d). The low anthropophily and affinity for feeding in the forest canopy was also observed by Walton et al. (1999).

Systematics. Anopheles nemophilous was recognized as a distinct geographical variant of An. leucosphyrys, the "Fraser's Hill form" of Colless (1956b, 1957). Previously, Reid (1968) adopted the name Fraser's Hill form and suggested that it could be a mountain variant of An. introlatus, from which it could be distinguished by morphological differences in both adult and pupal stages. Based on cross-mating and chromosomal evidence, Baimai et al. (1988d) confirmed that An. balabacensis Fraser's Hill form was a distinct species of the Dirus Complex and designated it Anopheles dirus F. Peyton \& Ramalingam (1988) described An. nemophilous and listed several morphological characters to distinguish $A n$. nemophilous from An. dirus and An. introlatus. Morphological distinction of An. nemophilous from other members of the Dirus Complex is difficult based only on characters of the adults, but identification is more reliable when fourth-instar larval characters are used. Additionally, they concluded that An. nemophilous was closely related to $A n$. cracens and that it could have arisen from a common ancestral 
Table 30. Number of branches for setae of the larva of An. nemophilous: range (mode).

\begin{tabular}{|c|c|c|c|c|c|c|c|c|c|c|c|c|c|}
\hline \multirow{2}{*}{$\begin{array}{l}\text { Seta } \\
\text { No. }\end{array}$} & \multirow{2}{*}{$\begin{array}{c}\text { Head } \\
\text { C }\end{array}$} & \multicolumn{3}{|c|}{ Thorax } & \multicolumn{9}{|c|}{ Abdominal segments } \\
\hline & & $\mathrm{P}$ & $\mathrm{M}$ & $\mathrm{T}$ & $\mathrm{I}$ & II & III & $\mathrm{IV}$ & $\mathrm{V}$ & $\mathrm{VI}$ & VII & VIII & $\mathrm{X}$ \\
\hline$\overline{0}$ & 1 & 1 & - & - & - & 1 & 1 & 1 & 1 & 1 & 1 & 1 & - \\
\hline 1 & 1 & $10-21(17)$ & $21-32(27)$ & $1-3(1)$ & $5-10(7)$ & $9-19(14)$ & $18-23(19)$ & $15-22(20)$ & $17-21(19)$ & $16-19(17)$ & $11-15(13)$ & 1 & 1 \\
\hline 2 & 1 & $8-15(11)$ & $1-7(3)$ & $1-2(1)$ & $1-2(1)$ & $4-8(6)$ & $4-7(5)$ & $3-4(4)$ & $3-4(4)$ & $3-5(4)$ & $4-8(6)$ & $5-9(6) 1$ & $15-17(16)$ \\
\hline 3 & 1 & 1 & 1 & $3-10(7)$ & $1-3(1)$ & 1 & $1-2(1)$ & $1-4(3)$ & 1 & 1 & $2-5(3)$ & $4-8(8)$ & $7-13(8)$ \\
\hline 4 & $1-2(1)$ & $13-23(18)$ & $1-3(2)$ & $2-4(3)$ & $4-7(5)$ & $2-7(6)$ & $3-5(4)$ & $3-4(3)$ & $2-4(3)$ & 1 & 1 & 1 & 9 \\
\hline 5 & $10-18(11)$ & $18-29$ & 1 & $28-36(28)$ & 3 & $4-6(4)$ & $3-5(3)$ & $2-4(3)$ & $3-5(4)$ & $3-6(4)$ & $3-6(4)$ & $3-6(4)$ & - \\
\hline 6 & $11-19(14)$ & 1 & $3-5(4)$ & $2-4(3)$ & $17-24(20)$ & $17-27(19)$ & $15-22(15)$ & $2-3(2)$ & $2-3(3)$ & $2-5(3)$ & $3-7(4)$ & $1-S$ & $4-6(4)$ \\
\hline 7 & $14-18(16)$ & $23-33(28)$ & $2-3(3)$ & $27-38(32)$ & $12-20(20)$ & $16-24(23)$ & $3-7(4)$ & $3-5(4)$ & $3-5(4)$ & $2-3(3)$ & $3-5(3)$ & $2-S$ & $5-8(6)$ \\
\hline 8 & $1-2(1)$ & $21-33(21)$ & $21-32(25)$ & $26-35(28)$ & - & $1-3(2)$ & $1-3(2)$ & $2-4(2)$ & $2-4(3)$ & $1-3(3)$ & $4-6(4)$ & $6-S$ & $2-4(3)$ \\
\hline 9 & $1-5(3)$ & 1 & 1 & 1 & $3-6(5)$ & $6-12(10)$ & $6-9(8)$ & $5-10(8)$ & $4-8(6)$ & $5-8(7)$ & $2-6(4)$ & $7-S$ & $1-2(1)$ \\
\hline 10 & $1-4(1)$ & 1 & 1 & 1 & 1 & $2-4(3)$ & 1 & 1 & 1 & $1-4(3)$ & $5-8(6)$ & 8-S & $2-4(3)$ \\
\hline 11 & $18-31(29)$ & 1 & 1 & 1 & $3-4(3)$ & 1 & $2-4(3)$ & $2-3(3)$ & $1-3(3)$ & $2-3(2)$ & $1-3(2)$ & 9-S & $2-4(3)$ \\
\hline 12 & $1-2(1)$ & 1 & 1 & $2-3(2)$ & $3-5(4)$ & 1 & $2-3(2)$ & $2-4(3)$ & $1-3(2)$ & 1 & 1 & - & - \\
\hline 13 & $4-9(5)$ & $3-7(5)$ & $4-8(5)$ & $2-4(4)$ & $3-7(3)$ & $4-7(4)$ & $3-6(4)$ & $3-4(3)$ & $3-4(3)$ & $5-8(6)$ & $2-4(3)$ & - & - \\
\hline 14 & $6-16(6)$ & $6-11(8)$ & $5-9(7)$ & - & - & - & - & 1 & 1 & 1 & 1 & 1 & - \\
\hline 15 & $5-9(6)$ & - & - & - & - & - & - & - & - & - & - & - & - \\
\hline
\end{tabular}

n.c. $=$ not counted

stock. Recently, Walton et al. (1999) developed a PCR based method using ASA method for ITS2 rDNA to separate five species of the Dirus Complex in Thailand, including An. nemophilous.

Distinction of An. nemophilous based on morphological features of the adult is not always possible and some individuals can be misidentified as An. introlatus. Anopheles nemophilous can be recognized by possessing the following combination of characters. Adult: 1) proboscis dark-scaled, as long as or slightly longer than forefemur (ratio 1.00-1.17), ratio of proboscis length to forefemur length 1.00-1.15 (mean =1.09); 2) split of cell $R_{2}$ basal to split o cell $M_{1+2} ; 3$ ) ASP spot always absent on vein $\mathrm{C}$; 4) hindtarsomere 4 usually with welldeveloped band of pale scales at base, rarely entirely darkscaled at base; 5) PSD spot of vein R often not extending basally beyond level of PSD wing spot on vein C (level 3); 6) apical band on palpomere 5 distinctly white or whitish, not strongly contrasting with light bands of palpomeres 2 and 3; 7) all pale scales of wing cream-colored to golden to yellowish, including PSP and SP spots. Fourth-instar larva: 1) seta 3-C single; 2) seta 4-C not strongly developed; 3) seta 1-II noticeably less developed than seta 1 -III-VI; 4) seta 5-C conspicuosly longer than antenna; 5) basal sclerotized tubercle of seta 1-P with prominent tooth or spine on posterodorsal margin; 6) seta 4-C long, extending well beyond base of 2-C, ratio of length of 4-C to distance between insertions of 2-C and 4-C 1.20-2.74; 7) seta 1-II moderately developed, with distinct, moderately broad leaflets, basal stem stout and distinctly inflated; 8) individual leaflets of seta 1-VII without apicolateral serrations or rarely few leaflets with weak apicolateral serration, apical filament not clearly distinct. The pupal stage of An. nemophilous cannot be distinguished from those of other members of the Dirus Complex except for those of An. scanloni and male pupa of An. cracens. The characters to separate these species are listed under An. scanloni and An. cracens.

\section{TAXONOMIC DISCUSSION}

Morphological distinction of members of the Dirus Complex is not always possible using characters of a single life stage, so the immatures should also be used for identification and confirmation. Some species are identical in the adult stage, whereas others exhibit characters that have some degree of variation and overlap. As mentioned before, species of the Dirus Complex can be distinguished from those of the Leucosphyrus Complex in having the ASP spot always absent on vein $\mathrm{C}$ and hindtarsomere 4 with band of pale scales at base on dorsal surface, except for a few individuals of $A n$. nemophilous in which the basal pale band is absent. Individuals of An. nemophilous, in which the hindtarsomere is dark basally, can be misindentified as An. introlatus, especially because in a few individuals of An. introlatus examined for this study the ASP spot was absent on the vein C. Generally, adults of An. nemophilous can be distinguished from the remaining members of the Dirus Complex in having all wing pale scales cream-colored to golden to yellowish, including the PSP and SP spots, whereas in the remaining species the PSP and SP spots of the vein C are whitish or white, contrasting with the pale cream-colored spots on the posterior veins. Distinction of An. takasagoensis and An. elegans from the remaining species of the Dirus Complex is not possible using morphological characters of the adult, however these species are allopatric relative to the other members of the complex. Consequently, geographical ranges should be considered when making identifications. Anopheles takasagoensis is found only in Taiwan, and An. elegans is known from southwestern India (Karnataka and Tamil Nadu). Individuals of An. cracens can be distinguished from those of An. dirus, An. scanloni, and An. baimaii by possessing a small posteromedial patch of dark scales on abdominal sternum VI, which is always present on both males and females, whereas in the remaining species it is either absent or there are 1 or 2 
dark scales present. Adults of An. scanloni from Kanchanaburi, Thailand possess a narrow dark linear extension onto the basal portion of the apical pale band of the hindtibia, which is absent in An. dirus, An. cracens, An. scanloni from other localities, and An. baimaii. Some individuals of An. baimaii and An. scanloni can be distinguished from An. dirus by having a long spot of pale scales on vein 1A at the level of the PSD spot of vein $\mathrm{C}$ on at least one wing, whereas in some other individuals of An. baimaii and in An. dirus there is no pale spot noticeably longer than the remaining spots of vein $1 \mathrm{~A}$. Those individuals of An. baimaii with a long pale spot on vein $1 \mathrm{~A}$ can be separated from An. scanloni in having the dorsolateral surface of foretarsomeres 1 and/or foretarsomere 2 with pale areas more dominant than the dark areas, and sometimes forming a long line or splashes of pale scales, at least in one leg. In An. scanloni, the pale areas are more discrete, occupying less surface than the dark areas along the dorsolateral line, with the dark dominant along the dorsolateral line. Comparing the number of pale spots on foretersomere 1 and hindtarsomere 1 of An. dirus, An. scanloni, and An. baimaii, An. scanloni usually has less pale spots than the other two species. The sum of pale spots on foretarsomere 1 of both combined left and right legs of An. scanloni is 6-10 $($ mean $=4.3)$ and for hindtarsomere 1 is 5-16 (mean $=5.53)$, whereas in the other species it varies from 8-18 in foretarsomere 1 and 13-28 in hindtarsomere 1. Distinction between An. dirus and An. baimaii is more problematic. The following characters may help the identification of these species. In An. dirus, the PSD spot on vein R extends basally beyond the corresponding spot on at least on one wing, usually reaching the HD spot or beyond or at least beyond middle of the PSD spot, whereas in An. baimaii the PSD spot of vein $\mathrm{R}$ is usually equal to the corresponding spot on the vein $\mathrm{C}$ or extends slightly further, usually to no more than the middle of PSP of vein C. Additionally, An. dirus has the brightest, shiny white scales on wing spots PSP and SP, with the scales similar to those of the halter in color. The PSP spot is the whitest spot, strongly contrasting with the SCP and PP spots, which are yellowish, and the other spots, which are pale cream-colored. Also, the pale basal band on hindtarsomere 4 is very narrow or incomplete ventrally, sternum VI is without scales or with 1,2 dark scales posteromedially, and the pale bands on palpomeres 3,4 are relatively short, equal to or slightly shorter than basal dark band on palpomere 5 .

Based on morphological characters of the fourth-instar larva, it is possible to distinguish two major groups within the Dirus Complex. One group has seta 5-C noticeably longer than the antenna and one group has seta 5-C shorter, as long as, or slightly longer than the antenna, but never conspicuously longer. The former group comprises An. baimaii, An. cracens, An. dirus, and An. nemophilous, and the latter An. elegans, An. scanloni, and An. takasagoensis. Fourth-instar larva of An. takasagoensis can be separated from An. elegans and An. scanloni in having seta 4-C not reaching the base of 2-C, the basal tubercle of seta 1-P broadly joined to tubercle of 2,3-P, seta 2-C with minute spicules apically, ratio of length of 4-C to distance between the base of 2-C and 4-C 0.46-0.76, and seta $1-\mathrm{X}$ inserted at the edge of saddle, whereas in An. elegans and An. scanloni seta 4-C extends distinctly beyond the base of 2$\mathrm{C}$, the basal tubercle of seta 1-P is narrowly joined or entirely separate from that of 2,3-P, seta 2-C is simple and the ratio of length of 4-C to distance between base of 2-C and 4-C varies from 0.80-3.26. Anopheles elegans can be distinguished from An. scanloni in having the basal tubercle of seta 1-P narrowly joined to the tubercle of setae 2,3-P by an anterior basal bridge, the length of seta $4-\mathrm{C}$ is $0.07-0.10 \mathrm{~mm}$ and the ratio of length of 4-C to distance between the base of 2-C and 4-C is 0.80-1.09, whereas in An. scanloni the tubercle of seta 1-P is well separated from that of 2,3-P at least on one side, the length of 4-C is $0.10-0.22 \mathrm{~mm}$, and the ratio of length of 4-C to distance between 2-C and 4-C is 1.20-3.26. Anopheles nemophilous can be distinguished from An. dirus, An. baimaii, and An. cracens in having seta 1-II moderately developed, with distinct moderately broad leafletes arising from a distinct inflated basal stem; from An. cracens and An. dirus by possessing seta 3-C long, extending beyond anterior margin of head, and seta 4-C extending noticeably beyond base of 2-C. In An. dirus and An. cracens seta 3-C is short, extending to or only slightly beyond anterior margin of head, seta 4-C extends slightly beyond, near or does not reach the base of 2-C. Distinction between An. baimaii, An. cracens, and An. dirus is more difficult because the position of seta $4-\mathrm{C}$ relative to base of $2-\mathrm{C}$ is variable in An. baimaii, and thus some individuals can exhibit seta 4-C not reaching base of 2-C, whereas in the others seta 4-C can either reach or extend slightly beyond base of 2-C. However, in the specimens of An. baimaii examined for the present study, seta $2-\mathrm{C}$ is frequently simple, rarely with 1,2 spicules, whereas in An. cracens and An. dirus seta 2-C is spiculate at apical 0.5. Also, in An. dirus seta 1-X is inserted inside or at the edge of the saddle and seta 14-P has 3-5 branches, whereas in An. cracens and An. baimaii seta 14-P has $4-8$ branches and seta $1-\mathrm{X}$ is inserted in a marginal notch or at the edge of saddle.

Recognition of species of the Dirus Complex based on morphological features of the pupal stage is not currently possible at this moment except for the male pupa of $A n$. cracens, which has the male genitalia case distinctly constricted near the middle length. Also, the pupa of An. scanloni can be distinguished from other members of the Dirus Complex as well as from all other species of the Leucosphyrus Group by the absence of a fringe of filamentous spicules on the inner margin of the paddle. However, An. elegans exhibits polymorphism for this character and in a few individuals examined the fringe of spicules is absent on the inner margin of the paddle, but as previously noted, An. elegans is restricted to southwestern India.

\section{HACKERI SUBGROUP}

Colless (1956b) named the Elegans Subgroup because $A n$. elegans was included in it and was considered the nominotypical species. Peyton (1989) confirmed the 
classification of the Leucosphyrus Group suggested by Colless (1956b) and showed additional morphological evidence to define the Elegans Subgroup. While examining the holotype of An. elegans, Sallum et al. (2005) observed that An. elegans is, in fact, a member of the Dirus Complex of the Leucosphyrus Subgroup of Peyton (1989). Consequently, Sallum et al. (2005) transferred An. elegans to the Dirus Complex and described a new species, An. mirans, which had been largely misidentified as An. elegans. Because the "Elegans Subgroup" no longer contained its nominotypical species, Sallum et al. (2005) proposed the Hackeri Subgroup for the other species, $A n$. hackeri, An. pujutensis, An. sulawesi, An. recens, and An. mirans. The Hackeri Subgroup can be distinguished from the Riparis and Leucosphyrus Subgroups by possessing the proboscis considerably longer than the forefemur, the ratio between proboscis length and forefemur length 1.16-1.45 (mean $=1.27$ ) (Table 2.1). Members of the Hackeri Subgroup are of medical or veterinary importance as vectors of simian or human Plasmodium parasites. Anopheles hackeri is an important vector of simian Plasmodium on the coastal mangrove zone of Malaysia, whereas An. pujutensis is probably a vector in both coastal mangrove zone and lowland swamp forests, whereas An. sulawesi is vector of human Plasmodium in the Celebes (= Sulawesi) Island (Warren \& Wharton 1963).

\section{Anopheles (Cellia) mirans Sallum \& Peyton}

(Figs. 5, 7, 8, 33, 34, 49, 51, 52, 58)

Anopheles mirans Sallum \& Peyton (2005) (F, M, P*, L*). Holotype female with associated larval and pupal exuviae on microscope slide, deposited in the NMNH.

Anopheles leucosphyrus var. elegans of Cogill (1903:330) (larval bionomics, in part, $\left.\mathrm{F}^{*}, \mathrm{M}, \mathrm{P}, \mathrm{L}^{*}\right)$; James \& Liston (1904:82) (F*, $\mathrm{L}^{*}$, in part, Plate XII, transferred to genus Anopheles); Reid (1949:46) (taxonomic notes, in part, distribution).

Anopheles leucosphyrus of Carter (1925:74) (F, bionomics notes); Covell (1927:47) (in part, distribution, Sri Lanka); Covell (1931b:241) (in part, distribution); Wijesundara (1942:451) (bionomics notes); D'Abrera (1944:354) (E); Carter (1950:87) (checklist).

Anopheles leucosphyrus species group of Harrison et al. (1974:142) (distribution notes).

Anopheles balabacensis of Reid (1970:56) (in part, west cost of India, systematics).

Anopheles elegans of Colless (1956b:75) (F*, M, P*, E, taxonomic notes, identification key, distribution); Choudhury et al. (1963a:243) (vector competence), (1963b:237) (vector competence); Reid (1968:303) (F*, taxonomy, bionomics notes, identification key); Nelson et al. (1971:46) (vector competence); Amerasinghe (1982:81) (bionomics); Mendis et al. (1984:318) (L*, P*, bionomics); Peyton (1989:197) (taxonomy); Das et al. (1990a:135) (A, identification key).

Myzomyia leucosphyra of Swellengrebel (1921:36) (M, identification key).

Neomyzomyia elegans of James \& Liston (1911:105) (F*, L*, Plate $\mathrm{XV})$.

Neomyzomyia leucosphyra of Swellengrebel (1916:82) (in part, taxonomy, distribution); Swellengrebel \& Swellengrebel De Graff (1920a:33) (L*, key, biology, mixed with An. elegans).

Female (Figs. 5, 7, 8). Head: proboscis uniformly darkscaled, length $2.17-2.86 \mathrm{~mm}$ (mean $=2.59 \mathrm{~mm}$ ), ratio of length to forefemur length 1.19-1.31 (mean $=1.25)$, maxillary palpus (Fig. 7) length $1.85-2.45 \mathrm{~mm}$ (mean $=2.22 \mathrm{~mm})$, ratio of length to proboscis length $0.84-0.93$ (mean $=0.87$ ), ratio of length to forefemur length 1.02-1.15 $($ mean $=1.10)($ Table 2.2), ratio of length of palpomeres $3 / 41.35-1.77($ mean $=1.55), 3 / 51.93-2.54$ $($ mean $=2.21), 4 / 51.27-1.73($ mean $=1.43), 4-5 / 3$ 1.04-1.18 (mean $=1.10$ ), palpomeres $2-4$ with narrow apical silvery-white bands, bands similar in size and color, pale scales of palpomere 5 white, similar to scales on palpomeres 2-4, length of apical pale band of palpomere $50.83-2.67($ mean $=1.40)$ length of basal dark band of palpomere 5 , ratio of length of apical pale band of palpomere 4 to length of basal dark band of palpomere 5 0.33-1.00 $($ mean $=0.6)($ Table 3$)$. Thorax: pleural setae as follows: 2-5 upper proepisternal, 0-1 prespiracular, 4-8 prealar, 3,4 upper mesokatepisternal, 2,3 lower mesokatepisternal, 2-6 upper mesepimeral. Wing (Fig. 5): length 2.88-4.23 mm (mean $=3.64 \mathrm{~mm}+0.34$ ), pale scales of PHP, HP, PSP, SP, and SCP spots white on vein $\mathrm{C}, \mathrm{SCP}$ spot pale cream-colored to yellowish on subcosta, pale scales on remaining veins pale cream-colored to yellowish, none strongly contrasting with others, PHP spot of vein C usually prominent, sometimes reduced, HP, PSP and SP spots always present, prominent, ASP spot absent, PP spot 0.46-1.89 (mean = 1.00) length of SCP spot, AD spot 1.94-8.00 (mean = 3.27) length of PP spot, PSD spot of vein R extending basally from level 1 to level 4, often to level 1 and level 2 on one or both wings (Table 4), PSD spot of vein $R$ without pale spot (Table 5), SD spot of vein $R$ with 1 pale spot (Table 6), sum of pale interrupitons on PSDPD spots of vein R always 2 on both wings, ratio of length of cell $\mathrm{R}_{2}$ to vein $\mathrm{R}_{2+3}$ 1.29-1.80 (mean = 1.52), ratio of length of cell $\mathrm{R}_{2}$ to cell $\mathrm{M}_{1+2}$ 1.13-1.29 (mean=1.22). Legs (Fig. 8): femora, tibiae, and tarsomeres dark-scaled, speckled with pale spots; foretarsomere 2 with conspicuous basal and apical pale bands, middle dark area with 1-3 pale spots or entirely dark, foretarsomere 3 with basal and apical pale bands, foretarsomere 4 with basal and apical pale bands, occasionally apical pale band absent, foretarsomeres 5 dark at base, apex pale-scaled, basal and apical pale bands on foretarsomeres 2-5 evident on ventral surface; midtarsomeres 2-4 with apical pale spot on dorsal surface, pale spots not noticeable on ventral surface, midtarsomere 5 pale-scaled at apex; hindtarsomeres 2,3 with minute basal pale spot or dark-scaled at base, always with apical pale band, hindtarsomere 4 with basal and apical pale bands, hindtarsomere 5 with basal pale band, rarely entirely dark at base, apex always pale-scaled. Abdomen: tergum VI usually without scales, rarely with few dark scales posteriorly, tergum VII usually without scales, occasionally with few apicolateral scales, tergum VIII covered with golden scales posteromedially, dark scales basally; sternum VI with posteromedial patch of dark scales, sternum VII with posteromedial patch of dark scales, sternum VIII with few, occasionally numerous lateral pale cream-colored scales.

Male. Essentially as in female except for sexual characters. Palpomere 2 with dorsal patch of pale scales at middle, apex of palpomere 2 bare, palpomere 3 with long dorsal patch of pale scales at middle, extending to lateral surface, apex with a broad 
band of pale scales, covering dorsal, lateral and ventral surfaces except for a small ventrolateral patch of dark scales at apex, palpomere 4 mainly pale-scaled with basal dark band extending along ventral surface, palpomere 5 pale-scaled with basal dark band extending along ventral surface and reaching apex. Abdomen: sternum VIII covered with pale cream-colored to golden scales. Genitalia: 4 parabasal spines; ventral clapette with 1 long apicolateral seta, longer than club of dorsal claspette, 1 short, slender apicomedial seta, and 1 short, slender subapical seta; dorsal claspette with 4 apical setae fused into a stout club with distinct basal stems; aedeagus elongate, columnar, dorsally curved with about 7 leaflets on each side of tip, leaflets serrated on one or both edges.

Pupa (Figs. 33). Position and development of setae as figured; range and modal number of branches in Table 31. All measurements from 20-40 specimens. Integument without distinctive pattern of darkened spots, mostly light brown to yellowish; sterna II-VI with narrow, dark band near anterior margin. Cephalothorax: seta 1-3-CT about equal in length, 4CT usually double, 5-CT with 3-7 branches, 6-CT single to triple, 7- CT usually triple, 8-CT single or double, 9-CT with 24 branches, 10-CT single to triple, 11-CT single to 5-branched, 12-CT double or triple. Seta 9-II lightly pigmented, 9-III-VII pigmented medium to dark brown from base to apex, 9-VIII pigmented light brown, darker at base. Abdomen: seta 6-I single or double, 7-I with 2-5 branches; 1-II dendritic, with fine branches arising from basal stem, 6-II single or double, 7-II with 2-5 branches, 8-II absent, 9-II very short, stout, arising distad from posterior margin of segment, length $0.01-0.02 \mathrm{~mm}$ $($ mean $=0.01 \mathrm{~mm}), 10$-II single to triple, $11-\mathrm{II}$ absent or present; 1-III with 3-8 branches, 5-III with 5-9 branches, 6-III usually double, 9-III short, stout, length 0.01-0.02 $\mathrm{mm}$ (mean $=0.02$ $\mathrm{mm}$ ); 1-IV with 2-6 branches, 5-IV with 4-7 branches, 6-IV single or double, 9-IV short, either with or without spicules, length 0.03-0.06 mm (mean $=0.04 \mathrm{~mm}$ ), ratios of length of 9-IV/9-III 1.409-3.231 (mean = 2.32) and 9-IV/9-V 0.29-0.52 (mean=0.41); 1-V single to triple, 5-V with 3-7 branches, $6-\mathrm{V}$ always single, 9-V long, either with or without spicules, length $0.08-0.12 \mathrm{~mm}$ $($ mean $=0.11 \mathrm{~mm}$ ); 1-VI single or double, 5-VI with 4-7 branches, 6-VI single, 9-VI long, either with or without spicules, length $0.07-0.14 \mathrm{~mm}$ (mean $=0.11 \mathrm{~mm}) ; 1$-VII single or double, 5-VII with 4-7 branches, 6-VII usually single, 9-VII long, either with or without spicules, length $0.08-0.12 \mathrm{~mm}$ (mean $=0.11 \mathrm{~mm}$ ); 9VIII with 8-13 branches. Paddle: lightly tanned, buttress slightly darker, midrib faint; outer basolateral serration prominent, filamentous spicules on outer margin and most of inner margin prominent; seta 1-Pa strong, dark pigmented, 2-Pa with 1,2 branches, toothed margin index 0.78-0.94 (mean $=0.85)$, paddle teeth tapering to apex, ending in pointed, sharply acute apex.

Larva (Figs. 33, 34, 49, 51, 52). Position and development of branches as figured; range and modal number of branches in Table 32. All measurements from 22-44 specimens unless otherwise indicated. Head: integument light brown to yellowish with dark spots on dorsal apoteme and labiogula: 1 small dark spot placed posteriorly at dorsal apoteme and 2 more developed dark spots slightly anterior; a more developed, unique dark spot posteriorly to area between seta 8-C and 2 small dark spots laterally; 2 lateral dark spots at dorsal apoteme, posteriorly to seta $7-\mathrm{C} ; 1$ dark spot at ventral lateralia in the area of insertion of 12-C; 2 dark spots placed laterally at the level of posterior tentorial pit, and a unique, dark spot placed posteriorly on hypostomal ecdysial line; length $0.66-0.74 \mathrm{~mm}$ $($ mean $=0.72 \mathrm{~mm})$, width $0.70-0.80 \mathrm{~mm}($ mean $=0.76 \mathrm{~mm})$; antenna length $0.29-0.33 \mathrm{~mm}$ ( mean $=0.31 \mathrm{~mm})$, ratio of distance base to 1-A to antenna length $0.32-0.50($ mean $=0.39)$; seta 2$\mathrm{C}$ long, single, occasionally with sparse spicules on apical 0.5 ; 3 -C single, length $0.07-0.10 \mathrm{~mm}($ mean $=0.08 \mathrm{~mm})$; distance between base of 2-C and 3-C 0.03-0.06 (mean $=0.04 \mathrm{~mm}$ ); 4-C posterolaterad of 2-C, single to triple, length $0.10-0.16 \mathrm{~mm}$ (mean 0.12), extending beyond base of 2-C, distance between basal insertions of 2-C and 4-C 0.07-0.12 $\mathrm{mm}$ (mean $=0.09 \mathrm{~mm}$ ), ratio of length of 4-C to distance between the insertions of 2$\mathrm{C}$ and 4-C 1.05-2.12 (mean $=1.454)$, distance between base of 3-C and 4-C 0.05-0.11 mm (mean $=0.08 \mathrm{~mm})$; 5-C longer than antenna, extending beyond anterior margin of head, 7-14 branches, 6-C with 10-17 branches, 7-C with 12-18 branches. Thorax: tubercles of all large setae light to medium brown; seta 1-P with 15-20 branches, stem stout, flattened, not noticeably expanded, arising from a large tubercle, which is slightly smaller than tubercle of 2-P, tubercle of seta 1-P usually entirely joined basally to tubercle of 2,3-P, rarely separate, both tubercles with strong, pointed or somewhat rounded apical tooth projecting forward over base of 1,2-P, 14-P with 712 branches; 4-M single to triple, 6-M usually 4-branched, 14$\mathrm{M}$ with 6-12 branches; 3-T (Fig. 52) moderately developed, not palmate, with narrow branches arising from distinct level of a basal stem. Abdomen: seta 1-I poorly developed, somewhat palmate, with 3-7 narrow, lanceolate, nearly transparent leaflets arising from a basal stem, 2-I single to 4-branched, 3-I single to triple, 9-I with 3-7 branches; 1-II (Fig. 51) poorly developed, more pigmented than 1-I, somewhat palmate, with narrow, lanceolate, nearly transparent leaflets arising from distinct level of a basal stem, basal stem narrow, moderately pigmented; 2 IV with 3-5 branches, 3-IV single to triple, 13-IV with 3,4 branches, long, ratio of length to 10-IV 0.80-1.14 (mean $=0.93$ ); $2-\mathrm{V}$ with $3-5$ branches; 1 -VII smaller and less pigmented than 1-VI with 10-16 moderately broad, lanceolate leaflets with minute, apicolateral serration and slender apical filament; 1 -X long, single or double, inserted on saddle; $13-15$ pecten spines, 5,6 long spines alternating with 7-10 short spines (Fig. 49).

Type data. Holotype adult female with associated larval and pupal exuviae on microscope slide [Acc. no. 316-1], collected in Sri Lanka, Western Province, Kalatuara, Morapitiya, Sinharaja Forest Reserve (6 $\left.6^{\circ} 33^{\prime} \mathrm{N} 80^{\circ} 19^{\prime} \mathrm{E}\right), 18$ July 1975 by Huang and Peyton, 18 July 1975, deposited in the $\mathrm{NMNH}$.

Material examined. One thousand forty-nine specimens, as follows: 235F, 183M, 210Le, 359Pe, 63L derived from 94 separate collections from natural habitats (14 adult, 80 immature). INDIA. Kerala: Travancore (9³0’N 7650'E), 1934, 1F (M.O.T. Iyengar, D.H. Colless). Karnataka [Mysore]: Kåwår, North Canara (Kanara] (14 ${ }^{\circ} 53^{\prime} \mathrm{N}$ $74^{\circ} 35^{\prime} \mathrm{E}$ ), [24,25], 1 Oct. 1902, 2F (each on concave slide with cover 
Table 31. Number of branches for seta of pupae of An. mirans: range (mode).

\begin{tabular}{|c|c|c|c|c|c|c|c|c|c|c|c|}
\hline \multicolumn{2}{|c|}{ Seta Cephalothorax } & \multicolumn{9}{|c|}{ Abdominal segments } & \multirow{2}{*}{$\begin{array}{c}\text { Paddle } \\
\text { Pa }\end{array}$} \\
\hline No. & $\mathrm{CT}$ & I & II & III & IV & $\mathrm{V}$ & VI & VII & VIII & IX & \\
\hline$\overline{0}$ & - & - & 1 & 1 & 1 & 1 & 1 & 1 & 1 & - & - \\
\hline 1 & 2 & n. c. & $11-25$ & $3-8(5)$ & $2-6(3)$ & $1-3(2)$ & $1,2(1)$ & $1,2(1)$ & - & 1 & 1 \\
\hline 2 & $2,3(2)$ & $3-10(7)$ & $5-7(6)$ & $3-8(6)$ & $2-4(3)$ & $2-4(2)$ & $1,2(1)$ & $2-4(3)$ & - & - & $1,2(2)$ \\
\hline 3 & $2,3(2)$ & $1-3(2)$ & $2-5(3)$ & $4-10(5)$ & $3-7(5)$ & $2,3(2)$ & $1-4(2)$ & $2-4(3)$ & - & - & - \\
\hline 4 & $2-4(2)$ & $2-8(4)$ & $2-5(3)$ & $2-4(3)$ & $2-8(4)$ & $2-5(3)$ & $1-3(2)$ & $1,2(2)$ & $2,3(2)$ & - & - \\
\hline 5 & 3-7 (4) & $2-5(3)$ & $2-5(2)$ & $5-9(7)$ & 4-7 (4) & 3-7 (4) & 4-7 (5) & 4-7 (4) & - & - & - \\
\hline 6 & $1-3(2)$ & $1,2(1)$ & $1,2(1)$ & $1-3(2)$ & $1,2(1)$ & 1 & 1 & $1,2(1)$ & - & - & - \\
\hline 7 & $2-4(3)$ & $2-5(3)$ & $2-5(3)$ & $2-8(4)$ & $2-5(2)$ & $2-6(4)$ & $1,3(1)$ & $1,2(2)$ & - & - & - \\
\hline 8 & $1,2(1)$ & - & - & $2-4(3)$ & $2-4(2)$ & $1-3(2)$ & $1,3(2)$ & $1,2(2)$ & - & - & - \\
\hline 9 & $2-4(2)$ & 1 & 1 & 1 & 1 & 1 & 1 & 1 & $8-13(11)$ & - & - \\
\hline 10 & $1-3(2)$ & - & $1-3(2)$ & $2,3(3)$ & $1,2(2)$ & $1-3(2)$ & $1,2(2)$ & $2,3(2)$ & - & - & - \\
\hline 11 & $1-5(3)$ & - & $0-2(0)$ & $1,2(1)$ & $1,2(1)$ & 1 & $1,2(1)$ & $1-4(2)$ & - & - & - \\
\hline 12 & $2,3(2)$ & - & - & - & - & - & - & - & - & - & - \\
\hline 13 & $0-2(0)$ & - & - & - & - & - & - & - & - & - & - \\
\hline 14 & - & - & - & - & 1 & 1 & 1 & 1 & 1 & - & - \\
\hline
\end{tabular}

n.c. $=$ not counted

slipe ringed with Canada balsam); [330], 3 Sept. 1902, 1F; [332], 1 Oct. 1902, 1M; [333], 1 Oct. 1902, 1F; [335], 1 Oct. 1902, 1M; [336], 1 Oct. 1902, 1M; [357], 10 Oct. 1902, 1F; [361], 12 Oct. 1902, 1F; [373], 29 Oct. 1902, 1F; [381], 12 Jan. 1903, 1M (H. Cogill).

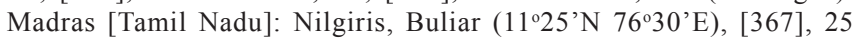
June 1975, 3F, 1M; [388], 6 Aug. 1975, 2F; [606], 16 Mar. 1977, 2F; [607], 16 Mar. 1977, 1M; [611], 25 Mar. 1977, 1F, 1M; [638], 1 Dec. 1977, 1M, 1Le; [649], 8 Dec. 1977, 2F, 1M, 3Pe; [654], 13 Dec. 1977, 2M, 1LePe; [655], 13 Dec. 1977, 20F, 12M, 13LePe, 16Pe; [659], 15 Dec. 1977, 7F, 6M, 4LePe, 9Pe; [660], 17 Dec. 1977, 10F, 1M, 3LePe, 3Pe; [662], 23 Dec. 1977, 10F, 5M, 8LePe, 7Pe; [63], 23 Dec. 1977, 10F, 8M, 13LePe, 6Pe, 7L; [664], 23 Dec. 1977, 4F, 4M, 4LePe, 2Pe; [665], 7F, 4M, 5LePe, 6Pe; [666], 23 Dec. 1977, 3M, 3LePe; [667], 29 Dec. 1977, 2F, 1M, 3LePe; [668], 29 Dec. 1977, 2F, 2M, 2LePe, 2Pe; [669], 22 Dec. 1977, 3F, 1M, 3LePe, 1Le; [670], 5 Jan. 1978, 9F, 4M, 3LePe, 10Pe; [676], 12 Jan. 1978, 1F, 3M, 4LePe; [677], 12 Jan. 1978, 1M, 1Pe; [678], 12 Jan. 1978, 1F, 1Pe; [679], 12 Jan. 1978, 3F, 1M; [680], 12 Jan. 1978, 2F, 6M, 6LePe, 2Pe; [688], 27 Feb. 1978, 1F, 1M, 1LePe, 1Pe; [689], 27 Feb. 1978, 1F, 3M, 2LePe, 2Pe; [690], 27 Feb. 1978, 5F, 5M, 2LePe, 6Pe; [691], 3 Apr. 1978, 6F, 6M, 8LePe; [692], 3 Apr. 1978, 3F, 5M, 3LePe, 1Pe; [694], 9 Mar. 1978, 3F, 2M, 4LePe, 3Pe; [695], 9 Mar. 1978, 1M, 1Pe; [697], 8F, 3M, 8LePe, 3Pe; [698], 23 Mar. 1978, 1F, 1M, 1LePe, 1Pe; [699], 23 Mar. 1978, 8F, 4M, 4LePe, 8Pe; [700], 14 May 1978, 2F, 2M, 3LePe; [701], 14 May 1978, 5F, 5M; [709], 6 June 1978, 2F, 1Pe; [718], 16 June 1978, 1F, 1M, 1LePe, 1Pe; [722], 28 June 1978, 11F, 2M, 5LePe, 8Pe; [725], 9 July 1978, 2F, 1M, 2LePe, 1Pe; [727], 22 July 1978, 1F, $3 \mathrm{M}, 3 \mathrm{LePe}, 1 \mathrm{Pe}$. Kallar $\left(11^{\circ} 21^{\prime} \mathrm{N}\right.$ 76 $\left.6^{\circ} 4^{\prime} \mathrm{E}\right), 18$ Mar. 1950, 1F; [416], 15 Sept. 1975, 2F; [684], 6 Feb. 1978, 1M, 1LePe. Coimbatore, Mettupalaiyan (11 $\left.{ }^{\circ} 18^{\prime} \mathrm{N} 76^{\circ} 54^{\prime} \mathrm{E}\right)$, [597], 9 Feb. 1977, 1F (NICD colony). Kanjafani (?), [573], 25 Nov. 1975, 3F, 1M. SRI LANKA. Central: Kandy, Udawatekelle Forest Reserve ( $\left.7^{\circ} 15^{\prime} \mathrm{N} 80^{\circ} 37^{\prime} \mathrm{E}\right)$, [43], June 1975, 1M, 1LePe, E.L. Peyton and Y.-M. Huang); 1982/83, (colony, University of Colombo), 1F, 1M, 8Le, 16Pe, 3L (K.N. Mendis).Kandy, Wakarawatta, Roseneath ( $\left.7^{\circ} 17^{\prime} \mathrm{N} 80^{\circ} 38^{\prime} \mathrm{E}\right), 25 \mathrm{Mar}$. 1971, 1L (B.A. Harrison et al.). Matale $\left(7^{\circ} 22^{\prime} \mathrm{N} 80^{\circ} 4^{\prime} \mathrm{E}\right)$, [121], 26 June 1975, 2M, 1LePe, 3L; [126], 26 June 1975, 1F, 1Pe; Jan. 1944, 1F. Imbulpitiya (7²6’ $\left.6^{\prime} 80^{\circ} 40^{\prime} \mathrm{E}\right)$, [127], 26 June 1975, 3F, 4LePe. Yatawatta $\left(7^{\circ} 34^{\prime} \mathrm{N} 80^{\circ} 35^{\prime} \mathrm{E}\right), 10 \mathrm{Feb}$. 1942, 1F. Sabaragamuwa: Ratnapura, Vaddagala, Sinharaja Forest Reserve (6 $\left.6^{\circ} 4^{\prime} \mathrm{N} 80^{\circ} 27^{\circ} \mathrm{E}\right)$, [286], 17 July 1975, 1M, 1LePe; [295], 17 July 1995, 9F, 15M, 19LePe, 4Pe, 22L; [299], 17 July 1975, 1M, 1LePe; [300], 17 July 1975, 1F, 1LePe. Southern: Galle, Kanneliya Forest Reserve (6 $\left.{ }^{\circ} 14^{\prime} \mathrm{N} 80^{\circ} 20^{\prime} \mathrm{E}\right)$, [199], 9 July 1975, 1F, 1LePe, 1L; [201], 9 July 1975, 1LePe; [204], 9 July 1975, 1LePe; [207], 9 July 1975, 5F, 2M, 6LePe, 1Pe, 1L; [209], 9 July 1975, 1M, 1LePe; [211], 9 July 1975, 1F; [263], 13 July 1975,
1M, 1Pe; [264], 13 July 1975, 1F, 3M, 3LePe, 2Pe, 2L. North Western: Karunegala $\left(7^{\circ} 29^{\prime} \mathrm{N} 80^{\circ} 20^{\prime} \mathrm{E}\right)$, Aug. 1926, 2F. Western: Colombo, Labugama Reservoir (6 ${ }^{\circ} 50^{\prime} \mathrm{N}$ 800'ㄹ), [420], 7 Aug. 1975, 1M, 1Pe; [422], 7 Aug. 1975, 2F, 4M, 4LePe, 2Pe; [423], 7 Aug. 1975, 1M, 1L; [424], 7 Aug. 1975, 1F, 1M, 1LePe, 1Pe, 4L; [425], 7 Aug. 1975, 1F, $1 \mathrm{M}, 1 \mathrm{LePe}, 1 \mathrm{Pe}, 2 \mathrm{~L}$; [427], 7 Aug. 1975, 1M, 1LePe; [428], 7 Aug. 1975, 3F, 4M, 4LePe, 3Pe, 5L; [429], 7 Aug. 1975, 2F, 2LePe, 7L; [430], 7 Aug. 1975, 2F, 2M, 2LePe, 2Pe, 4L; [431], 7 Aug. 1975, 14F, $13 \mathrm{M}, 12 \mathrm{LePe}, 15 \mathrm{Pe}$. Kalatuara, Morapitiya, Sinharaja Forest Reserve (63'ㅅ 80¹9'E), [316], 18 July 1975, 5F, 6M, 5LePe, 6Pe, 2Le. Kalatuara, Kalatuara $\left(6^{\circ} 49^{\prime} \mathrm{N} 80^{\circ} 11^{\prime} \mathrm{E}\right), 8$ Aug. 1975, 1LePe. (All above, E.L. Peyton and Y.-M. Huang coll.). Province unknown: Kapitigalla, Nov. 1921, 1F; Jan. 1922, 1F (R.S. White). Sudugaua [Suduganga?, 7²9’N 80³8'E], 21 Feb. 1925, 1M (J.A. Reid).

Distribution (Fig. 58). Anopheles mirans is known from southwestern India (State of Kerala, State of Karnataka, State of Tamil Nadu), Sri Lanka (Central Province, Sabaragamuwa Province, Southern Province, North Western Province, Western Province).

Bionomics and medical importance. In Tamil Nadu, India, immatures of An. mirans were found in shallow, large and small ground pools, shallow or deep large or small rock pools, flood pools, and swamps. The water was clear or turbid, in partial or heavy shade, sometimes with decaying leaves. The larval habitats were situated in mountainous areas.

In Sri Lanka, immatures were collected in cultivated areas, in ditches along road sides, animal footprints, concrete wells, small rock pools, wheel ruts, ground pools, flood pools, pools along side roads, small or large rock pools, swamps, rock pools along stream edges, and in a semipermanent gem pit. The water was fresh, stagnant, colored, turbid, or clear, in partial or heavy shade, and usually with leaves and sticks. The habitats were in secondary rain forest with mixed scrub vegetation, situated in mountainous terrain, at elevations from 200 to 900 $\mathrm{m}$ above sea level. Immatures of An. mirans were found in association with An. maculatus, Cx. mimulus, $C x$. minutissimus (Theobald), Cx. uniformis (Theobald), Cx. pallidothorax Theobald, Cx. fragilis Ludlow, Cx. wardi Sirivanakarn, Cx. quadripalpis (Edwards), Cx. bailyi Barraud, 
Table 32. Number of branches for setae of larvae of An. mirans: range (mode).

\begin{tabular}{|c|c|c|c|c|c|c|c|c|c|c|c|c|c|}
\hline \multirow{2}{*}{$\begin{array}{l}\text { Seta } \\
\text { No. }\end{array}$} & \multirow{2}{*}{$\begin{array}{c}\text { Head } \\
\text { C }\end{array}$} & \multicolumn{3}{|c|}{ Thorax } & \multicolumn{9}{|c|}{ Abdominal segments } \\
\hline & & $P$ & $\mathrm{M}$ & $\mathrm{T}$ & $\mathrm{I}$ & II & III & IV & $\mathrm{V}$ & VI & VII & VIII & $\mathrm{X}$ \\
\hline$\overline{0}$ & 1 & 1 & - & - & - & 1 & 1 & 1 & 1 & 1 & 1 & 1 & - \\
\hline 1 & 1 & $15-20(15)$ & $25-34(28)$ & $1-4(3)$ & $3-7(3)$ & $10-17(10)$ & $14-21(17) 1$ & $16-21(18)$ & $14-22(18)$ & $11-21(17)$ & $10-16(13)$ & 1 & $1-2(1)$ \\
\hline 2 & 1 & $10-14(12)$ & $1-5(3)$ & 1 & $1-4(3)$ & $5-10(7)$ & $5-8(7)$ & $3-5(4)$ & $3-5(4)$ & $4-6(5)$ & $6-10(10)$ & $4-12(7)$ & $13-23$ \\
\hline 3 & $1-2(1)$ & 1 & 1 & $5-11(7)$ & $1-3(2)$ & 1 & $1-2(1)$ & $1-3(2)$ & 1 & 1 & $3-5(3)$ & $5-7(7) 6$ & $6-14(10)$ \\
\hline 4 & $1-3(1)$ & $13-18(13)$ & $1-3(2)$ & $1-5(3)$ & $3-7(5)$ & $4-9(7)$ & $3-5(4)$ & $3-5(4)$ & $2-3(3)$ & $1-2(1)$ & 1 & 1 & 9 \\
\hline 5 & $7-14(10)$ & $21-51(33)$ & 1 & $27-37(27)$ & $3-4(3)$ & $4-6(6)$ & $3-6(3)$ & $3-5(3)$ & $3-5(3)$ & $3-6(4)$ & $3-5(4)$ & $3-4(3)$ & - \\
\hline 6 & $10-17(13)$ & 1 & $4-5(4)$ & $1-3(2)$ & $8-20(8)$ & $13-28(19)$ & $11-15(15)$ & $2-3(3)$ & $2-3(3)$ & $3-7(3)$ & $4-9(5)$ & $1-S$ & $4-9(5)$ \\
\hline 7 & $12-18(15)$ & $22-30$ & $2-3(3)$ & $16-31()$ & $9-17()$ & $11-24(17)$ & $3-7(6)$ & $4-7(5)$ & $3-8(4)$ & $2-3(3)$ & $2-5(3)$ & $2-S$ & $5-8(8)$ \\
\hline 8 & $1-2(2)$ & $19-28(28)$ & $19-35(24)$ & $10-26()$ & - & $2-4(2)$ & $1-3(2)$ & $2-3(2)$ & $2-4(3)$ & $2-4(3)$ & $3-6(5)$ & $6-S$ & $2-5(3)$ \\
\hline 9 & $1-6(2)$ & 1 & 1 & $1-2(1)$ & $3-7(5)$ & $5-10(8)$ & $5-8(7)$ & $5-7(5)$ & $4-7(5)$ & $5-9(6)$ & $5-8(6)$ & $7-S$ & $1-2(1)$ \\
\hline 10 & $1-2(1)$ & $1-2(1)$ & $1-2(1)$ & 1 & 1 & $2-3(3)$ & 1 & $1-2(1)$ & $1-2(1)$ & $1-4(4)$ & $1-9(7)$ & 8-S & $2-6(4)$ \\
\hline 11 & $17-29(27)$ & 1 & 1 & 1 & $2-4(3)$ & 1 & $2-4(3)$ & $2-4(3)$ & $1-3(3)$ & $2-4(3)$ & $2-3(2)$ & 9-S & $3-6(3)$ \\
\hline 12 & $1-2(2)$ & $1-3(1)$ & 1 & $2-4(2)$ & $2-4(3)$ & 1 & $2-3(3)$ & $2-3(3)$ & $2-4(3)$ & $1-4(1)$ & $1-2(1)$ & - & - \\
\hline 13 & $3-6(3)$ & $3-6(5)$ & $4-9(7)$ & $2-3(3)$ & $3-8(5)$ & $3-7(5)$ & $3-6(4)$ & $3-4(3)$ & $3-4(3)$ & $6-12(9)$ & $2-3(2)$ & - & - \\
\hline 14 & $3-5(5)$ & $7-12(8)$ & $6-12(9)$ & - & - & - & - & 1 & 1 & 1 & 1 & 1 & - \\
\hline 15 & $5-8(6)$ & - & - & - & - & - & - & - & - & - & - & - & - \\
\hline
\end{tabular}

n.c. $=$ not counted

Cx. lasiopalpis Sirivanakarn, and Ur. bicolor. Immatures were also found in ground pools in association with Ae. krombeini, Ve. pseudomediofasciata, Ar. subalbatus, and Cx. fuscocephala (Amerasinghe 1982).

Adults were collected in Kandy, Central Province of Sri Lanka, a small forest bordering a city situated in the central hills of the country at elevation of $518 \mathrm{~m}$ above sea level. The vegetation consisted of tall trees with dense undergrowth. Larval habitats were muddy water in car tracks, tire marks and similar depressions on an infrequently used gravel road. The water was clean except for a few fallen leaves, and it was heavily shaded. Additionally, immatures were found in association with several other culicine species but were the only anopheline larvae encountered throughout the rainy season. However, when the drought was approaching, immatures of An. mirans declined in numbers (Mendis et al. 1984).

Wild-caught females of An. mirans, collected in a small locality in the foothills of the eastern Nilgiris were found infected with sporozoites and oocysts of P. cynomolgi Mayer and $P$. inui Halberstaedter and von Prowazek (Choudhury et al. 1963a). Additionally, this species was incriminated as a natural vector of simian malaria parasites in Sri Lanka where adults were found naturally infected with sporozoites of $P$. inui shortli Bray and P. fragile Dissanaike, Nelson and Garnham (NELSON et al. 1971). In another study carried out under laboratory conditions, females of An. mirans were infected with $P$. cynomolgi and $P$. inui when fed on monkeys, however infection of Macaca radiata (Geoffroy) by these mosquitoes was not attempted (Choudhury et al. 1963b).

Systematics. Anopheles mirans has, for the most part, been misindentified as An. elegans since Cogill (1903). Anopheles mirans belongs to the Hackeri Subgroup based on the proboscis being noticeably longer than the forefemur (Sallum et al. 2005). Adult females can be recognized by the following combination of characters: 1) proboscis longer than forefemur, ratio between proboscis length and forefemur length 1.19-1.31; 2) proboscis longer than maxillary palpus, ratio between palpus length and proboscis length $0.84-0.93 ; 3$ ) proboscis entirely dark-scaled; 4) PSD spot of vein R without pale interruptions; 5) number of pale interruptions on PSD-PD spots of vein $R$ always $2 ; 5$ ) ratio of length of apical pale band of palpomere 5 to the length of basal dark band of palpomere $5,0.83-2.67 ; 6$ ) apical pale band of hindtibia with a continuous dark longitudinal stripe extending into the basal portion. Fourthinstar larva: 1) 3-C single; 2) seta 1-II not fully developed, distinct from 1-III-VI; 3) seta 5-C conspicuously longer than antenna; 4) basal tubercle of seta 1-P with prominent tooth or spine on posterodorsal margin; 5) seta 4-C long, extending noticeably beyond base of 2-C, ratio of length of 4-C to distance between insertions of 2-C and 4-C 1.05-2.12; 6) seta 1-II poorly developed with 10-17 very narrow leaflets; 7) ratio of length of seta 13-IV to 10-IV 0.80-1.14 (mean $=0.93)$; 8) seta 13-IV,V with 3,4 branches; 9) seta 2-VII with 6-10 branches; 10) seta 9-VII with 5-8 branches. The pupal stage of An. mirans cannot be distinguished from those of other members of the Hackeri Subgroup.

\section{Anopheles (Cellia) pujutensis Colless}

(Figs. 5, 7, 8, 35, 36, 49, 51, 52, 58)

Anopheles leucosphyrus pujutensis Colless (1948:101) (F*, M*, L). Holotype female with associated larval and pupal exuviae deposited in CSIRO, Canberra, Australia.

Anopheles leucosphyrus of Roper (1914:137) (bionomics, in part). Anopheles leucosphyrus var. hackeri of Edwards (1921:69) (taxonomic notes, in part).

Anopheles leucosphyrus var. pujutensis of Reid (1949:44) (F, identification key, taxonomic notes, distribution); Mcarthur (1950b:399) (bionomics notes); Bonne-Wepster \& Swellengrebel (1953:259) (F*, M*, L*, identification key, bionomics, distribution).

Anopheles pujutensis of Senevet \& Andarelli $(1955: 112,335)$ (L); 
Colless (1956b:72) (F*, M, $\mathrm{P}^{*}, \mathrm{~L}^{*}$, identification key, distribution, elevated to species); Chow (1961:WHO/MAL/290) (F identification key, distribution); Reid \& Weitz (1961:180) (simian malaria, bionomics); Warren \& Wharton (1963:892) (simian malaria, bionomics); Wharton et al. (1964:56) (simian malaria, bionomics); Peyton \& Scanlon 1966:7, 35) (F*, identification key); Scanlon et al. (1967:78) (taxonomic, bionomics notes), (1968a:26) (checklist); Reid (1968:303) (F*, M, P*, L*, identification key, distribution); Reid et al. (1952:23) (bionomics notes); Rattanarithikul \& Harrison (1973:13) (L, identification key, Thailand); Tsukamoto et al. (1987:291) (checklist); Peyton (1989:197) (taxonomy).

Female (Figs. 5, 7, 8). Head: proboscis dark-scaled with apical pale band basal to labella, length 2.33-2.93 $\mathrm{mm}$ (mean = $2.58 \mathrm{~mm})$, ratio of length to forefemur 1.29-1.45 $($ mean $=1.35)$, maxillary palpus (Fig. 7) length $1.92-2.58 \mathrm{~mm}($ mean $=2.11 \mathrm{~mm})$, ratio of length to proboscis $0.76-0.88$ (mean $=0.82)$, ratio of length to forefemur 1.06-1.18 $($ mean $=1.11)$, ratio of length of palpomeres 3/4 1.47-1.86 $($ mean $=1.67)($ Table 2.2), 3/5 2.17$2.73($ mean $=2.44), 4 / 51.25-1.64($ mean $=1.46), 4-5 / 3$ 0.92-1.12 $(\mathrm{mean}=1.01)$, palpomeres $2-4$ with narrow apical silvery white bands, white band of palpomere 4 larger than those on palpomeres 2,3, pale scales on palpomere 5 white to pale cream, length of apical pale band of palpomere 5 0.67-4.00 (mean = 1.50 ) length of basal dark band of palpomere 5 , ratio of length of apical pale band of palpomere 4 to length of basal dark band of palpomere $50.10-1.00($ mean $=0.51)($ Table 3$)$. Thorax: pleural setae as follows: 1-4 upper proepisternal, 0-2 prespiracular, 46 prealar, 3-6 upper mesokatepisternal, 2,3 lower mesokatepisternal, 4-6 upper mesepimeral. Wing (Fig. 5): length 3.04-3.67 $\mathrm{mm}($ mean $=3.35 \mathrm{~mm})$, pale scales on all veins light cream-colored, PHP, HP, PSP, and SP spots of vein C slightly paler not strongly contrasting with others, PHP spot frequently present and prominent, occasionally reduced or absent, HP, PSP, SP spots always present, ASP spot present, occasionally absent on vein C, PP spot 0.61-1.64 (mean $=1.00)$ length of SCP spot, AD spot 1.11-2.70 (mean = 1.75) length of PP spot, PSD spot of vein R extending basally usually to level 1 and level 2 on one or both wings, rarely to level 3 on one wing (Table 4), PSD spot of vein R without pale interruption (Table 5), SD spot of vein $R$ with 1-3 pale interruptions (Table 6), sum of pale interruptions on PSD-PD spots of vein R 1-6 for each wing, ratio of length of cell $R_{2}$ to vein $R_{2+3} 1.28-1.92$ (mean = 1.61), ratio of length of cell $\mathrm{R}_{2}$ to cell $\mathrm{M}_{1+2} 1.20-1.44$ (mean = 1.27). Legs (Fig. 8): femora, tibiae, and tarsomeres dark-scaled with pale spots; foretarsomeres 2,3 with conspicuous basal and apical pale bands, middle dark area of foretarsomere 2 with 1,2 pale spots or entirely dark, foretarsomere 4 with basal and apical pale bands, apical pale bands sometimes absent, foretarsomere 5 usually with basal and apical pale bands, basal pale band rarely absent, foretarsomeres 4,5 occasionally entirely pale-scaled, foretarsomeres $2-5$ pale-scaled along ventral surface, basal, and apical pale bands not noticeably on ventral surface; midtarsomeres 2-5 with apical pale spot on dorsal surface, midtarsomeres 4,5 occasionally with basal pale spots on dorsal surface, dark middle area of midtarsomere 2 entirely dark or with 1-3 pale spots, midtarsomeres 2-5 dark- scaled along ventral surface; hindtarsomeres 2-4 with apical pale bands, hindtarsomere 5 usually pale-scaled at apex, occasionally entirely dark. Abdomen: tergum VI without scales, tergum VII usually without scales, occasionally with 2-4 pale cream-colored scales posteriorly, tergum VIII covered with narrow, elongate, pale golden scales posteromedially; sternum VI without scales, sternum VII with posteromedial patch of dark scales, sternum VIII with basolateral patches of whitish scales.

Male. Essentially as in female except for sexual characters. Wing generally paler with reduced scaling, pale spots usually longer than in female. Palpomere 2 with dorsal patch of pale scales at middle, apex of palpomere 2 bare, palpomere 3 with long dorsal patch of pale scales at middle, apex with broad band of pale scales covering dorsal, lateral, and ventral surfaces except for small ventrolateral patch of dark scales at apex, palpomeres 4,5 mainly pale-scaled with basal dark band. Abdomen: sternum VIII covered with pale cream-colored scales. Genitalia: 4 parabasal spines; ventral clapette with 1 long apicolateral seta, as long as club of dorsal claspette, 1 short slender apicomedial seta, and 2 short slender subapical setae; dorsal claspette with 4 apical setae fused into stout club with distinct basal stems; aedeagus elongate, columnar, dorsally curved with about 7 leaflets on each side of tip, leaflets serrated on one or both edges.

Pupa (Fig. 35). Position and development of setae as figured; range and modal number of branches in Table 33. All measurements from 15-18 specimens. In general similar to $A n$. mirans, except for the following characters. Cephalothorax: seta 10-CT with 2-6 branches. Seta 9-III-VIII pigmented light to medium brown, 9-V-VIII, slightly darker at base. Abdomen: seta 1-II with $15-30$ branches, 9 -II length $0.008-0.010 \mathrm{~mm}$ (mean $=0.010 \mathrm{~mm}), 10,11-\mathrm{II}$ absent; 1 -III with $5-11$ branches, 9-III length $0.01-0.02 \mathrm{~mm}$ (mean $=0.01 \mathrm{~mm}$ ); 9-IV length $0.01-0.03$ $\mathrm{mm}($ mean $=0.02 \mathrm{~mm})$, ratios of length of 9-IV/9-III 1.00-1.67 $(\mathrm{mean}=1.22)$ and $9-\mathrm{IV} / 9-\mathrm{V} 0.16-0.53($ mean $=0.27) ; 9-\mathrm{V}$ length $0.03-0.09 \mathrm{~mm}$ (mean $=0.07 \mathrm{~mm}$ ); 9-VI length $0.06-0.10 \mathrm{~mm}$ (mean $=0.09 \mathrm{~mm}) ; 9-\mathrm{VII}$ length $0.07-0.11 \mathrm{~mm}($ mean $=0.09 \mathrm{~mm}) ; 9-\mathrm{VIII}$ with 10-17 branches. Paddle: toothed margin index 0.78-0.89 (mean $=0.83$ ), paddle teeth similar to that of An. mirans however more developed.

Larva (Figs. 35, 36, 49, 51, 52). Position and development of setae as figured; range and modal number of branches in Table 34. All measurements from 12-26 specimens unless otherwise indicated. In general similar to An. mirans, except for the following characters. Head: integument light brown to yellowish without pattern of dark spots; length $0.61-0.70 \mathrm{~mm}$ $($ mean $=0.65 \mathrm{~mm})(\mathrm{n}=5)$, width $0.66-0.69 \mathrm{~mm}($ mean $=0.67 \mathrm{~mm})$ $(\mathrm{n}=5)$; antenna length $0.24-0.31 \mathrm{~mm}$ ( mean $=0.27 \mathrm{~mm})$, ratio of distance base to 1-A to antenna length $0.28-0.44($ mean $=0.37)$, seta 2-C with sparse spicules on apical 0.5 ; 3-C length 0.05 $0.07 \mathrm{~mm}$ (mean $=0.06 \mathrm{~mm}$ ), distance between base of 2-C and 3-C 0.03-0.04 mm (mean $=0.03 \mathrm{~mm}$ ), 4-C single, length 0.04-0.07 $\mathrm{mm}($ mean $=0.05 \mathrm{~mm})$, not reaching base of 2-C, distance between basal insertions of 2-C and 4-C 0.07-0.10 mm (mean = $0.08 \mathrm{~mm}$ ), ratio of length of $4-\mathrm{C}$ to distance between insertions 
of 2-C and 4-C 0.46-0.75 (mean $=0.63$ ), distance between base of 3-C and 4-C 0.06-0.09 $\mathrm{mm}$ (mean $=0.08 \mathrm{~mm}$ ). Thorax: seta 1,2-P less developed than those of An. mirans, tubercle of seta 1-P partially joined basally to tubercle of 2,3-P by posterodorsal bridge, tubercle of seta 1,2-P without, or with very small, pointed apical tooth projecting forward over base of seta, 14-P with 4,5 branches; 3-T (Fig. 52) somewhat palmate, with 6-8 narrow, lanceolate, nearly transparent leaflets. Abdomen: seta 1-I small, somewhat palmate, with 3-9 slender branches arising from basal stem; 1-II (Fig. 51) moderately developed, palmate, with 10-14 narrow, lanceolate, nearly transparent leaflets; ratio of length of 13-IV to 10-IV 0.27-0.50 (mean=0.39); apical filament of seta 1-VII stronger than that of An. mirans; 11-14 pecten spines, 4,5 long spines, alternating with 7-10 short spines (Fig. 49).

Type data. Holotype female with larval and pupal exuviae associated, collected in Pujut, northern Sarawak, Borneo, Malaysia. The type is deposited in CSIRO, Canberra, Australia.

Material examined. One hundred seventeen specimens, as follows: 47F, 32M, 8Le, 10Pe, 14L derived from 62 separate collections from natural habitats (31 adults, 31 immatures). INDONESIA. No localities, no dates, probably Kalimantan and Sumatra, [collection numbers: 1299, 12-97, 13-02, 13-03, 13-05, 13-16, 13-56], 5F, 2M (Bonne-

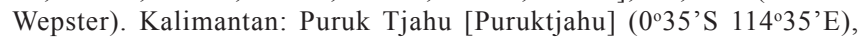

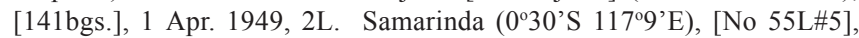
4 Feb. 1975, 1L. Tarakan ( $3^{\circ} 18^{\prime}$ 'S $\left.117^{\circ} 38^{\prime} \mathrm{E}\right)$, 5 June 1945, 1F, 3M. Balikpapan ( $1^{\circ} 17^{\prime}$ S $\left.116^{\circ} 30^{\prime} \mathrm{E}\right)$, [13-11, 13-12, 13-13], no dates, 3M (Bonne-Wepster). Sumatra Island: Djambi Moearatebo [Muaratebo] (1'30'S 102 $\left.26^{\circ} \mathrm{E}\right)$, [13-17], $1 \mathrm{M}$; [13-06], 1M; [13-07], 1M (BonneWepster). Oostkust [East Coast], Medan ( $3^{\circ} 35^{\prime} \mathrm{N}$ 98 $\left.8^{\circ} 40^{\prime} \mathrm{E}\right),[12-94$, 12-95], no dates, 2F, [both on same pin], (Bonne-Wepster). Palembang ( $2^{\circ} 55^{\prime}$ S $\left.104^{\circ} 45^{\prime} \mathrm{E}\right), 19$ Mar. 1927, 2L. Selatan, Baturaja [Baturaja]Martapura (4 $\left.{ }^{\circ} 8^{\prime} \mathrm{S} 104^{\circ} 22^{\prime} \mathrm{E}-4^{\circ} 19^{\prime} \mathrm{S} 104^{\circ} 22^{\prime} \mathrm{E}\right), 29$ Oct. 1977, $1 \mathrm{~F}$.

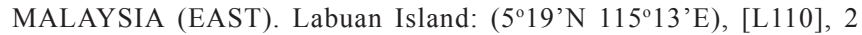
June 1950, 1L; [L110F], 6 Feb. 1950, 1LePe; Jan. 1950, 1LePe; June 1950, 1F, 1M, (D.H. Colless). Sabah: Beaufort Forest Reserve $\left(5^{\circ} 20^{\prime} \mathrm{N}\right.$ $115^{\circ} 45^{\prime}$ E), [S-322], 2 Apr. 1970, 1L. Kemabong, Tenom $\left(5^{\circ} 8^{\prime} \mathrm{N}\right.$ 11557'E), [S-433], 8 Apr. 1970, 4L (S. Ramalingam). Membakut or Nawao $\left(5^{\circ} 28^{\prime} \mathrm{N} 115^{\circ} 47^{\prime} \mathrm{E}\right), 4$ Oct. 1913, 3F; 15 July 1913, $1 \mathrm{M}$ (R. Roper). Tambunan $\left(5^{\circ} 40^{\prime} \mathrm{N} 116^{\circ} 22^{\prime} \mathrm{E}\right), 1949,3 \mathrm{~F}, 1 \mathrm{M}$. Tawau $\left(4^{\circ} 15^{\prime} \mathrm{N}\right.$
11754'E), [B60/17], Feb. 1960, 1F, 3M (D.H. Colless coll., J.A. Reid det. as An. balabacensis). Sarawak: Limbang $\left(4^{\circ} 45^{\prime} \mathrm{N} 115^{\circ} 0^{\prime} \mathrm{E}\right)$, Dec. 1951, 1F (D.H. Colless). Pujut $\left(4^{\circ} 25^{\prime} \mathrm{N} 114^{\circ} 1^{\prime} \mathrm{E}\right)$, [B47, B48], Aug. 1945, 2F, 2M (paratypes) (D.H. Colless). MALAYSIA (WEST). Malaya or Malay Peninsula, no dates, 2L. Federated Malay States (Mal. Bur.), [440C.1], no date, 1M. Johore: Sungai Sedeli $\left(2^{\circ} 2^{\prime} \mathrm{N} 103^{\circ} 48^{\prime} \mathrm{E}\right)$, June

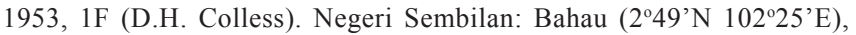
[228], 21 Aug. 1946, 1F (R.D. Rajamoney); [228, probably same coll.), 18 Jan 1946, 2F, 1M (J.A. Reid det as An. leucosphyrus ). Kampong Nuri, Kuala Pilah $\left(2^{\circ} 33^{\prime} \mathrm{N} 102^{\circ} 15^{\prime} \mathrm{E}\right),[404 / 1,2]$, 1949, 2F, 1LePe.

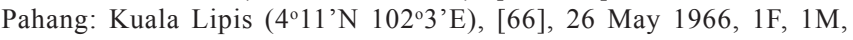
$1 \mathrm{LePe}, 1 \mathrm{Pe}$; [682], 29 Apr. 1967, 1F. Kuantan, Kampong Lamir $\left(3^{\circ} 31^{\prime} \mathrm{N} 102^{\circ} 43^{\prime} \mathrm{E}\right)$, [1773], 11 Sept. 1968, 1F. Pulau Jerejak [Jerijak], [236U], 19 Jan. 1922, 1F, 1L (W.A. Lamborn coll, B.A.R. Gater det. as An. leucosphyrus var. hackeri). Merapoh (442'N 102 ${ }^{\circ}$ 'E), [643], 22 Apr. 1967, 2F. Perak: Klah (35'N 101²0’E), [7536], 6 Apr. 1934, 1F, 1M, 2LePe (E.P. Hodgkin coll., J.A. Reid det as An. leucosphyrus var. pujutensis); [7601], 15 Apr. 1934, 1M (E.P. Hodgkin), [7601/7], 1LePe (J.A. Reid det. as An. riparis). Sauk Padi (4¹9'N $\left.100^{\circ} 56^{\prime} \mathrm{E}\right)$, [30], 2 Oct. 1964, 1M; [34], 21 Oct. 1964, 1F. (USAMRU). Selangor: [243], 31 Oct. 1946, 1F (P.D. Rajamoney). Ampang ( $3^{\circ} 9^{\prime} \mathrm{N}$ 101ํ6'E), [332A2], 7 Feb. 1922, 1M (W.A. Lamborn, B.A.R. Gater det.). B1 Cares (?) Estate, [907/4], 8 Feb. 1935, 1M (E.P. Hodgkin). Kampong Sementa ( $\left.3^{\circ} 0^{\prime} \mathrm{N} 101^{\circ} 23^{\prime} E\right), 2$ Aug. 1946, 1F. Klang [Kelang]: $\left(3^{\circ} 2^{\prime} \mathrm{N} 101^{\circ} 27^{\prime} \mathrm{E}\right),[16756], 8$ Aug. 1946, 3F, 3M (E.P. Hodgkin, J.A. Reid det. as An. leucosphyrus var.). Puchong Road ( $3^{\circ} 0$ 'N 101'37'E), [61], 17 Jan. 1926, 1F. Rantau Panjang (323'N 101'29'E), [450/3], 8 Feb. 1951, 1M; [457/3], 26 Oct. 1951, 1M; 13 Nov. 1951, 1F; 2 Jan. 1952, 1F (All, J.A. Reid det.). Terengganu: Kuala Brang [Berang] (5²'N $\left.103^{\circ} 1^{\prime} \mathrm{E}\right), 3$ Oct. $1970,1 \mathrm{M} ; 7$ Oct. 1970, 1F; 9 Oct. 1970, 1F; 26 June 1972, 1F (R.G. Andre, USAMRU). THAILAND. Narathiwat: Waeng (5'56'N 101 $\left.{ }^{\circ} 54^{\prime} \mathrm{E}\right)$, [NV97], 2 Mar. 1965, 2F, 1LePe, 1Pe (J.E. Scanlon).

Distribution (Fig. 58). Anopheles pujutensis is known from Indonesia (Kalimantan, Sumatra Island), East Malaysia (Labuan Island, Sabah, Sarawak), West Malaysia (Johore, Negeri Sembilan, Pahang, Perak, Selangor, Klang [Kelang], Terengganu), and Thailand (Narathiwat).

Bionomics and medical importance. Anopheles pujutensis was found from the coastal zone to the lower hills in Malaya and Borneo (Reid 1968), and along the costal mangrove region

Table 33. Number of branches for setae of the pupa of An. pujutensis: range (mode).

\begin{tabular}{|c|c|c|c|c|c|c|c|c|c|c|c|}
\hline \multicolumn{2}{|c|}{ Seta Cephalothorax } & \multicolumn{9}{|c|}{ Abdominal segments } & \multirow{2}{*}{$\begin{array}{c}\text { Paddle } \\
\mathrm{Pa}\end{array}$} \\
\hline No. & $\mathrm{CT}$ & $\mathrm{I}$ & II & III & IV & $\mathrm{V}$ & VI & VII & VIII & IX & \\
\hline 0 & - & - & 1 & 1 & 1 & 1 & 1 & 1 & 1 & - & - \\
\hline 1 & $1-3(2)$ & n.c. & $15-30(15)$ & $5-11(6)$ & $3-7(4)$ & $2-4(2)$ & $1-3(2)$ & $1-3(2)$ & - & 1 & 1 \\
\hline 2 & 2 & $4-10(6)$ & $5-6(5)$ & $5-8(5)$ & $3-5(3)$ & $3-5(4)$ & $3-4(3)$ & $3-5(3)$ & - & - & $1-2(1)$ \\
\hline 3 & $1-3(2)$ & $1-2(1)$ & $2-3(3)$ & $2-3(2)$ & $5-7(6)$ & $1-3(2)$ & $1-3(1)$ & $2-4(3)$ & - & - & - \\
\hline 4 & $2-3(2)$ & $3-6(5)$ & $3-6(5)$ & $3-6(4)$ & $3-5(4)$ & $4-6(5)$ & $1-3(2)$ & $1-3(2)$ & $1-2(2)$ & - & - \\
\hline 5 & $4-6(5)$ & $2-4(2)$ & $2-4(3)$ & $5-8(7)$ & $4-6(5)$ & $4-5(5)$ & $4-6(5)$ & $5-6(5)$ & - & - & - \\
\hline 6 & $1-3(2)$ & $1-2(2)$ & $1-2(2)$ & $1-2(2)$ & $1-2(1)$ & 1 & 1 & $1-2(1)$ & - & - & - \\
\hline 7 & $2-4(3)$ & $2-4(3)$ & $2-4(3)$ & $3-5(4)$ & $2-5(4)$ & $2-4(3)$ & $1-2(1)$ & $1-2(1)$ & - & - & - \\
\hline 8 & $1-3(2)$ & - & - & $1-4(3)$ & $1-4(3)$ & $1-3(2)$ & $1-3(2)$ & $1-3(2)$ & - & - & - \\
\hline 9 & $1-3(1)$ & 1 & 1 & $6-9(6)$ & $7-15(8)$ & 1 & 1 & 1 & $10-17(15)$ & - & - \\
\hline 10 & $2-6(2)$ & - & - & $2-3(3)$ & $1-2(1)$ & $1-2(2)$ & $1-2(2)$ & $1-3(2)$ & - & - & - \\
\hline 11 & $1-3(3)$ & - & - & 1 & 1 & 1 & 1 & $1-3(2)$ & - & - & - \\
\hline 12 & $1-3(2)$ & - & - & - & - & - & - & - & - & - & - \\
\hline 13 & - & - & - & - & - & - & - & - & - & - & - \\
\hline 14 & - & - & - & - & 1 & 1 & 1 & 1 & 1 & - & - \\
\hline
\end{tabular}

n.c. $=$ not counted 
Table 34. Number of branches for setae of the larva of An. pujutensis: range (mode).

\begin{tabular}{|c|c|c|c|c|c|c|c|c|c|c|c|c|c|}
\hline \multirow{2}{*}{$\begin{array}{l}\text { Seta } \\
\text { No. }\end{array}$} & \multirow{2}{*}{$\begin{array}{c}\text { Head } \\
\text { C }\end{array}$} & \multicolumn{3}{|c|}{ Thorax } & \multicolumn{9}{|c|}{ Abdominal segments } \\
\hline & & $\mathrm{P}$ & M & $\mathrm{T}$ & $\mathrm{I}$ & II & III & $\mathrm{IV}$ & V & $\mathrm{VI}$ & VII & VIII & $\mathrm{X}$ \\
\hline 0 & 1 & 1 & - & - & - & 1 & 1 & 1 & 1 & 1 & 1 & 1 & - \\
\hline 1 & 1 & $10-17(13)$ & $24-34(25)$ & $1-3(2)$ & $3-9(6)$ & $10-14(11)$ & $17-22(19)$ & $17-23(19)$ & $15-21(17)$ & $16-18(18)$ & $10-14(13)$ & $1-2(1)$ & 1 \\
\hline 2 & 1 & $9-12(10)$ & $1-4(2)$ & 1 & $1-3(2)$ & $5-7(6)$ & $4-6(5)$ & $3-4(4)$ & $3-6(4)$ & $4-6(5)$ & $4-7(6)$ & $5-8(7) 1$ & $14-20(19)$ \\
\hline 3 & 1 & 1 & 1 & $6-8(6)$ & $1-2(1)$ & 1 & 1 & $2-3(2)$ & 1 & 1 & $3-4(3)$ & $7-10(7)$ & $8-9(8)$ \\
\hline 4 & 1 & $13-17(15)$ & 2 & $3-5(4)$ & $4-6(6)$ & $5-9(6)$ & $3-5(3)$ & $3-4(3)$ & $3-4(3)$ & 1 & 1 & 1 & $6-9(7)$ \\
\hline 5 & $7-12(10)$ & n.c. & 1 & $24-38(31)$ & $2-3(3)$ & $3-6(4)$ & $3-6(3)$ & $3-5(3)$ & $3-4(3)$ & $3-6(5)$ & $3-7(5)$ & $4-5(5)$ & - \\
\hline 6 & $11-14(11)$ & 1 & 3 & $2-3(2)$ & $14-21(16)$ & $20-29(22)$ & $16-18(17)$ & $2-3(2)$ & $2-3(2)$ & $2-3(3)$ & $2-5(4)$ & $1-\mathrm{S}$ & $3-5(4)$ \\
\hline 7 & $11-14(12)$ & $14-29(20)$ & $2-3(2)$ & $26-29(27)$ & $13-18(13)$ & $20-23(23)$ & $4-7(5)$ & $4-6(5)$ & $3-5(5)$ & $2-3(2)$ & $3-4(3)$ & $2-S$ & $5-7(6)$ \\
\hline 8 & $1-2(1)$ & $22-32(25)$ & $20-30$ & $26-30$ & - & $1-3(2)$ & $1-3(2)$ & $2-4(2)$ & $2-4(2)$ & $2-3(3)$ & $3-5(5)$ & $6-S$ & $2-3(2)$ \\
\hline 9 & $1-3(2)$ & 1 & 1 & 1 & $3-4(3)$ & $5-9(5)$ & $5-8(7)$ & $5-10(8)$ & $5-9(8)$ & $5-9(7)$ & $3-6(4)$ & $7-S$ & 1-2(1) \\
\hline 10 & $1-2(2)$ & 1 & 1 & 1 & 1 & $2-4(3)$ & 1 & 1 & 1 & $3-4(3)$ & $4-6(6)$ & $8-\mathrm{S}$ & $2-3(3)$ \\
\hline 11 & $22-32(26)$ & 1 & 1 & 1 & 3 & 1 & $3-5(4)$ & $3-5(3)$ & $2-4(3)$ & $3-5(3)$ & $2-3(2)$ & 9-S & $2-4(3)$ \\
\hline 12 & $1-3(2)$ & 1 & 1 & $2-3(2)$ & $2-3(3)$ & 1 & $2-5(3)$ & $3-4(3)$ & $3-5(3)$ & 1 & 1 & - & - \\
\hline 13 & $4-6(5)$ & $3-5(5)$ & $4-7(5)$ & $2-3(3)$ & $4-5(5)$ & $3-5(5)$ & $4-6(5)$ & $4-6(4)$ & $3-4(3)$ & $5-7(6)$ & $2-3(3)$ & - & - \\
\hline 14 & $4-6(6)$ & $4-5(4)$ & $5-8(6)$ & - & - & - & - & 1 & 1 & 1 & 1 & 1 & - \\
\hline 15 & $6-7(6)$ & - & - & - & - & - & - & - & - & - & - & - & - \\
\hline
\end{tabular}

n.c. $=$ not counted

in the peninsular Malaysia (Warren \& Wharton 1963). Adults were found at or below ground level together with An. hackeri, An. kochi Dönitz, and An. lesteri de Meillon, resting in dark cavities between the old leaf bases of nipah palms (Nipa fruticans) (Reid et al. 1952; Reid \& Weitz 1961). Adults were attracted to monkey traps on the ground and on a platform 4.5 $\mathrm{m}$ above ground level (Reid et al. 1952). Adults feed preferentially on monkeys in the canopy of both mangrove and lowland swamp forests but are seldom attracted to humans and domestic animals at ground level (Wharton et al. 1964; Warren \& Wharton 1963). It is suspected to be vector of simian malaria parasites on the coastal mangrove zone and also in the lowland swamp forests of Malaysia (Warren \& Wharton 1963) since adults were found infected with Plasmodium parasites presumed to be from monkeys (Reid \& Weitz 1961).

Colless (1948) found immatures of An. pujutensis in ground pools in an open environment under light to medium shade, and in small shallow ground pools (Reid 1949; Reid et al. 1952; Reid \& Weitz 1961). In collections carried out in Selangor, Malaya, An. hackeri and An. pujutensis were found associated with the brackish water zone (Bonne-Wepster \& Swellengrebel 1953). In Thailand, immatures were taken from ground pools in forests located in mountainous areas. The water was fresh, stagnant, clear or turbid, and in partial shade. Immatures were found in association with An. introlatus, An. latens, An. macarthuri, and Ur. bicolor. In field collections carried out in west Malaysia, immatures were found in deep pools with grassy edges and floating vegetation, in ground pools with Nipa and leaves, ground pools between Nipa fronds, hoofprints, seepage pools in rock with decaying leaves, slow moving streams with decaying leaves, grass, muddy pools, truck trail pools, wooden wells, buffalo hoofprints, drains with grass and algae along road sides, rock pools next to rivers, artificial containers, and pools in drains with decaying leaves at the bases of Nipa palms. The immature habitats were situated in mountainous rain forest areas, in rubber plantations, or in coconut plantations at elevations of 30-60 m above sea level. The water was fresh, stagnant, colored or clear, in partial shade, and sometimes with decaying leaves. Immatures were found in association with Ae. caecus, Ae. albopictus (Skuse), An. insulaeflorum Swellengrebel and Swellengrebel de Graaf, An. maculatus, Cx. traubi Colless, Cx. reidi Colless, Cx. fuscanus Wiedemann, $C x$. minor (Leicester), Cx. quinquefasciatus (Say), Cx. mimulus, Cx. nigropunctatus Edwards, Cx. brevipalpis (Giles), Cx. fragilis Ludlow, Cx. scanloni Bram, Ur. bicolor, Ur. macfarlanei Edwards, and Armigeres spp.

In East Malaysia, immatures were collected in pools along streams, stream margin and wheel tracks. The water was fresh, slowly moving or stagnant, always clear, and in partial shade. The larval habitats were situated in rain forests, rubber plantations, and in villages in hilly areas at elevations of 150$250 \mathrm{~m}$ above sea level. Immatures were found in association with Ae. albolineatus (Theobald), An. bengalensis Puri, $C x$. malayi (Leicester), Cx. quadripalpis (Edwards), and $C x$. mimulus.

Systematics. Adults of An. pujutensis are recognized by possessing the following combination of characters: 1) proboscis longer than forefemur, ratio of proboscis length to forefemur length $1.29-1.45 ; 2$ ) proboscis longer than maxillary palpus, ratio of maxillary palpus length to proboscis length $0.76-0.88 ; 3$ ) proboscis with pale scales at apex basal to labella; 4) PSD spot of vein R without pale interruption; 5) apical pale band of hinditibia without longitudinal extension of dark scales; 6) PSD-PD spots of vein R with 1-6 pale interruptions; 7) SD spot of vein $R$ with 1-3 pale interruptions; 8) PD spot of vein $R$ with 1-3 pale interruptions; 9) apical pale band of palpomere 5 conspicuous, ratio of apical pale band and basal dark band of palpomere 5 varying from $0.67-4.00$. Fourth-instar larva: 1) seta 3-C single; 2) seta 1-II not fully developed, distinct from 1-IIIVI; 3) seta 5-C conspicuosly longer than antenna; 4) basal 
sclerotized tubercle of seta 1-P without prominent tooth or spine on posterodorsal margin, occasionally with very small pointed apical tooth projecting over base of seta; 5) basal sclerotized tubercle of seta 1,2-P partially joined basally to tubercle of 2,3-P by posterodorsal bridge; 6 ) seta 3-T with 6-8 branches; 7) seta 4-C short, never reaching base of 2-C, ratio of length of 4-C to distance between 2-C and 4-C 0.46-0.75; 8) length of seta 13-IV equal to or less than 0.5 length of 10-IV. Based on morphological characters of the pupa, An. pujutensis cannot be distinguished from other members of the Hackeri Subgroup, except from An. hackeri and An. recens.

\section{Anopheles (Cellia) hackeri Edwards}

(Figs. 5, 7, 8, 37, 38, 49, 51-53, 58)

Anopheles leucosphyrus var. hackeri Edwards (1921:70) (F). Holotype female, deposited in the NHM.

Anopheles leucosphyrus Type 2 of Stanton (1915b:169) (L*); Hacker (1921:33).

Anopheles leucosphyrus var. hackeri of Christophers (1924:72, 103) (type information, identification key), (1933:177, 181) (type information, systematics notes); Gater \& Rajamoney (1929:10, 25) (larval bionomics); Haga (1930:363) (identification key, F, M, L); Swellengrebel \& Rodenwaldt (1932:194) (F*, M*, L*); Dunnewold (1934:170) (L*); King \& Baisas (1936:88) (taxonomic notes, identification key); Russell et al. (1943:116) (identification key, distribution, bionomics notes); Taylor (1944:44) (A*, L*, distribution, bionomics, identification key); Puri (1949:489) (distribution, bionomics notes, F, identification key); Reid (1949:44) (F, identification key, taxonomic notes, type information); Stoker \& Koesoemawinangoen (1949:46) (taxonomic, bionomics notes); McArthur (1950b:399) (bionomics notes); Van Hell (1952:45) (distribution).

Anopheles hackeri of Gater (1933:39) (elevated to species); Gater (1934:118) (L*), (1935:188) (F*, M*, identification key, taxonomic notes); Hodgkin (1945:13) (identification key); Sandosham (1945:165) (taxonomic, bionomics notes); Reid et al. (1952:23) (bionomics notes, blood feeding precipitin test); BonneWepster \& Swellengrebel (1953:259) (M*, F*, L*, identification key, distribution, bionomics notes); Senevet \& Andarelli (1955:112, 335) (L); Colless (1956b:78) (F*, M, P*, L*, E, distribution, elevated to species); Sandosham (1959:184); MacDonald \& Traub (1960:79) (bionomics notes); Chow (1961:WHO/MAL/290) (identification key, distribution); Reid \& Weitz (1961:180) (bionomics); Wharton \& Eyles (1961:279) (Plasmodium knowlesi infection); Warren \& Wharton (1963:892) (bionomics); Wharton et al. (1963b:32) (bionomics), (1964:56) (vector competence, simian Plasmodium); Peyton \& Scanlon (1966:7, 34) (F*, identification key); Scanlon et al. (1967:78) (taxonomic, bionomics notes); Reid (1968:300) (F*, $\mathrm{P}^{*}, \mathrm{~L}^{*}$, distribution, bionomics); Scanlon et al. (1968a:21) (checklist); Rattanarithikul \& Harrison (1973:13) (L, identification key, Thailand); Tsukamoto et al. (1985:149) (checklist), (1987:291) (checklist); Abu Hassan et al. (1997:109) (distribution).

Myzomyia leucosphyrus of Daniels (1908:4) (bionomics, bamboo); Leicester (1908b:28) (F, M, in part).

Female (Figs. 5, 7, 8). Head: proboscis dark-scaled with narrow pale ring at apex basal to labella, length $2.25-2.83 \mathrm{~mm}$ (mean $=2.53 \mathrm{~mm}$ ), ratio of length to forefemur 1.22-1.38 (mean $=1.31$ ), maxillary palpus (Fig. 7) length 1.69-2.02 $\mathrm{mm}$ (mean = $1.90 \mathrm{~mm}$ ), ratio of length to proboscis $0.72-0.81($ mean $=0.75)$, ratio of length to forefemur 0.93-1.04 $($ mean $=0.98)($ Table 2.2 $)$, ratio of length of palpomeres 3/4 1.62-2.08 $($ mean $=1.71), 3 / 5$
2.60-3.37 $($ mean $=2.87), 4 / 51.33-2.00($ mean $=1.63), 4-5 / 30.81$ $0.96($ mean $=0.92)$, palpomeres $2-4$ with narrow apical silverywhite bands of similar size, palpomere 5 variable, entirely darkscaled or sometimes with silvery-white scales at apex, length of apical pale band of palpomere $50.00-0.50($ mean $=0.16)$ length of basal dark band of palpomere 5, ratio of length of apical pale band of palpomere 4 to length of basal dark band of palpomere $50.12-0.40($ mean $=0.23)($ Table 3$)$. Thorax: pleural setae as follow: 2-6 upper proepisternal, 1-4 prespiracular, 5-8 prealar, 3,4 upper mesokatepisternal, 1,2 lower mesokatepisternal, 2-4 upper mesepimeral. Wing (Fig. 5): length $2.88-4.23 \mathrm{~mm}(\mathrm{mean}=3.64 \mathrm{~mm})$, pale cream scales, slightly contrasting with white scales of remaining pale spots, PHP spot of vein $\mathrm{C}$ variable, absent, small, or prominent, HP present, small to prominent, PSP usually present and prominent, rarely absent, SP always present, prominent, ASP always absent, PP spot 0.50-1.50 (mean = 1.04) length of SCP spot, AD spot 1.715.00 (mean $=2.65$ ) length of PP spot, PSD spot of vein $\mathrm{R}$ extending basally from level 1 to level 4 in one or both veins (Table 4), PSD spot of vein R entirely dark-scaled (Table 5), SD spot of vein $R$ with 1 pale interruption (Table 6), 2 pale interruptions on PSD-PD spots of vein R, ratio of length of cell $R_{2}$ to vein $R_{2+3} 1.46-1.95$ (mean $=1.70$ ), ratio of length of cell $R_{2}$ to cell $\mathrm{M}_{1+2}$ 1.18-1.49 (mean=1.32). Legs (Fig. 8): femora, tibia, and tarsomeres dark-scaled, speckled with pale spots, foretarsomeres 2,3 with conspicuous basal and apical pale bands, middle dark area of foretarsomere 2 entirely dark-scaled, or rarely with 1,2 pale spots on dorsal surface, foretarsomere 3 without pale spots on middle dark area, foretarsomere 4 with basal and apical bands, apical pale band rarely absent, apical, and basal pale bands of foretarsomeres 2-4 not evident on ventral surface, foretarsomere 5 without basal pale band, rarely with trace of pale scales, apical pale band always present, rarely reduced or with trace of pale cream-colored scales; midtarsomeres 2-4 mainly dark-scaled, midtarsomere 2 rarely with 1 pale spots on middle dark area, midtarsomeres 3,4 with inconspicuous patches of pale scales at apex on dorsal surface, midtarsomere 5 with faint apical pale band; hindtarsomeres 24 with apical pale band, basal pale bands absent on hindtarsomeres 2,3 , hindtarsomere 4 variable, with or without basal band of pale scales, hindtarsomere 5 usually pale scaled at apex, rarely entirely dark-scaled or with basal pale band. Abdomen: terga VI,VII without scales, tergum VIII with posterior patch of yellowish scales, sometimes with dark scales laterally; sternum VI without scales, sternum VII usually without scales, occasionally with 2,3 scales posteriorly, sternum VIII with lateral patches of pale scales.

Male (Fig. 7). Essentially as in female except for sexual characters. Wing generally paler with reduced scaling, pale spots usually longer than in female. ASP spot usually absent but occasionally present. Proboscis (Fig. 7) with pale scales on dorsal surface. Palpomere 2 with dorsal patch of pale scales at middle, apex of palpomere 2 bare; palpomere 3 with long dorsal patch of pale scales at middle, apex of palpomere 3 with broad band of pale scales covering dorsal, lateral and ventral surfaces except for small ventrolateral patch of dark scales at 
apex; palpomere 4 mainly pale-scaled with basal dark band, palpomere 5 mainly pale-scaled with basal dark band, occasionally extending along ventral surface. Abdomen: sternum VIII covered with pale cream-colored scales. Genitalia: 4 large parabasal setae; ventral clapette with 1 long apicolateral seta, equivalent in length to club of dorsal claspette, 1 short slender apicomedial seta, and 1 short slender subapical seta; dorsal claspette with 4 apical setae fused into stout club with distinct basal stem; aedeagus elongate, columnar, dorsally curved with about 4-6 leaflets on each side of apex, leaflets serrated on one or both edges.

Pupa (Fig. 37). Position and development of setae as figured; range and modal number of branches in Table 35. All measurements from 20-24 specimens. In general as described for An. mirans except for the following characters. Cephalothorax: seta 4-CT usually triple, 8-CT single to 5branched, 10-CT single to 7-branched, 12-CT with 2-5 branches. Seta 9-III-VIII pigmented light to medium brown, 9V-VIII slightly darker at base. Abdomen: seta 1-II with 10-23 branches, 9-II length 0.007-0.013 $\mathrm{mm}$ (mean $=0.01 \mathrm{~mm}$ ), 10-II usually absent, occasionally present, with 2 branches; 1-III with 7-15 branches, 5-III with 5-15 branches, 9-III length 0.01$0.02 \mathrm{~mm}$ (mean $=0.02 \mathrm{~mm}$ ); 1 -IV with 3-8 branches, 5-IV with 510 branches, 6-IV always single, 9-IV length $0.02-0.03 \mathrm{~mm}$ (mean $=0.02 \mathrm{~mm})$, ratios of length of 9-IV/9-III 1.00-1.75 $($ mean $=1.28)$ and 9-IV/9-V 0.12-0.23 (mean $=0.17) ; 1-\mathrm{V}$ with 2-7 branches, 5$\mathrm{V}$ with $6-8$ branches, $9-\mathrm{V}$ without spicules, rarely bifid at apex, length $0.11-0.16 \mathrm{~mm}$ (mean $=0.14 \mathrm{~mm})$; 1 -VI with 2-6 branches, 5-VI with 5-9 branches, 6-VI single or double, 9-VI without spicules, rarely bifid at apex, length $0.12-0.17 \mathrm{~mm}$ ( mean $=0.15$ $\mathrm{mm}$ ); 9-VII without spicules, rarely forked at apex, length 0.12$0.17 \mathrm{~mm}$ (mean $=0.15 \mathrm{~mm}$ ); 9-VIII with $11-17$ branches. Paddle: seta 1-Pa pigmented light brown, 2-Pa single to 4-branched, toothed margin index 0.71-0.85 $($ mean $=0.79)$.

Larva (Figs. 37, 38, 49, 51-53). Position and development of setae as figured; range and modal number of branches in Table 36. All measurements from 18-36 specimens unless otherwise indicated. Head: pattern of dark spots similar to that of $A n$. mirans except for presence of dark, faint area on lateralia along frontal ecdysial line and absence of dark spot on hypostomal ecdysial line; length $0.64-0.74 \mathrm{~mm}($ mean $=0.71 \mathrm{~mm})(\mathrm{n}=8)$, width $0.68-0.76 \mathrm{~mm}$ (mean $=0.73 \mathrm{~mm})(\mathrm{n}=8)$; apical 0.25 of antenna more dark pigmented, length $0.27-0.33 \mathrm{~mm}(0.30 \mathrm{~mm})$, ratio of distance base to 1-A to antenna length 0.31-0.49 (mean $=0.38) ; 3-\mathrm{C}$ length $0.13-0.18 \mathrm{~mm}($ mean $=0.14 \mathrm{~mm})$, distance between base of 2-C and 3-C 0.03-0.04 mm (mean $=0.04 \mathrm{~mm}$ ), 4$\mathrm{C}$ length $0.12-0.21 \mathrm{~mm}($ mean $=0.16 \mathrm{~mm})$, distance between basal insertions of 2-C and 4-C 0.06-0.09 $\mathrm{mm}$ (mean $=0.07 \mathrm{~mm}$ ), ratio of length of 4-C to distance between the insertion of 2-C and 4-C 1.54-3.12 (mean $=2.30)$, distance between base of 3-C and $4-\mathrm{C} 0.05-0.08 \mathrm{~mm}$ (mean $=0.06 \mathrm{~mm}$ ), $5-\mathrm{C}$ with $12-16$ branches, 6-C with 14-19 branches, 7-C with 14-23 branches. Thorax: tubercles of all large seta light brown to yellowish; seta 1-P 1632 branched with short, flattened, well expanded stem, arising from large tubercle smaller than tubercle of 2-P, tubercle of 1-P entirely separate from tubercles of 2,3-P (Fig. 53), both tubercles without apical tooth or spine, 14-P with 4-8 branches; 3-T (Fig. 52) moderately developed, palmate, with 7-14 narrow lanceolate nearly transparent leaflets. Abdomen: seta 1-I poorly to moderately developed, palmate, with 3-8 narrow lanceolate, nearly transparent leaflets, 9-I with 3-5 branches; 1-II (Fig. 51) palmate, fully developed, similar in development to seta 1-III, with 18-27 leaflets; 3-IV with 2-5 branches, 13-IV single to triple, long, ratio of length to 10-IV 1.07-1.49 (mean $=1.25) ; 2$ V single to 4-branched; 1-VII with 13-19 leaflets; 1-X always single; $12-15$ pecten spines, 5-12 long spines alternating with 3-9 short spines (Fig. 49).

Type data. Holotype female, collected in Perak River mouth (?), West Malaysia, collected by H.P. Hacker, deposited in the NHM.

Material examined. Two hundred seventeen specimens, as follows: 75F, 40M, 29Le, 44Pe, 29L, derived from 42 collections from natural habitats (15 adult, 27 immature). MALAYSIA (EAST). Sabah: Tambunan $\left(5^{\circ} 40^{\prime} \mathrm{N} 116^{\circ} 22^{\circ} \mathrm{E}\right), 6 / 50,1 \mathrm{~F}, 2 \mathrm{Le}, 4 \mathrm{Pe}$ (on 2 slides), (D.H.

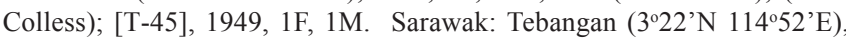
6/53, 1F, 1M (D.H. Colless). MALAYSIA (WEST). Malaya, 1F, holotype, (H.P. Hacker); no date, 2F, 1M; Federal Malaya States, no date, 25F, 4M. Federated Malay States, no date, 1F (G.F. Leicester). Kelantan: Ayer Lanas (5'20'N 10200'E), 12 June 1972, 2F (R.G. Andre). Pahang: Gunong Benom ( $\left.3^{\circ} 50^{\prime} \mathrm{N} 102^{\circ} 06^{\prime} \mathrm{E}\right)$, [505], 21 Mar. 1967, 1F; [536], 28 Mar. 1967, 2F, 3M, 1LePe, 2Pe, 1L. (U. Malaya). Selangor: [17], 19 Apr. 1934, 1F, (slide mounted wing only, labeled "Figured by Gater 1934" as leucosphyrus var. hackeri). Pahang Road, 12 Aug. 1903, 1F (G.F. Leicester). Klang ( $3^{\circ} 00^{\prime}$ N $101^{\circ} 23^{\prime}$ 'E), [7628], 19 Apr. 1934, 3F, 3M (F.P. Hodgkin). Bukit Lanjan ( $\left.3^{\circ} 11^{\prime} \mathrm{N} 101^{\circ} 36^{\prime} \mathrm{E}\right)$, 12 Mar., 1970, 1M (RG Andre). Ulu Gombak ( $\left.3^{\circ} 18^{\prime} \mathrm{N} 101^{\circ} 47^{\prime} \mathrm{E}\right)$, [1698], 24 Aug. 1968, 1F, 1LePe. (U. Malaya). Kuala Lumpur, 5 3/4 miles from) $\left(3^{\circ} 10^{\prime} \mathrm{N} 101^{\circ} 15^{\prime} \mathrm{E}\right), 31$ Mar. 1903, 1F; Sept. 1903, 1F; 18 Mar. 1903, 1F; 19 Feb. 1903, 2M; 24 Apr. 1903, 1F; 21 Feb. 1903, 1M; 2 Sept. 1903, 1M (G.F. Leicester). Rantau Panjang ( $\left.2^{\circ} 53^{\prime} \mathrm{N} 101^{\circ} 29^{\prime} \mathrm{E}\right), 4$ June 1954, 2F, 2M; 13 Nov. 1954, 2F, 2M; 24 Apr. 1952, 2F (J.A. Reid); [42], 1F; [47], 20 Dec. 1965, 1M; [552], 6 Apr., 1967, 1F, 1M, 2LePe, 1L; [554], 6 Apr. 1967, 1L; [1083], 23 Mar.?? 1967, 2F, 1M. $1 \mathrm{LePe}, 1 \mathrm{Pe}, 1 \mathrm{~L}$. (U. Malaya); [00.032], 3 June 1965, 1F, 1M (USAMRU); [385], 5 May 1949, 1M (J.A. Reid). PHILIPPINE ISLANDS. Balabac: Cape Melville ( $7^{\circ} 49^{\prime} \mathrm{N} 117^{\circ} 1$ 'E), [1625], 24 June 1945, 1L. Palawan: (Central, 9³0’N 118³0’E), 11 Nov. 1981, 2M;

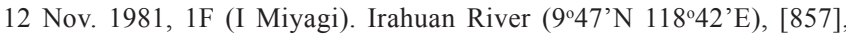
4 June 1945, 2F, 2LePe; [882], 11 June 1945, 2F, 2LePe. THAILAND. Phattalung: Kilometer 30 Trang to Phattalung Road ( $7^{\circ} 30^{\prime} \mathrm{N}$ 99 $\left.55^{\prime} \mathrm{E}\right)$, [PU-18], 1F, 1Pe, 1L. Nakhon Si Thammarat: Ban Thuan Lek $\left(8^{\circ} 26^{\prime} \mathrm{N}\right.$ 994ㄱ'E), [01146], 15 June 1966, 1M, 1Pe, 1L. Narathiwat: Waeng,

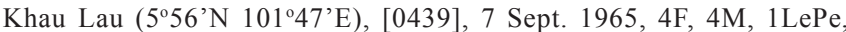
7Pe, 3L. Songkhla: Ton Nga Chang Waterfall $\left(6^{\circ} 47^{\prime} \mathrm{N} 100^{\circ} 15^{\prime} \mathrm{E}\right)$, [SL65], 25 Mar. 1965, 8F, 7M, 15LePe, 1Pe, 8L. Yala: Yalabong $\left(6^{\circ} 16^{\prime} \mathrm{N}\right.$ $\left.101^{\circ} 22^{\prime} \mathrm{E}\right),[0507], 15$ Sept. 1965, 8L; [0509], 15 Sept. 1965, 1M, 2LePe; [0513], 15 Sept. 1965, 3L (all, AFRIMS).

Distribution (Fig. 58). Anopheles hackeri is known from East Malaysia (Sabah, Sarawak), West Malaysia (Kelantan, Pahang, Selangor), Philippine Islands (Balabac, Palawan), Thailand (Phattalung, Nakhon Si Thammarat, Narathiwat, Songkhla, Yala).

Bionomics and medical importance. Immatures of $A n$. hackeri were found in breeding places inside the jungle, in dead, hollow, and split bamboos (Gater \& Rajamoney 1929; Gater 1934; Macdonald \& Traub 1960; Reid 1968), in muddy pools with grass and decayed leaves, grassy drains, and artificial containers (Gater \& Rajamoney 1929). Immatures were 
Table 35. Number of branches for seta of the pupa of An. hackeri: range (mode).

\begin{tabular}{|c|c|c|c|c|c|c|c|c|c|c|c|}
\hline \multicolumn{2}{|c|}{ Seta Cephalothorax } & \multicolumn{9}{|c|}{ Abdominal segments } & \multirow{2}{*}{$\begin{array}{c}\text { Paddle } \\
\mathrm{Pa}\end{array}$} \\
\hline No. & $\mathrm{CT}$ & $\mathrm{I}$ & II & III & IV & $\mathrm{V}$ & VI & VII & VIII & IX & \\
\hline 0 & - & - & 1 & 1 & 1 & 1 & 1 & 1 & 1 & - & - \\
\hline 1 & $2-3(2)$ & n.c. & $10-23(17)$ & $7-15(12)$ & $3-8(7)$ & $2-7(3)$ & $2-6(3)$ & $1-3(1)$ & - & 1 & $1,2(1)$ \\
\hline 2 & $2-3(2)$ & $3-10(7)$ & $4-8(5)$ & 4-7 (6) & $2-8(4)$ & $1-5(3)$ & $1-5(3)$ & $2,3(3)$ & - & - & $1-4(1)$ \\
\hline 3 & 2 & $1-3(1)$ & $1-5(3)$ & $2-6(3)$ & $3-11(6)$ & $2-5(3)$ & $1-4(3)$ & $2-5(4)$ & - & - & - \\
\hline 4 & $2-3(3)$ & $3-7(7)$ & $2-10(5)$ & $1-7(3)$ & $2-6(5)$ & $2-6(4)$ & $1-3(2)$ & $1-3(2)$ & $1-3(2)$ & - & - \\
\hline 5 & $4-9(5)$ & $2,3(3)$ & $2,3(2)$ & $5-15(10)$ & $5-10(6)$ & $6-8(6)$ & $5-9(7)$ & $3-8(7)$ & - & - & - \\
\hline 6 & $1-3(2)$ & $1-3(2)$ & $1,2(2)$ & $1-3(2)$ & 1 & 1 & 1,2 (1) & 1,2 (1) & - & - & - \\
\hline 7 & $1-4(3)$ & $3-6(3)$ & $3-6(4)$ & $1-5(3)$ & $2-4(2)$ & $1-5(3)$ & 1,2 (2) & 1,2 (1) & - & - & - \\
\hline 8 & $1-5(2)$ & - & - & $2-4(3)$ & $1-4(3)$ & $2-4(3)$ & $1-4(2)$ & $2-4(3)$ & - & - & - \\
\hline 9 & $1-3(2)$ & 1 & 1 & 1 & 1 & 1 & 1 & 1 & $11-17(11)$ & - & - \\
\hline 10 & $1-7(2)$ & - & $0-2$ & $2,3(2)$ & $1,2(2)$ & $1-3(2)$ & $1-3(2)$ & $1-4(2)$ & - & - & - \\
\hline 11 & $1-5(2)$ & - & - & - & 1 & $1-2(1)$ & 1,2 (1) & $1-3(2)$ & - & - & - \\
\hline 12 & $2-5(2)$ & - & - & - & - & - & - & - & - & - & - \\
\hline 13 & - & - & - & - & - & - & - & - & - & - & - \\
\hline 14 & - & - & - & - & 1 & 1 & 1 & 1 & 1 & - & - \\
\hline
\end{tabular}

n.c. $=$ not counted

found less often in pools on logs (Reid 1968), tree holes (Dunnewold 1934), Nipa swamps (Gater 1935), Nipa swamps in brackish water zones (Bonne-Wepster \& Swellengrebel 1953), and collections of rain water at ground level in old leaf bases of Nipa palms (Reid et al. 1952; Wharton et al. 1964; Reid 1968). In West Malaysia, immatures were also collected in fallen tree trunks and small ground pools. The breeding habitats were in mangroves and in rain forests in mountainous or plains areas. The water was fresh or brackish, stagnant, colored, and in partial shade. They were found in association with Ae. fumidus Edwards, An. introlatus, Cx. obscurus (Leicester), Cx. halifaxii, Cx. papuensis, Ae. amesii (Ludlow), An. sinensis Wiedemann, Armigeres jugraensis (Leicester), $C x$. bicornutus Theobald, Cx. ganapathi Colless, $C x$. mammilifer (Leicester), Cx. fragilis (Ludlow), Cx. spathifurca (Edwards), Cx. scanloni Bram, and Cx. minor (Leicester). In Thailand, immatures were found in pools enclosed in tree roots, tree trunks, fallen tree trunks, and elephant footprints. The water was fresh, stagnant, colored or turbid, in full sun, partial shade, or heavy shade; sometimes the habitats were covered with leaves and sticks. The breeding habitats were in primary or secondary rain forests, in mountainous areas varying from 76 to $183 \mathrm{~m}$ above sea level. Immatures were found in association with Ae. orbitae, Oc. macfarlanei Edwards, Oc. pallirastris (Edwards), Oc. harveyi (Barraud), An. montanus Stanton and Hacker, An. introlatus, An. macarthuri, An. sintonoides Ho, An. nemophilous, Cx. scanloni, $C x$. papuensis, and Cx. halifaxii. In Palawan and Balabac, Philippine Islands, immatures were found in densely shaded coconut husks and in large metal lined boxes in association with immatures of An. hackeri and An. balabacensis. The breeding habitats were inland and on the coast in hilly forests (Reid 1968).

Adults were found resting during the day on the base of Nipa palms and close to houses but apparently they do not bite humans and domestic animals (Reid et al. 1952; Wharton
\& Eyles 1961; Wharton et al. 1964; Reid 1968). They were also collected using monkey traps on the ground and on a platform $4.5 \mathrm{~m}$ above ground (Reid et al. 1952). They fed predominantly on monkeys (Reid \& Weitz 1961) and prefer to feed in the canopy of mangrove forests (Wharton \& Eyles 1961; Wharton et al. 1964). Adults were also caught on human-baited net trap at ground level (Wharton \& Eyles 1961). Anopheles hackeri is involved in the transmission of monkey malaria parasites in areas where Nipa palms are cultivated above tidal level, and was identified as an important vector of monkey malaria on the coastal mangrove zone of peninsular Malaysia. Plasmodium inui, $P$. knowlesi, P. coatneyi, P. fieldi, and $P$. cynomolgi were isolated from specimens of An. hackeri (Wharton \& Eyles 1961; Wharton et al. 1964). Abu Hassan et al. (1997) used cow-baited traps to attract females of $A n$. hackeri and noted possible disappearance of the species in coastal areas of northern peninsular Malaysia. However, An. hackeri prefers to feed on monkeys (Reid \& Weitz 1961; Wharton \& Eyles 1961; Wharton et al. 1964), the absence of the species in the traps can be a result of the kind of animal (cow) used to attract females.

Systematics. Anopheles hackeri can be distinguished from those of other members of the Hackeri Subgroup in having the following combination of characters. Adults: 1) proboscis longer than forefemur, ratio of proboscis length to forefemur length $1.22-1.38 ; 2$ ) proboscis longer than maxillary palpus, ratio of palpus length to proboscis length $0.72-0.81 ; 3$ ) proboscis dark with narrow pale apical ring basal to labella; 4) PSD spot of vein R entirely dark-scaled; 5) SD spot of vein R with one pale interruption; 6) PD spot of vein $\mathrm{R}$ with one pale interruption; 7) number of pale interruptions on PSD-PD spots of vein R always $2 ; 8$ ) apical pale band of hinditibia either with or without narrow, dark, longitudinal extension on ventral surface, occasionally dark extension is short; 9) ratio of length of apical pale band to length of basal dark band of palpomere 5, 0.00-0.50. Fourth-instar larvae of An. hackeri can be easily 
Table 36. Number of branches for setae of the larva of An. hackeri: range (mode).

\begin{tabular}{|c|c|c|c|c|c|c|c|c|c|c|c|c|c|}
\hline \multirow{2}{*}{$\begin{array}{l}\text { Seta } \\
\text { No. }\end{array}$} & \multirow{2}{*}{$\begin{array}{l}\text { Head } \\
\text { C }\end{array}$} & \multicolumn{3}{|c|}{ Thorax } & \multicolumn{9}{|c|}{ Abdominal segments } \\
\hline & & $\mathrm{P}$ & M & $\mathrm{T}$ & I & II & III & IV & $\mathrm{V}$ & VI & VII & VIII & $\mathrm{X}$ \\
\hline$\overline{0}$ & 1 & 1 & - & - & - & 1 & 1 & 1 & 1 & 1 & 1 & 1 & - \\
\hline 1 & 1 & $16-32(21)$ & $24-41(35)$ & $1-4(2)$ & $3-8(5)$ & $18-27(22)$ & $17-26(20)$ & $18-27(20)$ & $18-26(22)$ & $14-23(20)$ & $13-19(17)$ & $1-2(1)$ & 1 \\
\hline 2 & $1-2(1)$ & $13-34(18)$ & $1-5(1)$ & 1 & $1-3(1)$ & $4-6(5)$ & $4-7(5)$ & $2-5(3)$ & $1-4(3)$ & $2-6(3)$ & $3-6(6)$ & $4-6(4)$ & $16-20(16)$ \\
\hline 3 & 1 & 1 & $1-3(1)$ & $7-14(12)$ & $1-2(1)$ & 1 & 1 & $2-5(3)$ & 1 & $1-2(1)$ & $3-5(4)$ & $3-5(3)$ & $4-7(5)$ \\
\hline 4 & $1-2(1)$ & $15-24(18)$ & $1-2(2)$ & $1-4(3)$ & $3-7(6)$ & $3-9(6)$ & $2-7(3)$ & $1-4(3)$ & $2-5(3)$ & 1 & 1 & $1-2(1)$ & $9-10(9)$ \\
\hline 5 & $12-16(13)$ & $18-37(34)$ & $1-3(1)$ & $31-44(39)$ & $2-4(3)$ & $3-6(4)$ & $3-5(4)$ & $2-3(3)$ & $3-4(3)$ & $3-4(3)$ & $2-5(3)$ & 3 & - \\
\hline 6 & $14-19(15)$ & 1 & $3-7(4)$ & $1-2(2)$ & $12-24(18)$ & $18-31(30)$ & $13-28(15)$ & $1-3(2)$ & $1-2(2)$ & $2-3(3)$ & $2-4(3)$ & $1-S$ & $4-5(5)$ \\
\hline 7 & $14-23(19)$ & $21-30(30)$ & $1-4(3)$ & $23-39(35)$ & $10-210$ & $18-26(23)$ & $3-6(4)$ & $3-6(4)$ & $3-5(4)$ & $1-3(2)$ & $1-3(2)$ & $2-S$ & $2-5(3)$ \\
\hline 8 & $1-2(1)$ & $25-33(25)$ & $14-27(23)$ & $19-39(27)$ & - & $1-2(1)$ & $1-3(2)$ & $1-4(3)$ & $2-5(2)$ & $2-4(3)$ & $5-7(7)$ & 6-S & $1-5(2)$ \\
\hline 9 & $1-4(3)$ & $1-4(1)$ & $1-2(1)$ & $1-2(1)$ & $3-5(4)$ & $5-8(7)$ & $4-8(7)$ & $5-9(6)$ & $3-7(5)$ & $2-6(5)$ & $2-6(4)$ & 7-S & 1 \\
\hline 10 & $1-4(1)$ & $1-2(1)$ & 1 & 1 & 1 & $1-3(2)$ & 1 & 1 & 1 & $1-3(2)$ & $1-10(6)$ & 8-S & $1-2(2)$ \\
\hline 11 & $13-25(17)$ & 1 & 1 & 1 & $2-4(3)$ & 1 & $1-5(2)$ & $2-3(2)$ & $1-2(1)$ & $1-2(2)$ & $1-2(2)$ & 9-S & $2-4(3)$ \\
\hline 12 & $1-2(1)$ & $1-4(1)$ & 1 & $1-2(2)$ & $2-4(3)$ & 1 & $1-2(1)$ & $1-2(1)$ & $1-3(2)$ & $1-3(1)$ & $1-2(1)$ & - & - \\
\hline 13 & $2-5(4)$ & $3-5(3)$ & $4-7(4)$ & $1-3(2)$ & $4-7(5)$ & $2-6(3)$ & $2-6(2)$ & $1-3(2)$ & $1-3(2)$ & $5-12(6)$ & $1-3(3)$ & - & - \\
\hline 14 & $3-11(6)$ & $4-8(6)$ & $7-12(10)$ & - & - & - & - & 1 & 1 & 1 & 1 & 1 & - \\
\hline 15 & $2-7(4)$ & - & - & - & - & - & - & - & - & - & - & - & - \\
\hline
\end{tabular}

n.c. $=$ not counted

recognized in having seta 1-II fully developed, equal to or approximating 1-III-VI in development, individual leaflets with clearly differentiated apical filaments. Pupa: 1) ratio of length of seta 9-IV to length of seta 9-V 0.12-0.23 (mean =0.17);2) seta 9-V-VII long and narrow, without spicules; 3 ) seta $1-\mathrm{VI}$ with 2-6 branches; 4) seta 9-VII long, length 0.12-0.17 mm (mean $=0.15 \mathrm{~mm}$ ).

\section{Anopheles (Cellia) recens Sallum \& Peyton}

(Figs. 5, 6p, 7, 8, 39, 40, 51, 52, 58)

Anopheles recens Sallum \& Peyton (2005) (F, M, P*, L*). Holotype female with associated larval and pupal exuviae on microscope slide, deposited in the NMNH.

Anopheles leucosphyrus Sumatra species of Peyton (1989:197) (taxonomy).

Female (Figs. 5, 6p, 7, 8). Head: proboscis uniformly darkscaled or with long ventral patch of pale scales on apical 0.2 of ventral surface, length $2.28-2.68 \mathrm{~mm}$ (mean $=2.50 \mathrm{~mm}$ ), ratio of length to forefemur length 1.16-1.30 (mean $=1.21)$, maxillary palpus (Fig. 7) length $1.80-2.33 \mathrm{~mm}($ mean $=2.10 \mathrm{~mm})$, ratio of length to proboscis length $0.79-0.86($ mean $=0.83)$, ratio of length to forefemur length $0.97-1.05($ mean $=1.01)($ Table 2.2$)$, ratio of length of palpomeres $3 / 4$ 1.67-2.54 (mean $=1.94), 3 / 5$ $2.50-3.62($ mean $=3.05), 4 / 51.22-2.12($ mean $=1.60), 4-5 / 30.70$ $1.00($ mean $=0.85)$, palpomeres $2-4$ with narrow apical pale cream-colored bands, pale scales on palpomere 5 almost yellowish, apical pale band of palpomere $50.00-1.00$ (mean = 0.5 ) length of basal dark band of palpomere 5 , ratio of length of apical pale band of palpomere 4 to length of basal dark band of palpomere $50.00-0.67$ (mean $=0.21)($ Table 3$)$. Thorax: pleural setae as follows: 2-5 upper proepisternal, 0-2 prespiracular, 59 prealar, 6,7 upper mesokatepisternal, 3-6 lower mesokatepisternal, 3-8 upper mesepimeral. Wing (Figs. 5, 6p): length $3.64-4.55 \mathrm{~mm}($ mean $=4.05 \mathrm{~mm})$, pale scales on all veins light cream-colored, spots on subcosta and SCP, PP and AP spots of vein $\mathrm{C}$ more obviously cream-colored nearly yellowish, HP spot present, prominent, PSP spot rarely absent, SP spot usually present, prominent, ASP spot absent on vein $\mathrm{C}$, PP spot 0.79-3.80 (mean = 1.31) length of SCP spot, AD spot 1.053.63 (mean $=2.58)$ length of PP spot, PSD spot of vein R extending basally from level 2 to level 4 on both wings (Table 4), PSD spot of vein R with 1-4 pale interruptions (Table 5), SD spot of vein R usually with 1,2 pale interruptions, rarely with 3 pale interruptions on both wings (Table 6), sum of pale interruptions on PSD-PD spots of vein R 3-8 for each wing; ratio of length of cell $\mathrm{R}_{2}$ to vein $\mathrm{R}_{2+3} 1.36-1.79$ (mean $=1.58$ ), ratio of length of cell $\mathrm{R}_{2}$ to cell $\mathrm{M}_{1+2} 1.27-1.48$ (mean = 1.36). Legs (Fig. 8): foretarsomeres 2,3 with short basal and apical bands of pale scales, foretarsomere 2 with 2-4 pale spots on middle of dorsal surface, foretarsomere 4 with indistinct basal and apical pale bands, usually without basal pale band, foretarsomere 5 with pale scales at apex or entirely dark-scaled, foretarsomeres 2-4 entirely dark-scaled on ventral surface; midtarsomeres 2-4 with small, apical patches of pale scales on dorsal surface, midtarsomeres 2,3 with 1-3 pale spots on middle dark area, dark-scaled ventrally, midtarsomere 5 entirely darkscaled; hindtarsomeres 2-4 with short apical pale bands, hindtarsomere 2 with 2-4 pale spots on median dark area, hindtarsomere 5 dark-scaled. Abdomen: tergum VI without scales, tergum VII with 2-4 dark scales on posterior margin, tergum VIII with patch of dark scales medially, few golden scales posterolaterally; sternum VI usually without scales, rarely with 2,3 posteromedial scales, sternum VII without scales or with posteromedial patch of dark scales, sternum VIII without scales, rarely with 2,3 anterolateral pale scales.

Male (Fig. 7). Essentially as in female except for sexual characters. Wing generally paler with reduced scaling, pale spots usually longer than in female. Proboscis (Fig. 7) darkscaled without ventral patch of pale scales; palpomere 2 with 
dorsal patch of pale scales at middle, apex of palpomere 2 bare, palpomere 3 with long dorsal patch of pale scales at middle extending laterally, sometimes reaching ventral surface, apex of palpomere 3 variable, with broad band of pale scales covering dorsal and lateral surfaces, with dorsal patch of pale scales, or entirely dark-scaled, palpomere 4 variable, pale-scaled with basal band of dark scales, less frequently with patch of dark scales on ventral and dorsal surfaces, palpomere 5 variable, pale-scaled with basal dark, or with basal dark band with extension along ventral surface not reaching apex of segment, or mostly dark-scaled with lateral patch of pale scales. Abdomen: sternum VIII covered with pale cream-colored to whitish scales. Genitalia: 4 large parabasal setae; ventral clapette with 1 long apicolateral seta, shorter than club of dorsal claspette, 2 short, slender apicomedial setae, and 1,2 subapical setae; dorsal claspette with 3,4 apical setae fused into stout club with distinct basal stems; aedeagus elongate, columnar, dorsally curved with about 7-9 leaflets on each side of tip, leaflets serrated in one or both edges.

Pupa (Fig. 39). Position and development of setae as figured; range and modal number of branches in Table 37. All measurements from 7-10 specimens. In general similar to $A n$. mirans except for the following characters. Cephalothorax: seta 9-CT single or double; seta 9-III lightly pigmented, 9-IVVII light to medium brown pigmented, slightly darker at base. Abdomen: seta 1-II dendritic, with 8-18 slender branches arising from a basal stem, 9-II length $0.01-0.02 \mathrm{~mm}$ (mean $=0.02$ $\mathrm{mm}$ ), 10,11-II absent; 6-III usually single, 9-III length 0.02-0.03 $\mathrm{mm}$ (mean $=0.02 \mathrm{~mm}$ ); 6-IV single, 9-IV long, without spicules, length $0.05-0.08 \mathrm{~mm}$ (mean $=0.06 \mathrm{~mm}$ ), ratios of length of 9-IV/ 9-III 1.92-3.26 $($ mean $=2.27)$ and 9-IV/9-V 0.326-0.762 $($ mean $=$ $0.44) ; 9-\mathrm{V}$ without spicules, length $0.11-0.14 \mathrm{~mm}$ (mean $=0.13$ $\mathrm{mm}) ; 9$-VI without spicules, length $0.12-0.15 \mathrm{~mm}$ (mean $=0.13$ $\mathrm{mm}$ ); 1-VII single, 9-VII without spicules, length $0.12-1.15 \mathrm{~mm}$ $($ mean $=0.14 \mathrm{~mm})$; 9-VIII with 6-13 branches. Paddle: 2-Pa single, toothed margin index 0.84-0.93 (mean $=0.89$ ).

Larva (Figs. 39, 40, 51, 52). Position and development of setae as figured; range and modal number of branches in Table 38. All measurements from 8-16 specimens unless otherwise indicated. In general similar to An. mirans except for the following characters. Head: similar to An. mirans except for the presence of 1 dark spot placed centrally on dorsal apoteme, posteriorly to seta $5,6-\mathrm{C}$; length $0.75-0.81 \mathrm{~mm}($ mean $=0.79$ $\mathrm{mm})(\mathrm{n}=5)$, width $0.73-0.83 \mathrm{~mm}($ mean $=0.76 \mathrm{~mm})(\mathrm{n}=5)$; antenna length $0.33-0.40 \mathrm{~mm}$ (mean $=0.3710 \mathrm{~mm})$, ratio of distance base to 1-A to antenna length 0.32-0.43 ( mean $=0.38$ ); seta 2-C usually without spicules, rarely with few, sparse, minute spicules, $3-\mathrm{C}$ length $0.11-0.15 \mathrm{~mm}$ (mean $=0.13 \mathrm{~mm}$ ), distance between base of 2-C and 3-C 0.04-0.06 $\mathrm{mm}$ (mean = $0.05 \mathrm{~mm}$ ), 4-C always single, length $0.18-0.17 \mathrm{~mm}$ (mean $=0.14$ $\mathrm{mm}$ ), extending beyond base of 2-C, distance between basal insertions of 2-C and 4-C 0.08-0.11 mm (mean $=0.09 \mathrm{~mm}$ ), ratio of length of 4-C to distance between the insertions of 2-C and 4-C 1.44-2.0 (mean = 1.68), distance between base of 3-C and 4$\mathrm{C} 0.05-0.08 \mathrm{~mm}($ mean $=0.07 \mathrm{~mm}), 5-\mathrm{C}$ shorter than antenna, not reaching anterior margin of head. Thorax: seta 14-P with 5-
9 branches; 14-M with 4-7 branches; 3-T (Fig. 52) somewhat palmate, with 3-6 narrow, lanceolate, nearly transparent leaflets. Abdomen: seta 1-I not palmate, with 3,4 slender branches arising from basal stem, 2,3-I always single, 9-I with 3,4 branches; 1-II (Fig. 51) poorly developed, more pigmented than 1-I, somewhat palmate, with narrow, lanceolate, nearly transparent leaflets arising from distinct level of a basal stem, basal stem narrow, moderately pigmented; 2-II somewhat palmate, with 5-8 narrow, lanceolate, nearly transparent leaflets arising from basal stem; 2-IV always triple, 13-IV single or double, ratio of length to 10-IV 0.91-1.24 (mean =1.11) $(\mathrm{n}=7)$; 14-17 pecten spines (Fig. 39), 5-8 long spines alternating with 6-11 short spines.

Type data. Holotype female with associated larval and pupal exuviae on microscope slide [IN-704-10], collected in Indonesia, Sumatra, Gunong Dempo (4'2'S $\left.103^{\circ} 9^{\prime} \mathrm{E}\right)$ by U. Malaya team, 5 Apr. 1978, deposited in the NMNH.

Material examined. Forty-four specimens were examined, as follows: $11 \mathrm{~F}, 12 \mathrm{M}, 7 \mathrm{Le}, 7 \mathrm{Pe}, 7 \mathrm{~L}$ derived from 2 separate collections from natural habitats (2 immature). INDONESIA. Sumatra: Gunong Dempo (42'S 1039'E), [IN704], 5 Apr. 1978, 9F, 11M, 7LePe, 5L; [IN705], 5 Apr. 1978, 2F, 1M, 2L. (U. Malaya).

Distribution (Fig. 58). Anopheles recens is known only from Indonesia, Sumatra.

Bionomics and medical importance. Nothing is known about the medical importance of An. recens or the involvement of this species in the transmission of parasites to humans and other animals. Immatures of An. recens were taken from temporary ground pools in cloud forests. The water was fresh, stagnant or slow moving, clear with or without emergent vegetation, and in partial shade or full sun. The larval habitats were located at elevations of $1,550 \mathrm{~m}$ above sea level.

Systematics. Anopheles recens was included in the Hackeri Subgroup (Peyton, 1989, as Elegans Group) by possessing the proboscis noticeably longer than the forefemur and the maxillary palpus shorter than the proboscis. Adults can be distinguished by the following characters: 1 ) proboscis longer than forefemur, ratio of proboscis length to forefemur length 1.16-1.30 (mean $=1.20) ; 2)$ proboscis longer than maxillary palpus, ratio of maxillary palpus length to proboscis length $0.79-0.86 ; 3)$ proboscis entirely dark-scaled or with ventral patch of pale scales on apical 0.2 ; 4 ) palpomere 5 entirely dark-scaled or with apical pale band, ratio of length of apical pale band to length of basal dark band 0.00-1.00 (mean $=0.50)$; 5) PSD spot of vein R extending from level 1 to level 4; 6) PSD spot of vein $\mathrm{R}$ with 1-4 pale interruptions; 7) number of pale interruptions on PSD-PD spots of vein R 3-8 for each wing; 8) SCP, PP and AP spots of vein C cream-colored, almost yellowish, strongly contrasting with other pale spots; 9) apical pale band of hindtibia entirely white-scaled or with a patch of dark scales on anterior surface; 10) tergum VIII with a patch of dark scales medially and few golden scales posterolaterally; 11) hindtarsomeres 2-5 without pale scales at base; 12) ASP spot absent from vein C. Fourth-instar larva: 1) seta 5-C conspicuously longer than antenna; 2) basal sclerotized 
Table 37. Number of branches for setae of pupae of An. recens: range (mode).

\begin{tabular}{|c|c|c|c|c|c|c|c|c|c|c|c|}
\hline \multicolumn{2}{|c|}{ Seta Cephalothorax } & \multicolumn{9}{|c|}{ Abdominal segments } & \multirow{2}{*}{$\begin{array}{c}\text { Paddle } \\
\mathrm{Pa}\end{array}$} \\
\hline No. & $\mathrm{CT}$ & I & II & III & IV & $\mathrm{V}$ & VI & VII & VIII & IX & \\
\hline$\overline{0}$ & - & - & 1 & 1 & 1 & 1 & 1 & 1 & 1 & - & - \\
\hline 1 & 2 & $9-16(12)$ & $8-18(12)$ & $3-5(4)$ & $2-4(3)$ & $1-2(2)$ & $1-2(1)$ & 1 & - & 1 & 1 \\
\hline 2 & 2 & $3-5(4)$ & $2-4(4)$ & $2-5(3)$ & $2-3(2)$ & $1-2(2)$ & $1-2(2)$ & $2-3(2)$ & - & - & 1 \\
\hline 3 & 2 & 1 & $1-2(2)$ & $1-3(2)$ & $2-5(4)$ & $1-2(2)$ & $1-2(2)$ & $2-3(3)$ & - & - & - \\
\hline 4 & $1-2(2)$ & $2-4(3)$ & $2-4(2)$ & $2-4(3)$ & $2-4(3)$ & $2-4(3)$ & $1-2(2)$ & $1-2(2)$ & $1-2(1)$ & - & - \\
\hline 5 & $3-5(4)$ & $2-5(3)$ & $2-4(2)$ & $5-8(6)$ & $4-5(4)$ & $4-6(4)$ & $3-5(4)$ & $4-6(4)$ & - & - & - \\
\hline 6 & $1-2(1)$ & $1-2(1)$ & $1-2(1)$ & $1-2(1)$ & 1 & 1 & 1 & 1 & - & - & - \\
\hline 7 & $2-4(2)$ & $2-4(3)$ & $2-3(3)$ & $1-3(2)$ & $2-3(2)$ & $2-3(2)$ & $1-2(1)$ & 1 & - & - & - \\
\hline 8 & $1-3(2)$ & - & - & $2-3(3)$ & $1-3(2)$ & $1-3(2)$ & $2-3(2)$ & $1-2(2)$ & - & - & - \\
\hline 9 & $1-2(2)$ & 1 & 1 & 1 & 1 & 1 & 1 & 1 & $6-13(7)$ & - & - \\
\hline 10 & $2-3(2)$ & - & - & $2-3(2)$ & $1-2(1)$ & $1-2(1)$ & $1-2(2)$ & $1-2(2)$ & - & - & - \\
\hline 11 & $1-4(2)$ & - & - & 1 & 1 & 1 & 1 & $1-2(1)$ & - & - & - \\
\hline 12 & $2-3(2)$ & - & - & - & - & - & - & - & - & - & - \\
\hline 13 & - & - & - & - & - & - & - & - & - & - & - \\
\hline 14 & - & - & - & - & 1 & 1 & 1 & 1 & 1 & - & - \\
\hline
\end{tabular}

n.c. $=$ not counted

tubercles of setae 1,2-P with prominent tooth or spine projecting from posterodorsal margin forward over base of each seta; 3) seta 3-C single, long, extending beyond anterior margin of head; 4) seta 4-C always extending noticeably beyond base of 2-C, ratio of length of 4-C to distance between the insertions of 2-C and 4-C 1.44-2.0; 5) seta 1-II distinctly less developed than 1-III-VI, with 5-8 translucent or very lightly pigmented narrow leaflets, leaflet stem not inflated; 6) seta 13IV single or double, about length of 10-IV, ratio of length of 13IV to 10 -IV never less than 0.80 ; 7) seta $13-V$ double; 8 ) seta 2VII with 4-6 branches; 9) seta 9-VII with 3,4 branches.

\section{Anopheles (Cellia) sulawesi Koesoemawinangoen} (Figs. 5, 7, 8, 41, 42, 52, 58)

Anopheles leucosphyrus var. Sulawesi Koesoemawinangoen (1954:63) (F, key). Neotype female with associated larval and pupal exuviae on microscope slide, deposited in the NMNH. NEOTYPE HERE DESIGNATED.

Anopheles leucosphyrus var. hackeri of Swellengrebel \& Rodenwaldt (1932:195) (F, in part, Celebes and probably Sangihe and Talaud Islands); Colless (1948:104) (A, taxonomy); Reid (1949:45) (identification notes, in part, Celebes specimens); McArthur (1951:683) (Celebes); Van Hell (1952:45) (distribution, biology).

Anopheles leucosphyrus var. hackeri, Celebes form, of Reid (1949:45) (A, taxonomy); Bonne-Wepster \& Swellengrebel (1953:297) (A*, taxonomy); Colless (1956b:81) (F*, taxonomy); Chow (1961) (taxonomic notes).

Anopheles sulawesi of Reid (1968:303) ( $\mathrm{F}^{*}$, elevated to species status); Knight \& Stone (1977:54) (catalog); Hii et al. (1988a:41) (A*, $\mathrm{P}^{*}, \mathrm{~L}^{*}$, distribution, bionomics, authorship); Peyton (1989:197) (taxonomy).

Neomyzomyia leucosphyra of Swellengrebel \& Swellengrebel De Graaf (1920b:91) (in part, Celebes); Brug \& Haga (1923:635) (Celebes, Madjene).

Female (Figs. 5, 7, 8). Head: proboscis dark-scaled with narrow ring of pale scales at apex, basal to labella, pale scales sometimes not evident on dorsal side, length $2.28-3.04 \mathrm{~mm}$ $($ mean $=2.53 \mathrm{~mm})$, ratio of length to forefemur 1.23-1.30 (mean
$=1.25)($ Table 2.2), maxillary palpus (Fig. 7) length $1.62-2.38 \mathrm{~mm}$ (mean $=1.97 \mathrm{~mm}$ ), ratio of length to forefemur 0.88-1.06 (mean $=0.97)$, ratio of length of palpomeres $3 / 4$ 1.58-2.18 (mean $=$ $1.86), 3 / 52.33-3.25($ mean $=2.67), 4 / 51.10-1.75($ mean $=1.45)$, 45/3 0.83-1.00 $($ mean $=0.91)$, palpomeres $2-4$ with narrow silverywhite apical bands of similar size and development, palpomere 5 variable, entirely dark-scaled or sometimes with apical white band, length of apical pale band of palpomere $50.00-0.20$ (mean $=0.09$ ) length of basal dark band of palpomere 5 , ratio of length of apical pale band of palpomere 4 to length of basal dark band of palpomere $50.15-0.27($ mean $=0.19)($ Table 3$)$. Thorax: pleural setae as follow: 2-5 upper proepisternal, 1,2 prespiracular, 3-7 prealar, 4-7 upper mesokatepisternal, 1-3 lower mesokatepisternal, 2-5 upper mesepimeral. Wing (Fig. 5): length $3.04-3.67 \mathrm{~mm}($ mean $=3.31 \mathrm{~mm})$, pale scales on all veins light cream-colored, none strongly contrasting with others, SP, SCP and PP spots of vein C slightly darker, bordering to pale yellow, PHP spot of vein $C$ absent or present, when present small to prominent, HP usually present and prominent, rarely absent, PSP frequently present and prominent, rarely absent on 1 wing or reduced to few scales, SP usually present, rarely absent on 1 wing or reduced to few scales, ASP spot always absent, PP spot 0.92-2.00 $($ mean = 1.39) length of SCP spot, AD spot 1.162.46 (mean $=1.76)$ length of preapical pale spot, PSD spot of vein R extending basally from level 2 to level 5 on one or both veins (Table 4), PSD spot of vein R with 1-4 small pale interruptions on one or both veins (Table 5), SD spot of vein $\mathrm{R}$ with 2-5 pale interruptions (Table 6), sum of pale interruptions on PSD-PD spots of vein R 6-10 for each wing, ratio of length of cell $R_{2}$ to vein $R_{2+3} 1.48-2.73$ (mean $=1.81$ ), ratio of length of cell $\mathrm{R}_{2}$ to cell $\mathrm{M}_{1+2} 1.15-1.34$ (mean=1.23). Legs (Fig. 8): femora, tibiae, and tarsomeres dark-scaled with pale spots; foretarsomeres 1-4 with broad apical pale bands, foretarsomeres 2-4 with basal pale bands, bands more or less complete but less distinct on ventral surface, foretarsomere 2 occasionally entirely pale-scaled along dorsal surface, 
Table 38. Number of branches for setae of larvae of An. recens: range (mode).

\begin{tabular}{|c|c|c|c|c|c|c|c|c|c|c|c|c|c|}
\hline \multirow{2}{*}{$\begin{array}{l}\text { Seta } \\
\text { No. }\end{array}$} & \multirow{2}{*}{$\begin{array}{c}\text { Head } \\
\text { C }\end{array}$} & \multicolumn{3}{|c|}{ Thorax } & \multicolumn{9}{|c|}{ Abdominal segments } \\
\hline & & $\mathrm{P}$ & $\mathrm{M}$ & $\mathrm{T}$ & I & II & III & IV & $\mathrm{V}$ & VI & VII & VIII & $X$ \\
\hline$\overline{0}$ & 1 & 1 & - & - & - & 1 & 1 & 1 & 1 & 1 & 1 & 1 & - \\
\hline 1 & 1 & $14-20(16)$ & $23-30(26)$ & 1 & $3-4(4)$ & $5-8(5)$ & $16-23(18)$ & $13-22(16)$ & $15-21(18)$ & $14-20(16)$ & $8-12(8)$ & 1 & $1-2(1)$ \\
\hline 2 & 1 & $11-14(11)$ & $1-3(1)$ & 1 & 1 & $4-8(5)$ & $4-6(5)$ & 3 & $3-5(3)$ & $3-5(4)$ & $4-6(5)$ & $3-5(4)$ & $11-16(14)$ \\
\hline 3 & 1 & 1 & 1 & $3-6(5)$ & 1 & 1 & 1 & $1-2(1)$ & 1 & $1-2(1)$ & $1-3(2)$ & $3-5(4)$ & $5-7(6)$ \\
\hline 4 & 1 & $10-15(14)$ & $1-2(1)$ & 2 & $3-5(3)$ & $3-4(4)$ & $1-3(2)$ & $1-3(2)$ & $1-3(3)$ & 1 & 1 & 1 & 9 \\
\hline 5 & $9-12(12)$ & $16-28(25)$ & 1 & $26-34$ & 3 & $3-5(4)$ & $3-4(3)$ & 3 & $2-3(3)$ & $3-5(3)$ & $2-4(3)$ & $2-5(3)$ & - \\
\hline 6 & $10-13(12)$ & 1 & $3-4(4)$ & $2-3(3)$ & $12-17(14)$ & $12-18(14)$ & $10-16(12)$ & $2-3(2)$ & $1-2(2)$ & $1-3(2)$ & $2-4(2)$ & $1-S$ & $4-6(4)$ \\
\hline 7 & $11-15(13)$ & $16-23(21)$ & $2-4(2)$ & $23-27(25)$ & $9-14(11)$ & $10-15(13)$ & $2-4(3)$ & $1-5(3)$ & $2-4(3)$ & 2 & $2-3(3)$ & $2-S$ & $4-8(5)$ \\
\hline 8 & $1-2(1)$ & $16-30(17)$ & $16-23(16)$ & $22-30(30)$ & - & $1-2(2)$ & $1-2(1)$ & $1-2(2)$ & 2 & $1-2(2)$ & $2-4(3)$ & $6-\mathrm{S}$ & $2-3(2)$ \\
\hline 9 & $2-4(2)$ & 1 & 1 & 1 & $3-4(3)$ & $4-8(7)$ & $4-8(7)$ & $5-8(5)$ & $4-7(4)$ & $4-9(5)$ & $3-4(3)$ & $7-S$ & $1-2(2)$ \\
\hline 10 & 1 & 1 & 1 & 1 & 1 & $1-3(2)$ & 1 & 1 & 1 & $2-3(2)$ & $4-5(4)$ & 8-S & $1-2(2)$ \\
\hline 11 & $16-24(17)$ & 1 & 1 & 1 & 3 & $1-2(1)$ & 2 & 2 & $2-3(2)$ & $1-3(1)$ & $1-2(1)$ & 9-S & $2-4(3)$ \\
\hline 12 & $1-2(2)$ & 1 & 1 & $2-3(3)$ & 3 & 1 & $1-2(2)$ & $1-2(2)$ & $1-2(1)$ & 1 & $1-3(1)$ & - & - \\
\hline 13 & $3-5(4)$ & $3-5(4)$ & $3-5(5)$ & $1-3(2)$ & $3-6(4)$ & $2-4(3)$ & $2-4(3)$ & $1-2(2)$ & 2 & $4-8(4)$ & 2 & - & - \\
\hline 14 & $3-6(4)$ & $5-9(8)$ & $4-7(5)$ & - & - & - & - & 1 & 1 & 1 & 1 & 1 & - \\
\hline 15 & $4-6(4)$ & - & - & - & - & - & - & - & - & - & - & - & - \\
\hline
\end{tabular}

n.c. $=$ not counted

foretarsomeres 3,4 occasionally predominantly pale-scaled along dorsal surface; midtarsomere 2 usually with 1-4 pale spots, midtarsomeres 2-4 with basal pale bands, bands more evident on dorsal surface, midtarsomere 2 occasionally completely pale, midtarsomere 3,4 occasionally mostly palescaled on dorsal surface, midtarsomere 5 without basal pale band, pale-scaled at apex; hindtarsomeres 1-4 with narrow apical pale bands, basal pale band on hindtarsomere 4 usually absent, rarely present, basal pale band on hindtarsomeres 2,3 weak or absent, hindtarsomere 5 without basal pale band, pale-scaled at apex. Abdomen: tergum VI usually without scales, occasionally with 1-3 dark lateral scales, tergum VII occasionally with few dark scales on posterior margin, tergum VIII with golden scales posteriorly, occasionally with few basal dark scales and posteromedial white scales; sternum VI usually without scales, rarely with 2,3 scales or with small patch of dark scales posteromedially, sternum VII with patch of dark scales posteromedially, sternum VIII with few basolateral pale scales.

Male (Fig. 7). Essentially as in female except for sexual characters. Wing generally paler with reduced scaling, pale spots usually longer than in female. Palpomere 2 (Fig. 7) variable, usually with dorsal patch of pale scales at middle, apex of palpomere 2 bare; palpomere 3 usually with long dorsal patch of pale scales at middle, apex with broad pale band except for small ventrolateral dark area; palpomere 4 mostly palescaled with basal dark band, ventral surface of palpomere 4 with narrow line of dark scales; palpomere 5 mostly pale-scaled, usually with basal dark band, sometimes dark scales limited to small spot on ventral surface, palpomere 5 with ventral line of dark scales extending from base to near apex. Abdomen: sterna VI,VII but sometimes with pale scales posteromedially, scales usually dark, sternum VIII covered with pale cream-colored scales. Genitalia: 4 large parabasal setae; ventral clapette with 1 long apicolateral seta, shorter than club of dorsal claspette,
1 short slender apicomedial seta and 2 subapical setae; dorsal claspette with 4,5 apical setae fused into stout club with distinct basal stems; aedeagus elongate, columnar, dorsally curved with about 4,5 leaflets on each side of tip, leaflets serrated on one or both edges.

Pupa (Fig. 41). Position and development of branches as figured, range and modal number of branches in Table 39. All measurements from 17 or 18 specimens. In general similar to An. mirans except for the following characters. Cephalothorax: seta 4-CT usually triple, 10,11-CT single to 5-branched; seta 9III-VIII light brown pigmented, darker at base. Abdomen: seta 6-I single to triple, 1-II dendritic with 15-25 slender branches, setae 8,10,11-II absent, 9-II length 0.01-0.02 $\mathrm{mm}$ (mean $=0.01$ $\mathrm{mm}$ ), 1-III with 4-11 branches, 9 -III length $0.01-0.02 \mathrm{~mm}$ (mean $=0.02 \mathrm{~mm})$; 9-IV length $0.02-0.06 \mathrm{~mm}($ mean $=0.04 \mathrm{~mm})$, ratios of length of 9-IV/9-III 1.39-3.08 $($ mean $=1.85)$ and $9-I V / 9-V$ $0.28-0.57$ (mean $=0.36) ; 9-\mathrm{V}$ length $0.08-0.11 \mathrm{~mm}($ mean $=0.10$ $\mathrm{mm}$ ); 6-VI single or double, 9-VI length 0.08-0.12 $\mathrm{mm}$ (mean = $0.10 \mathrm{~mm}$ ); 6-VII single or double, 9-VII length 0.09-0.12 mm $($ mean $=0.11 \mathrm{~mm}) ; 9$-VIII with 11-18 branches. Paddle: toothed margin index 0.76-0.88 (mean $=0.83)$, paddle tooth more developed than those of An. mirans.

Larva (Figs. 41, 42, 52). Position and development of setae as figured; range and modal number of branches in Table 40. All measurements from 10-16 specimens unless otherwise indicated. In general similar to An. mirans except for following characters. Head: pattern of dark spots similar to that of $A n$. mirans except for the presence of 1 relatively small dark spot placed in central area of dorsal apoteme posterior to seta 5-C; lateralia darkened along dorsal ecdysial line, without definite pattern of darkened spots, ventral surface of lateralia with 1 dark spot on area of insertion of seta 12-C and 1 spot placed slightly posterior; length and width not measured; antenna pigmented light to medium brown, length $0.28-0.35 \mathrm{~mm}$ (mean $=0.32 \mathrm{~mm}$ ), ratio of distance base to 1-A to antenna length 
0.31-0.42 (mean $=0.35)$; seta 2-C single, simple; $3-\mathrm{C}$ length $0.08-0.15 \mathrm{~mm}$ (mean $=0.10 \mathrm{~mm})$; distance between base of $2-\mathrm{C}$ and 3-C 0.04-0.05 mm (mean $=0.04 \mathrm{~mm}$ ); 4-C single, rarely forked at apex, length $0.08-0.15 \mathrm{~mm}($ mean $=0.12 \mathrm{~mm})$, distance between basal insertions of 2-C and 4-C 0.07-0.10 mm (mean = $0.09 \mathrm{~mm}$ ), ratio of length of 4-C to distance between insertions of 2-C and 4-C 0.97-1.71 (mean = 1.40), distance between base of $3-\mathrm{C}$ and $4-\mathrm{C} 0.06-0.09 \mathrm{~mm}$ (mean $=0.08 \mathrm{~mm}$ ). Thorax: tubercles of seta 1-P entirely or partially joined to tubercle of 2,3-P, 1-P with 14-22 branches; 3-T (Fig. 52) moderately developed, somewhat palmate, with 3-6 narrow lanceolate nearly transparent leaflets arising from long slender basal stem. Abdomen: seta 1-I moderately developed, not palmate, with 37 slender branches arising from basal stem; 1-II palmate with 7-15 narrow lanceolate light grayish leaflets; ratio of length of 13-IV to 10-IV 0.59-0.83 (mean =0.74); 1-VII with 12-15 leaflets; 13-15 pecten spines (Fig. 41), 5,6 long spines alternating with 7-10 short spines.

Type data. NEOTYPE DESIGNATION, female with associated larval and pupal exuviae, coll. no. 0016-13, collected in Sulawesi, Toraut, Bone-Dumoga Forest Reserve $\left(0^{\circ} 35^{\prime} \mathrm{S}\right.$ $\left.123^{\circ} 54^{\prime} \mathrm{E}\right), 23$ September 1985 by J. Hii, deposited in the NMNH. Reid (1949) described specimens identified as An. leucosphyrus from Celebes, which he considered more similar to An. hackeri than to any other form of An. leucosphyrus. Koesoemawinangoen (1954) recognized specimens morphologically similar to those of Reid (1949) and designated them "A. leucosphyrus var. (Sulawesi)." The ICZN (1999), chapter 10, page 48, Article 45, 45.6.4 determines that a subspecific name following a binomen "is subspecific if first published before 1961 and its author expressly used one of the terms "variety" or "form"....., unless its author also expressly gave it infrasubgeneric rank, or content of the work unambiguously reveals that the name was proposed for an infrasubspecific entity, in which case it is infrasubspecific." Since Koesoemawinangoen (1954) used the term "var.", and his work does not unambiguously reveal that the name was proposed for an infrasubspecific entity, the term "sulawesi" has subspecific rank. Additionally, the name was adopted as a valid species name by Reid (1968). Even though K Koesoemawinangoen (1954) cited the name "sulawesi" in parentheses and used an upper case initial letter it does not render the name unavailable (article 11.2, page 10; articles 27 and 28, page 32) (ICZN, 1999). Consequently the name "sulawesi" is valid. However, Koesoemawinangoen (1954) did not designate the type or type series since he did not formally describe and name the species. To reserve nomenclatural stability, the neotype of An. sulawesi is designated in the present study.

Material examined. Eighty-four specimens as follow: 26F, 26M, 12Le, $17 \mathrm{Pe}$, derived from 7 separate collections from natural habitats (6 adult, 1 immature). INDONESIA. Butung: Wonco, Tenggara (500'S $122^{\circ} 55^{\prime}$ E), 18 Jan. 1977, 2F. Sulawesi: Lindoe Meer [Lindu Danau] $\left(1^{\circ} 18^{\prime} \mathrm{S} 119^{\circ} 53^{\prime} \mathrm{E}\right)$, [Bonne-Wepster collection numbers, 1-23-84, 123-85, 1-23-86], 1F, 2M. Paloe [Palu] (05' 119 $\left.53^{\circ} \mathrm{E}\right)$, [BonneWepster collection numbers 1-22-59, 1-31-89, 1-31-76], 2F, 1M;
[Bonne-Wepster collection numbers 1-22-58, 1-22-60], 1F, 1M. Pasiluang, Majene [Madjene], Selantan (3'33'S 118 $\left.57^{\circ} \mathrm{E}\right), 1 \mathrm{~F}$. Toraut, Bone-Dumoga Forest Reserve $\left(0^{\circ} 35^{\prime} \mathrm{S} 123^{\circ} 54^{\prime} \mathrm{E}\right), 23$ Sept. 1985, 19F, 19M, 12LePe, 5Pe (J. Hii). Unknown localities, 3M.

Distribution (Fig. 58). Anopheles sulawesi is known from Indonesia (Butung and Sulawesi).

Bionomics and medical importance. Immatures of $A n$. sulawesi were found in shaded rock pools, stream pools and pools in drying stream beds along the margin of the Tumpah River. The pools were approximately $8-15 \mathrm{~cm}$ deep and partially shaded. The bottom of the larval habitats had decaying vegetation or black muddy soil. Additionally, immatures were taken from a bamboo platform raised $0.2 \mathrm{~m}$ above a rock stream (Hii et al. 1988a). Females of An. sulawesi were not attracted in outdoor human-biting collections carried out between 1800$2300 \mathrm{~h}$ or bed net traps (1800-0600 h) in sites situated 3-5 m from larval habitats. One female was collected resting indoors and was blood-engorged (Hii et al. 1988a). Van Hell (1952) noted that larvae and adults of An. sulawesi were found in 13 localities in south Sulawesi, however more frequently as larvae. Immature habitats were marshy fields, stopped-up gutters and ditches, pools, and small wells. The water was stagnant and in sunlight. In Lamuru, immatures were found in association with An. maculatus and An. flavirostris (Ludlow) in the tributaries of the River Walanae. In Tjenrana, in 1937, An. sulawesi was considered to be a house mosquito, breeding in slow-moving basins with growth of algae of the Sunabak River. Adults were found infected of the gut with oocysts of Plasmodium in Malili. The natural infection index was 5\%, but no salivary glands were found infected. Anopheles sulawesi was recognized as a vector of human malaria parasites in Sulawesi (Warren \& Wharton 1963).

Systematics. Anopheles sulawesi can be recognized by having the following combination of characters. Adult: 1) proboscis longer than forefemur, ratio of proboscis length to forefemur length $1.23-1.30 ; 2$ ) proboscis mainly dark-scaled with ring of pale scales at apex basal to labella; 3 ) palpomere 5 mainly dark-scaled, ratio of length of apical pale band and basal dark band $0.00-0.20$; 5) PSD spot of vein R extending from level 2 to level 5; 6) PSD spot of vein R with 1-4 pale spots; 10) ASP spot absent; 2) SD spot of vein $R$ with 2-5 pale spots; 3) PD spot of vein R with 1-4 pale spots; 7) number of pale interruptions in PSD-PD spots of vein R 6-10 in each wing; 8) tergum VIII with golden scales posteriorly; 9) hindtarsomeres 2-5 without pale scales at base; 3 ) apical pale band on hindtibia with narrow dark longitudinal extension on ventral surface in addition to a separate dark spot. Fourthinstar larva: 1) seta 3-C single; 2) seta 1-II not fully developed, less developed than 1-III-VI; 3) seta 5-C conspicuously longer than antenna; 4) basal sclerotized tubercles of seta 1-P with prominent tooth on posterodorsal margin; 5) seta 4-C long, extending well beyond base of 2-C; 6) seta 13-IV shorter than $10-I V$, ratio of length of 13 -IV to 10 -IV never exceeding 0.88 (range $=0.46-0.88$ ). 
Table 39. Number of branches for setae of the pupa of An. sulawesi: range (mode).

\begin{tabular}{|c|c|c|c|c|c|c|c|c|c|c|c|}
\hline \multicolumn{2}{|c|}{ Seta Cephalothorax } & \multicolumn{9}{|c|}{ Abdominal segments } & \multirow{2}{*}{$\begin{array}{c}\text { Paddle } \\
\mathrm{Pa}\end{array}$} \\
\hline No. & $\mathrm{CT}$ & $\mathrm{I}$ & II & III & IV & $\mathrm{V}$ & VI & VII & VIII & IX & \\
\hline 0 & - & - & 1 & 1 & 1 & 1 & 1 & 1 & 1 & - & - \\
\hline 1 & $2-3(2)$ & n.c. & $15-25(15)$ & $4-11(7)$ & $3-5(5)$ & $2-4(2)$ & $1-3(2)$ & $1-2(1)$ & - & 1 & $1-2(2)$ \\
\hline 2 & $2-3(2)$ & $3-6(4)$ & $3-6(5)$ & $4-6(5)$ & $3-5(3)$ & $3-4(3)$ & $1-3(2)$ & $2-4(3)$ & - & - & $1-2(2)$ \\
\hline 3 & $1-3(2)$ & $1-3(1)$ & $2-4(4)$ & $2-5(3)$ & $3-8(5)$ & $2-4(3)$ & $3-4(3)$ & $3-5(4)$ & - & - & - \\
\hline 4 & $2-4(3)$ & $3-5(4)$ & $3-6(6)$ & $3-4(3)$ & $2-4(3)$ & $2-5(4)$ & 2 & $1-2(2)$ & 2 & - & - \\
\hline 5 & $3-5(4)$ & $3-6(3)$ & $2-4(3)$ & $6-8(7)$ & $5-9(8)$ & $2-6(4)$ & $4-6(5)$ & $4-7(6)$ & - & - & - \\
\hline 6 & $2-3(2)$ & $1-3(1)$ & $1-2(2)$ & $1-2(1)$ & $1-2(1)$ & 1 & $1-2(1)$ & $1-2(1)$ & - & - & - \\
\hline 7 & $2-4(4)$ & $2-5(2)$ & $1-4(2)$ & $2-4(2)$ & $2-4(2)$ & $1-3(2)$ & $1-2(1)$ & 1 & - & - & - \\
\hline 8 & $1-3(2)$ & - & - & $2-4(2)$ & $2-3(2)$ & $1-2(1)$ & $1-3(2)$ & $1-3(2)$ & - & - & - \\
\hline 9 & $3-4(3)$ & 1 & 1 & 1 & 1 & 1 & 1 & 1 & $11-18(14)$ & - & - \\
\hline 10 & $1-5(3)$ & - & - & $1-4(3)$ & $1-2(1)$ & $1-3(1)$ & $1-2(1)$ & $2-3(2)$ & - & - & - \\
\hline 11 & $1-3(2)$ & - & - & 1 & $1-2(1)$ & 1 & 1 & $1-2(2)$ & - & - & - \\
\hline 12 & $1-4(2)$ & - & - & - & - & - & - & - & - & - & - \\
\hline 13 & - & - & - & - & - & - & - & - & - & - & - \\
\hline 14 & - & - & - & - & 1 & 1 & 1 & 1 & 1 & - & - \\
\hline
\end{tabular}

n.c. $=$ not counted

\section{TAXONOMIC DISCUSSION}

Females of An. recens and An. sulawesi can be distinguished from those of other members of the Hackeri Subgroup by possessing the PSD spot of vein R with 1-4 pale interruptions, whereas in An. mirans, An. hackeri, and An. pujutensis, it is entirely dark. Anopheles recens can be separated from An. sulawesi in having the proboscis usually entirely dark-scaled or with a patch of pale scales at apical 0.2 of ventral surface, the apical pale band on the hindtibia lack a dark extension into the white area, or occasionally has a middle dark spot on the lateral surface, and tergum VIII has a patch of dark scales medially and a few golden scales posterolaterally. In An. sulawesi, the proboscis is dark-scaled with an apical pale ring basal to labella, the apical pale band on the hindtibia has a dark longitudinal extension on the ventral surface, and a middle isolated dark spot, and tergum VIII predominatly has golden scales posteriorly, occasionally with a few basal dark scales and posteromedial white scales. The adult stage of $A n$. mirans can be distinguished from those of An. hackeri and An. pujutensis by possessing the proboscis dark-scaled without an apical pale ring, whereas in An. hackeri and An. pujutensis the proboscis has one apical pale ring at the apex basal to labella. Anopheles hackeri can be separated from An. pujutensis in having palpomere 5 entirely dark-scaled or with at most 0.5 of dark basal band, whereas in An. pujutensis the apical pale band is more noticeably, and the ratio between the length of the apical pale band and basal dark band of palpomere 5 is variable from $0.67-4.00$.

Morphological distinction among members of the Hackeri Subgroup based on immature stages is problematic except for the fourth-instar larva of An. hackeri, which can be easily separated from An. mirans, An. pujutensis, An. recens, and An. sulawesi in having seta 1-II fully developed, palmate, similar to seta 1-III-VI, with 18-27 leaflets, the antenna is pigmented dark at apical 0.25 , the stem of seta 1-P is noticeably expanded and tubercles of seta 1,2-P are well separated, whereas in the remaining 4 species, seta 1 -II is weakly to moderately developed, with 5 to 17 branches, the antenna is lightly pigmented at apical 0.25 , the stem of seta $1-\mathrm{P}$ is not noticeably expanded and the tubercles of seta 1,2-P are partially or entirely joined basally. Anopheles pujutensis can be distinguished from An. mirans, An. recens, and An. sulawesi in having seta 4-C short, not reaching the base of 2-C, the tubercles of seta 1,2-P are partially joined by a posterior basal bridge and the tubercle of seta 1-P lacks a tooth or spine arising apically; An. sulawesi can be separated from An. mirans and An. recens by possessing seta 13-IV shorter than 10-IV, never longer than 0.88 length of 10-IV and seta 2-C without spicules, whereas in An. mirans and An. recens seta $13-\mathrm{IV}$ is always longer than 0.78 length of 10 -IV and seta 2-C is finely aciculate; An. mirans can be distinguished from $A n$. recens by possessing seta 1-II with 10-17 branches, seta $13-\mathrm{IV}, \mathrm{V}$ is 3,4-branched, 2-VII has 610 branches and 9-VII has 5-8 branches, whereas in An. recens seta 1-II has 5-8 branches, 13-IV,V is single or double, 2-VII has 4-6 branches, and 9-VII has 3,4 branches. The pupa of $A n$. hackeri is more similar to that of An. recens than to any other species of the Hackeri Subgroup in having setae 9-V-VII smooth, without spicules, whereas in An. mirans, An. pujutensis, and An. sulawesi they are spiculate. The pupa of An. hackeri can be distinguished from that of An. recens in having seta 9-V-VII curved, whereas in An. recens they are nearly straight. Additionally, An. hackeri can be separated from $A n$. recens in having seta 1-III with 7-15 branches and seta 1-VI has 2-6 branches, whereas in An. recens seta 1-III has 3-5 branches and seta $1-\mathrm{VI}$ is single or double. The ratio of the length of 9-IV/9-V varies from 0.12-0.23 (mean $=0.17)$ in An. hackeri and 0.33-0.76 (mean $=0.44)$ in An. recens. The pupal stages of An. mirans, An. pujutensis, and An. sulawesi are indistinguishable. 
Table 40. Number of branches for setae of the larva of An. sulawesi: range (mode).

\begin{tabular}{|c|c|c|c|c|c|c|c|c|c|c|c|c|c|}
\hline \multirow{2}{*}{$\begin{array}{l}\text { Seta } \\
\text { No. }\end{array}$} & \multirow{2}{*}{$\begin{array}{c}\text { Head } \\
\mathrm{C}\end{array}$} & \multicolumn{3}{|c|}{ Thorax } & \multicolumn{9}{|c|}{ Abdominal segments } \\
\hline & & $P$ & $\mathrm{M}$ & $\mathrm{T}$ & I & II & III & IV & $\mathrm{V}$ & VI & VII & VIII & $\mathrm{X}$ \\
\hline$\overline{0}$ & 1 & 1 & - & - & - & 1 & 1 & 1 & 1 & 1 & 1 & 1 & - \\
\hline 1 & 1 & $14-22(16)$ & $30-40(33)$ & $1-3(1)$ & $3-7(5)$ & $7-15(10)$ & $15-23(18)$ & $16-21(18)$ & $15-20(18)$ & $14-21(16)$ & $12-15(14)$ & 1 & 1 \\
\hline 2 & 1 & $10-18(11)$ & $1-4(1)$ & 1 & $1-3(2)$ & $6-8(6)$ & $5-7(5)$ & $3-5(3)$ & $3-5(3)$ & $4-6(5)$ & $4-7(6)$ & $4-9(6)$ & 20 \\
\hline 3 & 1 & 1 & 1 & $3-6(4)$ & $1-3(2)$ & 1 & 1 & $2-3(3)$ & 1 & 1 & $2-4(4)$ & $3-8(7)$ & $7-11(9)$ \\
\hline 4 & 1 & $12-19(15)$ & $2-3(3)$ & $3-6(5)$ & $4-7(5)$ & $4-7(5)$ & $2-5(3)$ & $2-4(3)$ & $1-3(3)$ & 1 & 1 & 1 & $8.5-9(9)$ \\
\hline 5 & $8-16(11)$ & n.c. & 1 & $31-43(36)$ & $2-4(3)$ & $3-6(5)$ & $3-5(4)$ & $3-4(3)$ & $3-4(3)$ & $2-5(4)$ & $3-5(4)$ & $3-7(4)$ & - \\
\hline 6 & $10-15(10)$ & 1 & $2-5(3)$ & $2-3(3)$ & $17-24(19)$ & $15-31(24)$ & $12-20(16)$ & $2-3(2)$ & $2-3(2)$ & $3-4(3)$ & $3-6(4)$ & $1-S$ & $4-6(5)$ \\
\hline 7 & $10-16(16)$ & $21-31(26)$ & $2-3(3)$ & $24-33(30)$ & $15-21(16)$ & $16-24(24)$ & $4-6(4)$ & $3-6(4)$ & $3-5(4)$ & $3-4(3)$ & $3-5(4)$ & $2-S$ & $4-7(6)$ \\
\hline 8 & $1-2(1)$ & $22-38(38)$ & $23-35(26)$ & $25-37(28)$ & - & $1-3(2)$ & $1-2(2)$ & $1-3(2)$ & $2-3(2)$ & $2-5(3)$ & $4-7(4)$ & $6-S$ & $1-3(2)$ \\
\hline 9 & $1-4(2)$ & 1 & 1 & 1 & $4-6(5)$ & $6-10(8)$ & $7-11(9)$ & $5-11(8)$ & $5-10(6)$ & $3-9(6)$ & $3-6(4)$ & $7-S$ & 2 \\
\hline 10 & $1-2(1)$ & 1 & 1 & 1 & 1 & $1-3(2)$ & 1 & $1-2(1)$ & 1 & $2-4(3)$ & $4-9(6)$ & $8-S$ & $2-3(2)$ \\
\hline 11 & $26-37(32)$ & 1 & 1 & 1 & $3-4(3)$ & 1 & $2-3(2)$ & $2-4(3)$ & $1-3(3)$ & $2-3(3)$ & $2-3(2)$ & 9-S & $2-4(3)$ \\
\hline 12 & $1-3(2)$ & 1 & 1 & $1-4(2)$ & $3-5(4)$ & 1 & $2-3(2)$ & $1-3(3)$ & $2-3(3)$ & $1-4(1)$ & $1-2(1)$ & - & - \\
\hline 13 & $4-7(6)$ & $4-6(4)$ & $4-9(5)$ & $2-5(3)$ & $3-7(5)$ & $3-6(4)$ & $3-7(5)$ & $2-4(3)$ & 3 & $5-7(7)$ & $2-3(3)$ & - & - \\
\hline 14 & $\mathrm{nc}$ & $6-9(7)$ & $5-10(8)$ & - & - & - & - & 1 & 1 & 1 & 1 & $1-2(1)$ & - \\
\hline 15 & $5-12(5)$ & - & - & - & - & - & - & - & - & - & - & - & - \\
\hline
\end{tabular}

n.c. $=$ not counted

\section{RIPARIS SUBGROUP}

The Riparis Subgroup includes An. riparis, An. cristatus, and An. macarthuri. The Negros Form (NF) has been included in this subgroup because of the short proboscis and the ratio of proboscis and forefemur length, which suggests that NF is morphologically more similar to An. riparis, An. cristatus, and An. macarthuri than to any other member of the Leucosphyrus Group (Peyton 1989). Unfortunately, there were few specimens available for the present study and they are not in good condition. For this reason the Negros Form has not been included. Members of the Riparis Subgroup (except the Negros Form) can be recognized by possessing the sternum VII without median posterior patch of scales, the PSD spot is without pale interruptions, the $\mathrm{SD}$ and $\mathrm{PD}$ spots of vein $\mathrm{R}$ have 1 pale spot each, the hindtibia has a narrow line of dark scales extending into apical white band, and the hindtarsomere 5 is dark-scaled at base.

\section{Anopheles (Cellia) riparis King \& Baisas}

(Figs. 5, 6o, 7, 8, 43, 44, 49-53, 59)

Anopheles leucosphyrus riparis of King \& Baisas (1936:38) (F*, M*, $\left.\mathrm{L}^{*}\right)$. Holotype female with associated larval exuviae on microscope slide, deposited in the NMNH.

Anopheles leucosphyrus of Russell \& Baisas (1934a:300) (aquatic habitat, Mindanao), (1934b:328) (taxonomy, in part, Mindanao), (1936:38) (in part Mindanao, systematic notes); Baisas (1936a:71) ( $\mathrm{P}^{*}$, cibarial teeth*, in part, Mindanao only, Plate 15 , bionomics note).

Anopheles leucosphyrus var. riparis of Baisas (1936b:214) (P*, identification key), (1938:224) (L, P, A); Simmons \& Aitken (1942:140) (taxonomic, bionomics notes); Russell et al. (1943:131) (identification key, bionomics notes); Bohart (1945:18) (bionomics notes, distribution, identification key); Puri (1949:489) (bionomics, distribution notes, F, identification key); Reid (1949:50) (taxonomic notes, type information, distribution, in part); McArthur (1950b:399) (bionomics notes); Bonne-Wepster \& Swellengrebel
(1953:259) $\left(\mathrm{F}^{*}, \mathrm{M}^{*}, \mathrm{~L}^{*}\right.$, distribution, identification key, in part); Cook (1954:79) (L, A, pictorial identification key); Koesoemawinangoen (1954:63, 93) (identification).

Anopheles riparis of Mendoza (1954) (A, L, pictorial identification key); Senevet \& Andarelli (1955:327, 334) (L); Colless (1956b:65) (F*, M, L, elevated to species, distribution, identification key); Chow (1961) (F, identification key); Baisas \& Dowell (1965:10, 41) (F*, L*, identification key); Cagampang-Ramos et al. (1985:1) (distribution); Tsukamoto et al. (1985:149) (checklist); Peyton (1989:197) (taxonomy).

Anopheles riparis riparis of Chow (1961:WHO/MAL/290) (distribution, F, identification key); Cagampang-Ramos \& Darsie (1970) (A, L, identification keys).

Female (Figs. 5, 6o, 7, 8). Head: proboscis uniformly darkscaled, length $1.42-1.69 \mathrm{~mm}$ (mean $=1.60 \mathrm{~mm})$, ratio of length to forefemur $0.88-0.96$ (mean $=0.92)$, maxillary palpus (Fig. 7) length 1.21-1.64 $\mathrm{mm}$ (mean $=1.49 \mathrm{~mm})$, ratio of length to proboscis $0.86-0.97$ (mean $=0.93)$, ratio of length to forefemur 0.81-0.89 $($ mean $=0.85)($ Table 2$)$, ratio of length of palpomeres 3/4 1.75-2.10 $($ mean $=1.92), 3 / 52.50-3.33($ mean $=2.83), 4 / 51.37$ $1.80($ mean $=1.49), 4-5 / 30.80-0.95($ mean $=0.88)$, palpomeres 2 4 with narrow apical silvery white bands, similar in size and development, pale scales of palpomere 5 pale cream-colored bordering to yellowish, length of apical pale band of palpomere $50.25-1.00$ (mean $=0.69)$ length of basal dark band of palpomere 5 , ratio of length of apical pale band of palpomere 4 to length of basal dark band of palpomere $50.40-0.50$ (mean $=0.50$ ) (Table 3). Thorax: pleural setae as follow: 1-3 upper proepisternal, 14 prespiracular, 4-6 prealar, 3-5 upper mesokatepisternal, 2-4 lower mesokatepisternal, 1-5 upper mesepimeral. Wing (Figs. $5,6 \mathrm{~g})$ : length $2.66-3.39 \mathrm{~mm}(\mathrm{mean}=2.98 \mathrm{~mm})$, pale scales on all veins light cream-colored, none strongly contrasting with others, pale scales on veins $C$, subcosta and R slightly darker than those on remaining veins, PHP and HP spots of vein C always present, small to prominent, PSP and SP spots of vein $\mathrm{C}$ always present and prominent, ASP spot usually present and prominent, rarely absent on vein C, PP spot 1.00-1.92 (mean 
$=1.39)$ length of SCP spot, AD spot 0.60-1.69 (mean = 1.06) length of preapical pale spot, PSD spot of vein R usually extending basally to level 1, occasionally to level 2 and 3 on one or both veins (Table 4), PSD spot of vein $\mathrm{R}$ without pale interruption (Table 5), SD spot of vein R usually with 1 pale interruption, occasionally with 2 pale interruptions on one or both wings (Table 6), sum of pale interruptions on PSD-PD spots of vein R 2-4 for each wing, ratio of length of cell $R_{2}$ to vein $R_{2+3}$ 1.14-1.39 (mean $=1.26$ ), ratio of length of cell $R_{2}$ to cell $M_{1+2}$ 0.98-1.26 (mean=1.06). Legs (Fig. 8): femora, tibiae, and tarsomeres 1 dark-scaled, speckled with pale spots; foretarsomeres 2,3 with basal and apical pale bands, basal pale band rarely absent on foretarsomere 3 , foretarsomere 2 with 1,2 pale spots on middle dark area, foretarsomere 4 usually with basal pale band, rarely absent, apical pale band absent, foretarsomere 5 without apical and basal pale bands; midtarsomeres 2-4 mainly dark-scaled, with poorly evident, incomplete short apical pale band on dorsal surface, darkscaled along ventral surface, midtarsomere 5 dark-scaled; hindtarsomeres 2-4 with short apical band of pale scales, hindtarsomere 5 with few pale scales at apex. Abdomen: tergum VI without scales, tergum VII usually without scales, rarely with 2,3 posterolateral scales, tergum VIII covered with yellowish scales posteriorly; sterna VI,VII without scales, sternum VIII with few pale cream-colored scales laterally.

Male. Essentially as in female except for sexual characters. Wing generally paler with reduced scaling, pale spots usually longer than in female. Palpomere 2 with dorsal patch of pale scales at middle, extending laterally, apex of palpomere 2 bare; palpomere 3 with long dorsal patch of pale scales at middle extending to lateral surface, apex of palpomere 3 with broad basal band of pale scales covering dorsal, lateral, and ventral surfaces except for small ventrolateral patch of dark scales at apex; palpomeres 4,5 mainly pale-scaled with basal band of dark scales, sometimes with narrow dark line along ventral surface of both palpomeres. Abdomen: sternum VIII covered with pale cream-colored scales. Genitalia: 4 large parabasal setae; ventral clapette with 1 long apicolateral seta, shorter than club of dorsal claspette, 1 short, slender apicomedial seta, and 1 subapical seta; dorsal claspette with 4 apical setae fused into stout club with distinct basal stems; aedeagus elongate, columnar, dorsally curved with about 5 leaflets on each side of apex, leaflets serrate on one or both edges.

Pupa (Fig. 43). Position and development of setae as figured; range and modal number of branches in Table 41. All measurements from 5 or 6 specimens. Integument without distinctive color pattern, mostly light brown to yellowish; sterna II-V with narrow dark band near anterior margin. Cephalothorax: setae 1,3-CT about equal in length, 4-CT triple, 5-CT with 3-5 branches, 6-CT usually double, 7-CT triple to 4branched, 8-CT double or triple, 9-CT double, 10-CT with 4-6 branches, 11-CT with 2-4 branches, 12-CT with 2-4 branches. Seta 9-II lightly pigmented, 9-III-VIII pigmented light brown from base to apex, slightly darker at base. Abdomen: seta 6-I single or double, 7-I with 3-7 branches; 1-II dendritic, with 812 fine branches arising from basal stem, 6-II single or double,
7-II with 4-7 branches, 8-II absent, 9-II very short, stout, arising distad from posterior margin of segment, length $0.01-0.02 \mathrm{~mm}$ $($ mean $=0.02 \mathrm{~mm}$ ), 10,11-II absent; 1-III with 3-6 branches, 5-III with 9-12 branches, 6-III single or double, 9-III short, stout, sometimes bifid at apex, length $0.016-0.02 \mathrm{~mm}$ (mean $=0.02$ $\mathrm{mm}$ ); 1 -IV with 2-6 branches, 5 -IV with 5-10 branches, 6 -IV always single, 9-IV short, without spicules, length 0.02-0.03 $\mathrm{mm}($ mean $=0.02 \mathrm{~mm})$, ratios of length of 9-IV/9-III 1.10-1.25 $($ mean $=1.20)$ and 9-IV/9-V 0.19-0.24 $($ mean $=0.21) ; 1-\mathrm{V}$ with 25 branches, $5-\mathrm{V}$ with $5-8$ branches, $6-\mathrm{V}$ single, $9-\mathrm{V}$ long, without spicules, length $0.10-0.13 \mathrm{~mm}(\mathrm{mean}=0.12 \mathrm{~mm}) ; 1-\mathrm{VI}$ double, 5-VI with 5-7 branches, 6-VI single, 9-VI long, without spicules, length 0.11-0.13 mm (mean $=0.13 \mathrm{~mm}$ ); 1-VII single or double, 5-VII with 5,6 branches, 6-VII double, 9-VII long, with or without spicules, length $0.11-0.13 \mathrm{~mm}$ (mean $=0.12 \mathrm{~mm}$ ); 9-VIII with 1416 branches. Paddle: lightly tanned, buttress slightly darker, midrib faint; outer basolateral serrations prominent, filamentous spicules on outer margin and most of inner margin prominent; seta 1-Pa strong, dark pigmented, 2-Pa with 1-3 branches, toothed margin index 0.64-0.77 $($ mean $=0.69)$, paddle teeth approximate, tapered, ending in sharply acute apices.

Larva (Figs. 43, 44, 49-53). Position and development of setae as figured; range and modal number of branches in Table 42. All measurements from 3-6 specimens. Head: integument light brown to yellowish with 2 dark spots posteriorly on dorsal apoteme; 1 dark spot on dorsal apoteme in area between seta 8-C, slightly posterior to insertion of 8-C; 1 dark spot on ventral lateralia in area of insertion of 12-C; 2 dark spots on labiogula laterally at level of posterior tentorial pit; length and width not measured; antenna length $0.27-0.28 \mathrm{~mm}$ (mean $=0.28 \mathrm{~mm}$ ), ratio of distance base to 1-A to antenna length 0.24-0.49 (mean = 0.37 ); seta 2-C long, single with spicules arising from basal 0.2 to apex, 3-C single, length $0.08-0.09 \mathrm{~mm}$ (mean $=0.08 \mathrm{~mm}$ ), distance between base of 2-C and 3-C 0.03-0.04 mm (mean = $0.03 \mathrm{~mm}$ ), 4-C posterolaterad to 2-C, single, length $0.08-0.10$ $\mathrm{mm}($ mean $=0.09 \mathrm{~mm})$, extending beyond base of $2-\mathrm{C}$, distance between basal insertions of 2-C and 4-C 0.07-0.09 $\mathrm{mm}$ (mean = $0.08 \mathrm{~mm}$ ), ratio of length of 4-C to distance between insertions of 2-C and 4-C 0.92-1.39 $\mathrm{mm}$ (mean $=1.10 \mathrm{~mm}$ ), distance between base of 3-C and 4-C 0.06-0.07 $\mathrm{mm}$ (mean $=0.06 \mathrm{~mm}$ ), 5-C longer than antennal shaft, extending to anterior margin of head, 1015 branches, $6-\mathrm{C}$ with $13-16$ branches, $7-\mathrm{C}$ with $11-15$ branches. Thorax: tubercles of all large setae light brown; seta 1-P with 9-20 branches, stem stout, flattened, not noticeably expanded, arising from large tubercle, which is smaller than tubercle of 2$\mathrm{P}$, tubercle of seta 1-P almost entirely joined basally to tubercle of 2,3-P (Fig. 53) by posterior bridge, both tubercles without teeth or spines projecting over base of setae, 14-P with 5,6 branches; 4-M single or double, 6-M triple, $14-\mathrm{M}$ with 6-8 branches; 3-T (Fig.52) moderately developed, somewhat palmate, with 2-5 narrow lanceolate nearly transparent leaflets arising from basal stem. Abdomen: seta 1-I moderately developed, not palmate, with 3-6 branches, 2-I single, 3-I single or double, 9-I with 4-6 branches; 1-II (Fig. 51) moderately developed, palmate, with 14,15 narrow lanceolate nearly transparent leaflets arising from narrow moderately pigmented 
basal stem; 2-IV with 3,4 branches, 3-IV double, 13-IV triple, long, ratio of length to 10-IV 0.57-0.83 (mean $=0.68) ; 2-\mathrm{V}$ with 3,4 branches; 1 -VII (Fig. 50) smaller and less pigmented than 1-VI, with 11-16 moderately broad lanceolate leaflets with minute apicolateral serrations and slender apical filaments; 1 X long, single, inserted on saddle; pecten plate (Fig. 49) with minute denticles dorsal to pecten spines, 12,13 pecten spines, 3,4 long spines alternating with 8,9 short spines.

Type data. Holotype female with associated larval and pupal exuviae on microcope slide, deposited in the NMNH. Type locality: the Philippines, Mindanao, Lanao Province, vicinity of Kolambugan.

Material examined. One hundred thirty-five specimens as follow: $35 \mathrm{~F}, 23 \mathrm{M}, 54$ Le. $14 \mathrm{Pe}, 11 \mathrm{~L}$, derived from 19 separate collections from natural habitats (19 immature). PHILLIPINE ISLANDS. Mindanao: Lanao, Kolambugan, Titunod ( $\left.8^{\circ} 7^{\prime} \mathrm{N} 123^{\circ} 55^{\prime} \mathrm{E}\right)$, [113], Aug. 1934, 2M; [350], 23 Mar. 1932, 2F, 1M, 3LePe, 1Le, 3L; [358], 30 Mar. 1932, 4F, 3M, 5LePe, 3Le, 1L; [365], 6 Apr. 1932, 2M, 1LePe, 1Le; [336], 6 Apr. 1932, 1F, 1M, 1LePe, 2Le; [367a], 8 Apr. 1932, 1F, 1LePe; [372], 13 Apr. 1932, 1F, 1M, 4 Le, 1L; [378], 16 Apr. 1932, 4F, 1M, 6L; [380a], 20 Apr. 1932, 3M, 5Le, 1L (W.V. King; F.E. Baisas); [382], 22 Apr. 1932, 6F, 1M, 8Le; [385], 23 Apr. 1932, 6F, 1M, 8Le; [386], 28 Apr. 1932, 1F, 1Le; [396], 12 May 1932, 2F, 4M; [398], 13 May 1932, 2F (W.V. King); [R21], 22 Mar. 1934, 1F, 1Le

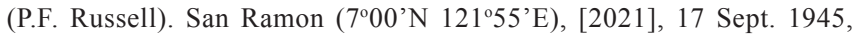
1F. Zamboanga (watershed area) (6 $\left.6^{\circ} 54^{\prime} \mathrm{N} 122^{\circ} 4^{\prime} \mathrm{E}\right)$, [2057], 29 Sept.

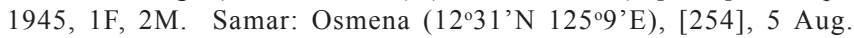
1945, 5L; [1314], 5 Aug. 1945, 2F, 1M, 3LePe.

Distribution (Fig. 59). Anopheles riparis is known from the Philippine Islands (Mindanao and Samar).

Bionomics and medical importance. Nothing is known about the involvement of An. riparis in the transmission of malaria parasites to either humans or animals. On Mindanao, immatures were taken from rock holes, pools in stream beds, between boulders at the edge of streams (King \& Baisas 1936), in rock holes, and stagnant pools in the beds of mountain creeks in heavily shaded places (Russell \& Baisas 1934a).
Immatures were found in rock holes in forest creeks, shallow rock holes and in shady pools in streambeds. The habitats were inside the forest, in heavy or partial shade, sometimes with decaying leaves. They were found in association with immatures of An. cristatus

Systematics. Anopheles riparis can be distinguished by having the following combination of characters. Adults: 1) ASP spot well developed on vein C, sometimes fused with SP spot on vein $\mathrm{R}$ and occasionally on vein $\mathrm{C}$; 2) dark extension on white apical band of hindtibia long, extending to about $3 / 4$ length; 3) midtarsomere 1 dark-scaled, speckled with small pale spots; 4) midtarsomeres 2-4 with short apical pale bands on dorsal surface; 5) split of cell $\mathrm{M}_{1+2}$ proximal to split of cell $\mathrm{R}_{2}$; 6) PHP spot present. Fourth-instar larva: 1) seta 3-C single; 2) seta 4-C not strongly developed; 3) seta 1-II less developed than seta 1 -III-VI; 4) seta 5-C noticeably longer than antenna; 5) basal sclerotized tubercle of seta 1-P without prominent tooth or spine arising from posterodorsal margin; 6) basal sclerotized tubercles of setae 1,2-P joined basally by posterior bridge; 7) seta 3-T with 2-5 branches; 8 ) seta 4-C long, ratio of length of 4-C to distance between 4-C and 2-C 0.92-1.39. Pupa of An. riparis cannot be distinguished from those of the remaining members of the Riparis Subgroup.

\section{Anopheles (Cellia) cristatus King \& Baisas \\ (Figs. 5, 7, 8, 45, 46, 49-53, 59)}

Anopheles (Myzomyia) cristatus King \& Baisas (1936:79) (F*, M* $\left.\mathrm{L}^{*}\right)$. Holotype female with associated larval and pupal exuviae on microscope slide, deposited in the NMNH.

Anopheles near leucosphyrus of Russell \& Baisas (1934a:302) (bionomics), (1934b:328) (L*, Figs. 28, 31, larval identification key), (1936:38) (in part, taxonomy); Baisas (1936a:84) (A*, $\mathrm{P}^{*}$, cibarial teeth*, Figs. 15.3, 15.6, bionomics).

Anopheles cristatus of Baisas (1936b:214) (P*, identification key), (1938:224) (L, P, A, cibarial teeth); Russell et al. (1943:130) (distribution, bionomics notes); Simmons \& Aitken (1942:134)

Table 41. Number of branches for setae of the pupa of An. riparis: range (mode).

\begin{tabular}{|c|c|c|c|c|c|c|c|c|c|c|c|}
\hline \multirow{2}{*}{$\begin{array}{l}\text { Seta } \\
\text { No. }\end{array}$} & \multirow{2}{*}{$\begin{array}{c}\text { Cephalothorax } \\
\text { CT }\end{array}$} & \multicolumn{9}{|c|}{ Abdominal segments } & \multirow{2}{*}{$\begin{array}{c}\text { Paddle } \\
\mathrm{Pa}\end{array}$} \\
\hline & & $\mathrm{I}$ & II & III & IV & $\mathrm{V}$ & $\mathrm{VI}$ & VII & VIII & IX & \\
\hline 0 & - & - & 1 & 1 & 1 & 1 & 1 & 1 & 1 & - & - \\
\hline 1 & $2-3(2)$ & n.c. & $8-12(12)$ & $3-6(3)$ & $2-6(4)$ & $2-5(3)$ & 2 & $1-2(2)$ & - & 1 & 1 \\
\hline 2 & $2-3(3)$ & $6-10(9)$ & $3-8(6)$ & $3-6(4)$ & $3-4(3)$ & $1-3(3)$ & $2-3(2)$ & $3-4(3)$ & - & - & $1-3(1)$ \\
\hline 3 & $2-4(3)$ & $2-3(2)$ & $2-3(3)$ & $2-3(3)$ & $6-7(6)$ & $2-3(2)$ & 2 & $2-4(3)$ & - & - & - \\
\hline 4 & 3 & $2-3(3)$ & $4-6(4)$ & $3-6(3)$ & $3-4(3)$ & $3-5(4)$ & $2-3(2)$ & $1-2(2)$ & $2-3(2)$ & - & - \\
\hline 5 & $3-5(4)$ & $3-6(4)$ & $3-4(3)$ & $9-12(9)$ & $5-10(6)$ & $5-8(7)$ & $5-7(7)$ & $5-6(6)$ & - & - & - \\
\hline 6 & $2-3(2)$ & $1-2(2)$ & $1-2(2)$ & $1-2(1)$ & 1 & 1 & 1 & 2 & - & - & - \\
\hline 7 & $3-4(3)$ & $3-7(3)$ & $4-7(6)$ & $2-5(5)$ & $3-6(6)$ & $2-4(3)$ & $2-3(2)$ & 2 & - & - & - \\
\hline 8 & $2-3(3)$ & - & - & $4-6(5)$ & $2-3(2)$ & $2-4(2)$ & 2 & $1-4(2)$ & - & - & - \\
\hline 9 & 2 & 1 & 1 & $1-2(1)$ & $1-2(1)$ & 1 & 1 & 1 & $14-16(14)$ & - & - \\
\hline 10 & $4-6(6)$ & - & - & $3-4(3)$ & $2-3(2)$ & $1-2(2)$ & 2 & 2 & - & - & - \\
\hline 11 & $2-4(3)$ & - & - & 1 & 1 & 1 & 1 & $1-4(2)$ & - & - & - \\
\hline 12 & $2-4(2)$ & - & - & - & - & - & - & - & - & - & - \\
\hline 13 & - & - & - & - & - & - & - & - & - & - & - \\
\hline 14 & - & - & - & - & 1 & 1 & 1 & 1 & 1 & - & - \\
\hline
\end{tabular}

n.c. $=$ not counted 
Table 42. Number of branches for setae of the larva of An. riparis: range (mode).

\begin{tabular}{|c|c|c|c|c|c|c|c|c|c|c|c|c|c|}
\hline \multirow{2}{*}{$\begin{array}{l}\text { Seta } \\
\text { No. }\end{array}$} & \multirow{2}{*}{$\begin{array}{c}\text { Head } \\
\text { C }\end{array}$} & \multicolumn{3}{|c|}{ Thorax } & \multicolumn{9}{|c|}{ Abdominal segments } \\
\hline & & $P$ & $\mathrm{M}$ & $\mathrm{T}$ & I & II & III & IV & $\mathrm{V}$ & VI & VII & VIII & $\mathrm{X}$ \\
\hline$\overline{0}$ & 1 & 1 & - & - & - & 1 & 1 & 1 & 1 & 1 & 1 & 1 & - \\
\hline 1 & 1 & $9-20(17)$ & $27-34(30)$ & 1 & $3-6(3)$ & $14-15$ & $14-20(20)$ & $16-18(18)$ & $16-21(16)$ & $12-16(15)$ & $11-16(11)$ & 1 & 1 \\
\hline 2 & 1 & $8-13(8)$ & $1-2(2)$ & 1 & 1 & $5-6(5)$ & $3-5(5)$ & $3-4(3)$ & $3-4(3)$ & $3-4(4)$ & $4-6(5)$ & 7 & n.c. \\
\hline 3 & 1 & 1 & 1 & $2-5(4)$ & $1-2(1)$ & 1 & 1 & 2 & 1 & 1 & $3-4(4)$ & $6-9(7)$ & $6-11(8)$ \\
\hline 4 & 1 & $12-17$ & $1-2(2)$ & $2-3(3)$ & $2-4(3)$ & $4-5(4)$ & 3 & 3 & $2-3(3)$ & 1 & 1 & 1 & $8-9.5(8)$ \\
\hline 5 & $10-15(13)$ & n.c. & 1 & $32-39(32)$ & 3 & $3-4(4)$ & 3 & $3-4(3)$ & $3-4(3)$ & $3-5(5)$ & $3-5(5)$ & $3-4(3)$ & - \\
\hline 6 & $13-16(13)$ & 1 & 3 & 2 & $18-22(20)$ & 29,30 & $12-17$ & $2-3(2)$ & 2 & $2-3(3)$ & $5-6(6)$ & $1-\mathrm{S}$ & $3-6(5)$ \\
\hline 7 & $11-15(13)$ & 25 & $2-3(2)$ & $21-29$ & $12-18$ & 18,24 & $3-4(4)$ & 4 & $3-4(4)$ & $2-4(3)$ & 3 & $2-S$ & $5-7(6)$ \\
\hline 8 & 2 & $25-34$ & $25-31(27)$ & 29 & - & 2 & $1-2(2)$ & $2-3(2)$ & $2-4(4)$ & $2-3(3)$ & $4-8(6)$ & $6-S$ & $2-3(2)$ \\
\hline 9 & $1-3(3)$ & 1 & 1 & 1 & $4-6(5)$ & $8-10(10)$ & $7-9(7)$ & $7-10(8)$ & $5-6(6)$ & 7,8 & $5-7(5)$ & $7-S$ & $1-2(2)$ \\
\hline 10 & $1-2(1)$ & 1 & 1 & 1 & 1 & $2-3(2)$ & 1 & 1 & 1 & 3 & $5-6(5)$ & $8-\mathrm{S}$ & 2 \\
\hline 11 & 31 & 1 & 1 & 1 & 3 & 1 & $2-3(2)$ & $2-3(2)$ & $2-3(2)$ & $2-3(2)$ & 2 & 9-S & $3-4(4)$ \\
\hline 12 & $1-2(2)$ & 1 & 1 & $1-3(2)$ & $3-4(4)$ & 1 & 2 & 2 & 2 & 1 & 1 & - & - \\
\hline 13 & $4-7(6)$ & $4-5(5)$ & $6-8(7)$ & $3-4(3)$ & $4-5(5)$ & $5-7(6)$ & $6-8(7)$ & 3 & $3-4(3)$ & 8 & 3 & - & - \\
\hline 14 & n.c. & $5-6(6)$ & $6-8(8)$ & - & - & - & - & 1 & 1 & 1 & 1 & 1 & - \\
\hline 15 & $3-5$ & - & - & - & - & - & - & - & - & - & - & - & - \\
\hline
\end{tabular}

n.c. $=$ not counted

(bionomics notes); Bohart (1945:16) (taxonomic, bionomics notes, distribution); Puri (1949:489) (bionomics, distribution notes, F, identification key); Reid (1949:50) (taxonomic notes, F, identification notes); McArthur (1950b:399) (bionomics notes); Bonne-Wepster \& Swellengrebel (1953:259) (F*, M*, L*, bionomics notes, distribution, identification keys); Mendoza (1954) (A, L, pictorial key); Koesoemawinangoen $(1954: 63,93)$ (adult identification key); Senevet \& Andarelli (1955:327,334) (L); Colless (1956b:70) (F, M, P, L*, identification keys); Chow (1961) WHO/ MAL/290 (distribution, F, identification key); Baisas \& Dowell $(1965: 9,46)\left(\mathrm{F}^{*}, \mathrm{~L}^{*}\right.$, identification key); Reid (1968:284,309) (A, identification key, taxonomic notes); Cagampang-Ramos \& Darsie (1970) (A, L, identification keys); Cagampang-Ramos et al. (1985:1) (distribution); Tsukamoto et al. (1985:149) (checklist); Peyton (1989:197) (taxonomy).

Female (Figs. 5, 7, 8). Head: proboscis dark-scaled, length $1.34-1.67 \mathrm{~mm}$ (mean $=1.48 \mathrm{~mm})$, ratio of length to forefemur 0.89-0.98 (mean $=0.93)$, maxillary palpus (Fig. 7) length 1.26$1.64 \mathrm{~mm}($ mean $=1.38 \mathrm{~mm})$, ratio of length to proboscis 0.88 1.00 (mean $=0.93$ ), ratio of length to forefemur 0.81-0.93 (mean $=0.87$ ) (Table 2), ratio of length of palpomeres 3/4 1.67-2.37 $($ mean $=2.07), 3 / 52.67-3.80($ mean $=3.27), 4 / 51.28-2.00($ mean $=$ $1.59), 4-5 / 30.68-0.90($ mean $=0.79)$, palpomeres $2-4$ with narrow apical silvery-white bands of similar size and development, pale scales of palpomere 5 pale cream-colored, length of apical pale band of palpomere $50.17-1.00($ mean $=0.59)$ length of basal dark band of palpomere 5 , ratio of length of apical pale band of palpomere 4 to length of basal dark band of palpomere $50.00-2.00($ mean $=0.92)($ Table 3$)$. Thorax: pleural setae as follow: 1,2 upper proepisternal, $0-2$ prespiracular, 4 prealar, 2 upper mesokatepisternal, 2 lower mesokatepisternal, 1-3 upper mesepimeral. Wing (Fig. 5): length 2.63-3.29 $\mathrm{mm}$ (mean $=2.88$ $\mathrm{mm}$ ), pale scales on all veins light cream-colored, none strongly contrasting with others, except SCP and PP spots which are slightly more cream-colored, PHP spot of vein C absent, HP spot usually present, small or prominent, rarely absent, PSP spot always present and prominent, rarely with 1,2 pale scales,
SP always present and prominent, ASP variable, present or absent on vein $C$, PP spot 0.85-2.44 (mean $=1.24)$ length of SCP spot, AD spot 0.80-2.18 (mean 1.63) length of preapical pale spot, PSD spot of vein R extending basally to level 1 (Table 4), PSD spot of vein R entirely dark-scaled (Table 5), SD spot of vein $\mathrm{R}$ with 1 pale interruption (Table 6), PSD-PD spots of vein $\mathrm{R}$ with 1 or 2 pale interruptions in each wing, ratio of length of cell $R_{2}$ to vein $R_{2+3} 1.00-1.38($ mean $=1.20)$, ratio of length of cell $\mathrm{R}_{2}$ to cell $\mathrm{M}_{1+2} 1.19-1.43$ (mean =1.30). Legs (Fig. 8 ): femora, tibiae, foretarsomere 1 , and hindtarsomere 1 darkscaled with spots of pale scales, midtarsomere 1 dark-scaled or occasionally few pale spots; foretarsomeres 2,3 with basal and apical pale bands, foretarsomere 4 with basal pale band, foretarsomere 5 dark-scaled, pale bands not evident on ventral surface, ventral surface dark-scaled; midtarsomeres 2 and 3 with inconspicuous, faint, basal pale spots, or entirely darkscaled, midtarsomeres 4,5 dark-scaled; hindtarsomeres 2-4 darkscaled with short apical pale bands, hindtarsomere 5 darkscaled. Abdomen: terga VI and VII without scales, tergum VIII with basomedial patch of dark scales, pale cream scales apically; sterna VI and VII without scales, sternum VIII with 2,3 creamcolored scales laterally.

Male (Fig. 7). Essentially as in female except for sexual characters. Wing generally paler with reduced scaling, pale spots usually longer than in female. Palpomere 2 (Fig. 7) with dorsal patch of pale scales at middle, apex of palpomere 2 bare; palpomere 3 with long dorsal patch of pale scales at middle, apex of palpomere 3 with broad pale band covering dorsal, lateral and ventral surfaces except for small ventrolateral patch of dark scales; palpomeres 4,5 mainly pale-scaled with basal dark band and dark extension along ventral surface of both segments. Genitalia: 4 large parabasal setae; ventral claspette with 1 long, well-developed apicolateral seta, 1,2 short apicomedial setae, and 1 subapical seta; dorsal claspette with 2-5 apical setae fused apically in stout club with distinct basal 
stem, occasionally 1 seta arising separate from the club; aedeagus elongate, columnar, dorsally curved, with 7-9 apical leaflets on each side, some leaflets with serrated margins.

Pupa (Fig. 45). Position and development of branches as figured; range and modal number of branches in Table 43. All measurements from 4-8 specimens. In general similar to $A n$. riparis except for the following characters. Seta 9-II pigmented light brown, darker at base. Abdomen: seta 1-II branched, not dendritic, with $10-12$ branches, 9-II length 0.008-0.010 mm (mean $=0.010 \mathrm{~mm})$; 9-III length $0.015-0.020 \mathrm{~mm}($ mean $=0.017 \mathrm{~mm}) ; 6$ IV single or double, 9-IV length $0.018-0.022 \mathrm{~mm}$ ( mean $=0.020$ $\mathrm{mm}$ ), ratios of length of 9-IV/9-III 1.00-1.38 (mean $=1.19)$ and 9IV/9-V 0.18-0.22 (mean =0.19); 9-V with spicules, length 0.10$0.11 \mathrm{~mm}($ mean $=0.10 \mathrm{~mm})$; 1 -VI with 3-5 branches, 5-VI with 613 branches, 6-VI usually double, 9-VI with spicules, length $0.10-0.12 \mathrm{~mm}$ (mean $=0.11 \mathrm{~mm}$ ); 5 -VII with 7-12 branches, 9-VII with spicules, length $0.10-0.12 \mathrm{~mm}$ (mean $=0.11 \mathrm{~mm}$ ); 9-VIII with 11-15 branches. Paddle: toothed margin index 0.56-0.67 (mean $=0.61)$.

Larva (Figs. 45, 46, 49-53). Position and development of setae as figured; range and modal number of branches in Table 44. No larval measurement were made because available specimens were not in good condition. In general similar to An. riparis except for the following characters. Head: seta 2-C with well developed spicules, 3-C aciculate, 4-C well developed, aciculate (Fig. 45), 5-C with 9-15 branches, 7-C with 9-16 branches. Thorax: tubercles of all large setae light to medium brown; seta 1-P with 15-18 branches, tubercle of seta 1-P entirely separated from that of 2,3-P (Fig. 53), both tubercles with short blunt teeth arising from posterodorsal margin, 14-P with 4-8 branches; 3-T (Fig. 52) well-developed, palmate, with 9,10 leaflets. Abdomen: seta 1-I somewhat palmate, with 2-6 leaflets; 1-II (Fig. 51) moderately developed, palmate, with 1124 leaflets; 2-IV double; 2-V double; 1-VII (Fig. 50) smaller and less pigmented than 1-VI, with 12-14 moderately broad lanceolate leaflets with minute apicolateral serrations and slender apical filaments; 10-12 pecten spines (Fig. 49) somewhat similar in size and development, shortest spine slightly shorter than longest spine.

Type data. Holotype female with associated larval and pupal exuviae on microscope slide, deposited in the NMNH. Type locality: Philippines, Mindanao, Lanao Province, Kolambugan, Titunod.

Material examined. Seventy eight specimens, as follows: 14F, 18M, 26Le, $11 \mathrm{Pe}, 9 \mathrm{~L}$, derived from 11 separate collections from natural habitats (11 immature). PHILIPPINE ISLANDS. Mindanao: Lanao, Kolambugan, Titunod ( $\left.8^{\circ} 7^{\prime} \mathrm{N} 123^{\circ} 55^{\prime} \mathrm{E}\right)$, [350], 23 Mar. 1932, 2F, 6M, 5LePe, 5Le, 4L; [358], 30 Mar. 1932, 5F, 4M, 2LePe, 1Le, 5L; [365], 6 Apr. 1932, 2F, 2M, 4Le; [377], 16 Apr. 1932, 1M, 1Le (F.E. Baisas and W.V. King); [113], Mar. 1934, 1F; [126], Aug. 1934, 1M; [R21], 22 Mar. 1934, 1Le; [R115], 1934, 1F; [R123], 9 Aug. 1934, 1F (P.F. Russell); [111D], 26 Dec. 1930, 1F, 2M, 4LePe, 1Le; [111E], 24 Dec. 1930, 1F, 2M, 2Le (Santiago and W.V. King).

Distribution (Fig. 59). Anopheles cristatus is only known from the Phillipine Islands (Mindanao).

Bionomics and medical importance. Immatures of $A n$. cristatus were found in rock holes along small streams. Most of the rock holes were a few centimeters in diameter and located in the dense shade of overhanging bushes (King \& Baisas 1936). Immatures were also taken from rock holes that varied in diameter from a few centimeters to several meters. Green algae were sometimes present and the rock holes were always well shaded. Larvae were found chiefly in the rainy season (Russell \& Baisas 1934a); once in a tree hole (Baisas 1936a; Russell et al. 1943). Nothing is known about the bionomics of the adults and their relation to malaria transmission.

Systematics. Anopheles cristatus can be recognized by having the following combination of characters: 1) ASP usually absent on vein C, occasionally present; 2) ASP spot often fused with SP spot on vein R and sometimes on vein $C$; 3 ) midtarsomere 1 dark-scaled, occasionally with 1,2 small pale spots on dorsal surface; 4) midtarsomere 2-4 dark-scaled or with short, inconspicuous apical pale spots on dorsal surface; 5) dark extension on white apical band of hindtibia short, extending about 0.5 length; 6 ) split of cell $\mathrm{M}_{1+2}$ distal to split of cell $\mathrm{R}_{2 .}$ 7) PHP spot absent on vein C. Fourth-instar larva: 1) seta 3-C distinctly branched; 2) seta 4-C strongly developed, branched, somewhat plumose; 3) seta 4-C extending well beyond base of $2-\mathrm{C}$; 4) seta $5-\mathrm{C}$ noticeably longer than antenna; 5) basal tubercle of 1-P separated from that of 2,3-P; 6) basal sclerotized tubercles of seta 1,2-P with short blunt teeth arising from posterodorsal; 7) seta 3-T well developed, palmate, with 9,10 leaflets; 8) seta 1-II less developed than seta 1-III-VI. The pupa of An. cristatus is indistinguishable from those of An. riparis and An. macarthuri.

\section{Anopheles (Cellia) macarthuri Colless}

(Figs. 5, 7, 8, 47-52, 59)

Anopheles riparis macarthuri Colless (1956b:67-70) (F*, $\mathrm{M}^{*}, \mathrm{P}^{*}$, $\left.\mathrm{L}^{*}\right)$. Holotype female with associated larval and pupal exuviae on microscope slide, deposited in the NHM.

Anopheles riparis macarthuri of Sandosham (1959:198); Macdonald \& Traub (1960:79) (bionomics notes); Chow (1961:WHO/MAL/ 290) (distribution, F, identification key); Scanlon \& Sandhinand (1965:61) (distribution); Peyton \& Scanlon (1966:7, 24, 34) (F*, identification key); Scanlon et al. (1967:78) (taxonomic, bionomics notes), (1968a:27) (checklist); Rattanarithikul \& Harrison (1973:13) (L, identification key); Tsukamoto et al. (1987:291) (checklist).

Anopheles leucosphyrus of Gater (1935:186) (F*, M*); Crawford (1938) (P).

Anopheles leucosphyrus var. riparis of Reid (1949:44, 50) (A, identification key, distribution); Bonne-Wepster \& Swellengrebel (1953:287, 301) (M*, F*, L, A, identification key).

Anopheles macarthuri of Hii et al. (1988a:41) (elevated to species status); Peyton (1989:197) (taxonomy); Harrison et al. (1990:205) (bionomics, distribution notes).

Female (Figs. 5, 7, 8). Head: proboscis uniformly darkscaled, length $1.42-2.00 \mathrm{~mm}($ mean $=1.80 \mathrm{~mm})$, ratio of length to forefemur $0.90-0.99($ mean $=0.95)$, maxillary palpus $($ Fig. 7$)$ length $1.34-1.85 \mathrm{~mm}$ (mean $=1.69 \mathrm{~mm})$, ratio of length to proboscis $0.88-0.98$ (mean $=0.94)$, ratio of length to forefemur $0.82-0.97($ mean $=0.90)($ Table 2$)$, ratio of length of palpomeres $3 / 41.82-2.50($ mean $=2.10), 3 / 52.22-3.57($ mean $=2.84), 4 / 51.07$ - 
Table 43. Number of branches for setae of the pupa of An. cristatus: range (mode).

\begin{tabular}{|c|c|c|c|c|c|c|c|c|c|c|c|}
\hline \multirow{2}{*}{$\begin{array}{l}\text { Seta } \\
\text { No. }\end{array}$} & \multirow{2}{*}{$\begin{array}{l}\text { Cephalothorax } \\
\text { CT }\end{array}$} & \multicolumn{9}{|c|}{ Abdominal segments } & \multirow{2}{*}{$\begin{array}{c}\text { Paddle } \\
\mathrm{Pa}\end{array}$} \\
\hline & & I & II & III & IV & $\mathrm{V}$ & VI & VII & VIII & IX & \\
\hline 0 & - & - & 1 & 1 & 1 & 1 & 1 & 1 & 1 & - & - \\
\hline 1 & $3-4(3)$ & n.c. & $10-12(10)$ & $5-10(9)$ & $3-7(4)$ & $2-4(3)$ & $3-5(3)$ & $1-3(1)$ & - & 1 & $1-2(2)$ \\
\hline 2 & $2-3(3)$ & $6-9(8)$ & $4-6(4)$ & $4-6(5)$ & $2-3(2)$ & $1-3(2)$ & $1-3(3)$ & $2-3(3)$ & - & - & $1-2(2)$ \\
\hline 3 & $2-3(2)$ & $1-2(2)$ & $3-5(5)$ & $4-7(4)$ & $6-10(9)$ & $3-5(4)$ & 2 & $2-3(3)$ & - & - & - \\
\hline 4 & $3-5(3)$ & $3-6(5)$ & $4-8(8)$ & $4-6(6)$ & $3-6(6)$ & $2-6(4)$ & $2-4(4)$ & $1-2(1)$ & $2-3(2)$ & - & - \\
\hline 5 & $3-4(4)$ & $3-4(4)$ & $2-3(2)$ & $6-11(6)$ & $6-11(6)$ & $6-9(8)$ & $6-13(7)$ & $7-12(10)$ & - & - & - \\
\hline 6 & 3 & $2-3(3)$ & $1-3(2)$ & $1-2(2)$ & $1-2(2)$ & $1-2(2)$ & $1-2(2)$ & $1-3(1)$ & - & - & - \\
\hline 7 & $2-3(3)$ & $4-6(4)$ & $4-7(5)$ & $3-5(4)$ & $3-6(3)$ & $3-4(4)$ & 2 & 2 & - & - & - \\
\hline 8 & $2-3(2)$ & - & - & $2-4(3)$ & $2-3(2)$ & $2-3(3)$ & $1-2(2)$ & 2 & - & - & - \\
\hline 9 & $1-3(3)$ & 1 & 1 & 1 & 1 & 1 & 1 & 1 & $11-15(12)$ & - & - \\
\hline 10 & $4-6(5)$ & - & - & $2-4(2)$ & 2 & $1-2(2)$ & $2-3(2)$ & 2 & - & - & - \\
\hline 11 & $2-3(3)$ & - & - & 1 & 1 & 1 & 1 & 2 & - & - & - \\
\hline 12 & $2-4(3)$ & - & - & - & - & - & - & - & - & - & - \\
\hline 13 & - & - & - & - & - & - & - & - & - & - & - \\
\hline 14 & - & - & - & - & 1 & 1 & 1 & 1 & 1 & - & - \\
\hline
\end{tabular}

n.c. $=$ not counted

$1.86($ mean $=1.36), 4-5 / 30.72-1.00($ mean $=0.87)$, palpomeres 2 4 with narrow apical silvery white bands, band on palpomere 4 larger than those on palpomeres 2,3 , pale scales on palpomere 5 pale cream-colored to yellowish, length of apical pale band of palpomere $50.40-2.50($ mean $=1.36)$ length of basal dark band of palpomere 5, ratio of length of apical pale band of palpomere 4 to length of basal dark band of palpomere 50.40 $2.33($ mean $=1.00)($ Table 3$)$. Thorax: pleural setae as follows: 1,2 upper proepisternal, 1-4 prespiracular, 3-6 prealar, 3-6 upper mesokatepisternal, 2,3 lower mesokatepisternal, 2-4 upper mesepimeral. Wing (Fig. 5): length 2.88-3.64 mm (mean =3.22 $\mathrm{mm}$ ), pale scales on all veins light cream-colored, none strongly contrasting with others, HP, SCP, PP, and AP spots slightly more cream-colored bordering to yellowish, PHP spot of vein $\mathrm{C}$ usually present and prominent, rarely absent in one or both wings, HP spot always present and prominent, PSP spot present and prominent, rarely inconspicuous, SP spot always present and prominent, ASP spot usually absent on vein $\mathrm{C}$, rarely reaching inner side of vein, never complete on vein $C$, PP spot 0.71-2.13 $($ mean = 1.24) length of SCP spot, AD spot 1.00-2.50 (mean = 1.69) length of PP spot, PSD spot of vein $R$ extending basally to level 1 (Table 4), PSD spot of vein R without pale interruption (Table 5), SD spot of vein $\mathrm{R}$ with 1 pale interruption (Table 6), sum of pale interruptions on PSDPD spots of vein R 1,2 for each wing, ratio of length of cell $R_{2}$ to vein $R_{2+3} 1.24-1.93$ (mean $\left.=1.46\right)$, ratio of length of cell $R_{2}$ to cell $\mathrm{M}_{1+2}$ 1.14-1.39 $($ mean =1.26). Legs $($ Fig. 8): femora, tibiae, foretarsomere, and hindtarsomere 1 dark-scaled speckled with pale spots, midtarsomere 1 mostly dark-scaled with 1-5 pale spots, pale spots more or less noticeably; foretarsomeres 2,3 with conspicuous basal and apical pale bands, foretarsomere 2 with pale spots in middle dark area of dorsal surface, foretarsomere 4 with basal pale band and short apical pale band, foretarsomere 5 dark-scaled or with few apical pale scales, foretarsomeres 2-4 dark-scaled on ventral surface; midtarsomere 2 with basal pale scales, occasionally with narrow apical pale band, midtarsomeres 3,4 dark-scaled, occasionally with narrow apical patches of pale scales, midtarsomere 5 darkscaled; hindtarsomeres 2-4 with apical pale band, hindtarsomere 5 dark-scaled. Abdomen: terga VI,VII without scales, tergum VIII with few apical yellowish scales, rarely without scales; sterna VI,VII without scales, sternum VIII usually without scales, occasionally with 2-4 lateral pale scales.

Male. Essentially as in female except for sexual characters. Wing generally paler with reduced scaling, pale spots usually longer than in female. Palpomere 2 with dorsal patch of pale scales at middle, apex of palpomere 2 bare; palpomere 3 with long dorsal patch of pale scales at middle extending laterally, apex of palpomere 3 with broad band of pale scales covering dorsal, lateral, and ventral surfaces; palpomere 4 mainly palescaled with narrow basal band of dark scales; palpomere 5 mainly pale-scaled with basal patches of dark scales on ventral and dorsal surfaces, sometimes becoming narrow dark band, palpomeres 4,5 occasionally with narrow line of dark scales extending to ventral surface, rarely palpomeres 4,5 entirely pale-scaled. Genitalia: 4 large parabasal setae; ventral claspette with 1 long, apicolateral seta, longer than dorsal claspette club, 1 short, slender apicomedial seta and 1 short subapical seta, ventral claspette setae arising from short protuberance; dorsal claspette with 4,5 apical setae fused into stout club with distinct basal stems; aedeagus elongate, columnar, dorsally curved with 6-9 leaflets on each side of tip, leafletes serrate on one or both edges.

Pupa (Fig. 47). Position and development of setae as figured; range and modal number of branches in Table 45. All measurements from 22-26 specimens. In general similar to $A n$. riparis except for the following characters. Cephalothorax: seta 8-CT single to 4-branched, 9-CT with 1-5 branches. Seta 9-II usually short and stout, rarely slender and pointed, 9-III-VII lightly pigmented, 9-VIII pigmented light brown, slightly darker at base. Abdomen: seta 6-I single to 4-branched; 1-II with 1025 branches, 6-II single to 4-branched, 9-II length 0.01-0.02 
Table 44. Number of branches for setae of the larva of An. cristatus: range (mode).

\begin{tabular}{|c|c|c|c|c|c|c|c|c|c|c|c|c|c|}
\hline \multirow{2}{*}{$\begin{array}{l}\text { Seta } \\
\text { No. }\end{array}$} & \multirow{2}{*}{$\begin{array}{c}\text { Head } \\
\mathrm{C}\end{array}$} & \multicolumn{3}{|c|}{ Thorax } & \multicolumn{9}{|c|}{ Abdominal segments } \\
\hline & & $\mathrm{P}$ & $\mathrm{M}$ & $\mathrm{T}$ & $\mathrm{I}$ & II & III & $\mathrm{IV}$ & $\mathrm{V}$ & $\mathrm{VI}$ & VII & VIII & $\mathrm{X}$ \\
\hline 0 & 1 & 1 & - & - & - & 1 & 1 & 1 & 1 & 1 & 1 & 1 & 1 \\
\hline 1 & 1 & $15-18(15)$ & $28-31$ & 1 & $2-6(3)$ & $11-24(11)$ & $20-22(22)$ & $18-20(19)$ & $18-19(18)$ & $17-18(17)$ & $12-14(13)$ & 1 & 1 \\
\hline 2 & 1 & $12-14(14)$ & $1-3(1)$ & 1 & 1 & $4-5(4)$ & 3 & 2 & 2 & $2-3(2)$ & $2-4(3)$ & $4-5(4)$ & n.c. \\
\hline 3 & 1 & 1 & 1 & $9-10(9)$ & $1-2(1)$ & 1 & 1 & $2-3(2)$ & 1 & 1 & $2-3(2)$ & $2-3(2)$ & n.c. \\
\hline 4 & 1 & $14-16(16)$ & 2 & 2 & $3-5(4)$ & $4-6(6)$ & $2-3(2)$ & $1-2(2)$ & $1-2(2)$ & 1 & 1 & 1 & 9 \\
\hline 5 & $9-15$ & n.c. & 1 & $32-39(32)$ & 3 & $4-5(4)$ & $3-4(4)$ & 3 & 3 & 3 & 3 & $2-3(3)$ & - \\
\hline 6 & $11-14(13)$ & 1 & 3 & 2 & $16-18(18)$ & $20-22(20)$ & $6-14(6)$ & $2-6(3)$ & $2-4(3)$ & $2-3(3)$ & $2-3(2)$ & $1-S$ & $3-4(3)$ \\
\hline 7 & $9-16$ & 28 & $2-3(3)$ & $24-31$ & $15-17(15)$ & $19-21(20)$ & 3 & 3 & 3 & $2-3(3)$ & $2-3(2)$ & $2-S$ & $2-3(2)$ \\
\hline 8 & $1-2(1)$ & 32 & $25-28$ & $29-31$ & - & $1-2(2)$ & 2 & $2-3(2)$ & $2-3(2)$ & 2 & 3 & $6-\mathrm{S}$ & 2 \\
\hline 9 & $1-2(2)$ & 1 & 1 & 1 & $5-6(6)$ & $7-8(8)$ & $5-7(6)$ & $4-7(5)$ & 5 & $4-5(5)$ & 3 & $7-S$ & 2 \\
\hline 10 & 2 & 1 & 1 & 1 & 1 & $2-4(2)$ & 1 & 1 & 1 & $2-3(2)$ & $4-5$ & 8-S & 3 \\
\hline 11 & $19-28(28)$ & 1 & 1 & 1 & $3-4(3)$ & 1 & 1 & 2 & 1 & 2 & 1 & 9-S & 2 \\
\hline 12 & 2 & 1 & 1 & $1-3(2)$ & $3-4(3)$ & 1 & $1-2(2)$ & $1-2(1)$ & 2 & $1-2(1)$ & 1 & - & - \\
\hline 13 & $3-5(4)$ & 4 & $5-7(6)$ & $1-3(2)$ & $4-6(5)$ & $3-5(3)$ & 3 & $2-3(3)$ & 3 & $4-5(4)$ & $2-3(2)$ & - & - \\
\hline 14 & $4-8$ & $6-13(10)$ & $7-9(7)$ & - & - & - & - & 1 & 1 & 1 & 1 & 1 & - \\
\hline 15 & 3 & - & - & - & - & - & - & - & - & - & - & - & - \\
\hline
\end{tabular}

n.c. $=$ not counted

$\mathrm{mm}($ mean $=0.01 \mathrm{~mm}) ; 1$-III with 3-11 branches, 5-III with 3-13 branches, 6-III single to 4-branched, 9-III length 0.01-0.02 mm (mean $=0.02 \mathrm{~mm}$ ); 6-IV single or double, 9-IV length 0.02-0.06 $\mathrm{mm}($ mean $=0.03 \mathrm{~mm})$, ratios of length of 9-IV/9-III 1.00-4.92 $($ mean $=1.72)$ and 9-IV/9-V 0.12-0.57 $($ mean $=0.21)$; 6-V single or double, $9-\mathrm{V}$ rarely with few minute spicules, length 0.10 $0.14 \mathrm{~mm}($ mean $=0.12 \mathrm{~mm})$; 1-VI single to 3-branched, 6-VI single or double, 9-VI rarely with few minute spicules, length 0.11-0.14 mm $($ mean $=0.12 \mathrm{~mm})$; 5-VII with 5-12 branches, 6-VII single to triple, 9-VII rarely with few minute spicules, length $0.10-0.14 \mathrm{~mm}($ mean $=0.12 \mathrm{~mm})$; 9 -VIII with $10-17$ branches. Paddle: toothed margin index 0.71-0.86 $($ mean $=0.80)$.

Larva (Figs. 47-52). Position and development of setae as figured; range and modal number of branches in Table 46. All measurements from 10-24 specimens. In general similar to $A n$. riparis except for the following characters. Head: integument with dark spots similar to those of An. riparis except for presence of dark spot on dorsal apoteme laterally between insertions of setae 7-C and 8-C; length 0.57-0.68 mm (mean = $0.61 \mathrm{~mm}$ ), width $0.57-0.66 \mathrm{~mm}$ (mean $=0.62 \mathrm{~mm})$; antenna length $0.26-0.30 \mathrm{~mm}$ (mean $=0.27 \mathrm{~mm})$; seta $3-\mathrm{C}$ length $0.06-0.08 \mathrm{~mm}$ $($ mean $=0.07 \mathrm{~mm})$, distance between base of 2-C and 3-C 0.03$0.04 \mathrm{~mm}($ mean $=0.03 \mathrm{~mm}), 4-\mathrm{C}$ single or double, length 0.05 $0.09 \mathrm{~mm}($ mean $=0.07 \mathrm{~mm})$, distance between basal insertions of $2-\mathrm{C}$ and $4-\mathrm{C} 0.06-0.08 \mathrm{~mm}$ (mean $=0.07 \mathrm{~mm}$ ), ratio of length of 4-C to distance between the insertions of 2-C and 4-C 0.61$1.47($ mean $=1.06)$, distance between base of 3-C and 4-C 0.05$0.07 \mathrm{~mm}($ mean $=0.06 \mathrm{~mm}), 5-\mathrm{C}$ extending beyond anterior margin of head. Thorax: tubercles of seta 1,2-P usually joined basally, rarely entirely separate from each other in one or both sides, both tubercles with prominent broad blunt apical tooth projecting over base of each seta, 4-M single to 4-branched, 14-M with 4-10 branches; 3-T (Fig. 52) with 5-10 leaflets. Abdomen: seta 1-I palmate, with 2-8 narrow lanceolate nearly transparent leaflets, 2-I single to 4-branched, 9-I with 5-8 branches; 1-II (Fig. 51) with 6-15 leaflets; ratio of length of 13IV to 10-IV 0.30-0.46 (mean =0.39); 1-VII (Fig. 50) with 8-18 leaflets; 10-14 pecten spines (Fig. 49), 3-5 long spines alternating with 7-10 short spines.

Type data. Holotype female with associated larval and pupal exuviae deposited in the NHM. Type locality: East Malaysia, Sarawak, Long Tebangan, Fourth Division.

Material examined. Seven hundred five specimens as follow: $114 \mathrm{~F}$, $99 \mathrm{M}, 97 \mathrm{Le}, 139 \mathrm{Pe}, 256 \mathrm{~L}$, derived from 159 separate collections from natural habitats (13 adult, 146 immature). MALAYSIA (EAST). Sabah: Beaufort $\left(5^{\circ} 20^{\prime} \mathrm{N} 115^{\circ} 45^{\prime} \mathrm{E}\right),[\mathrm{S}-301], 1$ Apr. 1970, 1M, 1L; Mt. Kinabalu (General, 6 $\left.{ }^{\circ}{ }^{\prime} \mathrm{N} 116^{\circ} 33^{\prime} \mathrm{E}\right)$, [S-208], 23 Mar. 1970, 1L; [S-211], 24 Mar. 1970, 3L; [S-212], 24 Mar. 1970, 1F, 1M, 1Pe; [S217], 24 Mar. 1970, 2M, 1LePe, 1Pe; [S-218], 24 Mar. 1970, $1 \mathrm{M}$.

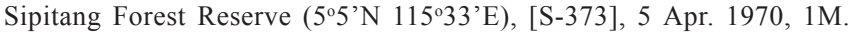
(U. Malaya). Sarawak: Long Tebangan, $4^{\text {th }}$ District $\left(3^{\circ} 22^{\prime} \mathrm{N} 114^{\circ} 52^{\prime} \mathrm{E}\right)$, [LT/8/4, LT/8/8, LT/8/10. LT/12/12], July 1953, 2F, 2M, 4LePe, (holotype and paratypes) (D.H. Colless). MALAYSIA (WEST). Malaya: (central, $\left.4^{\circ} 00^{\prime} \mathrm{N} 102^{\circ} 00^{\prime} \mathrm{E}\right), 10$ Jan. 1904, $1 \mathrm{~F}$ (G.F. Leicester), [483, E8, E9], 1920, 1F, 2Le; [479,F1,F2], 2M, [967/83], 1LePe. Negeri Sembilan: Angasi Forest Reserve ( $\left.2^{\circ} 41^{\prime} \mathrm{N} 102^{\circ} 7^{\prime} \mathrm{E}\right)$, Sept. 1969, 1F. Ulu Bendol (2 $\left.{ }^{\circ} 44^{\prime} \mathrm{N} 102^{\circ} 8^{\prime} \mathrm{E}\right)$, [391/5], 2 June 1949, 1F, 1M (J.A. Reid). Kuala Pilah $\left(2^{\circ} 44^{\prime} \mathrm{N} 102^{\circ} 15^{\prime} \mathrm{E}\right)$ [391/6], June 1949, 1F, 1LePe (J.A. Reid); [393/3], 1Le (D.H. Colless). Pahang: Gunong Benom, near base of Mountain (general, $3^{\circ} 58^{\prime} \mathrm{N} 102^{\circ} 6^{\prime} \mathrm{E}$ ), [508], 21 Mar. 1967, 3L; [509], 21 Mar. 1967, 1F, 1M, 2LePe, 2L; [515], 22 Mar. 1967, 1M; [519], 23 Mar. 1967, 1M; [530], 27 Mar. 1967, 2F, 1LePe, 1Pe; [513], 27 Mar. 1967, 1F, 1Pe, 1L; [532], 27 Mar. 1967, 1F, 1L; [537], 28 Mar. 1967, 1L; [538], 28 Mar. 1967, 1F, 1M, 2Pe (IMR). Perak: Cameron Highlands Road, $13^{\text {th }}$ and $23^{\text {rd }}$ mile (general, $4^{\circ} 29^{\prime} \mathrm{N} 101^{\circ} 23^{\prime} \mathrm{E}$ ), [1571], 24 July 1968, 1F, 3L; [1615], 29 July 1968, 2F; [1634], 30 July 1968, 1F, 2L (U. Malaya). Maxwell's Hill, Taiping (451'N $\left.100^{\circ} 44^{\prime} \mathrm{E}\right)$, [1450], 30 June 1968, 1LePe (U. Malaya). Penang [Pinang]: (State of: $5^{\circ} 21^{\prime} \mathrm{N} 100^{\circ} 20^{\prime} \mathrm{E}$ ), no date, 2L (S.T. Darling, ca. 1920). Selangor: (general, $\left.3^{\circ} 10^{\prime} \mathrm{N} 101^{\circ} 30^{\prime} \mathrm{E}\right)$, [00.050], 19 July 1965, 2F, 2M (USAMRU); $7^{\text {th }}$ mile, Kuala Lumpur, 2 Sept. $1903,1 \mathrm{M} ; 6^{\text {th }}$ mile, Kuala Lumpur, 31 Oct. 1903, 1F; Pahang Road, 10 Jan. 1903, 1F (G.F. Leicester). Bukit Kutu ( $\left.3^{\circ} 11^{\prime} \mathrm{N} 101^{\circ} 36^{\prime} \mathrm{E}\right)$, [1309], 14 May 1968, 1L (U. Malaya). Bukit Lanjan ( $\left.3^{\circ} 11^{\prime} \mathrm{N} 101^{\circ} 36^{\prime} \mathrm{E}\right), 24$ Feb. 1970, 1F; 25 Feb. 1970, 1F; 2 Mar. 1970, 1F; 26 Feb. 1970, 1F; 11 June 1971, 1F (R.G. Andre). Kepong ( $\left.3^{\circ} 13^{\prime} \mathrm{N} 101^{\circ} 38^{\prime} \mathrm{E}\right)$, [638/18], 26 June 1953, 1F 
(J.A. Reid). Ulu Gombak, 12 $2^{\text {th }}$ mile, [071], 28 Sept. 1965, 1F; $15^{\text {th }}$ mile, [026], 7 July $1965,1 \mathrm{M}$ (USAMRU); $17^{\text {th }}$ mile $\left(3^{\circ} 18^{\prime} \mathrm{N} 101^{\circ} 46^{\prime} \mathrm{E}\right)$, [0130], 21 Jan. 1957, 1F, 1M; $18^{\text {th }}$ mile $\left(3^{\circ} 19^{\prime} \mathrm{N} 101^{\circ} 46^{\prime} \mathrm{E}\right)$, [199], 2 Sept. 1966, 1F, 1LePe; 23 1/2 mile ( $\left.3^{\circ} 20^{\prime} \mathrm{N} 101^{\circ} 47^{\prime} \mathrm{E}\right)$, [217], 16 Sept. 1966, $1 \mathrm{~F}, 1 \mathrm{LePe}$ (U. Malaya); $16^{\text {th }}$ mile $\left(3^{\circ} 18^{\prime} \mathrm{N} 101^{\circ} 45^{\prime} \mathrm{E}\right)$, [231/6],

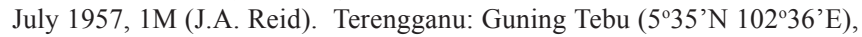
7 Aug. 1958, [0608/5], 1F (W.W. Macdonald). Kampong Tapah: Kuala Berang, (5 $\left.4^{\circ} \mathrm{N} 103^{\circ} 1{ }^{\prime} \mathrm{E}\right),[10-8,10-13], 15$ Aug. 1973, $1 \mathrm{~F}, 1 \mathrm{M}$ (USAMRU). THAILAND. Nakhon Si Thammarat: Ban Thuan Lek ( $\left.8^{\circ} 27^{\prime} \mathrm{N} 99^{\circ} 45^{\prime} \mathrm{E}\right),[01080], 10$ June 1966, 2L; ( $\left.8^{\circ} 26^{\prime} \mathrm{N} 99^{\circ} 47^{\prime} \mathrm{E}\right)$, [01146], 15 June 1966, 1L. Chong Khao ( $\left.8^{\circ} 10^{\prime} \mathrm{N} 99^{\circ} 45^{\prime} \mathrm{E}\right)$, [01073], 8 June 1966, 7L. Khao Luang ( $8^{\circ} 26^{\prime} \mathrm{N}$ 99 $\left.46^{\circ} \mathrm{E}\right)$, [01133], 4 June 1966, 4L; [01138], 14 June 1966, 3L. Narathiwat: Yingo, Bo Cho

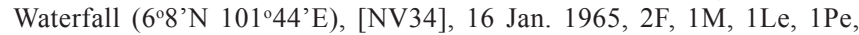
3L. Bacho, near Huai Ta Yung Ru Mae Ko Waterfall (6 $\left.{ }^{\circ} 31^{\prime} \mathrm{N} 101^{\circ} 37^{\prime} \mathrm{E}\right)$, [NV47], 17 Jan. 1965, 1M, 5L. Bacho, (Belou) Todo Waterfall, [NV48], 17 Jan. 1965, 1M, 3L; [NV49], 17 Jan. 1965, 1L; [NV50], 17 Jan. 1965, 1L; [NV51], 17 Jan. 1965, 1M, 1Pe, 3L; [NV52], 17 Jan. 1965, 1F, 4L; [NV54], 17 Jan. 1965, 1L; [NV55], 17 Jan. 1965, 1L; [NV56], 17 Jan. 1965, 1L. Waeng, Soi Teo 5 (5 $\left.56^{\circ} \mathrm{N} 101^{\circ} 54^{\prime} \mathrm{E}\right)$, [NV74], 22 Feb. 1965, 1L; [NV77], 22 Feb. 1965, 1L. Kilometer 11 between Waeng and Soi Teo, [NV80], 23 Feb. 1965, 2F, 2LePe; Waeng, [NV97], 2 Mar. 1965, 1F, 1M, 1LePe, 1Pe; [NV98], 2 Mar. 1965, 1F, 3L; [NV99], 2 Mar. 1965, 1M; Waeng, kilometer 12, Ban Mamong, New Settlement, [NV100], 4 Mar. 1965, 2F, 1M, 1Pe, 1L; [NV101], 4 Mar. 1965, 1F, 1M; [NV103], 4 Mar. 1965, 2L; [NV104], 4 Mar. 1965, 3F,

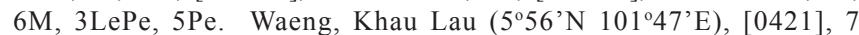
Sept. 1965, 17L; [0422], 7 Sept. 1965, 1F, 2Pe; [0423], 7 Sept. 1965, 1M, 1Pe; [0424], 7 Sept. 1965, 1L; [0425], 7 Sept. 1965, 1F, 1M, 2Pe, 2L; [0429], 7 Sept. 1965, 1M, 1Pe, 2L; (556'N 101 $\left.{ }^{\circ} 48^{\prime} \mathrm{E}\right)$, [0450], 8 Sept. 1965, 1F, 1M; [0451], 8 Sept. 1965, 17L; [0460], 8 Sept. 1965, $1 \mathrm{M}, 1 \mathrm{Pe} ;\left(5^{\circ} 56^{\prime} \mathrm{N} 101^{\circ} 49^{\prime} \mathrm{E}\right),[0471]$, 9 Sept. 1965, 1Pe; [0473], 9 Sept. 1965, 1L; [0474], 9 Sept. 1965, 1L; [0480], 11 Sept. 1965, 10L.

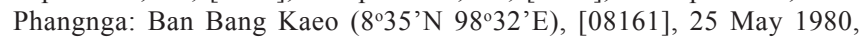
3M, 3LePe; [08162], 25 May 1980, 3M, 1LePe; [08628], 29 June 1980, 5F, 4LePe, 1Pe; [TH498], 28 May 1987, 2F, 1LePe, 1Pe, 2L; [TH499], 28 May 1987, 5F, 2M, 6LePe, 1Pe, 1L; [TH500], 28 May 1987, 6F, 1M, 2LePe, 1Pe, 3L. Ban Bang Ra Ko ( $\left.8^{\circ} 38^{\prime} \mathrm{N} 98^{\circ} 32^{\prime} \mathrm{E}\right)$, [08166], 26 May 1980, 2L; [08167], 26 May 1980, 1Le; [08169], 26 May 1980, 2F, 2LePe, 1L; [08170], 26 May 1980, 1F, 1LePe; [08183], 29 May 1980, 3L; [08213], 3 June 1980, 2L; [TH485], 26 May 1987, 5F, 1M, 4LePe, 2Pe, 4L. Ban Bang Miang ( $\left.8^{\circ} 32^{\prime} \mathrm{N} 98^{\circ} 33^{\prime} \mathrm{E}\right)$, [08634], 30 June 1980, 1LePe. Phattalung: 41 kilometer, Pattalung to Trang Road (7³0'N 99 $\left.55^{\prime} \mathrm{E}\right)$, [PU17], 15 Oct. 1964, 1LePe. Puket: Khao Prathiu $\left(8^{\circ} 1^{\prime} \mathrm{N} 98^{\circ} 22^{\prime} \mathrm{E}\right),[02506], 26 \mathrm{Feb} .1968,1 \mathrm{M}, 1 \mathrm{Pe}, 4 \mathrm{~L}$; [02507], 26 Feb. 1968, 2M, 2LePe; [02508], 26 Feb. 1968, 2M, 1LePe, 1Pe, 9L; [02509], 26 Feb. 1968, 6F, 2M, 5LePe, 2Pe, 7L; [02510], 26 Feb. 1968, 3L; [02514], 26 Feb. 1968, 1F, 1Pe, 6L; [02517], 26 Feb. 1968, 4L; [02518], 26 Feb. 1968, 2L; [02519], 26 Feb. 1968, 1L; Bang Khian, [02522], 27 Feb. 1968, 2L. Ban Huai Luk (7'56' N 98²0'E), [02526], 27 Feb. 1968, 1F, 1M, 2LePe, 4L; [02527], 27 Feb. 1968, 1F, 1Pe. Ranong: Ban Set Takuat (106'N 98 $\left.41^{\prime} \mathrm{E}\right)$, [02610], 20 Mar. 1968, 1M, 1Pe; [02611], 20 Mar. 1968, 1M, 1LePe, 6L; [02614], 20 Mar. 1968, 1M, 1Pe, 1L. Songkhla: Rattaphum, 50 kilometers from Hat Yai, road to Satun, Boriphat Waterfall $\left(7^{\circ} 5^{\prime} \mathrm{N}\right.$ $100^{\circ} 14^{\prime} \mathrm{E}$ ), [SL-3], 16 Mar. 1965, 1M; [SL-5], 16 Mar. 1965, 2M, 1LePe, 2L; [SL-7], 16 Mar. 1965, 1M, 1LePe, 4L; [SL-10] 16 Mar. 1965, 4L; [SL-20], 17 Mar. 1965, 2L; [SL-33], 20 Mar. 1965, 3L; [SL36], 20 Mar. 1965, 2L; [SL-38], 20 Mar. 1965, 3L. Ton Nga Chang Waterfall $\left(6^{\circ} 54^{\prime} \mathrm{N} 100^{\circ} 15^{\prime} \mathrm{E}\right)$, [SL-47], 22 Mar. 1965, 2M, 3Pe; [SL57], 22 Mar. 1965, 2F, 1M, 2LePe; [SL-68], 23 Mar. 1965, 1L; [SL69], 23 Mar. 1965, 1L; [SL-74], 24 Mar. 1968, 1L; [SL-75], 25 Mar. 1965, 1F, 1LePe, 2L; [SL-87], 27 Mar. 1965, 1M (all above, AFRIMS). Trang: (general, 7³0’N 99³0’E), Aug. 1933, 1M (O.R. Causey). Chong, Village No. 1, [31], 13 Apr. 1960, 2F, 3M, 4LePe, 1Pe, 12L; [43], 29 Apr. 1960, 2L; [49], 10 May 1960, 4L; [50], 10 May 1960, 2L; [54], 24 May 1960, 1LePe (E.L. Coher and P.F. Beales). Khao Kra Chong ( $\left.7^{\circ} 33^{\prime} \mathrm{N} 99^{\circ} 48^{\prime} \mathrm{E}\right)$, [TG-22], 7 Oct. 1964, 3F, 1M. Ton Nam Plue Waterfall, National Park $\left(7^{\circ} 33^{\prime} \mathrm{N} 99^{\circ} 48^{\prime} \mathrm{E}\right)$, [TG-94], 11 Oct.

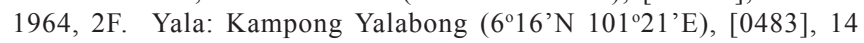

Sept. 1965, 1F, 2Pe; [0485], 14 Sept. 1965, 1F, 2M, 1LePe, 2Pe. Kg. Yalabong $\left(6^{\circ} 15^{\prime} \mathrm{N} 101^{\circ} 21^{\prime} \mathrm{E}\right),[0486], 14$ Sept. 1965, 2L; [0489], 14 Sept. 1965, 3L; [0492], 14 Sept. 1965, 1F, 1M, 1LePe, 1Pe; [0495], 14 Sept. 1965, 1F, 2M, 1LePe, 2Pe; [0496], 14 Sept. 1965, 3L; [0497], 14 Sept. 1965, 1F, 1LePe, 4L; [0499], 14 Sept. 1965, 2L; [0503], 14 Sept. 1965, 1F, 1LePe; [523], 16 Sept. 1965, 1F, 1Pe; [0524], 15 Sept. $1965,1 \mathrm{~F}, 1 \mathrm{Pe} . \mathrm{Kg}$. Yalabong $\left(6^{\circ} 16^{\prime} \mathrm{N} 101^{\circ} 22^{\prime} \mathrm{E}\right)$, [0512], 14 Sept. 1965, 5L; [0513], 15 Sept. 1965, 1L; [0514], 15 Sept. 1965, 2L; [0516], 15 Sept. 1965, 2F, 2M, 1LePe, 1Pe, 2L; [0518], 15 Sept. $1965,1 \mathrm{~F}, 1 \mathrm{M}, 1 \mathrm{LePe}, 1 \mathrm{Pe}$. Kg. Yalabong (6 $\left.{ }^{\circ} 15^{\prime} \mathrm{N} 101^{\circ} 23^{\prime} \mathrm{E}\right)$, [0519], 16 Sept. 1965, 1F, 1L; Kg. Yalabong (6 $\left.{ }^{\circ} 16^{\prime} \mathrm{N} 101^{\circ} 18^{\prime} \mathrm{E}\right)$, [0521], 16 Sept. 1965, 5F, 4M, 5LePe, 2Pe (all above, AFRIMS).

Distribution (Fig. 59). Anopheles macarthuri is known from East Malaysia (Sabah, Sarawak), West Malaysia (Negeri Sembilan, Pahang, Perak, Penang [Pinang], Selangor, Terengganu, Kampong Tapah), and Thailand (Nakhon Si Thammarat, Narathiwat, Phangnga, Phattalung, Puket, Ranong, Songkhla, Trang, Yala).

Bionomics and medical importance. In West Malaysia, immatures of An. macarthuri breed in clean seepage pools and side pools of streams (Macdonald \& Traub 1960). Immatures were also found in pools in the course of hillside streams, edges of hillside streams, streams pocket pools, ground pools beside rivers, stream pools, ground pools, roadside pits, marshy depressions beside streams, stream margins, sandy pools on sides of streams, pools on sides of roads, and seepage pools. They were also found in rock pools, rock pools at the foot of water falls, and rock pools along stream margins and in bamboo. The habitats were inside the jungle, in primary and secondary rain forests situated in valleys or in hilly or mountainous areas at elevation up to $884 \mathrm{~m}$ above sea level. The water was fresh, stagnant, colored or clear, in partial or heavy shade, sometimes with decaying leaves. Immatures were found in association with Ae. albopictus, Oc. saxicola Edwards, Ae. orbitae Edwards, An. bengalensis Puri, An. maculatus, An saungi Colless, An. latens, Cx. foliatus Brug, Cx. fuscanus Wiedmann, Cx. scanloni, Cx. mammilifer, $C x$. papuensis, Cx. halifaxii, Cx. bailyi Barraud, $C x$. bicornutus Theobald, Cx. quadripalpis (Edwards), $C x$. murrelli Lien, and $C x$. minor. Adults were collected with light traps in the canopy of the forest.

In West Malaysia, immatures were taken from pools, sandy pools at the edges of streams with decaying leaves. In Thailand, immatures of An. macarthuri were found in stream margins, stream pools, seepage pools near the base of mountains, seepage pools around rattan clumps, ground pools, elephant footprints, sandy pools $12.70 \mathrm{~cm}$ in diameter, large and small pools near stream margins, shallow stream pools, shallow sandy stream pools, flood pools in dry stream beds, seepage pools near streams, flood pools, seepage springs, sandy pools in banks of streams, small shallow vanishing streams, seepage wells, ground pools, seepage streams, sandy stream pools, elephant wallow, and ground pools in yellow clay. They were also found in natural container habitats, sandy rock pools near water falls, rock pools in stream margins, small and large rock pools along streams, and in fallen tree trunks. The habitats were situated in primary and secondary forest, in 
Table 45. Number of branches for setae of the pupa of An. macarthuri: range (mode).

\begin{tabular}{|c|c|c|c|c|c|c|c|c|c|c|c|}
\hline \multicolumn{2}{|c|}{ Seta Cephalothorax } & \multicolumn{9}{|c|}{ Abdominal segments } & \multirow{2}{*}{$\begin{array}{c}\text { Paddle } \\
\mathrm{Pa}\end{array}$} \\
\hline No. & $\mathrm{CT}$ & I & II & III & IV & $\mathrm{V}$ & VI & VII & VIII & IX & \\
\hline$\overline{0}$ & - & - & 1 & 1 & 1 & 1 & 1 & 1 & 1 & - & - \\
\hline 1 & $2-4(3)$ & $9-25(11)$ & $10-25(18)$ & $3-11(6)$ & $3-6(4)$ & $1-5(3)$ & $1-3(2)$ & $1-3(1)$ & - & 1 & $1-2(1)$ \\
\hline 2 & $2-3(3)$ & $4-12(6)$ & $4-8(6)$ & $3-8(5)$ & $2-4(3)$ & $1-3(2)$ & $1-3(2)$ & $3-5(3)$ & - & - & $1-2(1)$ \\
\hline 3 & $1-3(3)$ & $1-2(1)$ & $1-5(2)$ & $2-6(3)$ & $6-9(7)$ & $2-4(3)$ & $1-2(2)$ & $2-4(3)$ & - & - & - \\
\hline 4 & $1-5(3)$ & $4-8(4)$ & $2-6(4)$ & $2-7(5)$ & $2-6(4)$ & $2-7(4)$ & $1-3(2)$ & $1-3(1)$ & $1-3(3)$ & - & - \\
\hline 5 & $4-6(5)$ & $2-5(3)$ & $2-5(3)$ & $3-13(5)$ & $4-9(6)$ & $5-9(6)$ & $5-9(9)$ & $5-12(6)$ & - & - & - \\
\hline 6 & $1-4(2)$ & $1-4(3)$ & $1-4(2)$ & $1-4(2)$ & $1-2(2)$ & $1-2(1)$ & $1-2(1)$ & $1-3(1)$ & - & - & - \\
\hline 7 & $3-5(3)$ & $3-9(4)$ & $2-7(5)$ & $2-7(6)$ & $2-7(5)$ & $1-5(3)$ & $1-4(2)$ & $1-4(2)$ & - & - & - \\
\hline 8 & $1-4(1)$ & - & - & $2-6(4)$ & $2-5(3)$ & $1-3(2)$ & $2-4(3)$ & $2-6(3)$ & - & - & - \\
\hline 9 & $1-5(3)$ & 1 & 1 & 1 & 1 & 1 & 1 & 1 & $10-17(14)$ & - & - \\
\hline 10 & $2-7(6)$ & - & - & $1-6(3)$ & $1-3(2)$ & $1-3(2)$ & $1-3(2)$ & $2-4(2)$ & - & - & - \\
\hline 11 & $2-4(3)$ & - & - & 1 & $1-2(1)$ & $1-2(1)$ & $1-2(1)$ & $1-3(2)$ & - & - & - \\
\hline 12 & $1-5(3)$ & - & - & - & - & - & - & - & - & - & - \\
\hline 13 & - & - & - & - & - & - & - & - & - & - & - \\
\hline 14 & - & - & - & - & 1 & 1 & 1 & 1 & 1 & - & - \\
\hline
\end{tabular}

n.c. $=$ not counted

hilly and mountainous areas or in valleys, at elevations up to $610 \mathrm{~m}$ above sea level. The water was slow, fresh, stagnant, clear, colored, turbid or with some degree of pollution, sometimes with decaying leaves or without any trace of vegetation. The breeding habitats were partially or heavily shaded or in full sun. In southern Thailand, immatures were taken from rock pools along usually shallow, hill or mountain streams. Adults were never collected biting humans in that area (Harrison et al. 1990).

Systematics. Anopheles macarthuri was described as a subspecies of An. riparis and elevated to species status by Hii et al. (1988a). Anopheles macarthuri can be recognized by possessing the following combination of characters. Adult: 1) ASP spot usually absent on vein $C$, rarely with 2,3 pale scales on vein $C$, never covering the entire vein; 2) ASP short on both $\mathrm{C}$ and $\mathrm{R}$ veins, when present; 3 ) midtarsomere 1 mostly dark-scaled, sometimes with 1-5 pale spots on dorsal surface; 4) midtarsomeres 2-4 mostly dark-scaled or with short apical pale patches on dorsal surface; 5) split of cell $\mathrm{M}_{1+2}$ distal to the split of cell $\mathrm{R}_{2}$; 6) PHP spot usually present, rarely absent; 7) dark extention on apical white band of hindtibia moderately short, extending to about 0.5 length. The fourth-instar larva: 1) seta 3-C single; 2) seta 4-C not strongly developed, ratio of length of 4-C to distance between 4-C and 2-C 0.61-1.47; 2) seta 1-II less developed than 1-III-VI; 3) seta 5-C noticeably longer than antenna; 5) basal sclerotized tubercle of setae 1,2$\mathrm{P}$ with prominent broad rounded posterodorsal lip arising from each tubercle; 4) basal sclerotized tubercles of setae 1,2-P usually joined basally, rarely entirely separate from each other in one or both sides; 5) seta 3-T with 5-10 branches. The pupa is indistinguishable from those of An. riparis and An. cristatus.

\section{TAXONOMIC DISCUSSION}

The adult stage of An. cristatus can be distinguished from that of An. riparis and An. macarthuri in having PHP spot always absent on the vein $\mathrm{C}$, midtarsomere 1 is usually darkscaled, rarely with 1,2 small pale spots on dorsal surface, midtarsomeres 2-4 are dark-scaled, rarely with poorly noticeably apical pale patches on dorsal surface, the ASP spot is usually absent on vein $C$, occasionally small or with 2,3 pale scales, the ASP spot is either fused or separate from the SP spot on vein $\mathrm{R}$ forming a long pale spot which is sometimes fused to the SP on the vein $\mathrm{C}$, the split of cell $\mathrm{M}_{1+2}$ is distal to the split of cell $R_{2}$ and the dark extension on the apical white band of the hindtibia is short, extending to about 0.5 of its length. In An. riparis, the $\mathrm{PHP}$ spot is always present on the vein $\mathrm{C}$, midtarsomere 1 is dark-scaled, speckled with pale spots, midtarsomeres 2-4 are dark-scaled with short, apical pale spots on the dorsal surface, the ASP spot is present and well developed on vein $\mathrm{C}$, the ASP spot is sometimes fused with the SP spot on vein $\mathrm{R}$ and on vein $\mathrm{C}$, forming a long pale spot, the split of cell $\mathrm{M}_{1+2}$ is proximal to the fork of cell $\mathrm{R}_{2}$ and the dark extension on the apical white band of the hindtibia is long, extending to about 0.7 of its length. In An. macarthuri, the PHP spot is usually present on the vein $\mathrm{C}$, rarely absent, midtarsomere 1 is mostly dark-scaled, occasionally with 1-5 pale spots on the dorsal surface, midtarsomeres 2-4 is mostly dark-scaled, with narrow apical pale patches, the ASP spot is usually absent on vein $\mathrm{C}$, rarely with 2 pale scales, never covering the vein $\mathrm{C}$, the split of cell $\mathrm{M}_{1+2}$ is distal to the fork of cell $\mathrm{R}_{2}$ and the dark extension on the apical white band of the hindtibia is short, extending to about 0.5 length.

The fourth-instar larva of An. cristatus can be easily distinguished from those of An. riparis and An. macarthuri by possessing seta 4-C well-developed, branched, somewhat plumose, extending well beyond base of $2-\mathrm{C}$, and seta $3-\mathrm{C}$ is strong, branched, whereas in An. macarthuri seta 4-C is weak, short, not reaching the base of 2-C, usually single, rarely double, and seta 3-C is single and simple. In An. riparis, seta 4-C is weak, single, extending slightly beyond base of 2-C, and seta $3-\mathrm{C}$ is single and simple. The fourth-instar larva of 
Table 46. Number of branches for setae of the larva of An. macarthuri: range (mode).

\begin{tabular}{|c|c|c|c|c|c|c|c|c|c|c|c|c|c|}
\hline \multirow{2}{*}{$\begin{array}{l}\text { Seta } \\
\text { No. }\end{array}$} & \multirow{2}{*}{$\begin{array}{c}\text { Head } \\
\text { C }\end{array}$} & \multicolumn{3}{|c|}{ Thorax } & \multicolumn{9}{|c|}{ Abdominal segments } \\
\hline & & $\mathrm{P}$ & $\mathrm{M}$ & $\mathrm{T}$ & $\mathrm{I}$ & II & III & $\mathrm{IV}$ & $\mathrm{V}$ & $\mathrm{VI}$ & VII & VIII & $\mathrm{X}$ \\
\hline 0 & 1 & 1 & - & - & - & 1 & 1 & 1 & 1 & 1 & 1 & 1 & - \\
\hline 1 & 1 & $11-21(18)$ & $22-37(29)$ & $1-3(2)$ & $2-8(5)$ & $6-15(9)$ & $17-25(20)$ & $14-22(20)$ & $14-22(19)$ & $15-20(18)$ & $8-18(12)$ & 1 & 1 \\
\hline 2 & 1 & $9-16(11)$ & $1-5(3)$ & 1 & $1-4(2)$ & $4-8(6)$ & $4-8(5)$ & $3-5(4)$ & $3-5(4)$ & $3-6(5)$ & $3-7(5)$ & $5-8(6)$ & $16-22(18)$ \\
\hline 3 & 1 & 1 & 1 & $5-10(6)$ & $1-3(3)$ & $1-2(1)$ & $1-2(1)$ & $2-3(3)$ & 1 & 1 & $3-5(3)$ & $5-10(8)$ & $8-12(10)$ \\
\hline 4 & $1-2(1)$ & $13-19(16)$ & $1-4(2)$ & $2-3(3)$ & $2-7(3)$ & $5-8(7)$ & $2-3(3)$ & $2-3(3)$ & $2-4(3)$ & $1-2(1)$ & $1-2(1)$ & 1 & $8.5-9(9)$ \\
\hline 5 & $9-15(13)$ & $36-39$ & 1 & $23-41(40)$ & $3-7(5)$ & $3-5(3)$ & $3-4(3)$ & $2-3(3)$ & $3-4(3)$ & $4-10(5)$ & $4-8(5)$ & $4-7(4)$ & - \\
\hline 6 & $10-17(14)$ & 1 & $1-3(2)$ & $2-3(2)$ & $15-25(22)$ & $21-30(24)$ & $12-21(17)$ & $2-3(2)$ & $2-3(2)$ & $2-4(3)$ & $3-6(4)$ & $1-S$ & $3-7(4)$ \\
\hline 7 & $11-18(16)$ & $18-28(25)$ & $2-3(3)$ & $26-34(29)$ & $13-19(17)$ & $13-25(22)$ & $4-6(5)$ & $3-7(5)$ & $3-5(4)$ & $2-4(2)$ & $2-5(3)$ & $2-S$ & $4-6(5)$ \\
\hline 8 & $1-2(1)$ & $21-36(27)$ & $21-30(30)$ & $24-39(32)$ & - & $1-3(2)$ & $1-2(2)$ & $2-5(3)$ & $2-5(3)$ & $2-4(3)$ & $4-7(5)$ & $6-S$ & $2-3(2)$ \\
\hline 9 & $2-5(3)$ & $1-3(1)$ & 1 & $1-2(1)$ & $5-8(5)$ & $7-13(9)$ & $8-12(9)$ & $8-12(10)$ & $7-13(8)$ & 7-9(9) & $4-7(5)$ & $7-S$ & $1-2(2)$ \\
\hline 10 & $1-2(2)$ & 1 & 1 & 1 & 1 & $2-4(3)$ & $1-2(1)$ & 1 & 1 & $1-4(3)$ & $5-10(6)$ & 8-S & $2-5(3)$ \\
\hline 11 & $21-35(28)$ & 1 & 1 & 1 & $3-4(3)$ & 1 & $2-4(3)$ & $2-4(3)$ & $2-4(2)$ & $2-4(3)$ & $2-3(2)$ & 9-S & $3-4(3)$ \\
\hline 12 & $2-3(2)$ & 1 & 1 & $2-3(2)$ & $2-5(4)$ & 1 & $2-3(3)$ & $2-4(3)$ & $2-4(3)$ & $1-2(1)$ & $1-2(1)$ & - & - \\
\hline 13 & $3-6(5)$ & $3-6(4)$ & $5-10(6)$ & $2-4(3)$ & $3-7(4)$ & $5-8(6)$ & $5-8(6)$ & $3-7(5)$ & $3-4(3)$ & $5-8(7)$ & $2-4(3)$ & - & - \\
\hline 14 & $4-6(4)$ & $4-7(5)$ & $4-10(6)$ & - & - & - & - & 1 & 1 & 1 & 1 & 1 & - \\
\hline 15 & $3-6(6)$ & - & - & - & - & - & - & - & - & - & - & - & - \\
\hline
\end{tabular}

n.c. $=$ not counted

An. macarthuri can be separated from that of An. riparis in having a prominent, broad, apically rounded posterodorsal process or lip arising from the tubercle of seta 1-P, seta 1-I somewhat palmate, seta 1-VII with minute, poorly evident, apicolateral serration and seta 13-IV shorter than 0.5 length of 10-IV, whereas in An. riparis tubercle of seta 1-P has no process or lip arising from posterior border, seta 1-I is not palmate, seta 1 -VII has evident apicolateral serrations and seta 13-IV is longer than 0.5 length of 10-IV. The pupae of An. riparis, An. macarthuri and An. cristatus are morphologically indistinguishable.

Identification keys for species of the Leucosphyrus Group Fourth-instar larvae

1. Seta 3-C branched; seta 4-C strongly developed, branched, somewhat plumose cristatus

Seta 3-C single; seta 4-C variably developed, never strongly developed or plumose ... 2

2(1). Seta 1-II fully developed, equal to or approximating seta 1-III-VI in development, individual leaflets with clearly differentiated apical filaments; basal sclerotized tubercle of seta 1-M with a distinct pointed or angular apicomedial tooth .......... hackeri

Seta 1-II weakly or moderately developed, with attenuate or narrow lanceolate leaflets, rarely with a few leaflets showing slight differentiation of apical filaments, never approximating seta 1-III-VI in development; basal sclerotized tubercle of seta 1-M not produced into a distinct pointed or angular tooth at apicomedial margin ... 3

3(2). Seta 5-C shorter, as long as or slightly longer than antenna
Seta 5-C conspicuously longer than antenna ...... 6

4(3). Seta 1-X inserted at the edge of saddle; seta 2-C sparsely aciculate at distal end; tubercle of seta 1-P broadly joined to tubercle of setae 2,3-P; seta 4-C short (range 0.04-0.07 mm), never reaching base of seta 2-C, ratio of length of seta $4-\mathrm{C}$ to distance between seta $2-\mathrm{C}$ and seta $4-\mathrm{C}$ 0.46-0.76

takasagoensis

Seta 1-X inserted inside saddle; seta $2-\mathrm{C}$ without aciculae; tubercle of seta 1-P usually separate or narrowly joined to tubercle of setae 2,3-C; seta 4-C longer (range $=0.07-0.22 \mathrm{~mm}$ ), nearly reaching or extending well beyond base of seta $2-\mathrm{C}$, ratio of length of seta 4-C to distance between seta 2-C and seta 4-C variable from 0.80 to 3.26

5(4). Tubercle of seta 1-P narrowly joined to tubercle of setae 2,3-P by an anterior, basal bridge; length of seta 4-C varying from $0.07-0.10 \mathrm{~mm}$, ratio of length of seta 4-C to distance between seta 2-C and seta 4C 0.80-1.09 elegans

Tubercle of seta 1-P usually separate from tubercle of setae 2,3-P at least on one side, usually on both sides; length of seta 4-C 0.10-0.22 mm, ratio of length of seta 4-C to distance between seta 2-C and seta 4C 1.20-3.26 scanloni

6(3). Basal sclerotized tubercle of seta 1-P with a prominent tooth or spine arising from posterodorsal margin .. 7

Basal sclerotized tubercle of seta 1-P without prominent tooth or spine arising from posterodorsal margin, usually with a broad, short, apically rounded lip or tooth, or occasionally with a small short pointed tooth. 
7(6). Setae 3,4-C short, seta 4-C extending slightly beyond to near or not reaching base of seta $2-\mathrm{C}$, seta $3-\mathrm{C}$ extending to or only slightly beyond anterior margin of head. ...8

Setae 3,4-C long, seta 4-C always extending noticeable beyond base of seta $2-\mathrm{C}$, seta $3-\mathrm{C}$ extending well beyond anterior margin of head. .. 10

8(7). Seta 1-II moderately developed with distinct splayed, narrow lanceolate leaflets arising from a rather expanded basal stem; seta 2-IV,V with 3,4 branches balabacensis

Seta 1-II weakly developed with narrow, lanceolate or filiform branches, usually not splayed arising from a narrow basal stem; seta 2-IV,V with 3-5 branches ... 9

9(8). Seta 1-X inserted in a marginal notch or at the edge of saddle cracens; baimaii; baisasi

Seta 1-X inserted inside or at the edge of saddle . dirus

10(7). Seta 1-II moderately developed, with distinct, moderately broad leaflets, lightly to darkly pigmented brown and basal stem usually stout and distinctly inflated .. 11

Seta 1-II weakly developed with very narrow leaflets, clear translucent or very lightly pigmented, basal stem weak, not inflated 12

11(10). Individual leaflets of seta 1-VII with clearly differentiated apicolateral serration and apical filament introlatus

Individual leaflets of seta 1-VII without apicolateral serrations or rarely a few leaflets may exhibit weak apical serration, apical filament not clearly differentiated.... nemophilous

12(10). Seta 13-IV shorter than 10-IV, ratio of length of seta 13IV to seta 10 -IV never exceeding 0.88 (range $=0.46-$ $0.88)$ 13

Seta 13-IV slightly shorter or longer than seta 10-IV, ratio of length of seta 13 -IV to seta 10 -IV never less than $0.80($ range $=0.80-1.24)$ 14

13(12). Individual leaflets of palmate seta $1-\mathrm{IV}, \mathrm{V}$ with a long and slender apical filament sulawesi

Individual leaflets of palmate seta $1-\mathrm{IV}, \mathrm{V}$ with a short and strong apical filament baimaii

14(12). Seta 1-II with 10-17 branches; seta 13-IV,V with 3,4 branches; seta 2-VII with 6-10 branches; seta 9-VII with $5-8$ branches mirans

Seta 1-II with 5-8 branches; seta 13-IV single or double, seta 13-IV double; seta 2-VII with 4-6 branches; seta 9-VII with 3,4 branches recens

15(6). Basal sclerotized tubercles of setae 1,2-P usually separate, that of seta 1-P conspicuously smaller than that of seta 2-P, distance between bases wide, equal to or greater than basal width of tubercle of seta 1-P leucosphyrus; latens

Basal sclerotized tubercles of setae 1,2-P usually broadly joined, rarely separate on one side, bases approximate, less than basal width of tubercle of seta 1-P 16

16(15). Basal sclerotized tubercle of seta 1-P with a prominent, broad, apically rounded, posteroapical process or lip ......................................................... macarthuri

Basal sclerotized tubercle of seta 1-P with at most a very small, short, pointed teeth or none 17

17(16). Seta 3-T with 6-8 branches; seta 4-C short, length 0.040 $0.066 \mathrm{~mm}$, ratio of length of seta $4-\mathrm{C}$ to distance between seta 2-C and seta 4-C 0.46-0.75; length of 3C 0.05-0.07 mm; seta 13-IV equal or less than 0.5 length of seta 10-IV pujutensis

Seta 3-T with 2-5 branches; seta 4-C long, length 0.08$0.10 \mathrm{~mm}$, ratio of length of seta $4-\mathrm{C}$ to distance between seta 4-C and seta 2-C 0.92-1.39; length of seta 3-C 0.08-0.09 mm; seta 13-IV longer than 0.5 length of seta $10-\mathrm{IV}$ riparis

Females

1. Proboscis distinctly longer than forefemur (ratio 1.16$1.45)$, usually much longer than maxillary palpus ... 2

Proboscis shorter or only slightly longer than forefemur (ratio $0.88-1.17$ ), at most only slightly longer than maxillary palpus

... 6

2(1). Presector dark (PSD) spot of vein R with 1-4 pale interruptions 3

Presector dark (PSD) spot of vein R without pale interruptions

3(2). Proboscis either entirely dark-scaled or with a patch of pale scales at apical 0.2 of ventral surface; apical band of hindtibia entirely white-scaled or occasionally with a middle dark spot on lateral surface; known from Sumatra, Indonesia ...... recens

Proboscis dark-scaled with an apical pale ring basal to labella; apical pale band of hindtibia with a longitudinal dark extention and a dark spot on middle area on ventral surface; known from Sulawesi, Indonesia sulawesi

4(2). Proboscis dark-scaled; apical pale band of hindtibia with a dark, longitudinal extension on ventral surface; palpomere 5 mostly pale-scaled ...... mirans

Proboscis with an apical pale ring, basal to labella; apical pale band of hindtibia variable, with or without dark extension on ventral surface; palpomere 5 
variable, either mostly dark-scaled or with apical pale band nearly as long as basal dark band ..... .. 5

5(4). Maxillary palpus with very narrow pale bands, palpomere 5 merely tipped with white scales; apical pale band of hindtibia with or without dark longitudinal stripe extending into basal portion; accessory sector pale (ASP) spot usually very small and restricted to vein $\mathrm{R}$, much shorter than basal dark spot of middle dark spot (MD) of vein $R$ and sometimes reduced to 1,2 scales hackeri

Maxillary palpus with broader pale bands, band at apex of palpomere 5 about as broad as basal dark band; apical white band of hindtibia without dark extension; accessory sector pale (ASP) spot large and prominent, markedly longer than the basal dark spot of middle dark spot (MD) of vein R often extending onto vein $\mathrm{C}$ at least on one wing ............. pujutensis

6(1). Proboscis shorter than forefemur, ratio of proboscis length to forefemur length 0.88-0.99; presector dark (PSD) spot of vein R always without pale interruption on both wings

Proboscis as long as or slightly longer than forefemur, ratio of proboscis length to forefemur length 1.001.17; presector dark (PSD) spot of vein $\mathrm{R}$ variable with or without pale interruption 10

7(6). Prehumeral pale (PHP) spot absent 8

Prehumeral pale (PHP) spot present 9

8(7). Accessory sector pale (ASP) spot usually absent on vein $\mathrm{C}$, rarely with 1,2 pale scales or ASP present only on inner side of, never encircling vein; midtarsomeres 2-4 dark-scaled with narrow apical patches of pale scales; known from East and West Malaysia and Thailand ............. macarthuri (in part)

Accessory sector pale (ASP) spot usually absent on vein $C$, occasionally present; midtarsomeres $2-4$ dark-scaled or with inconspicuous apical pale patch on dorsal surface; known from Philippines, Mindanao cristatus

9(7). Accessory sector pale (ASP) spot well developed on vein $C$; split of cell $\mathrm{M}_{1+2}$ proximal to split of cell $\mathrm{R}_{2}$; known from Philippines, Mindanao and Samar ...... riparis

Accessory sector pale (ASP) spot usually absent on vein $C$, rarely with only 1,2 pale scales or if longer, never reaching the outer margin of vein $C$; split of cell $\mathrm{M}_{1+2}$ distal to split of cell $\mathrm{R}_{2}$; known from East/ West Malaysia and Thailand ..... macarthuri (in part)

10(6). Split of cell $\mathrm{R}_{2}$ distal to split of cell $\mathrm{M}_{1+2}$; known from Philippines, Luzon baisasi

Split of cell $\mathrm{R}_{2}$ basal to split of cell $\mathrm{M}_{1+2}$.................. 11
11(10). Accessory sector pale (ASP) spot usually extending onto vein $\mathrm{C}$ at least on one wing and/or hindtarsomere 4 without an obvious basal pale band or patch (a minute and inconspicuous patch sometimes present); hindtarsomere 5 without basal pale band .. 12

Accessory sector pale (ASP) spot absent on vein C and usually absent on subcosta, or hindtarsomere 4 with an obvious basal pale band or patch of pale scales on dorsal surface; hindtarsomere 5 often with minute basal pale band

12(11). Presector dark (PSD) spot of vein R often not extending basally beyond level of PSD wing spot on vein C (level 3) and rarely extending onto apical 0.5 of humeral dark (HD) spot on vein C, never extending beyond middle of HD (level 4); apical pale band on palpomere 5 distinctly white or whitish, not strongly contrasting with light bands on palpomeres 2 and 3

.. 13

Presector dark (PSD) spot of vein R usually extending basally well onto level of humeral dark (HD) spot of vein $\mathrm{C}$ or beyond (level 4 and level 6); apical pale band on palpomere 5 distinctly cream-colored or yellowish, strongly contrasting with the silverywhite band on palpomeres 2 and 3 14

13(12). Hindtarsomere 4 entirely dark-scaled at base ...... introlatus nemophilous

Hindtarsomere 4 with patch of pale scales at base balabacensis (in part)

14(12). Known only from Sumatra, Indonesia .... leucosphyrus Known from Indonesia (Kalimantan), East Malaysia, West Malaysia and Thailand ..... latens

15(11). All pale scales of wing, cream-colored to golden to yellowish, including those on presector pale (PSP) spot and sector pale (SP) spot 16

Pale scales on anterior veins of wing, specially those on presector pale (PSP) and sector pale (SP) spots of vein $\mathrm{C}$, white, contrasting with pale spots on remaining posterior veins

16(15). Hindtarsomere 4 usually with noticeable band of pale scales at base, rarely basal pale band absent nemophilous

Hindtarsomere 4 usually with reduced, incomplete basal pale band, rarely more developed balabacensis (in part)

17(15). Known only from Republic of China (Taiwan) takasagoensis

Not found in the Republic of China (Taiwan) .......... 18

18(17). Known only from southwestern India (Karnataka, Tamil 
Nadu)

Not found in southwestern India elegans 19

19(18). Apical pale band of hindtibia with short to long, narrow, dark linear extension onto basal portion on ventral surface (specimens from Kanchanaburi, Thailand only) scanloni (in part)

Apical pale band on hindtibia without dark extension onto basal portion 20

20(19). Vein 1A with a long pale spot at level of presector dark (PSD) spot of vein $\mathrm{C}$ at least on one wing, ratio of length to PSD $0.28-1.36$, at least 0.4 on one wing, this spot always longest of pale spots on $1 \mathrm{~A}$.... 21

Vein 1A without a noticeably longer pale spot at level of PSD, if a long pale spot is present, then usually less than 0.33 length of PSD spot of vein $\mathrm{C}$ and not noticeably longer than other pale spot on $1 \mathrm{~A}$, especially most basal spot 22

21(20). Combined pale spots and bands along dorsolateral line of foretarsomeres 1 and /or 2 dominating the dark portions along this line, often 2 or more of these spots on foretarsomere 1 fused, forming long line or splashes of pale along entire length at least in one leg; foretarsomere 2 with or without 1,2 dorsomedial pale spots, often with bands and spots fused and completely pale dorsally or bands longer, reducing dark in middle of tarsomere 2 to narrow basal band baimaii (in part)

Combined pale spots and bands along dorsolateral line of foretarsomeres 1 and 2 smaller, more discrete, usually occupying less surface than dark along dorsolateral line; pale spots on foretarsomere 1 usually not fused or forming long lines or splashes of pale along entire length, often restricted to 2-4 spots on basal 0.6 , foretarsomere 2 occasionally with small dorsomedian pale spot but usually without,

the dark is always dominant along this aspect scanloni (in part)

22(20). Abdominal sternum VI with a small posteromedial patch of dark scales cracens

Abdominal sternum VI without scales or with at most 1,2 dark posteromedial scales 23

23(22). Presector dark (PSD) spot on vein R extending basally beyond corresponding spot on vein $\mathrm{C}$ at least on one wing, usually reaching humeral dark (HD) of vein $\mathrm{C}$ or beyond, or at least beyond middle of presector pale (PSP) spot of vein C dirus

Presector dark (PSD) spot of vein R usually equal to corresponding spot on vein $\mathrm{C}$ or extending only slightly longer, usually no more than middle of presector pale (PSP) spot of vein C

baimaii (in part)

Acknowledgments. We greatly appreciate the efforts of the following individuals who continued to work in Southeast Asia on different aspects of this project well beyond the initial phase and contributed significantly to our understanding of the Leucosphyrus Group. They are: R.G. Andre, V. Baimai, J.R. Burge, P. Damrongphol, S.V. Dixon, S.P. Frances, J.B. Gingrinch, C.A. Green, R.E. Harbach, J.L.K. Hii, T.A. Klein, K.J. Linthicum, L.W. Pang, S. Panyim, A. Poopittayasataporn, S. Ramalingam, R. Rattanarithikul, R. Rosenberg, Y. Sawadipanich, S. Sukowati, S. Wibowo, and S. Yasothornsrikul. We also gratefully acknowledge the field and laboratory assistance of the Department of Entomology employees at the Armed Forces Research Institute of Medical Sciences (AFRIMS), Bangkok, Thailand, for their skillful and devoted collection of specimens, and the preparation and processing of those specimens for study. Ralph E. Harbach and John Reinert are acknowledged for critically reviewing the manuscript. We also thanks James Pecor for helping in collecting literature data and curating the specimens used for the study, and Taina Litwak, Ann Dery and Vichai Malikul for drawing the illustrations. MAMS is a senior research fellow supported by U.S. National Research Council (NRC) Grant DAMD 17-00-2-0002. The Walter Reed Army Instutute of Research and Department of Entomology, and the National Museum of Natural History, Smithsonian Institution are acknowledged for providing logistical support that fostered the conclusion of the revision. 


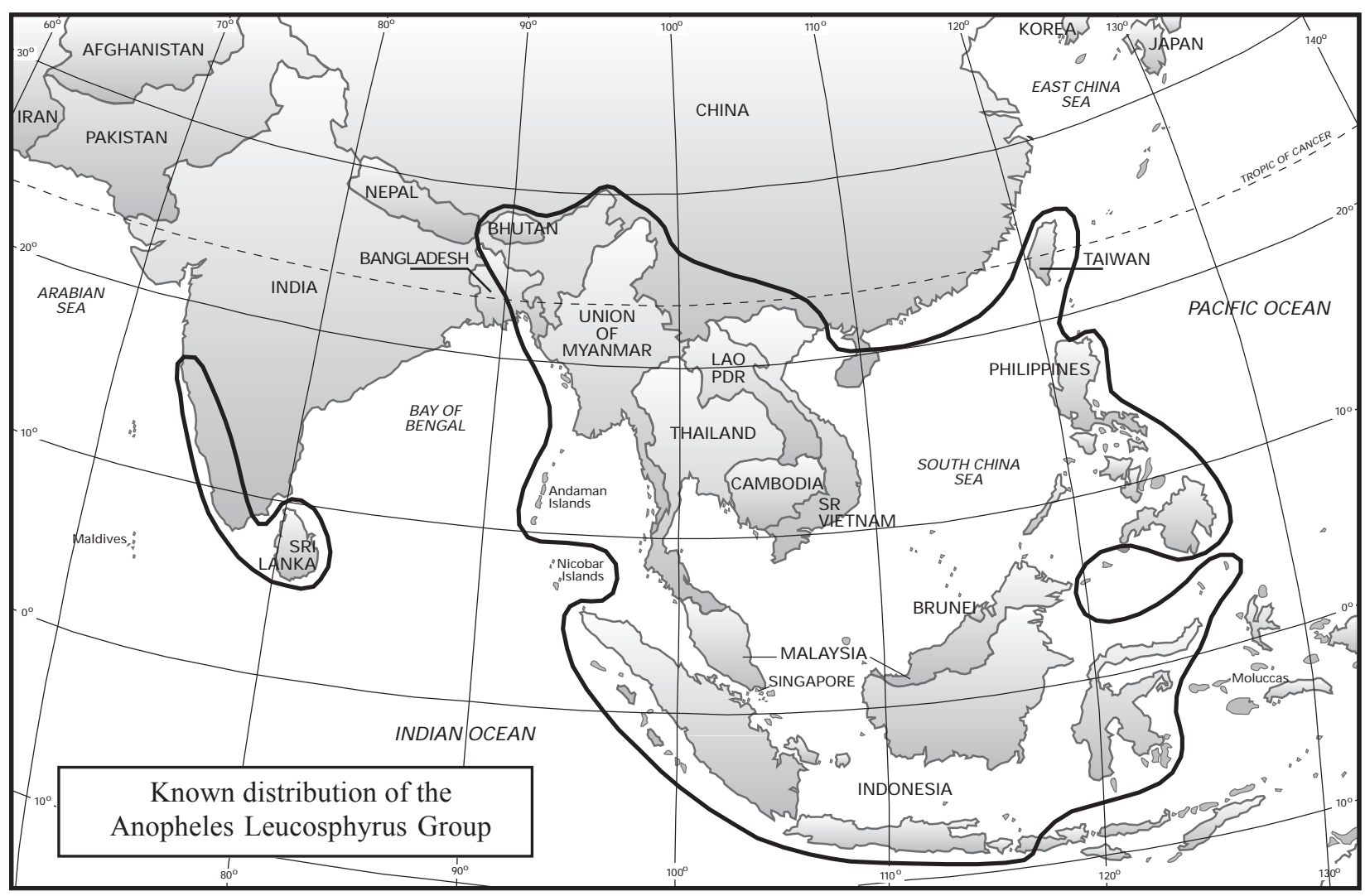

Fig. 1. Map showing the current known distribution of the Leucosphyrus Group.

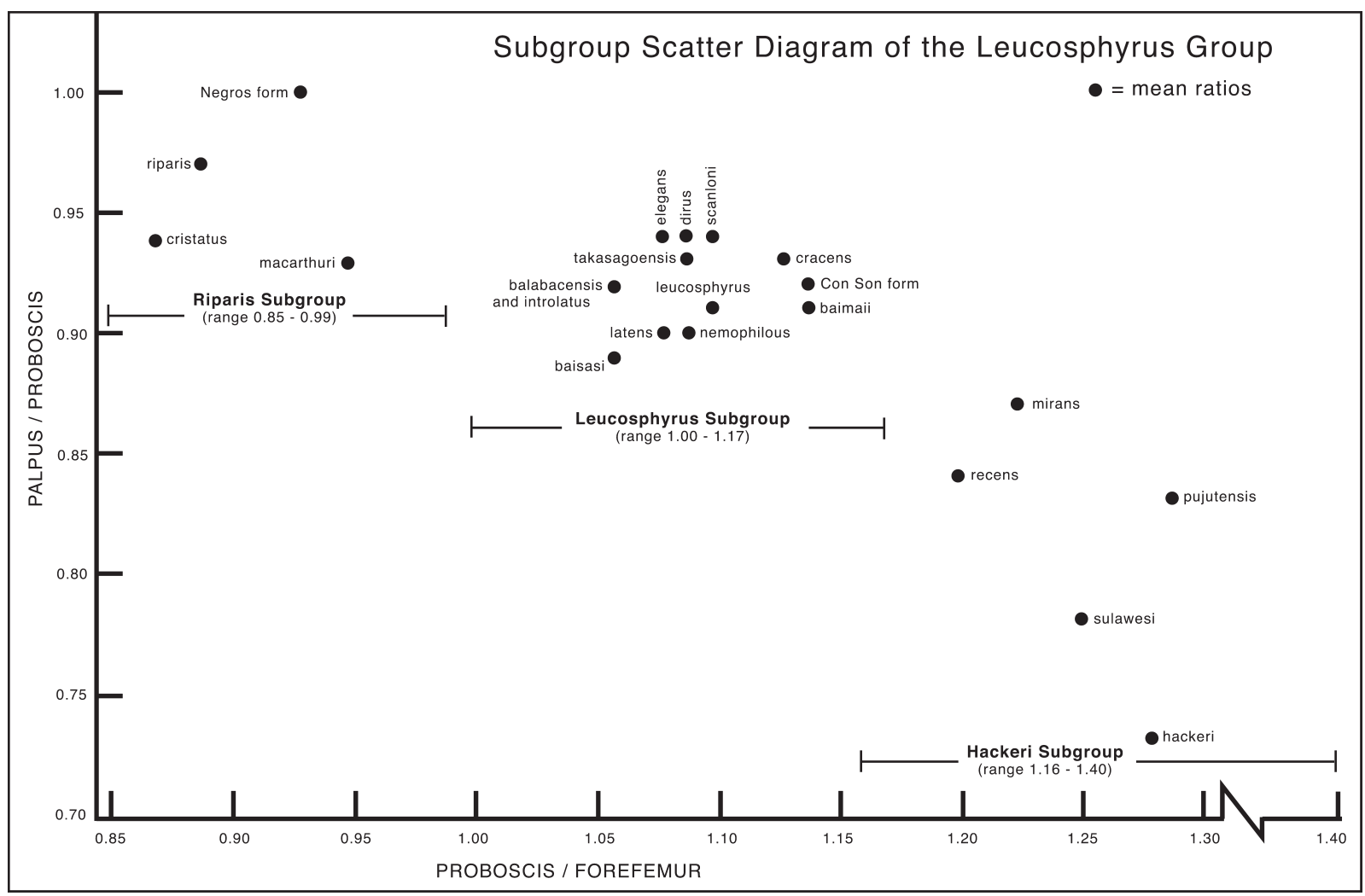

Fig. 2. Diagram showing the subgroup classification within the Leucosphyrus Group. 
Standardized abbreviations for costal wing spots, cross veins, cells and veins.

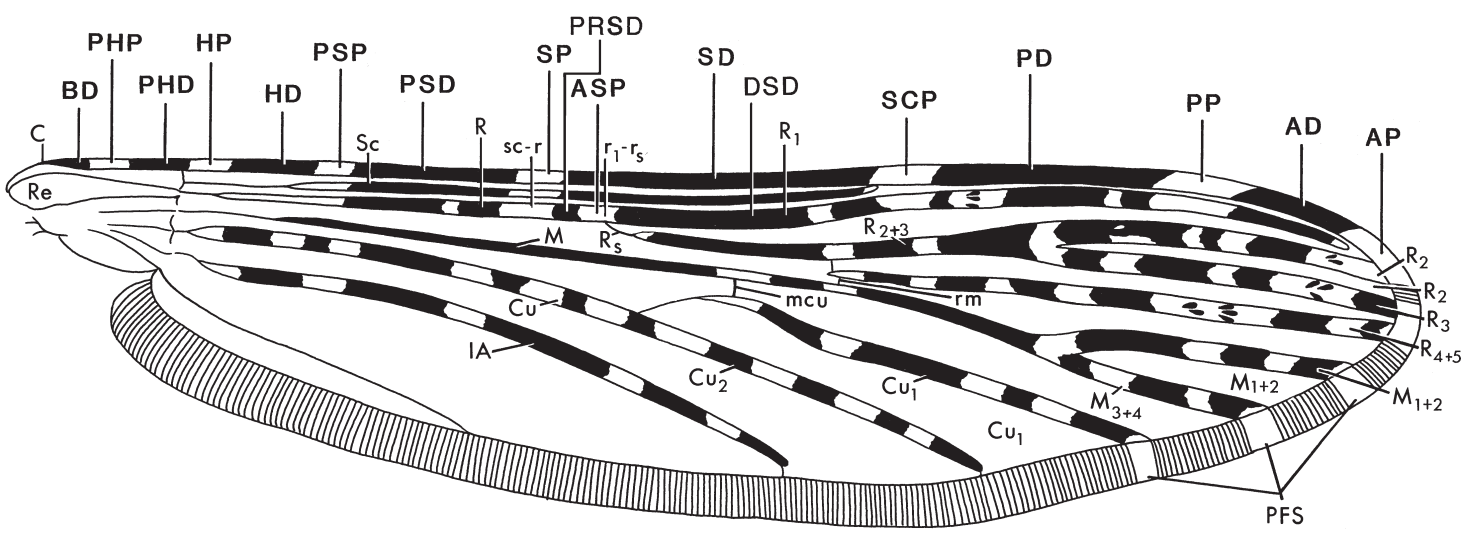

Standardized numerical levels for expressing the degree of basal extension of PSD on vein $\mathbf{R}$.

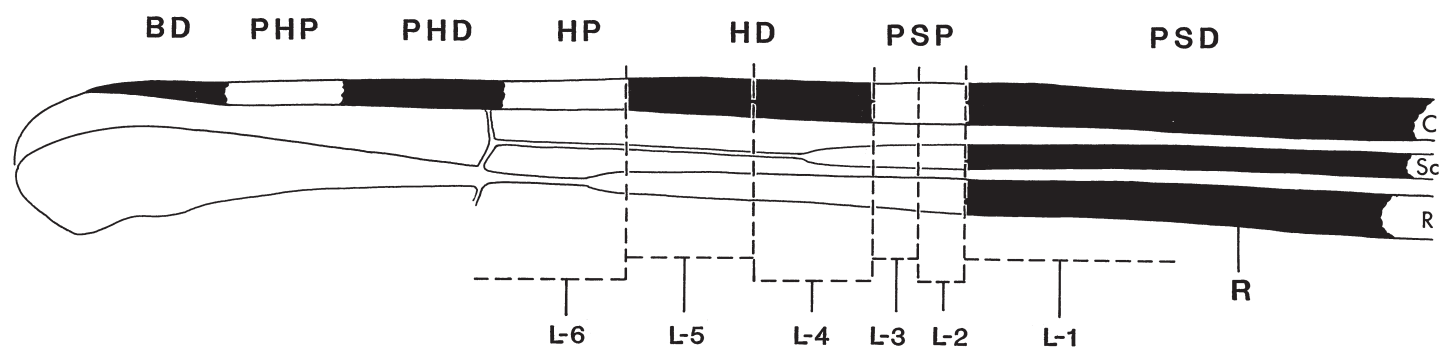

Basal extention of Presector Dark spot (PSD) on vein $\mathbf{R}$ as compared to the Humeral Dark (HD), Presector Pale (PSP) and Presector Dark (PSD) spots on Costa.

Level 1. Not extending basally beyond PSD on Costa or barely so.

Level 2. Extending basally but not beyond 0.5 of PSP.

Level 3. Extending basally beyond 0.5 of PSP but not into level of HD.

Level 4. Extending basally into level of HD but not beyond 0.5 of HD.

Level 5. Extending basally beyond 0.5 of HD but not beyond HD.

Level $6 . \quad$ Extending basally beyond HD.

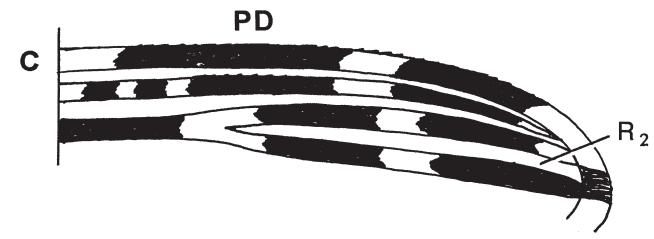

Cells $\mathbf{R}_{2}$ /Preapical Dark Index.

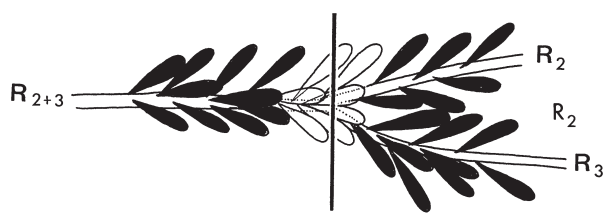

Point of measurement at the furcation of veins $\mathbf{R}_{2+3}$ and $M_{1+2}$ (bases of cells $\mathbf{R}_{2}$ and $\mathbf{M}_{1+2}$ at insertion of first pale scale).

Fig. 3. Standardized abbreviations for costal wing spots, cross veins, cells, and veins. AD, apical dark spot; ASP, accessory sector pale spot; HD, humeral dark spot spot; HP, humeral pale spot; PD, posterior dark spot; PHP, prehumeral pale spot; PP, preapical pale spot; PSD, presector dark spot; PSP, presector pale spot; SCP, subcostal pale spot; SD, sector dark spot; SP, sector pale spot. Detail of the anteroproximal veins showing the basal extension of the presector dark spot on vein $\mathrm{R}$ as compared to the humeral dark, presector pale and presector dark spots on vein $\mathrm{C}$. 

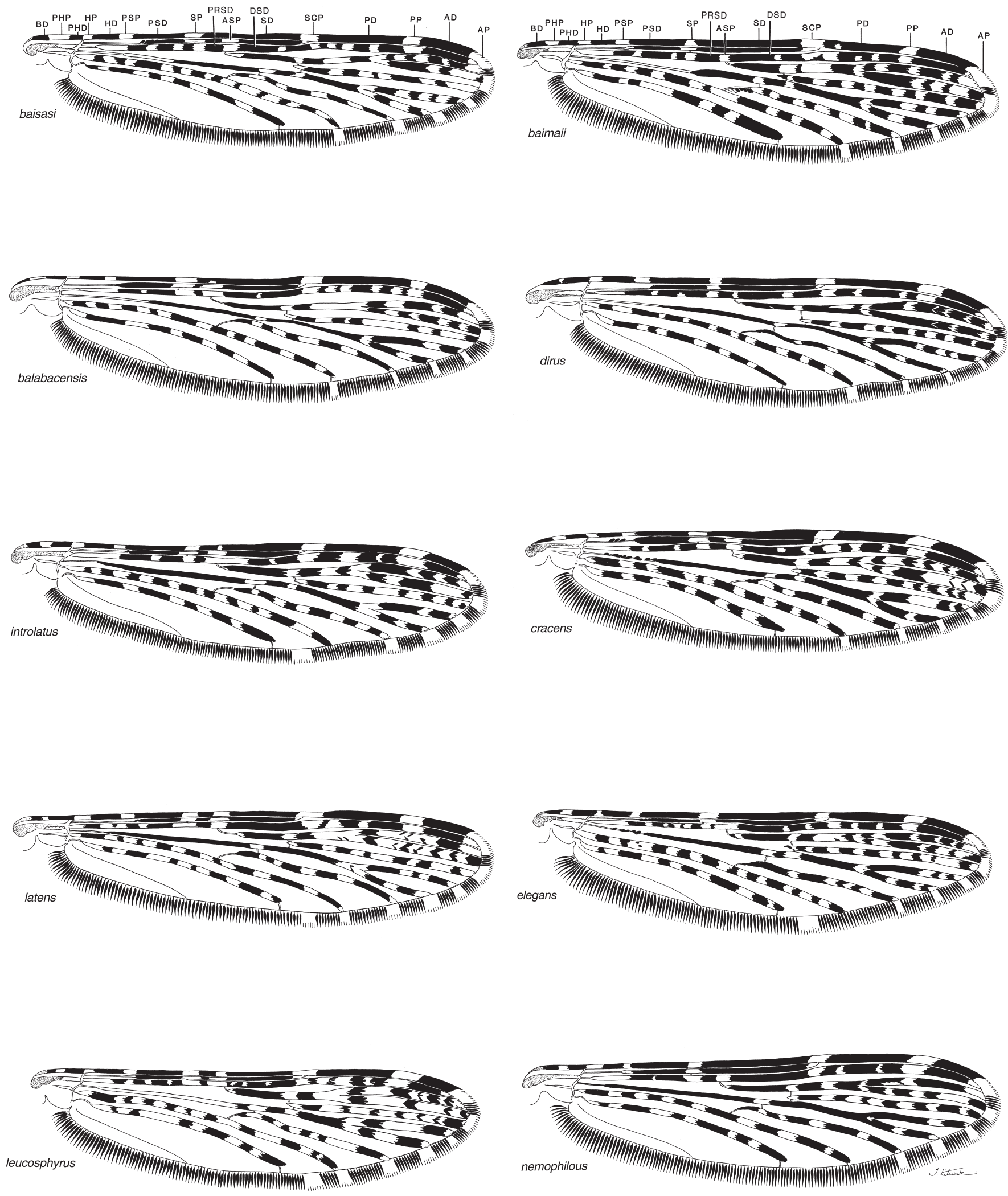

Fig. 4. Anopheles baisasi, An. balabacensis, An. introlatus, An. latens, An. leucosphyrus, An. baimaii, An. dirus, An. cracens, An. elegans, and An. nemophilous: right wing, dorsal view, showing wing spots. 

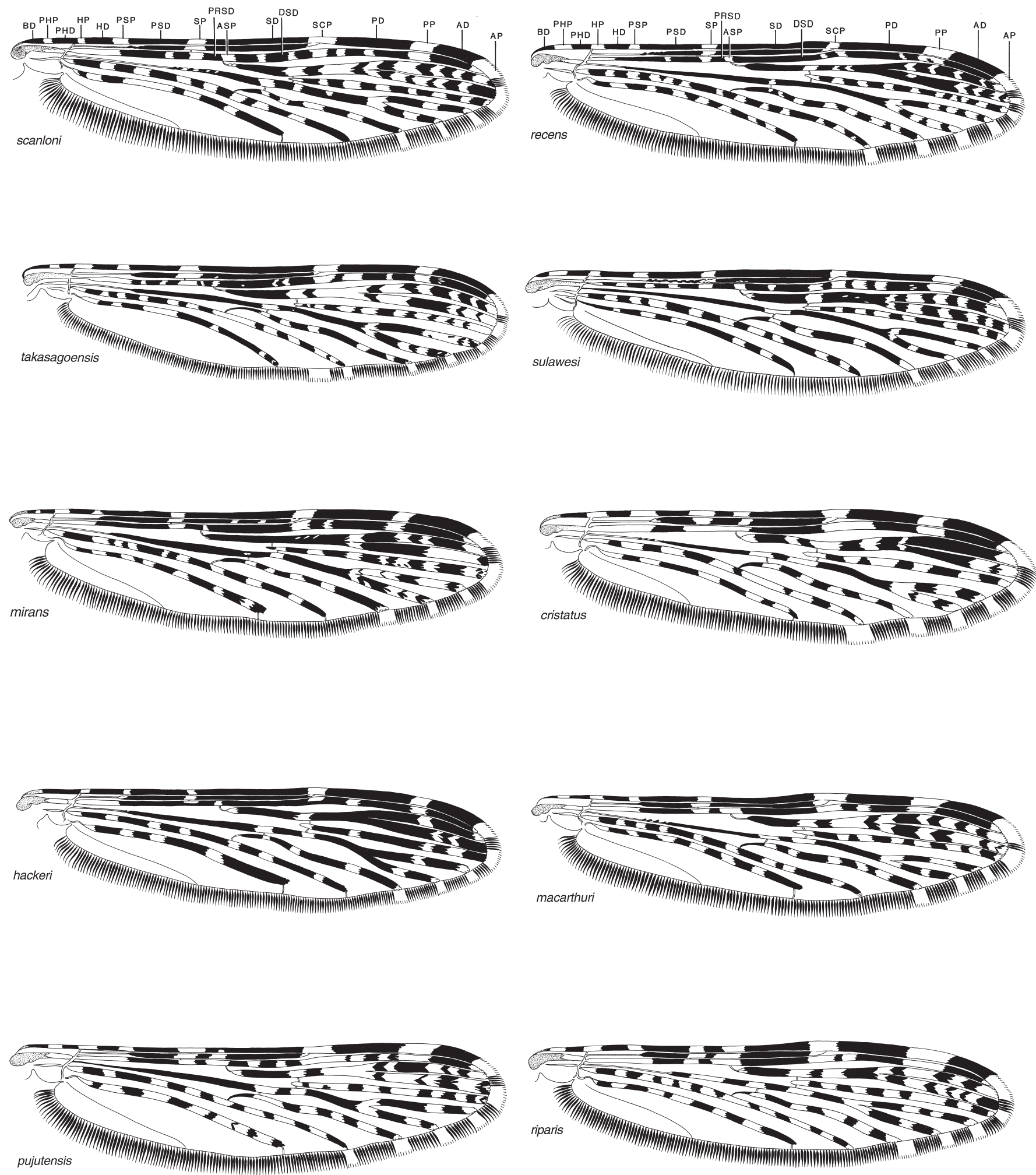

Fig. 5. Anopheles scanloni, An. takasagoensis, An. mirans, An. hackeri, An. pujutensis, An. recens, An. sulawesi, An. cristatus, An. macarthuri, and $A n$. riparis: right wing, dorsal view, showing wing spots. 

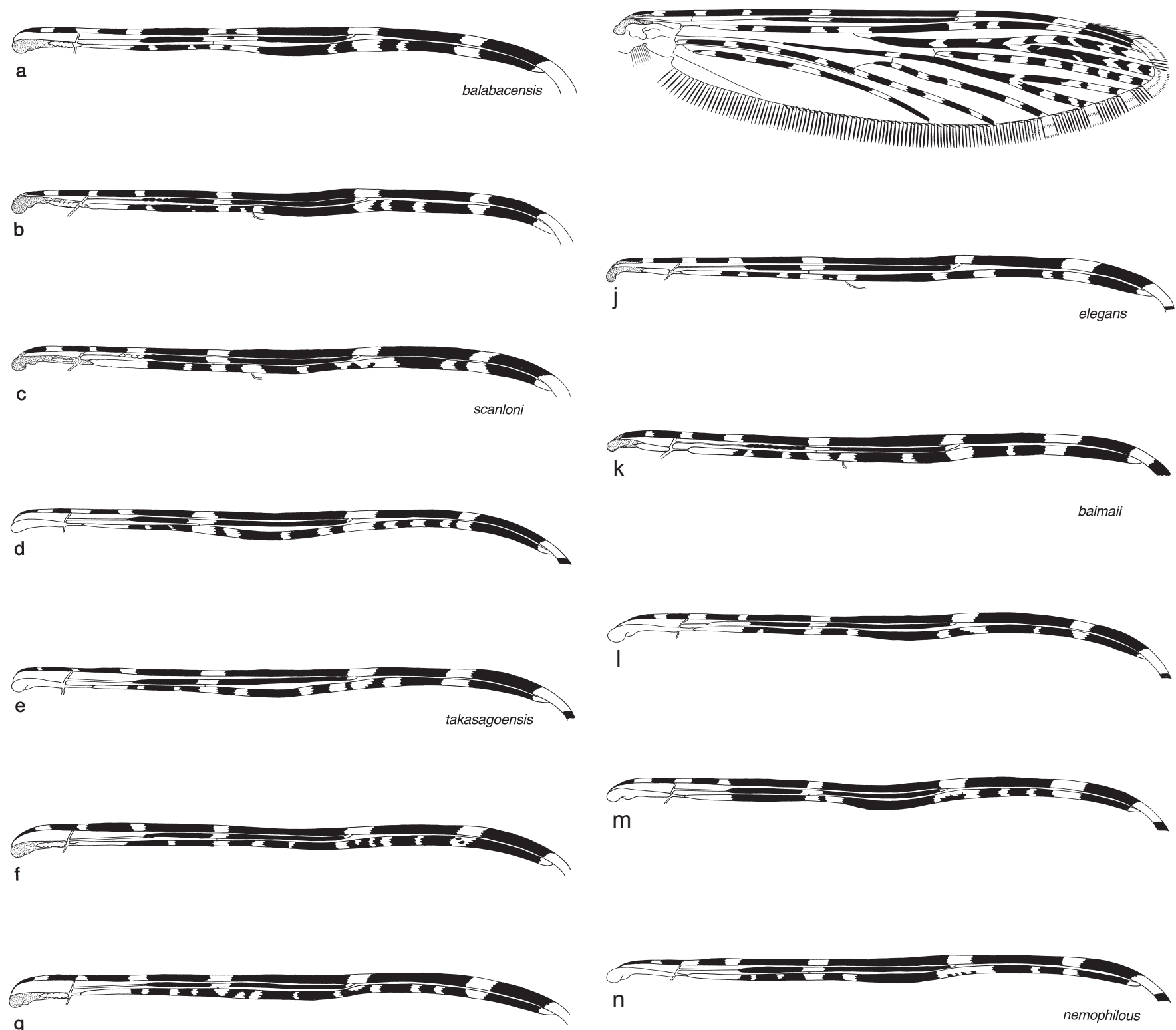

$$
\text { g }
$$
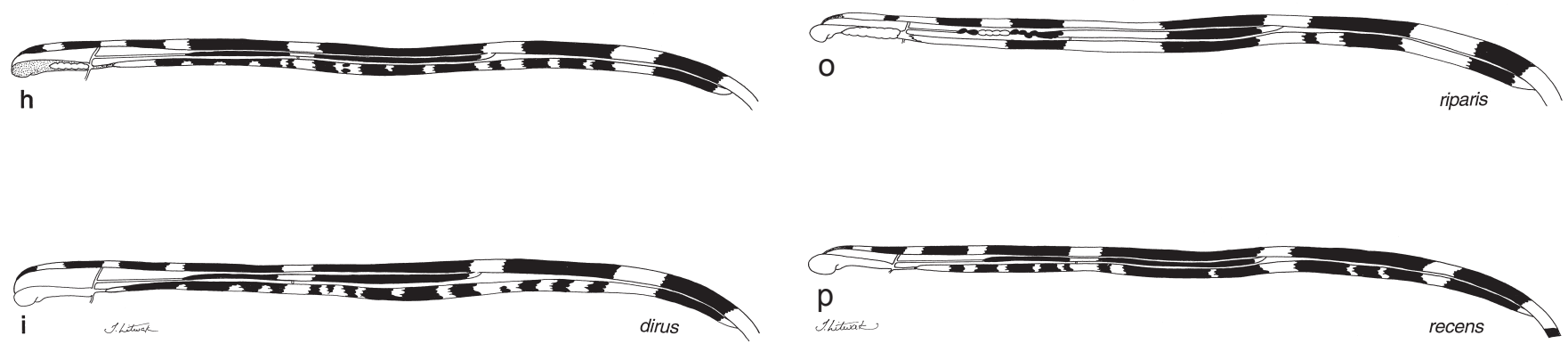

Fig. 6. a,b. Anopheles balabacensis, c,d. An. scanloni, e-h. An. takasagoensis, i. An. dirus, j. An. elegans, k-m. An. baimaii, n. An. nemophilous, o. An. riparis, and p. An. recens: right wing, dorsal view, showing variation in the wing spots of veins $\mathrm{C}$, subcosta, $\mathrm{R}_{\text {and }} \mathrm{R}_{1}$. 

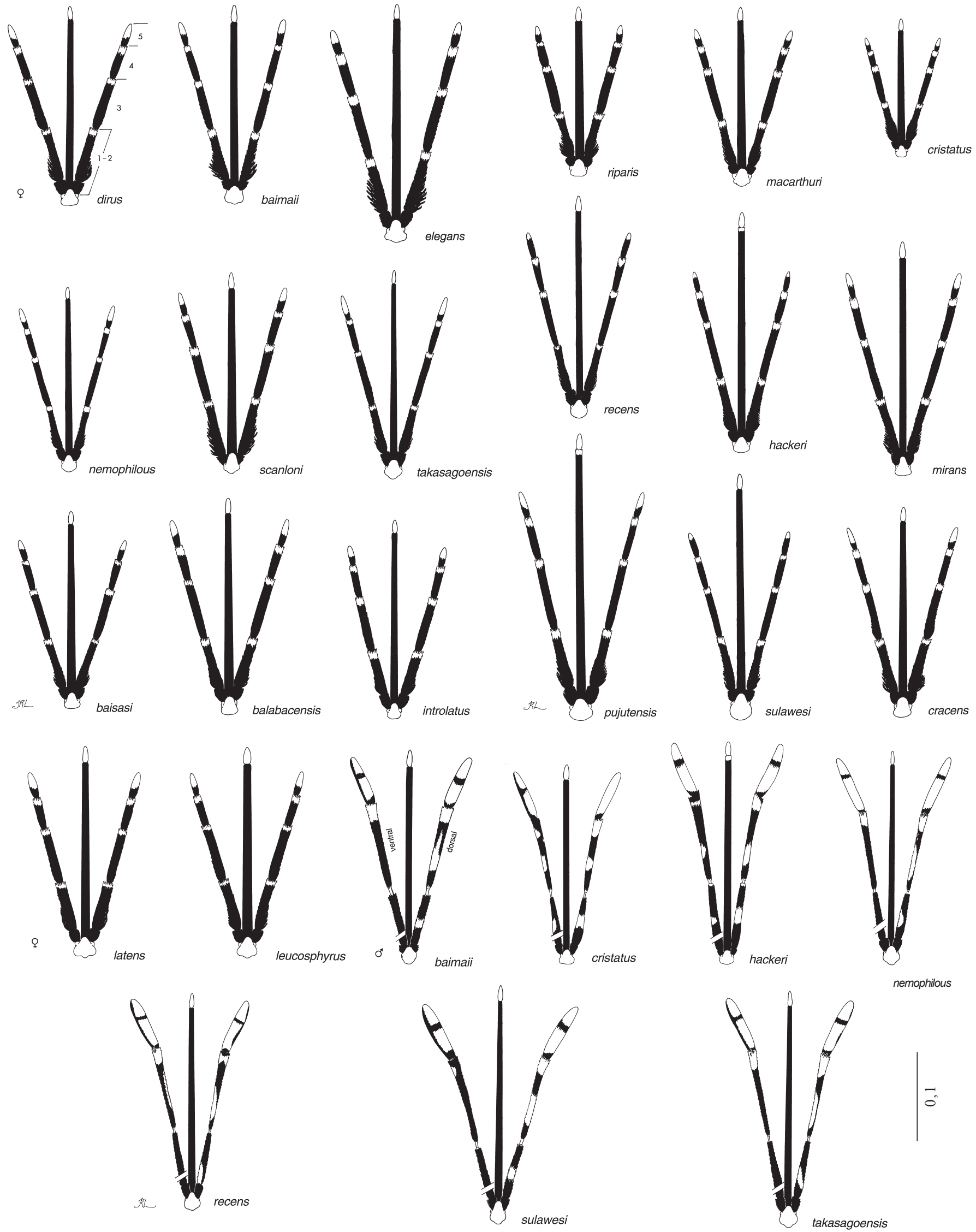

Fig. 7. Maxillary palpi, proboscis, and clypeus of females and males. Scales in millimeters. 


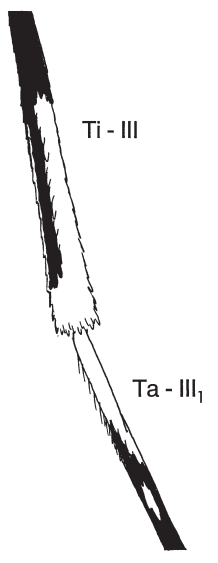

riparis

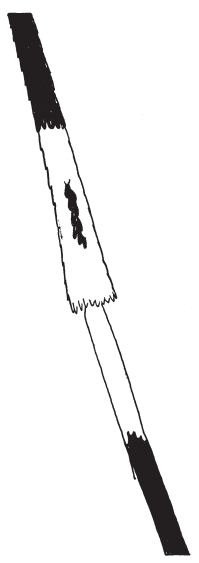

recens

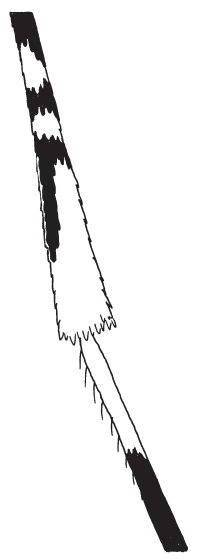

cristatus

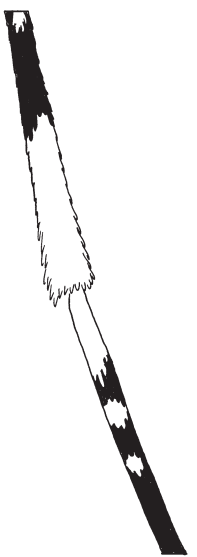

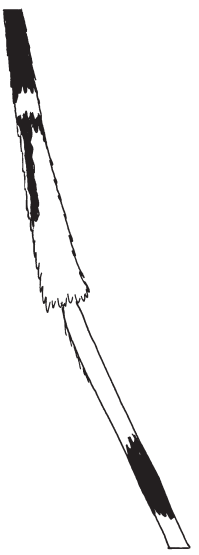

macarthur

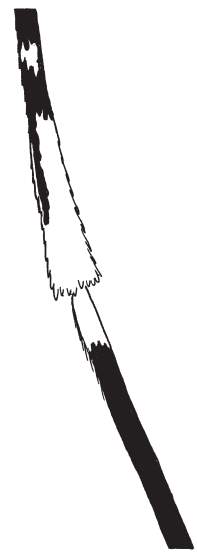

hackeri

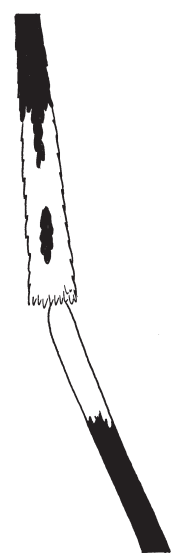

sulawesi

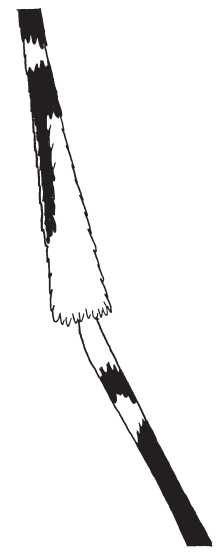

mirans

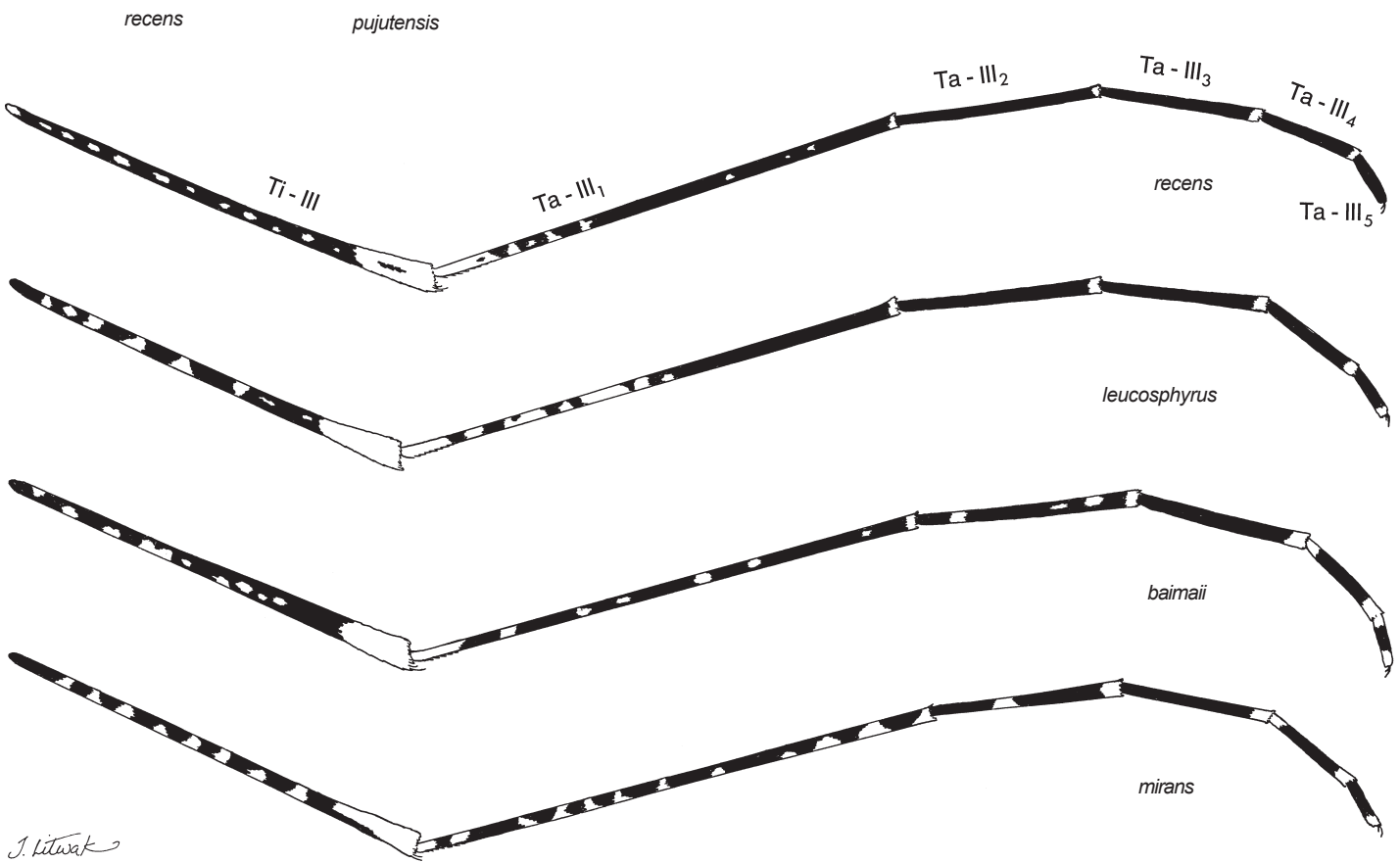

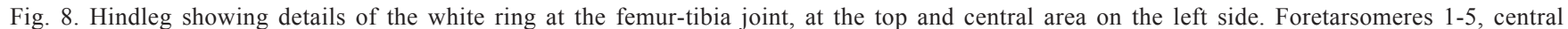
area on the right side. Hindleg showing the white ring at the femur-tibia joint and hindtarsomeres 1-5. 

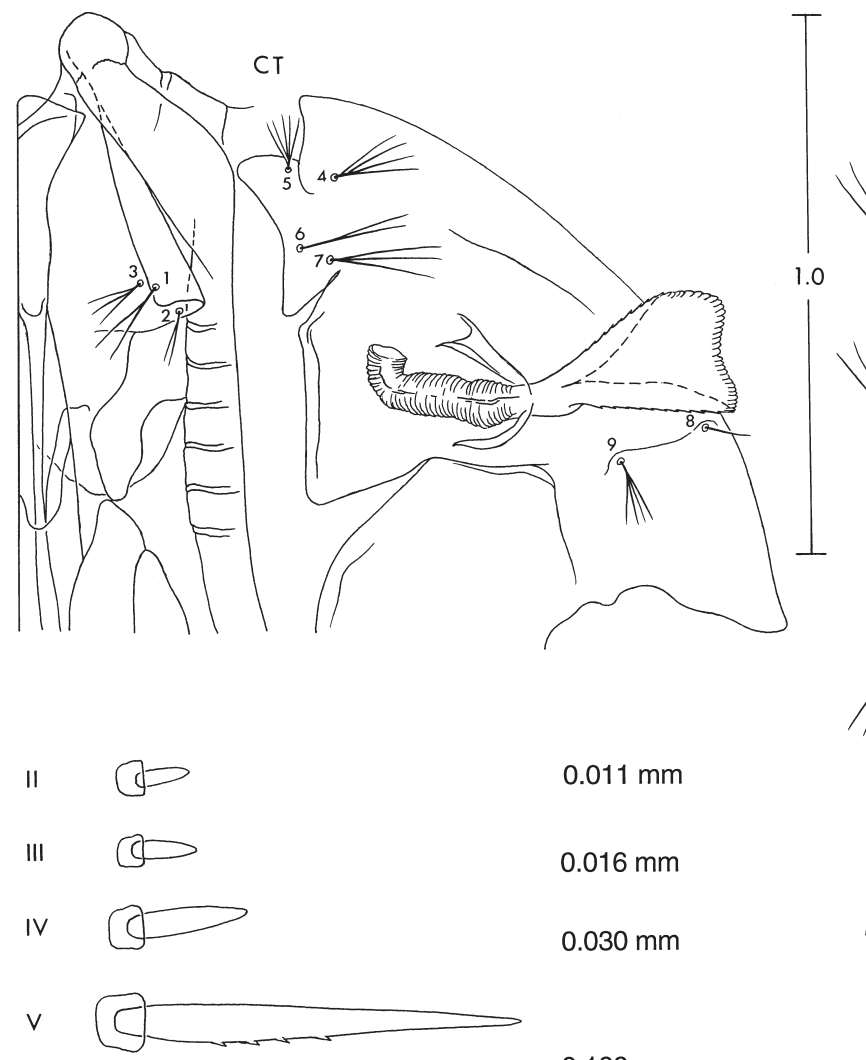

$0.011 \mathrm{~mm}$

$0.016 \mathrm{~mm}$

$0.030 \mathrm{~mm}$

$0.100 \mathrm{~mm}$

vi

$0.104 \mathrm{~mm}$

VII

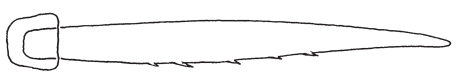

$0.104 \mathrm{~mm}$
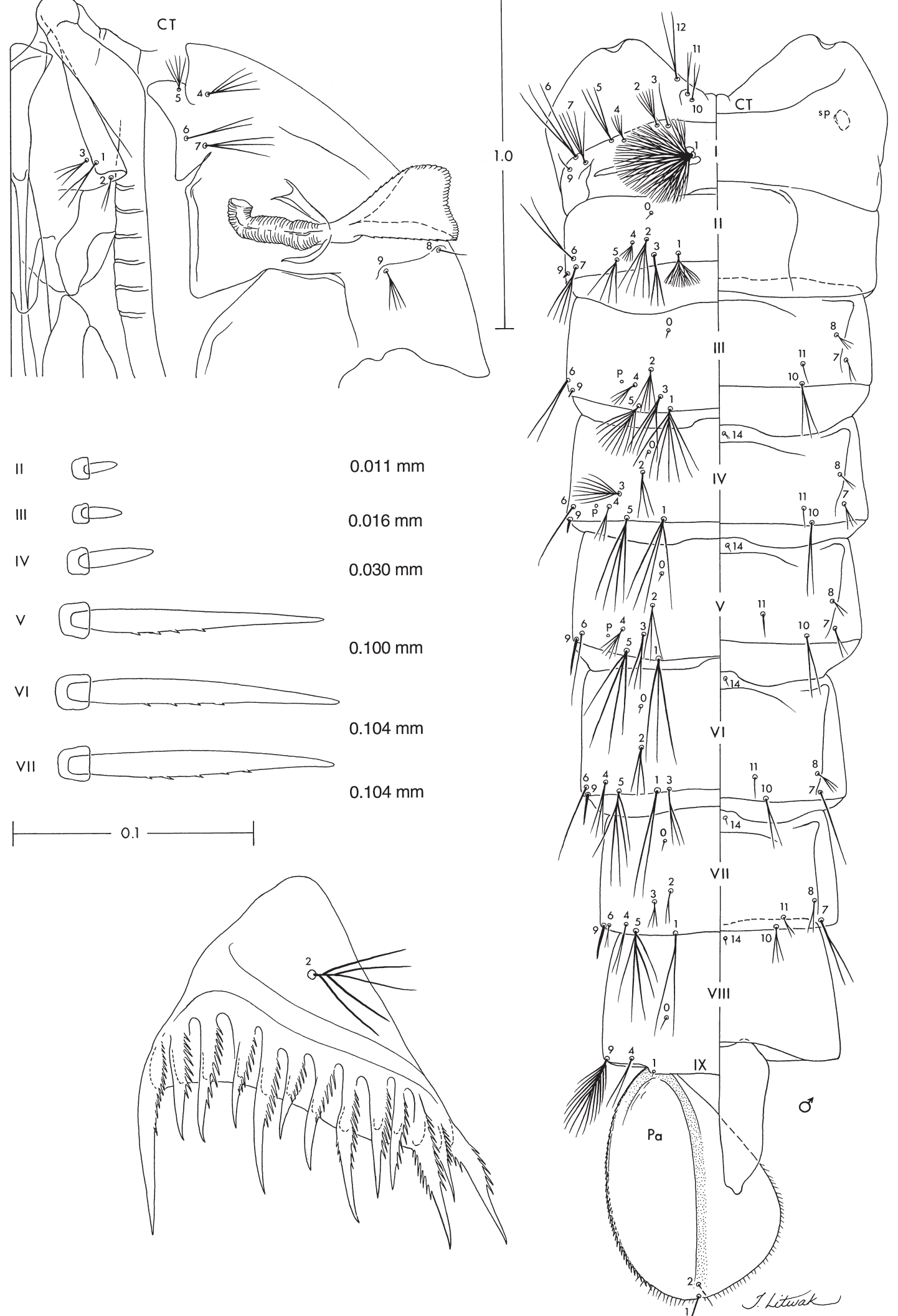

Fig. 9. Anopheles leucosphyrus, pupa and pecten plate of fourth-instar larva. CT, cephalothorax. Pa, paddle. I-IX, abdominal segments (dorsal on left, ventral on right), numbers on the left side denote setae 9 of segments II-VII. Scales in millimeters. 


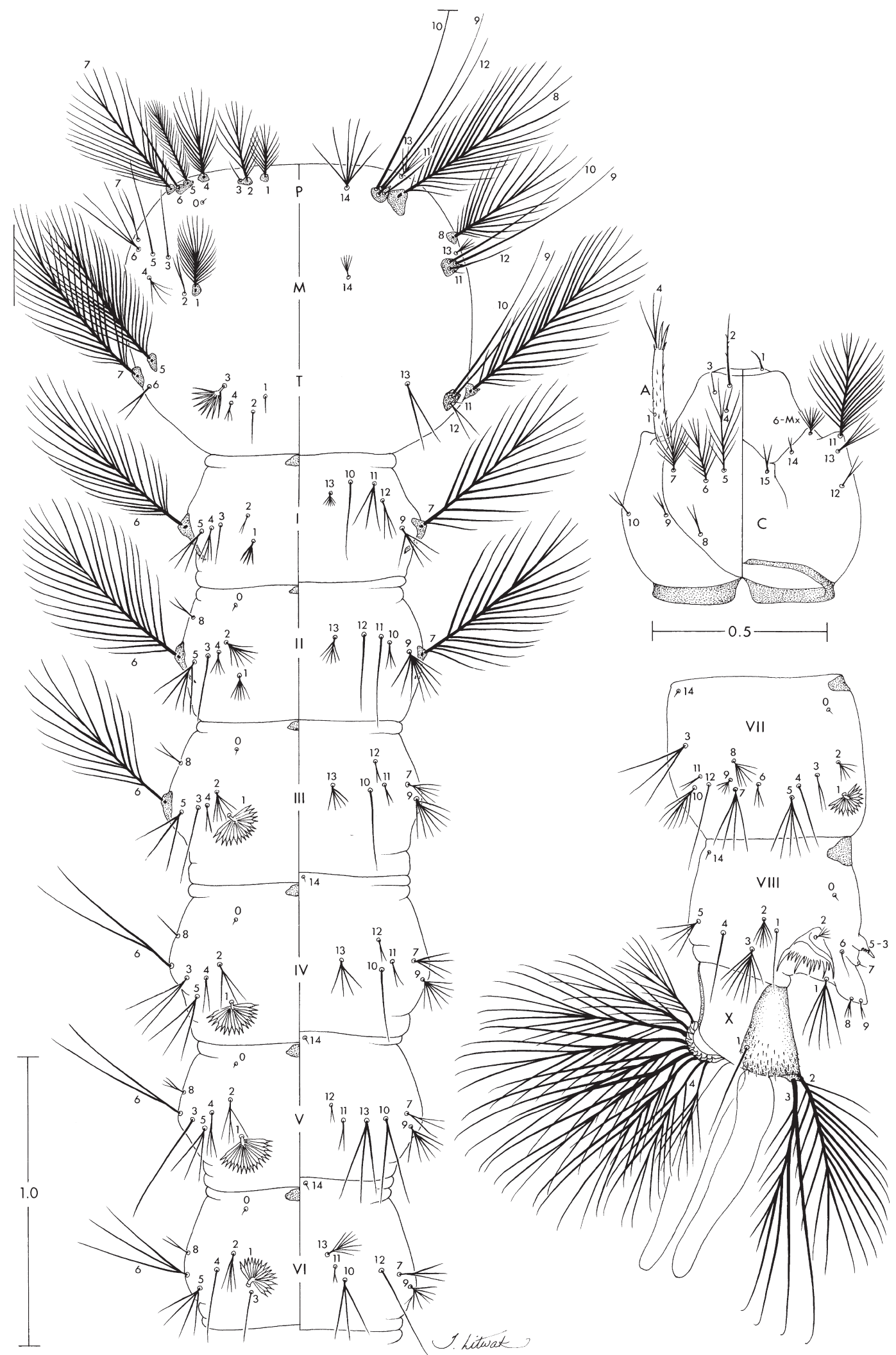

Fig. 10. Anopheles leucosphyrus, larva. C, head. P, prothorax. M, mesothorax. T, metathorax. I-VI, abdominal segments, left side dorsal, right side ventral. VII-X abdominal segments, lateral (left side) view. Scales in millimeters. 

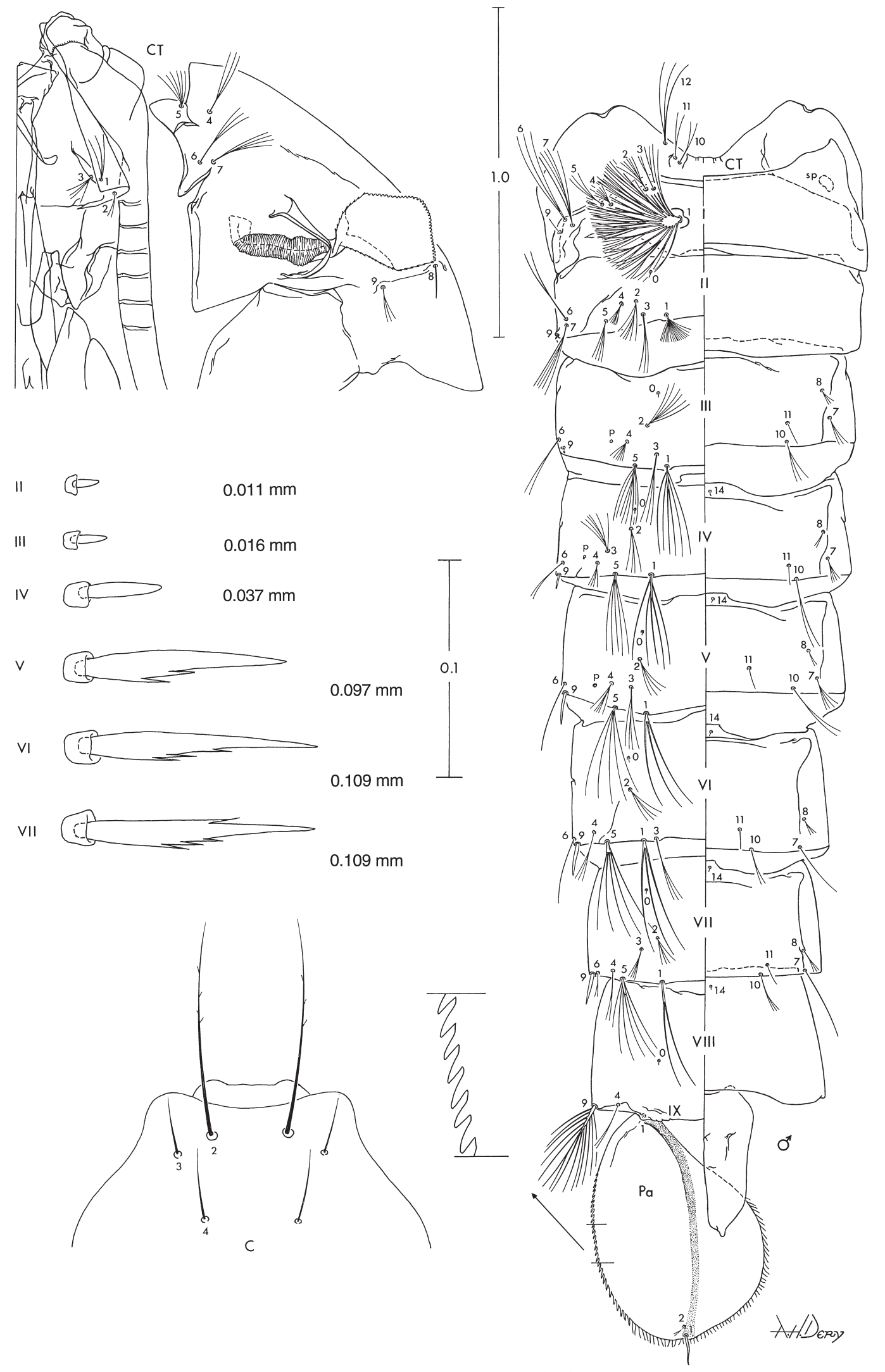

Fig. 11. Anopheles latens, pupa and larva. C, anterior part of head of fourth-instar larva. CT, cephalothorax. Pa, paddle. I-IX, abdominal segments of pupa (dorsal on left, ventral on right), numbers on the left side denote setae 9 of segments II-VII. Scales in millimeters. 


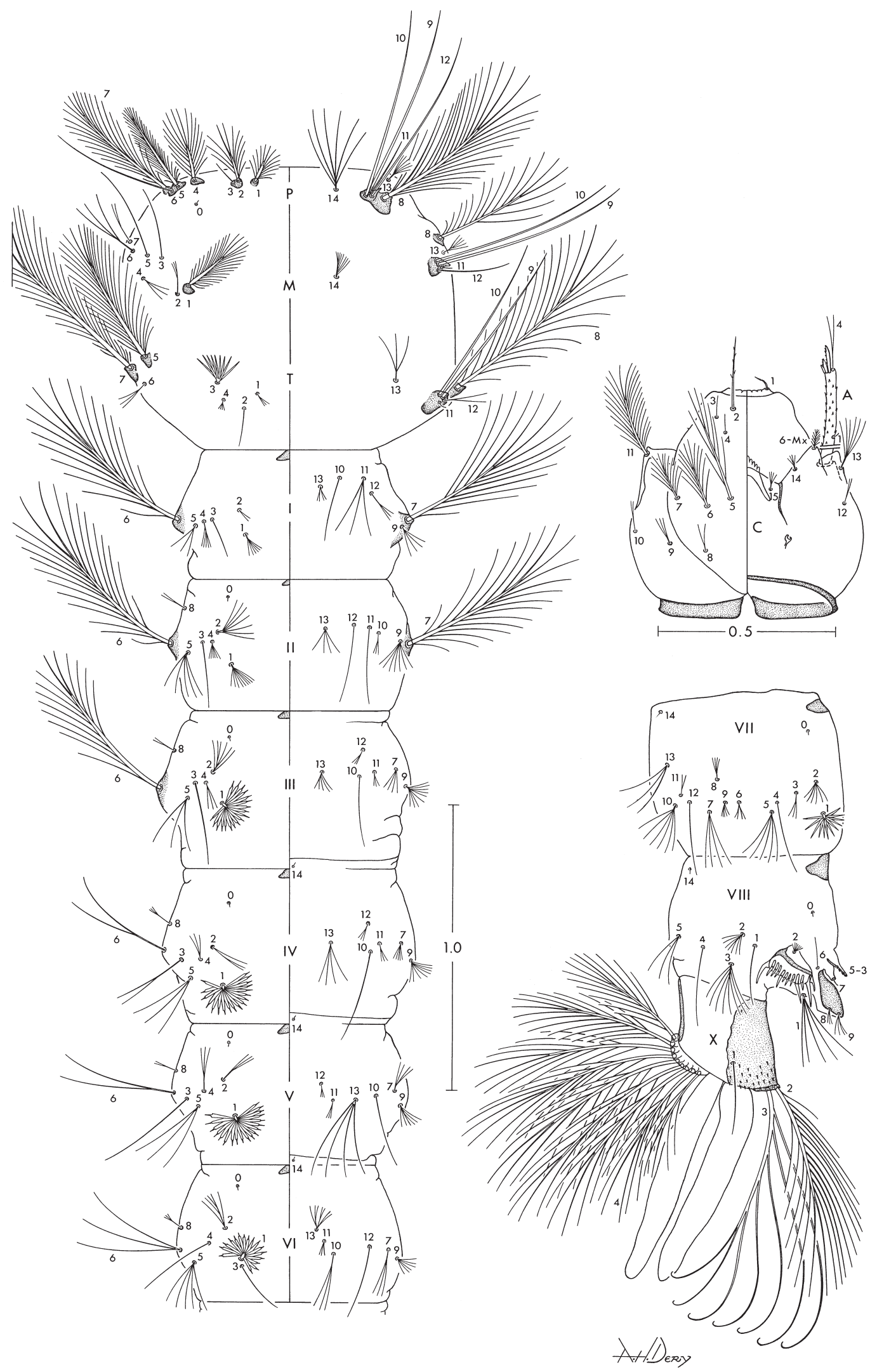

Fig. 12. Anopheles latens, larva. C, head. P, prothorax. M, mesothorax. T, metathorax. I-VI, abdominal segments, left side dorsal, right side ventral. VII-X abdominal segments, lateral (left side) view. Scales in millimeters. 

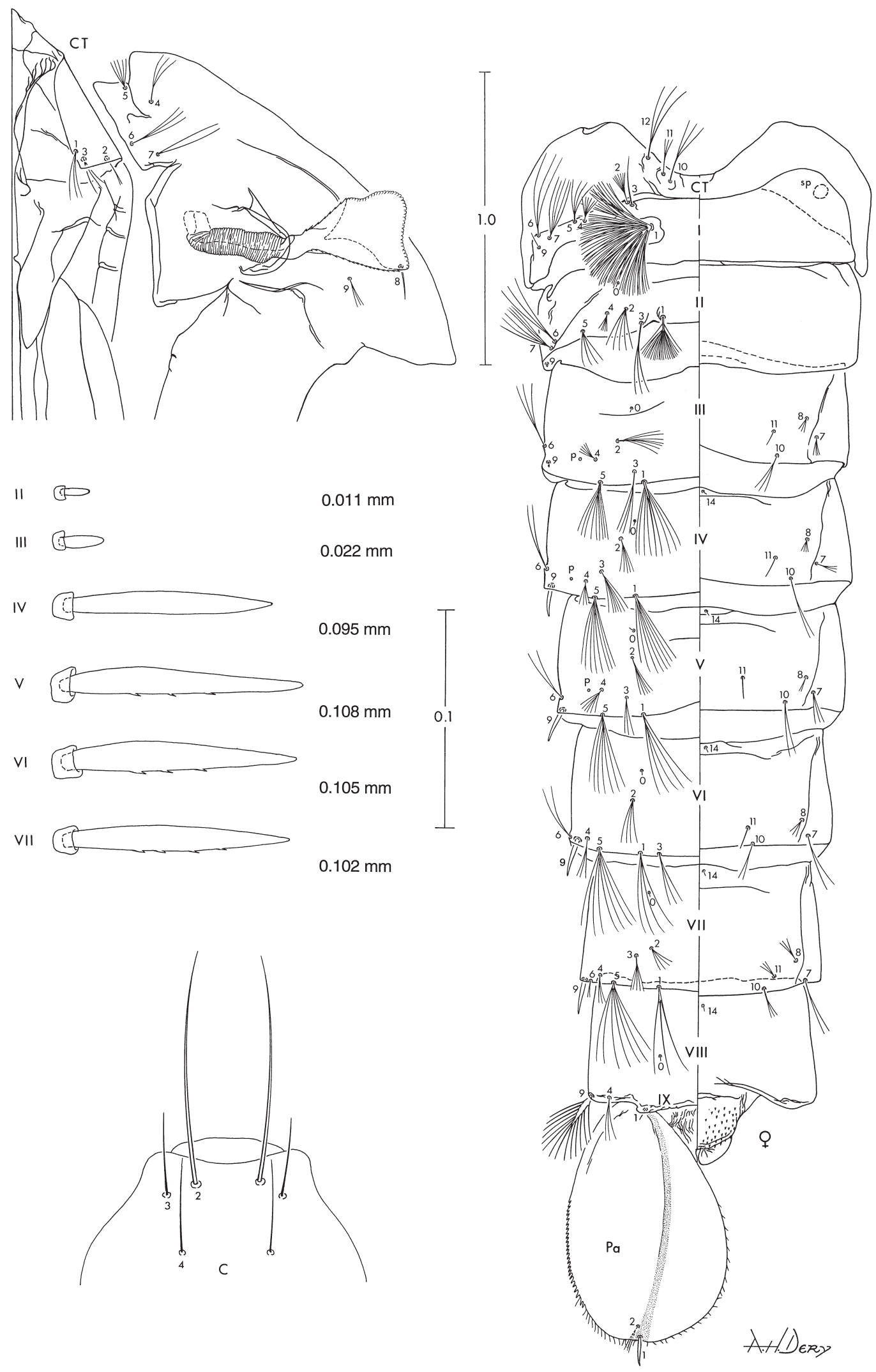

Fig. 13. Anopheles introlatus, pupa and larva. C, anterior part of head of fourth-instar larva; CT, cephalothorax. Pa, paddle. I-IX, abdominal segments of pupa (dorsal on left, ventral on right), numbers on the left side denote setae 9 of segments II-VII. Scales in millimeters. 


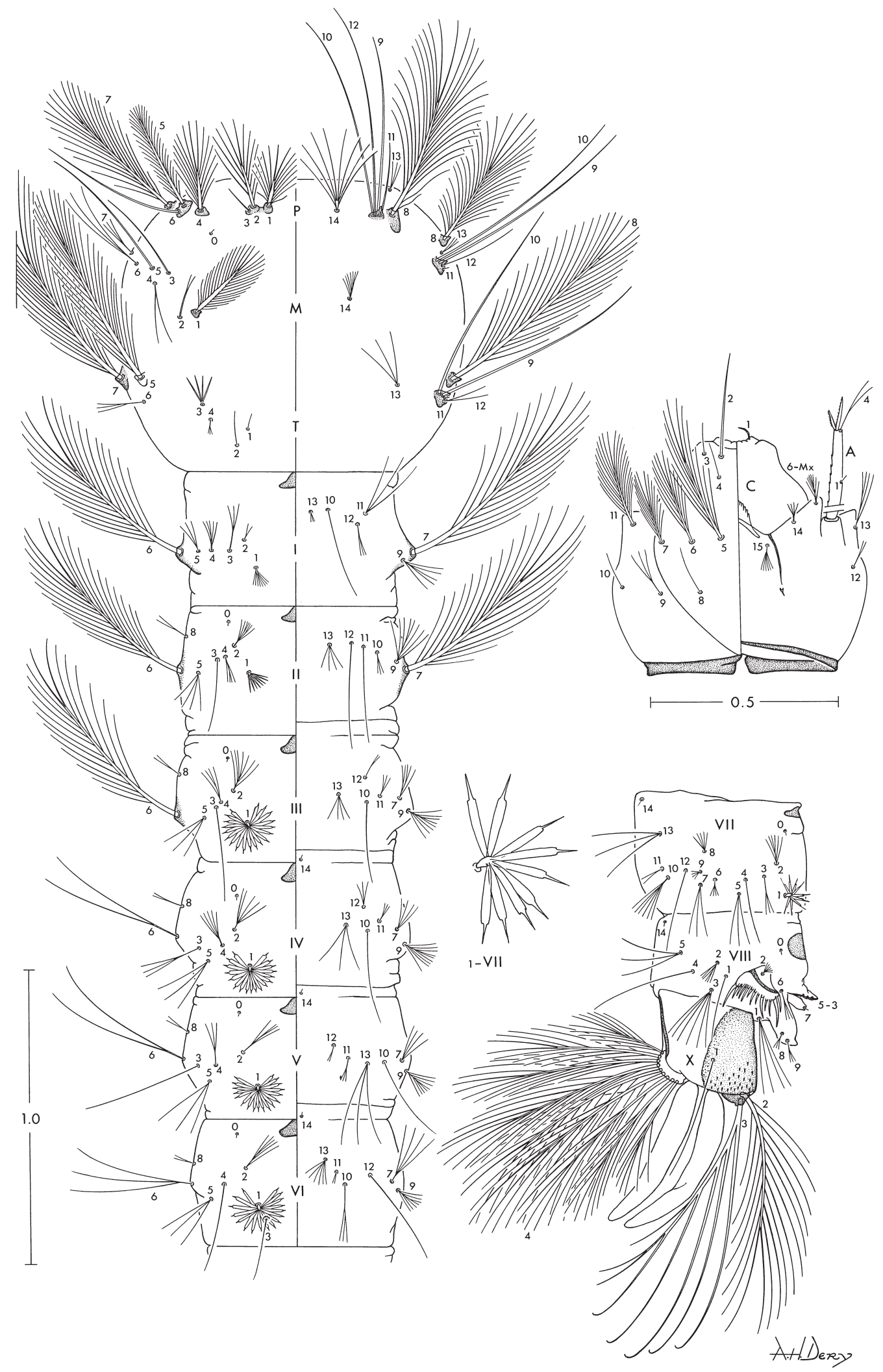

Fig. 14. Anopheles introlatus larva. C, head. P, prothorax. M, mesothorax. T, metathorax. I-VI, abdominal segments, left side dorsal, right side ventral. VII-X abdominal segments, lateral (left side) view. Scales in millimeters. 

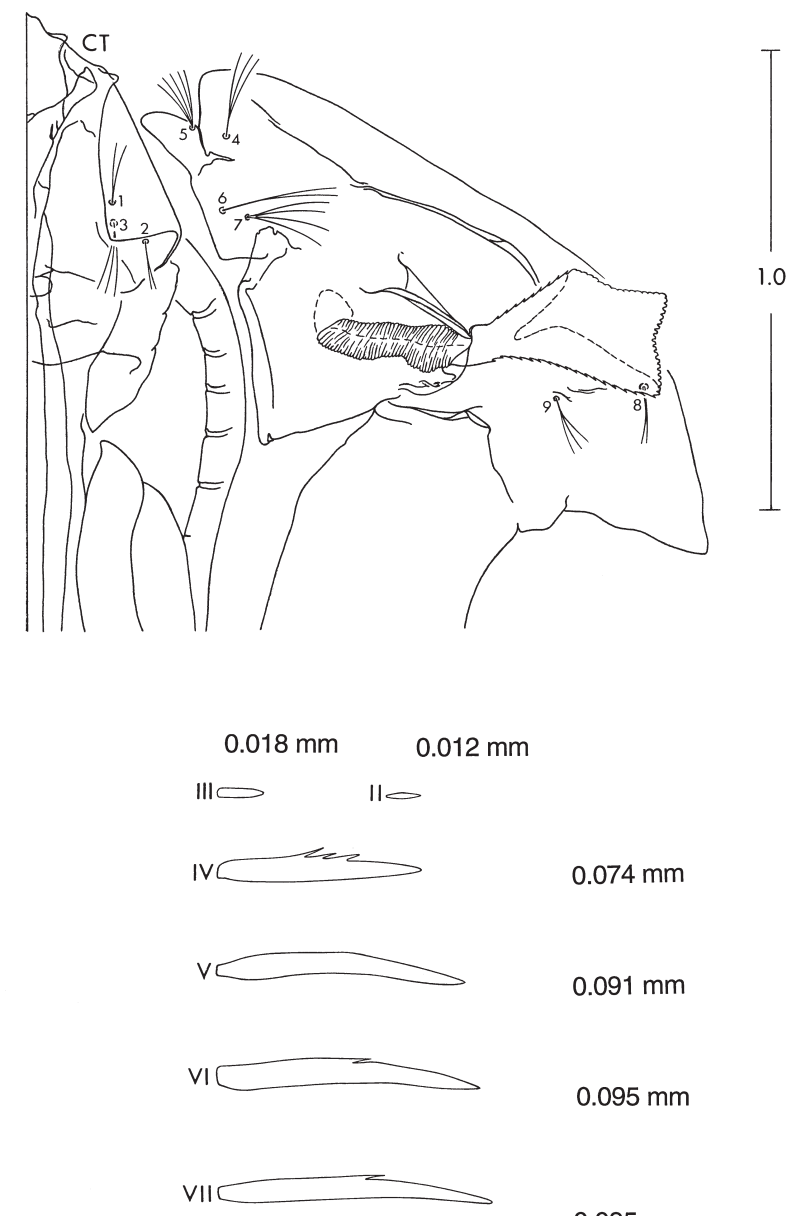

$0.074 \mathrm{~mm}$

$0.091 \mathrm{~mm}$

$0.095 \mathrm{~mm}$

$0.095 \mathrm{~mm}$
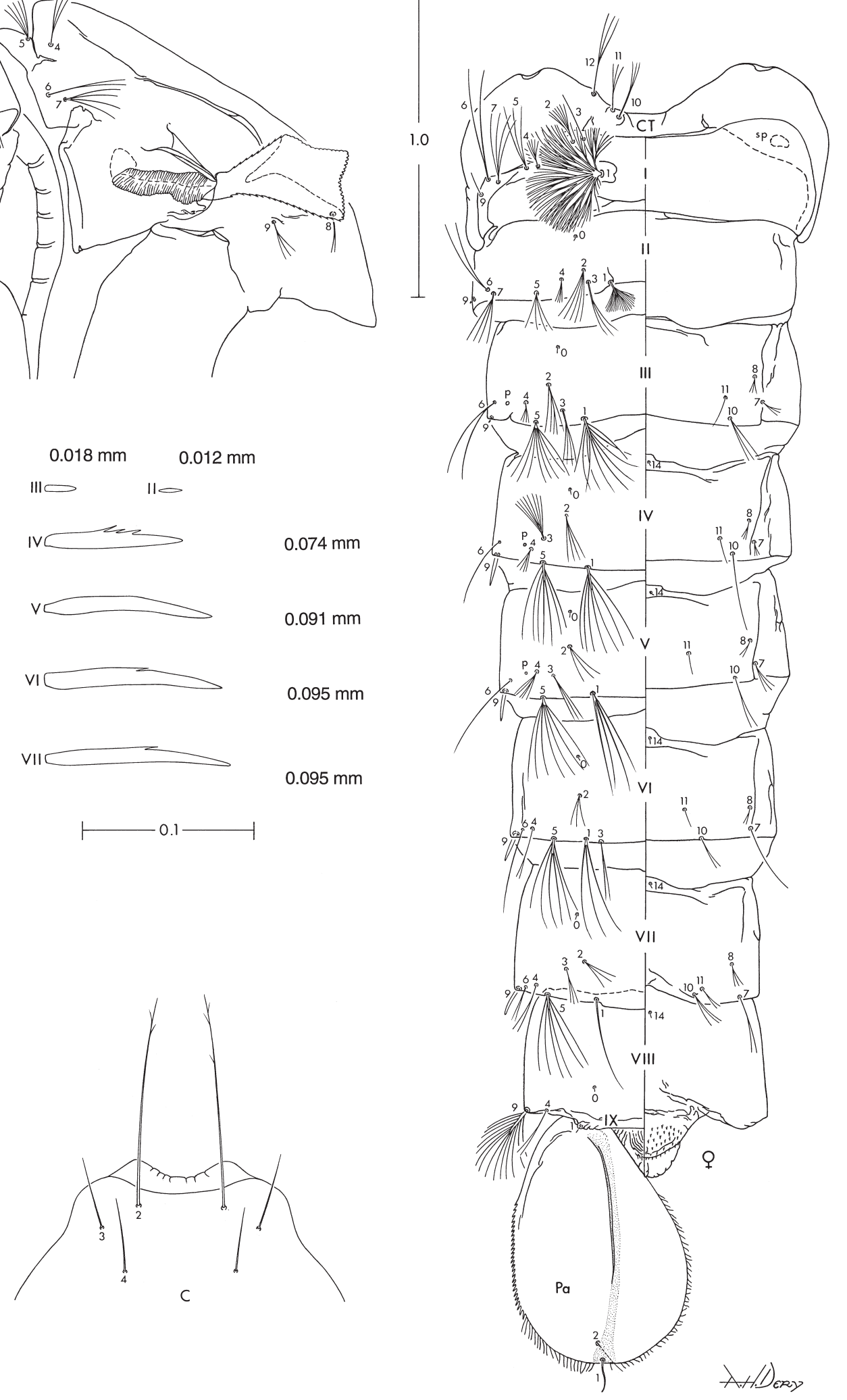

Fig. 15. Anopheles balabacensis, pupa and larva. C, anterior part of head of fourth-instar larva. CT, cephalothorax. Pa, paddle. I-IX, abdominal segments of pupa (dorsal on left, ventral on right), numbers on the left side denote setae 9 of segments II-VII. Scales in millimeters. 


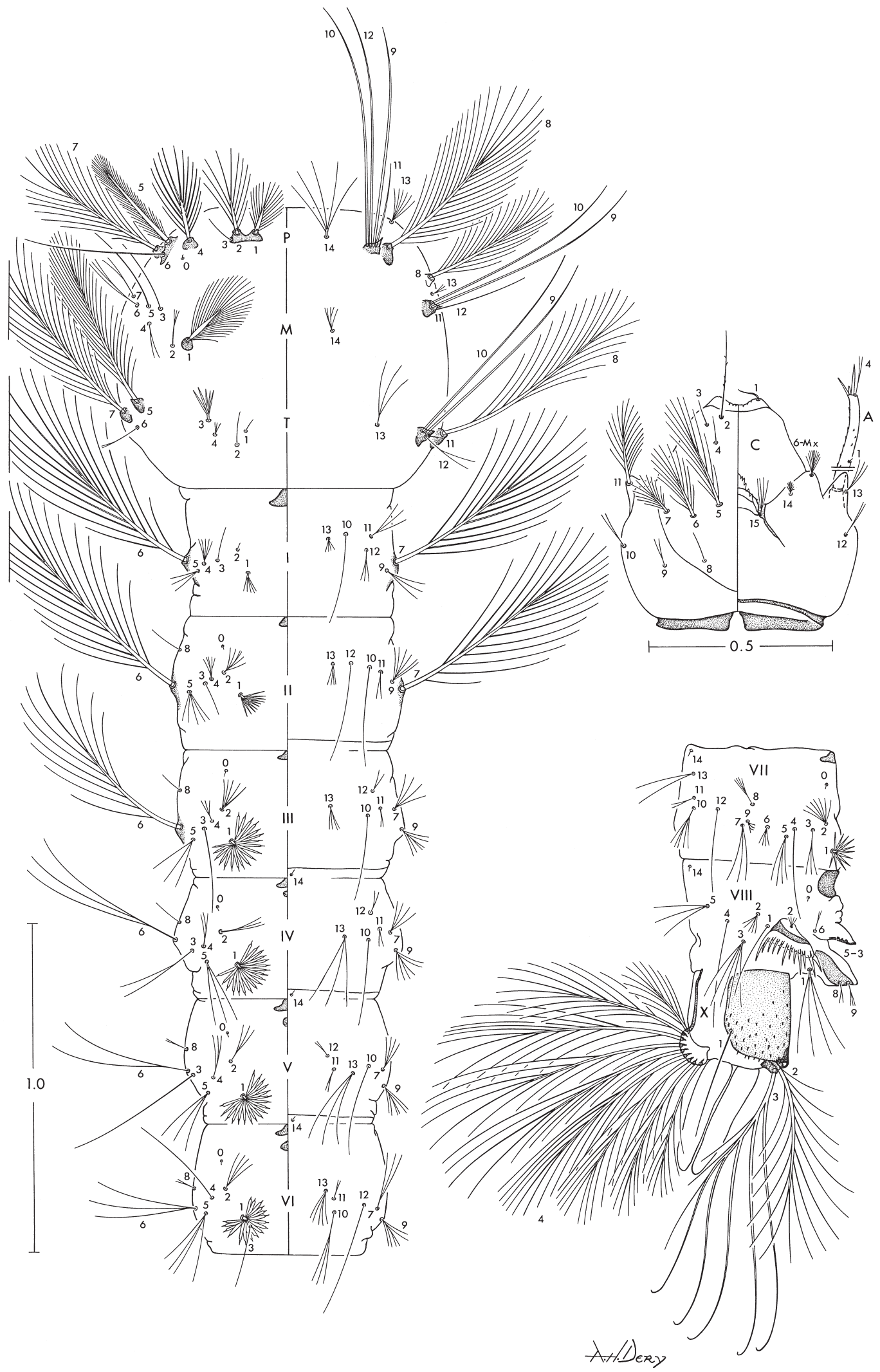

Fig. 16. Anopheles balabacensis, larva. C, head. P, prothorax. M, mesothorax. T, metathorax. I-VI, abdominal segments, left side dorsal, right side ventral. VII-X abdominal segments, lateral (left side) view. Scales in millimeters. 

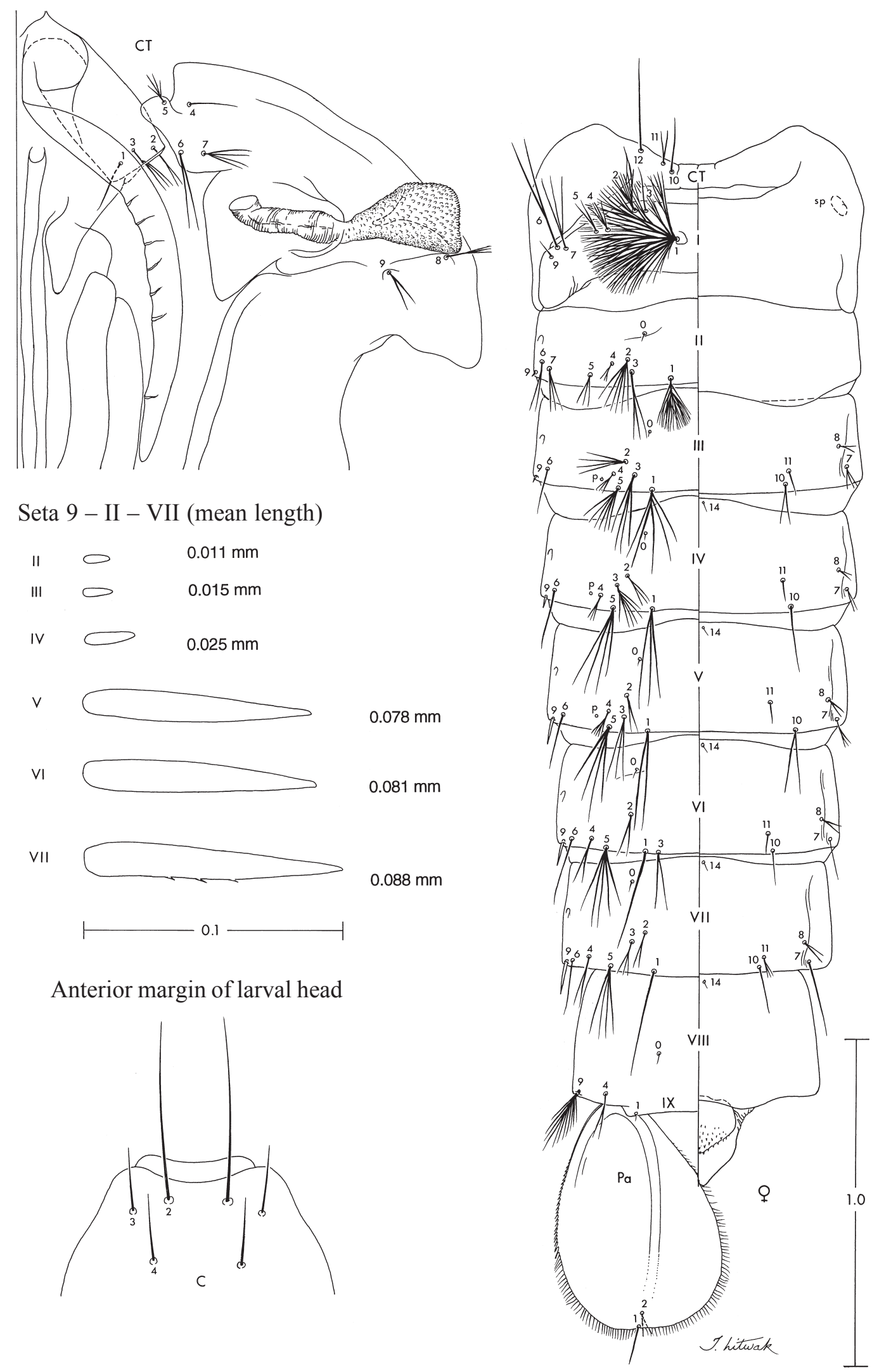

Fig. 17. Anopheles baisasi, pupa and larva. C, anterior part of head of fourth-instar larva. CT, cephalothorax. Pa, paddle. I-IX, abdominal segments of pupa (dorsal on left, ventral on right), numbers on the left side denote setae 9 of segments II-VII. Scales in millimeters. 


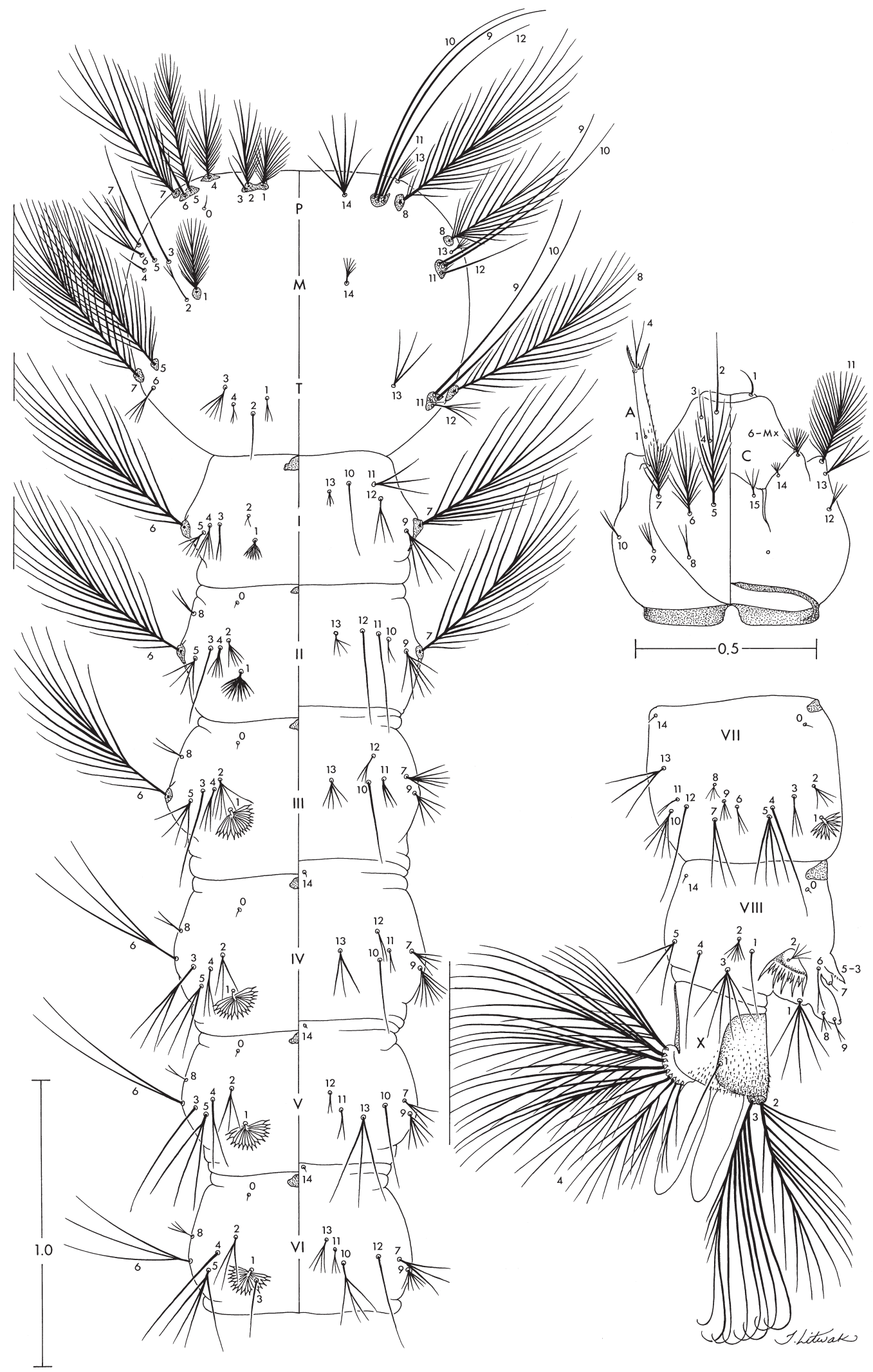

Fig. 18. Anopheles baisasi, larva. C, head. P, prothorax. M, mesothorax. T, metathorax. I-VI, abdominal segments, left side dorsal, right side ventral. VII-X abdominal segments, lateral (left side) view. Scales in millimeters. 

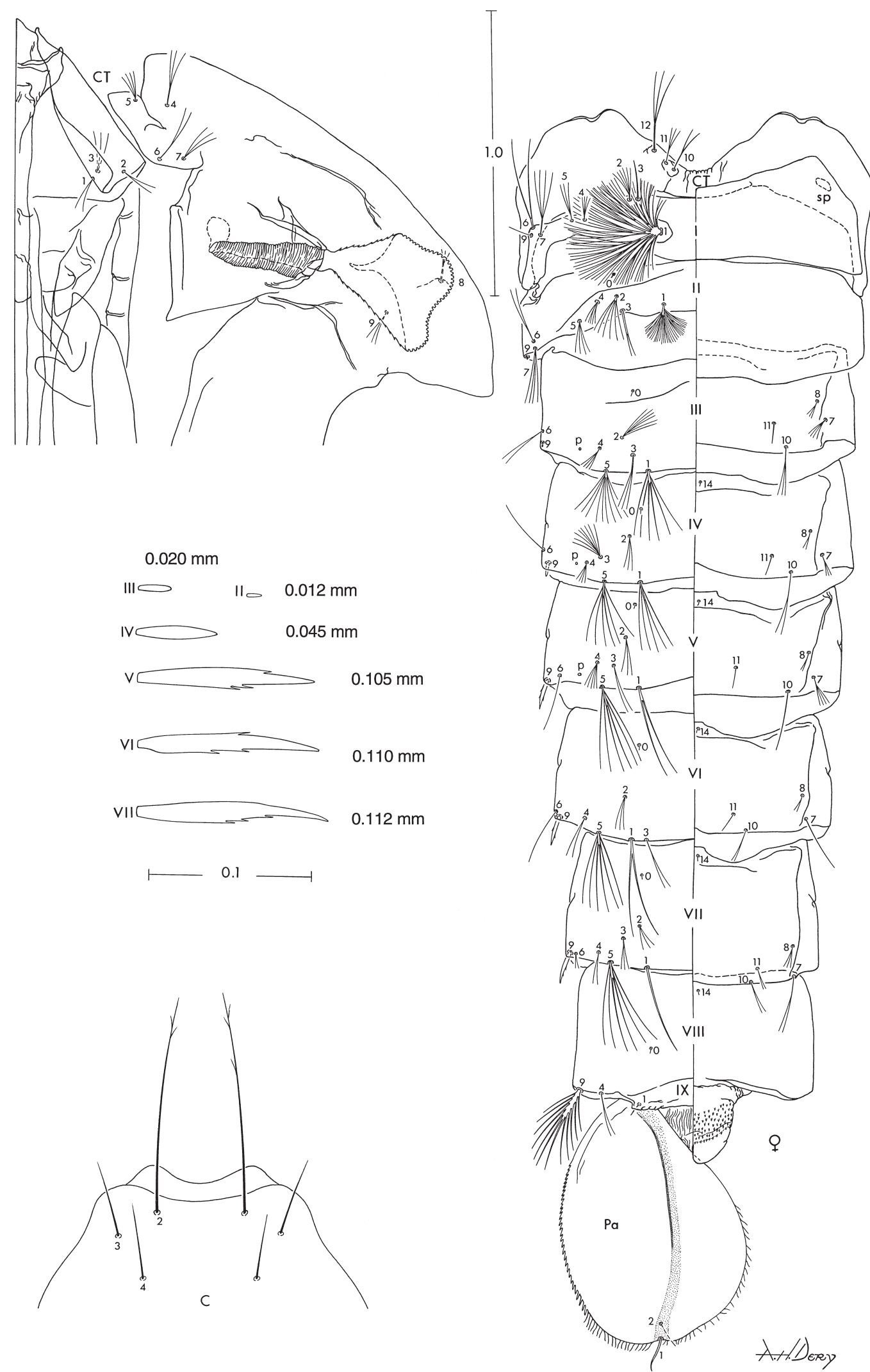

Fig. 19. Anopheles dirus, pupa and larva. C, anterior part of head of fourth-instar larva. CT, cephalothorax. Pa, paddle. I-IX, abdominal segments of pupa (dorsal on left, ventral on right), numbers on the left side denote setae 9 of segments II-VII. Scales in millimeters. 


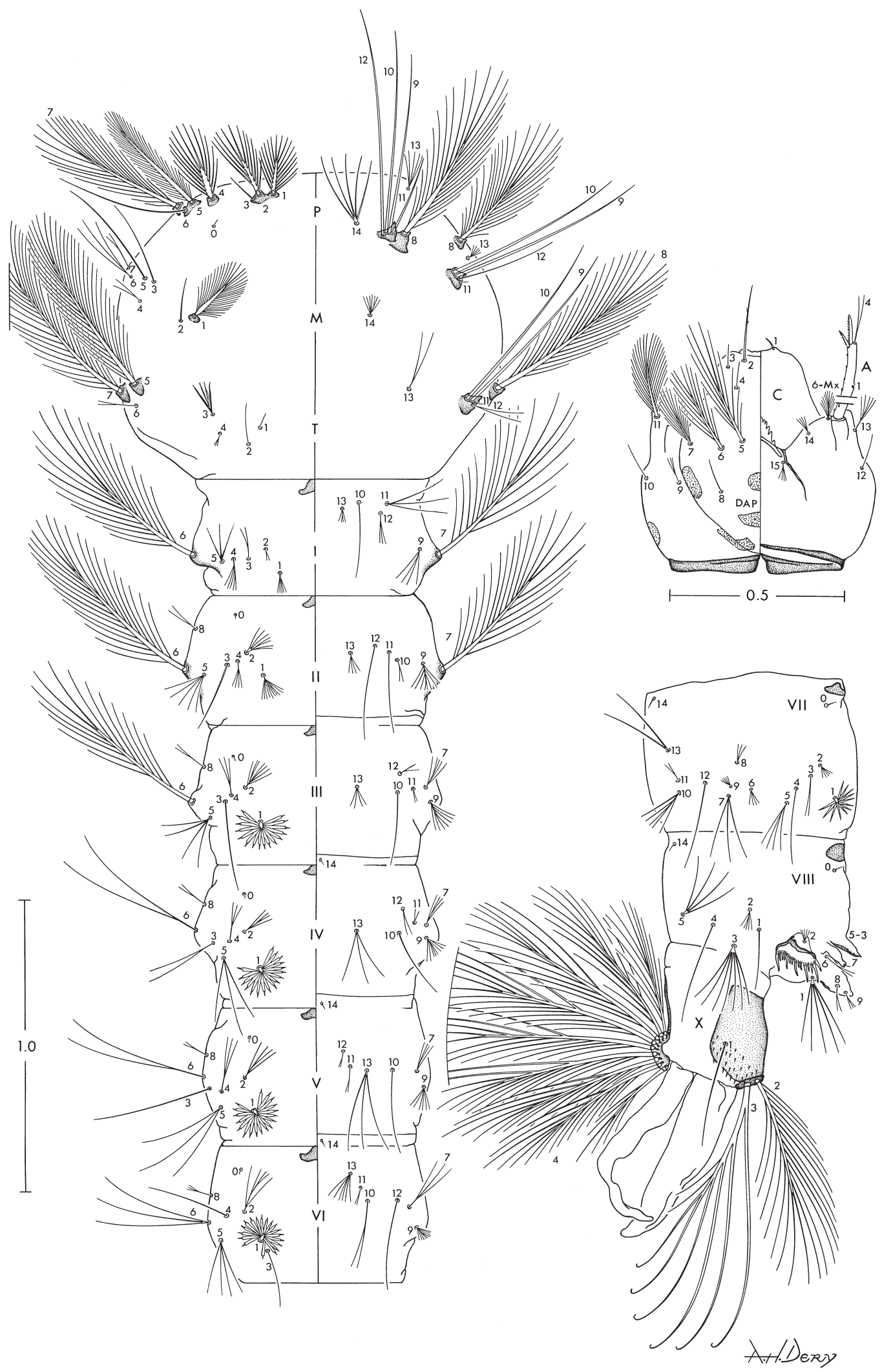

Fig. 20. Anopheles dirus, larva. C, head. P, prothorax. M, mesothorax. T, metathorax. I-VI, abdominal segments, left side dorsal, right side ventral. VII-X abdominal segments, lateral (left side) view. Scales in millimeters. 

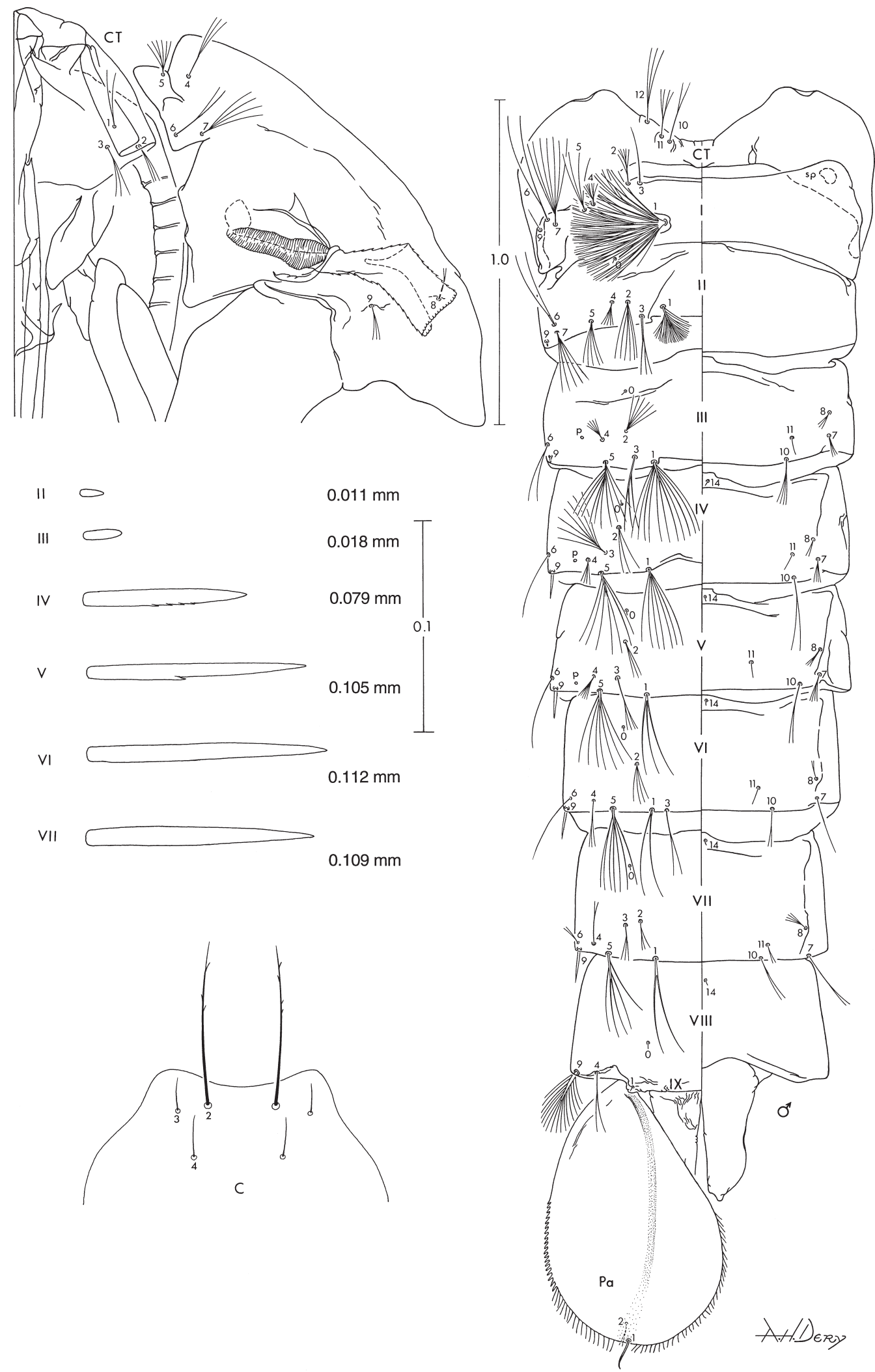

Fig. 21. Anopheles cracens, pupa and larva. C, anterior part of head of fourth-instar larva. CT, cephalothorax. Pa, paddle. I-IX, abdominal segments of pupa (dorsal on left, ventral on right), numbers on the left side denote setae 9 of segments II-VII. Scales in millimeters. 


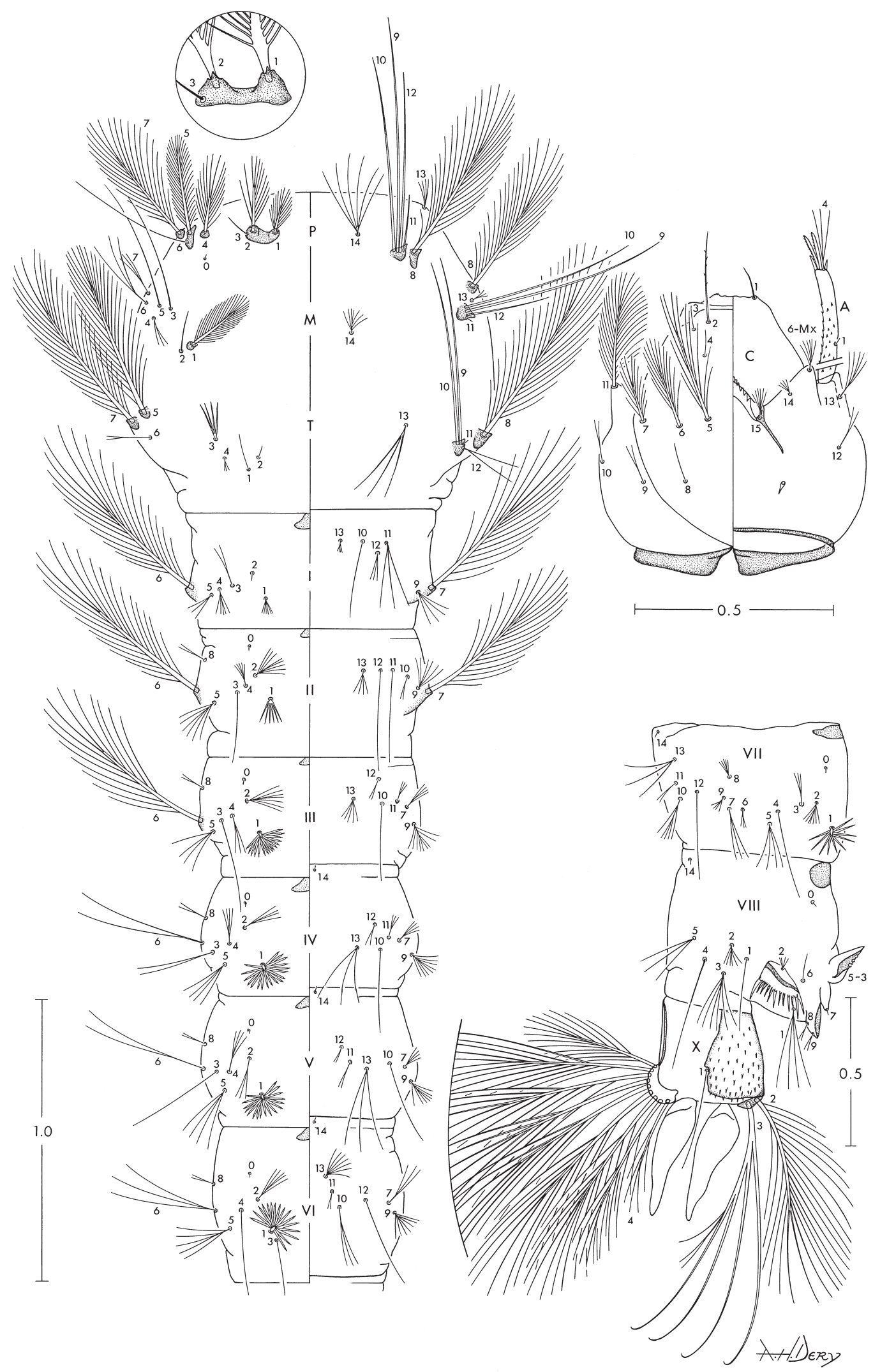

Fig. 22. Anopheles cracens, larva. C, head. P, prothorax. M, mesothorax. T, metathorax. I-VI, abdominal segments, left side dorsal, right side ventral. VII-X abdominal segments, lateral (left side) view. Detail inside the circle shows setae 1-3-P. Scales in millimeters. 

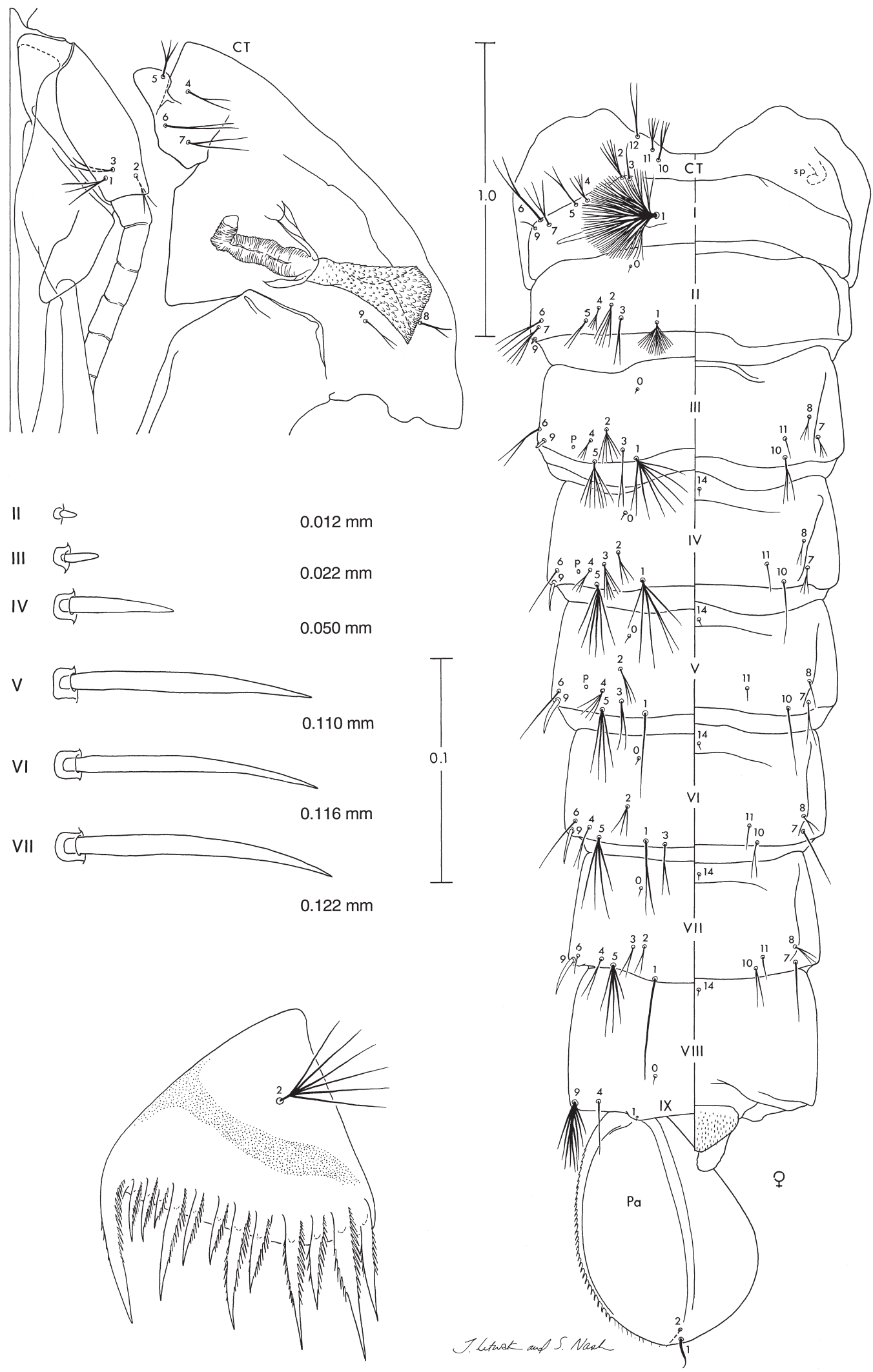

Fig. 23. Anopheles scanloni, pupa and larva. CT, cephalothorax. Pa, paddle. Pecten plate of fourth-instar larva, bottom on the left side. I-IX, abdominal segments of pupa (dorsal on left, ventral on right), numbers on the left side denote setae 9 of segments II-VII. Scales in millimeters. 


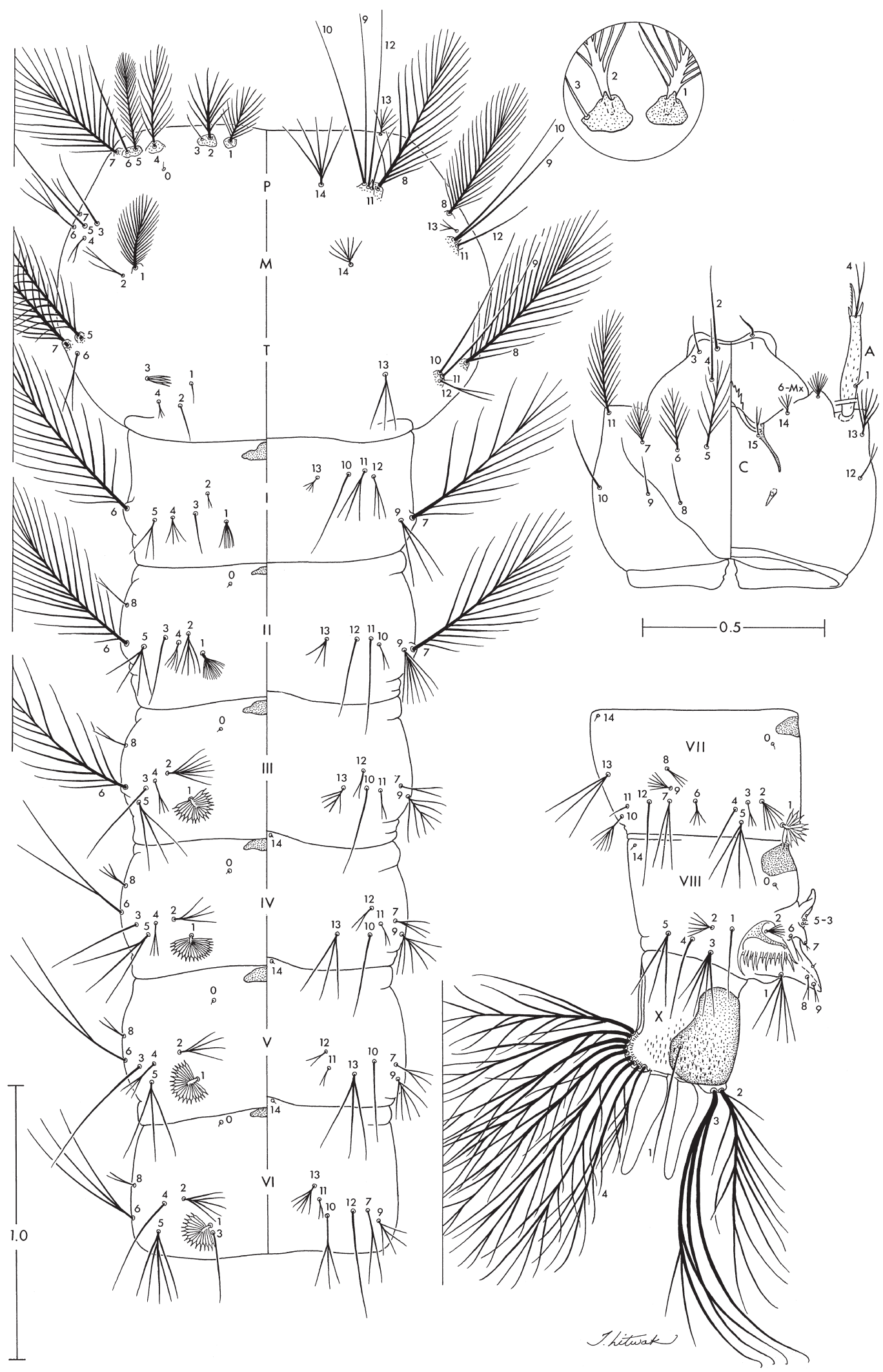

Fig. 24. Anopheles scanloni, larva. C, head. P, prothorax. M, mesothorax. T, metathorax. I-VI, abdominal segments, left side dorsal, right side ventral. VII-X abdominal segments, lateral (left side) view. Detail inside the circle shows setae 1-3-P. Scales in millimeters. 

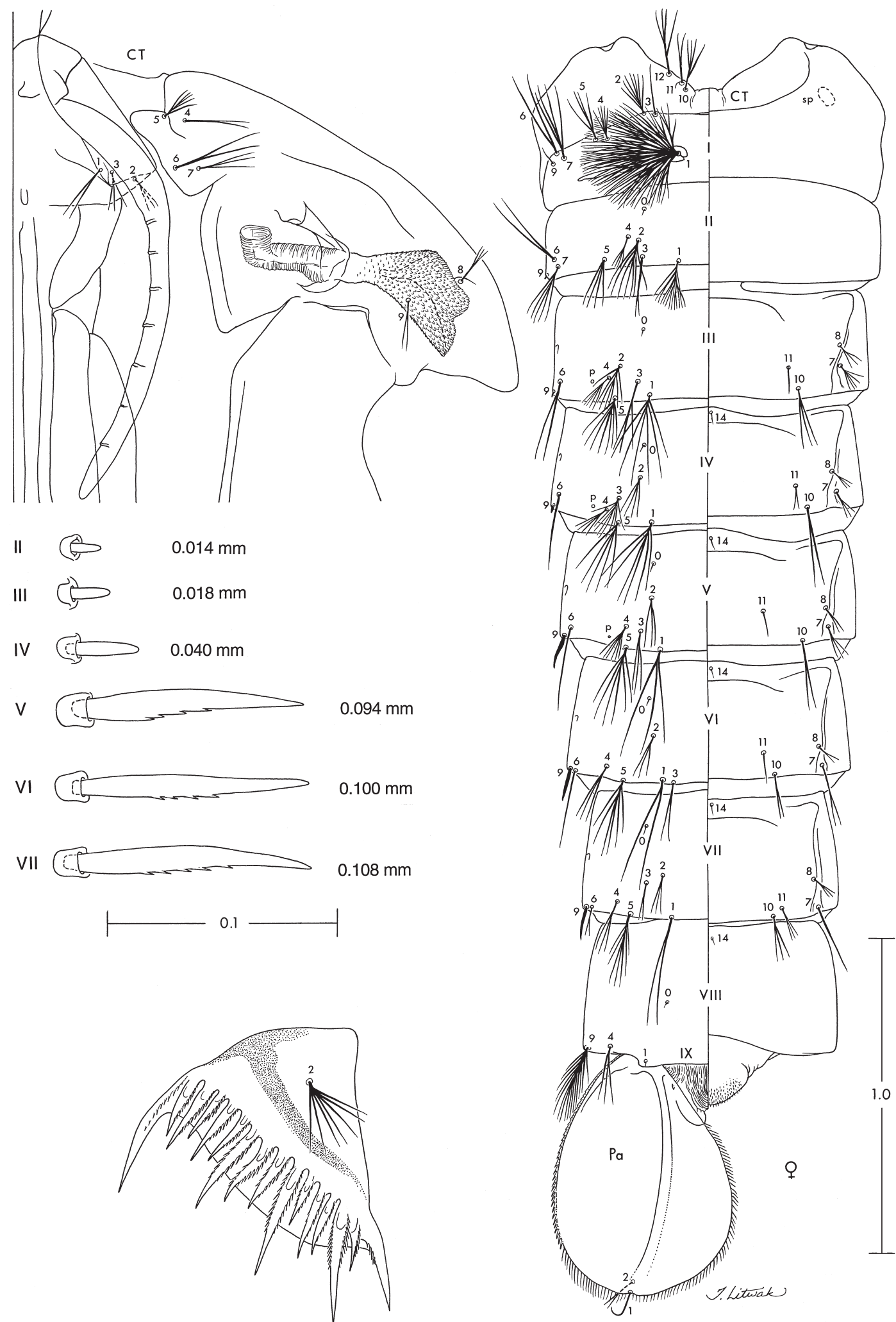

Fig. 25. Anopheles baimaii, pupa and larva. CT, cephalothorax. Pa, paddle. Pecten plate of fourth-instar larva, bottom on the left side. I-IX, abdominal segments of pupa (dorsal on left, ventral on right), numbers on the left side denote setae 9 of segments II-VII. Scales in millimeters. 


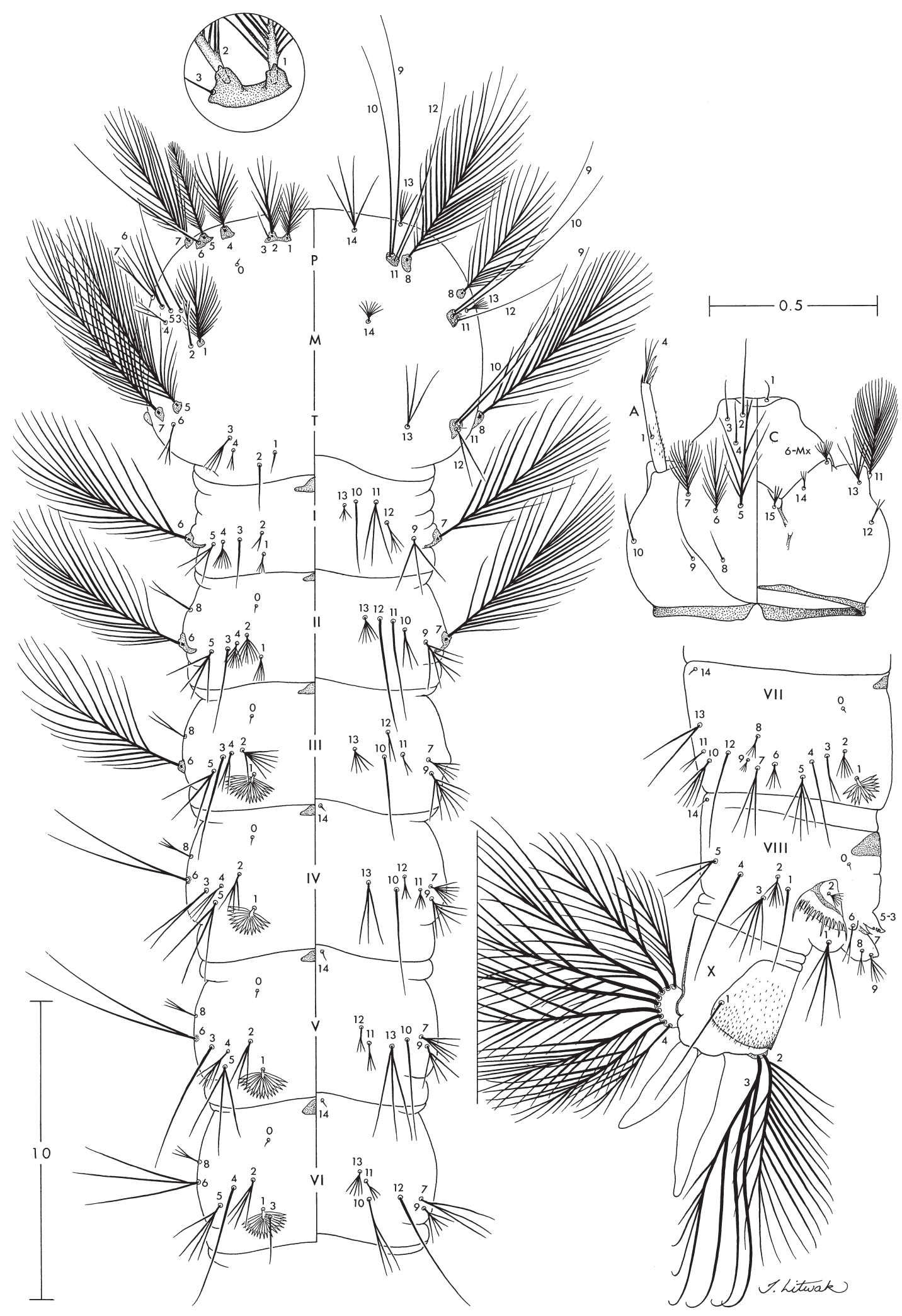

Fig. 26. Anopheles baimaii, larva. C, head. P, prothorax. M, mesothorax. T, metathorax. I-VI, abdominal segments, left side dorsal, right side ventral. VII-X abdominal segments, lateral (left side) view. Detail inside the circle shows setae 1-3-P. Scales in millimeters. 

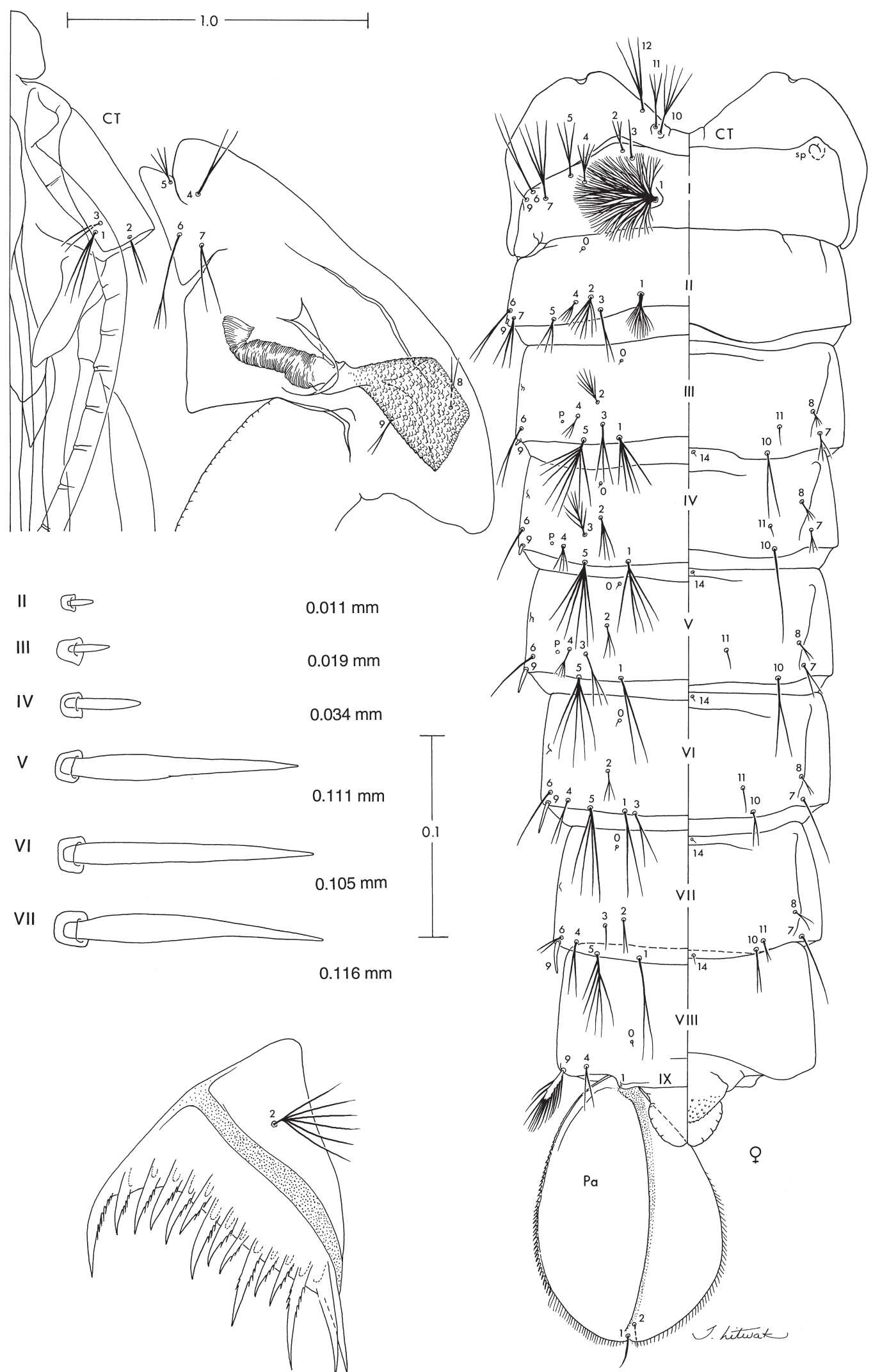

Fig. 27. Anopheles elegans, pupa and larva. CT, cephalothorax. Pa, paddle. Pecten plate of fourth-instar larva, bottom on the left side. I-IX, abdominal segments of pupa (dorsal on left, ventral on right), numbers on the left side denote setae 9 of segments II-VII. Scales in millimeters. 


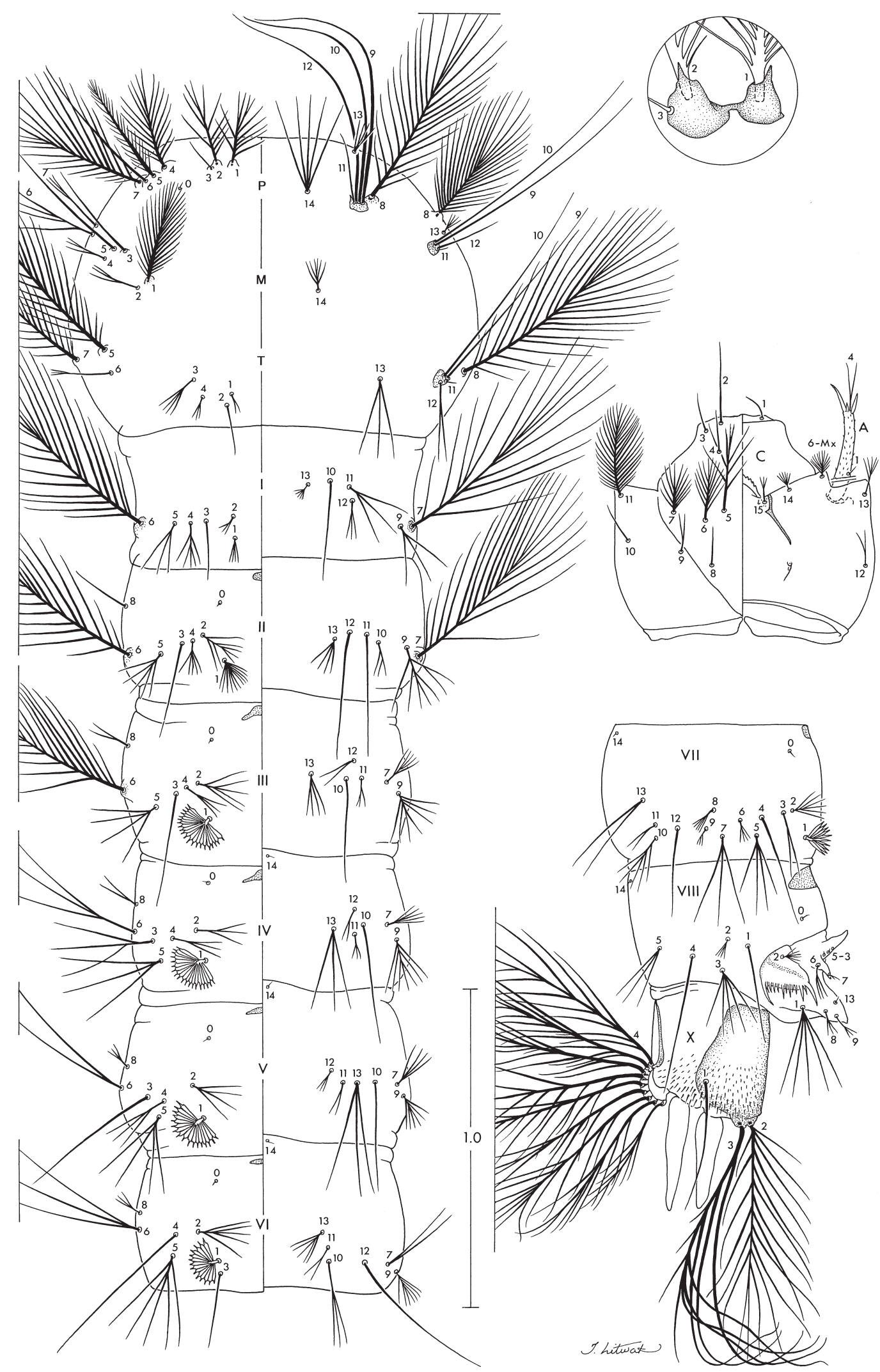

Fig. 28. Anopheles elegans, larva. C, head. P, prothorax. M, mesothorax. T, metathorax. I-VI, abdominal segments, left side dorsal, right side ventral. VII-X abdominal segments, lateral (left side) view. Detail inside the circle shows setae 1-3-P. Scales in millimeters. 

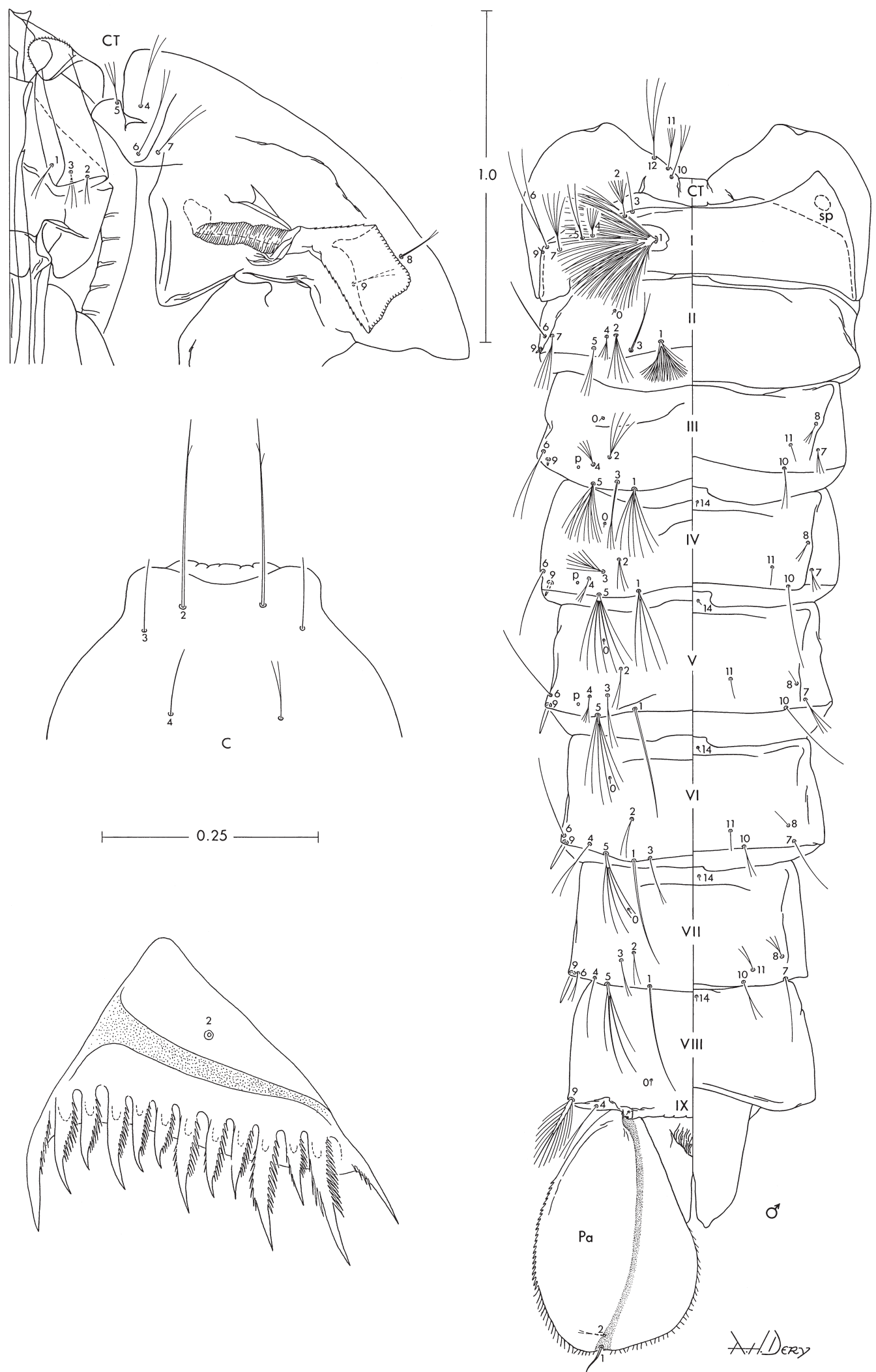

Fig. 29. Anopheles takasagoensis, pupa and larva. C, anterior part of head of fourth-instar larva. CT, cephalothorax. Pa, paddle. Pecten plate of fourth-instar larva, bottom on the left side. I-IX, abdominal segments of pupa (dorsal on left, ventral on right), numbers on the left side denote setae 9 of segments II-VII. Scales in millimeters. 


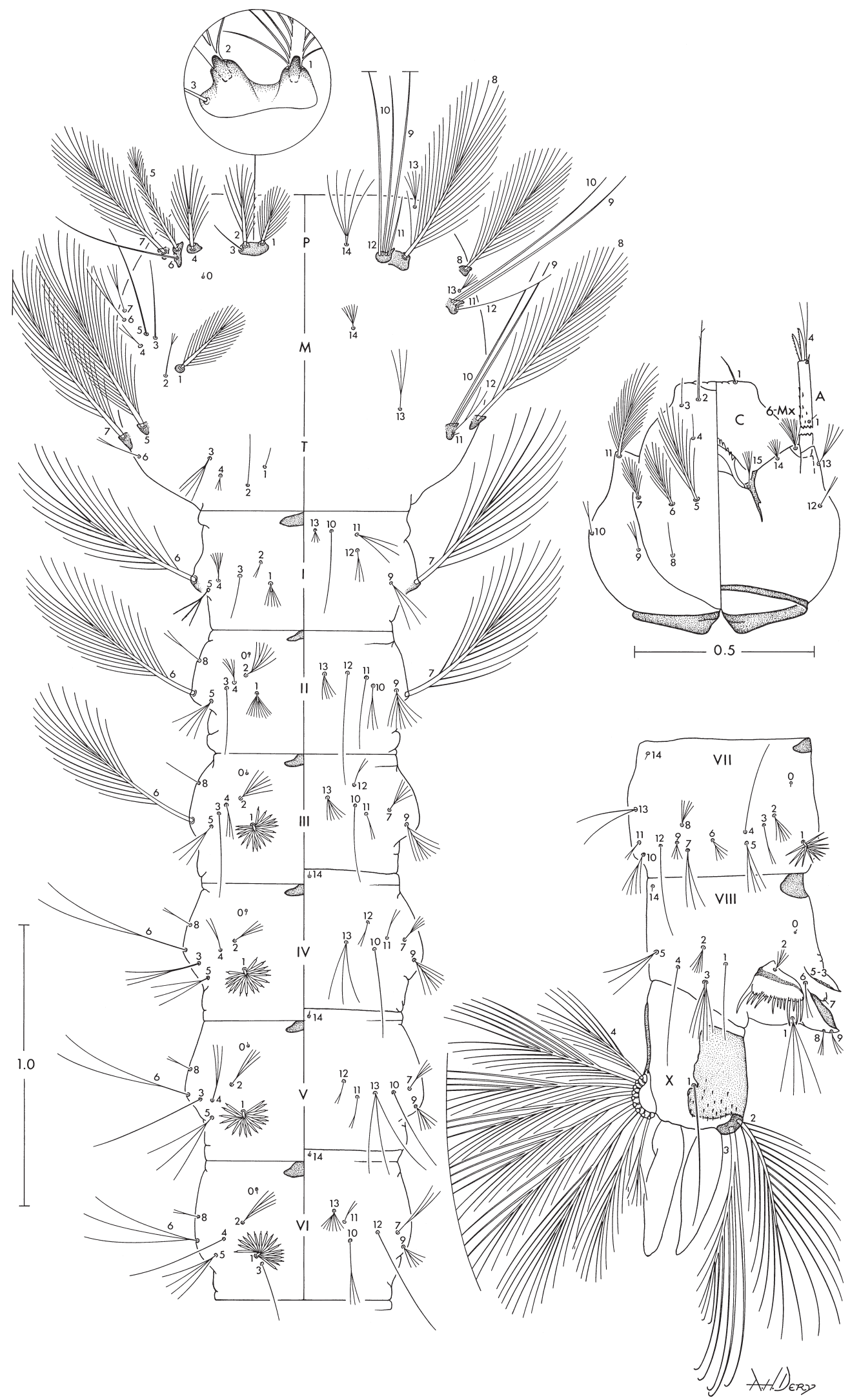

Fig. 30. Anopheles takasagoensis, larva. C, head. P, prothorax. M, mesothorax. T, metathorax. I-VI, abdominal segments, left side dorsal, right side ventral. VII-X abdominal segments, lateral (left side) view. Detail inside the circle shows setae 1-3-P. Scales in millimeters. 

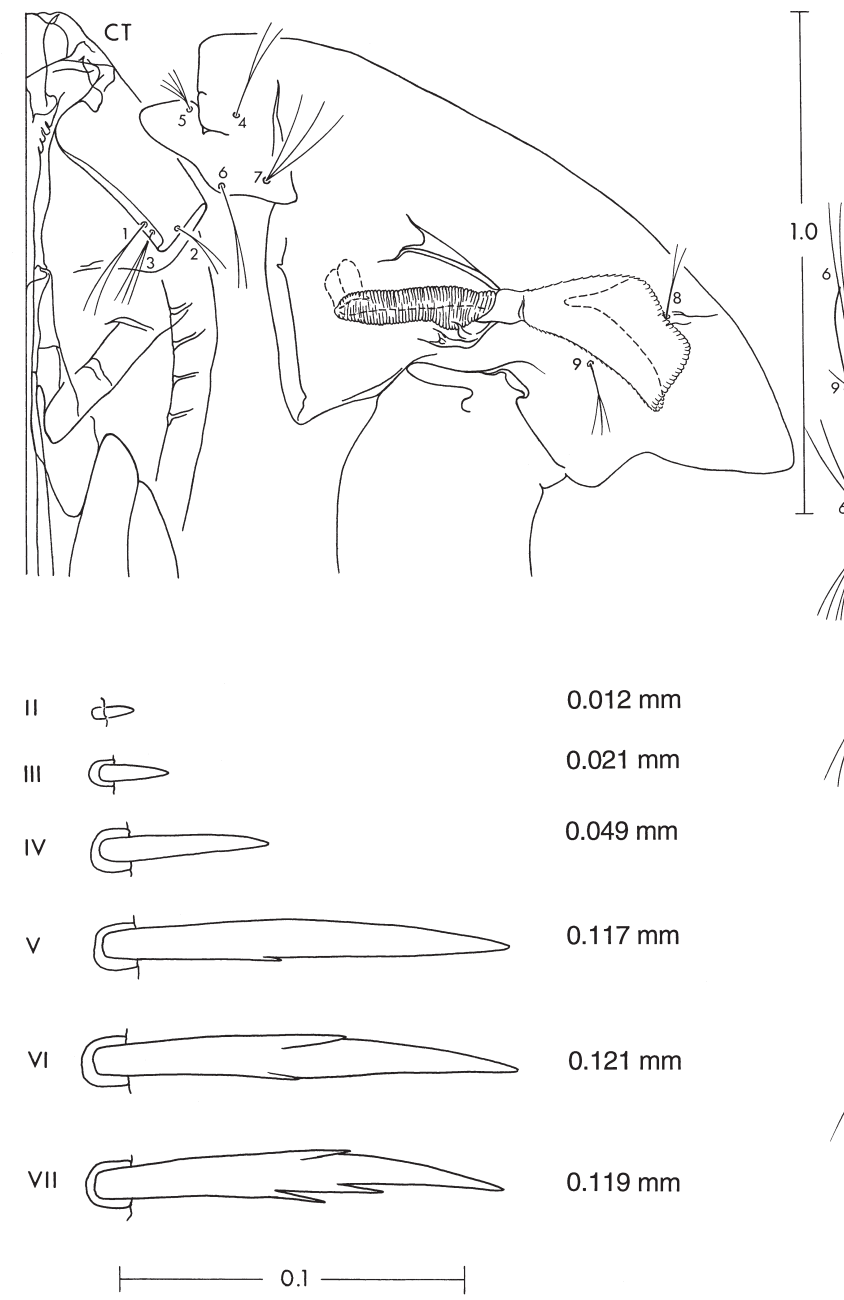

$0.012 \mathrm{~mm}$

$0.021 \mathrm{~mm}$

$0.049 \mathrm{~mm}$

$0.117 \mathrm{~mm}$

$0.121 \mathrm{~mm}$

$0.119 \mathrm{~mm}$
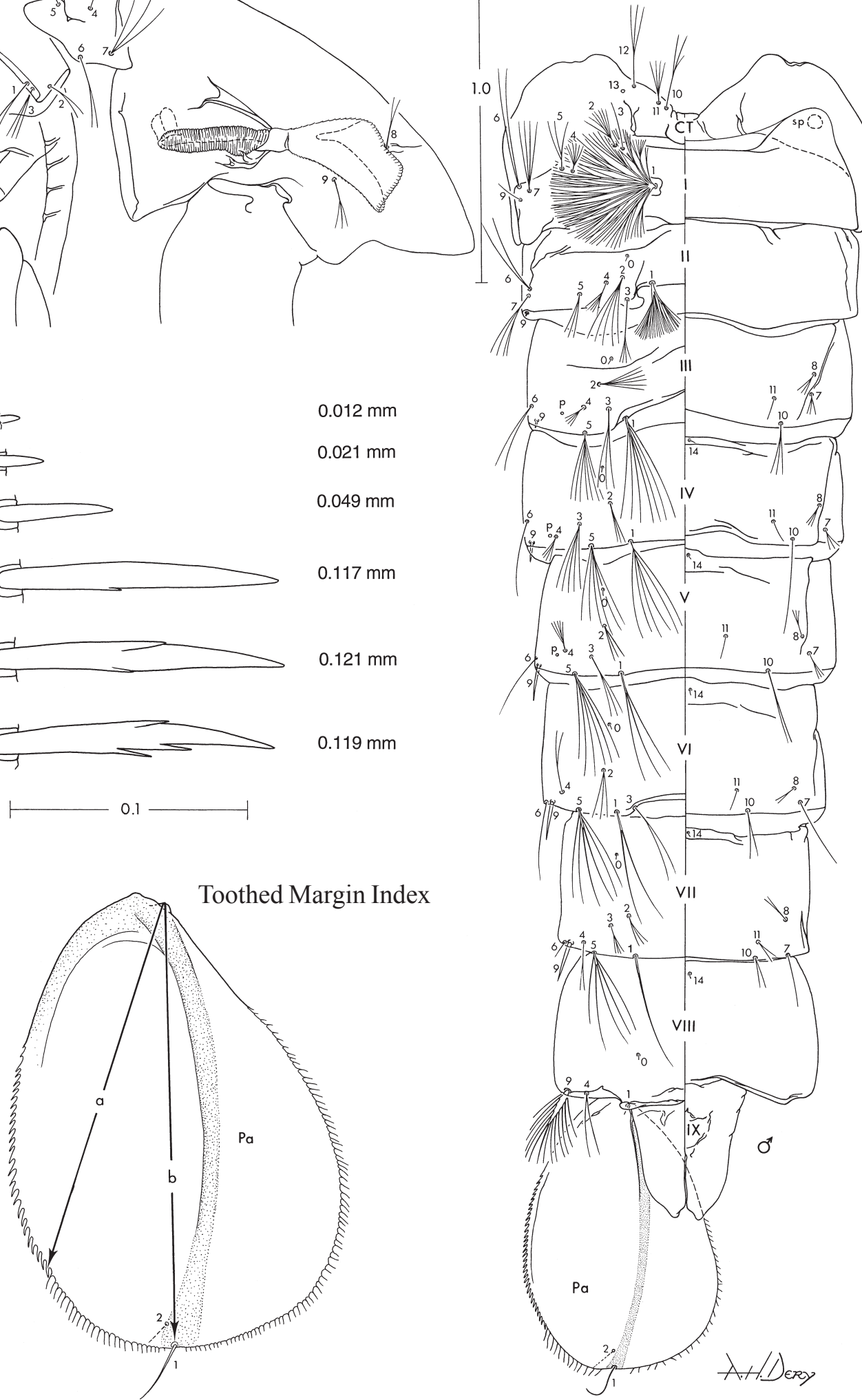

Fig. 31. Anopheles nemophilous, pupa and larva. CT, cephalothorax. Pa, paddle, showing toothed margin index. I-IX, abdominal segments of pupa (dorsal on left, ventral on right), numbers on the left side denote setae 9 of segments II-VII. Scales in millimeters. 


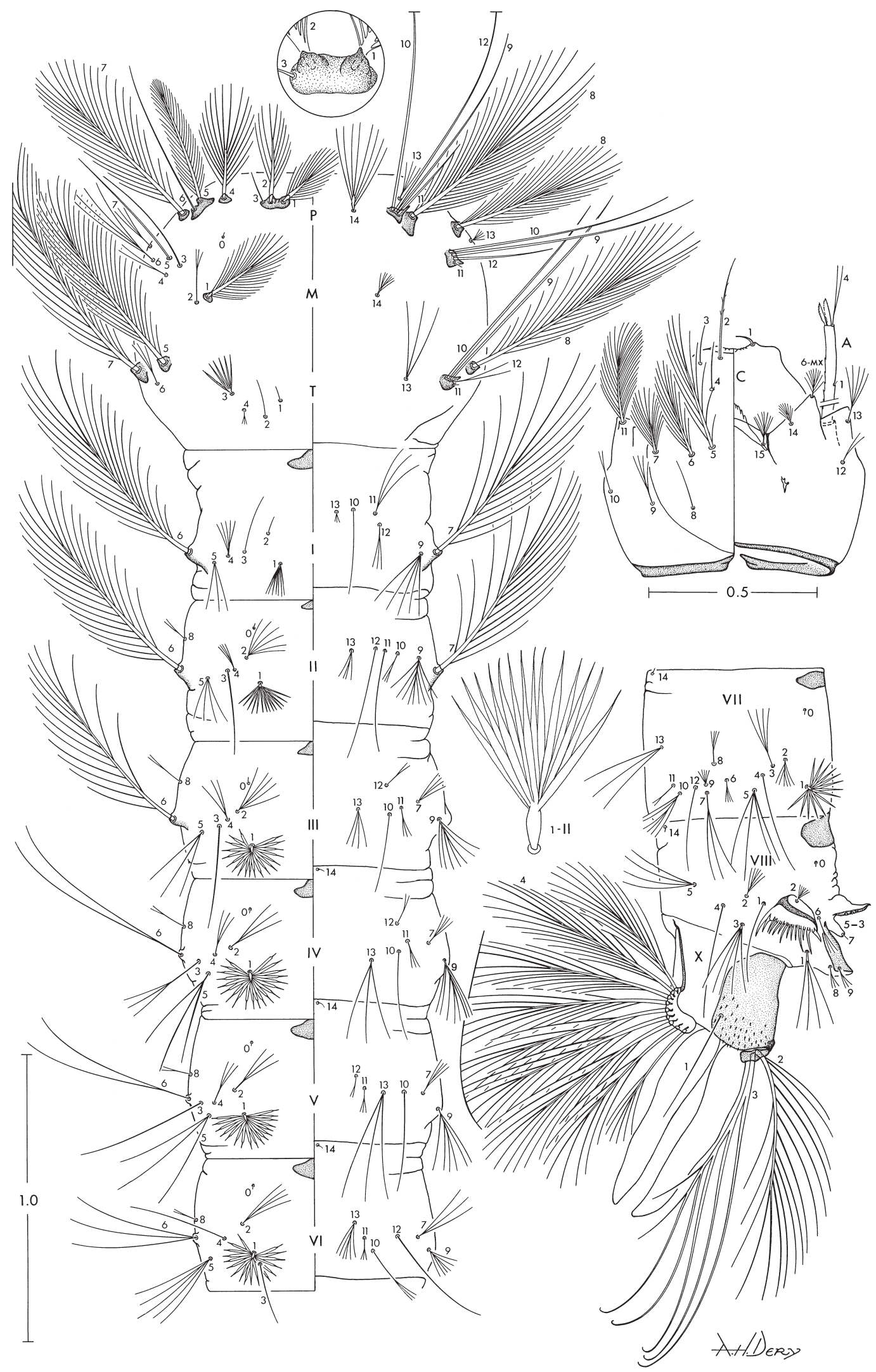

Fig. 32. Anopheles nemophilous, larva. C, head. P, prothorax. M, mesothorax. T, metathorax. I-VI, abdominal segments, left side dorsal, right side ventral. VII-X abdominal segments, lateral (left side) view. Detail inside the circle shows setae 1-3-P. Scales in millimeters. 

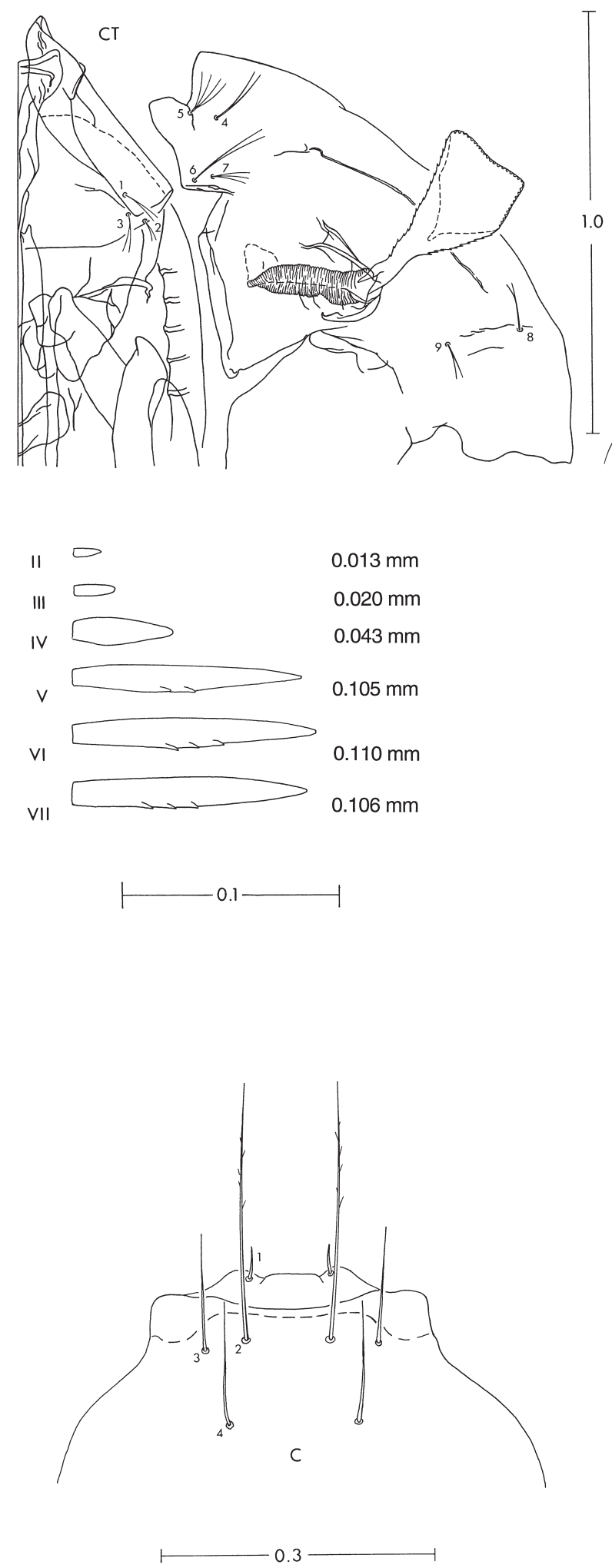

J. Litwak

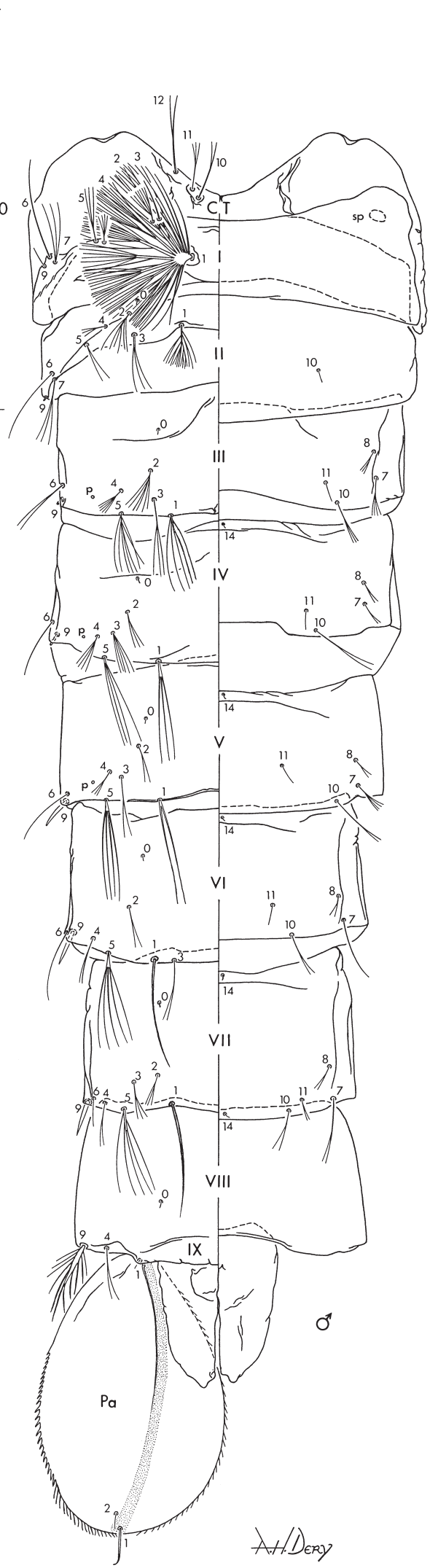

Fig. 33. Anopheles mirans, pupa and larva. C, anterior part of head of fourth-instar larva. CT, cephalothorax. Pa, paddle. I-IX, abdominal segments of pupa (dorsal on left, ventral on right), numbers on the left side denote setae 9 of segments II-VII. Scales in millimeters. 


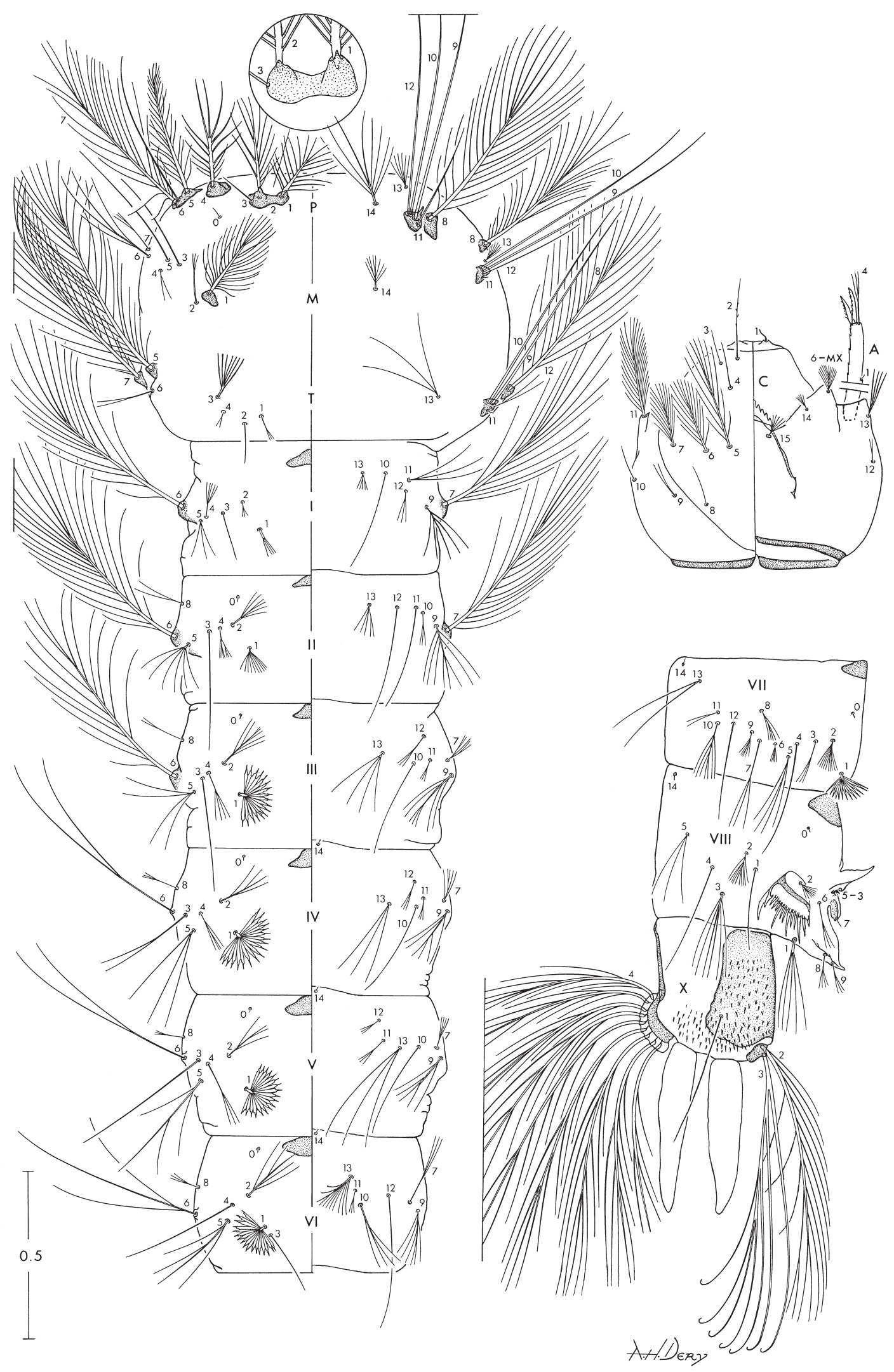

Fig. 34. Anopheles mirans, larva. C, head. P, prothorax. M, mesothorax. T, metathorax. I-VI, abdominal segments, left side dorsal, right side ventral. VII-X abdominal segments, lateral (left side) view. Detail inside the circle shows setae 1-3-P. Scales in millimeters. 

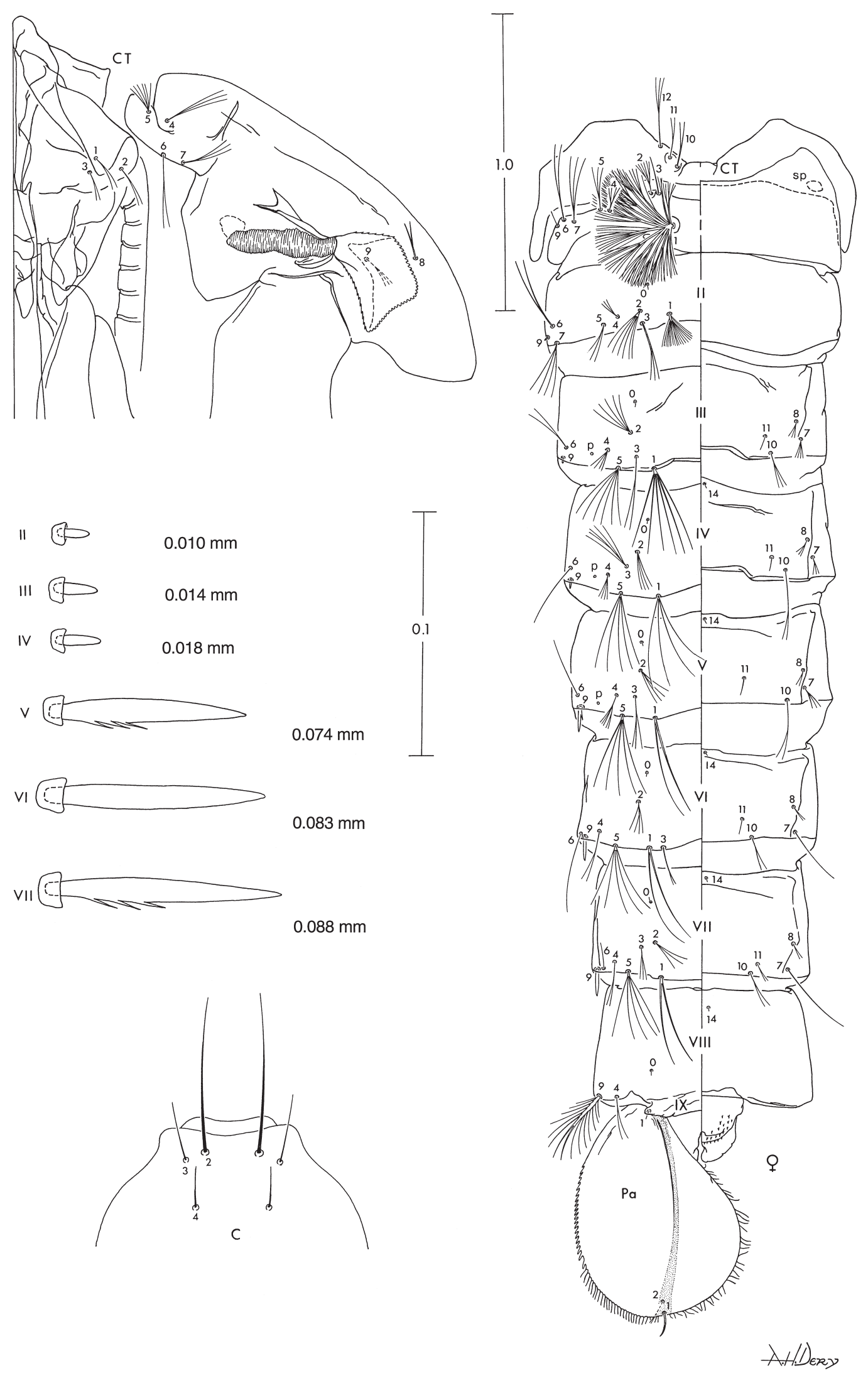

Fig. 35. Anopheles pujutensis, pupa and larva. C, anterior part of head of fourth-instar larva. CT, cephalothorax. Pa, paddle. I-IX, abdominal segments of pupa (dorsal on left, ventral on right), numbers on the left side denote setae 9 of segments II-VII. Scales in millimeters. 


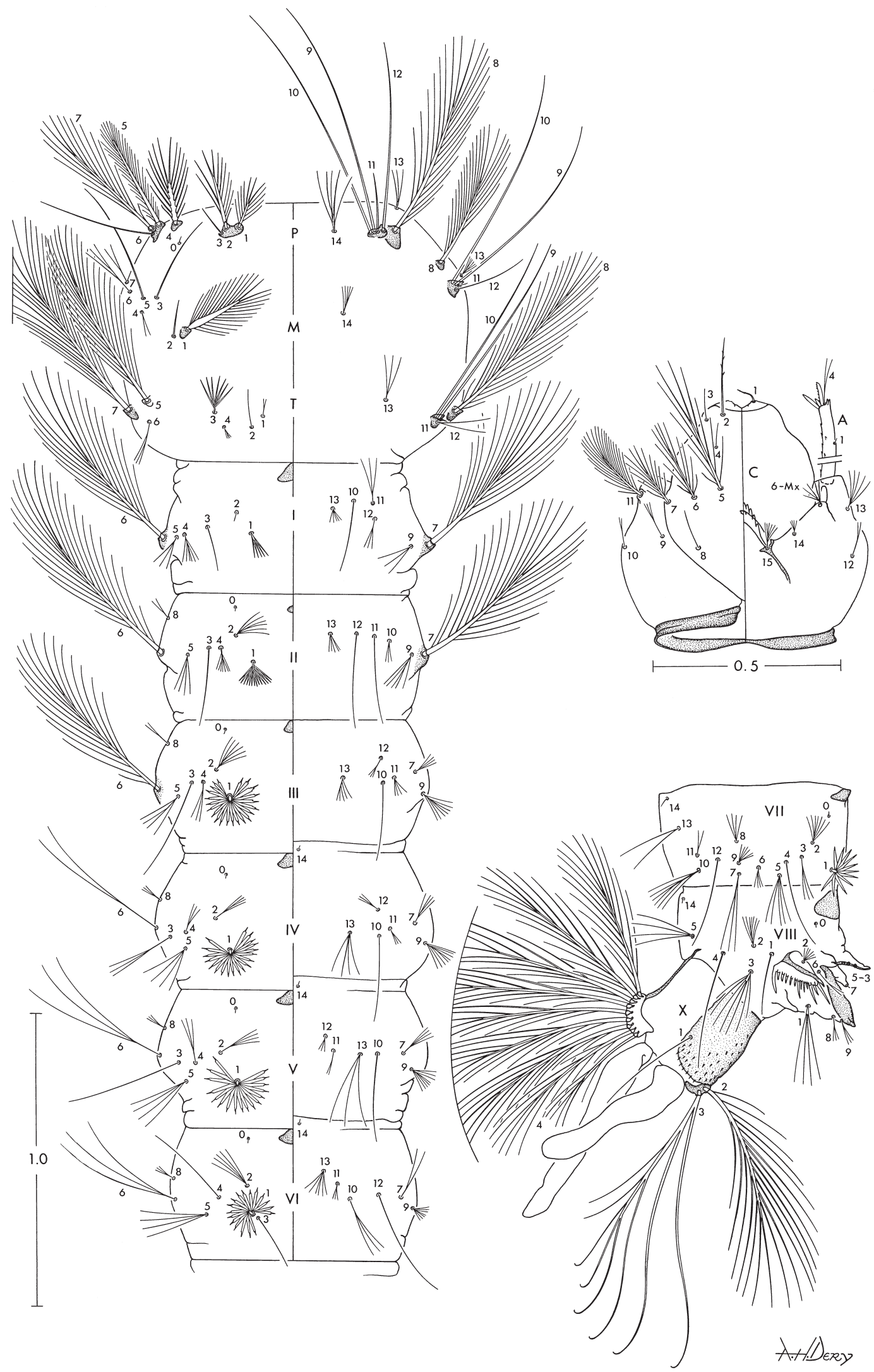

Fig. 36. Anopheles pujutensis, larva. C, head. P, prothorax. M, mesothorax. T, metathorax. I-VI, abdominal segments, left side dorsal, right side ventral. VII-X abdominal segments, lateral (left side) view. Scales in millimeters. 

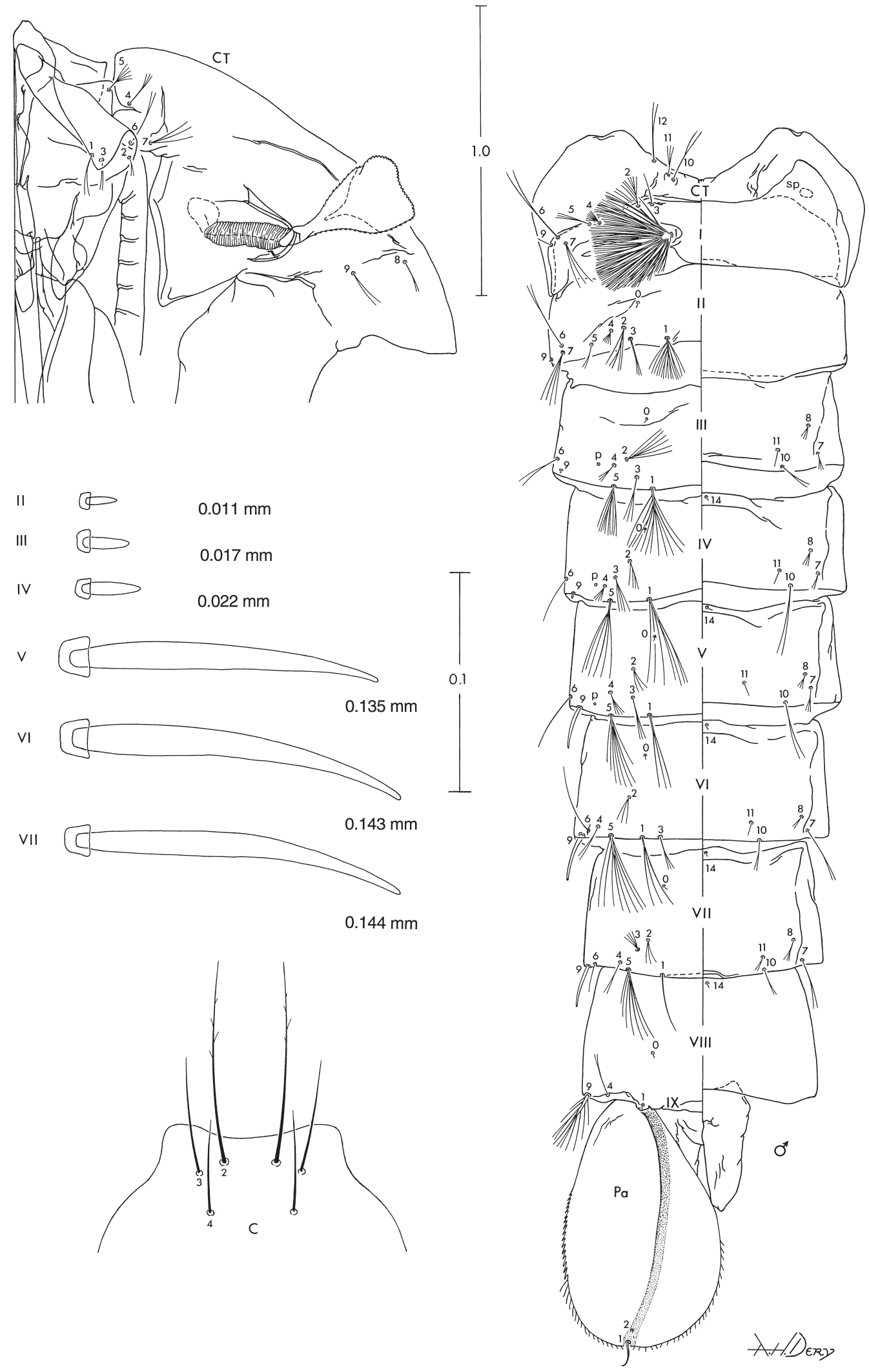

Fig. 37. Anopheles hackeri, pupa and larva. C, anterior part of head of fourth-instar larva. CT, cephalothorax. Pa, paddle. I-IX, abdominal segments of pupa (dorsal on left, ventral on right), numbers on the left side denote setae 9 of segments II-VII. Scales in millimeters. 


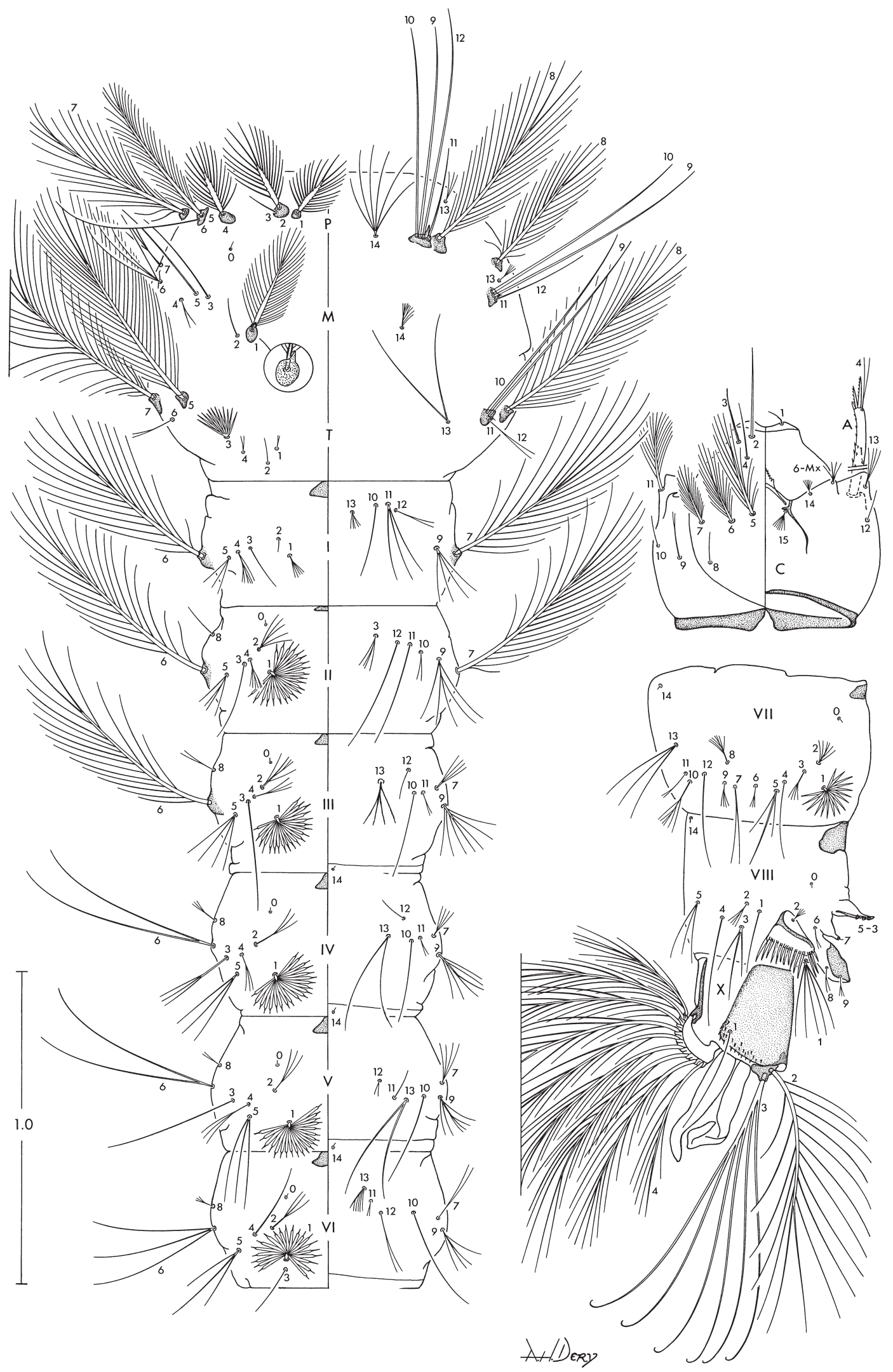

Fig. 38. Anopheles hackeri, larva. C, head. P, prothorax. M, mesothorax. T, metathorax. I-VI, abdominal segments, left side dorsal, right side ventral. VII-X abdominal segments, lateral (left side) view. Detail inside the circle shows tubercle of seta 1-M. Scales in millimeters. 

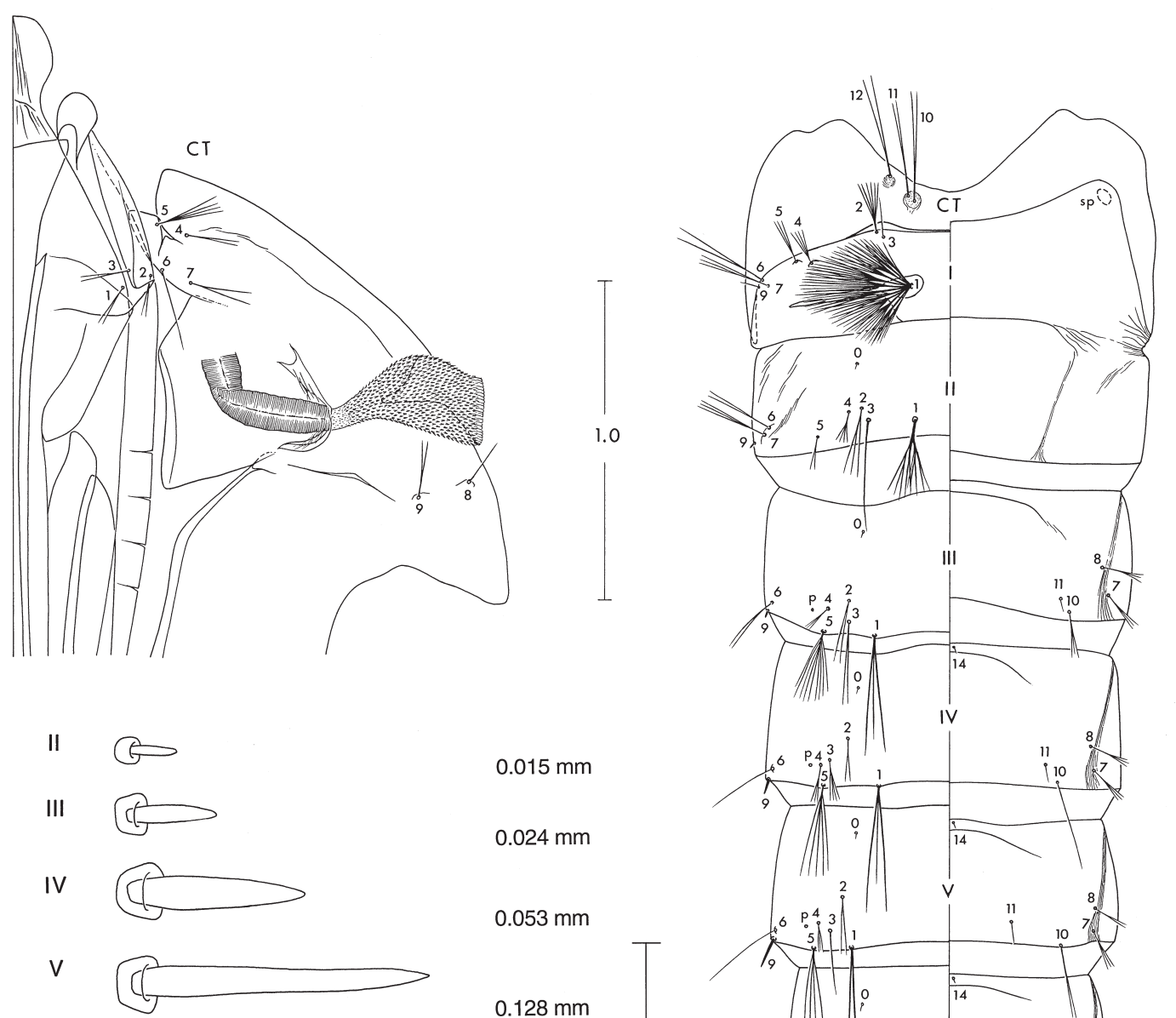

$0.015 \mathrm{~mm}$

$0.024 \mathrm{~mm}$

$0.053 \mathrm{~mm}$

$0.128 \mathrm{~mm}$

VI

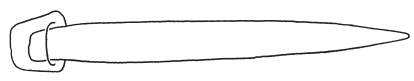

0.1

VII
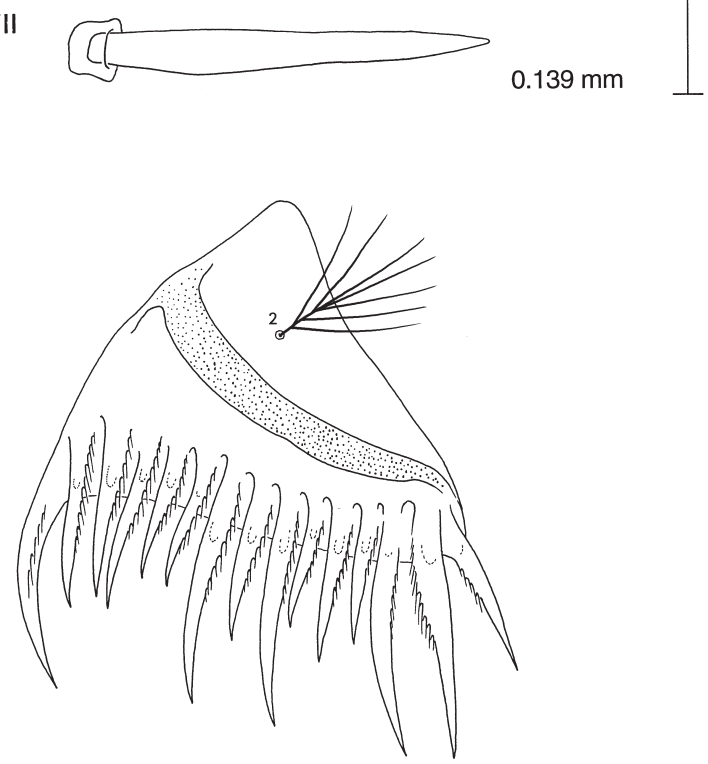

1
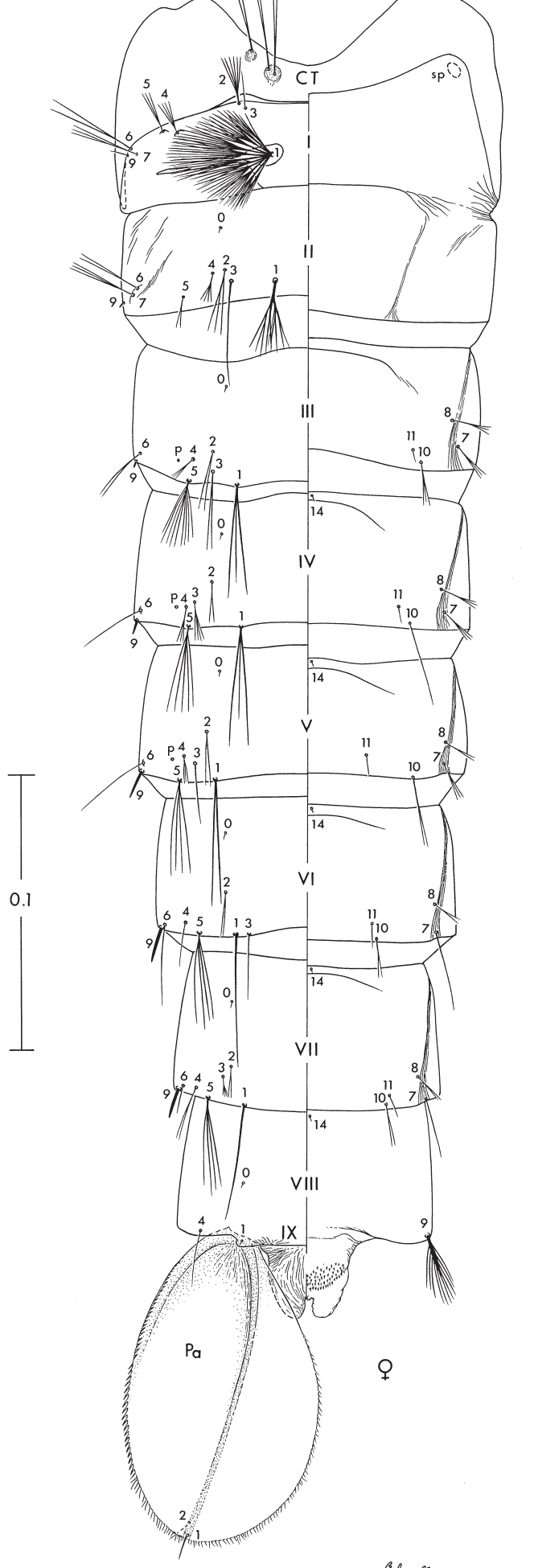

Vichaidmalibuls

Fig. 39. Anopheles recens, pupa and larva. CT, cephalothorax. Pa, paddle. Pecten plate of fourth-instar larva, bottom on the left side. I-IX, abdominal segments of pupa (dorsal on left, ventral on right), numbers on the left side denote setae 9 of segments II-VII. Scales in millimeters. 


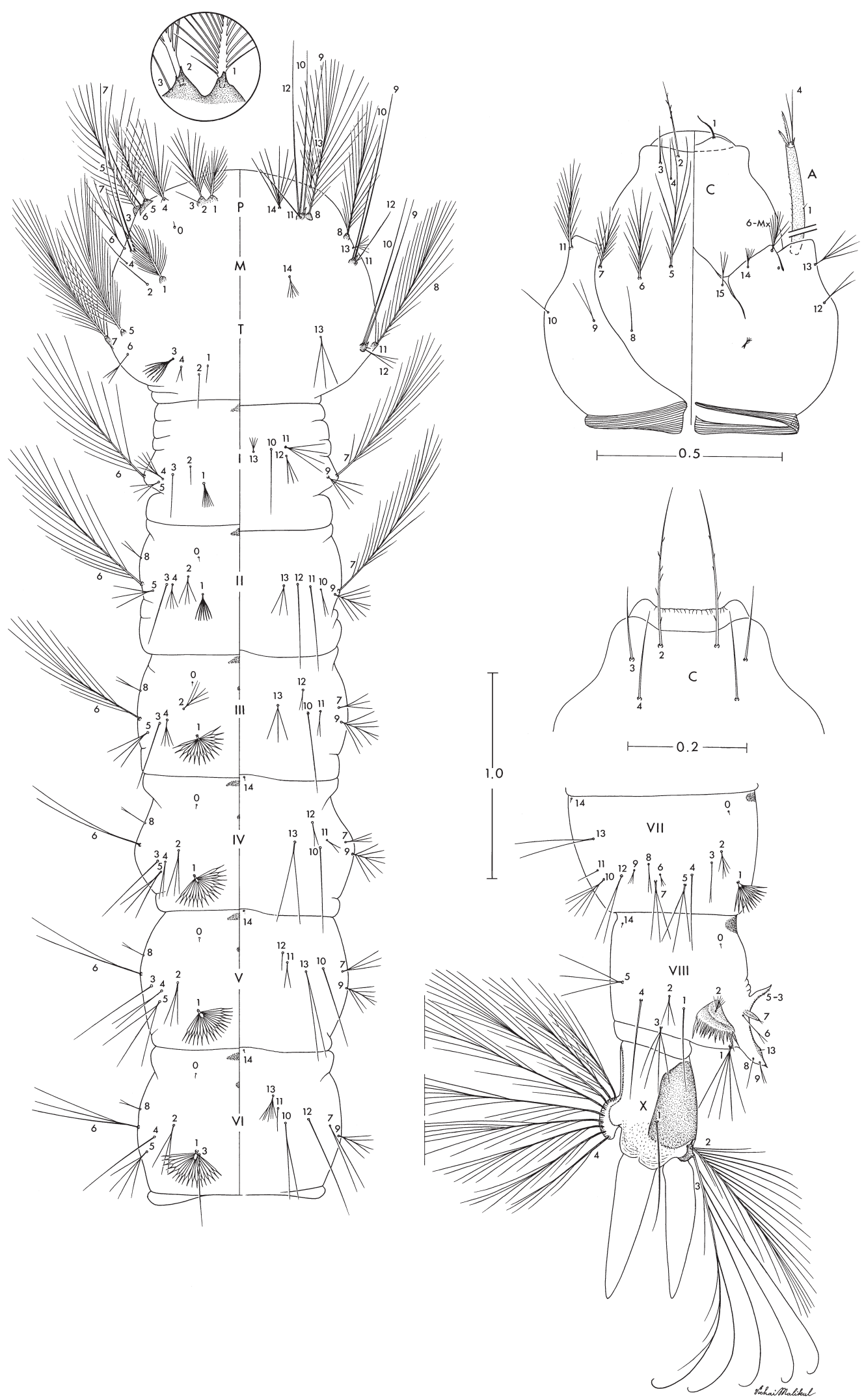

Fig. 40. Anopheles recens, larva. C, head and detail of anterior part of head. P, prothorax. M, mesothorax. T, metathorax. I-VI, abdominal segments, left side dorsal, right side ventral. VII-X abdominal segments, lateral (left side) view. Detail inside the circle shows setae 1-3-P. Scales in millimeters. 

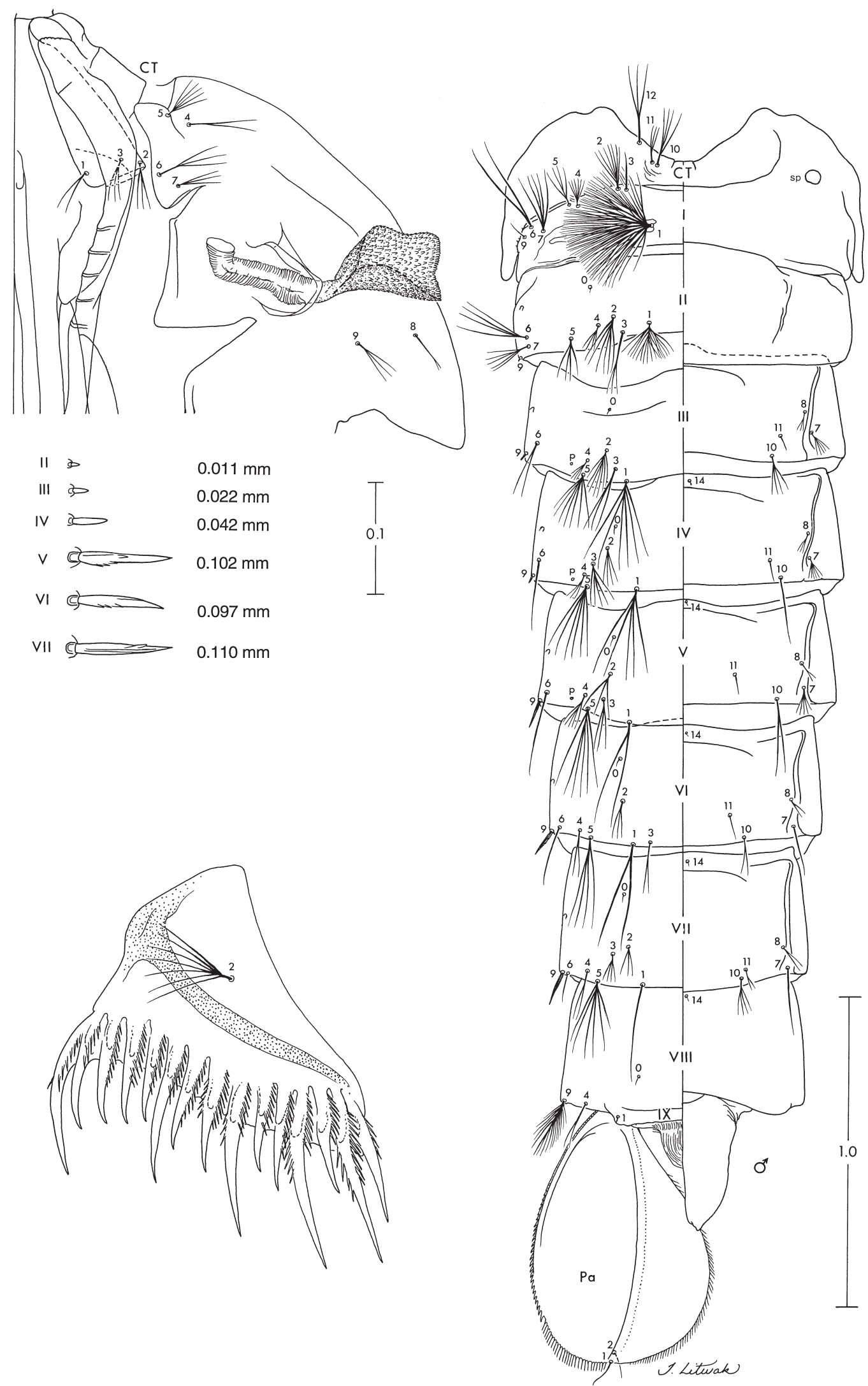

Fig. 41. Anopheles sulawesi, pupa and larva. CT, cephalothorax. Pa, paddle. Pecten plate of fourth-instar larva, bottom on the left side. I-IX, abdominal segments of pupa (dorsal on left, ventral on right), numbers on the left side denote setae 9 of segments II-VII. Scales in millimeters. 


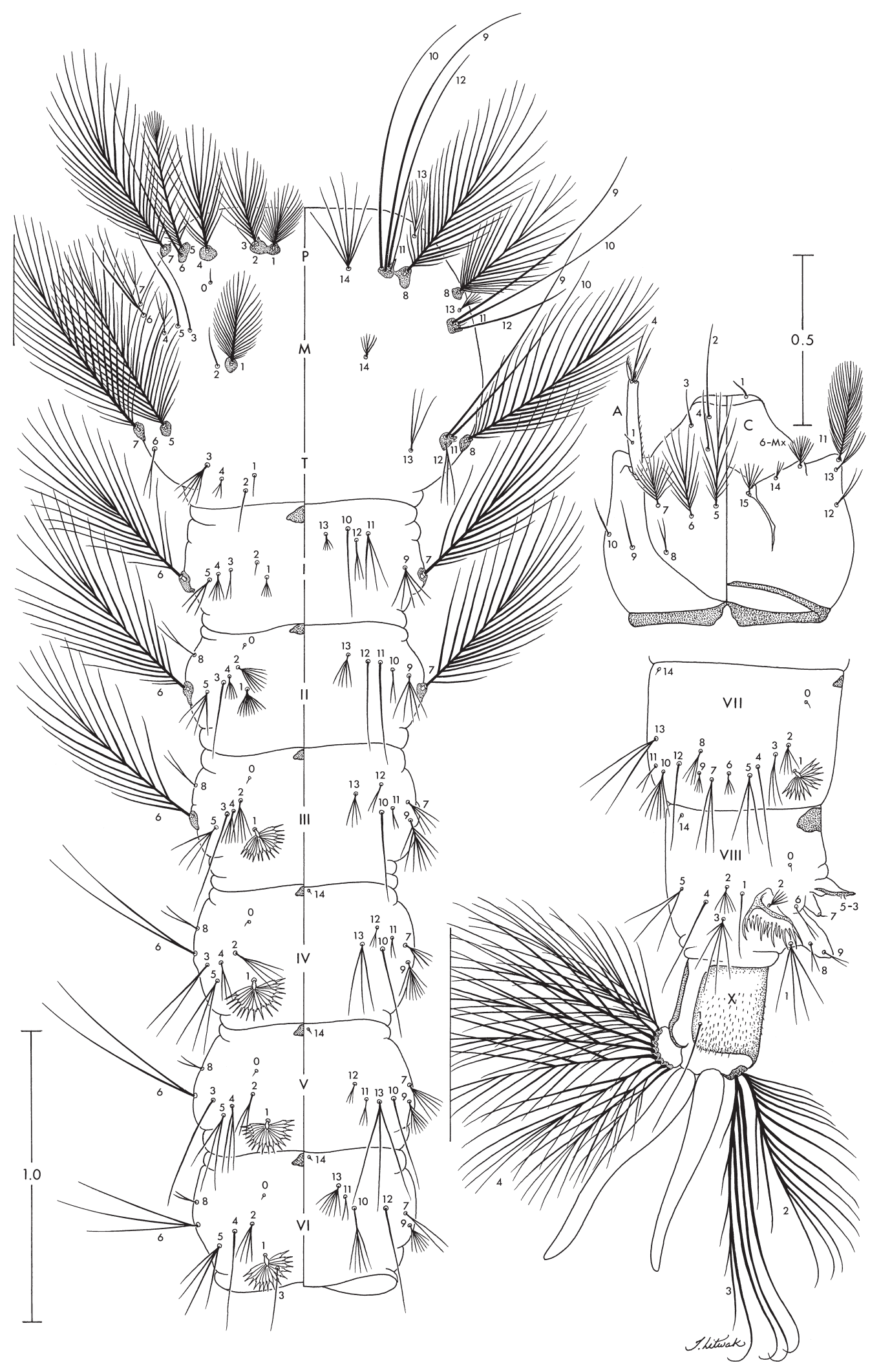

Fig. 42. Anopheles sulawesi, larva. C, head. P, prothorax. M, mesothorax. T, metathorax. I-VI, abdominal segments, left side dorsal, right side ventral. VII-X abdominal segments, lateral (left side) view. Scales in millimeters. 

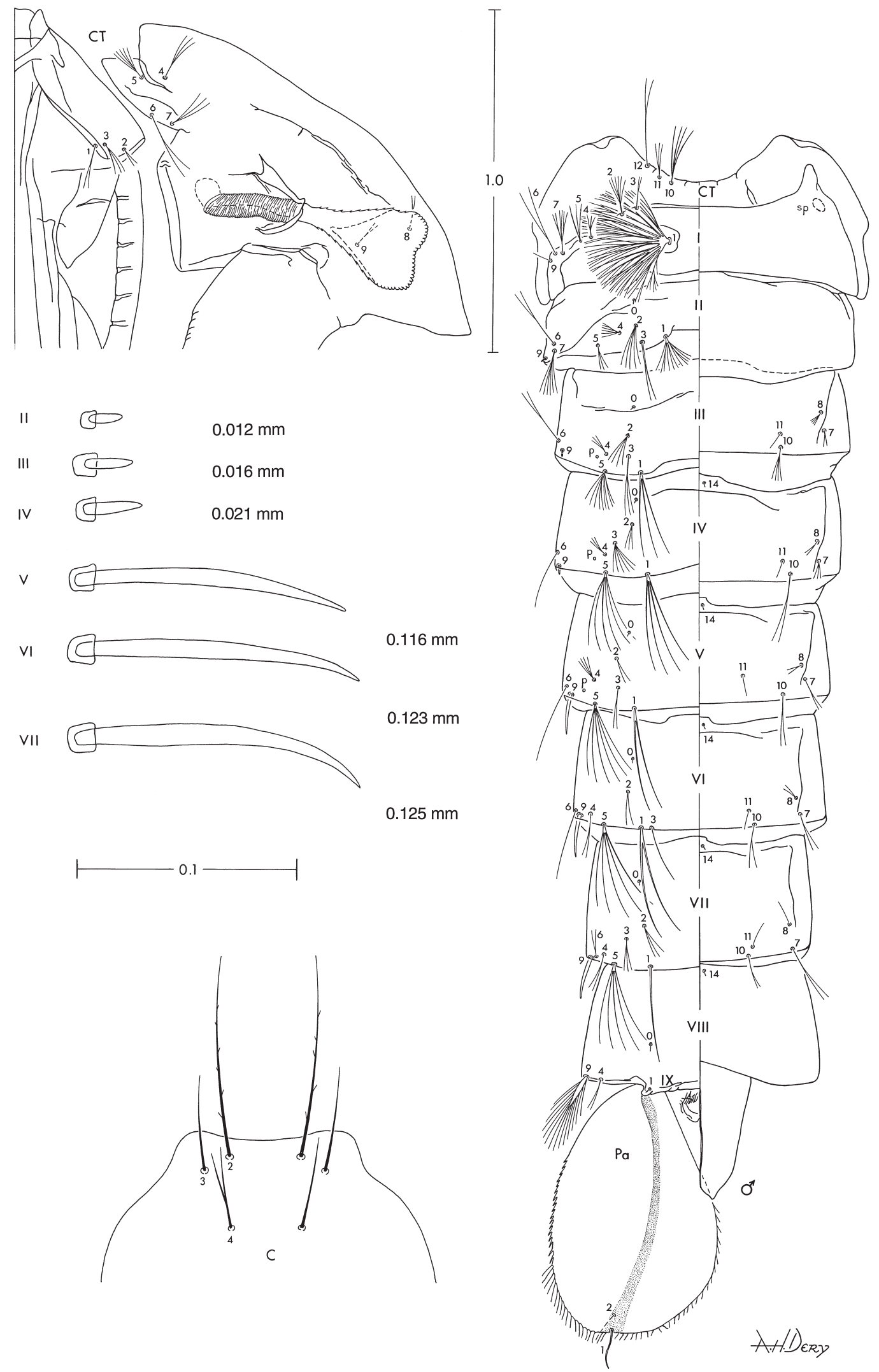

Fig. 43. Anopheles riparis, pupa and larva. C, anterior part of head of fourth-instar larva. CT, cephalothorax. Pa, paddle. I-IX, abdominal segments of pupa (dorsal on left, ventral on right), numbers on the left side denote setae 9 of segments II-VII. Scales in millimeters. 


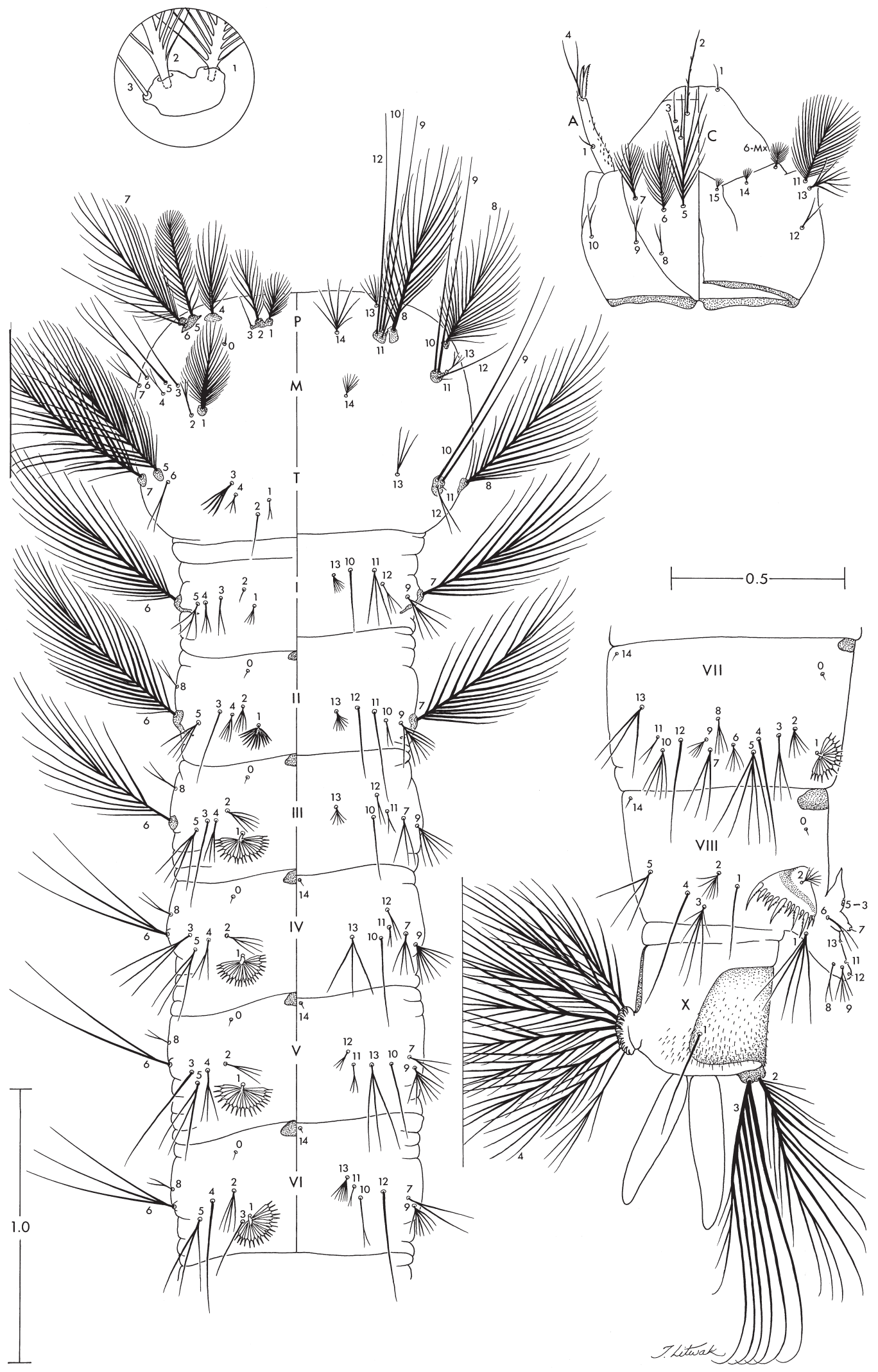

Fig. 44. Anopheles riparis, larva. C, head. P, prothorax. M, mesothorax. T, metathorax. I-VI, abdominal segments, left side dorsal, right side ventral. VII-X abdominal segments, lateral (left side) view. Detail inside the circle shows setae 1-3-P. Scales in millimeters. 

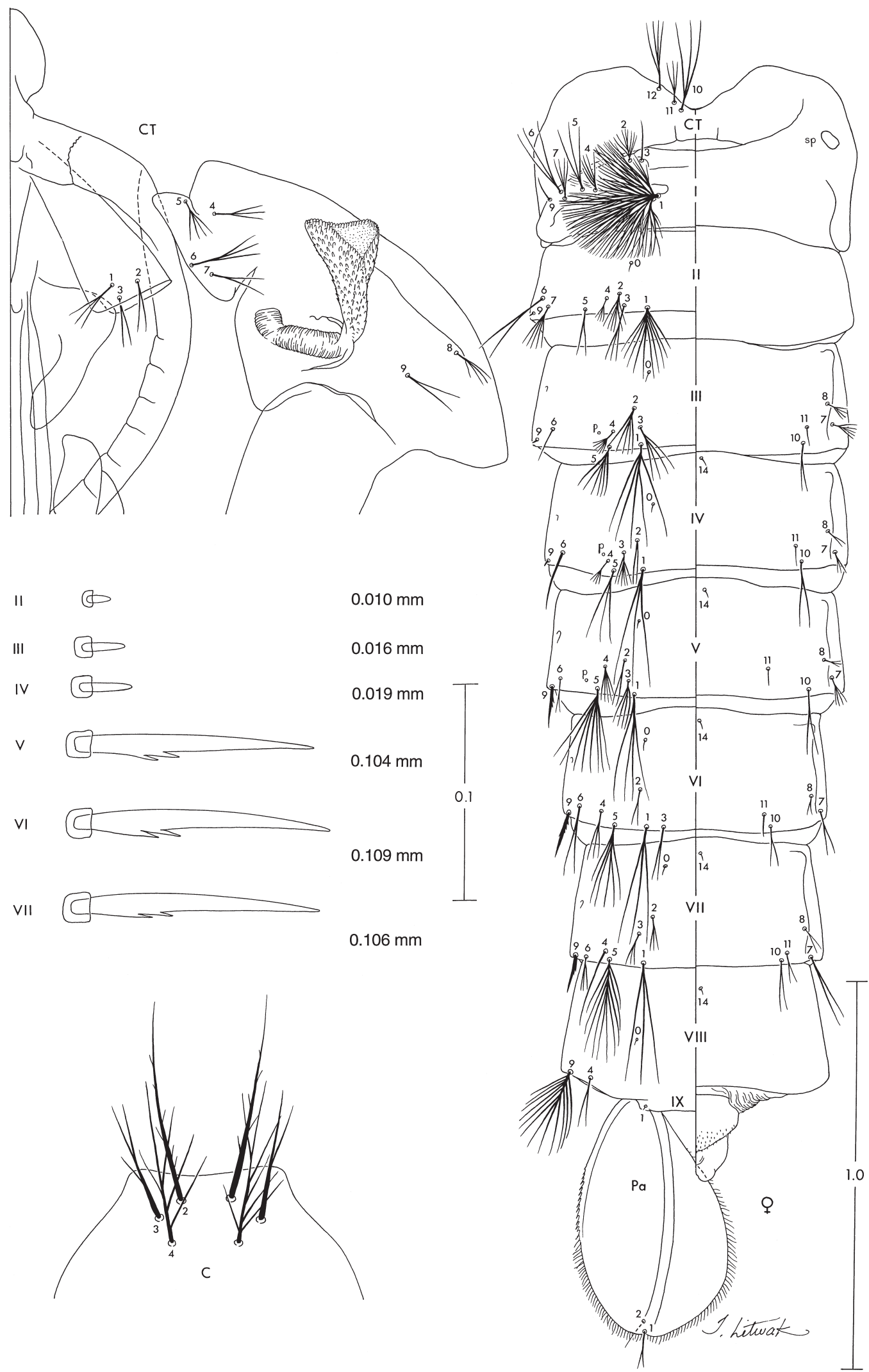

Fig. 45. Anopheles cristatus, pupa and larva. C, anterior part of head of fourth-instar larva. CT, cephalothorax. Pa, paddle. I-IX, abdominal segments of pupa (dorsal on left, ventral on right), numbers on the left side denote setae 9 of segments II-VII. Scales in millimeters. 


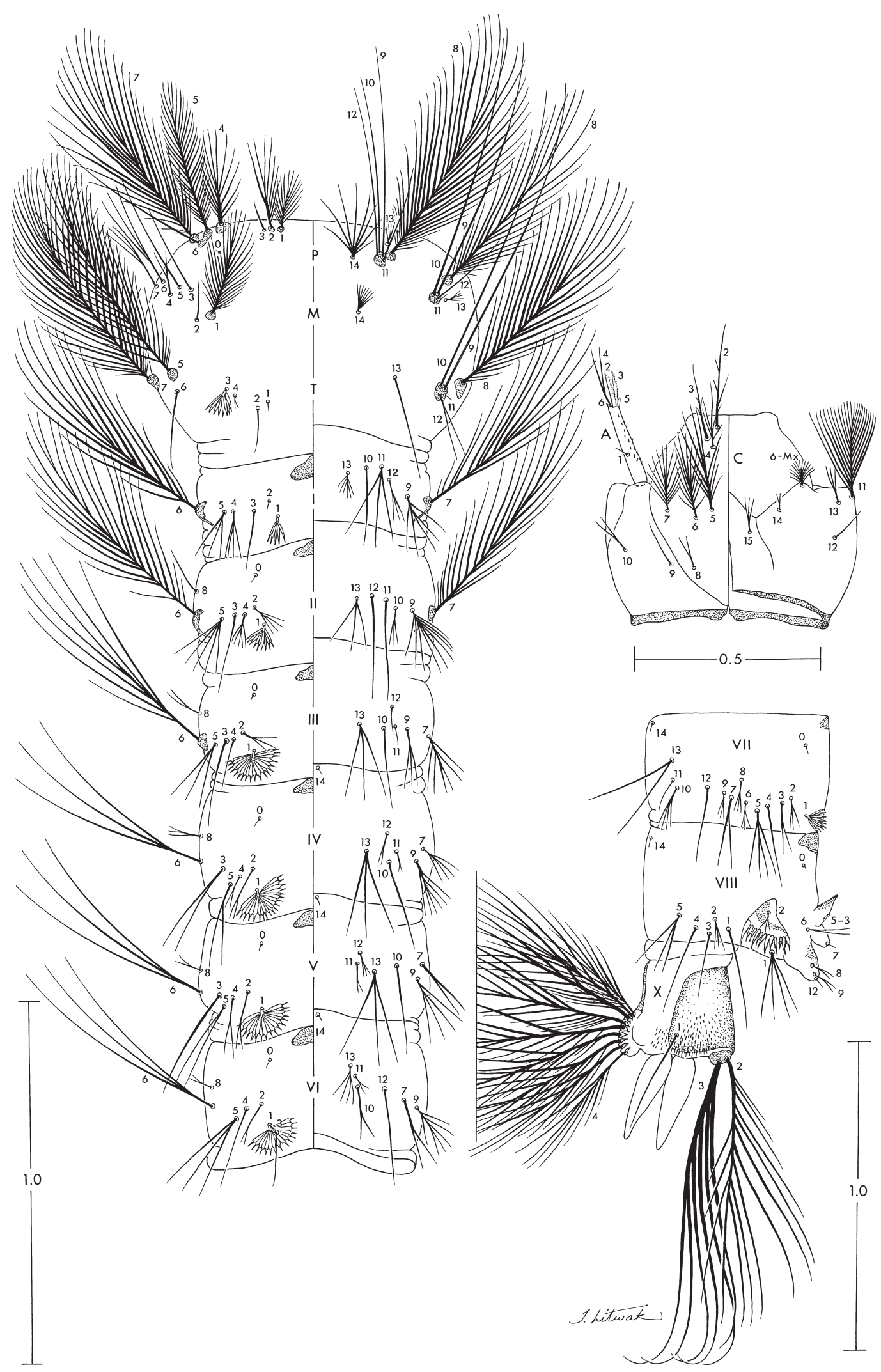

Fig. 46. Anopheles cristatus, larva. C, head. P, prothorax. M, mesothorax. T, metathorax. I-VI, abdominal segments, left side dorsal, right side ventral. VII-X abdominal segments, lateral (left side) view. Scales in millimeters. 

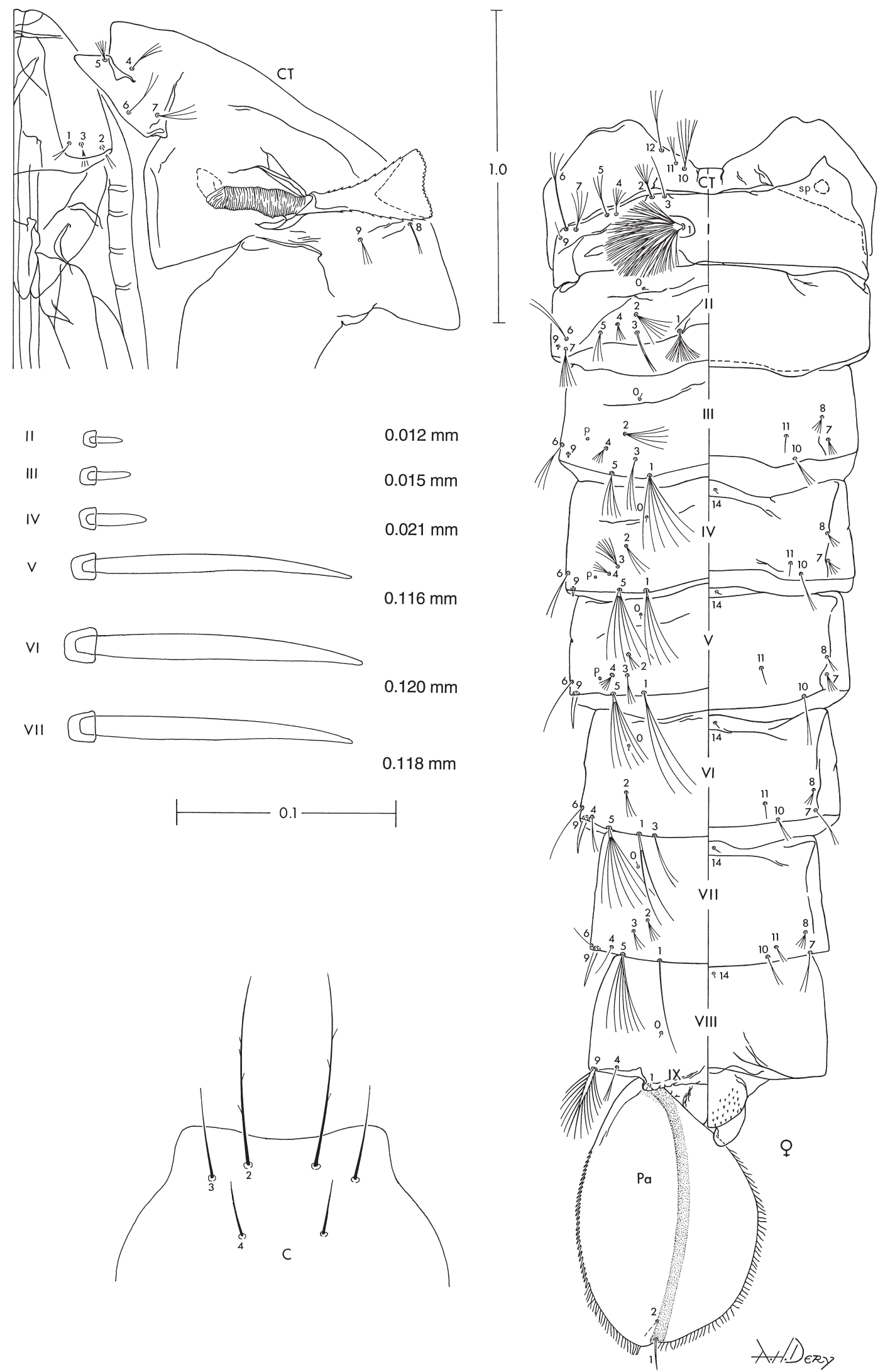

Fig. 47. Anopheles macarthuri, pupa and larva. C, anterior part of head of fourth-instar larva. CT, cephalothorax. Pa, paddle. I-IX, abdominal segments of pupa (dorsal on left, ventral on right), numbers on the left side denote setae 9 of segments II-VII. Scales in millimeters. 


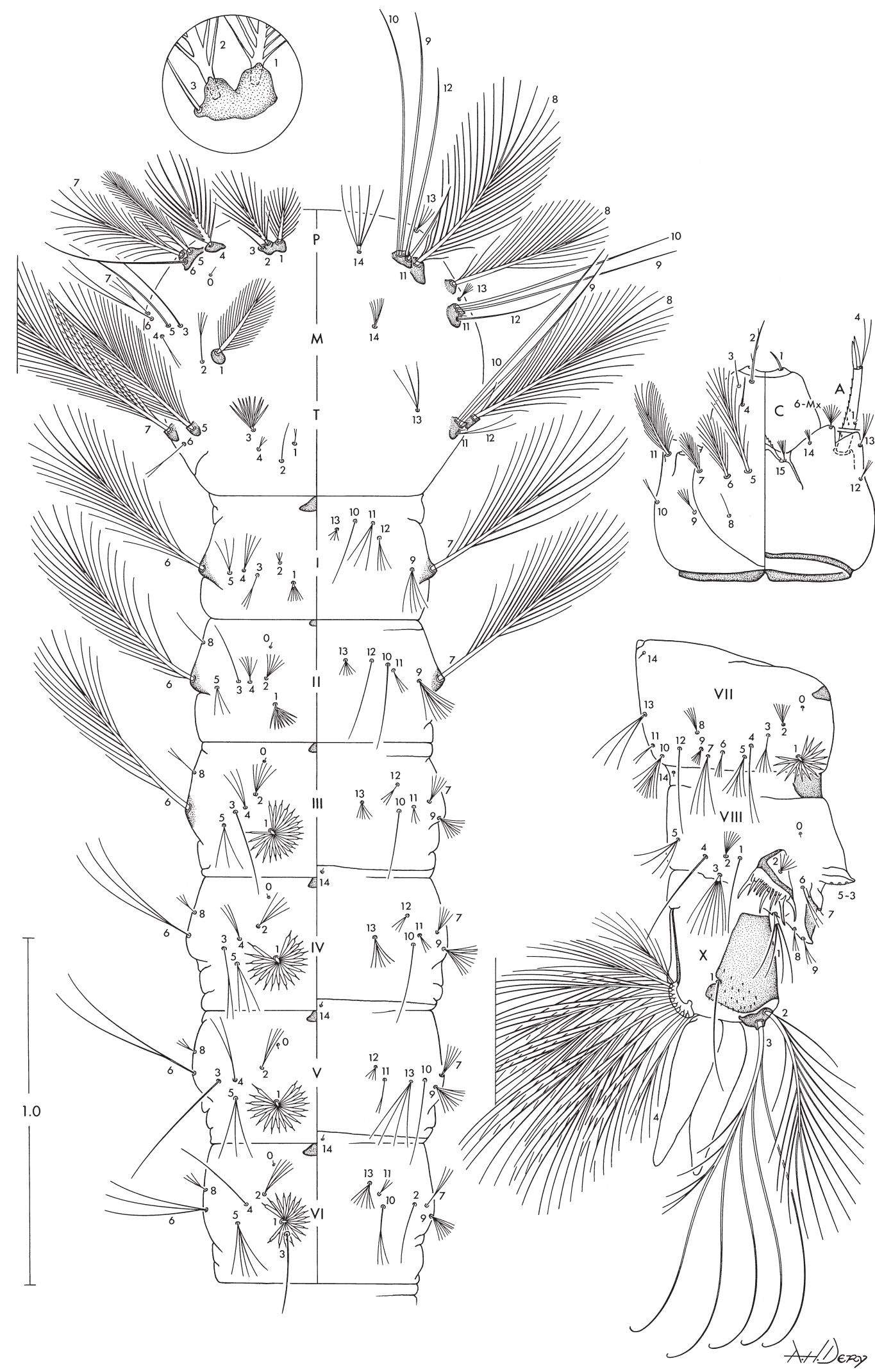

Fig. 48. Anopheles macarthuri, larva. C, head. P, prothorax. M, mesothorax. T, metathorax. I-VI, abdominal segments, left side dorsal, right side ventral. VII-X abdominal segments, lateral (left side) view. Detail inside the circle shows setae 1-3-P. Scales in millimeters. 

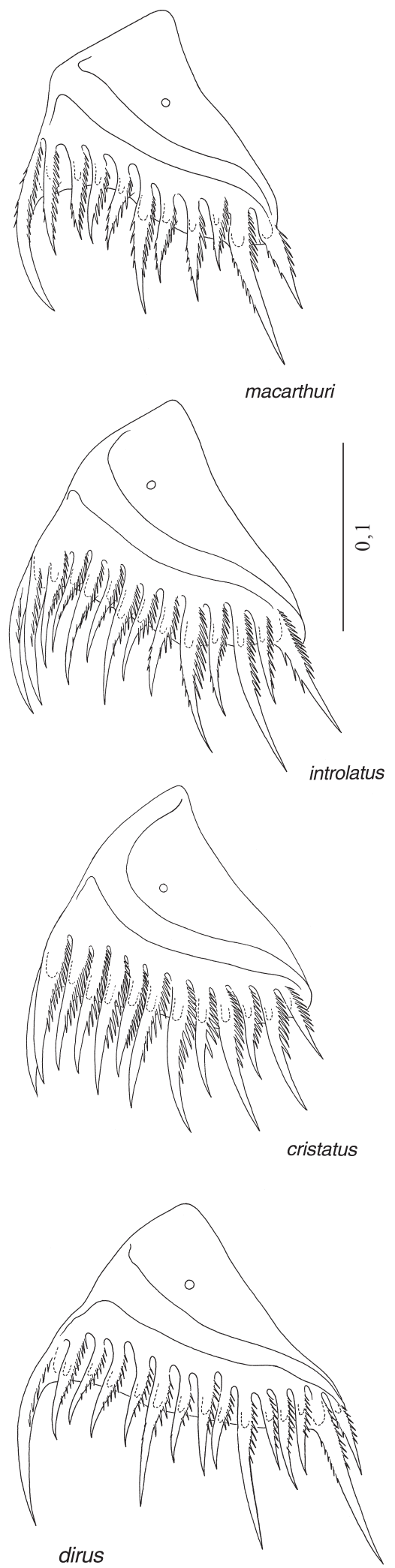
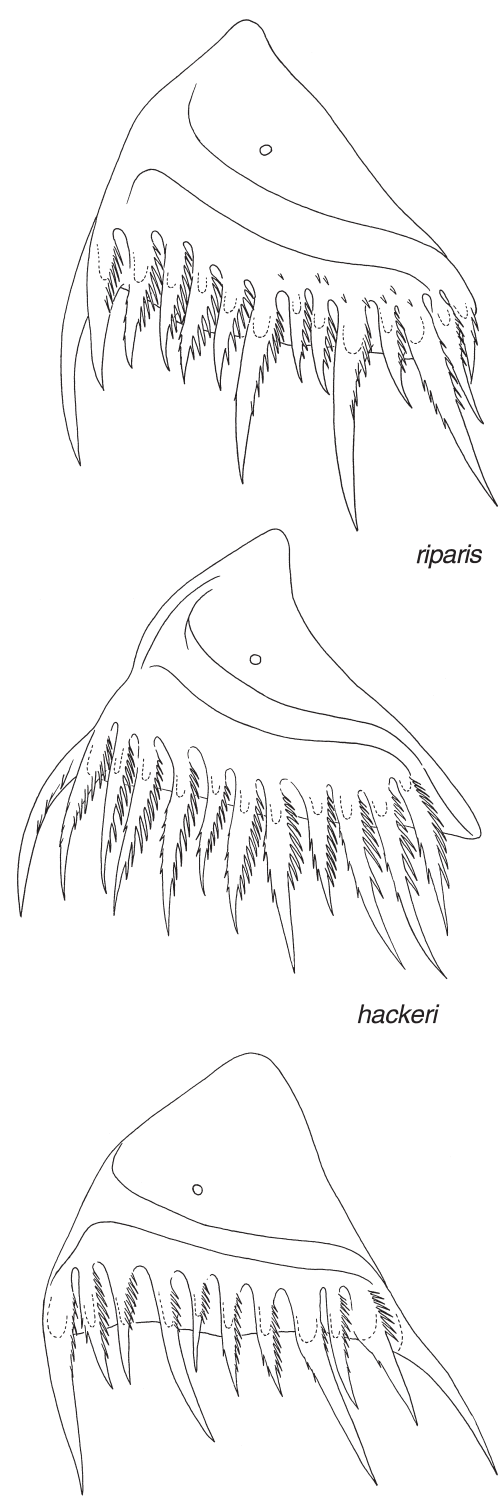

pujutensis

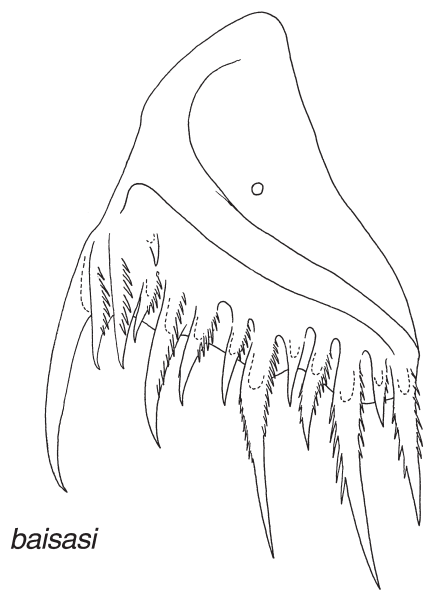

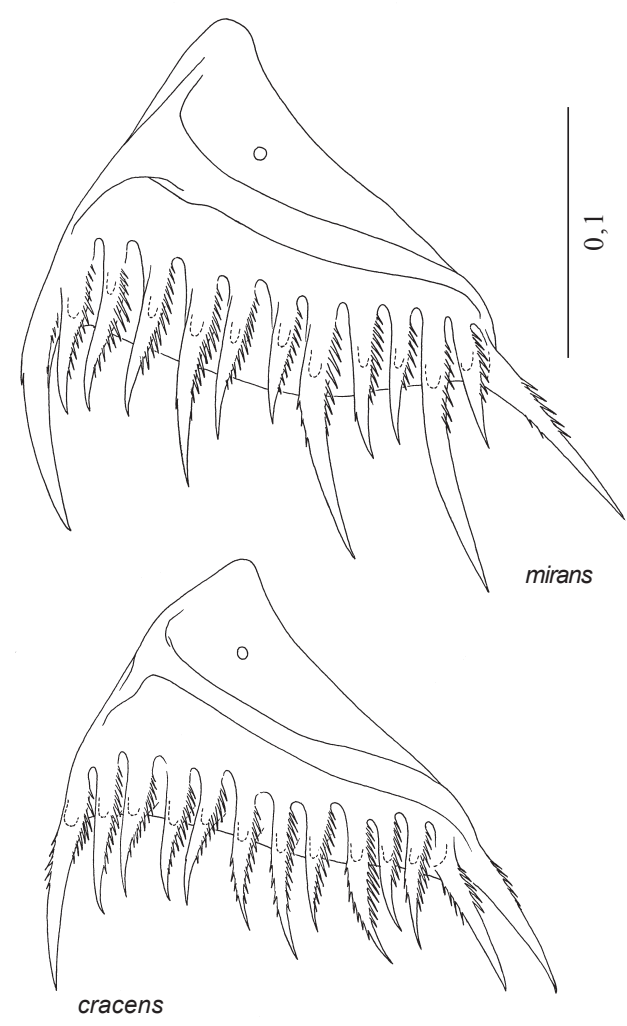
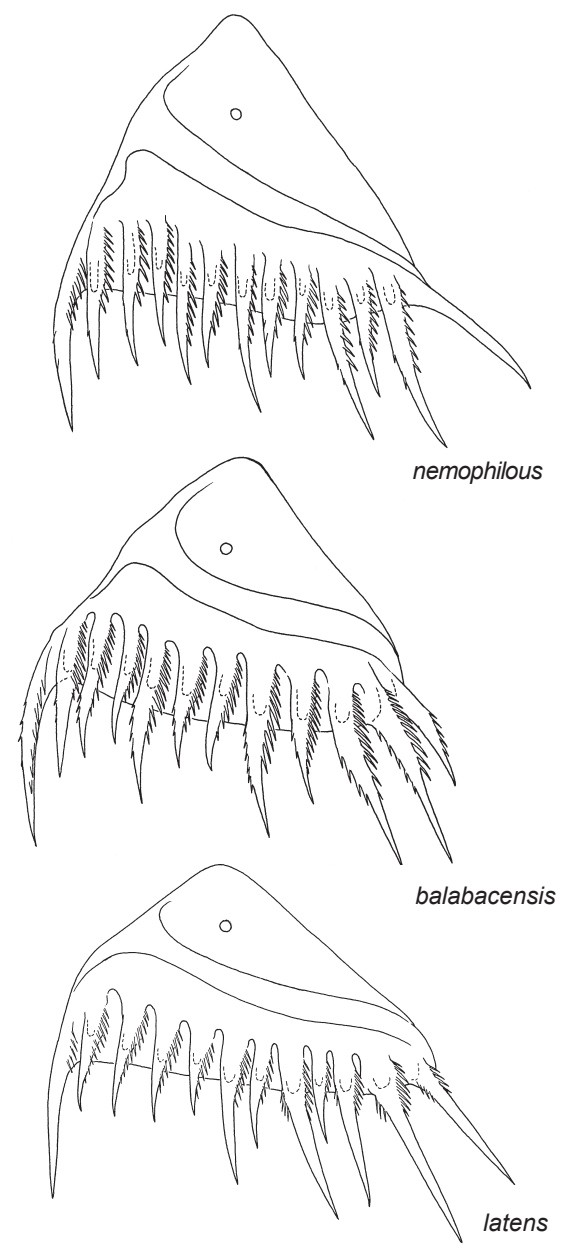

Fig. 49. Pecten plates of the fourth-instar larvae. Scales in milimeters. 

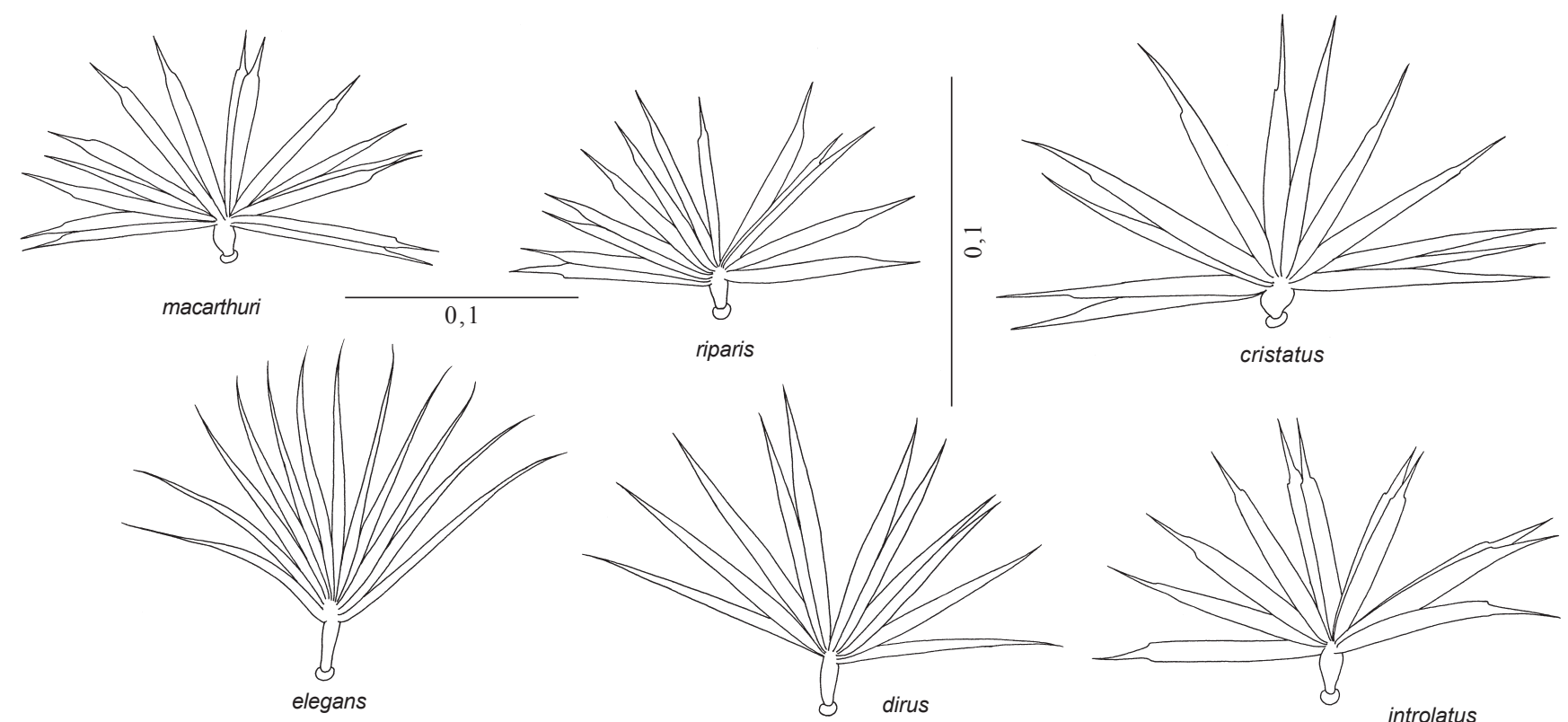

Fig. 50. Seta 1-VII of the fourth-instar larvae. Scales in milimeters.
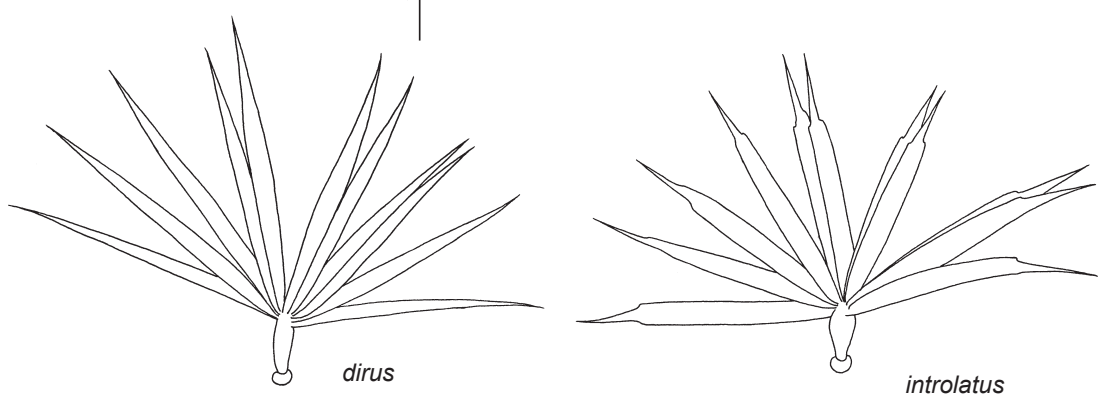

introlatus

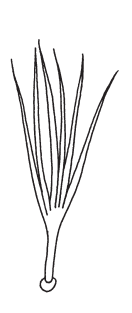

elegans

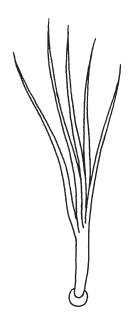

cracens
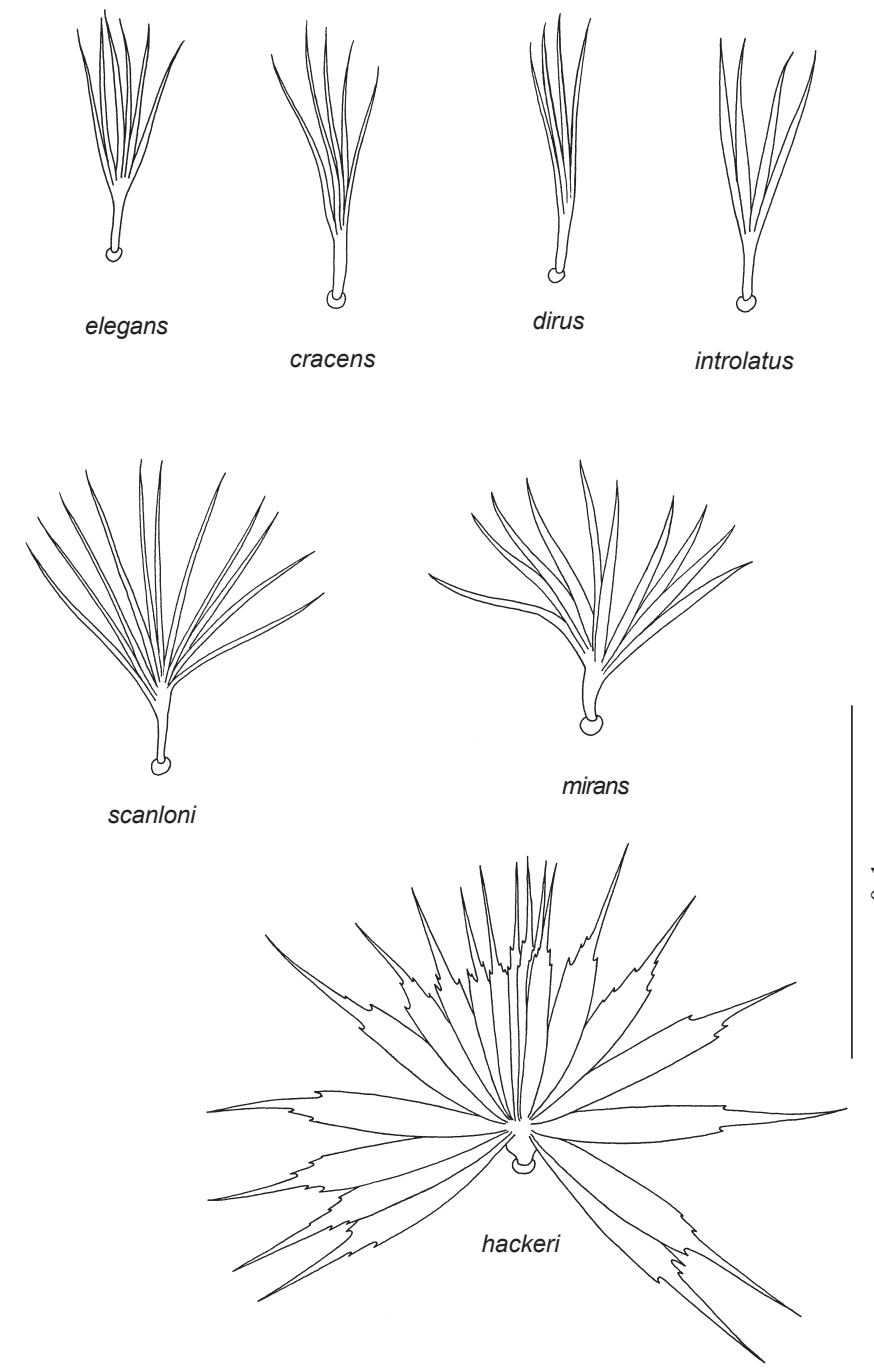

mirans

Fig. 51. Seta 1-II of the fourth-instar larvae. Scales in milimeters.

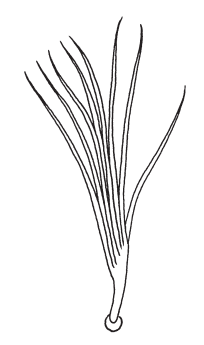

macarthuri

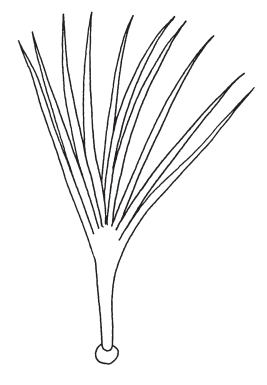

recens 

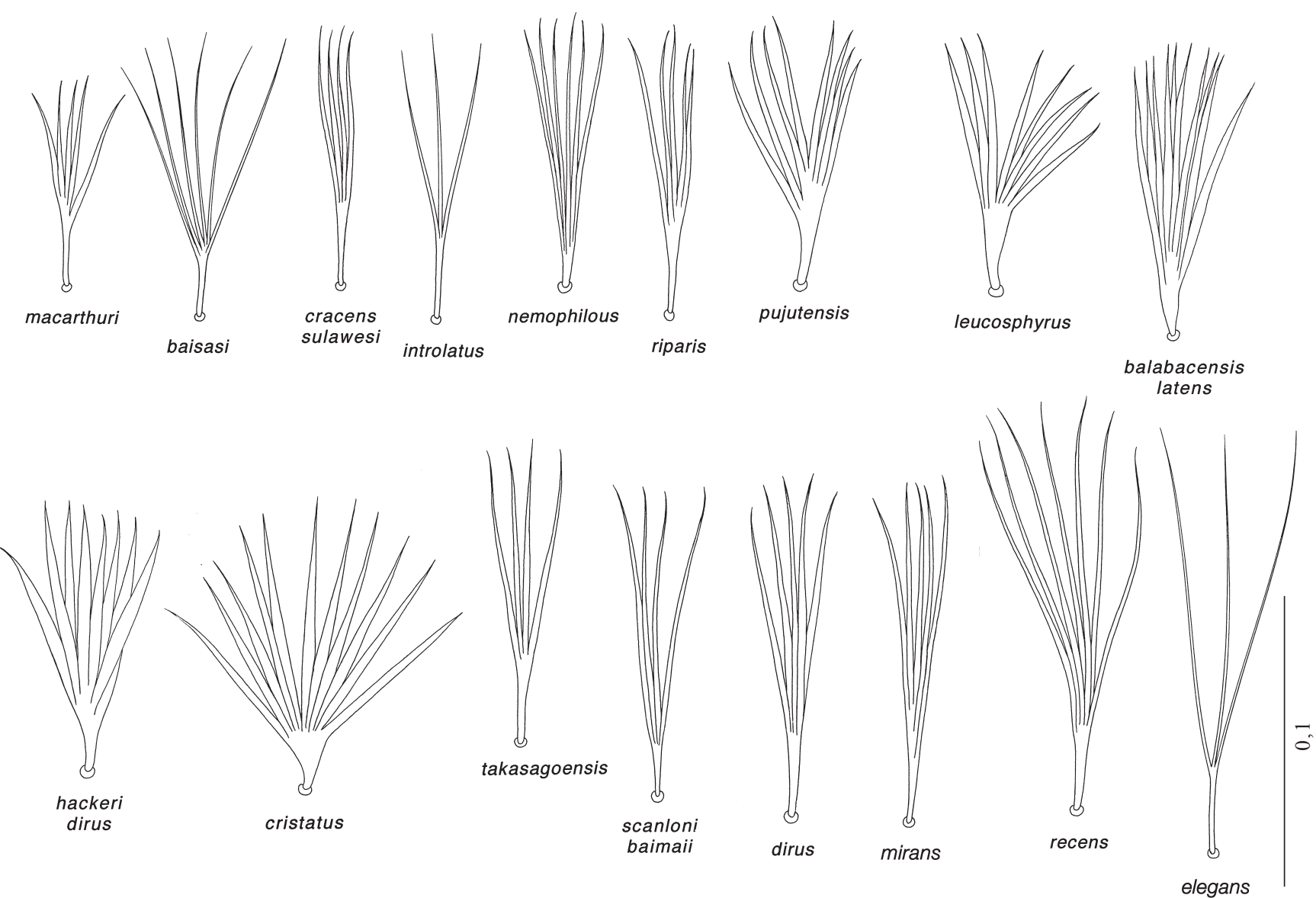

Fig. 52. Seta 3-T of the fourth-instar larvae. Scales in milimeters.
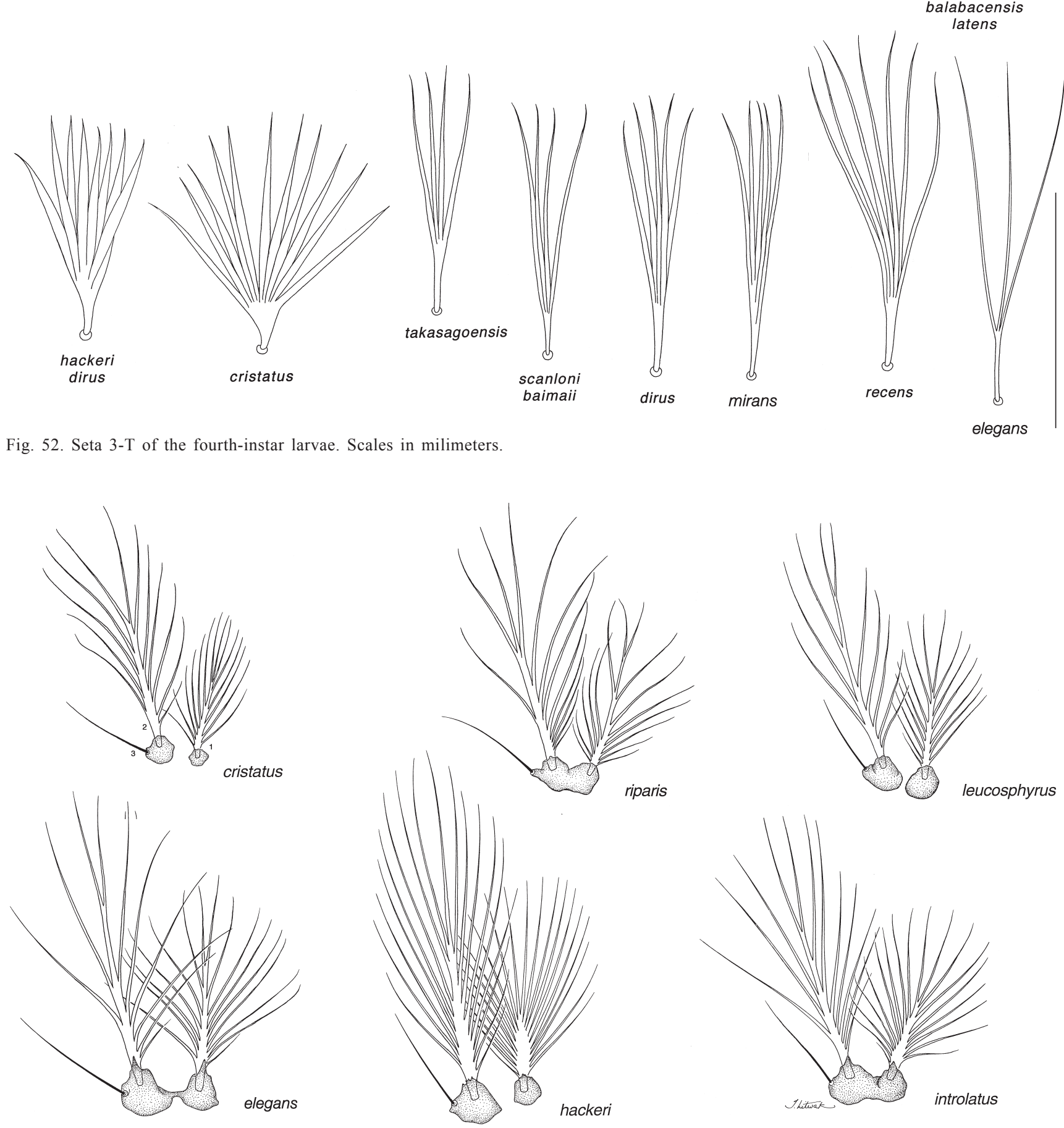

riparis

Fig. 53. Seta 1-3-P and support plates of the fourth-instar larvae.

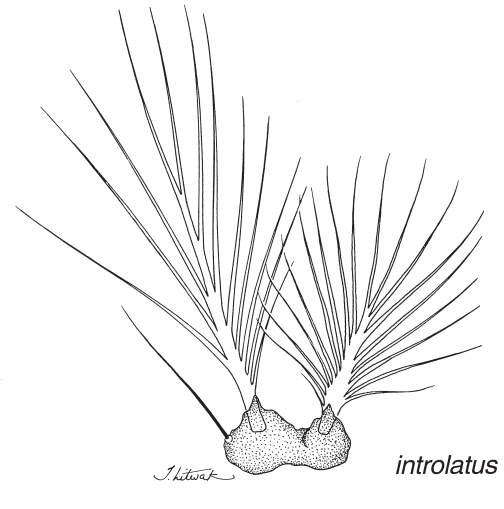



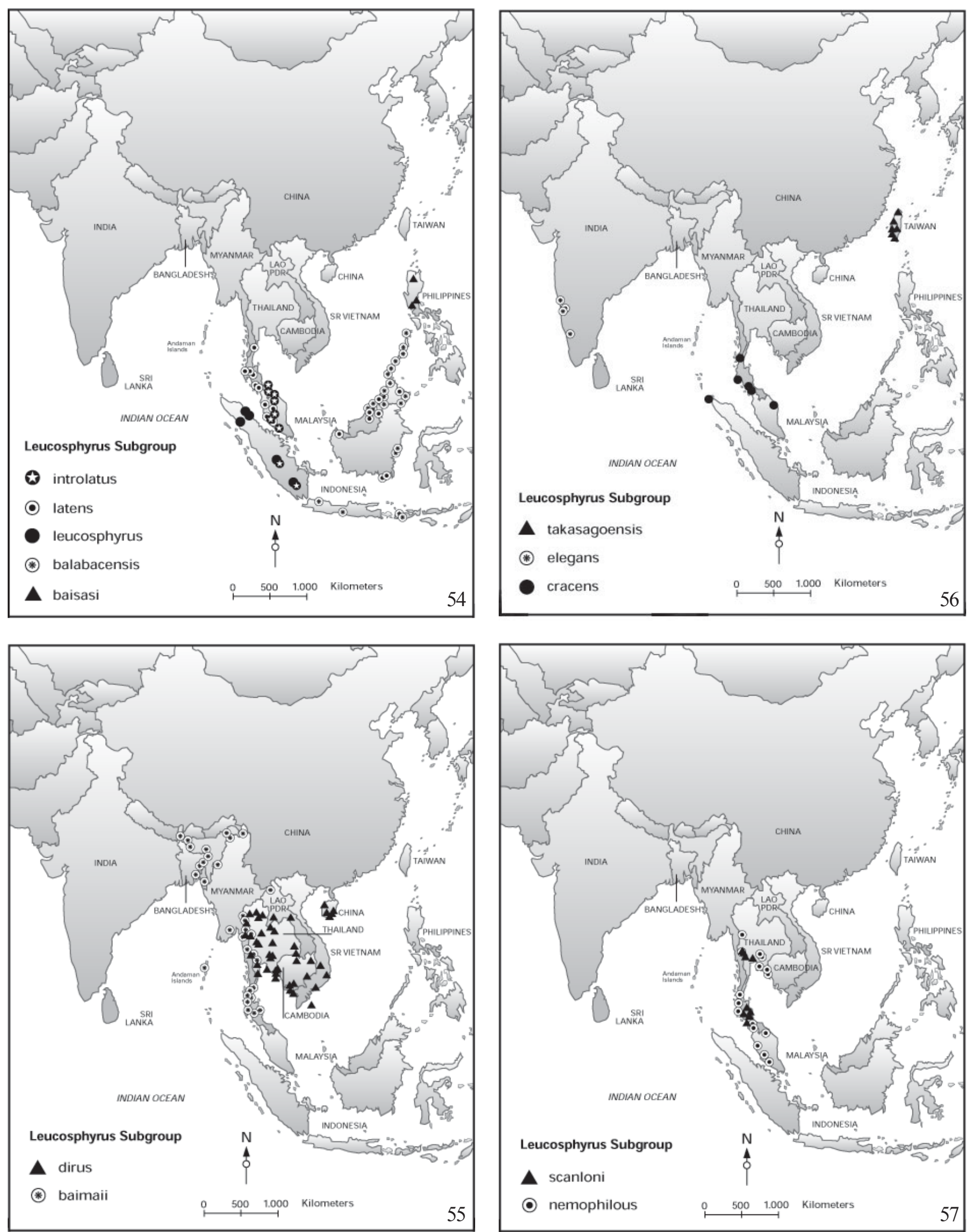

Figs. 54-57. 54, distribution of An. baisasi, An. balabacensis, An. introlatus, An. latens, and An. leucosphyrus. 55, distribution of An. baimaii and An. dirus. 56. distribution of An. cracens, An. elegans, and An. takasagoensis. 57, distribution of An. nemophilous and An. scanloni. 

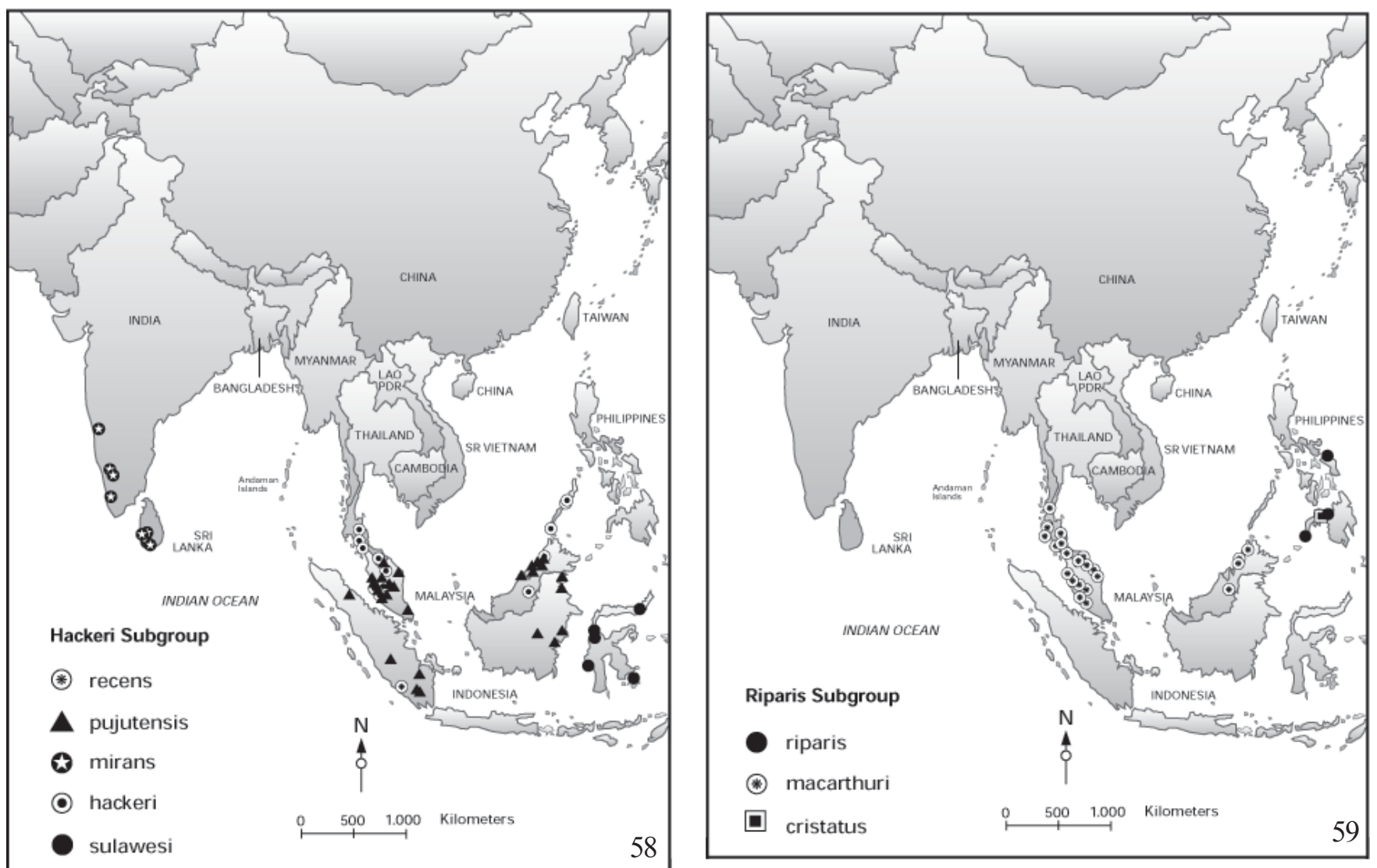

Figs. 58-59. 58, distribution of An. hackeri, An. mirans, An. pujutensis, An. recens, and An. sulawesi. 59, distribution of An. cristatus, An. macarthuri, and An. riparis.

\section{REFERENCES}

Abu Hassan, A.; W. A. Rahman; M. R. Salmah; M. Z. Rashid; Z. Jaal; C. R. Adanan \& M. R. Shahrem. 1997. The distribution of common Anopheles mosquitoes in northwestern Peninsular Malaysia. Journal of Vector Ecology 22: 109-114.

Amerasinghe, F. P. 1982. Observations on the mosquitoes (Diptera: Culicidae) of Udawattakele Forest, Sri Lanka. Journal of the National Science Council of Sri Lanka 10: 81-97.

Atmosoedjono, S.; Djoharti; Purnomo \& M. J. Bangs. 1993. Anopheles balabacensis (Diptera: Culicidae), a vector of Wuchereria kalimantani (Nematoda: Onchocercidae) in East Kalimantan (Borneo), Indonesia. Medical and Veterinary Entomology 7: 390-392.

Audtho, M.; A. Tassanakajon; V. Boonsaeng; S. Tpiankijaguin \& S. Panyim. 1995. Simple nonradioactive DNA hybridization method for identification of sibling species of Anopheles dirus (Diptera: Culicidae) complex. Journal of Medical Entomology 32: 107111.

Ayurakitkosol, L. \& M. E. Griffith. 1962. Progress toward malaria eradication in Thailand. Proceedings Ninth Pacific Science Congress (Bangkok 1957) 17: 122-136.

Baba, K. 1950. A study of anopheline mosquitoes in relation to the epidemiology of malaria in Canton Delta, South China. I. Species of anopheline mosquitoes recorded from Kwangtong Province, South China and their breeding habits. Transaction of the Kansai Entomological Society 15: 1-11.

Baimai, V. 1984. Review of current research on some Anopheles species complexes in Thailand and the significant implications for epidemiology. Informal consultation on malaria vector species complexes and intra specific variations. UNDP/World Bank/WHO
Programme for Research and Training in Tropical Diseases, Bangkok 36-47.

Baimai, V. 1988a. Constitutive heterochromatin differentiation and evolutionary divergence of karyotype in Oriental Anopheles (Cellia). Pacific Science 42: 13-27.

Baimai, V. 1988b. Population cytogenetics of the malaria vector Anopheles leucosphyrus group. The Southeast Asian Journal of Tropical Medicine and Public Health 19: 667-680.

Baimai, V. 1989. Speciation and species complexes of the Anopheles malaria vectors in Thailand. p. 146-162. In: Proceedings of the third conference on malaria research in Thailand, Bangkok

Baimai, V. \& C. A. Green. 1985. Cytogenetic studies of Anopheles balabacensis and Anopheles maculatus complexes in Thailand. The Southeast Asian Journal of Tropical Medicine and Public Health 16: 187

Baimai, V. \& A. Traipakvasin. 1987. Intraspecific variation in sex heterochromatin of species B of the Anopheles dirus complex in Thailand. Genome 29: 401-404.

Baimai, V. \& C. A. Green. 1987. Monandry (monogamy) in natural populations of anopheline mosquitoes. Journal of the American Mosquito Control Association 3: 481-484.

Baimai, V.; B. A. Harrison \& V. Nakavachara. 1980. The salivary gland chromosomes of Anopheles (Cellia) dirus (Diptera: Culicidae) of the Southeast Asian Leucosphyrus Group. Proceedings of the Entomological Society of Washington 82: 319-328.

Baimai, V.; B. A. Harrison \& L. Somchit. 1981. Karyotype differentiation of three anopheline taxa in the Balabacensis Complex of Southeast Asia (Diptera: Culicidae). Genetica 57: 81-86.

Baimai, V.; C. A. Green; R. G. Andre; B. A. Harrison \& E L Peyton. 1984a. Cytogenetic studies of some species complexes of Anopheles 
in Thailand and Southeast Asia. The Southeast Asian Journal of Tropical Medicine and Public Health 15: 536-546.

Baimai, V.; R. G. Andre \& B. A. Harrison. 1984b. Heterochromatin variation in the sex chromosomes in Thailand populations of Anopheles dirus A (Diptera: Culicidae). Canadian Journal of Genetics and Cytology 26: 633-636.

Baimai, V.; R. G. Andre; B. A. Harrison; U. Kijchalao \& L. Panthusiri. 1987. Crossing and chromosomal evidence for two additional sibling species within the taxon Anopheles dirus Peyton and Harrison (Diptera: Culicidae) in Thailand. Proceedings of the Entomological Society of Washington 89: 157-166.

Baimai, V.; A. Poopittayasataporn \& U. Kijchalao. 1988a. Cytological differences and chromosomal rearrangments in four members of the Anopheles dirus complex (Diptera: Culicidae). Genome 30: 372-379.

Baimai, V.; M. M. Thu; M. Paing \& N. P. Maheswary. 1988b. Distribution and chromosomal polymorphism of the malaria vector Anopheles dirus species D. The Southeast Asian Journal of Tropical Medicine and Public Health 19: 661-665.

Baimai, V.; R. E. Harbach \& S. Sukowati. 1988c. Cytogenetic evidence for two species within the current concept of the malaria vector Anopheles leucosphyrus in Southeast Asia. Journal of the American Mosquito Control Association 4: 44-50.

Baimai, V.; R. E. Harbach \& U. Kijchalao. 1988d. Cytogenetic evidence for a fifth species within the taxon Anopheles dirus in Thailand. Journal of the American Mosquito Control Association 4: $333-338$.

Baimai, V.; U. Kijchalao; P. Sawadwongporn \& C. A. Green. 1988e. Geographic distribution and biting behaviour of four species of the Anopheles dirus complex (Diptera: Culicidae) in Thailand. The Southeast Asian Journal of Tropical Medicine and Public Health 19: 151-161.

Baird, J. K.; P. Sismadi; S. Masbar; A. Ramzan; B. W. Purnomo; S. E. Tjitra, B. W. Rumoko \& P. R. Arbani. 1996. A focus of endemic malaria in central Java. The American Journal of Tropical Medicine and Hygiene 54: $98-104$.

Bais, W. J. 1920. Over verbreiding en bestrijding van eenige ziekten onder arbeiders in de tropen. Kolon. Inst. Amsterdam. Mededeeling XIII. Afdeel. Trop. Hyg. 8: 1-137. (Dissertation, University of Amsterdam). (n. v., cited in Swellengrebel and Rodenwaldt 1932:196 and McArthur 1951:196).

Baisas, F. E. 1932. The morphology of some Philippine Anopheles. Transaction of the Eighth Congress Far-East Association of Tropical Medicine (Bangkok 1930) 8: 252-257.

Baisas, F. E. 1936a. Notes on Philippine mosquitoes, IV. The pupal and certain adult characters of some rare species of Anopheles. Philippine Journal of Science 59: 65-84.

Baisas, F. E. 1936b. Notes on Philippine mosquitoes, VI. The pupal characters of anophelines of the subgenus Myzomyia. Philippine Journal of Science 61: 205-220.

Baisas, F. E. 1938. Notes on Philippine mosquitoes, VII. A-Culex (Culex) with banded proboscis and tarsi. B-Anopheles: the pupae of three rare species; the leucosphyrus-subgroup. Monthly Bulletin of Bureau of Health (Manila) 18: 175-232.

Baisas, F. E. 1946. Notes on Philippine mosquitoes, VIII. Species found in the jungles of Llavac. Monthly Bulletin of Bureau of Health (Manila) 22: 27-49.

Baisas, F. E. 1963. Appendix. Keys to the anophelines of the world. 6. The Philippines, p. 697-700. In: P. F. Russell; L. D. West; R. D. Manwell \& G. MacDonald. Practical Malariology. (Second edition). London, Oxford University Press, $x v+750$ p.

Baisas, F. E. \& A. U. Pagayon. 1956. Notes on Philippine mosquitoes, XVII. The eggs and first-instar larvae of some Neomyzomyias. Philippine Journal of Science 85: 212-227.

Baisas, F. E. \& F. H. Dowell. 1965. Keys to the adult female and larval anopheline mosquitoes of the Philippines. PACAF Epidemiology Laboratory Technical Report 13-65: 1-52.

Barcus, M. J.; F. Laihad; M. Sururi; P. Sismadi; H. Marwoto; M. J. Bangs \& J. K. Baird. 2002. Epidemic malaria in the Menoreh Hills of Central Java. American Journal of Tropical Medicine and
Hygiene 66: 287-292.

Barnes, M. E. 1923a. Anopheline mosquitoes with special reference to the species found in Siam. Journal of the Natural History Society of Siam 6: 65-79.

Barnes, M.E. 1923b. Notes on the anopheline mosquitoes of Siam. American Journal of Hygiene 3: 121-126.

Barraud, P. J. \& S. R. Christophers. 1931. On a collection of anopheline and culicine mosquitoes from Siam. Records of the Malaria Survey of India 2: 269-285.

Belkin, J. N. 1962. The mosquitoes of the South Pacific (Diptera, Culicidae). Volumes 1 and 2. Los Angeles and Berkeley, University of California Press, $608 \mathrm{p}$.

Bhat, H. R. 1988. A note on Anopheles dirus Peyton and Harrison, 1979 [An. balabacensis (sensu lato) Baisas, 1936] in India. Indian Journal of Malariology 25: 103-105.

Blanchard, R. 1905. Les moustiques histoire naturelle et medicale. Paris, F. R. de Rudeval, 673p.

Bohart, R. M. 1945. A synopsis of the Philippine mosquitoes. United State Naval Medicine 580: 1-88 (Washington).

Bonne-Wepster, J. 1963. Appendix. Keys to the anophelines of the world. 7. The Malayan Region. p. 701-712. In: P. F. Russell; L. D. West; R. D. Manwell \& G. MacDonald. Practical Malariology. (Second edition). London, Oxford University Press, $x v+750 \mathrm{p}$.

Bonne-Wepster, J. \& N. H. Swellengrebel. 1953. The anopheline mosquitoes of the Indo-Australian Region. Amsterdam, J.H. de Bussy. 504 p.

Borel, E. 1930. Les moustiques de la Cochinchine et du Sud Annam. Collection de La Société de Pathologie Exotique. Monographie III. Paris, Masson et $\mathrm{C}^{\mathrm{ie}}$, Éditeurs. 423 p.

Brug, S. L. \& J. Haga. 1923. Aanteekening omtrent muskieten. Geneeskundig Tijdschrift voor Nederlandsch-Indie 63: 635640 .

Brug, S. L. \& F. W. Edwards. 1931. Fauna Sumatrensis. Culicidae (Diptera). Tijdschrift voor Entomologie 74: 251-261.

Brug, S. L. \& J. Bonne-Wepster. 1947. The geographical distribution of the mosquitoes of the Malay Archipelago. Chronica Naturae 103: 179-197.

Büttiker, W. W. \& P. F. Beales. 1964. Keys to the anopheline mosquitos of Cambodia with references to species occurring in some neighbouring territories. Mitteilungen der Schweizerischen Entomologischen Gesellschaft 37: 190-214.

Cagampang-Ramos, A. \& R. F. Darsie, JR. 1970. Illustrated keys to the Anopheles mosquitoes of the Philippine Islands. USAF Fifth Epidemiology Flight, PACAF Technical Report 70-1. 49 p.

Cagampang-Ramos, A.; R. J. McKenna \& D. D. Pinkovsky. 1985. A list of Philippine mosquitoes (Diptera: Culicidae). Mosquito Systematics 17: 1-31.

Carter, H. F. 1921. The blood-sucking Nematocera. Tribe Anophelini, p. 345-356. In: W. Byam \& R. G. Archibald. Medicine in the Tropics. vol. 1.

Carter, H. F. 1925. The anopheline mosquitoes of Ceylon. Part I. The differential characters of the adults and larvae. Ceylon Journal Science 1: 57-97.

Carter, H. F. 1950. Ceylon mosquitoes: lists of species and names of mosquitoes recorded from Ceylon. Ceylon Journal Science (B) 24: 85-115.

Catangui, F. P. 1985. Bionomics of malaria vectors in the Philippines. The Southeast Asian Journal of Tropical Medicine and Public Health 16: 190.

Causey, O. R. 1937. Some anopheline and culicine mosquitoes of Siam with remarks on malaria control in Bangkok. American Journal of Hygiene 25: 400-420.

Chang M. S.; P. Doraisingam; S. Hardin \& N. Nagun. 1995. Malaria and filariasis transmission in a village/forest setting in Baram District, Sarawak, Malaysia. The Journal of Tropical Medicine and Hygiene 98: 192-198.

Chang, T. L. \& T. C. Huang. 1954. A practical guide to the identification of anopheline mosquitoes in Taiwan, China. Chinese Medical Journal 1: 341-346.

Chang, T. L. \& T. C. Huang. 1955. A practical guide to the identification 
of anopheline mosquitoes in Taiwan, China. Part II. The larvae. Chinese Medical Journal 1: 57-77.

Chang, T. L.; R. B. Watson \& C. Y. Chow. 1950. Notes on seasonal prevalence of Anopheles mosquitoes in southern Formosa. Indian Journal of Malariology 4: 281-293.

Chareonviriyaphap, T.; M. J. Bangs \& S. Ratanatham. 2000. Status of malaria in Thailand. The Southeast Asian Journal of Tropical Medicine and Public Health 31: 225-237.

Cheng, F. Y. 1967. Observations on Anopheles balabacensis responses to specific patterns of DDT-spraying in Sabah, East Malaysia. WHO/Mal/67: 620, $20 \mathrm{p}$.

Cheong, W. H.; A. H. B. Omar \& M. Warren. 1966. The known vectors of simian malaria in Malaya today. The Medical Journal of Malaya 20: 327-329.

Cheong, W. H.; A. H. B. Omar \& S. Mahadevan. 1968. The 24-hour activity of $A$. balabacensis balabacensis in nature. The Medical Journal of Malaya 22: 243.

Cheong, W. H.; K. P. Loong; S. Mahadevan; J.W. Mak \& S.K.P. Kan. 1984. Mosquito fauna of the Bengkoka peninsula Sabah, Malaysia. The Southeast Asian Journal of Tropical Medicine and Public Health 15: 19-26.

Cheong, W. H.; M. Warren; A. H. B. Omar \& S. Mahadevan. 1965. Anopheles balabacensis balabacensis identified as vector of simian malaria in Malaysia. Science 150: 1314-1315.

Chiang, G. L.; W. H. Cheong; W. A. Samarawickrema; J. W. Mak \& S. K. P. Kan. 1984. Filariasis in Bengkoka peninsula, Sabah Malaysia: vector studies in relation to the transmission of filariasis. The Southeast Asian Journal of Tropical Medicine and Public Health 15: 179-189.

Chin, W. 1969. Report of activities for year ending 30, June 1969, Thailand malaria operational research unit. Malaria Eradication Program, Public Health Service, U.S. Department of Health, Education and Welfare. Atlanta, Georgia 12 p.

Chin, W. 1970. Activities for year ending June 30, 1970, Thailand malaria operational research unit. Malaria Eradication Program, Public Health Service, U.S. Department of Health, Education and Welfare. Atlanta, Georgia, 14 p.

Chin, W.; P. G. Contacos; W. E. Collins; M. H. Jeter \& E. Alpert. 1968. Experimental mosquito-transmission of Plasmodium knowlesi to man and monkey. The American Journal of Tropical Medicine and Hygiene 17: 355-358.

Choochote, W.; W. Maleewong; S. Sucharit \& T. Tesana. 1987. Scanning electron microscopic study of pupal seta 9-III-V of Anopheles balabacensis (Perlis Form) and Anopheles dirus (Bangkok strain). The Southeast Asian Journal of Tropical Medicine and Public Health 18: 511-573.

Choudhury, D. S.; B. L. Wattal \& S. P. Ramakrishnan. 1963a. Incrimination of Anopheles elegans James (1903) as a natural vector of simian malaria in the Nilgiris, Madras State, India. Indian Journal of Malariology 17: 243-247.

Choudhury, D. S.; B. N. Mohan; S. Prakash \& S. P. Ramakrishnan. 1963b. Experimental susceptibility of anopheline mosquitoes to simian malaria in the Nilgiris, Madras State, South India. Indian Journal of Malariology 17: 237-242.

Chow, C. Y. 1949. The anopheline mosquitoes of Taiwan (Formosa), China. Quarterly Journal of the Taiwan Museum (Taipei) 2: $1-8$.

Chow, C. Y. 1961. Pictorial key to the "Anopheles leucosphyrus" group. WHO/MAL/290. Unpublished WHO document.

Chow, C. Y. 1970. Bionomics of malaria vectors in the Western Pacific Region. The Southeast Asian Journal of Tropical Medicine and Public Health 1: 40-57.

Christophers, S. R. 1916. A revision of the nomenclature of Indian Anophelini. The Indian Journal of Medical Research 3: 454488.

Christophers, S. R. 1924. Provisional list and reference catalogue of the Anophelini. Part I. Provisional list of species. Part II. Descriptive synopsis. Indian Medical Research Memoirs Supplementary Series 3: 1-105.

Christophers, S. R. 1933. The fauna of British India, including
Ceylon and Burma. Diptera, volume IV. Family Culicidae. Tribe Anophelini. London, Taylor and Francis, xi+388 p.

Christophers, S. R.; J. A. Sinton \& G. Covell. 1927. Synoptic table for the identification of the anopheline mosquitoes of India. Indian Health Bulletin 10: 1-22.

Chuang, C.-H.; J.-C. Lein \& S.-Y. Lin. 1965. Studies on siamian malaria in Taiwan. $\mathrm{WHO} / \mathrm{Mal} / 505.65,7 \mathrm{p}$.

Chuang, C.-H.; J.-C. Lein \& S.-Y. Lin. 1967. Futher studies on simian malaria in Taiwan. WHO/Mal/66.567, $18 \mathrm{p}$.

Coatney, G. R.; W. E. Collins; M. Warren \& P. G. Contacos. 1971. The primate malarias. National Institute of Health, U.S. Department of Health, Education and Welfare. Bethesda, MD

Cogill, H. 1903. The Anopheles of Karwar (North Kanara). Journal Bombay Natural History Society 15: 327-336.

Colless, D. H. 1948. The anopheline mosquitoes of North-West Borneo. Proceedings Linnean Society of New South Wales 73: 71119.

Colless, D. H. 1950. The identity of the malaria vector, A. leucosphyrus. Indian Journal of Malariology 4: 377-383.

Colless, D. H. 1956a. Observations on anopheline mosquitos of the Akah River, 4th Division, Sarawak. Bulletin of Entomological Research 47: 115-123.

Colless, D. H. 1956b. The Anopheles leucosphyrus group. The Transaction of the Royal Entomological Society of London 108: $37-116$.

Colless, D. H. 1957. Further notes on the systematics of the Anopheles leucosphyrus group (Diptera: Culicidae). Proceedings of the Royal Entomological Society of London (B) 26: 131-139.

Collins, W. E.; P. G. Contacos \& E. G. Guinn. 1967a. Studies on the transmission of the $\mathrm{H}$ strain of Plasmodium knowlesi by Anopheles balabacensis balabacensis. The Journal of Parasitology 53 : 841-844.

Collins, W. E.; P. G. Contacos; E. G. Guinn \& J. R. Held. 1967b. Studies on the transmission of simian malaria. III. Infection and transmission of Plasmodium coatneyi with Anopheles freeborni and A. balabacensis balabacensis mosquitoes. The Journal of Parasitology 53: 1130-1134.

Collins, W. E.; P. G. Contacos; E. G. Guinn \& J. R. Held. 1968. Transmission of Plasmodium fieldi by Anopheles maculatus, A. stephensi and A. balabacensis. The Journal of Parasitology 54: 376.

Collins, W. E.; P. G. Contacos; J. C. Skinner \& E. G. Guinn. 1971. Studies on the transmission of simian malaria. IV. Further studies on the transmission of Plasmodium knowlesi by Anopheles balabacensis balabacensis mosquitoes. The Journal of Parasitology 57: 961-966.

Cook, D. R. 1954. Pictorial keys to the mosquitoes of medical importance. VI. Philippine Islands. Mosquito News 14: 79-82.

Covell, G. 1927. The distribution of anopheline mosquitoes in India and Ceylon. Indian Medical Research Memoirs Supplementary Series 5: 1-85.

Covell, G. 1931a. The distribution of anopheline mosquitoes in India. Health Bulletin (Malaria Bureau no. 8) 17:1-39.

Covell, G. 1931b. The distribution of anopheline mosquitoes in India and Ceylon: additional records, 1926-1930. Records of the Malaria Survey of India 2:235-268.

Covell, G. 1944. Notes on the distribution, breeding places, adult habits and relation to malaria of the anopheline mosquitoes of India and the Far East. Journal of Malaria Institute of India 5: 399 434.

Covell. G. \& J. Harbhagwan. 1939. Malaria in the Wynaad, South India. Journal of Malaria Institute of India 2: 341-376.

Crawford, R. 1938. Some anopheline pupae of Malaya with a note on pupal structure. Malaria Advisory Board, Federated Malay States, Singapore, $110 \mathrm{p}$

Cui, K. L.; Z. G. Wang; M. X. Li; M. S. Wang; N. Hong \& G. M. He. 1992. Distinguishing Anopheles dirus of Hainan Province by gas chromatography of cuticular hydrocarbons. Chung Kuo Chi Sheng Chung Hsueh Yu Chi Sheng Chung Ping Tsa Chih 10: $283-286$. 
D'Abrera, V. ST. E. 1944. The eggs of the Ceylon anopheline mosquitoes. Journal of Malaria Institute of India 5: 337-359.

Damrongphol, P. \& V. Baimai. 1989. Scanning electron microscope observations and differentiation of eggs of the Anopheles dirus complex. Journal of the American Mosquito Control Association 5: 563-568.

Daniels, G.W. 1908. Breeding grounds of Culicidae. Studies of Institute of Medical Research, Federated Malay States 3: 1-7.

Das, B. P.; R. Rajagopal \& J. Akiyama. 1990a. Pictorial key to the species of Indian anopheline mosquitoes. Journal of Pure and Applied Zoology 2: 131-162.

Das, S. C.; M. Bhuyan \& D. Baruah. 1990b. Active malaria transmission in South Mizoram. Indian Journal of Malariology 28: 127134.

Das, S. C.; M. Bhuyan; D. Baruah \& P. K. Talukdar. 1991. Mosquito survey in Tripura. Indian Journal of Malariology 28: 129134.

De Meijere, J. C. H. 1913. Studien uber Sud-Ostasiatische Dipteren, VII. Culicidae. Tijdschrift voor Entomologie 56: 338-354.

Deng, D.; H.-L. Qian \& X.-S. Yang. 1982. Rectification of Hainan's Anopheles b. balabacensis to A. dirus Peyton et Harrison, 1979. Acta Zootaxonomica Sinica 7: 332-333.

Dönitz, W. 1901. Nachrichten aus dem Berliner Entomologischen Verein. Insekten-Borse 18: 36-40.

Dönitz, W. 1902. Beitrage zur Kenntniss der Anopheles. Zeitschrift fur Hygiene und Infektionskrankheiten 41: 15-88.

Doorenbos, W. B. 1927. Zijn de muskieten, die malaria onderhouden, abnormaal levende exemplaren? Geneeskundig Tijdschrift voor Nederlandsch-Indie 67: 21-27.

Doorenbos, W. B. 1931a. Eenige ervaringen op malariagebied. Geneeskundig Tijdschrift voor Nederlandsch-Indie 71: $1228-1248$

Doorenbos, W. B. 1931b. Eenige ervaringen op malariagebied. Geneeskundig Tijdschrift voor Nederlandsch-Indie 71: $1459-1478$

Do-Van-Quy. 1962a. Apercu sur le comportement trophique des Anopheles dans les hautes regions au Sud-Vietnam. Rapport Annuel sur le Fonctionnement Technique de l'Institut Pasteur du Viêt-Nam (Chapitre 111, Entomologie) p. 23-26.

Do-Van-Quy. 1962b. Clefs pour la determination des 25 especes les plus communes d'Anopheles (adultes femelles et larves ) du SudVietnam. Rapport Annuel sur le Fonctionnement Technique de 1'Institut Pasteur du Viêt-Nam. (Chapitre III, Entomologie) p. 26-34.

Dunnewold, R. 1934. Een nieuwe Anopheles-larve (A. leucosphyrus var. hackeri?). Geneeskundig Tijdschrift voor NederlandschIndie 74: 170-173.

Dutta, P.; D. R. Bhattacharyya \& L. P. Dutta. 1989a. Incrimination of Anopheles dirus as a vector of malaria in Dibrugarh district, Assam. Indian Journal of Malariology 26: 149-52.

Dutta, P.; D. R. Bhattacharyya \& L. P. Dutta. 1991. Epidemiological observations on malaria in some parts of Tengakhat PHC Dibrugarh District Assam. Indian Journal of Malariology 28: 121-128.

Dutta, P.; D. R. Bhattacharyya; C. K. Sharma \& L.P. Dutta. 1989b. The importance Anopheles dirus (A. balabacensis) as a vector of malaria in northeast India. Indian Journal of Malariology 26: 95-101.

Dutta, P.; D. R. Bhattacharyya; C. K. Sharma \& L. P. Dutta. 1992. Anopheline fauna of part of Tirap District, Arunachal Pradesh with reference to malaria transmission. The Indian Journal of Medical Research 95: 245-249.

Dutta, P.; D. R. Bhattacharyya; S. A. Khan; C. K. Sharma \& J. Mahanta. 1996. Feeding patterns of Anopheles dirus, the major vector of forest malaria in northeast India. The Southeast Asian Journal of Tropical Medicine and Public Health 27: 378-381.

Dutta, P.; S. A. Khan; C. K. Sharma \& J. Mahanta. 1997. A report of mosquito fauna survey and vector incrimination in Goalpara district of Assam. Indian Journal of Malariology 34: 204-207.

Dutta, P.; V. Dev \& D. R. Bhattacharyya. 1993. Anopheline fauna and malaria incidence in Changlang District (Arunachal Pradesh). Indian
Journal of Malariology 30: 135-143.

Edwards, F. W. 1921. Mosquito notes-II. Bulletin of Entomological Research 12: 69-80.

Edwards, F. W. 1932. Diptera Fam. Culicidae. In: P. Wytsman (ed.). Genera Insectorum. Fascicule 194. Tervueren, DesmetVerteneuil, $258 \mathrm{p}$.

Erhart, A.; N. D. Thang; N. Q. Hung; V. Le Toi; X. Le Hung; T. Q Tuy; D. Le Cong; N. Speybroeck; M. Coosemans \& U. D'Alessandro. 2004. Forest malaria in Vietnam: a challenge for control. The American Journal of Tropical Medicine and Hygiene 70: $110-118$

Eyles, D. E.; M. Warren; E. Guinn; R. H. Wharton \& C. P. Ramachandran. 1963. Identification of Anopheles balabacencis introlatus as a vector of monkey malaria in Malaya. Bulletin of the World Health Organization 28: 134-135.

Eyles, D. E.; R. H. Wharton; W. H. Cheong \& M. Warren. 1964. Studies on malaria and Anopheles balabacensis in Cambodia. Bulletin of the World Health Organization 30: 7-21.

Fooden, J. 1994. Malaria in macaques. International Journal of Primatology 15: 573-596.

Frances, S. P.; T. A. Klein; R. A. Wirtz; C. Eamsila; C. Pilakasiri \& K. J. Linthicum. 1996. Plasmodium falciparum and P. vivax circumsporite proteins in anophelines (Diptera: Culicidae) collected in eastern Thailand. Journal of Medical Entomology 33: 990991

Gater, B. A. R. 1933. Notes on Malayan mosquitoes, I. The genus Anopheles. Malayan Medical Journal 8: $39-42$.

Gater, B. A. R. 1934. Aids to the identification of anopheline larvae in Malaya. Malaria Advisory Board, Federated Malay States, $160 \mathrm{p}$.

Gater, B. A. R. 1935. Aids to the identification of anopheline imagines in Malaya. Malaria Advisory Board, Federated Malay States, $242 \mathrm{p}$

Gater, B. A. R. \& P. D. Rajamoney. 1929. A summary of records of anopheline breeding-places in Malaya. Bulletin of the Institute of Medical Research Federated Malay States 2: 1-33.

Giles, G. M. 1902. A handbook of the gnats or mosquitoes giving the anatomy and life history of the Culicidae together with descriptions of all species noticed up to the present date. (Second edition, rewritten and enlarge ). London, John Bale and Sons and Danielsson, Ltd.

Gillies, M. T. \& M. Coetzee. 1987. A supplement to the Anophelinae of Africa south of Sahara. Publication 55. South African Institute for Medical Research. Joannesburg, South Africa.

Gingrich, J. B.; A. Weatherhead; J. Sattabongkot; C. Pilakasiri \& R. A. Wirtz. 1990. Hyperendemic malaria in a Thai village dependence of year-round transmission on focal and seasonally circumscribed mosquito (Diptera Culicidae) habitats. Journal of Medical Entomology 27: 1016-1026.

Gomes, M.; K. Linthicum \& M. Haile. 1998. Malaria: the role of agriculture in changing the epidemiology of malaria, 87-99 p. In: Greenwood, B. \& De Cock, K. (ed.). New and resurgent infections: prediction, detection and management of tomorrow's epidemics. Chichester, Ed. John Wiley \& Sons, 236 p.

Gould, D. J.; J. E. Scanlon \& R. A. Ward. 1966. Anopheles vectors of malaria in Southeast Asia. Army Science Conference Proceedings 1: $361-373$.

Green, C. A.; L. E. Munstermann; S. G. Tan; S. Panyim \& V. Baimai. 1992. Population genetic evidences for species A, B, C, and D of the Anopheles dirus complex in Thailand and enzyme electromorphs for their identification. Medical and Veterinary Entomology 6: 29-36.

Hacker, H. P. 1921. Malaria Bureau Reports I-II. Federated Malay States (1920) 2: 1-47.

Haga, J. 1930. Tabellen voor determinatie der in Nederlandsch-OostIndie voorkomende anophelinen. Geneeskundig Tijdschrift voor Nederlandsch-Indie 70: $363-382$.

Haq, M. I. \& N. P. Maheswary. 1991. "Forest related malaria in Bangladesh, p. 67-79. In: V. P. Sharma \& A. V. Kondrashin (eds.). 
Forest malaria in Southeast Asia. Proceedings of the Informal Consult Meeting WHO/MRC (1991), New Delhi.

Harbach, R. E. 2004. The classification of the genus Anopheles (Diptera: Culicidae): a working hypothesis of phylogenetic relationships. Bulletin of Entomological Research 94: 537-553.

Harbach, R. E. \& K. L. Knight. 1980. Taxonomists' glossary of mosquito anatomy. Marlton, New Jersey, Plexus Publishing, Inc. $\mathrm{xi}+415 \mathrm{p}$.

Harbach, R. E. \& K. L. Knight. 1982. Corrections and additions to Taxonomists' glossary of mosquito anatomy. Mosquito Systematics 13: 201-217

Harbach, R. E.; J. B. Gingrich \& L. W. Pang. 1987a. Some entomological observations on malaria transmission in a remote village in northwestern Thailand. Journal of the American Mosquito Control Association 3: 296-301.

Harbach, R. E.; V. Baimai \& S. Sukowati. 1987b. Some observations on sympatric populations of the malaria vectors Anopheles leucosphyrus and Anopheles balabacensis in a village-forest setting in South Kalimantan. The Southeast Asian Journal of Tropical Medicine and Public Health 18: 241-247.

Harinasuta, T.; K. E. Dixon; D. A. Warrell \& E. B. Doberstyn. 1982. Recent advances in malaria with special reference to Southeast Asia. The Southeast Asian Journal of Tropical Medicine and Public Health 13: 1-33.

Harrison, B. A. \& J. M. Klein. 1975. A revised list of the Anopheles of Cambodia. Mosquito Systematics 7: 9-12.

Harrison, B. A.; J. F. Reinert; S. Sirivanakarn; Y. -M. Huang; EL Peyton \& B. De Meillon. 1974. Distributional and biological notes on mosquitoes from Sri Lanka (Ceylon) (Diptera: Culicidae). Mosquito Systematics 6: 142-162.

Harrison, B. A.; R. Rattanarithikul; EL Peyton \& K. Mongkolpanya. 1990. Taxonomic changes, revised occurrence records and notes on the Culicidae of Thailand and neighboring countries. Mosquito Systematics 22: 196-227.

Hii, J. L. K. 1980. Responses of Anopheles balabacensis balabacensis Baisas to ultra-low-volume aerosols of sumithion in Sabah, Malaysia. Journal of Community Diseases 12: 14-21.

Hii, J. L. K. 1984a. Insecticide susceptibility of three cryptic species of the Anopheles balabacensis complex. The Southeast Asian Journal of Tropical Medicine and Public Health 15: 104111.

Hii, J. L. K. 1984b. Involvement of the X-chromosome in hybrid male sterility from crosses between species A and species B of the taxon Anopheles dirus. Mosquito News 44: 192-196.

Hii, J. L. K. 1985a. Genetic investigations of laboratory stocks of the complex of Anopheles balabacensis Baisas (Diptera: Culicidae). Bulletin of Entomological Research 75: 185-197.

Hii, J. L. K. 1985b. Evidence for the existence of genetic variability in the tendency of Anopheles balabacensis to rest in houses and to bite man. The Southeast Asian Journal of Tropical Medicine and Public Health 16: 173-182.

Hii, J. L. K. 1986. Multivariate morphometrics of the immature stages of the Anopheles balabacensis complex (Diptera: Culicidae). Mosquito Systematics 18: 125-133.

Hii, J. L. K. \& Y. S. Vun. 1985. A study of dispersal, survival and adult population estimates of the malaria vector, Anopheles balabacensis Baisas (Diptera: Culicidae) in Sabah, Malaysia. Tropical Biomedicine 2: 121-131.

Hii, J. L. K. \& Y. S. Vun. 1987. The influence of heterogeneous environment on host feeding behavior by Anopheles balabacensis (Diptera: Culicidae). Tropical Biomedicine 4: 67-70.

Hii, J. L. K.; S. Kan; C. K. Foh \& M. K. C. Chan. 1984. Anopheles (Cellia) balabacensis Baisas is a vector of Wuchereria bancrofti in Sabah, Malaysia. Transactions of the Royal Society of Tropical Medicine and Hygiene 78: 281-282.

Hii, J. L. K.; S. Kan; M. Pereira; S. S. Parma; R. L. Campos \& M. K. C. Chan. 1985. Bancroftian filariasis and malaria in island and hinterland populations in Sabah, Malaysia. Tropical Geographic Medicine 37: 93-101.

Hii, J. L. K.; E L Peyton \& Y. S. Vun. 1988a. Redescription of the adult and first description of the larva and pupa of Anopheles (Cellia) sulawesi Waktoedi, a species of the Leucosphyrus Group from Sulawesi, Indonesia (Diptera: Culicidae). Mosquito Systematics 20: $41-54$.

Hii, J. L. K.; M. Chew; Y. S. Vun; M. Nasir \& M. S. Chang. 1988b. Enzyme polymorphism of the malaria vector, An. balabacensis (Diptera: Culicidae) revisited - why sample natural populations? The Southeast Asian Journal of Tropical Medicine and Public Health 19: 689-701.

Hii, J. L. K.; S. Kan; Y. S. Vun; K. F. Chin; S. Tambakau; M. K. C. Chan; M. S. Lye; J. W. Mak \& A. H. Cochrane. 1988c. Transmission dynamics and estimates of malaria vectorial capacity for Anopheles balabacensis and An. flavirostris (Diptera: Culicidae) on Banggi Island, Sabah, Malaysia. Annals of Tropical Medicine and Parasitology 82: 91-101.

Hii, J. L. K.; M. H. Birley \& Y. S. Vun. 1990. Estimation of survival rate and oviposition interval of Anopheles balabacensis mosquitoes from mark-recapture experiments in Sabah, Malaysia. Medical and Veterinary Entomology 4: 135-140.

Hii, J. L. K.; M. Chew; V. Y. Sang; L. E. Munstermann; S. G. Tan; S. Panyim \& S. Yasothornsrikul. 1991. Population genetic analysis of host seeking and resting behavior in the malaria vector Anopheles balabacensis (Diptera: Culicidae). Journal of Medical Entomology 28: 675-684.

Hodgkin, E. P. 1945. The Anopheles of Malaya. Keys for the identification of the females and larvae of the Anopheles mosquitoes found in the Malay Peninsula. Perth W. Australia, $48 \mathrm{p}$.

Hoedojo. 1989. Vectors of malaria and filariasis in Indonesia. Buletin Penelitian Kesehatan 17: 181-190.

Htay-Aung; S. Minn; S. Thaung; M. M. Mya; S. M. Than; T. Hlaing; Soe-Soe; P. Druilhe \& F. Queuche. 1999. Well-breeding Anopheles dirus and their role in malaria transmission in Myanmar. The Southeast Asian Journal of Tropical Medicine and Public Health 30: 447-453.

Huong, N. T.; P. Sonthayanon; A. J. Ketterman \& S. Panyim. 2001. A rapid polymerase chain reaction based method for identification of the Anopheles dirus sibling species. The Southeast Asian Journal of Tropical Medicine and Public Health 32:615-620.

ICZN. 1999. International Code of Zoological Nomenclature, $4^{\text {th }}$ ed. London, The International Trust for Zoological Nomenclature, NHM, xxix $+306 \mathrm{p}$.

Ismail, I. A. H.; N. Notananda \& J. Schepens. 1974. Studies on malaria and responses of Anopheles balabacensis balabacensis and Anopheles minimus to DDT residual spraying in Thailand. Part I. Pre-spraying observations. Acta Tropica 31: 129-164.

Ismail, I. A. H.; N. Notananda \& J. Schepens. 1975. Studies on malaria and responses of Anopheles balabacensis balabacensis and Anopheles minimus to DDT residual spraying in Thailand. Part II. Post-spraying observations. Acta Tropica 32: 206-231.

Iwangaga, S. K. \& T. Kanda. 1990. Studies on the effective attractants of Anopheline mosquitoes I. Blood-feeding mating and flight activity of female Anopheles balabacensis (Diptera: Culicidae). Applied Entomology and Zoology 25: 231-238.

James, S. P. 1903. Myzomyia(?) elegans. p. 51. In: F.V. Theobald. 1903. A monograph of the Culicidae or mosquitoes. Volume 3. London, British Museum (Natural History).

James, S. P. \& W. G. Liston. 1904. A monograph of the Anopheles mosquitoes of India. First edition. Calcutta, Thacker, Spink and Co. vi $+132 \mathrm{p}$.

James, S. P. \& W. G. Liston. 1911. Anopheline mosquitoes of India. Second edition. Calcutta, Thacker, Spink and Co. 128p.

James, S. P. \& A. T. Stanton. 1912. Revision of the names of Malayan anophelines. Paludism 5: 59-63.

Jayaprakash 1990. Chromosome studies of Oriental anophelines: a comparison of the salivary gland chromosomes of Anopheles leucosphyrus and A. jeyporiensis. Entomon 15: 11-19.

Jianwei, X. \& L. Hui. 2000. Forests, mountains and malaria in Asia, Africa and South America. Mosquito Borne Diseases Bulletin 17: $6-9$. 
Kanda, T.; C. G. Lian; K. Ito; W. Tumurasvin \& K. P. Loong. 1980. Cytogenetic observations on Anopheles dirus of the leucosphyrus complex. Mosquito News 40: 585-592.

Kanda, T.; K. Takai; G. L. Chiang; W. H. Cheong \& S. Sucharit. 1981. Hybridization and some biological facts of seven strains of the Anopheles leucosphyrus group (Reid, 1968). Japanese Journal Sanitary Zoology 32: 321-329.

Kanda, T.; K. Takai; G. L. Chiang; K. P. Loong; S. Sucharit \& W. H. Cheong. 1983. Phylogenetic interpretation and chromosomal polymorphism among nine strains of human malaria vectors of the Anopheles leucosphyrus group. Japanese Journal of Genetics 58: 193-208.

Kanda, T.; T. Matsunari; K. Takai; W. H. Cheong; K. P. Loong \& S. Sucharit. 1985. Biological validity of a morphological species Anopheles takasagoensis Morishita, 1946. Japanese Journal of Genetics 60: 381-386.

Ketrangsee, S.; S. Suvannadabba; K. Thimasarn; C. Prasittisuk \& W. Rooney. 1991. Malaria situation in Thailand with special reference to forest related Malaria. p. 193-220. In: V. P. Sharma \& A. V. Kondrashin (eds.). Forest malaria in Southeast Asia. Proceedings of an informal consultative meeting WHO/MRC, New Delhi.

Khan, S. A.; R. Handique; S. C. Tewari; P. Dutta; K. Narain \& J. Mahanta. 1998. Larval ecology and mosquito fauna of Upper Brahmaputra valley, northeast India. Indian Journal of Malariology 35: 131 145.

Khin-Maung-Kyi. 1970. Malaria vectors in Burma. 2. Anopheles balabacensis balabacensis Baisas, 1936. Union of Burma Journal Life Science 3: 217-225.

Khin-Maung-Kyi. 1971. The anopheline mosquitoes of Burma. 2. Subgenus Myzomyia Blanchard groups Neomyzomyia and Pseudomyzomyia Christophers. Union of Burma Journal Life Science 4: 297-305.

Khin-Maung-Kyi. 1974. Further observations on Anopheles balabacensis balabacensis and malaria in Burma. WHO/Mal/ $74.838,15 \mathrm{p}$.

Khin-Maung-Kyi \& S. M. Winn. 1976. Studies on malaria and Anopheles balabacensis balabacensis and Anopheles minimus in Burma. WHO/Mal/76.875, 23 p.

King, W. V. \& F. E. Baisas. 1936. A new species and a new variety of Philippine Anopheles related to Anopheles leucosphyrus Doenitz. Proceedings of the Entomological Society of Washington 38: 79-89.

Kirnowardoyo, S. 1985. Status of Anopheles malaria vectors in Indonesia. The Southeast Asian Journal of Tropical Medicine and Public Health 16: 129-132.

Kirnowardoyo, S. 1988. Anopheles malaria vector and control measures applied in Indonesia. The Southeast Asian Journal of Tropical Medicine and Public Health 19: 713-716.

Kitthawee, S.; J. D. Edman \& E. S. Upatham. 1992a. Anopheles dirus size and fecundity: relationship to larval density and protein accumulation. The Southeast Asian Journal of Tropical Medicine and Public Health 23: 128-131.

Kitthawee, S.; J. D. Edman \& E. S. Upatham. 1992b. Relationship between female Anopheles dirus (Diptera: Culicidae) body size and parity in a biting population. Journal of Medical Entomology 29: 921-926.

Kitthawee, S.; J. D. Edman \& E. S. Upatham. 1993. Mosquito larvae and associated macroorganisms occurring in gem pits in southern Tha Mai District, Chanthaburi Province, Thailand. The Southeast Asian Journal of Tropical Medicine and Public Health 24: $143-151$.

Kitthawee, S.; J. D. Edman \& E. S. Upatham. 1995. Effect of seasonal variation in the aquatic habitat of immature Anopheles dirus (Diptera: Culicidae) on the size and survivorship of emerging adults. The Southeast Asian Journal of Tropical Medicine and Public Health 26: 573-581.

Kitthawee, S.; J. D. Edman \& J. Sattabongkot. 1990. Evaluation of survival potential and malaria susceptibility among different size classes of laboratory-reared Anopheles dirus. The American Journal of Tropical Medicine and Hygiene 43: 328-332.
Kitthawee, S.; J. D. Edman. 1995. Adult body size and biting activity of field populations of Anopheles dirus (Diptera: Culicidae). The Southeast Asian Journal of Tropical Medicine and Public Health 26: $582-585$.

Klein, J. M. 1977. La faune des moustiques du Cambodge. 1.Anophelinae (Diptera, Culicidae). Cahiers O.R.S.T.O.M. Entomologie médicale et parasitologie. 15: 107-122.

Klein, T. A.; B. A. Harrison; J. S. Grove; S. V. Dixon \& R. G. Andre. 1986. Correlation of survival rates of Anopheles dirus A (Diptera: Culicidae) with different infection densities of Plasmodium cynomolgi. Bulletin of the World Health Organization 64: 901-907.

Klein, T. A.; B. A. Harrison; R. G. Andre; R. E. Whitmire \& I. Inlao. 1982. Detrimental effects of Plasmodium cynomolgi infections on the longevity of Anopheles dirus. Mosquito News 42: 265271.

Klein, T. A.; B. A. Harrison; S. V. Dixon \& J. R. Burge. 1991. Comparative susceptibility of Southeast Asian Anopheles mosquitoes to the simian malaria parasite Plasmodium cynomolgi. Journal of the American Mosquito Control Association 7: 481-487.

Knight, K. L. \& A. Stone. 1977. A catalog of the mosquitoes of the world (Diptera: Culicidae). (Second edition). College Park, Maryland, The Thomas Say Foundation, Entomological Society of America. 611 p.

Kobayashi, J.; S. Nambanya; I. Miyagi; B. Vanachone; K. Manivong; T. Koubouchan; H. Amano; H. Nozaki; S. Inthakone \& Y. Sato. 1997. Collection of anopheline mosquitos in three villages endemic for malaria in Khammouane, Lao PDR. The Southeast Asian Journal of Tropical Medicine and Public Health 28: 615620.

Kobayashi, J.; S. Phompida; T. Toma; S. Looreensuwan; H. Toma \& I. Miyagi. 2004. The effectiveness of impregnated bed net in malaria control in Laos. Acta Tropica 89: 299-308.

Koesoemawinangoen, R. W. 1954. Anophelini di Indonesia. Djilid 1. Djakarta. $191 \mathrm{p}$.

Koidzumi, M. 1925. Classification of Formosan Anopheles. Dobutsugaku Zasshi (Journal of Zoology Society) 37: 314377.

Kondrashin, A. V. 1986. Malaria in Southeast Asia. The Southeast Asian Journal of Tropical Medicine and Public Health 17: $642-655$.

Kondrashin, A. V.; R. K. Tung \& J. Akiyama. 1991. Ecological aspects of forest malaria in Southeast Asia. p. 1-28. In: V. P. Sharma \& A. V. Kondrashin (eds.). Forest malaria in Southeast Asia. Proceedings of informal consultative meeting WHO/MRC, New Delhi.

Krishnan, K. S. \& P. G. Halernkar. 1967. Anopheline fauna of Andaman Islands. Bulletin of the Indian Society of Malaria and Other Communicable Diseases 4: 35-43.

Krzywinski, J.; R. C. Wilkerson \& N. J. Besansky. 2001a. Evolution of mitochondrial and ribosomal gene sequences in Anophelinae (Diptera: Culicidae): implications for phylogeny reconstruction. Molecular Phylogenetics and Evolution 18: 479-478.

Krzywinski, J.; R. C. Wilkerson \& N. J. Besansky. 2001b. Toward understanding Anophelinae (Diptera: Culicidae) phylogeny: insights from nuclear single copy genes and the weight of evidence. Systematic Biology 50: 540-556.

Leicester, G. F. 1903. A breeding place of certain forest mosquitoes in Malaya. The Journal of Tropical Medicine 6: 291-292.

Leicester, G. F. 1908a. Report of an investigation of the mosquitoes of Port Swettenham, Klang and Jugra. Studies of the Institute for Medical Research, Federated Malay States 3: 7-14.

Leicester, G. F. 1908b. The Culicidae of Malaya. Studies of the Institute for Medical Research, Federated Malay States 3: $18-261$.

Leicester, G. F. 1908c. Notes as to the pathogenicity of certain mosquitoes with respect to filaria nocturna and malignant tertian malaria. Studies from the Institute for Medical Research Federated Malay States 3: 267-269. 
Lien, J. C. 1991. Anopheline mosquitoes and malaria parasites in Taiwan. The Kaohsiung Journal of Medical Sciences 7: 207-223.

Macan, T. T. 1948. Mosquitos and malaria in the Kabaw and Kale valleys, Burma. Bulletin of Entomological Research 39: 237268, $1 \mathrm{pl}$.

Macan, T. T. 1950. Malaria survey of the Arakan region of Bengal and Burma. Parasitology 40: 290-297.

MacDonald, W. W. \& R. Traub. 1960. Malaysian parasites XXXVII. An introduction to the ecology of the mosquitoes of the lowland dipterocarp forest of Selangor, Malaya. Studies of the Institute for Medical Research, Federated Malaya States 29: 79-109.

Malhotra, P. R.; B. C. Chakraborty; N. G. Das; R. N. Verma ; S. G. Neogi \& U. Chandra. 1987a. Anopheline mosquitoes of Tenga Valley (Arunachal Pradesh). Indian Journal of Public Health 31: 225229.

Malhotra, P. R.; M. Bhuyan \& I. Baruah. 1984. Mosquitoes of Mizoram. Indian Journal of Malariology 21: 125-126.

Malhotra, P. R.; P. K. Sarkar; N. G. Das; S. Hazarika \& V. M. John. 1987b. Mosquito survey in Tirap and Subansiri districts of Arunachal Pradesh. Indian Journal of Malariology 24: 151-158.

Manguin, S.; P. Kengne; L. Sonnier; R. E. Harbach; V. Baimai; H. D. Trung \& M. Coosemans. 2002. SCAR markers and multiplex PCRbased identification of isomorphic species in the Anopheles dirus complex in Southeast Asia. Medical and Veterinary Entomology 16: $46-54$.

Martin, P. \& H. H. Stage. 1954. Clef pour la determination succinte des Anopheles femelles d'Indochine. Report U.S. Foreign Operation Adm. Viet Nam \& Institut Pasteur, 16 p.

Marwoto, H. A. \& P. R. Arbani. 1991. Forest malaria in Indonesia. p. 115-131. In: V. P. Sharma \& A. V. Kondrashin (eds.). Forest malaria in Southeast Asia. Proceedings of informal consultative meeting WHO/MRC, New Delhi.

Matumoto, T. \& F. Matoura. 1939. On a species of anopheline mosquito found in Prefecture Karenko. Journal of the Formosan Medical Association 38: $1642-1649$.

May, K. 1987. Karyological identification of two taxa of the Anopheles balabacensis complex from Burma. Genome 29: 886-887.

McArthur, J. 1946. Malaria transmission in Borneo. Lancet 251: $117-$ 118 .

McArthur, J. 1947. The transmission of malaria in Borneo. Transactions of the Royal Society of Tropical Medicine and Hygiene 40: 537-558.

McArthur, J. 1948. Malaria in Borneo. An account of the work of the malaria research department, North Borneo. London, Cyclostyled by Colonial Office, $250 \mathrm{p}$.

McArthur, J. 1949. The Anopheles of Tambunan, North Borneo. Bulletin of Entomological Research 40: 53-60.

McArthur, J. 1950a. Malaria and its vectors in Borneo. A study of Borneo's greatest problem, and of the mosquitoes responsible for its transmission, throughout North Borneo and Labuan, Sarawak, Brunei and Dutch Borneo, to the end of the first half of the twentieth century. Indian Journal of Malariology 4: 1-30.

McArthur, J. 1950b. The importance of Borneo Anopheles. A study of the relative importance of the different species of Borneo Anopheles, from records of observers throughout North Borneo and Labuan, Sarawak, Brunei and Dutch Borneo. Indian Journal of Malariology 4: 391-447.

McArthur, J. 1951. The importance of Anopheles leucosphyrus. Transactions of the Royal Society of Tropical Medicine and Hygiene 44: 683-694.

McArthur, J. 1954. The control of malaria in Borneo (An account of the Tambunan experiment). Transactions of the Royal Society of Tropical Medicine and Hygiene 48: 234-241.

Meek, S. R. 1995. Vector control in some countries of Southeast Asia: comparing the vectors and the strategies. Annals of Tropical Medicine and Parasitology 89: 135-147.

Mendis, K.; R. L. Ihalamull; E L Peyton \& S. Nanayakkara. 1984. Biology and descriptions of the larva and pupa of Anopheles (Cellia) elegans James (1903). Mosquito Systematics (1983) 15: $318-$ 324 .

Mendoza, J. B. 1954. Pictorial keys to Philippine anopheline adults and larvae. Division of Malaria. Public Health Research Laboratories, Manila

Misra, S. P.; J. Nandi; M. V. V. L. Narasimham. \& R. Rajagopal. 1993. Malaria transmission in Nagaland, India. Part I - Anophelines and their seasonality. Journal of Community Diseases 25: 62-66.

Miyagi, I.; T. Toma; M. Mogi; Martono; S. Yotopranoto; Z. Arifin \& V. P. Dachlan. 1994. Mosquito species (Diptera: Culicidae) from Lombok Island, Indonesia. Mosquito Systematics 26: 19-24.

Miyagi, I.; T. Toma; M. Tsukamoto; M. Horio; M. Mogi; T. Okazawa; Y. Tokuyama; S. Sucharit; W. Tumrasvin; C. Khamboonruang \& W. Choochote. 1986. New distribution records of mosquitoes from Thailand with a collection list of 1983-1984 surveys. Tropical Biomedicine 3: 181-192.

Miyagi, T. 1973. Studies on malaria vector in Philippines, especially on Anopheles balabacensis balabacensis and monkey malaria in Palawan I. Jpn. The Journal of Tropical Medicine 2: 163.

Moore, S. J; D. Zunwei; Z. Hongning; W. Xuezhong; L. Hongbing; X. Yujiang \& N. Hill. 2001. The efficacy of different mosquito trapping methods in a forest-fringe village, Yunnan Province, southern China. The Southeast Asian Journal of Tropical Medicine and Public Health 32: 282-289.

Morishita, K. 1946. A new variety of Formosan Anopheles -Anopheles leucosphyrus var. takasagoensis var. nov. Journal of the Formosan Medical Association 45: 21,65-70.

Mya, M. M.; R. K.Saxena \& Paing Soe. 2002. Study of malaria in a village of lower Myanmar. Indian Journal of Malariology 39: 96-102.

Myo-Paing; A. A. Sebastian \& W. Tun-Lin. 1989a. Anopheline mosquitoes of Myanmar. 1. Anopheles (Cellia) dirus Peyton and Harrison, 1979. Myanmar Health Science Research Journal 1: $122-129$.

Myo-Paing; W. Tun-Lin; S. Min \& Z. Myint. 1989b. Malaria situation in a forested foot-hill area of Pegu Division. Burma Health Sciences Research Journal 1: $52-54$.

Myo-Paing; S. Min; Z. Myint \& T. T.- Naing. 1990. Comparison of malaria situation in a forested foot-hill area of Bago Division between monsoon and cool-dry season. Myanmar Health Science Research Journal 2: 88-90.

Nagpal, B. N. \& V. P. Sharma. 1983. Mosquitoes of Andaman Islands. Indian Journal of Malariology 20: 7-13.

Nagpal, B. N. \& V. P. Sharma. 1987. Survey of mosquito fauna of northeastern region of India. Indian Journal of Malariology 24: $143-149$.

Nagpal, B. N. \& V. P. Sharma. 1995. Indian anophelines. Bombay and Calcutta, New Delhi,Oxford \& IBH Publishing Co. vii +416 p.

Nandi, J.; J. S. Rao; R. K. Dasgupta \& R. S. Sharma. 1996. Ecological observations on the anopheline mosquitoes of Jalpaiguri duars, West Bengal. Journal of Community Diseases 28: 279-286.

Nandi, J.; S. M. Kaul; S. N. Sharma \& S. Lal. 2000. Anthropophily of anophelines in Duars of West Bengal and other regions of India. Journal of Community Diseases 32: 95-99.

Nandi, J.; S. P. Misra; R. Rajagopal \& M. V. V. L. Narasimham. 1993. Present perspectives of malaria transmission in Boko area of Assam. Journal of Community Diseases 25: 18-26.

Nelson, P.; J. M. R. Jayasuriya \& B. V. P. C. Bandarawatte. 1971. The establishment of Anopheles elegans as a natural vector of simian malaria in Ceylon. Ceylon Journal of Medical Science. D. 20: 46-51.

Oberst, R. B.; G. W. Schultz; L. W. Laughlin; N. E. Sy; M. N. Santos \& C. Casimiro. 1988. Epidemiological study of malaria in Palawan. Philippines Journal of Microbiology and Infectious Diseases 17: 41-48.

O'Conner, C. T. \& T. Sopa. 1981. A checklist of the mosquitoes of Indonesia. US Naval Medical Research Unit No. 2 Jakarta, Special Publication NAMRU-SP-45, 26 p.

O'Conner, C. T. \& S. Arwati. 1985. Illustrated key to female anophelines of Indonesia. Directorate of Communicable Diseases, Ministry of Health. Jakarta, 1979. Revised (English translation) $1989,40 \mathrm{p}$.

Oo, T. T.; V. Storch \& N. Becker. 2003. Anopheles dirus an its role in malaria transmission in Mynmar. Journal of Vector Ecology 28: 
$175-183$.

Panyim, S.; R. Rosenberg; R. Andre; V. Baimai; C. Green \& N. Tirawanchai. 1985. DNA probes: A new method to differentiate sibling species. The Southeast Asian Journal of Tropical Medicine and Public Health 16: 188.

Panyim, S.; S. Yasothornsrikul \& V. Baimai. 1988a. Species-specific DNA sequence from the Anopheles dirus complex: a potential for efficient identification of isomorphic species, p. 193-202. In: M. W. SERVICE (ed.). Biosystematics of haematophagous insects. Systematics Association, Special Volume 37. Oxford, Clarenden Press.

Panyim, S.; S. Yasothornsrikul; S. Tungpradubkul; V. Baimai; R. Rosenberg; R. G. Andre \& C. A. Green. 1988b. Identification of isomorphic malaria vectors using a DNA probe. The American Journal of Tropical Medicine and Hygiene 38: 47-49.

Pattanayak, S.; K. G. Samnotra \& A. Seni. 1980. A comparison, on a village scale, of the effect of pirimiphos-methyl and DDT on Anopheles balabacensis -vectored malaria. The Journal of Tropical Medicine and Hygiene 83: 211-221.

Peters, W.; P. C. C. Garnham; R. Killick-Kendrick; N. Rajapaksa; W. H. Cheong \& F.C. Cadigan. 1976. Malaria of the Orang-utan (Pongo pygmaeus) in Borneo. Philosophical Transactions of the Royal Society of London, Series B, Biological Sciences 275: 439482.

Peyton, EL. 1989. A new classification for the Leucosphyrus Group of Anopheles (Cellia). Mosquito Systematics 21: 197-205.

Peyton, EL \& J. E. Scanlon. 1966. Illustrated key to the female Anopheles mosquitoes of Thailand. United States Medical Component South East Asia Treaty Organization, Bangkok, 47 p.

Peyton, EL \& B. A. Harrison. 1979. Anopheles (Cellia) dirus, a new species of the Leucosphyrus Group from Thailand (Diptera: Culicidae). Mosquito Systematics 11: 40-52.

Peyton, EL \& B. A. Harrison. 1980. Anopheles (Cellia) takasagoensis Morishita 1946, an additional species in the Balabacensis Complex of Southeast Asia (Diptera: Culicidae). Mosquito Systematics 12: $335-347$.

Peyton, EL \& S. Ramalingam. 1988. Anopheles (Cellia) nemophilous, a new species of the Leucosphyrus Group from Peninsular Malaysia and Thailand (Diptera: Culicidae). Mosquito Systematics 20: 272-299.

Pletsch, D. J.; P-T. Tseng \& J. H. Chen. 1956. Daytime populations of anophelines in houses and stables of rural Taiwan (Formosa). China. Journal of the Formosan Medical Association 55: 614-621.

Pokrovskii, V. I.; T. A. Nguyen \& B. Godovannyi. 1986. A filariasis in the developing countries of Southeast Asia. MeditsinskayaParazitologiya-i-Parazitarnye-Bolezni 4: 47-50.

Poolsuwan, S. 1995. Malaria in prehistoric southeastern Asia. The Southeast Asian Journal of Tropical Medicine and Public Health 26: 3-22.

Poopittayasataporn, A. \& V. Baimai. 1995. Polytene chromosome relationships of five species of the Anopheles dirus complex in Thailand. Genome 38: 426-434.

Prakash, A.; D. R. Bhattacharyya; P. K. Mohapatra \& J. Mahanta. 1997a. Indoor biting behaviour of Anopheles dirus Peyton and Harrison, 1979 in upper Assam, India. Mosquito Borne Diseases Bulletin 14: 31-37.

Prakash, A.; D. R. Bhattacharyya; P. K. Mohapatra \& J. Mahanta. 1997b. Seasonal prevalence of Anopheles dirus and malaria transmission in a forest fringed village of Assam, India. Indian Journal of Malariology 34: 117-125.

Prakash, A.; D. R. Bhattacharyya; P. K. Mohapatra \& J. Mahanta. 1997c. Breeding and day resting habitats of Anopheles dirus in Assam, India. The Southeast Asian Journal of Tropical Medicine and Public Health 28: 610-614.

Prakash, A.; D. R. Bhattacharyya; P. K. Mohapatra \& J. Mahanta. 1998a. Insecticide susceptibility of Anopheles dirus in Assam. Journal of Community Diseases 30: 291-292.

Prakash, A.; D. R. Bhattacharyya; P. K. Mohapatra \& J. Mahanta. 1998b. House frequenting and host seeking mosquitoes in a forest fringed village of district Dibrugarh, Assam. Entomon 23: 191-
195.

Prakash, A.; D. R. Bhattacharyya; P. K. Mohapatra \& J. Mahanta. 2000a. Preliminary observations on man-mosquito contact in Soraipung village of District Dibrugarh, Assam (India). Indian Journal of Malariology 37: 97-102.

Prakash, A.; P. K. Mohapatra; D. R. Bhattacharyya; C. K. Sharma; B. K. Goswami; N. C. Hazarika \& J. Mahanta. 2000b. Epidemiology of malaria outbreak (Apr./May, 1999) in Titabor Primary Health Centre, district Jorhat (Assam). The Indian Journal of Medical Research 111: 121-126.

Prakash, A.; D. R. Bhattacharyya; P. K. Mohapatra \& J. Mahanta. 2001. Estimation of vectorial capacity of Anopheles dirus (Diptera: Culicidae) in a forested-fringed village of Assam (India). Vector Borne and Zoonotic Diseases 1: 231-237.

Prakash, A.; D. R. Bhattacharyya; P. K. Mohapatra \& J. Mahanta. 2002. Physico-chemical characteristics of breeding habitats of Anopheles dirus (Diptera: Culicidae) in Assam, India. The Journal of Environmental Biology 23: 95-100.

Prapanthadara, L.; N. Promtet; S. Koottathep; P. Somboon \& A. J. Ketterman. 2000 Isoenzymes of glutathione S-transferase from the mosquito Anopheles dirus species B: the purification, partial characterization and interaction with various insecticides. Insect Biochemistry and Molecular Biology 30: 395-403.

Prasittisuk, C. 1985. Present status of malaria in Thailand. The Southeast Asian Journal of Tropical Medicine and Public Health 16: 141-144.

Puri, I. M. 1949. Anophelines of the Oriental Region. p. 483-505. In: M. F. Boyd (ed.) Malariology. A comprehensive survey of all aspects of this group of diseases from a global standpoint. Volumes I and II. Philadelphia and London, W.B. Saunders Company, $787 \mathrm{p}$.

Qu, F. -Y; S. -B. Xu; J. -N. Xu \& X. -C. Xu. 1998. On the biosystematics of Anopheles dirus complex (Diptera: Culicidae) in China. Entomologica Sinica 5: 246-256.

Rahman, M.; M. D. Elias \& M. Ameen. 1977. Bionomics of Anopheles balabacensis balabacensis Baisas (Diptera: Culicidae) in Bangladesh and its relation to malaria. Bangladesh Journal Zoology 5: 123.

Rahman, W. A.; A. Che'Rus \& A. H. Ahman. 1997. Malaria and Anopheles mosquitos in Malaysia. The Southeast Asian Journal of Tropical Medicine and Public Health 28: 599-605.

Rajagopal, R. 1979. Role of Anopheles balabacensis balabacensis in the transmission of malaria in Assam. Journal of Community Diseases 10: 71-74.

Rajavel, A. R. \& P. K. Das. 1998. A review of Leucosphyrus Group with particular reference to the Anopheles dirus complex (Diptera: Culicidae) in India. Journal of Community Diseases 30: 57 67.

Ramachandra Rao, T. 1984. The anophelines of India. New Delhi, Indian Council of Medical Research.

Ramalingam, S. 1974. Some new records of Anopheles from Sabah, Malaysia. The Southeast Asian Journal of Tropical Medicine and Public Health 5: 147-148.

Ramsay, G. C. 1930. Some findings and observations in an anopheline malaria infectivity survey carried out in the Cachar District of Assam. The Indian Journal of Medical Research 18: 533552.

Rattanarithikul, R. \& B. A. Harrison. 1973. An illustrated key to the Anopheles larvae of Thailand. United State Army Medical Component, South East Asia Treaty Organization, Bangkok. 14 p.

Rattanarithikul, R. \& P. Panthusiri. 1994. Illustrated keys to the medically important mosquitoes of Thailand. The Southeast Asian Journal of Tropical Medicine and Public Health, Supplement 1, 25: 1-66.

Rattanarithikul, R.; E. Konishi \& K. J. Linthicum. 1996a. Detection of Plasmodium vivax and Plasmodium falciparum circumsporozoite antigen in anopheline mosquitoes collected in southern Thailand. The American Journal of Tropical Medicine and Hygiene 54: 114-121.

Rattanarithikul, R.; K. J. Linthicum \& E. Konishi. 1996b. Seasonal 
abundance and parity rates of Anopheles species in southern Thailand. Journal of the American Mosquito Control Association 12: 75-83.

Rattanarithikul, R.; K. J. Linthicum \& E. Konishi. 1996c. Observations on nocturnal biting activity and host preference of anophelines collected in southern Thailand. Journal of the American Mosquito Control Association 12: 52-57.

Rattanarithikul, R.; C. A. Green; S. Panyim; C. Noigamol; S. Chanaimong \& P. Mahapibul. 1995. Larval habitats of malaria vectors around a transmission focus in northwestern Thailand. Journal of the American Mosquito Control Association 11: 428-432.

Reid, J. A. 1949. A preliminary account of the forms of Anopheles leucosphyrus Dönitz (Diptera: Culicidae). Proceedings of the Royal Entomological Society of London B 18: 42-53.

Reid, J. A. 1968. Anopheles mosquitoes of Malaya and Borneo. Studies from the Institute for Medical Research Malaya 31: 1-520.

Reid, J. A. 1970. Systematics of malaria vectors. Anopheline systematics and malaria control, with special reference to Southeast Asia. Miscellaneous Publication of the Entomological Society of America 7: 56-62.

Reid, J. A. \& B. Weitz. 1961. Anopheline mosquitoes as vectors of animal malaria in Malaya. Annals of Tropical Medicine and Parasitology 55: 180-186.

Reid, J. A. \& K. L. Knight. 1961. Classification within the subgenus Anopheles (Diptera: Culicidae). Annals of Tropical Medicine and Parasitology 55: 474-488.

Reid, J. A.; R. H. Wharton \& A. Ganapathipillai. 1952. Division of Entomology. Annual Report of the Institute for Medical Research Kuala Lumpur, (1951) 20-25, Appendices VI, 2126.

Rohani, A; S. Lokman-Hakim; A. R. Hassan; S. T. Chan; Y. F. Ong; A. G. Abdullah \& H. L. Lee. 1999. Bionomics of Anopheles balabacensis Baisas, the principal malaria vector, in Ranau, Sabah. Tropical Biomedicine 16: 31-38.

Roper, R. 1914. An account of some anopheline mosquitos found in British North Borneo, with description of a new species. Bulletin of Entomological Research 5: 137-147.

Rosenberg, R. 1982. Forest malaria in Bangladesh. III. Breeding habits of Anopheles dirus. The American Journal of Tropical Medicine and Hygiene 31: 192-201.

Rosenberg, R. \& N. P. Maheswary. 1982a. Forest malaria in Bangladesh. I. Parasitology. The American Journal of Tropical Medicine and Hygiene 31: 175-182.

Rosenberg, R. \& N. P. Maheswary. 1982b. Forest malaria in Bangladesh. II. Transmission by Anopheles dirus. The American Journal of Tropical Medicine and Hygiene 31: 183-191.

Rosenberg, R. \& R. G. Andre. 1985. Highly efficient, dry season transmission of malaria in eastern Thailand. The Southeast Asian Journal of Tropical Medicine and Public Health 16: 188189.

Rosenberg, R.; R. G. Andre \& L. Somchit. 1990a. Highly efficient dry season transmission of malaria in Thailand. Transactions of the Royal Society of Tropical Medicine and Hygiene 84: 22-28.

Rosenberg, R.; R. G. Andre; S. Ngampatom; C. Hatz \& R. Burge. 1990b. A stable, oligosymptomatic malaria focus in Thailand. Transactions of the Royal Society of Tropical Medicine and Hygiene 84: 14-21.

Roy, D. N. 1942. The potential danger of Anopheles leucosphyrus in Assam. Indian Medical Gazette 77: 318-319.

Russell, P. F. \& F. E. Baisas. 1934a. Habitats of Philippine Anopheles larvae. Philippine Journal of Science 55: 297-306.

Russell, P. F. \& F. E. Baisas. 1934b. A practical illustrated key to larvae of Philippine Anopheles. Philippine Journal of Science 55: 307-335.

Russell, P. F. \& F. E. Baisas. 1936. A practical illustrated key to adults of Philippine Anopheles. Philippine Journal of Science 59: $15-64$.

Russell, P. F.; L. E. Rozeboom \& A. Stone. 1943. Keys to the anopheline mosquitoes of the world with notes on their identification, distribution, biology, and relation to malaria.
Philadelphia, American Entomological Society, Academy Natural Science, $152 \mathrm{p}$.

Russell, P. F.; L. S. West; R. D. Manwell \& G. MacDonald. 1963. Practical Malariology. London, Oxford University Press, 750p.

Rutledge, L. C.; D. J. Gould \& B. Tantichareon. 1969. Factors affecting the infection of anophelines with human malaria in Thailand. Transactions of the Royal Society of Tropical Medicine and Hygiene 63: 613-619.

Salazar, N. P.; M. E. G. Miranda; M. N. Santos \& L. A. De Las Llagas. 1988. The malaria situation in the Philippines with special reference to mosquito vectors. The Southeast Asian Journal of Tropical Medicine and Public Health 19: 709-712.

Sallum, M. A. M.; EL Peyton \& R. C. Wilkerson. 2005. Six new species of the Anopheles leucosphyrus group, with reinterpretation of $A n$. elegans and vector implications. Medical and Veterinary Entomology 19: 158-199.

Sallum, M. A. M.; T. R. Schultz \& R. C. Wilkerson. 2000. Phylogeny of Anophelinae based on morphological characters. Annals of the Entomological Society of America 93: 745-775.

Sallum, M. A. M.; T. R. Schultz; P. G. Foster; K. Aronstein; R. A. Wirtz \& R. C. Wilkerson. 2002. Phylogeny of Anophelinae (Diptera: Culicidae) based on nuclear ribosomal and mitochondrial DNA sequences. Systematics Entomology 27: 361-381.

Sandhinand, U. 1951. Anophelines of Chieng Mai Province, Thailand. Journal of the Medical Association of Thailand 34: 33-38.

Sandosham, A. A. 1945. Malaria in Malai. A handbook for antimalaria students. Singapore, Syonan Tokubetu-Si, 288p.

Sandosham, A. A. 1959. Malariology with special reference to Malaya. Singapore. University of Malaya Press. 327 p.

Sandosham, A. A. \& V. Thomas. 1982. Malariology with special reference to Malaya. Singapore, Singapore University Press. 382 p.

Sandosham, A. A.; R. H. Wharton; D. E. Eyles; M. Warren \& W. H. Cheong. 1963. Malaria in Perlis. The Medical Journal of Malaya 18: $46-51$

Sawadipanich, Y.; V. Baimai \& B. A. Harrison. 1990. Anopheles dirus species E: chromosomal and crossing evidence for another member of the Dirus Complex. Journal of the American Mosquito Control Association 6: 477-481.

Scanlon, J. E. \& S. Esah. 1965. Distribution in altitude of mosquitoes in northern Thailand. Mosquito News 25: 137-144.

Scanlon, J. E. \& U. Sandhinand. 1965. The distribution and biology of Anopheles balabacensis in Thailand (Diptera: Culicidae). Journal of Medical Entomology 2: 61-69.

Scanlon, J. E.; E L Peyton \& D. J. Gould. 1967. The Anopheles (Cellia) leucosphyrus Doenitz, 1901 group in Thailand. Proceedings of the California Mosquito Control Association 35: 78-83.

Scanlon, J. E.; E L Peyton \& D. J. Gould. 1968a. An annotated checklist of the Anopheles of Thailand. Thai National Science Papers, Fauna Series 2: 1-35.

Scanlon, J. E.; J. A. Reid \& W. H. Cheong. 1968b. Ecology of Anopheles vectors of malaria in the Oriental Region. Cahiers O.R.S.T.O.M. Entomologie médicale et parasitologie 6: 44-52.

Schultz, G. W. 1992. Biting activity of mosquitos (Diptera: Culicidae) at a malarious site in Palawan, Republic of Philippines. The Southeast Asian Journal of Tropical Medicine and Public Health 2: 464-469.

Schultz, G. W. 1993. A survey of the mosquitos (Diptera: Culicidae) of Napsan, Palawan, Republic of the Philippines. The Southeast Asian Journal of Tropical Medicine and Public Health 24: 376-383.

Sen, A. K.; V. M. John, K. S. Krishnan \& R. Rajagopal. 1973. Studies on malaria transmission in Tirap District, Arunachal Pradesh, (N.E.F.A.). Journal of Community Diseases 5: 98-110.

Senevet, G. \& L. Andarelli. 1955. Les soies antepalmees chez les larves d'Anopheles. Leur utilisation comme caractere de group (II note). Archives Institut Pasteur d'Algerie 33: 322-343.

Seng, C.-M.; A. Matusop \& F.-K. Sen. 1999. Differences in Anopheles composition and malaria transmission in the village settlements and cultivated farming zone in Sarawak, Malaysia. The Southeast 
Asian Journal of Tropical Medicine and Public Health 30 : 454-459.

Senior-White, R. 1925. Notes on Ceylon mosquitoes - I. Spolia Zeylonica 13: 213-222.

Service, M. W. 1993. Mosquitoes (Culicidae), p. 120-240. In: R. P. Lane \& R. W. Crosskey [eds.]. Medical Insects and Arachnids. London, Chapman \& Hall.

Sharma, V. P.; C. Prasittisuk \& A. V. Kondrashin. 1991. Magnitude of forest related malaria in the WHO Southeast Asia Region. p. 2953. In: V. P. Sharma \& A. V. Kondraslin (eds.). Forest malaria in Southeast Asia. Proceedings of informal consultative meeting WHO/MRC, New Delhi.

Simmons, J. S. \& T. H. G. Aitken. 1942. The anopheline mosquitoes of the northern half of the Western Hemisphere and of the Philippine Islands. (Distribution, habits, identification, importance as vectors and control). The Army Medical Bulletin 59: 1-213.

Singhasivanon, P.; K. Thimasarn; S. Yimsamran; K. Linthicum; K. Nualchawee; D. Dawreang; S. Kongrod; N. Premmanisakul; W. Maneeboonyang \& N. Salazar. 1999. Malaria in tree crop plantations in south-eastern and western provinces of Thailand. The Southeast Asian Journal of Tropical Medicine and Public Health 30: 399-404.

Sithiprasasna, R.; E. Luepromchai \& K. J. Linthicum. 1996. Effects of sublethal dosages of methoprene on Anopheles dirus species A and B. Journal of the American Mosquito Control Association 12: 483-486.

Sithiprasasna, R.; K. J. Linthicum; G.-Jun Liu; J. W. Jones \& P. Singhasivanon. 2003. Some spatial observations on temporal and spatial distribution of malaria vectors in three villages in northwestern Thailand using a geographic information system. The Southeast Asian Journal of Tropical Medicine and Public Health 34: 505-516.

Sloof, R. \& J. Verdrager. 1972. Anopheles balabacensis balabacensis Baisas, 1936 and malaria transmission in south-eastern areas of Asia. WHO/Mal/72.765. 25 p.

Soesilo, R. 1929a. Uittreksel uit het rapport omtrent het onderzoek naar de vespreiding van de malaria op een Eiland Nias. Mededeelingen Dienst Volksgezordh Nederlandsch-Indie 18: $1-27$.

Soesilo, R. 1929b. Uittreksel uit het rapport omtrent het onderzoek naar de verspreiding van de malaria op het Eiland Nias. Geneeskundig Tijdschrift voor Nederlandsch-Indie 69: 350 368.

Soesilo, R.; W. J. Stoker; J. C. Van Hoeve \& W. Gilbert. 1935. Afdeeling malaria bestrijding. Mededeelingen Dienst Volksgezordh Nederlandsch-Indie 24: 386-403.

Stanton, A. T. 1912. The Anopheles mosquitoes of Malaya and their larvae, with some notes on malaria-carrying species. Journal of the London School of Tropical Medicine 2: 3-11.

Stanton, A. T. 1915a. Notes on Sumatran Culicidae. The Indian Journal of Medical Research 3: 251-258.

Stanton, A. T. 1915b. The larvae of Malayan Anopheles. Bulletin of Entomological Research 6: 159-172.

Stojanovich, C. J. \& H. G. Scott. 1965. Illustrated key to the Anopheles mosquitoes of Vietnam. U. S. Public Health Service, Atlanta, $32 \mathrm{p}$.

Stojanovich, C. J. \& H. G. Scott. 1966. Illustrated key to the Anopheles mosquitoes of Thailand. U.S. Public Health Service, Atlanta, $44 \mathrm{p}$.

Stoker, W. J. 1934. Over de malariagevaarlijheid van A. leucosphyrus. Geneeskundig Tijdschrift voor Nederlandsch-Indie 74: $1342-1344$

Stoker, W. J. \& R. W. Koesoemawinangoen. 1949. Illustrated map of the anopheline imagines of Indonesia. Ministry Health, Djakarta, 69 p.

Stone, A. 1963. A synoptic catalog of the mosquitoes of the world, Supplement II (Diptera: Culicidae). Proceedings of the Entomological Society of Washington 65: 117-140.

Stone, A.; J. E. Scanlon; D. L. Bailey; M. D. Delfinado \& R. A. Bram. 1966. Preliminary keys to the mosquitoes of Vietnam. First revision. South East Asian Mosquito Project, U.S.N.M. Smithsonian Institution, $92 \mathrm{p}$.

Strickland, C. 1913. Revised list of Malayan anophelines. The Indian Journal of Medical Research 1: 203-205.

Strickland, C. 1925. A short key to both sexes of the anopheline species of India, Ceylon and Malaya. Calcutta and Simla, Thacker, Spink and Co., 67p

Strickland, C. \& K. L. Choudhury. 1927. An illustrated key to the identification of the anopheline larvae of India, Ceylon, and Malaya, west of Wallace's line with practical notes on their collection. Calcutta and Simla, Thacker, Spink and Co.,

Sucharit, S. \& W. Choochote. 1983. Comparative studies on the morphometry of male genitalia and frequency of clasper movements during induced copulation of Anopheles balabacensis (Perlis Form) and Anopheles dirus (Bangkok colony strain). Mosquito Systematics 15: 90-98.

Sucharit, S.; W. Choochote; N. Pratchynusorn; S. Limsuwan; C. Apiwathanasorn \& T. Kanda. 1983. Esterase patterns of Anopheles dirus (Bangkok strain) and Anopheles balabacensis (Perlis Form) in the laboratory. The Southeast Asian Journal of Tropical Medicine and Public Health 14: 127-132.

Suwonkerd, W.; B. Amg-Ung; K. Rimwangtraiul; S. Wongkattayakul; B. Kattiyamongkool; U. Chitprarop \& M. Takagi. 1990. A field study on the response of Anopheles dirus to DDT and fenitrothion sprayed to huts in Phetchabun Province, Thailand. Tropical Medicine 32: 1-5.

Sweet, W. C.; L. C. Feng; C. Y. Chow \& S. C. Hsu. 1942. Anophelines of southwestern Yunnan and their relation to malaria. Journal National Malaria Society 1: 25-32.

Swellengrebel, N. H. 1916. De anophelinen van Nederlandsch OostIndie. Kolon. Inst.. Amsterdam. Mededeeling VII. Afdeel. Trop. Hyg. 3: 11-82.

Swellengrebel, N. H. 1919. Eenigevoor Nederl.-Indie nieuwe anophelinen. Geneeskundig Tijdschrift voor NederlandschIndie 59: 1-12.

Swellengrebel N. H. 1921. De mannelijke genitalien der Nederlandsch Indische anophelinen. Tijdschrift voor Entomologie 64: 36-45.

Swellengrebel N. H.; W. Schuffner \& J. M. H Swellengrebel De Graaf. 1919. The susceptibility op anophelines to malarial-infections in Nederlands India. Mededeelingen Burgerlijken Geneeskundigen Dienst Nederlandsch-Indië 6: 1-64.

Swellengrebel, N. H. \& J. M. H. Swellengrebel De Graaf. 1920a. Description of the anopheline larvae of Netherland's India, so far as they are known till now. Mededeelingen Burgerlijken Geneeskundigen Dienst Nederlandsch-Indië (1919) 6: 147.

Swellengrebel, N. H. \& J. M. H. Swellengrebel De Graaf. 1920b. List of the anophelines of the Malay Archipelago with special reference to adults and larvae of new or incompletely described species or varieties. Bulletin of Entomological Research 11: 77-92.

Swellengrebel, N. H. \& E. Rodenwaldt. 1932. Die anophelen von Niederlandisch-Ostindien. (Third edition). Jena, Gustav Fischer, $242 \mathrm{p}$.

Takai, K. 1986. Discrimination among strains of the mosquito Anopheles leucosphyrus group by electrophoresis of proteins. Japanese Journal of Genetics 61: 45-59.

Takai, K.; T. Kanda; W. H. Cheong \& K. P. Loong. 1984. A recessive mutant, pale eye, and a cytoplasmic deleterious effect on viability in Anopheles leucosphyrus (Diptera: Culicidae). Journal of Medical Entomology 21: 145-148.

Tandon, N. \& A. K. Hati. 1978. Some recent malaria problems in the hill district of eastern India. Mem. Sch. Entomol. (India) 79: $187-192$

Tansathit, P.; B. Thavaramara; C. Chalawyoo \& C. Kampanardsaenyakara. 1962. Malaria in Sattahip Naval Base, Thailand. Proceedings Ninth Pacific Science Congress (Bangkok, 1957) 17: 137-143.

Taylor, F. H. 1944. The intermediary host of malaria in the Netherlands, East Indies. School Public Health and Tropical Medicine (University of Sydney). Service Publication (Second edition) 5: 1-92. 
Teng, T.; H.-L. Chien; Y.-C. Wang; C. Ho \& H.-S Yang. 1974. Morphological descriptions of Anopheles balabacensis balabacensis Baisas 1936 from Hainan Island, China. (In Chinese; English summary). Acta Entomologica Sinica 17: 463-473.

Tewari, S. C.; J. Hiriyam \& R. Reuben. 1987. Survey of the anopheline fauna of the Western Ghats in Tamil Nadu, India. Indian Journal of Malariology 24: 21-28.

Theobald, F. V. 1901. A monograph of the Culicidae or mosquitoes. Vol. 2. London, British Museum (Natural History).

Theobald, F. V. 1903. A Monograph of the Culicidae or mosquitoes. Vol. 3. London, British Museum (Natural History).

Theobald, F. V. 1910. A monograph of the Culicidae or mosquitoes. Vol. 5. London, British Museum (Natural History).

Thu, M. M.; M.-Paing \& T. Kanda. 1986a. A phylogenetically distinct species of the Anopheles leucosphyrus group in Burma. Japanese Journal Sanitary Zoology 37: 245-248.

Thu, M. M.; M.-Paing \& T. Kanda. 1986b. Chromosomal polymorphism in a Burmese taxon, one of malaria vector members of the Anopheles leucosphyrus group. Japanese Journal Sanitary Zoology 37: 249-257.

Thu, M. M.; W. Tun-Lin; A. Sebastian; T. Kanda \& K. May. 1985. Preliminary biological study on two taxa of the Anopheles balabacensis complex in Burma. Japanese Journal of Genetics 60: $394-380$.

Thurman, E. B. 1959. A contribution to a revision of the Culicidae of northern Thailand. College Park, University of Maryland Agricultural Experiment Station Bulletin A-100: 1-177.

Tin, F. \& T. Tun. 1991. Forest related malaria in Myanmar. p. 133140. In: V. P. Sharma \& A. V. Kondrashin (eds.). Forest malaria in Southeast Asia. Proceedings of informal consultative meeting WHO/MRC, New Delhi.

Toma, T.; I. Miyagi; T. Okazawa; J. Kobayashi; S. Saita; A. Tuzuki; H. Keomanila; S. Nambanya; S. Phompida; M. Uza \& M. Takakura. 2002. Entomological surveys of malaria in Khammouane Province, Lao PDR, in 1999 and 2000. Southeast Asian Journal of Tropical Medicine and Public Health 33: 532-546.

Townsend, B. C. 1990. Culicidae. p. 35-152. In: B. C. Towsend; J. E. Chainey; R. W. Crosskey; A. C. Pont; R. P. Lane; J. P. T. Boorman \& C. A. Crouch (eds.). A catalogue of the types of bloodsucking flies. London, Occasional Papers of the Natural History Museum. No. 7.

Trung, H. D.; W. Van Bortel; T. Sochantha; K. Keokenchanh; N. T. Quang; L. D. Cong \& M. Coosemans. 2004. Malaria transmission and major malaria vectors in different geographical areas of Southeast Asia. Tropical Medicine and International Health 9: 230-237.

Tsukamoto, M.; A. Miyata \& I. Miyagi. 1978. Surveys on simian malaria parasites and their vector in Palawan Island, the Philippines. Tropical Biomedicine 20: 39-50.

Tsukamoto, M.; I. Miyagi \& T. Toma. 1985. A revised checklist of the Philippine mosquitoes. Tropical Biomedicine 2: 149-160.

Tsukamoto, M.; I. Miyagi; T. Toma; S. Sucharit; W. Tumrasvin; C. Khamboonruang; W. Choochote; B. Phanthumachinda \& P. Phanurai. 1987. The mosquito fauna of Thailand (Diptera: Culicidae): An annotated checklist. Japanese Journal of Tropical Medicine and Hygiene 15: 291-326.

Tun-Lin, W.; A.-A.-Tin; H.-Pe \& T. Kanda. 1988. Allozyme polymorphism at the esterase loci of two taxa of the Anopheles balabacensis complex in Burma. Mosquito Borne Diseases Bulletin 4: 68-71.

Tun-Lin, W.; H.-Aung; M.-Moe; A. Sebastian; M.-Paing \& M.-M.Thu. 1987. Some enviromental factors influencing the breeding of Anopheles balabacensis complex (dirus) in domestic wells in Burma. Journal of Community Diseases 19: 291-299.

Tun-Lin, W.; M.-M.-Thu; S.-M.-Than \& M. M.-Mya. 1995. Hyperendemic malaria in a forested, hilly Myanmar village. Journal of the American Mosquito Control Association 11: 401-407.

van Hell, J. C. 1952. The anopheline fauna and malaria vectors in South Celebes. Documenta de Medicina Geographica et
Tropica 4: 45-56.

Van Bortel, W.; R. E. Harbach; H. D. Trung; P. Roelants; T. Backeljau \& M. Coosemans. 2001. Confirmation of Anopheles varuna in Vietnam, previously misidentified and mistargeted as the malaria vector Anopheles minimus. The American Journal of Tropical Medicine and Hygiene 65: 729-732.

Verdrager, J. 1986. Epidemiology of emergence and spread of drug resistant falciparum malaria in Southeast Asia. The Southeast Asian Journal of Tropical Medicine and Public Health 17: $111-118$.

Vythilingam, I.; K. Keokenchan; S. Phommakot; S. Nambanya \& S. Inthakone. 2001. Preliminary studies of Anopheles mosquitos in eight provinces in Lao PDR. The Southeast Asian Journal of Tropical Medicine and Public Health 32: 83-87.

Walton, C.; J. M. Handley; C. Kuvangkadilok; F. H. Collins; R. E. Harbach; V. Baimai \& R. K. Butlin. 1999. Identification of five species of the Anopheles dirus complex from Thailand, using allelespecific polymerase chain reaction. Medical and Veterinary Entomology 13: 24-32.

Walton, C.; J. M. Handley; W. Tun-Lin; F. H. Collins; R. E. Harbach; V. Baimai \& R. K. Butlin. 2000. Population structure and population history of Anopheles dirus mosquitoes in Southeast Asia. Molecular Biology and Evolution 17: 962-974.

Walton, C.; J. M. Handley; F. H. Collins; V. Baimai; R. E. Harbach; V. Deesin \& R. K. Butlin. 2001. Genetic population structure and introgression in Anopheles dirus mosquitoes in South-east Asia. Molecular Ecology 10: $569-580$.

Ward, R. A. 1984. Second supplement to "A catalog of the mosquitoes of the world." (Diptera: Culicidae). Mosquito Systematics 16: $227-270$.

Warren, M. \& R. H. Wharton. 1963. The vectors of simian malaria: identity, biology, and geographical distribution. The Journal of Parasitology 49: 892-904.

Warren, M.; D. E. Eyles; R. H. Wharton \& C. K. Ow Yang. 1963. The susceptibility of Malayan anophelines to Plasmodium cynomolgi bastianellit. Indian Journal of Malariology 17: 85-105.

Warren, M.; W. H. Cheong; H. K. Fredericks \& G. R. Coatney. 1970. Cycles of jungle malaria in West Malaysia. The American Journal of Tropical Medicine and Hygiene 19: 383-393.

Wattal, B. L. 1963. Appendix. Keys to the anophelines of the world. 5. Southern and northwestern Asia. p. 680-696. In: P. F. Russell; L. D. West; R. D. Manwell \& G. MacDonald. Practical Malariology. (Second edition). Oxford University Press. New York and Toronto.

Wharton, R. H. \& D. E. Eyles. 1961. Anopheles hackeri, a vector of Plasmodium knowlesi in Malaya. Science 134: 279-280.

Wharton, R. H.; D. E. Eyles; M. Warren \& D. E. Moorhouse. 1962. Anopheles leucosphyrus identified as a vector of monkey malaria in Malaya. Science 137: 758.

Wharton, R. H.; A. B. G. Laing \& W. H. Cheong. 1963a. Studies on the distribution and transmission of malaria and filariasis among aborigines in Malaya. Annals of Tropical Medicine and Parasitology 57: 235-254.

Wharton, R. H.; D. E. Eyles \& M. Warren. 1963b. The development of methods for trapping the vectors of monkey malaria. Annals of Tropical Medicine and Parasitology 57: 32-46.

Wharton, R. H.; D. E. Eyles; M. Warren \& W. H. Cheong. 1964. Studies to determine the vectors of monkey malaria in Malaya. Annals of Tropical Medicine and Parasitology 58: 56-77.

White, G. B. 1983. The importance of Anopheles leucosphyrus group mosquitoes as vectors of malaria and filariasis in relation to transmigration and forestry in Indonesia with assessments of Anopheles balabacensis ecology and vectorial capacity. Assignment Report: 12 July - 15 September 1982, WHO Project IR VBC 025. World Health Organization. Vector Biology and Control Research Unit, Jakarta, Indonesia.

Wibowo, S.; V. Baimai \& R. G. Andre. 1984. Differentiation of four taxa of the Anopheles balabacensis complex using H-banding patterns in the sex chromosomes. Canadian Journal of Genetics and Cytology 26: 425-429.

Wijesundara, D. P. 1942. Notes on the mosquito fauna of rot-holes in 
trees and bamboo stumps in Ceylon. Journal of Malaria Institute of India 4: 451-456.

Wilkerson, R. C.\& E L Peyton. 1990. Standardized nomenclature for the costal wing spots of the genus Anopheles and other spottedwing mosquitoes (Diptera: Culicidae). Journal of Medical Entomology 27: 207-224.

Wilkinson, R. N.; D. J. Gould \& P. Boonyakanist. 1972. Comparative susceptibility of Anopheles balabacensis and Anopheles minimus to naturally occurring Plasmodium falciparum in central Thailand. Proceedings of the Helminthology Society of Washington 39: 423-427.

Wilkinson, R. N.; D. J. Gould; P. Boonyakanist \& H. E. Segal. 1978. Observations on Anopheles balabacensis (Diptera: Culicidae) in Thailand. Journal of Medical Entomology 14: 666-671.

Wilkinson, R. N.; S. Noeypatimanondh \& D. J. Gould. 1976. Infectivity of falciparum malaria patients for anopheline mosquitoes before and after chloroquine treatment. Transactions of the Royal Society of Tropical Medicine and Hygiene 70: 306-307.

Wilkinson, R. N.; T. A. Miller \& S. Esah. 1970. Anthropophilic mosquitoes in Central Thailand, with notes on Anopheles balabacensis Baisas and malaria. Mosquito News 30: 146-148.

Wilson, T. \& J. A. Reid. 1949. Malaria among prisoners of war in Siam ("F" Force). Transactions of the Royal Society of Tropical Medicine and Hygiene 43: 257-272.

Xu, J.-N. \& F.-Y. Qu. 1997a. Investigation of the species status of $A n$. dirus (Diptera: Culicidae) from Hainan Province using rDNA. Chinese Journal of Parasitology and Parasitic Diseases 15: 272.

Xu, J.-N. \& F.-Y. Qu. 1997b. Ribosomal DNA difference between species $\mathrm{A}$ and $\mathrm{D}$ of the Anopheles dirus complex of mosquito from China. Medical and Veterinary Entomology 11: 134-138.

Xu, S.-B. \& F.-Y. Qu. 1991. Studies on chromosomes of thirteen species of anopheline mosquitoes in China. Journal of the Medical College of PLA 6: 286-291.

Xu, S.-B.; F.-Y. Qu; Q.-H. Zhang \& Y.-L. Lu. 1991. Scanning electron microscopic studies on the morphology of eggs of five anopheline mosquitoes from China. Chinese Journal of Parasitic Disease Control 4: 118-1.20.

Xu, X.; J.-N. Xu \& F.-Y Qu. 1998. A diagnostic polymerase chain reaction assay for species $\mathrm{A}$ and $\mathrm{D}$ of the Anopheles dirus (Diptera: Culicidae) species complex based on ribosomal DNA second internal transcribed spacer sequence. Journal of the American Mosquito Control Association 14: 385-389.

Yasothornsrikul, S.; S. Panyim \& R. Rosenberg. 1988. Diagnostic restriction fragment patterns of DNA from the four isomorphic species of Anopheles dirus. The Southeast Asian Journal of Tropical Medicine and Public Health 19: 703-708.

Ye-Y, D.-He \& J. Zheng. 1983. Observation on the sporogonic cycle of the Guangxi strain of Plasmodium inui in Anopheles balabacensis. Acta Zoologica Sinica 29: 48-54.

Yong, H. S.; W. H. Cheong; G. L.; Chiang; S. S. Dhaliwal; K. P. Loong \& K. P. Sarjan. 1983. Biochemical genetic relationship in three taxa of the malaria mosquito Anopheles balabacensis complex. Comparative Biochemistry and Physiology 76: 611-613.

Zahedi M. \& G. B. White. 1994. Filaria vector competence of some Anopheles species. Tropical Medicine and Parasitology 45: 27-32.

Zulueta, J. 1956. Malaria in Sarawak and Brunei. Bulletin of the World Health Organization 15: 65-671.

Zulueta, J. 1957. Observations on filariasis in Sarawak and Brunei. Bulletin of the World Health Organization 16: 699-705.

Zulueta, J. A. \& F. LaChance. 1956. A malaria-control experiment in the interior of Borneo. Bulletin of the World Health Organization 15: 673-693. 


\section{ÍNDICE}

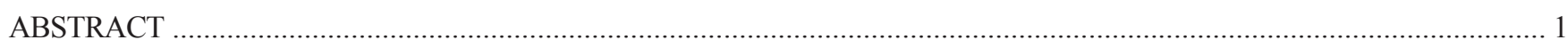

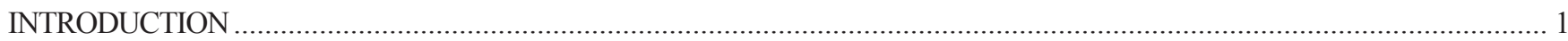

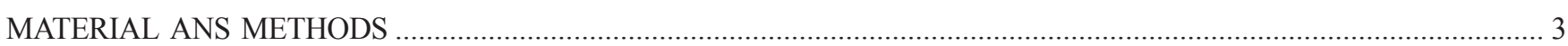

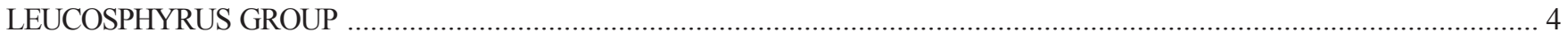

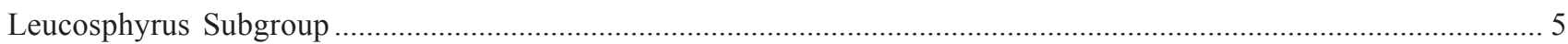

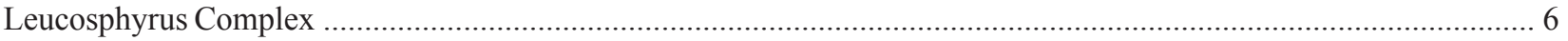

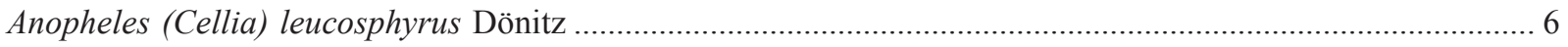

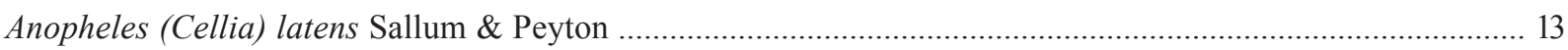

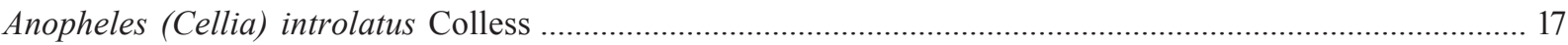

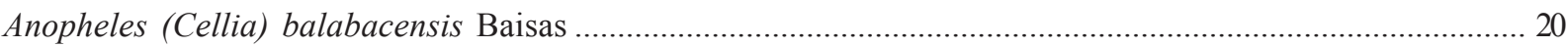

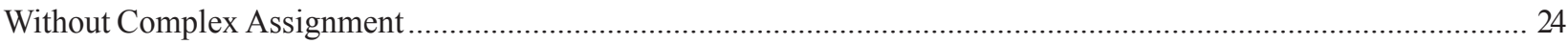

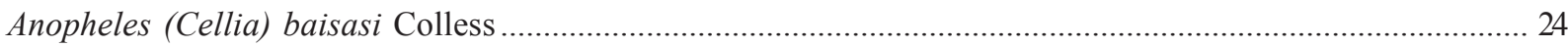

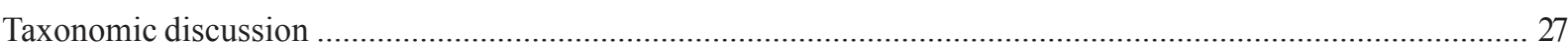

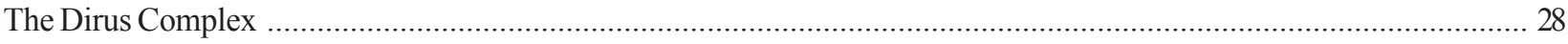

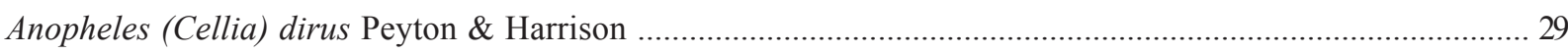

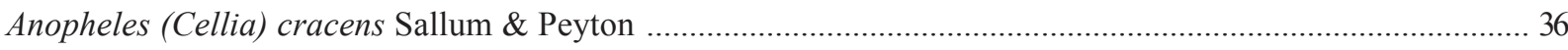

Anopheles (Cellia) scanloni Sallum \& Peyton ................................................................................................. 39

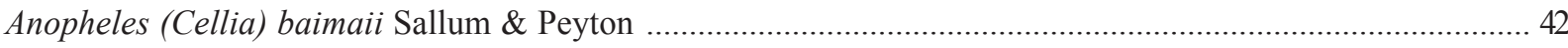

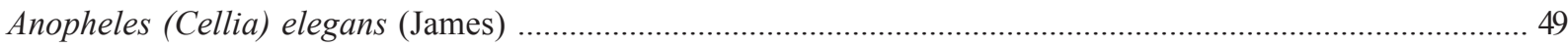

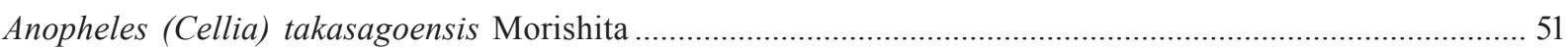

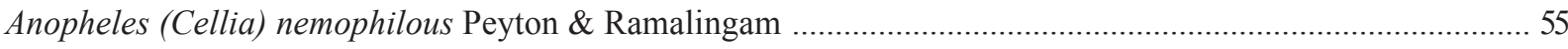

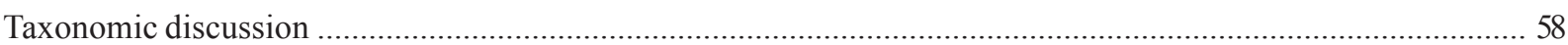

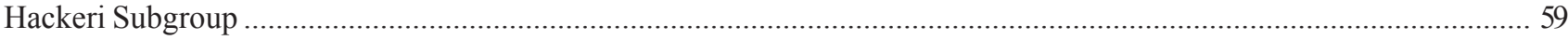

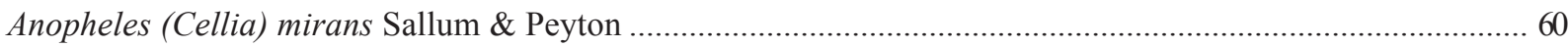

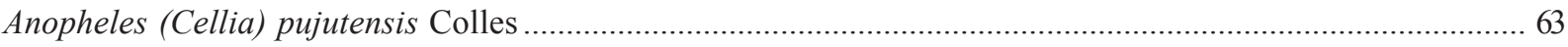

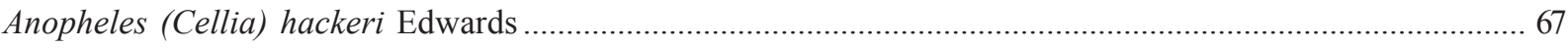

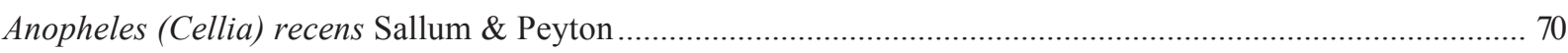

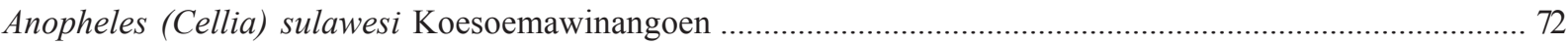

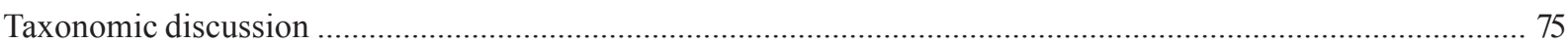

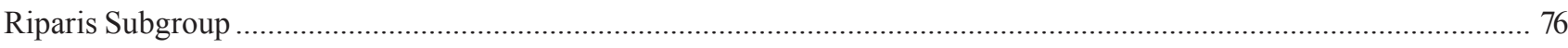

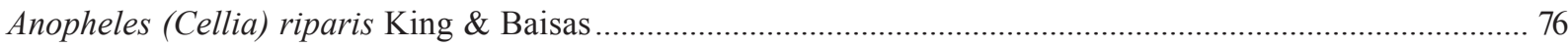

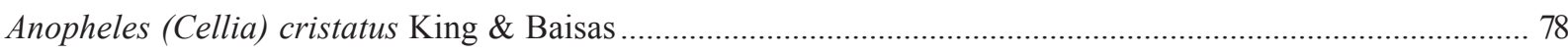

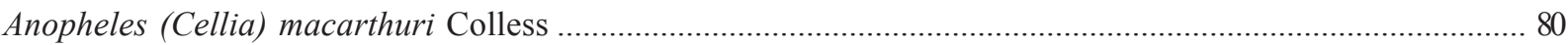

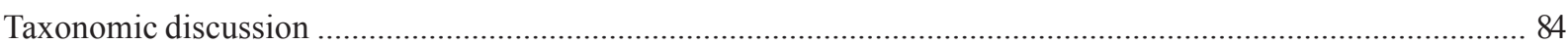

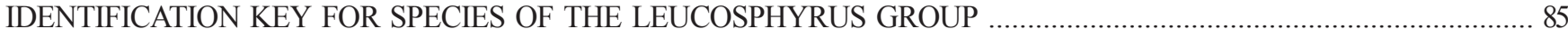

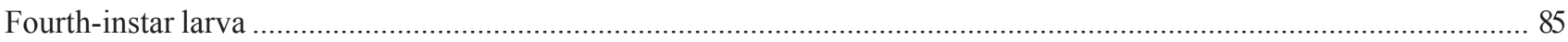

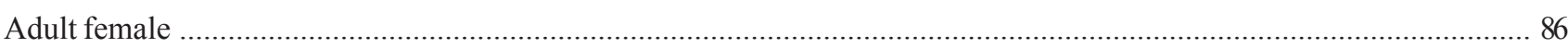

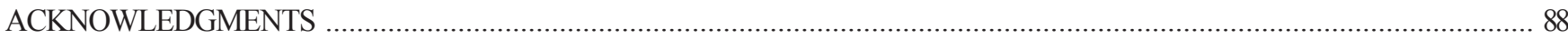

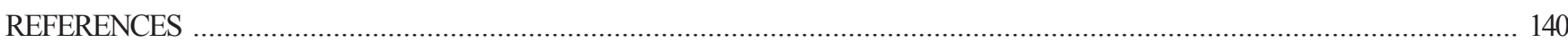

